\title{
FERNANDO GIRARDI DE ABREU
}

QUANTIFICAÇÃO DOS PREJUÍZOS ECONÔMICOS À ATIVIDADE COMERCIAL DERIVADOS DE INUNDAÇÕES URBANAS 



\title{
FERNANDO GIRARDI DE ABREU
}

Quantificação dos prejuízos econômicos à atividade comercial derivados de inundações urbanas

Tese apresentada à Escola de Engenharia de São Carlos, da Universidade de São Paulo, como parte dos requisitos para a obtenção do título de Doutor em Ciências: Engenharia Hidráulica e Saneamento.

Orientador: Eduardo Mario Mendiondo

\author{
VERSÃO CORRIGIDA \\ SÃO CARLOS \\ 2019
}




\begin{abstract}
AUTORIZO A REPRODUĈ̃O TOTAL OU PARCIAL DESTE TRABALHO, POR QUALQUER MEIO ÇONVENCIONAL OU ELETRÔNICO, PARA FINS DE ESTUDO E PESQUISA, DESDE QUE CITADA A FONTE.
\end{abstract}

Ficha catalográfica elaborada pela Biblioteca Prof. Dr. Sérgio Rodrigues Fontes da EESC/USP com os dados inseridos pelo(a) autor(a).

A162q Quantificação dos prejuízos econômicos à atividade comercial derivados de inundações urbanas / Fernando Girardi de Abreu; orientador Eduardo Mario Mendiondo. São Carlos, 2019.

Tese (Doutorado) - Programa de Pós-Graduação em Engenharia Hidráulica e Saneamento e Área de Concentração em Hidráulica e Saneamento -- Escola de Engenharia de São Carlos da Universidade de São Paulo, 2019 .

1. Curvas de danos por profundidade de submersão. 2. avaliação econômica de inundações. 3. valor anual médio dos prejuízos. 4. modelagem hidráulicahidrológica. I. Título.

Eduardo Graziosi Silva - CRB - 8/8907 


\section{FOLHA DE JULGAMENTO}

Candidato: Bacharel FERNANDO GIRARDI DE ABREU.

Título da tese: "Quantificação dos prejuízos econômicos à atividade conercial derivados de inundações urbanas".

Data da defesa: 19/08/2019.

\section{Comissão Julgadora:}

Prof. Dr. Eduardo Mario Mendiondo (Orientador)

(Escola de Engenharia de São Carlos/EESC)

Prof. Dr. Nilo de Oliveira Nascimento

(Universidade Federal de Minas Gerais/UFMG)

Prof. Titular Eduardo Amaral Haddad

(Núcleo de Economia Regional e Urbana da USP/NEREUS-USP)

Profa $^{a}$. Dr ${ }^{a}$. Melissa Cristina Pererira Graciosa

(Universidade Federal do ABC/UFABC)

Prof. Dr. Joel Avruch Goldenfum

(Universidade Federal do Rio Grande do SLI/UFRGS)
Resultado:
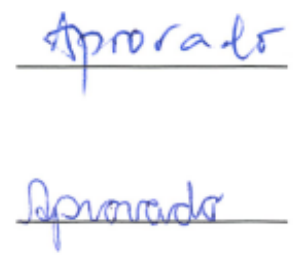
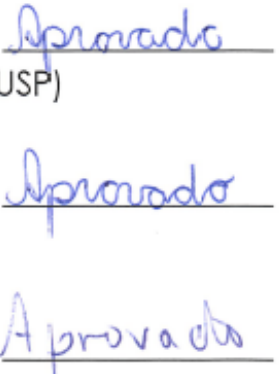

Coordenador do Programa de Pós-Graduação em Engenharia Hidráulica e Saneamento:

Prof. Dr. Eduardo Mario Mendiondo

Presidente da Comissão de Pós-Graduação:

Prof. Titular Murilo Araujo Romero 



\section{AGRADECIMENTOS}

Agradeço inicialmente ao Professor João Luiz Boccia Brandão (in memoriam), com quem iniciei essa jornada e por quem tive enorme admiração, como pessoa e profissional, e a sorte de compartilhar momentos agradáveis.

Ao Professor Eduardo Mario Mendiondo, por ter me acolhido como parte de sua equipe nessa transição, por todas as orientações, conversas e confraternizações que sempre fez questão de realizar, que muito colaborou para a união do grupo e por tornar essa jornada mais agradável e amigável.

Aos colegas do laboratório, notadamente Marina, Maria Clara, Felipe, Diego, Carol, Marcos, Cesar, Clarissa e Camilo, novos amigos que conheci nesses anos e com os quais pude compartilhar enormes risadas e saídas sem fim.

Aos amigos de São Carlos, com carinho especial: Júlia, Herisson, Rodolfo, Jesica e Natalia, que estiveram presentes nesses anos de minha vida e trouxeram muitas alegrias e cumplicidades.

A todos aqueles que passaram pelo meu mundo nesse tempo.

Aos meus pais, Odete e Rubem e irmãos, Robson e Luiza, pelo amor incondicional e toda a ajuda emocional que partilharam nesses momentos.

A CAPES pela concessão da bolsa de estudo. 



\title{
RESUMO
}

\author{
Abreu, F. G. (2019). Quantificação dos prejuízos econômicos à atividade comercial \\ derivados de inundações urbanas. Tese de doutorado - Escola de Engenharia de São \\ Carlos, Universidade de São Paulo, São Carlos - SP.
}

A inundação urbana é um desastre ambiental que causa prejuízos econômicos da ordem de bilhões por ano no Brasil. Apesar deste contexto, estudos sobre a quantificação desses prejuízos ainda são escassos, principalmente em escala nacional, tendo em vista a interdisciplinaridade necessária à sua execução. Em geral, são utilizadas funções que correlacionam o prejuízo por metro quadrado de área em detrimento da altura de inundação para se estabelecer o prejuízo de um dado evento de inundação, utilizando-se de modelos para a elaboração de manchas de inundação. Sendo assim, este estudo visa quantificar os prejuízos sob duas abordagens: com uso de dados à priori, por meio de modelagem hidráulica-hidrológica e curvas DPS sintéticas; e com dados à posteriori, com a obtenção de dados in loco na área de estudo. Dessa forma, foi possível quantificar os prejuízos diretos e indiretos relativos ao setor comercial para uma área densamente povoada por estabelecimentos comerciais na bacia do córrego do Gregório no município de São Carlos (SP). Para tal, foi elaborado o mapa de inundação da bacia com softwares da plataforma HEC e utilizados dados de projeto para modelagem, e dados observados em relação à precipitação e altura de água para verificação das incertezas. Com isso, foi estimado o prejuízo médio anual em diferentes cenários, verificado o custo-benefício de medidas mitigadoras propostas no plano diretor de drenagem de São Carlos, avaliadas as incertezas do uso de modelos hidráulico-hidrológicos unidimensionais na obtenção de alturas de inundação e quantificados os prejuízos diretos e indiretos dessa área de estudo. Como resultados, verificou-se que a distribuição temporal das chuvas pode trazer incertezas de até $46 \%$ na vazão de pico, $57 \%$ nas áreas da mancha de inundação da região e 1,5 metros; que as medidas mitigadoras estruturais obtiveram a mesma eficiência de redução de pico de vazão que as não estruturais; concluiu-se que utilização de modelos unidimensionais trazem incertezas significativas quanto aos valores verificados em loco. Além disso, verificou-se que os prejuízos indiretos podem subdimensionar o prejuízo total sofrido pelos comerciantes em até $60 \%$.

Palavras-chave: Curvas de danos por profundidade de submersão; avaliação econômica de inundações; valor anual médio dos prejuízos. modelagem hidráulica-hidrológica 



\section{ABSTRACT}

Abreu, F. G. (2019). Quantification of economic damage to commercial activity from urban flooding. Doctorate thesis. São Carlos of Engineering. University of São Paulo, São Carlos - SP

Urban floods are a disaster that cause economic damages of the order of billions per year in Brazil. Despite this context, studies about the quantification of losses are still scarce, specially at national level, considering the interdisciplinarity required for its execution. In general, functions that relate the damage per square meter of area in relation to the height of flood are used to establish the damage of a given flood event, using one-dimensional models for the elaboration of flood prone area. Thus, this study aims to quantify the losses under two approaches: using a priori data, hydraulic-hydrological modeling and synthetic DPS curves; and with posterior data, with the use of data in loco in the study area. In this way, it was possible to quantify the direct and indirect losses related to the commercial sector in an area densely populated by commercial establishments in the Gregório watershead in the city of São Carlos (SP). For this purpose, the flood map of the basin with HEC platform software was elaborated and project data were used for modeling, and observed data in relation to precipitation and water height to verify the uncertainties. Thus, the average annual loss in different scenarios was estimated, considering the cost-benefit of mitigation measures proposed in the drainage master plan of São Carlos city, evaluating the uncertainties of the use of one-dimensional hydraulichydrological models to obtain flood heights and to quantify the direct and indirect damages of this area of study. As a result, it was verified that the temporal distribution of the rains bring uncertainties of up to $46 \%$ in the peak flow, $57 \%$ in the area of the flood prone area and 1.5 meters flow height. Also, it was verified that the structural mitigating measures obtained the same efficiency of reduction of peak of flow that the non-structural ones. In adiction, it was concluded that the use of one-dimensional models bring significant uncertainties regarding the values verified in loco. In addition, it has been found that indirect losses may underestimate the total loss suffered by traders by up to $60 \%$.

Keywords: Stage damage curves; economic evaluation of floods; average annual value of the losses; hydrological modeling 




\section{ÍNDICE DE FIGURAS}

FIGURA 1.1 - SínteSE DOS OBJETIVOS, METOdologIA, RESULTAdOS E HIPÓTESES NORTEAdORAS ...................................... 4

FIGURA 2.1 - CRESCIMENTO POPULACIONAL EM ÁREAS URBANAS E RURAIS ........................................................ 5

FIGURA 2.2 - FLUXOGRAMA SIMPLIFICADO DO PLANO DIRETOR DE DRENAGEM DE ÁGUAS PLUVIAIS ............................... 8

FIGURA 2.3 - MÉTODO DA CURVA NÍVEL-PREJUÍZO PARA ESTIMATIVA DOS PREJUÍZZOS POR INUNDAÇÃO............................... 32

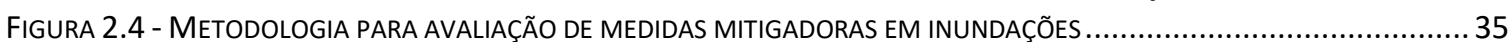

FIGURA 2.5 - CURVAS DE PROBABILIDADE DE EXCEDÊNCIA DE CHUVA DESCRITAS POR HUFF........................................... 48

FIGURA 2.6 - RESULTADOS OBTIDOS POR BRANDÃO ET AL. (2001) PARA OS POSTOS DE PORTUGAL E COMPARAÇÃO DESTES COM OS OBTIDOS POR HUFF (1967) COM 10\% DE PROBABILIDADE DE EXCEDÊNCIA..................................................5 50

FIGURA 2.7 - RESULTADOS DOS EVENTOS DE PRECIPITAÇÃO COM PICO NO $1^{\circ}$ QUARTIL PARA CHUVAS LOCALIZADAS NO CÓRREGO DO GREGÓRIO - SÃO CARLOS/SP. 51

FIGURA 2.8 - RESULTADOS DOS EVENTOS DE PRECIPITAÇÃO COM PICO NO $2^{\circ}$ QUARTIL PARA CHUVAS LOCALIZADAS NO CÓRREGO DO GREGÓRIO - SÃO CARLOS/SP 51

FIGURA 2.9 - RESULTADOS DOS EVENTOS DE PRECIPITAÇÃO COM PICO NO $3^{\circ}$ QUARTIL PARA CHUVAS LOCALIZADAS NO CÓRREGO DO GREGÓRIO - SÃO CARLOS/SP.

FIGURA 2.10 - RESULTADOS DOS EVENTOS DE PRECIPITAÇÃO COM PICO NO $4^{\circ}$ QUARTIL PARA CHUVAS LOCALIZADAS NO CÓRREGO DO GREGÓRIO - SÃo CARLOS/SP.

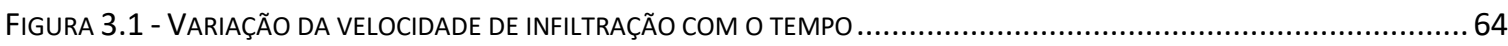

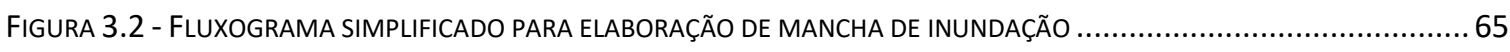

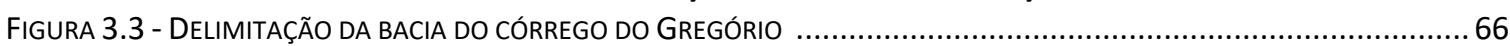

FIGURA 3.4 - INUNDAÇÃO OCORRIDA EM 7 DE OUTUBRO DE 1975 NA REGIÃO DO MERCADO MUNICIPAL............................67

FIGURA 3.5 - INUNDAÇÃO OCORRIDA EM 23 DE NOVEMBRO DE 2015 NA REGIÃO DO MERCADO MUNICIPAL........................67

FIGURA 3.6 - CONFIGURAÇÃO DAS SUB-BACIAS DO CÓRREGO DO GREGÓRIO PARA MODELAGEM CHUVA-VAZÃO ...................68

FIGURA 3.7 - COBERTURA E USO DA TERRA CLASSIFICADOS PARA A BACIA DO CóRREGO DO GREGÓRIO ...............................6 68

FIGURA 3.8 - MACROZONAS DO PLANO DIRETOR DE SÃo CARLOS PARA A BACIA DO CÓRREGO DO GREGÓRIO.......................69

FIGURA 3.9 - LOCALIZAÇÃO DOS RESERVATÓRIOS DE DETENÇÃO NA BACIA DO CÓRREGO DO GREGÓRIO...............................70

FIGURA 3.10 - DISTRIBUIÇÃO TEMPORAL DA CHUVA PELO MÉTODO DE HUFF 1ㅇ QUARTIL.............................................72

FIGURA 3.11 - COMPARAÇÃO ENTRE O PERCENTUAL ACUMULADO DE CHUVA EM RELAÇÃO AO TEMPO ENTRE A CHUVA DE PROJETO DE SÃO CARLOS/SP E A DISTRIBUIÇÃO DE HUFF 1ㅇ QUARTIL

FIGURA 3.12 - HIDROGRAMA DE CHEIA OBTIDO PELO SOFTWARE HEC-HMS COM TEMPO DE RETORNO DE 100 ANOS SOB MÉTODO DE DISTRIBUIÇÃO TEMPORAL BLOCOS ALTERNADOS .. 75

FIGURA 3.13 - HIDROGRAMA DE CHEIA OBTIDO PELO SOFTWARE HEC-HMS COM TEMPO DE RETORNO DE 100 ANOS SOB MÉTODO DE DISTRIBUIÇÃO TEMPORAL HUFF 1 QUARTIL. .75

FIGURA 3.14 - VAZÃO MÁXIMA SIMULADA NOS CENÁRIOS PROPOSTOS PARA A DISTRIBUIÇÃO TEMPORAL HUFF 1 QUARTIL.... 76

FIGURA 3.15 - VAZÃO MÁXIMA SIMULADA NOS CENÁRIOS PROPOSTOS E PARA A DISTRIBUIÇÃO TEMPORAL BLOCOS ALTERNADOS76

FIGURA 3.16 - PERCENTUAL DE MITIGAÇÃO DA VAZÃO MÁXIMA DECORRENTE DAS MEDIDAS MITIGADORAS PROPOSTAS PARA A DISTRIBUIÇÃO TEMPORAL BLOCOS ALTERNADOS E HUFF 1 QUARTIL.

FIGURA 3.17 - ÁREA MÁXIMA SIMULADA NOS CENÁRIOS PROPOSTOS PARA A DISTRIBUIÇÃO TEMPORAL BLOCOS ALTERNADOS 78 FIGURA 3.18 - ÁREA MÁXIMA SIMULADA NOS CENÁRIOS PROPOSTOS PARA A DISTRIBUIÇÃO TEMPORAL HUFF 1 QUARTIL ...... 78 FIGURA 3.19 - ÁREA DE ABRANGÊNCIA DA MANCHA DE INUNDAÇÃO NORMALIZADO DE ACORDO COM A VAZÃO SIMULADA..... 79 FIGURA 3.20 - MANCHA DE INUNDAÇÃO PARA TR 25 ANOS SOB O MÉTODO DE DISTRIBUIÇÃO TEMPORAL DE CHUVAS BLOCOS ALTERNADOS. .80

FIGURA 3.21 - MANCHA DE INUNDAÇÃO PARA TR 25 ANOS SOB O MÉTODO DE DISTRIBUIÇÃO TEMPORAL DE CHUVAS HUFF 1응 QUARTIL

FIGURA 3.22 - MANCHA DE INUNDAÇÃO PARA TR 50 ANOS SOB O MÉTODO DE DISTRIBUIÇÃO TEMPORAL DE CHUVAS BLOCOS ALTERNADOS....

FIGURA 3.23 - MANCHA DE INUNDAÇÃO PARA TR 50 ANOS SOB O MÉTODO DE DISTRIBUIÇÃO TEMPORAL DE CHUVAS HUFF 1응 QUARTIL

FIGURA 3.24 - MANCHA DE INUNDAÇÃO PARA TR 100 ANOS SOB O MÉTODO DE DISTRIBUIÇÃO TEMPORAL DE CHUVAS BLOCOS ALTERNADOS.

FIGURA 3.25 - MANCHA DE INUNDAÇÃO PARA TR 100 ANOS SOB O MÉTODO DE DISTRIBUIÇÃO TEMPORAL DE CHUVAS HUFF 1응 QUARTIL.

FIGURA 3.26 - PROFUNDIDADE MÁXIMA SIMULADA NOS CENÁRIOS PROPOSTOS A DISTRIBUIÇÃO TEMPORAL HUFF 1ㅇ QUARTIL 82 FIGURA 3.27 - VAZÃO MÁXIMA SIMULADA NOS CENÁRIOS CRIADOS PARA A DISTRIBUIÇÃO TEMPORAL BLOCOS ALTERNADOS ... 82 
FIGURA 3.28 - PROFUNDIDADE MÁXIMA E ÁREA DA MANCHA DE INUNDAÇÃO NORMALIZADA EM RELAÇÃO A VAZÃO..............8 82

FIGURA 4.1 - FLUXOGRAMA SIMPLIFICADO PARA ELABORAÇÃO DO CUSTO-BENEFÍCIO DE MEDIDAS MITIGADORAS...................88

FIGURA 4.2 - MAPA DE LOGRADOUROS DO MUNICÍPIO DE SÃO CARLOS - SP .......................................................89

FIGURA 4.3 - EXEMPLO DE VETORIZAÇÃO DOS POLÍGONOS DOS TELHADOS DOS IMÓVEIS INSERIDOS NA ÁREA SUJEITA A INUNDAÇÃO

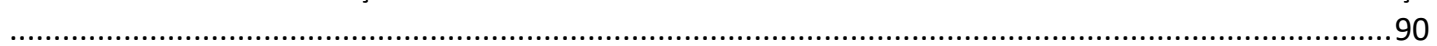

FIGURA 4.4 - CURVAS DE DANOS POR PROFUNDIDADE DE SUBMERSÃo (DPS) POR CATEGORIA DE ATIVIDADE COMERCIAL.......94

FIGURA 4.5 - MAPA DA MANCHA DE INUNDAÇÃO COM OS IMÓVEIS CADASTRADOS PARA O TEMPO DE RETORNO DE 25 ANOS EM UM CENÁRIO ATUAL E LIMITE DA ÁREA ATINGIDA PELA MANCHA DE INUNDAÇÃO (CENÁRIO FUTURO COM TR 100 ANOS) ....97

FIGURA 4.6 - PREJUÍZO TOTAL NOS CENÁRIOS PROPOSTOS COM DISTRIBUIÇÃO HUFF 1ㅇ QUARTIL ....................................98

FIGURA 4.7 - PREJUÍZO TOTAL NOS CENÁRIOS PROPOSTOS COM DISTRIBUIÇÃO BLOCOS ALTERNADOS ..................................98

FIGURA 4.8 - PERCENTUAL DE REDUÇÃO DO PREJUíZO DAS MEDIDAS MITIGADORAS COM A DISTRIBUIÇÃO HUFF 1 QUARTIL....98

FIGURA 4.9 - PERCENTUAL DE REDUÇÃO DO PREJUíZO DAS MEDIDAS MITIGADORAS COM A DISTRIBUIÇÃO TEMPORAL BLOCOS

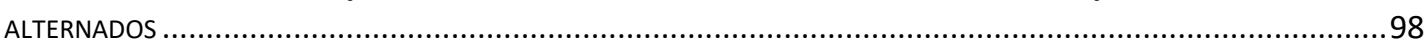

FIGURA 4.10 - MÉTODO DA CURVA NÍVEL-PREJUÍZO PARA ESTIMATIVA DOS PREJUÍZOS POR INUNDAÇÃO APLICADO A REGIÃO DE

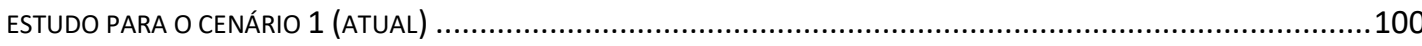

FIGURA 4.11 - MÉTODO DA CURVA NÍVEL-PREJUÍZO PARA ESTIMATIVA DOS PREJUÍZOS POR INUNDAÇÃO APLICADO A REGIÃO DE ESTUDO PARA O CENÁRIO 2 (ATUAL COM MEDIDAS MITIGADORAS) .......................................................... 101

FIGURA 4.12 - MÉTODO DA CURVA NÍVEL-PREJUÍZO PARA ESTIMATIVA DOS PREJUÍZOS POR INUNDAÇÃO APLICADO A REGIÃO DE

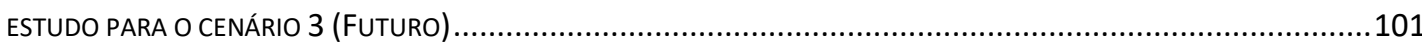

FIGURA 4.13 - MÉTODO DA CURVA NÍVEL-PREJUÍZO PARA ESTIMATIVA DOS PREJUÍZOS POR INUNDAÇÃO APLICADO A REGIÃO DE ESTUDO PARA O CENÁRIO 4 (FUTURO COM MEDIDAS ESTRUTURAIS) ......................................................... 102

FIGURA 4.14 - MÉTODO DA CURVA NÍVEL-PREJUíZO PARA ESTIMATIVA DOS PREJUÍZOS POR INUNDAÇÃO APLICADO A REGIÃO DE ESTUDO PARA O CENÁRIO 5 (FUTURO COM MEDIDAS NÃO ESTRUTURAIS) ….............................................102

FIGURA 4.15 - MÉTODO DA CURVA NÍVEL-PREJUÍZO PARA ESTIMATIVA DOS PREJUÍZOS POR INUNDAÇÃO APLICADO A REGIÃO DE ESTUDO PARA O CENÁRIO 6 (FUTURO COM MEDIDAS ESTRUTURAIS E NÃO ESTRUTURAIS) ....................................103

FIGURA 4.16 - CURVA PREJUÍZO POR PROBABILIDADE DE EXCEDÊNCIA PARA O CENÁRIO ATUAL SOB DISTRIBUIÇÃO HUFF 1으 QUARTIL

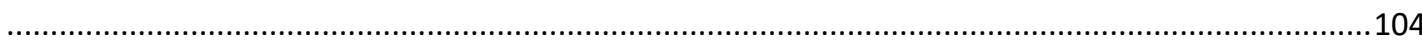

FIGURA 4.17 - CURVA PREJUÍZO POR PROBABILIDADE DE EXCEDÊNCIA PARA O CENÁRIO ATUAL COM MEDIDAS ESTRUTURAIS SOB DISTRIBUIÇÃO HUFF 1 QUARTIL. 104

FIGURA 4.18 - CURVA PREJUÍZO POR PROBABILIDADE DE EXCEDÊNCIA PARA O CENÁRIO FUTURO SOB DISTRIBUIÇÃO HUFF 1으ARTIL 104

FIGURA 4.19 - CURVA PREJUÍZO POR PROBABILIDADE DE EXCEDÊNCIA PARA O CENÁRIO FUTURO COM MEDIDAS ESTRUTURAIS SOB

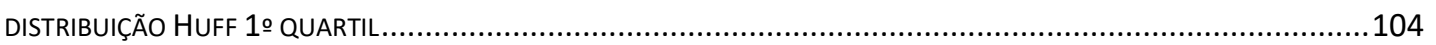

FIGURA 4.20 - CURVA PREJUÍZO POR PROBABILIDADE DE EXCEDÊNCIA PARA O CENÁRIO FUTURO COM MEDIDAS NÃO ESTRUTURAIS SOB DISTRIBUIÇÃO HUFF 1 QUARTIL. 104

FIGURA 4.21 - CURVA PREJUÍZO POR PROBABILIDADE DE EXCEDÊNCIA PARA O CENÁRIO FUTURO COM MEDIDAS ESTRUTURAIS E NÃO ESTRUTURAIS SOB DISTRIBUIÇÃO HUFF 1 QUARTIL .......................................................................... 104

FIGURA 4.22 - CURVA PREJUÍZO POR PROBABILIDADE DE EXCEDÊNCIA PARA O CENÁRIO ATUAL SOB DISTRIBUIÇÃO BLOCOS ALTERNADOS 105

FIGURA 4.23 - CURVA PREJUÍZO POR PROBABILIDADE DE EXCEDÊNCIA PARA O CENÁRIO ATUAL COM MEDIDAS ESTRUTURAIS SOB DISTRIBUIÇÃO BLOCOS ALTERNADOS.

FIGURA 4.24 - CURVA PREJUÍZO POR PROBABILIDADE DE EXCEDÊNCIA PARA O CENÁRIO FUTURO SOB DISTRIBUIÇÃO BLOCOS ALTERNADOS . .105

FIGURA 4.25 - CURVA PREJUÍZO POR PROBABILIDADE DE EXCEDÊNCIA PARA O CENÁRIO FUTURO COM MEDIDAS ESTRUTURAIS SOB

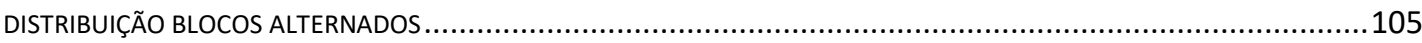

FIGURA 4.26 - CURVA PREJUÍZO POR PROBABILIDADE DE EXCEDÊNCIA PARA O CENÁRIO FUTURO COM MEDIDAS NÃO ESTRUTURAIS SOB DISTRIBUIÇÃO BLOCOS ALTERNADOS ..................................................................................... 105

FIGURA 4.27 - CURVA PREJUÍZO POR PROBABILIDADE DE EXCEDÊNCIA PARA O CENÁRIO FUTURO COM MEDIDAS ESTRUTURAIS E NÃO ESTRUTURAIS SOB DISTRIBUIÇÃO BLOCOS ALTERNADOS 105

FIGURA 4.28 - CURVA PREJUÍZO POR PROBABILIDADE DE EXCEDÊNCIA PARA OS CENÁRIOS PROPOSTOS SOB A DISTRIBUIÇÃO HUFF 1으 QUARTIL 108

FIGURA 4.29 - CURVA PREJUíZO POR PROBABILIDADE DE EXCEDÊNCIA PARA OS CENÁRIOS PROPOSTOS SOB A DISTRIBUIÇÃO BLOCOS ALTERNADOS .110

FIGURA 4.30 - MÉTODO DA CURVA NÍVEL PREJUÍZO PARA AVALIAÇÃO ECONÔMICA DE PROJETOS DE DRENAGEM PARA O CENÁRIO 4 (ATUAL COM MEDIDAS MITIGADORAS) E DISTRIBUIÇÃO HUFF 1ㅇ QUARTIL 112 
Figura 4.31 - MÉTOdo da CURVA NÍVEL PREJUízo PARA AVALIAÇÃo ECONÔMICA DE PROJETOS DE DRENAGEM PARA O CENÁRIO 4 (ATUAL COM MEDIDAS MITIGADORAS) E DISTRIBUIÇÃO BLOCOS ALTERNADOS.....

FiguRA 4.32 - MÉTOdO dA CURVA NÍVEL PREJUÍZO PARA AVALIAÇÃo ECONÔMICA DE PROJETOS DE DRENAGEM PARA O CENÁRIO 4 (ATUAL COM MEDIDAS MITIGADORAS) E DISTRIBUIÇÃO HUFF 1 QUARTIL.

FIGURA 4.33 - MÉTOdO DA CURVA NÍVEL PREJUÍZO PARA AVALIAÇÃO ECONÔMICA DE PROJETOS DE DRENAGEM PARA O CENÁRIO 4 (ATUAL COM MEDIDAS MITIGADORAS) E DISTRIBUIÇÃO BLOCOS ALTERNADOS. 112

FIGURA 4.34 - MÉTOdO DA CURVA NÍVEL PREJUÍZO NA AVALIAÇÃO ECONÔMICA DE PROJETOS DE DRENAGEM PARA CENÁRIO 5 (FUTURO COM MEDIDAS NÃO ESTRUTURAIS) E DISTRIBUIÇÃO HUFF 1ㅇ QUARTIL. 112

FIGURA 4.35 - MÉTOdO dA CURVA NÍVEL PREJUÍZO NA AVALIAÇÃo ECONÔMICA DE PROJETOS DE DRENAGEM PARA CENÁRIO 5 (FUTURO COM MEDIDAS NÃO ESTRUTURAIS) E DISTRIBUIÇÃO BLOCOS ALTERNADOS..... 112

FIgURA 4.36 - MÉTOdO dA CURVA NÍVEL PREJUÍZO NA AVALIAÇÃO ECONÔMICA DE PROJETOS DE DRENAGEM PARA CENÁRIO 6 (FUTURO COM AMBAS MEDIDAS) E DISTRIBUIÇÃO HUFF 1ㅇ QUARTIL. 113

FIgURA 4.37 - MÉTOdO dA CURVA NÍVEL PREJUíZO NA AVALIAÇÃo ECONÔMICA DE PROJETOS DE DRENAGEM PARA CENÁRIO 6 (FUTURO COM AMBAS MEDIDAS) E DISTRIBUIÇÃO BLOCOS ALTERNADOS. 113

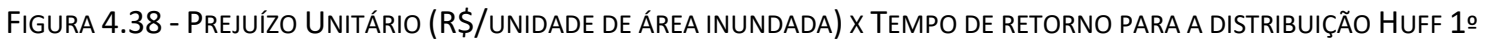
QUARTIL....

FIGURA 4.39 - PREJUÍZO UNITÁRIO (R\$̧/UNIDADE DE ÁREA INUNDADA) X TEMPO DE RETORNO PARA A DISTRIBUIÇÃO BLOCOS ALTERNADOS

FIGURA 4.40 - RELAÇão CUSTO UNITÁRIO (CUSTO/UNIDADE DE ÁREA INUNDADA) X VAZÃo UNITÁRIA (VAZÃo/ÁREA) PARA A ÁREA TOTAL DA BACIA

FIGURA 4.41- RELAÇÃo CUSTO UNITÁRIO (CUSTO/UNIDADE DE ÁREA INUNDADA) X VAZÃo UNITÁRIA (VAZÃO/ÁREA) PARA A ÁREA TOTAL DA BACIA.

FIGURA 4.42 - RELAÇÃO CUSTO UNITÁRIO X VAZÃO UNITÁRIA PARA A ÁREA DA MANCHA DE INUNDAÇÃO ..........................117

FIGURA 4.43 - RELAÇÃO CUSTO UNITÁRIO X VAZÃO UNITÁRIA PARA A ÁREA DA MANCHA DE INUNDAÇÃO ...........................117

FIGURA 4.44 - COMPARAÇÃO ENTRE O PREJUÍZO OBTIDO NAS PESQUISAS DE GRACIOSA E NA PRESENTE PARA O CENÁRIO ATUAL122

FIGURA 4.45 - COMPARAÇÃO ENTRE O PREJUÍZO OBTIDO NAS PESQUISAS DE GRACIOSA E NA PRESENTE PARA O CENÁRIO ATUAL122

FIGURA 5.1 - FLUXOGRAMA SIMPLIFICADO DA METODOLOGIA PARA COMPARAÇÃO ENTRE OS VALORES DE ALTURA SIMULADA E OBSERVADA .

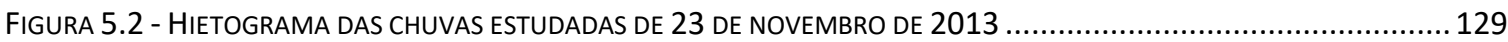

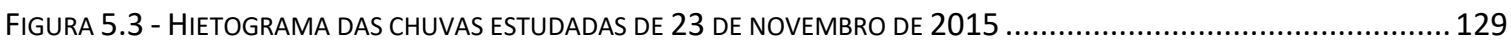

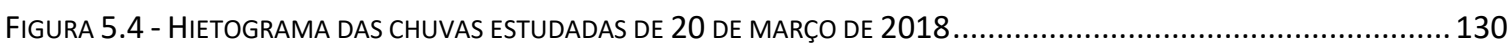

FIGURA 5.5 - PONTOS DE OBTENÇÃO DAS ALTURAS DE SUBMERSÃO ................................................................. 131

FIGURA 5.6 - CURVAS ADIMENSIONAIS PRECIPITAÇÃO X TEMPO DOS EVENTOS SIMULADOS E COMPARAÇÃO COM OS QUARTIS OBSERVADOS POR HUFF (1967)

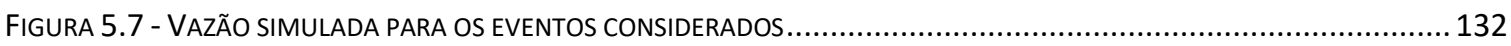

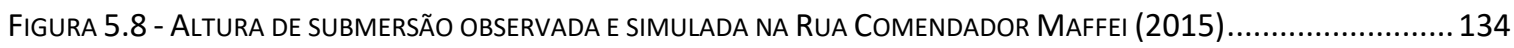

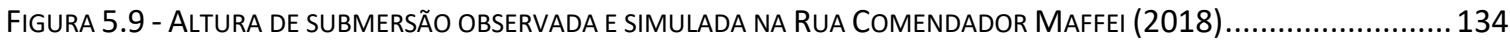

FIGURA 5.10 - AltURA DE SUBMERSÃO OBSERVAdA E SIMULAdA NA RUA EPISCOPAL (2015) ...................................134

FIGURA 5.11 - ALTURA DE SUBMERSÃO OBSERVAdA E SIMULADA NA RUA EPISCOPAL (2018) ........................................ 134

FIGURA 5.12 - ALTURA DE SUBMERSÃo OBSERVADA E SIMULADA NA RUA GEMINIANO COSTA (2015) .............................134

FIGURA 5.13 - ALTURA DE SUBMERSÃo OBSERVAdA E SIMULAdA NA RUA GEMINIANO COSTA (2018)............................ 134

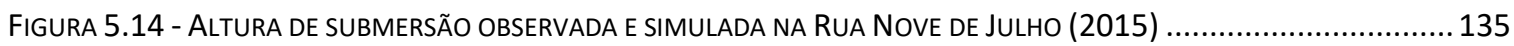

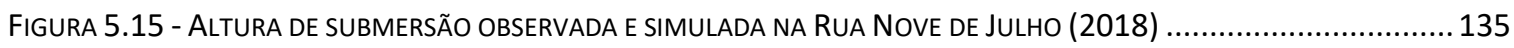

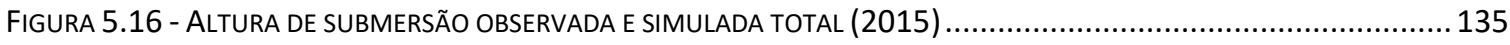

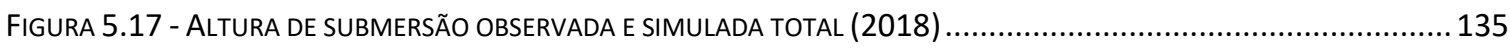

FIGURA 5.18 - BOXPLOT REFERENTE A ALTURA OBSERVADA X SIMULADA PARA A RUA COMENDADOR MAFFEI.....................137

FIGURA 5.19 - BOXPLOT REFERENTE A ALTURA OBSERVADA X SIMULADA PARA A RUA NOVE DE JULHO ..............................137

FIGURA 5.20 - BOXPLOT REFERENTE A ALTURA OBSERVADA X SIMULADA PARA A RUA EPISCOPAL.................................... 137

FIGURA 5.21 - BOXPLOT REFERENTE A ALTURA OBSERVADA X SIMULADA PARA A RUA GEMINIANO COSTA ......................... 137

FIGURA 5.22 - BOXPLOT REFERENTE A ALTURA OBSERVADA X SIMULADA TOTAL................................................... 137

FIGURA 6.1 - FLUXOGRAMA SIMPLIFICADA DA OBTENÇÃO DO PREJUÍZO TOTAL DOS DANOS PROVOCADOS PELA INUNDAÇÃO.. 141

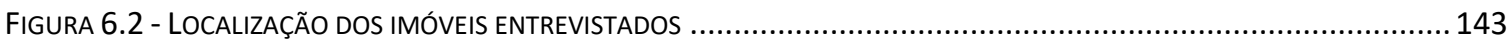

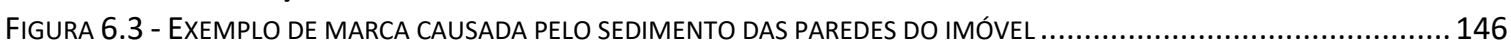

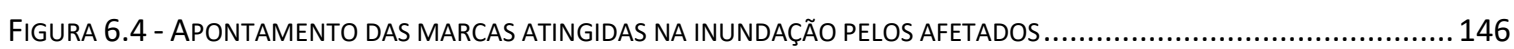


FIGURA 6.5 - MEDIÇÃO DA ALTURA DA COMPORTA E DA ALTURA DA PLANTA BAIXA EM RELAÇÃO A CALÇADO DOS IMÓVEIS ATINGIDOS

FIGURA 6.6 - VALOR MÉDIO SALARIAL DA CATEGORIA “VENDEDOR DE LOJA” DE ACORDO COM A EXPERIÊNCIA PROFISSIONAL.152

FIGURA 6.7 - CLIENTES AGUARDAM LIQUIDAÇÃO DE PRODUTOS ATINGIDOS PELA INUNDAÇÃO DE 2015 ............................157

FIGURA 6.8 - CLIENTES AGUARDAM LIQUIDAÇÃO DE PRODUTOS ATINGIDOS PELA INUNDAÇÃO DE 2018 ............................157

FIGURA 6.9 - RELAÇÃO ENTRE A FREQUÊNCIA DE EVENTOS DE INUNDAÇÃO E O TEMPO DE PERMANÊNCIA DO COMERCIANTE NO LOCAL

159

FIGURA 6.10 - RELAÇÃO SÓCIO HIDROLÓGICA ADAPTATIVA ENTRE AS INUNDAÇÕES E A POPULAÇÃO ATENDIDA ...................160

FIGURA 6.11 - RELAÇÃO ALTURA EXTERNA X INTERNA EM 2015 E 2018 ............................................................161

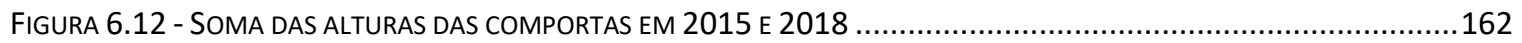

FIGURA 6.13 - GRÁFICO BOXPLOT DA ALTURA DA COMPORTA NOS EVENTOS DE 2015 E 2018 ...................................163

FIGURA 6.14 - EXEMPLOS DE COMPORTAS INSTALADAS NOS IMÓVEIS AFETADOS PELAS INUNDAÇÕES .................................163

FIGURA 6.15 - PREJUÍZO INDIVIDUAL POR ALTURA DE SUBMERSÃO SOFRIDO PELAS EMPRESAS ENTREVISTAS .........................165

FIGURA 6.16 - PREJUízO INDIVIDUAL POR ALTURA DE SUBMERSÃO SOFRIDO PELAS EMPRESAS ENTREVISTAS COM EXCLUSÃO DE OUTLIERS

FIGURA 6.17 - PREJUÍZO INDIVIDUAL POR ALTURA DE SUBMERSÃO SOFRIDO PELAS EMPRESAS ENTREVISTAS .......................166

FIGURA 6.18 - PREJUÍZO INDIVIDUAL APRESENTADO PELAS EMPRESAS AFETADAS ....................................................167

FIGURA 6.19 - PREJUízo UNITÁRIO (R\$\$/M2) POR ALTURA DE INUNDAÇÃo PARA OS EVENTOS DE 2015 E 2018.................171

FIGURA 6.20 - PREJUÍZO UNITÁRIO NORMALIZADO, ANÁLISE ESTATístICA E TESTE DE ANDERSON PARA O EVENTO DE 2015 ..172

FIGURA 6.21 - PREJUÍZO UNITÁRIO NORMALIZADO, ANÁLISE ESTATíSTICA E TESTE DE ANDERSON PARA O EVENTO DE 2018 ..172

FIGURA 6.22 - BOXPLOT DA VARIÁVEL PREJUÍZO POR ÁREA DO ESTABELECIMENTO PARA OS EVENTOS DE 2015 E 2018........172

FIGURA 6.23 - FREQUÊNCIA DE EMPRESAS POR CATEGORIA DE DANOS POR PROFUNDIDADE DE SUBMERSÃO PAR OS EVENTOS

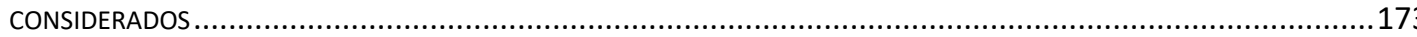

FIGURA 6.24 - RELAÇÃO PREJUÍZO/ESTOQUE POR ALTURA DE INUNDAÇÃO .........................................................174

FIGURA 6.25 - COMPARAÇÃO ENTRE OS PERCENTUAIS DE PREJUÍZO EM RELAÇÃO AO ESTOQUE POR ALTURA DE SUBMERSÃO OBTIDOS

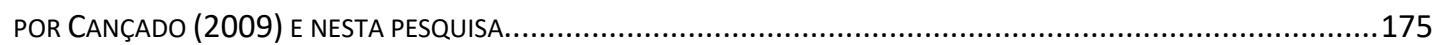

FIGURA 6.26 - QUANTIFICAÇÃO POR CATEGORIA DE PERDAS OBSERVADOS PELOS COMERCIANTES ..................................175

FIGURA 6.27 - NÚMERO DE FUNCIONÁRIOS EM RELAÇÃO AO ESTOQUE ..................................................................176

FIGURA 6.28 - COMPARAÇÃO ENTRE OS PREJUÍZOS SOFRIDOS PELAS EMPRESAS ENTREVISTAS E OS OBTIDOS POR MACHADO (2005)

FiguRA 6.29 - COMPARAÇÃo ENTRE OS VALORES DE PREJUÍZO UTILIZANDO AS CURVAS ELABORADAS POR MACHADO (2005) E AS

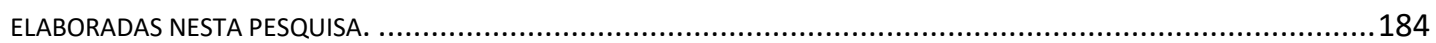

FIGURA 6.30 - CoMPARAÇão do PREJUízo dos IMÓVEIS COMERCIAS NAS PESQUISAS DE RIGUETTO (2005), MACHADO (2005) E NA

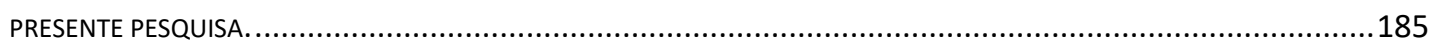

FIGURA 6.31 - COMPARAÇÃO ENTRE AS CURVAS DPS ELABORADAS POR MACHADO (2005) E AS ELABORADAS NESTA PESQUISA.186

FIGURA 6.32 - VALORES DE DISPONIBILIDADE A PAGAR OBTIDOS PELAS ENTREVISTAS DE RIGUETTO (2005) E NESTA PESQUISA187

FIGURA 6.33 - GRÁFICOS BOXPLOT DA DISPONIBILIDADE A PAGAR OBTIDOS NAS ENTREVISTAS DE RIGUETTO (2005) E NESTA PESQUISA 187

FIGURA 6.34 - CURVAS DE DISPONIBILIDADE A PAGAR ADIMENSIONALISADAS ELABORADAS BASEADAS NAS ENTREVISTAS DE RIGUETTO

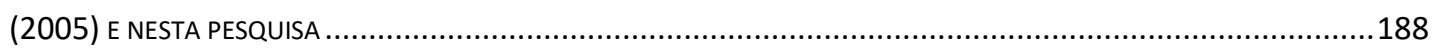

FIGURA 6.35 - ESTOQUE MÉDIO DECLARADO NAS PESQUISAS DE RIGUETTO (2005) E NESTA PESQUISA ............................189

FIGURA 6.36 - RELAÇÃO ENTRE ESTOQUE E PREJUÍZO NORMALIZADO VERIFICADO NAS PESQUISAS DE RIGUETTO (2005) E NESTA

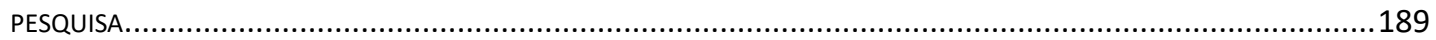

FIGURA 6.37 - COMPARAÇÃO ENTRE A DISPONIBILIDADE A PAGAR ENTRE A PRESENTE PESQUISA E A PESQUISA DE RIGUETTO (2005) 190

FIGURA 6.38 - COMPARAÇÃO ENTRE A DISPONIBILIDADE A PAGAR ENTRE A PRESENTE PESQUISA E A PESQUISA DE RIGUETTO (2005) 


\section{ÍNDICE DE TABELAS}

TABELA 2.1 - LOCALIZAÇÃO dOS CÓRREGOS DO MUNICÍPIO dE SÃo CARLOS NAS MACROZONAS.

TABELA 2.2 - MATRIZ DAS CURVAS DE PREJUÍZO BASEADAS NO TAMANHO E CLASSES DE VALORES COM MÉDIA DOS DANOS PARA CADA CLASSE.....

TABELA 2.3 - PRINCIPAIS VARIÁVEIS QUE INFLUENCIAM NOS DANOS POTENCIAIS AOS IMÓVEIS COMERCIAIS..........................2 21

TABELA 2.4 - ÍNDICE DE AMEAÇA DA INUNDAÇÃO AO CONTEÚDO DOS DOMICÍLIOS - IAM2 ..........................................24

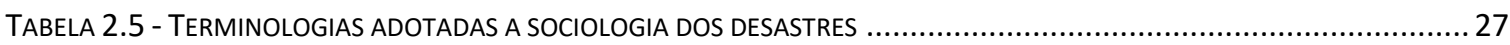

TABELA 2.6 - VANTAGENS E DESVANTAGENS DAS TÉCNICAS COMPENSATÓRIAS DE DRENAGEM URBANA...............................40

TABELA 2.7 - ALGUNS CONCEITOS UTILIZADOS PARA DEFINIR AS INUNDAÇÕES ........................................................... 44

TABELA 2.8 - PERCENTUAL DE CHUVA ACUMULAdA NO TEMPO PARA A DISTRIBUIÇÃO DE HUFF 1 QUARTIL COM 50 \% DE

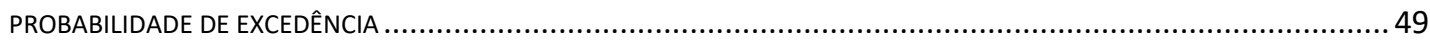

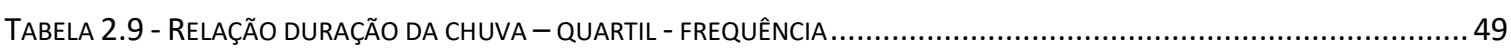

TABELA 3.1 - VALORES DE CN MÉDIO PARA CADA SUB-BACIA NOS RESPECTIVOS CENÁRIOS ............................................ 70

TABELA 3.2 - MÉdIA PONDERADA DO CURVE NUMBER (CN) PARA OS CENÁRIOS SIMULAdOS ..........................................71

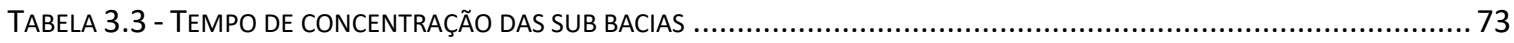

TABELA 4.1 - ORÇAMENTO DOS RESERVATÓRIOS DE DETENÇÃO NA BACIA DO CÓRREGO DO GREGÓRIO ...............................91

TABELA 4.2 - CUSTOS ENVOLVIDOS NA IMPLEMENTAÇÃO DOS RESERVATÓRIOS DE DETENÇÃO.........................................93

TABELA 4.3 - CLASSIFICAÇÃO DO TIPO DE ATIVIDADE E EQUAÇÃO UTILIZADA PARA CALCULAR OS DANOS POR PROFUNDIDADE DE SUBMERSÃO DAS EMPRESAS CONTIDAS NA MANCHA DE INUNDAÇÃO .......................................................... 94

TABELA 4.4 - COEFICIENTES OBTIDOS COM A OTIMIZAÇÃO PELOS MÉTODOS DE NASH E VOLUMÉTRICO............................... 105

TABELA 4.5 - VALOR MÉDIO ANUAL DOS DANOS PARA A DISTRIBUIÇÃO TEMPORAL HUFF 1ㅇ QUARTIL.................................106

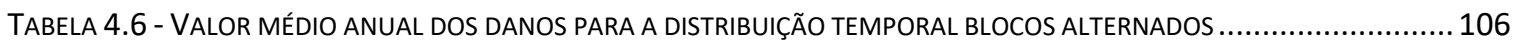

TABELA 4.7 - BENEFÍCIO DAS MEDIDAS MITIGADORAS PARA A DISTRIBUIÇÃO HUFF 1으. QUARTIL......................................109

TABELA 4.8 - BENEFÍCIO DAS MEDIDAS MITIGADORAS PARA A DISTRIBUIÇÃO BLOCOS ALTERNADOS..................................110

TABELA 4.9 - INCERTEZA ENTRE OS MÉTODOS DE DISTRIBUIÇÃO AVALIADOS PARA A DISTRIBUIÇÃO HUFF 1 QUARTIL ............115

TABELA 4.10 - VALOR DO CUSTO SUBTRAÍDO DO BENEFÍCIO ENTRE OS MÉTODOS DE DISTRIBUIÇÃO AVALIADOS ...................115

TABELA 5.1 - COMPARAÇÃO ESTATÍSTICA ENTRE OS VALORES REAIS DE ALTURA DE SIMULAÇÃO REAIS E SIMULADOS ..............136

TABELA 6.1 - TIPO DE ATIVIDADE COMERCIAL E MÉDIA NACIONAL DO FATURAMENTO E DO ESTOQUE EM 31.12.2015 ........150

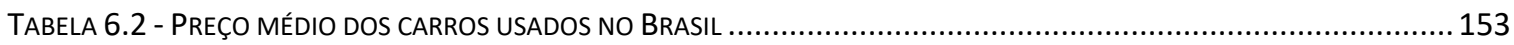

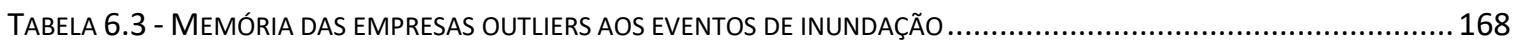

TABELA 6.4 - VALORES DE ESTOQUE E PREJUÍZO DAS EMPRESAS CONSIDERADAS OUTLIERS ...........................................169

TABELA 6.5 - PREJUÍZOS POR CATEGORIA DOS COMERCIANTES OUTLIERS ........................................................... 170

TABELA 6.6 - ÍNDICE DE AMAÇA A INUNDAÇÃO OBTIDOS POR CANÇADO (2009) PARA A ÁREA DE ESTUdO dE SÃo CARLOS ... 174

TABELA 6.7 - VALORES DECLARAdOS PELA PREFEITURA MUNICIPAL DE SÃo CARLOS REFERENTE AS OBRAS DE REPARO E SERVIÇOS EXECUTADOS.

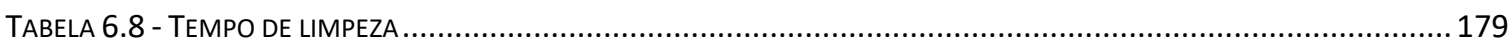

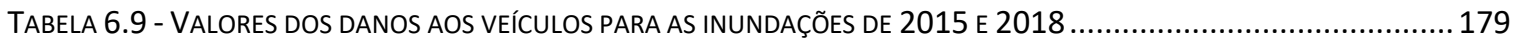

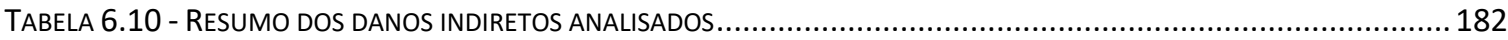

TABELA 6.11 - DANOS DIRETOS E INDIRETOS PROVOCADOS NOS EVENTOS ANALISADOS ............................................. 182 


\section{LISTA DE ABREVIAÇÕES}

$\mathrm{CN}$ - Curve Number

DPS - Danos por Profundidade de Submersão

HEC - Hidrological Engennering Center

HMS - Hidrological Model System

MDT - Model Digital do Terreno

NRCS - Natural Resources Conservation Service

PMSC - Prefeitura Municipal de São carlos

RAS - River Analysis System

SCS - Soil Conservation Service

SIG - Sistema de Informações Geográficas

TR - Tempo de Retorno 
SUMÁRIO

1. INTRODUÇÃO

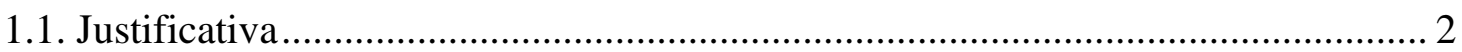

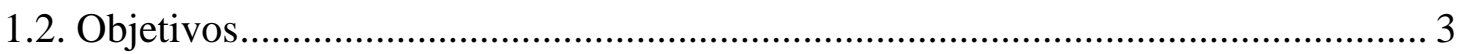

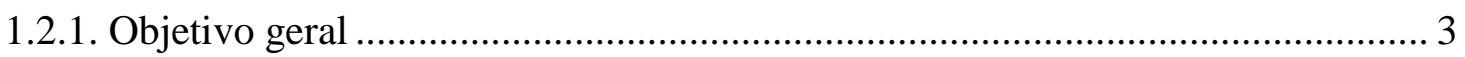

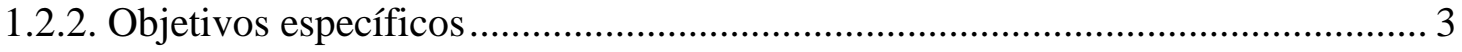

CAPÍTULO 2 - REVISÃO BIBLIOGRÁFICA.................................................................5

2.1. Processo de urbanização no Brasil ........................................................................ 5

2.2. Contexto histórico da drenagem urbana ............................................................. 5

2.2.1. Contexto da drenagem urbana no Brasil........................................................... 6

2.2.2. Conceitos relativos à gestão de drenagem urbana sustentável de águas pluviais. 7

2.3. Plano Diretor de Desenvolvimento Urbano …………………………………....... 9

2.4. Avaliação econômica de danos............................................................................... 17

2.4.1. Avaliação de danos provocados por inundações .................................................. 17

2.4.2. Pesquisas relacionadas a avaliação de danos de inundação .................................. 22

2.4.3. Índice de ameaça de inundação ao conteúdo dos imóveis..................................... 24

2.5. Conceitos e definições atribuídas a sociologia dos desastres .................................. 25

2.5.1. Vulnerabilidade social e prejuízos diretos decorrentes de inundações urbanas . 28

2.6. Classificação dos danos causados por inundações ………………………………... 29

2.7. Curvas de danos por profundidade de submersão (DPS) ………........................... 30

2.8. Avaliação de sistemas de controle de inundações ..................................................... 33

2.8.1. Técnicas compensatórias de drenagem urbana................................................. 36

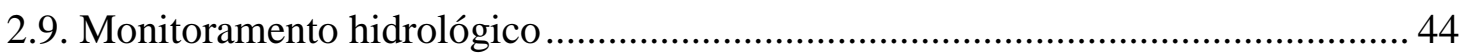

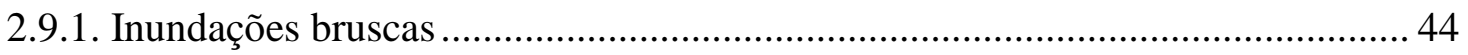

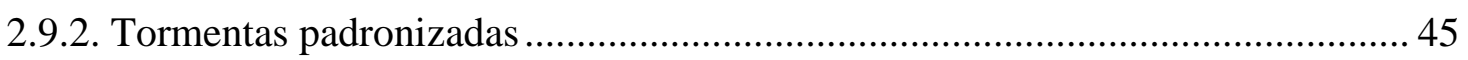

2.9.3. Distribuição temporal das chuvas ....................................................................... 46

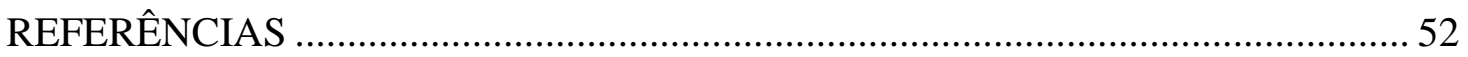

PARTE I _ANÁLISE A PRIORI ................................................................................5 59

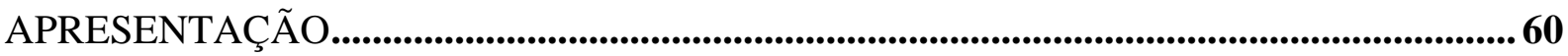

CAPÍTULO 3 - ANÁlISE DA DISTRIBUIÇÃO TEMPORAL DAS CHUVAS EM EVENTOS HIDROLÓGICOS EXTREMOS..................................................................62 
RESUMO. .62

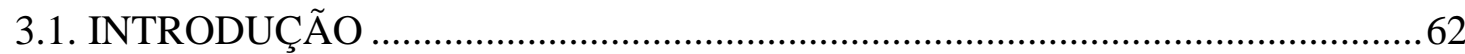

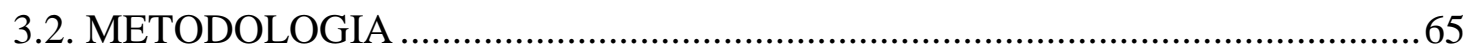

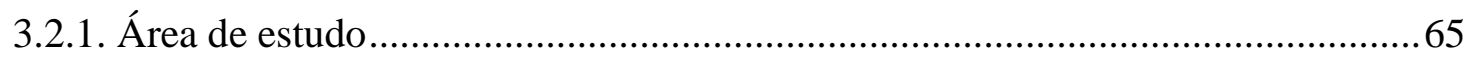

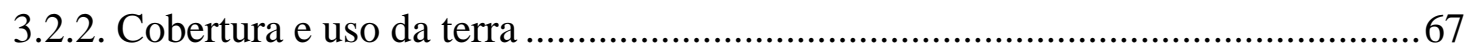

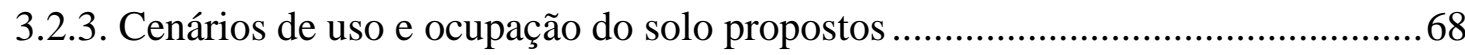

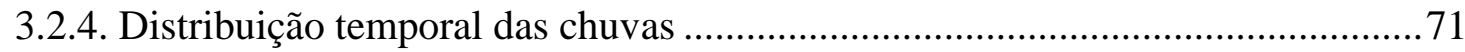

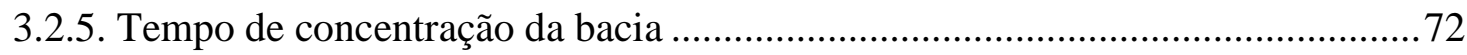

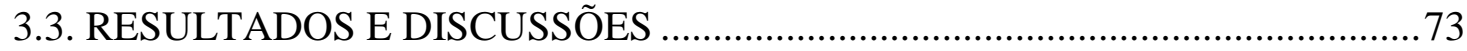

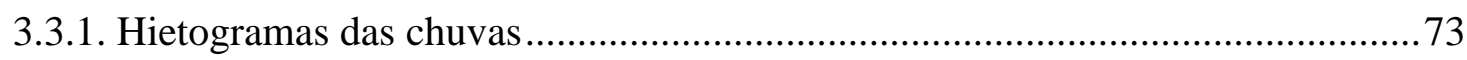

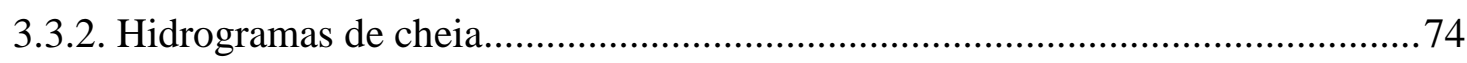

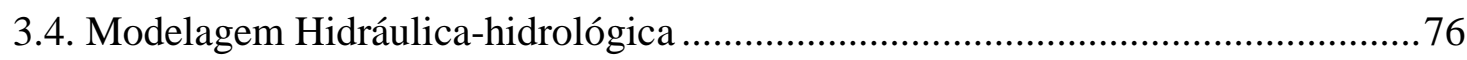

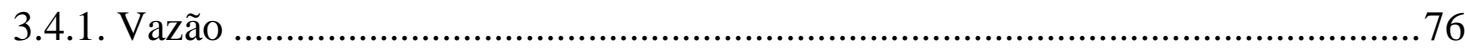

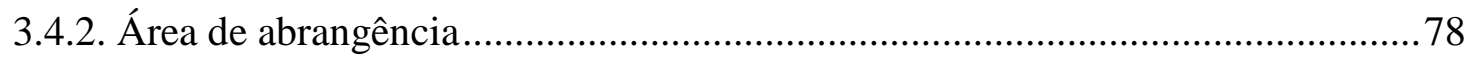

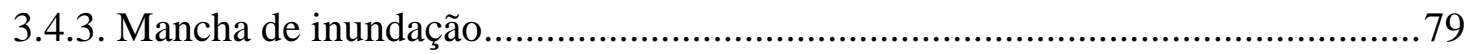

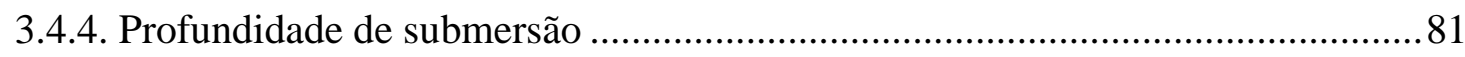

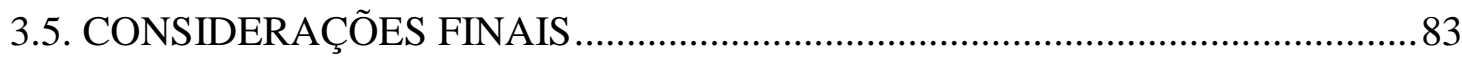

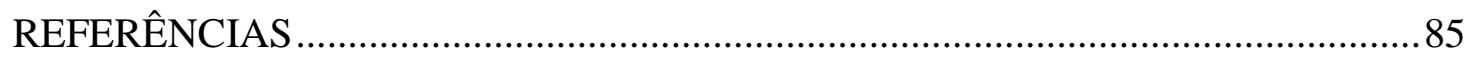

CAPÍTULO 4 - AVALIAÇÃO CUSTO-BENEFíCIO DE MEDIDAS MITIGADORAS

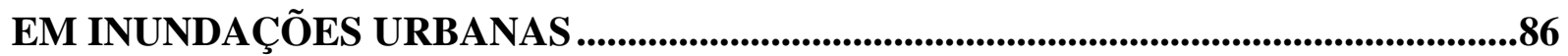

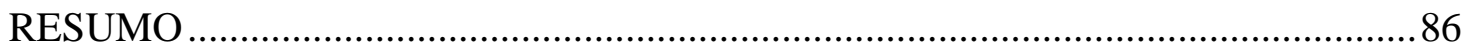

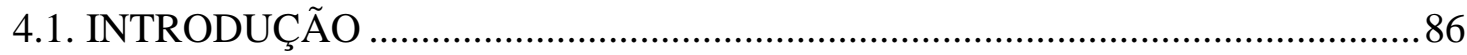

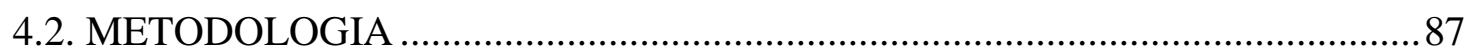

4.2.1. Identificação e cadastramento dos imóveis afetados ......................................... 88

4.2.2. Análise dos custos das medidas mitigadoras propostas ..................................91

4.2.3. Análise dos danos (benefícios) causados pela inundação ...................................93

4.2.4. Prejuízo médio anual esperado ........................................................................ 95

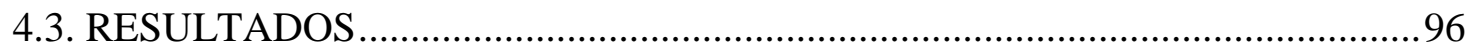

4.3.1. Mapeamento dos valores de altura de inundação...............................................96

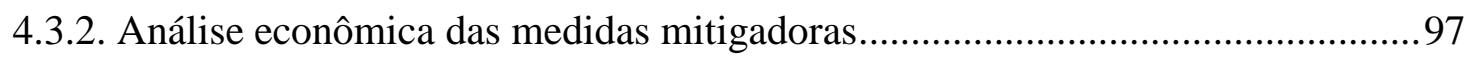

4.3.3. Valor do prejuízo médio anual esperado...................................................... 103

4.3.4. Avaliação dos benefícios das medidas mitigadoras propostas.......................... 107

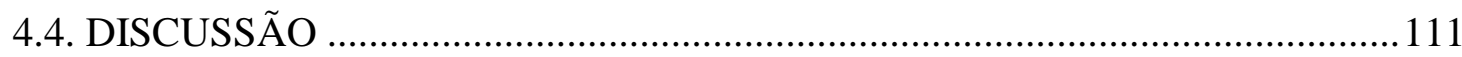


4.4.1. Análise custo-benefício

4.4.2. Análise unitária dos dados

4.4.3. Análise das incertezas baseada na escala de análise (micro e meso escala)..... 118

4.5. CONCLUSÕES

REFERÊNCIAS

PARTE II -_ANÁLISE A POSTERIORI.

CAPÍTULO 5 - INCERTEZAS DO USO DE MODELOS CONCEITUAIS UNIDIMENSIONAIS NA VALIDAÇÃO DE ALTURAS DE SUBMERSÃO.

RESUMO

5.1. INTRODUÇÃO

5.2. METODOLOGIA

5.2.1. Definição dos hietogramas de projeto e simulação hidráulica-hidrológica.....

5.2.2. Identificação e cadastramento dos imóveis afetados 130

5.3. RESULTADOS

5.3.1. Análise adimensional dos hietogramas dos eventos

5.3.2. Simulação hidrológica

5.3.3. Análise das alturas de inundação.

5.4. CONCLUSÃO.

REFERÊNCIAS BIBLIOGRÁFICAS

CAPÍTULO 6 - ANÁLISE QUALI-QUANTITATIVA DO EFEITOS DAS INUNDAÇÕES URBANAS AOS IMÓVEIS COMERCIAIS LOCALIZADOS NA REGIÃO DO MERCADO MUNICIPAL

RESUMO 140

6.1. INTRODUÇÃO..... 140

6.2. METODOLOGIA

6.2.1. Identificação e cadastramento dos imóveis afetados

6.2.2. Elaboração de questionário aplicado ao setor comercial

6.2.3. Aplicação de questionário aos comerciantes da região diretamente impactados pelas inundações.

6.2.4. Medição das variáveis obtidas in loco 145

6.2.5. Análise dos custos diretos e indiretos das inundações 147

6.2.6. Análise comparativa estatística dos dados obtidos nas entrevistas com aqueles obtidos por Machado (2005) e Riguetto (2005) 
6.3.1. Aspectos qualitativos

6.3.2. Aspectos quantitativos 164

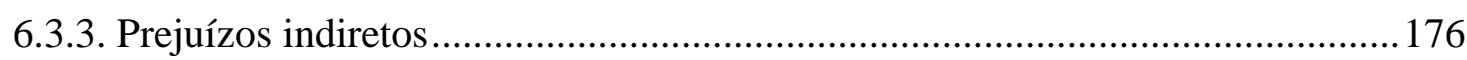

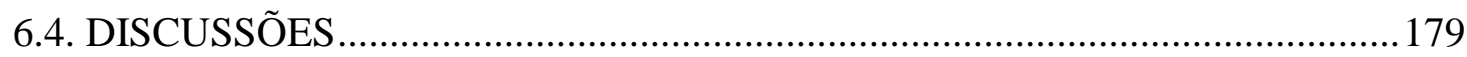

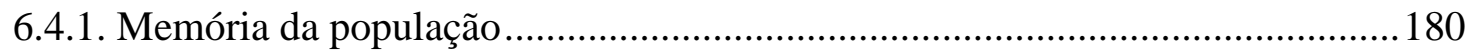

6.4.2. Prejuízo das empresas contidos na área de inundação ......................................181

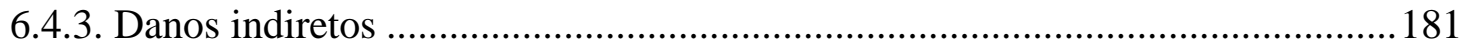

6.4.4. Análise comparativa estatística dos dados obtidos nas entrevistas com aqueles obtidos por Machado (2005) e Riguetto (2005).

6.5. CONCLUSÕES

7.1. Simulações hidráulica-hidrológica e alturas de submersão 195

7.2. Análise dos riscos e vulnerabilidade da região 196

7.3. Medidas mitigadoras e incertezas .197

7.3.1. Uso e ocupação do solo. 197

7.3.2. Medidas mitigadoras 198

7.3.3. Distribuição temporal das chuvas ................................................................. 198

7.4. Sócio hidrologia dos desastres .199

8. RECOMENDAÇÕES PARA TRABALHOS FUTUROS.

8.1. Realizar modelagem-hidrológica mais robustas, envolvendo quatro aspectos: uso do solo; distribuição temporal da chuva; modelagem distribuída e aspectos bidimensionais da área de estudo...........................................................................20

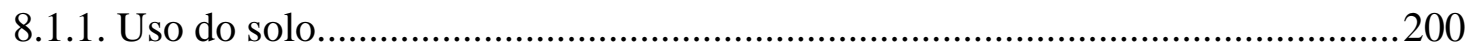

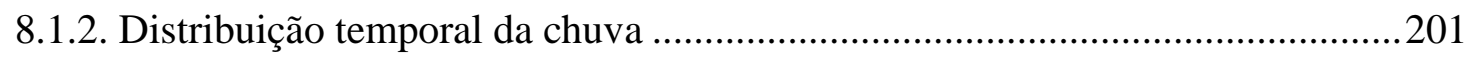

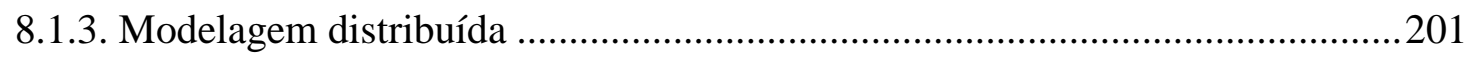

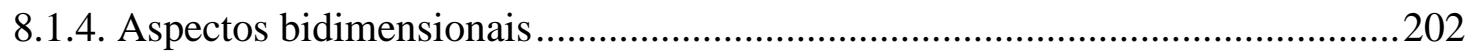

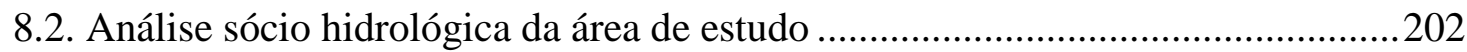

APÊNDICE 1 - DADOS DO FINANCIAMENTO DAS MEDIDAS MITIGADORAS

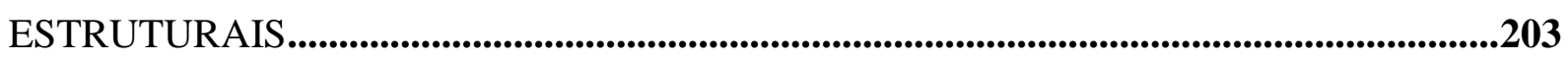
APÊNDICE 2 - EXEMPLO DE RELATÓRIO GERADO PELO SOFTWARE DOFORMS 
APÊNDICE 3 - TERMO DE LIVRE CONSCENTIMENTO UTILIZADO NAS ENTREVISTAS COM OS COMERCIÁRIOS ...................................................................205 APÊNDICE 4 - CARTA DE APRESENTAÇÃO APRESENTADA AOS COMERCIÁRIOS NO INÍCIO DE CADA ENTREVISTA...............................................................................206 APENDICE 5 - PRINCIPAIS RELATOS OBTIDOS PELOS COMERCIANTES POR MEIO DAS ENTREVISTAS 207 APÊNDICE 6 - RELAÇÃO RECEITA/ESTOQUE (LUCRO CESSANTE)........................209 APÊNDICE 7 - RESPOSTA DA PREFEITURA RELATIVA AO PROCESSO 6025/2018

APÊNDICE 8 - CUSTOS DE LIMPEZA DOS IMÓVEIS .212 APÊNDICE 9 - CARACTERIZAÇÃO SÓCIO ECONÔMICA LOCAL COM USO DOS MICRODADOS CENSITÁRIO DA ÁREA IMPACTADA ........................................................213 APÊNDICE 10 - MODELAGEM HIDRÁULICA E HIDROLÓGICA.................................... 218 ANEXO 1 - CURVA DPS DO SETOR DE COMÉRCIO E SERVIÇOS ................................. 220 ANEXO 2 - CURVA COTA-ÁREA E COTA-VOLUME DOS RESERVATÓRIOS PREVISTOS NA BACIA DO CÓRREGO DO GREGÓRIO 


\section{APRESENTAÇÃO}

A presente pesquisa busca trazer elementos relativos à análise de prejuízos aos imóveis comerciais em inundações urbanas. O capítulo introdutório busca trazer um entendimento geral sob a problemática da inundação e as justificativas para se quantificar os prejuízos de uma inundação, tema central dessa pesquisa. Já o capítulo 2 refere-se à revisão bibliográfica relativa ao tema desta pesquisa. Após a parte introdutória e a revisão bibliográfica, essa tese é dividida em duas seções.

A primeira parte é constituída por elementos chamados a priori, ou seja, busca quantificar os prejuízos com dados sintéticos não obtidos in loco na região de estudo. As análises desse capítulo não utilizam dados adquiridos em campo, sendo assim uma metodologia passível de ser replicada por pesquisadores sem sua presença física no local.

O capítulo 3 apresenta o modelo hidráulico-hidrológico utilizado na área de estudo, bem como define os cenários de uso e ocupação do solo e as medidas mitigadoras adotadas para elaboração das manchas de inundação, essas elaboradas com chuvas de projeto discretizados em duas distribuições temporais distintas.

Já no capítulo 4 são adicionadas as manchas de inundação à camada relativa ao modelo econômico, inserindo as empresas presentes na região e aplicando curvas sintéticas para quantificação dos prejuízos. Além disso, é realizado uma análise custo-benefício das medidas mitigadoras presentes no plano de drenagem de São Carlos.

A segunda seção é constituída por dados a posteriori, ou seja, uma pesquisa qualiquantitativa dos efeitos das inundações na região.

No Capítulo 5 apresenta o mesmo modelo hidrológico descrito no capítulo 3, porém ao invés de se utilizar de chuvas de projeto, são utilizados hietogramas de chuvas observados da bacia em estudo para realizar a modelagem dos dados. Assim, são avaliadas as incertezas do modelo unidimensional usado em comparação às alturas de inundação verificadas in loco.

No Capítulo 6, os dados coletados junto aos comerciários da área estudada são tabulados e apresentados sob a forma de dados quali-quantitativos, com o intuito de quantificar os prejuízos e estabelecer um panorama subjetivo das inundações sob o enfoque dos comerciários.

No capítulo de discussões, as análises desse estudo são comparadas com a literatura para estabelecer parâmetros de análise. 


\section{INTRODUÇÃO}

A urbanização tem potencial para aumentar tanto o volume quanto as vazões do escoamento superficial direto. A influência da ocupação de novas áreas deve ser analisada no contexto da bacia hidrográfica na qual estão inseridas, de modo a se efetuarem os ajustes necessários para minimizar a criação de futuros problemas de inundações.

De acordo com Tucci (1995), as inundações em áreas urbanas são consequência de dois processos: inundações em áreas ribeirinhas e inundações provocadas pela urbanização. As inundações em áreas ribeirinhas ocorrem principalmente pelo processo natural, no qual o rio ocupa o seu leito maior de acordo com eventos chuvosos extremos.

As funções primárias de um curso d'água e de sua várzea associada são a coleta, armazenamento e veiculação das vazões de cheias. Essas funções não podem ser relegadas a um plano secundário em favor de outros usos, sem a adoção de medidas compensatórias normalmente onerosas. Respeitada essa restrição, as várzeas têm a potencialidade de contribuir para a melhoria da qualidade da água e do ar, a manutenção de espaços abertos, a preservação de ecossistemas importantes e acomodação de redes de sistemas urbanos adequadamente planejados.

A simples canalização de um trecho de córrego, por exemplo, poderá reduzir os riscos de inundação de uma determinada área por certo tempo. Essa solução, entretanto, causará sérios impactos: a aceleração do escoamento agravará as inundações a jusante, aumentará o transporte de lixo e sedimentos, que se acumularão nos trechos de menor velocidade, e aumentará a erosão no trecho subsequente ao trecho canalizado.

A falsa sensação de segurança provocada pela obra atrairá a população e as atividades econômicas para as áreas mais próximas ao córrego, reduzindo o espaço natural das enchentes. Além disso, se juntamente com a obra não houver o controle da impermeabilização da bacia, as vazões aumentarão gradativamente até que a capacidade do canal seja superada.

Para contornar esses impactos, dentro desta mesma visão tradicional, amplia-se mais ainda a capacidade e a extensão do trecho canalizado, instalando-se aí um círculo vicioso, que levará à necessidade de investimentos cada vez maiores para solucionar um problema que poderia ter sido evitado na origem.

Os impactos sobre a população são causados pela ocupação inadequada do espaço urbano, condicionada aos seguintes fatores: inexistência ou inadequação de Planos Diretores Urbanos e de restrições ao loteamento de áreas sob perigo de inundações; invasão pela 
população de baixa renda de áreas ribeirinhas pertencentes ao poder público; ocupação de áreas de médio risco, que são atingidas com frequência menor; falta de um Plano Municipal de Saneamento Básico.

As inundações provocadas pela urbanização ocorrem pelo aumento da frequência e magnitude das enchentes devido à ocupação do solo com superfícies impermeáveis e às redes de condutos de escoamento. Além disso, obstruções ao escoamento nos condutos e canais, e projetos de drenagem inadequados podem agravar o problema.

\subsection{Justificativa}

As perdas econômicas decorrentes das inundações geram prejuízos da ordem de bilhões de reais, gerando gastos ao poder público e à população. Segundo Baptista e Nascimento (1996), as despesas com inundações urbanas no Brasil (com base no ano de 1996), foram estimadas em US\$ 2 bilhões por ano, tendo como parâmetro o índice de 0,3\% do PIB brasileiro (índice verificado em outros países pelos pesquisadores). Este índice corresponde ao prejuízo de US\$ 5,4 bilhões por ano, tendo como referência o ano de 2015.

Santos (2013) avaliou os prejuízos anuais provocados por alagamentos na cidade de São Paulo e chegou a valores em torno de R $\$ 336$ milhões, destacando que a cidade já possui 749 pontos de alagamentos e que cada ponto formado após uma chuva intensa causa um prejuízo diário médio de mais de $\mathrm{R} \$ 1$ milhão à cadeia produtiva nacional do país. Assim, suas projeções, realizadas com base no ano de 2008, atingiram prejuízos da ordem de R 762 milhões somente para as inundações ocorridas na cidade de São Paulo e considerando seus efeitos na cadeia produtiva nacional.

Mendes e Mendiondo (2007), ao analisarem as notícias históricas de jornais dos anos de 1940 a 2004, na cidade de São Carlos - SP, encontraram 82 eventos de inundações ou alagamentos. Somente na bacia do córrego do Gregório, onde se localiza o centro comercial do município, foram constatados 64 casos de inundações e 38 intervenções e obras relacionadas à drenagem da malha urbana. Contudo, o problema ainda persiste nesta região.

Apesar da importância do setor comercial para a economia no fornecimento de bens, serviços e emprego, Gissing e Russell (2004) afirmam que a investigação sobre danos causados pelas inundações tem se concentrado quase exclusivamente ao setor residencial. Os autores consideram que métodos para estimar as perdas neste setor são necessários para estimar prémios de seguros, avaliação de medidas mitigadoras de inundação e para determinação de efeitos econômicos na cadeia de produção. Assim, estimativas de perda inadequadas resultam em: 
alocações ineficientes de recursos para mitigação das inundações, exposição de companhias de seguros a seleções incorretas, criação de orçamento ineficiente e decisões políticas inapropriadas.

Os autores acreditam que essas estimativas simplificadas ainda persistem, pois os modelos que estimam prejuízos do setor comercial muitas vezes optam por maior celeridade de processos para reduzirem o tempo e os recursos envolvidos na determinação dos valores de perda. Porém, em diversas ocasiões, as amostras são demasiadamente pequenas para quantificar os efeitos com precisão.

Estudos que buscam quantificar os danos aos imóveis comerciais com o uso de curvas de danos por profundidade de submersão (DPS) têm tido, como resultado, coeficientes de correlação muito baixos, a exemplo de Machado (2005) e Gissing e Russell (2004).

As curvas DPS têm tido coeficientes de correlação altos para o setor residencial; porém, para o setor comercial, ainda representam um desafio a sua utilização, tendo em vista a alta variabilidade de bens existentes nos estabelecimentos comerciais (mesmo quando comparadas sob as mesmas categorias).

Assim, de maneira geral, esta pesquisa busca trazer avanços na quantificação dos danos causados aos imóveis comerciais. Além disso, pretende trazer avanços no auxílio à tomada de decisões quanto às técnicas compensatórias de drenagem urbana a serem implementadas. Na metodologia proposta, propõem-se uma abordagem estatística dos eventos chuva-vazão, através da adoção de distintas distribuições temporais de chuvas (HUFF, 1990), com enfoque à sensibilidade do modelo frente aos dados de entrada utilizados. Além disso, realizou-se uma análise quantitativa in loco para avaliar os reais prejuízos provocados pela inundação, e assim comparar os dados modelados com os dados reais.

\subsection{Objetivos}

\subsubsection{Objetivo geral}

O objetivo dessa pesquisa é quantificar os danos diretos e indiretos à atividade comercial derivados de inundação na bacia do córrego do Gregório e avaliar o custo-benefício de medidas mitigadoras.

\subsubsection{Objetivos específicos}

Foram considerados 2 objetivos específicos que nortearam essa pesquisa: 
- Analisar a relação entre os prejuízos diretos e indiretos derivados de inundações urbanos, correlacionando-os com aspectos socio-hidrológicos;

- Avaliar o custo-benefício de medidas de controle de inundação no tocante a mitigação de prejuízos.

A Figura 1.1 apresenta, a partir dos objetivos propostos, sua respectiva metodologia e os resultados obtidos em cada objetivo, além das hipóteses norteadoras desta pesquisa.

Figura 1.1 - Síntese dos objetivos, metodologia, resultados e hipóteses norteadoras

\begin{tabular}{|c|c|c|}
\hline Objetivos & Metodologia & Resultados \\
\hline
\end{tabular}

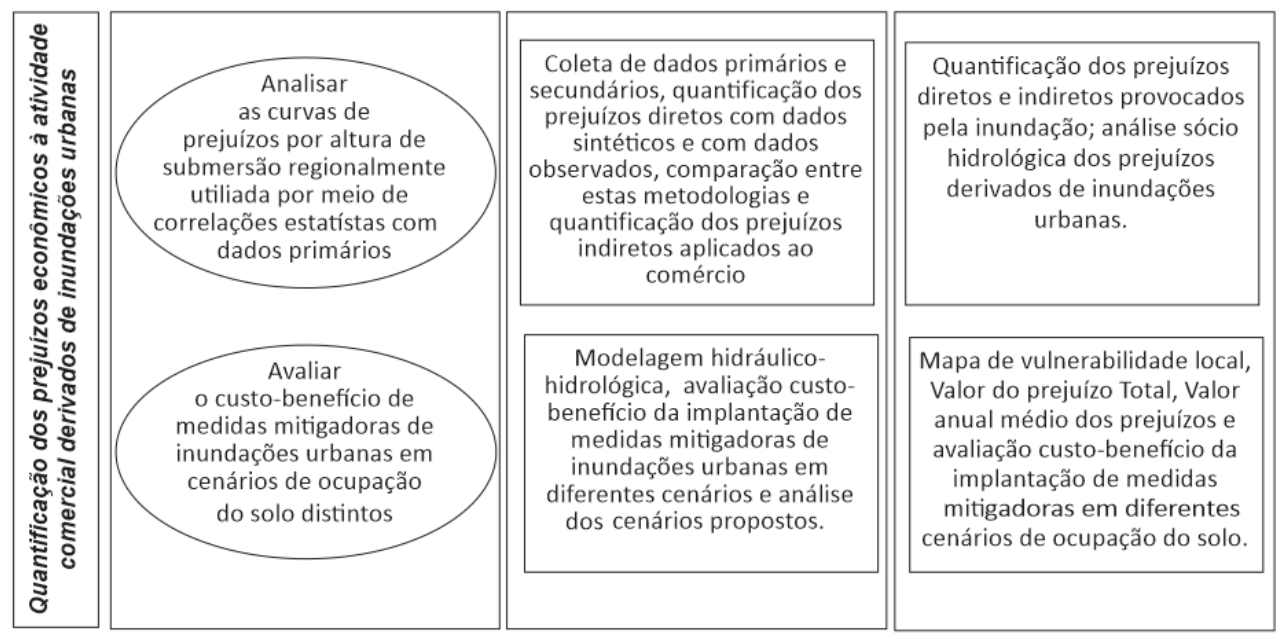

\begin{tabular}{|l|l|}
\hline As medidas mitiga doras de inundações urbanas se caracterizam tanto pelo controle da \\
vazão máxima em cenários de mudança de uso do solo quanto por ter custos inferiores \\
aos benefícioseconômicos proporcionados. \\
As relações de prejuízos por altura de submersão regionalmente utlizadas \\
apresentam boa correlação com dados experimentais em locais afetados por \\
inundações urbanas.
\end{tabular}




\section{CAPÍTULO 2 - REVISÃO BIBLIOGRÁFICA}

\subsection{Processo de urbanização no Brasil}

O processo de urbanização no Brasil se deu principalmente devido ao êxodo rural (1950 a 1980) decorrente da metropolização da urbanização brasileira, em que as cidades com mais de 500 mil habitantes passaram de $7,7 \%$ para $16,2 \%$ da população total (SCHMIDT e FARRET, 1986).

No período de 1980 a 1991, a população urbana cresceu de $68 \%$ para mais de $75 \%$, enquanto as áreas rurais enfrentavam um decréscimo de 0,6\% ao ano, representando um crescimento absoluto de mais 30 milhões de residentes urbanos (MARTINE, 1994).

Entre os anos 1991 a 2000 a população urbana passou a ser de 7,3 para 9,5 vezes maior que a população rural, o que ocasionou a redução da população rural na ordem de quatro milhões de pessoas (IBGE, 2001).

Em 2010, a população brasileira era composta de 190.732.694 habitantes, e destas $84,36 \%$ viviam em áreas urbanas e apenas $15,64 \%$ da população residiam em áreas rurais. O aumento da população no período de 1950 a 2010 é apresentado na Figura 2.1.

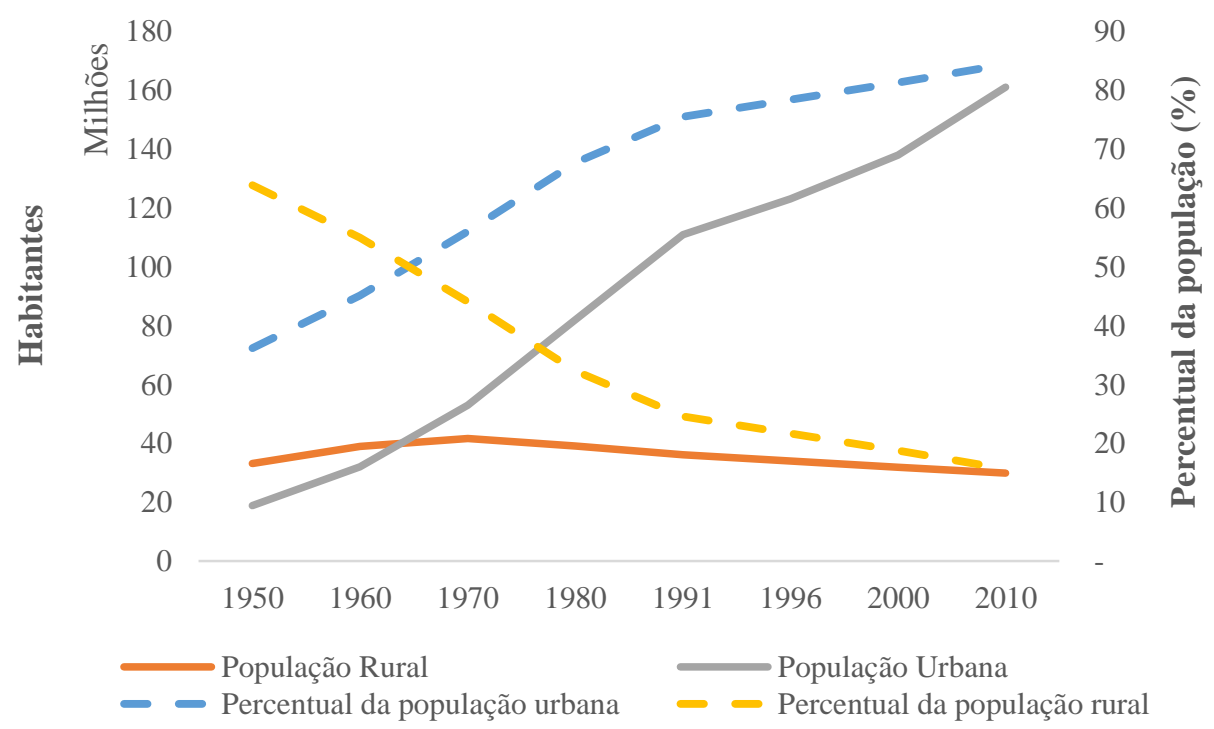

Figura 2.1 - Crescimento populacional em áreas urbanas e rurais

\subsection{Contexto histórico da drenagem urbana}

O desenvolvimento da drenagem urbana está estritamente ligado ao crescimento das populações nas áreas urbanas. As obras de evacuação das águas surgiram na Roma Antiga, 
denominada "cloaca máxima" (termo latim utilizado para designar "maior esgoto"), umas das primeiras obras de grandes dimensões a propiciar uma melhoria da qualidade de vida das populações. As redes romanas são classificadas como sistemas unitários de esgotamento sanitário e pluvial, pois transportam as águas residuais domésticas e as águas pluviais em um mesmo canal (BAPTISTA, NASCIMENTO e BARRAUD, 2005).

Segundo os autores supracitados, na Idade Média as áreas urbanas eram ocupadas de forma estratificada e as populações mais desfavorecidas ocupavam as áreas baixas propensas às inundações periódicas. Além disso, os sistemas de evacuação das águas pluviais e esgotamento sanitário caíram em desuso pela falta de manutenção, fato que levou ao conceito denominado "tout à La rue" acarretando em condições de vida humana insalubres, já que as águas residuais e pluviais não eram coletadas, sendo simplesmente lançadas na rua.

Essa situação deu origem ao termo "cidade pútrida", em que a lama misturada com esgoto tomava conta do sistema viário e deixava um odor desagradável perceptível a distância, tendo como consequências epidemias de cólera e tifo, levando a Europa a levantar as questões de insalubridade pública que só foram questionadas durante o Renascimento, quando os cursos de água foram transformados em esgotos com a realização de obras de regularização de canalização dos rios (BAPTISTA, NASCIMENTO e BARRAUD, 2005).

Tal situação não é muito diferente dos dias atuais, quando as populações economicamente menos favorecidas habitam as áreas mais baixas e ficam sujeitas às inundações que carregam toda a água contaminada lançada nas ruas.

\subsubsection{Contexto da drenagem urbana no Brasil}

No Brasil colonial, as soluções sanitárias (abastecimento público de água e evacuação dos dejetos) ficavam sob encargo dos indivíduos, como por exemplo, a captação de água em mananciais e as ações de saneamento voltadas à drenagem. No século XVII surgem as primeiras obras de drenagem: implantação de diques, canais e ancoradouros, aterramento e drenagem.

Já no século XVIII os serviços de infraestrutura eram feitos por intermédio de concessão à iniciativa privada e, embora tenha se construído algumas redes para abastecimento e esgotamento sanitário, estes serviços abrangiam apenas os núcleos centrais urbanos, que atendiam uma pequena parcela da população. Em 1850, devido ao surgimento da febre amarela, comissões de saúde e engenharia foram criadas para unificar os serviços sanitários do Império e instituir o Conselho Superior de Saúde Pública com funções normativas (SILVA, 2000). 
No século XIX, surge na Europa como medida de saúde pública o conceito higienista. Este visa afastar as águas pluviais e residuais dos centros urbanos e eliminação sistemática das águas paradas ou empoçadas nas cidades. No Brasil, as primeiras canalizações de esgoto ocorreram em 1864 no Rio de Janeiro, porém o conceito higienista só foi aplicado efetivamente a partir do ano de 1889 com a implantação do sistema separador absoluto que, diferentemente da Europa, conduzia as águas residuais e pluviais através de tubulações separadas e exclusivas (SANTOS, 1928 apud SILVEIRA, 1998).

O conceito de tecnologias alternativas de drenagem urbana surgiu na Europa e América do Norte em meados da década de 70, juntamente com técnicas de remediação conhecidas como medidas compensatórias de drenagem, ou Best Management Practices (BMPs), enquanto que no Brasil ainda se iniciava a implantação das redes de drenagem nas cidades.

As BMPs contrapõem a abordagem higienista de livrar-se das águas o mais rápido possível, mantendo o conceito de neutralizar os efeitos do processo de urbanização sobre os processos hidrológicos. Essas técnicas buscam tratar o escoamento pluvial no local em que é gerado, através dos processos de armazenamento, detenção e infiltração das águas pluviais.

Assim como as BMPs, surge em meados de 1990 uma nova abordagem de gestão sustentável de drenagem conhecida como Desenvolvimento de Baixo Impacto (Low Impact Development - LID). Esta busca compatibilizar projetos hidrologicamente funcionais e esteticamente agradáveis para controlar as águas pluviais e minimizar seus impactos sobre as superfícies urbanas (PRINCE GEORGE, 1999).

\subsubsection{Conceitos relativos à gestão de drenagem urbana sustentável de águas pluviais}

A gestão sustentável das águas pluviais urbanas tem como um de seus preceitos o conceito de desenvolvimento urbano de baixo impacto (LID), que se traduz em soluções mais eficazes e econômicas quando comparadas às soluções tradicionais de drenagem urbana. Este conceito consiste na preservação do ciclo hidrológico natural, a partir da redução do escoamento superficial adicional gerado pelas alterações da superfície do solo decorrentes do desenvolvimento urbano (PRINCE GEORGE, 1999).

A denominação Plano Diretor de Drenagem Sustentável é dada como referência ao plano que estabelece as diretrizes e objetivos relativos à drenagem urbana. Este é uma ferramenta de planejamento que possibilita implantar soluções efetivas de baixo impacto que trazem ao município benefícios tangíveis e duradouros. O plano tem como unidade de planejamento cada bacia hidrográfica do município (MINISTÉRIO DAS CIDADES, 2012). 
Para implantação do plano é necessário que este seja articulado com demais políticas de desenvolvimento urbano, tais como: zoneamento, habitação, infraestrutura, entre outros. O fluxograma do plano diretor de drenagem de águas pluviais é apresentado na Figura 2.2.

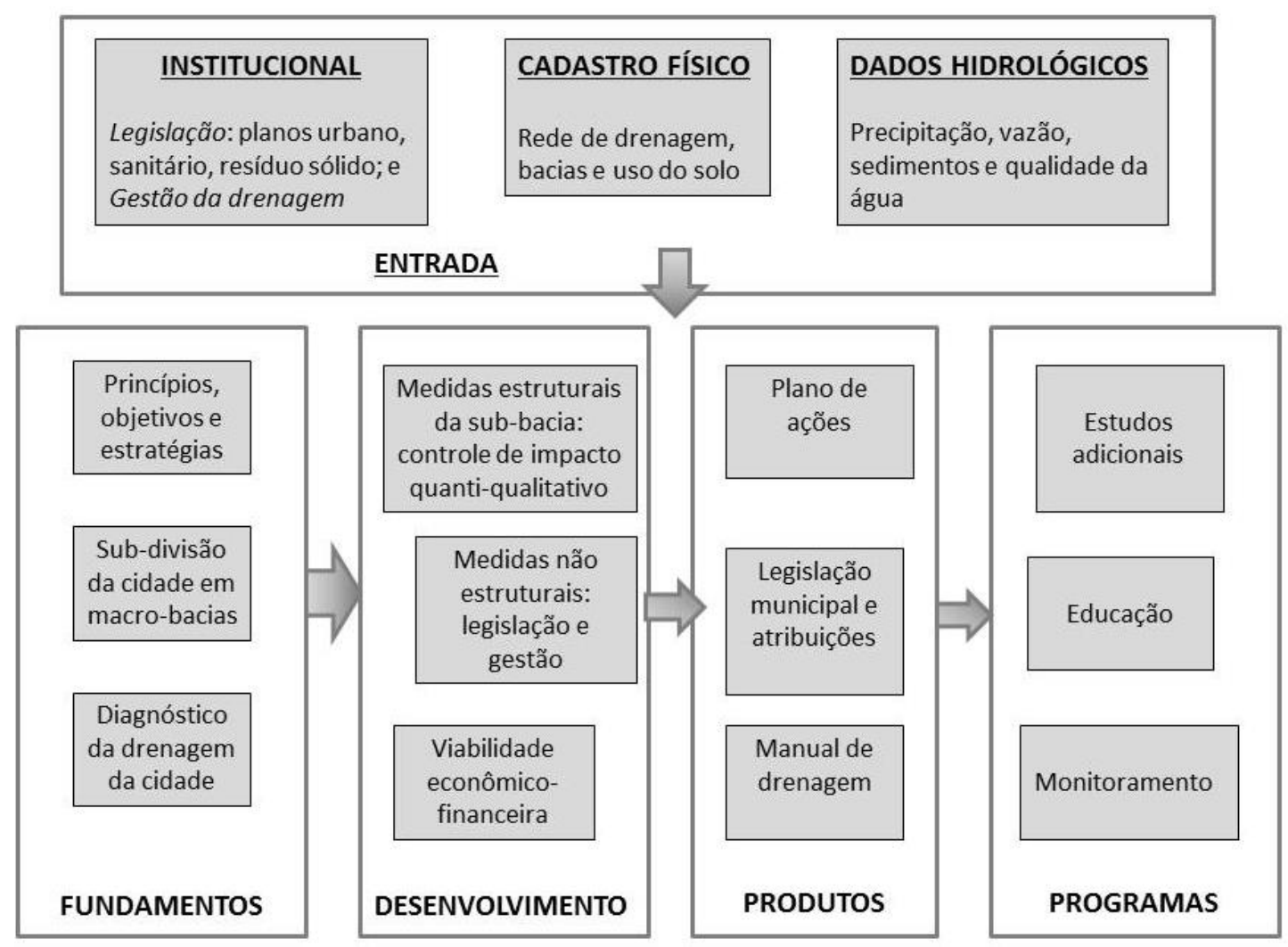

Figura 2.2 - Fluxograma simplificado do plano diretor de drenagem de águas pluviais Fonte: Adaptado de TUCCI (2002)

Segundo o Ministério das Cidades (2012), os princípios que regem o plano, na visão do desenvolvimento urbano sustentável, são interdisciplinares no diagnóstico e na solução dos problemas de inundação. Dentre os princípios, podem ser destacados:

$\checkmark \quad$ O escoamento pluvial não pode ser ampliado pela ocupação urbana da bacia;

$\checkmark \quad$ Cada empreendimento urbano deve implantar medidas de controle para que a cheia natural não aumente;

$\checkmark \quad$ As medidas de controle propostas para uma bacia não devem transferir impactos para outra bacia;

$\checkmark \quad$ O sistema de águas pluviais deve ser integrado ao sistema de saneamento ambiental;

$\checkmark \quad$ O plano deve propor medidas para o controle do material sólido e a redução da carga poluente das águas pluviais. 
Para que os parâmetros de escoamento superficial planejados não sejam superados, o plano de águas pluviais deve regulamentar a ocupação do território por meio do controle das áreas de expansão e da limitação do adensamento das áreas ocupadas.

\subsection{Plano Diretor de Desenvolvimento Urbano}

O Plano Diretor é uma lei municipal pautada pelo Estatuto da Cidade (Lei Federal 10.257/01), ou seja, é ele que diz como o Estatuto da Cidade será aplicado no município. Já o Estatuto da Cidade diz como deve ser feita a política urbana em todo o país. Este tem o objetivo de garantir o direito à cidade para todos e, para isso, traz algumas regras para se organizar o território do município. É ele que detalha e desenvolve os artigos 182 e 183 do capítulo II referente à política urbana da Constituição Federal.

O artigo 183 da Constituição Federal trata do usucapião das propriedades urbanas, com exceção de propriedades públicas. Já o artigo 182 diz respeito à política de desenvolvimento urbano, executada pelo poder público municipal, que tem por objetivo ordenar o pleno desenvolvimento das funções sociais da cidade e garantir o bem-estar de seus habitantes. Nos incisos deste capítulo destacam-se:

A obrigatoriedade do plano diretor para cidades com mais de vinte mil habitantes, sendo este o instrumento básico da política de desenvolvimento e de expansão urbana;

A importância do plano diretor, destacando que a propriedade urbana cumpre sua função social quando atende às exigências fundamentais de ordenação da cidade expressas no plano diretor;

$\checkmark \quad$ Destaca que as desapropriações de imóveis urbanos serão feitas com prévia e justa indenização em dinheiro;

A exigência mediante lei federal que o proprietário do solo urbano não edificado, subutilizado ou não utilizado de promover seu adequado aproveitamento, sob pena de: parcelamento ou edificação compulsórios; imposto sobre a propriedade predial e territorial urbana progressivo no tempo; e desapropriação com pagamento mediante títulos da dívida pública de emissão previamente aprovada pelo Senado Federal, com prazo de resgate de até dez anos, em parcelas anuais, iguais e sucessivas, assegurados o valor real da indenização e os juros legais.

O Estatuto da Cidade regulamenta os artigos citados acerca da política urbana e dispõe sobre o conteúdo mínimo de um Plano Diretor, estabelecendo que o processo de sua formulação seja necessariamente participativo. Também introduz cinco instrumentos para o ordenamento 
territorial: 1 - o parcelamento, edificação ou utilização compulsória (que podem vir a gerar o IPTU progressivo no tempo); 2 - o direito de preempção; 3 - a outorga onerosa do direito de construir e de alteração de uso do solo; 4 - as operações urbanas consorciadas; 5 - a transferência do direito de construir.

Segundo Braga (1995), os Planos Diretores são instrumentos políticos que objetivam tornar transparente e democratizar a política urbana e possuem três aspectos básicos: o aspecto político, o aspecto da transparência e o aspecto da democratização. Sobre o aspecto político, Braga (1995) destaca que os planos diretores de desenvolvimento urbano não podem ser um produto eminentemente técnico, sem participação efetiva do agente político, pois assim excluise a parcela da população do jogo político e ainda se justificam, pela suposta neutralidade científica, a tomada de decisões que favorecem determinadas parcelas da sociedade.

No aspecto da transparência, destaca-se a importância de tornar público as diretrizes e prioridades do crescimento urbano de maneira transparente. Já o aspecto da democratização é o que garante a transparência do processo e garante a participação de entidades representativas da sociedade no processo de planejamento municipal.

\subsubsection{Plano diretor de São Carlos}

O Plano Diretor de São Carlos foi instituído em novembro de 2005 pela Lei no 13.691 (PMSC, 2005). A lei é basicamente dividida em seis títulos que abordam: 1 - os princípios, objetivos e diretrizes gerais da política urbana; 2 - o ordenamento territorial do município; 3 o parcelamento, uso e ocupação do solo; 4 - os instrumentos de política urbana; 5 - o sistema de gestão e planejamento do desenvolvimento urbano; e 6 - as disposições gerais, finais e transitórias.

\section{1 - Princípios, objetivos e diretrizes gerais da política urbana}

É princípio da política urbana a compatibilidade com a preservação do meio ambiente, referente ao controle da poluição do ar, da água, do solo e da destinação dos resíduos, assim como a fluidez de drenagem das águas pluviais e dos corpos d'água, a maior permeabilidade do solo, à maior preservação de sua cobertura vegetal e da vegetação significativa existente.

\section{$\underline{2 \text { - Ordenamento territorial do município }}$}


O zoneamento, como estratégia da política urbana, consiste no estabelecimento de zonas com características semelhantes com o propósito de favorecer a implementação dos instrumentos de ordenamento e controle urbano. O macrozoneamento de São Carlos divide o território do município considerando a infraestrutura instalada, as características de uso e ocupação do território do município, as características do meio ambiente natural e construído, a implementação de ações de planejamento.

Acerca do ordenamento territorial do município, constituíram-se as Macrozonas e as Zonas e Áreas de Especial Interesse. As macrozonas dividem-se em Macrozona Urbana e Macrozona de Uso Multifuncional Rural:

Macrozona Urbana: composta por áreas dotadas de infraestrutura, serviços e equipamentos públicos e comunitários. Apresenta maior densidade construtiva e populacional, que requerem uma qualificação urbanística e condições de atrair investimentos imobiliários privados. Subdivide-se, por sua vez em:

$\checkmark \quad$ Zona de Ocupação Induzida - Zona 1: composta por áreas do território que requerem uma qualificação urbanística e que têm as melhores condições de infraestrutura da cidade. Tem como características o uso misto com predominância de comércio e serviços, em detrimento de uso habitacional na área central; concentração de população de alta renda, com predominância de população idosa no centro; concentração de imóveis de interesse histórico e cultural, e de imóveis não edificados, não utilizados e subtilizados. É contida inteiramente na faixa localizada entre as barreiras da mobilidade urbana formadas pela ferrovia da Rede Ferroviária Federal e da Rodovia Washington Luiz - SP 310.

$\checkmark \quad$ Zona de Ocupação Condicionada - Zona 2: é composta por áreas com predominância de uso misto do território com grande diversidade de padrão ocupacional. Tem como características fragmentação e descontinuidade do sistema viário; presença de áreas com carência de infraestrutura de drenagem; ocorrência de bolsões com deficiência de áreas públicas ou de equipamentos públicos; ocorrência de bairros que exigem a transposição das barreiras da mobilidade urbana em razão da ferrovia da Rede Ferroviária Federal e da Rodovia Washington Luiz - SP 310; ocorrência de loteamentos com uso misto consolidado ferindo o disposto nos contratos de loteamentos, mas passíveis de regularização por meio de outorga onerosa de alteração de uso do solo. 
Zona de Recuperação e Ocupação Controlada - Zona 3 (3A e 3B): são zonas com fragilidades sociais e ambientais:

- A zona 3A apresenta as seguintes características: encostas com alta declividade; solo suscetível a erosões com córregos assoreados; infraestrutura precária; parcelamentos irregulares, localizados nas proximidades de encostas de alta declividade; parcelamentos irregulares, localizados em áreas isoladas com precariedade de interligação viária com a malha urbana consolidada; concentração da população de baixa renda.

- A zona 3B apresenta as seguintes características: localização em área de proteção e recuperação do manancial de captação superficial do Córrego do Monjolinho; dificuldade de acesso em função da barreira formada pela Rodovia Washington Luiz - SP 310; loteamentos com precariedade no sistema de drenagem; carência de equipamentos públicos; ocorrência de loteamentos com uso misto consolidado ferindo o disposto nos contratos de loteamentos a serem regularizados por meio de outorga onerosa de alteração de uso do solo, mas passíveis de regularização por meio de outorga onerosa de alteração de uso do solo.

As áreas correspondentes aos campi universitários (UFSCar - Universidade Federal de São Carlos e USP - Universidade de São Paulo - Campus II) estão inseridas no macrozoneamento do município, porém não se enquadram em nenhuma das zonas já descritas. Na lei os campi são denominados apenas como Campi universitários contíguos à malha urbana.

Macrozona de Uso Multifuncional Rural: é composta por áreas de uso agrícola, extrativista ou pecuário, com áreas significativas de vegetação natural, com condições de permeabilidade próximas aos índices naturais; por áreas de preservação ambiental formadas por reservas florestais, parques e reservas biológicas; e por áreas de uso não agrícolas, como chácaras de recreio, lazer, turismo, fazendas históricas, indústrias e sedes de distritos.

Nesta macrozona há presença de nascentes da bacia do Ribeirão dos Negros e do Quilombo a leste, proximidade de nascentes da bacia do Ribeirão das Araras ao norte e proximidade com as nascentes da bacia do Ribeirão do Chibarro a oeste. E também região do espigão divisor de águas das duas grandes bacias hidrográficas do Município, Tietê - Jacaré e Mogi - Guaçu. Esta macrozona subdivide-se em:

$\checkmark \quad$ Zona de Regulação e Ocupação Controlada - Zona 4 (4A e 4B): apresentam como característica comum o fato de estarem localizadas em áreas com fortes tendências para a 
expansão urbana, apresentando usos diversificados, configurando-se como transição entre o meio rural e o meio urbano. Na zona 4B encontram-se nascentes do Córrego do Santa Maria do Leme e proximidade dos Córregos do Monjolinho, do Água Quente e do Água Fria.

$\checkmark \quad$ Zona de Proteção e Ocupação Restrita - Zona 5 (5A e 5B): são áreas de proteção e recuperação dos mananciais, de nascentes do Córrego do Gregório e parte da Área de Proteção Ambiental (APA) do Corumbataí. A zona 5B abrange parte da área de preservação do manancial de abastecimento público, formado pela bacia de captação do Córrego do Feijão.

$\checkmark \quad$ Zona de Produção Agrícola Familiar - Zona 6: é composta por pequenas e médias propriedades rurais baseadas na agricultura familiar, com tradições culturais e estrutura produtiva diversificada, tendo como objetivo garantir a produção agrícola de pequena e média escala. Esta zona é região de nascentes do Ribeirão dos Negros, do Quilombo e do Pântano.

$\checkmark \quad$ Zona de Uso Predominantemente Agrícola - Zona 7: tem como características a grande diversidade de produção agrícola e de agroecossistemas; abundância de recursos hídricos; diversidade de solos e de estrutura fundiária; predomínio das redes agroindustriais: sucroalcooleira, citrícola, láctea, de carne bovina e de avicultura de corte; áreas com grande potencial de lazer e turismo, com chácaras de recreio, cachoeiras, propriedades históricas e o Vale do Quilombo; abrange o Distrito de Santa Eudóxia. Há presença de parcelamentos clandestinos ou irregulares.

\section{$\underline{\text { Áreas de Especial Interesse Ambiental }}$}

As Áreas Especiais de Interesse Ambiental são porções do território destinadas a proteger e recuperar os mananciais, nascentes e corpos d’água; a preservação de áreas com vegetação significativa e paisagens naturais notáveis; áreas de reflorestamento e de conservação de parques e fundos de vale. São destacadas aqui somente as áreas de interesse hidrológico:

$\checkmark \quad$ Do Córrego Mineirinho ao Bosque Santa Fé, nas Zonas 1 e 2;

$\checkmark \quad$ Do Córrego do Cambuí ao bairro Santa Paula, nas Zonas 1, 2 e 4;

$\checkmark \quad$ Dos Córregos do Gregório, Lazzarini e Sorregotti, nas Zonas 1 e 2;

$\checkmark \quad$ Do Córrego do Tijuco Preto, nas Zonas 1 e 2;

$\checkmark \quad$ Do Córrego São Rafael, nas Zonas 3B e 5A; 
$\checkmark \quad$ Do "Conjunto Habitacional Dom Constantino Amstalden" ao Córrego do Monjolinho, na Zona 3B;

Do Córrego da Água Fria, na Zona3, excluindo-se a área do CEAT - Centro Empresarial de Alta Tecnologia "Dr. Emílio Fehr” e suas futuras ampliações, a serem definidas por Lei específica.

\section{Coeficientes de ocupação}

O Plano Diretor de São Carlos, além de zonear o território municipal, impondo usos proibitivos em determinadas áreas, estabelece também coeficientes máximos de ocupação, aproveitamento, permeabilidade e de cobertura vegetal. Esses coeficientes influenciam de forma direta o coeficiente de impermeabilização e, por conseguinte, o coeficiente de escoamento superficial, os volumes e as velocidades de escoamento superficial na bacia hidrográfica. Os seguintes coeficientes são apresentados no plano:

Coeficiente de ocupação $(\mathrm{CO})$ : é a relação existente entre a área de projeção da edificação no solo e a área do terreno.

Coeficiente de aproveitamento (CA): é a relação entre a área edificável e a área do terreno. Subdivide-se em coeficiente de aproveitamento básico (CAB) e o coeficiente de aproveitamento máximo (CAM), onde $\mathrm{CAB}$ é a relação entre a área edificável básica e a área do terreno e CAM é o fator pelo qual a área do lote deve ser multiplicada para se obter a área máxima de edificação permitida neste mesmo lote.

Coeficiente de permeabilidade $(\mathrm{CP})$ : é a relação existente entre a área permeável e a área do terreno.

Coeficiente de cobertura vegetal: é a relação entre a área coberta por vegetação arbórea ou arbustiva de um determinado imóvel e a sua área total. É aplicado somente em áreas de mananciais.

A cada zona do município são atribuídos valores específicos para esses coeficientes, dependendo das especificidades da área. O Plano Diretor estabelece áreas também que exigem tratamento especial por destacar determinadas especificidades ou cumprir funções especiais no planejamento e no ordenamento do território, complementando o zoneamento por meio de normas especiais de parcelamento, uso e ocupação do solo. São as chamadas Áreas de Especiais Interesses (AEI) e classificam-se em: AEI histórico; ambiental; turístico, histórico e ecológico; turístico, esportivo e ecológico; industrial; de transporte aéreo; social. (PMSC, 2013). 
A localização do sistema de drenagem fluvial de acordo com cada zona delimitada pelo plano diretor do município e seus coeficientes de ocupação (CO), coeficiente de aproveitamento (CA) e coeficiente de permeabilidade (CP) é apresentado na Tabela 2.1.

Tabela 2.1 - Localização dos córregos do município de São Carlos nas macrozonas

\begin{tabular}{|c|c|c|c|c|}
\hline Zonas & Córregos & CA & CO & $\mathbf{C P}$ \\
\hline $\begin{array}{l}1 \text { - Zona de Ocupação } \\
\text { Induzida }\end{array}$ & $\begin{array}{l}\text { Córrego do Gregório, Córrego do Monjolinho, Córrego } \\
\text { do Tijuco Preto, Córrego do Cambuí }\end{array}$ & 1,4 & $70 \%$ & $15 \%$ \\
\hline $\begin{array}{l}2 \text { - Zona de Ocupação } \\
\text { Condicionada }\end{array}$ & $\begin{array}{l}\text { Córrego da Fazenda Rancho Alegre, Córrego do } \\
\text { Gregório, Córrego do Sorregotti da Invernada, Córrego } \\
\text { Santa Maria do Leme }\end{array}$ & 1,4 & $70 \%$ & $15 \%$ \\
\hline $\begin{array}{l}\text { 3A - Zona de recuperação } \\
\text { e ocupação controlada }\end{array}$ & Córrego da Água Quente & $\begin{array}{l}1- \\
1,4\end{array}$ & $70 \%$ & $15 \%$ \\
\hline $\begin{array}{l}\text { 3B - Zona de recuperação } \\
\text { e ocupação controlada }\end{array}$ & $\begin{array}{l}\text { Córrego Ponte de Tábua, Córrego do Monjolinho, } \\
\text { Córrego São Rafael }\end{array}$ & $\begin{array}{l}1- \\
1,4 \\
\end{array}$ & $\begin{array}{l}50- \\
70 \% \\
\end{array}$ & $\begin{array}{l}15- \\
30 \% \\
\end{array}$ \\
\hline $\begin{array}{l}\text { 5A - Zona de Proteção e } \\
\text { ocupação restrita }\end{array}$ & Córrego do Espraido, Córrego da Martinha & & & \\
\hline Entre as Zonas & $\begin{array}{l}\text { Córrego Santa Fé, Córrego do Mineirinho, Córrego do } \\
\text { Monjolinho, Córrego do Tijuco Preto }\end{array}$ & & & \\
\hline
\end{tabular}

\section{Os instrumentos de política urbana}

Os instrumentos da política urbana contemplam: 1 - a utilização, edificação e parcelamento compulsórios; 2 - o imposto sobre a propriedade predial e territorial urbana progressivo no tempo; 3 - a desapropriação com pagamento em títulos; 4 - o direito de preempção; 5 - o direito de superfície; 6 - a outorga onerosa, que contemplam a outorga onerosa do direito de construir e a outorga onerosa de alteração de uso do solo; 7 - as operações urbanas consorciadas; 8 - o consórcio imobiliário; 9 - a transferência do direito de construir; 10 - o estudo de impacto de vizinhança; e por último a concessão de uso especial para fins de moradia.

\section{Sistema de Gestão e Planejamento do Desenvolvimento Urbano}

O Plano Diretor é parte integrante de um processo contínuo de planejamento e gestão municipal, em que estão assegurados os objetivos e as diretrizes definidas na referida lei, com participação popular na sua implementação ou revisão. Para tanto, compete ao poder executivo municipal articular e promover os canais democráticos de participação da sociedade civil na discussão e formulação de diretrizes da política urbana.

O sistema é um processo interativo dos diversos órgãos e setores da administração municipal e compete ao poder executivo criar o Conselho Municipal de Desenvolvimento Urbano, contemplando a participação do poder público e da sociedade civil como um órgão de 
caráter consultivo, fiscalizador, de acompanhamento e de assessoramento em relação às políticas urbanas.

São previstas nesta lei a criação do Fundo Municipal de Habitação e Desenvolvimento Urbano, destinado a propiciar apoio e suporte financeiro à consecução da política municipal de desenvolvimento urbano e habitação de interesse social, organizando a captação, o repasse e a aplicação de recursos, e a criação do Grupo Especial de Análise - GEA, composto por servidores públicos com qualificação técnica, a fim de assessorar a administração municipal (PMSC, 2013).

\subsubsection{Plano Diretor de drenagem ambientalmente sustentável do município de São}

\section{Carlos}

O Plano Diretor de Drenagem Urbana Ambientalmente Sustentável do Município de São Carlos PMSC (2011) foi elaborado para fornecer diretrizes e auxiliar a prefeitura municipal no gerenciamento da drenagem urbana do município, de modo a subsidiar a tomada de decisão quanto a redução dos impactos causados pelas inundações.

$\mathrm{Na}$ elaboração do plano foram estudadas as condições atuais da drenagem urbana para elaborar um diagnóstico da rede de drenagem de São Carlos e formular prognósticos para condições de ocupação e uso do solo futuras.

O plano propõe a adoção de medidas estruturais e não estruturais de controle de inundação. Dentre as medidas estruturais, é proposta a construção de 21 barragens de detenção in-line, com objetivo de amortecer as vazões veiculadas pelos córregos do Douradinho, Ponte de Tábua, Monjolinho, Santa Maria Madalena, Tijuco Preto, Paraíso, Mineirinho, Gregório,

Sorregotti, Lazzarini, Medeiros, Água Quente e Água Fria. São previstas também as canalizações de trechos do Córrego do Gregório e do Monjolinho.

Dentre as medidas não estruturais, destacam-se o treinamento dos técnicos envolvidos na gestão da drenagem urbana, educação ambiental, orientação para projetos de engenharia e a elaboração de um manual de drenagem urbana e a manutenção de áreas verdes nos espaços ainda não ocupados. 


\subsection{Avaliação econômica de danos}

\subsubsection{Avaliação de danos provocados por inundações}

O ato de avaliar pressupõe uma análise técnica, para identificar o valor de um bem, de seus custos, frutos e direitos, a uma determinada finalidade, situação e data (ABNT, 2001).

A avaliação dos danos permite priorizar políticas públicas de prevenção aos bens públicos e privados, como a retirada em definitivo de moradias, comércio e entidades públicas de áreas inundáveis, bem como ser uma importante ferramenta de análise "custo-benefício" na implantação de infraestrutura de contenção de cheias ou, ainda, lastrear coerentemente os bens e edifícios com apólices de seguros (TACHINI, 2010).

De acordo com Machado (2005), a quantificação dos prejuízos diretos às propriedades pela abordagem convencional implica no levantamento do prejuízo para cada unidade econômica localizada na área propensa à inundação. Esses levantamentos, em geral, demandam muito tempo e gastos, além de requerer a manipulação de uma grande quantidade de dados.

Como procedimento alternativo, a maioria dos estudos efetua o levantamento destes dados por amostragem, fazendo uso, diversas vezes, de dados secundários. A escolha do procedimento e do nível de detalhamento a ser adotado irá depender, principalmente, do tamanho da área inundada e da diversidade de usos do solo, assim como da precisão requerida na avaliação do benefício.

A estimativa de danos é parte integrante da formulação de uma política sobre inundações. A avaliação destes requer o uso de faixas de curvas de danos para diferentes classes de imóveis. Desta forma, é possível quantificar os custos da mitigação das inundações em detrimento dos benefícios da redução dos danos.

Para isto, a base da metodologia depende do desenvolvimento de curvas de danos locais e da simulação com curvas existentes em outras regiões que possuam características similares às da área de estudo, também denominadas "funções de prejuízo". De acordo com Smith (1994), esta função foi primeiramente esboçada por White (1964), que propôs uma metodologia para elaboração de curvas de prejuízos e designou para tais o termo "sintético".

Curvas sintéticas de danos não necessitam de informações do evento atual de inundação, mas são baseadas em análises hipotéticas. Essa abordagem proporciona curvas de danos para diferentes usos do solo, tipos específicos de construções e suas funções.

Na pesquisa de Penning-Roswell e Chatternon (1977), o primeiro passo foi classificar os imóveis em grandes categorias, como térreas, geminadas e terraço, sendo que todas são, 
predominantemente, de um ou dois andares. Essas categorias foram também classificadas pela idade, como pré-1918, 1918 a 1935, 1935 a 1965 e pós-1965. Isso gerou 21 diferentes tipos de habitação, que foram subdivididas pela classe social de seus ocupantes, baseada no censo britânico e na ocupação do chefe de família de cada residência, o que elevou o número de tipos de habitação para 84 .

As informações de danos foram divididas em duas categorias: (i) a estrutura do edifício; (ii) o conteúdo dos imóveis. As perdas de conteúdo foram baseadas em informações sobre taxas das propriedades obtidas em manuais de marketing e levantamento de pesquisa ao consumidor. Esses levantamentos relacionaram a propriedade e a classe social de seus membros. Assim, em 1975, por exemplo, 84\% da classe social AB possuíam máquinas de lavar, enquanto que apenas $58 \%$ da classe DE a possuíam.

Os dados do imóvel e de seu conteúdo foram alocados por tamanho para obter classes de curva de prejuízo em 15 profundidades, entre 0,3 a 2,0 m do nível do terreno. Os autores elaboraram 168 curvas DPS para propriedades residenciais, ao relacionar 21 categorias básicas de unidades residenciais, 5 alturas de inundação, 4 tipos de classes sociais e 2 períodos de cheias (menores e maiores que 12 horas), além de tais funções para o setor de comércio e serviços.

Os autores também apresentaram informações de curvas de danos para construções e perda de conteúdo no setor de comércio varejista, serviços e escritórios. Smith (1994) considera que esse aspecto dos prejuízos da inundação urbana é, geralmente, pouco analisado, tendo em vista que as perdas do setor comercial excedem, em geral, muito às do setor residencial, pois uma única grande indústria ou comércio pode incorrer danos diretos decorrentes de inundação que excedem a dezenas de habitações sob o mesmo risco.

Os autores consideram que a vulnerabilidade do conteúdo é, frequentemente, mais alta para as várias categorias do comércio do que para as residências, devido à combinação de elevado estoque e intenso uso do espaço. Portanto, para efetuar uma estimativa hipotética dos danos aos estoques de mercadorias é necessário realizar uma pesquisa com a finalidade de levantar a quantidade ou valor dos estoques característicos para cada tipo de categoria, levando em consideração também o tamanho da empresa.

Os autores observaram que somente uma pequena parte das mercadorias fica armazenada em níveis próximos ao solo e que a maior parte do estoque fica disposto, comumente, em alturas entre 0,6 e 2 metros. Foi constatado também que, para alturas superiores a 1,5 metros, nenhum dano adicional aos equipamentos é observado. 
Deve-se ainda considerar que a contaminação por esgoto, normalmente observada no caso de enchentes urbanas, afeta de forma considerável o valor dos danos, já que influencia de forma significativa nos custos de limpeza e danos ao mobiliário.

Gissing e Russell (2004) pesquisaram os prejuízos das inundações ao setor comercial no município de Kempsey, Austrália, para um evento de inundação ocorrido em 10 de março de 2001. O Tempo de Retorno (TR) dessa chuva foi calculado em 12 anos. A zona empresarial atingida compreende cerca de 200 empresas, incluindo uma variedade de lojas, estações de serviço, hotéis, restaurantes e garagens. A cidade possui estruturas para se proteger a um TR de 10 anos de inundação e possui sistema de previsão e alerta de enchentes com até 24 horas de antecedência.

Para avaliação dos danos, foi aplicado questionário a 95\% dos proprietários de imóveis comerciais atingidos. Foram relatados prejuízos ao imóvel em $92 \%$ das empresas pesquisadas. Foi verificado, no total de danos, que $85 \%$ do valor total do dano direto eram referentes ao conteúdo e $15 \%$ às construções. Do conteúdo danificado, $47 \%$ referiam-se ao estoque, $33 \%$ aos equipamentos e móveis, e $20 \%$ a acessórios.

Concluiu-se que os danos diretos desse evento representavam $44 \%$ dos danos diretos potenciais para aquela região. A pesquisa encontrou grandes variações estatísticas entre os valores apurados, os quais foram também encontrados por Higgins e Robinson (1981), Smith (1992) e SMEC (1975), uma vez que a variação dos danos comerciais é maior do que a variação de danos às residências, devido à grande variedade entre os tipos de empresas.

O SMEC (1975) verificou desvio padrão para o setor comercial de A $\$ 275 / \mathrm{m}^{2}$ para uma amostra de 247 empresas, sendo este maior que o desvio padrão para o setor residencial, estimado em A $125 / \mathrm{m}^{2}$ para uma amostra de 399 residências. Assim, são necessárias atribuições de valores em termos estatísticos. Os autores verificaram, por exemplo, que existe cerca de $20 \%$ de probabilidade de que um edifício comercial inundado na faixa de 1 a $2 \mathrm{~m}$, venha a sofrer danos entre $\mathrm{A} \$ 70$ e $\mathrm{A} \$ 120 / \mathrm{m}^{2}$ e que há uma chance de $40 \%$ de que os danos sofridos sejam maiores do que $\mathrm{A} \$ 120 / \mathrm{m}^{2}$.

ANUFLOOD é o modelo de estimativa de danos de inundação comercial desenvolvido por Greenaway e Smith (1993). O modelo utiliza curvas potenciais de danos com base em dados de inundações na Austrália e no Reino Unido.

Os imóveis comerciais são classificados pelo tamanho e por uma classe de valor que reflete a vulnerabilidade do conteúdo à inundação. Existem três categorias de tamanhos: pequeno (menores que $186 \mathrm{~m}^{2}$ ), correspondente à média das lojas das ruas; médio (186-650 
$\mathrm{m}^{2}$ ), relativo a pequenos supermercados; grandes (maior $650 \mathrm{~m}^{2}$ ). Os danos às pequenas e médias categorias são dados em termos absolutos, enquanto que os danos em grandes imóveis são representados em dólares australianos por metro quadrado.

Cinco categorias de classe de vulnerabilidade foram usadas. A classe de valor 1 referese às empresas com menor vulnerabilidade, como garagens e vendas de veículos, enquanto a classe de valor 5 refere-se às de maior vulnerabilidade, incluindo empresas como lojas de informática.

Os valores de perda são representativos de custos de substituição e não incluem os custos de limpeza. A matriz das curvas de prejuízo baseada no tamanho e classes de valores, com média dos danos para cada classe, foram estipuladas para 5 profundidades de submersão e são apresentadas na Tabela 2.2.

Tabela 2.2 - Matriz das curvas de prejuízo baseadas no tamanho e classes de valores com média dos danos para cada classe

\begin{tabular}{|c|c|c|c|c|c|}
\hline \multicolumn{6}{|c|}{$\begin{array}{l}\text { Curva de danos diretos potenciais para o setor comercial (A\$) } \\
\text { Ano base } 1993\end{array}$} \\
\hline \multicolumn{6}{|c|}{ Tamanho $1\left(\right.$ menor que $\left.186 \mathrm{~m}^{2}\right)$} \\
\hline & \multicolumn{5}{|c|}{$\begin{array}{r}\text { Classes de valores } \\
\end{array}$} \\
\hline Profundidade & 1 & 2 & 3 & 4 & 5 \\
\hline $0,00 \mathrm{~m}$ & 0 & 0 & 0 & 0 & 0 \\
\hline $0,25 \mathrm{~m}$ & 1755 & 3510 & 7020 & 14040 & 28080 \\
\hline $0,75 \mathrm{~m}$ & 4388 & 8775 & 17550 & 35100 & 70200 \\
\hline $1,25 \mathrm{~m}$ & 6581 & 13162 & 26325 & 52650 & 105300 \\
\hline $1,75 \mathrm{~m}$ & 7313 & 14625 & 29250 & 58500 & 117000 \\
\hline $2,00 \mathrm{~m}$ & 7750 & 15502 & 31005 & 62010 & 124020 \\
\hline \multicolumn{6}{|c|}{ Tamanho $2\left(186\right.$ a $\left.650 \mathrm{~m}^{2}\right)$} \\
\hline & \multicolumn{5}{|c|}{ Classes de valores } \\
\hline Profundidade & 1 & 2 & 3 & 4 & 5 \\
\hline $0,00 \mathrm{~m}$ & 0 & 0 & 0 & 0 & 0 \\
\hline $0,25 \mathrm{~m}$ & 5558 & 11115 & 22230 & 44460 & 88920 \\
\hline $0,75 \mathrm{~m}$ & 13455 & 26910 & 53820 & 107640 & 215280 \\
\hline $1,25 \mathrm{~m}$ & 20475 & 40950 & 81900 & 163800 & 327600 \\
\hline $1,75 \mathrm{~m}$ & 22668 & 45338 & 90675 & 181350 & 362700 \\
\hline $2,00 \mathrm{~m}$ & 24131 & 47263 & 96525 & 193050 & 386100 \\
\hline \multicolumn{6}{|c|}{ Tamanho $3\left(\mathrm{~A} \$ / \mathrm{m}^{2}\right)$} \\
\hline & \multicolumn{5}{|c|}{$\begin{array}{r}\text { Classes de valores } \\
\end{array}$} \\
\hline Profundidade & 1 & 2 & 3 & 4 & 5 \\
\hline $0,00 \mathrm{~m}$ & 0 & 0 & 0 & 0 & 0 \\
\hline $0,25 \mathrm{~m}$ & 3 & 6 & 13 & 25 & 50 \\
\hline $0,75 \mathrm{~m}$ & 16 & 32 & 65 & 126 & 253 \\
\hline $1,25 \mathrm{~m}$ & 33 & 66 & 133 & 265 & 530 \\
\hline $1,75 \mathrm{~m}$ & 54 & 109 & 218 & 435 & 870 \\
\hline $2,00 \mathrm{~m}$ & 65 & 130 & 260 & 520 & 1040 \\
\hline
\end{tabular}

A principal vantagem do método ANUFLOOD é que as curvas de danos podem ser construídas utilizando apenas amostras de pequenas dimensões, devido a essas categorias serem 
vagamente definidas. As desvantagens incluem a sua subjetividade e impossibilidade de comparar diretamente diferentes tipos de negócios (categorias de atividade), já que os valores são apresentados em classes de vulnerabilidade que agregam diversos setores em uma mesma classe.

Uma das dificuldades com a padronização das curvas sintéticas de danos para o setor comercial é que a classificação pode apresentar grandes variações. Por exemplo, a curva de uma loja de roupas de departamento pode ser muito diferente da de uma loja de artigos de luxo, que possui um pequeno número de itens de preço elevado, enquanto a primeira possui um grande número de itens com preço reduzido. Assim sendo, o dano a este último imóvel, por $\mathrm{m}^{2}$ de área, deverá ser maior.

A atribuição de classes para cada atividade comercial é uma atividade realizada para superar esse problema. Os questionários de reconhecimento para o setor comercial são baseados em informações do valor total do estoque e equipamentos, e o valor total do prejuízo é ponderado pela altura de inundação usando informações da distribuição vertical do estoque. Esses dados foram também abordados na pesquisa de Penning-Rowsell e Chatternon (1977).

De acordo com Smith (1994), pesquisas similares na Austrália confirmaram que as informações sobre a altura dos objetos podem ser extrapoladas para uso em outros países. Porém, apesar desse conjunto de dados ser uns dos mais abrangentes do tipo em todo o mundo, é improvável que possam ser utilizados sem ponderações para diferentes países, já que a informação sobre prejuízos da estrutura de construções de uma determinada inundação, as estatísticas de mercado e dos proprietários dos imóveis, além dos dados de classes sociais, não serem válidos para outras regiões.

Gissing e Russell (2004) acreditam que os possíveis determinantes da vulnerabilidade ao conteúdo dos edifícios são: i) a vulnerabilidade a que o edifício e o conteúdo estão expostos; ii) o tamanho e o peso do conteúdo; iii) a perecibilidade do conteúdo; iv) a resistência do conteúdo e do edifício aos danos provocados pela água; v) a extensão da contaminação pela água à qual o conteúdo e edifício foram expostos; vi) a facilidade com que o conteúdo pode ser movido. A Tabela 2.3 apresenta as variáveis determinantes na avaliação das incertezas dos danos às inundações.

Tabela 2.3 - Principais variáveis que influenciam nos danos potenciais aos imóveis comerciais

\begin{tabular}{lll}
\hline Variável & Descrição & Referência \\
\hline $\begin{array}{l}\text { Altura de } \\
\text { inundação }\end{array}$ & Quanto maior a altura de inundação, maiores os danos & Nicholas et al. (2001); USACE \\
& $\begin{array}{l}\text { às estruturas (físicos) e conteúdo (estoque, móveis e } \\
\text { acessórios) }\end{array}$ & $\begin{array}{l}\text { (1996); Smith e Tobin (1979); } \\
\text { Handmer (1986) }\end{array}$ \\
\hline
\end{tabular}




\begin{tabular}{|c|c|c|}
\hline Velocidade & $\begin{array}{l}\text { Quanto maior o aumento da velocidade da enxurrada, } \\
\text { maiores a probabilidade de danos a estrutura (físicos) } \\
\text { e conteúdo (estoque, móveis e acessórios) }\end{array}$ & $\begin{array}{l}\text { Nicholas et al. (2001); USACE } \\
\text { (1996); Smith e Tobin (1979); } \\
\text { Handmer (1986) }\end{array}$ \\
\hline $\begin{array}{l}\text { Taxa de } \\
\text { elevação da } \\
\text { altura d'água }\end{array}$ & $\begin{array}{l}\text { Quanto mais rápida o aumento da altura d’água no } \\
\text { estabelecimento, maiores são as dificuldades de } \\
\text { reduzir os danos provocados pela inundação. }\end{array}$ & $\begin{array}{l}\text { Smith e Tobin (1979); Handmer } \\
\text { (1986) }\end{array}$ \\
\hline Detritos & $\begin{array}{l}\text { A presença de lama e detritos na enxurrada aumenta o } \\
\text { potencial de danos estruturais do imóvel }\end{array}$ & Handmer (1986) \\
\hline $\begin{array}{l}\text { Sedimentos e } \\
\text { lama }\end{array}$ & $\begin{array}{l}\text { Incluem os sedimentos e a lama contaminada com } \\
\text { esgoto e poluentes presentes na enxurrada. A presença } \\
\text { desses contaminantes aumentam os custos de limpeza } \\
\text { (Nicholas } \text { et al. 2001). }\end{array}$ & $\begin{array}{l}\text { Nicholas et al. }(2001) ; \text { USACE } \\
\text { (1996); Smith and Tobin } \\
\text { (1979); Handmer (1986) }\end{array}$ \\
\hline $\begin{array}{l}\text { Frequência das } \\
\text { inundações }\end{array}$ & $\begin{array}{l}\text { Inundações recorrentes podem trazer efeitos } \\
\text { acumulados (principalmente sob móveis e estruturas } \\
\text { físicas), provocando aumento dos danos. }\end{array}$ & USACE (1996) \\
\hline $\begin{array}{l}\text { Duração da } \\
\text { inundação }\end{array}$ & $\begin{array}{l}\text { Inundações com longo tempo de duração aumentam a } \\
\text { probabilidade de danos por saturação da estrutura } \\
\text { (pisos e paredes) e conteúdo (principalmente móveis). }\end{array}$ & $\begin{array}{l}\text { Nicholas et al. (2001); USACE } \\
\text { (1996); Smith e Tobin (1979); } \\
\text { Handmer (1986) }\end{array}$ \\
\hline $\begin{array}{l}\text { Horário de } \\
\text { ocorrência do } \\
\text { evento }\end{array}$ & $\begin{array}{l}\text { Inundações que ocorrem a noite podem ser associadas } \\
\text { a maiores danos devido ao efeito pouco efetivo de } \\
\text { alerta de inundação. }\end{array}$ & $\begin{array}{l}\text { Smith e Tobin (1979); Smith } \\
\text { (1992) }\end{array}$ \\
\hline
\end{tabular}

Fonte: adaptado de Gissing e Russell (2004)

\subsubsection{Pesquisas relacionadas a avaliação de danos de inundação}

Smec (1980), sintetizou os danos das maiores inundações a partir de dados sintéticos e apresentou os resultados em termos de danos potenciais de prejuízos.

McBeanet al. (1988) aplicaram um questionário a sete comunidades na província de Ontário, Canadá, cujo conteúdo abrangia informações cadastrais das pessoas atingidas, bem como tipo de estrutura, descrição do conteúdo de cada peça das residências (móveis e eletrônicos) e custos dos bens em um total de 287 entrevistas. O autor considerou o valor do custo dos danos em relação à área construída.

DUTTA (2003) elaborou um estudo de caso na bacia do rio Ichinomiya, no Japão, com curvas DPS elaboradas a partir de dados sobre danos de inundações ocorridas nesse país, acumulados desde 1954 .

LIMA (2003) construiu histogramas por meio de entrevistas com a população afetada na cidade de Itajubá/MG, cujo resultado foi apresentado em termos de valores médios de danos de inundação em função de faixas de profundidade de submersão.

Machado (2005) adaptou a metodologia de Penning-Rowsell e Chatterton para o Brasil, relacionando características de residências com padrões de ocupação distintos e também diferentes categorias de comércio e serviços da cidade de Itajubá - MG. Para a obtenção das curvas, foram utilizados dados reais de prejuízos de imóveis decorrentes da cheia de janeiro de 
2000, em que 70\% dos imóveis do município foram submersos. Foram aplicados 469 questionários no setor habitacional e 200 aos setores de comércio e serviços.

Como resultado, alcançou-se uma correlação entre o prejuízo e a área construída dos imóveis decorrente da cheia em estudo. Estes resultados formaram a base de dados para a construção das curvas danos por profundidade de submersão (DPS) com os valores expressos em reais por metro quadrado de área construída $\left(\mathrm{R} \$ / \mathrm{m}^{2}\right)$ em relação a profundidade de submersão.

Canholi (2005) sugeriu que na ausência de informações, deve-se usar alguns valores típicos, cotados em janeiro de 2004: para áreas industriais, $\mathrm{R} \$ 200,00 / \mathrm{m}^{2}$, por evento de inundação e para áreas comerciais, cerca de $\mathrm{R} \$ 300,00 / \mathrm{m}^{2}$ para escritórios e $\mathrm{R} \$ 600,00 / \mathrm{m}^{2}$ para lojistas, por unidade de negócio (valores estimados considerando quanto os proprietários estariam dispostos a pagar para ficarem livre das cheias).

Milograna (2009) elaborou um sistema de suporte à decisão para seleção de alternativas de controle de inundações urbanas. A autora utilizou as curvas DPS elaboradas por Machado (2005) para os imóveis residenciais e comerciais, a fim de verificar os prejuízos causados por inundações em diferentes cenários da cidade de Itajubá - MG. A autora avaliou também os danos ocorridos na cidade, como interrupção no fonecimento de energia elétrica, telefonia, abastecimento de água, dentre outros, para compor o valor total dos prejuízos.

Cançado (2010) desenvolveu uma metodologia para avaliação do impacto das inundações nas edificações da cidade de Itajubá - MG, de forma a avaliar, principalmente, os danos indiretos e aqueles causados à cadeia de produção regional. Dentre os resultados obtidos, encontra-se a proposição de indicadores de vulnerabilidade e de ameaça à exposição do conteúdo das edificações em eventos de inundações urbanas.

Fadel (2015) aplicou metodologia baseado em Machado (2005) e Tachini (2010) para ao município de Lajeado/RS sob duas hipóteses de ocupação: ordenamento apresentado pelo plano diretor e outra com uma área de não ocupação. Três alternativas de medidas de controle foram avaliadas: a) manutenção da situação atual - não implementar nenhuma forma de controle; b) medida não estrutural de restrição de ocupação a partir de estudos de zoneamento (com duas zonas); c) medida estrutural de construção de um dique ao longo do rio Taquari e principais arroios urbanos do município. Como resultado a autora verificou que a solução com dique de proteção, apesar de resultar em menores riscos de prejuízos, foi a alternativa mais cara, sendo a alternativa de restrição de ocupação a que se mostrou com menores custos totais. 
Righetto e Mendiondo (2004) realizaram um levantamento do prejuízo após uma inundação registrada na região do mercado municipal, localizado na bacia do córrego do Gregório, em janeiro de 2004 (São Carlos- SP), por meio de entrevistas com 14 comerciários. Os resultados indicaram que, para uma inundação em que o nível de água atingiu cerca de 1 metro acima da calha do rio, o prejuízo declarado pelos comerciantes foi de $\mathrm{R} \$ 500.000,00$.

Outro estudo para esta bacia foi de Graciosa (2010), que encontrou valores da ordem de R 20 milhões em simulação, utilizando um cenário de cobertura e uso do solo atual com período de retorno de 100 anos e de $\mathrm{R} \$ 28$ milhões para cenários futuros no mesmo período de retorno. A autora apresentou proposta de seguro-enchente para a região e simulou a sustentabilidade de um fundo de seguros. Para análise econômica, simulou o prejuízo a partir das curvas DPS elaboradas por Machado (2005) e exibiu valores de danos em $\mathrm{R} \$ / \mathrm{m}^{2}$, de acordo com o uso do solo.

\subsection{3. Índice de ameaça de inundação ao conteúdo dos imóveis}

A estimativa da perda relativa percentual do conteúdo elaborada por Cançado (2009) relaciona a suscetibilidade média de perda do conteúdo do imóvel com a altura da inundação, criando um índice de perda para cada altura de submersão. Este índice foi denominado pela autora como Índice de ameaça da inundação ao conteúdo dos domicílios - IA 2 .

Na definição deste índice utiliza-se a profundidade como o fator de ameaça ao conteúdo das edificações. As escalas de profundidade foram baseadas os parâmetros apresentados em Penning-Rowsell \& Chatterton (1977), adaptados ao Brasil por Machado (2005). Os índices foram utilizados para definir as profundidades críticas associadas à suscetibilidade dos diferentes bens, em contato com a água, e utilizaram-se as curvas de suscetibilidade de cada bem estudado, sendo que a suscetibilidade varia em relação à profundidade.

Para melhor representatividade da curva de prejuízo e discretização dos resultados, os dados do índice de susceptibilidade apresentados pela autora foram interpolados e apresentados na Tabela 2.4. Por meio desta tabela, percebe-se que a profundidade mínima considerada é de $0,35 \mathrm{~m}$, profundidade na qual foi observado o início dos danos ao conteúdo.

Tabela 2.4 - Índice de ameaça da inundação ao conteúdo dos domicílios - IAM2

\begin{tabular}{l|l}
\hline $\begin{array}{l}\text { Profundidade } \\
(\mathrm{em} \mathrm{m})\end{array}$ & Índice $(\%)$ \\
\hline 0,35 a 0,45 & 0,05 \\
\hline 0,45 a 0,55 & 0,21 \\
\hline 0,55 a 0,70 & 0,31 \\
\hline 0,70 a 0,85 & 0,41 \\
\hline 0,85 a 0,95 & 0,54
\end{tabular}




\begin{tabular}{|c|c|}
\hline 0,95 a 1,05 & 0,67 \\
\hline 1,05 a 1,15 & 0,79 \\
\hline 1,15 a 1,45 & 0,94 \\
\hline 1,45 a 1,75 & 0,95 \\
\hline 1,75 a 2,05 & 0,97 \\
\hline Mais de 2,05 & 1,00 \\
\hline
\end{tabular}

Estes índices serão aplicados aos imóveis comerciais com o intuito de relacionar o valor do prejuízo encontrado através das curvas de danos por profundidade de submersão elaborada por Machado (2005) com o percentual de susceptibilidade de perda por profundidade de submersão elaborada por Cançado (2009), e estimar a perda média sofrida pelos imóveis em cada evento e a vulnerabilidade a que o conteúdo está exposto

Pela Tabela 2.4, é possível averiguar que profundidades de submersão entre 0,45 m e 1,15 m apresentam incrementos de $58 \%$ ao prejuízo dos imóveis e, que, acima de 1,45 m, mais de $94 \%$ do conteúdo do imóvel está ameaçado, profundidade em que os valores de prejuízo dos imóveis tornam-se próximo do prejuízo potencial.

Essa análise traz subsídios ao entendimento da sensibilidade do modelo econômico de prejuízos frente às incertezas das respostas dos modelos chuva-vazão para elaboração de mapas de manchas de inundação e análise de seus resultados, e demonstram a necessidade da acurácia do modelo na simulação dos prejuízos.

\subsection{Conceitos e definições atribuídas a sociologia dos desastres}

De acordo com Souza e Lourenço (2015), o desastre é uma função no processo de risco que traduz uma combinação entre processos perigosos, vulnerabilidade e incapacidade de conter os impactos negativos da manifestação do risco.

De acordo com os autores, o conceito de risco é sutil e pode causar certa insegurança conceitual, já que, por vezes, é difícil compreender o momento em que se passa do risco para o perigo e que esse se manifesta através do desastre.

O conceito de risco pode ser interpelado como sendo anterior aos conceitos de perigo e desastre, e é mensurável por referir-se à probabilidade de ocorrência danosa para a sociedade. Em termos temporais, o risco precede o desastre; em termos espaciais, as áreas de risco têm magnitude maior que as áreas efetivas que sofrem com o desastre [SOUZA \& LOURENÇO, 2015; ALMEIDA et al. 2016]. 
A resposta ao perigo é a capacidade de diminuir perdas e de salvar vidas. Para isso, chama-se a atenção para a importância da percepção do risco, como resposta fundamental que as populações darão ao perigo. As pessoas e os grupos sociais podem ter visão diferenciada do risco e, em geral, tal percepção está ligada aos princípios culturais de cada grupo [MARANDOLA \& HOGAN, 2005].

Para fazer a análise de risco é necessário estabelecer uma metodologia que determine a natureza e extensão do risco, analisando os processos potencialmente perigosos e as condições preexistentes de vulnerabilidade, que podem representar uma ameaça potencial e causar danos às pessoas, propriedades, meios de vida e ambiente de que dependem. Para desenvolver análises de risco, com uso de geotecnologias, é necessário caracterizar a severidade (perigosidade) dos processos potencialmente perigosos, identificando a sua suscetibilidade, probabilidade e intensidade, bem como a vulnerabilidade, através da exposição, sensibilidade e capacidade, podendo ainda estimar-se os danos potenciais, que se ilustram através do mapeamento das áreas de risco. Poderia dizer-se que o risco se apresenta em áreas vulneráveis e susceptíveis, onde existe a probabilidade de, por acaso ou azar, ocorrer algum tipo de ameaça, perigo, problema, impacto ou desastre. [UN-ISDR, 2004]

Segundo Alcántara-Ayala (2002), a ocorrência dos desastres naturais está ligada não somente à susceptibilidade dos mesmos, devido às características geoambientais, mas também à vulnerabilidade do sistema social sob impacto, isto é, o sistema econômico-social-políticocultural.

Westgate e O'Keefe (1976) afirmam que só o evento não é desastre, mas está alinhado ao desastre (não pode ser definido sem o evento), já que é necessário ainda a interação entre o agente físico e uma comunidade para se caracterizar o desastre. Sintetizando os conceitos, fica evidente a relação entre o evento perigoso (natural ou tecnológico) e os seres vivos (humanos e/ou outros seres vivos) para definir o conceito de desastre. Partindo da premissa que desastres partem de uma construção social, dificilmente um estudo acadêmico vai conseguir eliminar todas as suas lacunas, devido à magnitude que um desastre possui [ALEXANDER, 2000].

O termo suscetibilidade pode ser conceituado como a possibilidade de ocorrência de um determinado evento (Santos, 2012). Este evento pode ser qualificado como um fenômeno relacionado a perdas e danos à sociedade. O mapeamento da suscetibilidade depende das características naturais intrínsecas da área de estudo.

De acordo com Valencio et al. (2009), outra questão refere-se ao fato de que os danos derivados da suscetibilidade humana ao fator de ameaça não são de todo visíveis, quantificáveis 
e temporalmente simultâneos ao evento. Os efeitos psicossociais de um desastre estão para além dos ferimentos e das perdas materiais dos afetados bem como das limitações sanitárias e de saúde do local e, no geral, ficam sem resposta das autoridades.

Para Monte, Michel e Goldenfum (2018), o termo vulnerabilidade é complexo, pois abrange todas as questões que incluam o ser humano como agente determinante da sua própria situação, e isso inclui os conceitos de resiliência, capacidade de resposta, capacidade de enfrentamento, adaptação e suscetibilidade.

Em relação à vulnerabilidade, ressaltam-se os elementos expostos, tais como: infraestruturas urbanas, edificações, população, valores socioeconômicos e agropecuários, etc. Ressalta-se ainda que a vulnerabilidade, inserido em um contexto urbano, necessita de uma perspectiva de análise com escalas mais detalhadas, ou seja, em pequenas áreas. Nesta análise, as questões de cunho social e econômico ganham maior relevância e voltam-se predominantemente para os sítios urbanos, fortalecendo o conceito de vulnerabilidade socioeconômica. Assim, três variáveis devem consideradas (Klein \& Nicholls (1999), apud Nascimento, 2011):

- Suscetibilidade - potencial de ser afetado;

- Resistência - capacidade de resistir ao impacto;

- Resiliência - celeridade de recuperação após impacto.

Almeida et al. (2016) afirmam que é perceptível que os estudos focam no perigo e pouco concretizam análise em conjunto com a vulnerabilidade, deixando lacunas abertas.

Segundo Acselrad (2006), se com a noção de risco se procura estimar a probabilidade da ocorrência de um agravo em um determinado grupo, com a noção de vulnerabilidade se procura julgar a suscetibilidade desse mesmo grupo com relação a esse agravo. Para o autor, a vulnerabilidade comumente está conectada a uma exposição aos riscos, designando uma maior ou menor susceptibilidade de pessoas, lugares, infraestruturas ou dos três sofrerem infortúnios. No entanto, existem também os fatores subjetivos: ocorrem distintas concepções do que é tolerável ou não numa dada condição de existência. Assim, cabe-se sempre analisar o contexto social envolvente. [Valêncio et al. 2006].

Na Tabela 2.5 são apresentadas as definições adotadas das terminologias apresentadas anteriormente nesta seção.

Tabela 2.5 - Terminologias adotadas a sociologia dos desastres

Termo Autor Definição




\begin{tabular}{|c|c|c|}
\hline Perigo & $\begin{array}{l}\text { Tobin e } \\
\text { Montz (1997) }\end{array}$ & Situação potencialmente prejudicial. \\
\hline Desastre & $\begin{array}{l}\text { Tobin e } \\
\text { Montz (1997) }\end{array}$ & Materialização do perigo. \\
\hline Risco & EMA (2004) & $\begin{array}{l}\text { Interações potenciais e reais entre os perigos a que determinada } \\
\text { comunidade está exposta e a vulnerabilidade dos elementos dessa } \\
\text { comunidade a essa exposição. }\end{array}$ \\
\hline $\begin{array}{l}\text { Risco } \\
\text { (geografia) }\end{array}$ & $\begin{array}{l}\text { UN-ISDR } \\
(2004)\end{array}$ & $\begin{array}{l}\text { Pode ser compreendido como sendo a probabilidade de consequências } \\
\text { prejudiciais ou perdas esperadas (mortes, ferimentos, a propriedade, } \\
\text { meios de subsistência, a atividade econômica interrompida ou ambiente } \\
\text { danificado) resultantes de interações entre os riscos naturais ou induzidas } \\
\text { pelo homem e as condições vulneráveis. Convencionalmente risco é } \\
\text { expresso pela notação de risco = Processos potencialmente perigosos x } \\
\text { Vulnerabilidade. }\end{array}$ \\
\hline $\begin{array}{l}\text { Risco } \\
\text { (sociologia) }\end{array}$ & Yvette (2007) & $\begin{array}{l}\text { O risco, objeto social, define-se como a percepção do perigo, da catástrofe } \\
\text { possível. Ele existe social ou profissional, uma comunidade, uma } \\
\text { sociedade que o apreende por meio de representações mentais e com ele } \\
\text { convive por meio de práticas específicas. Não há risco sem uma } \\
\text { população ou indivíduo que o perceba e que poderia sofrer seus efeitos. } \\
\text { Correm-se riscos, que são assumidos, recusados, estimados, avaliados, } \\
\text { calculados. O risco é a tradução de uma ameaça, de um perigo, para aquele } \\
\text { que está sujeito a ele e o percebe como tal. }\end{array}$ \\
\hline Susceptibilidade & Santos (2012) & Possibilidade de ocorrência de um determinado evento \\
\hline Vulnerabilidade & $\begin{array}{l}\text { Acselrad } \\
(2006)\end{array}$ & $\begin{array}{l}\text { Exposição aos riscos, designando uma maior ou menor susceptibilidade } \\
\text { de pessoas, lugares, infraestruturas ou os três sofrerem infortúnios }\end{array}$ \\
\hline Vulnerabilidade & $\begin{array}{l}\text { Cardona } \\
(2004)\end{array}$ & $\begin{array}{l}\text { A noção de vulnerabilidade contribui para o melhor entendimento dos } \\
\text { conceitos de risco e desastre, pois estes são apenas concentrados no } \\
\text { evento, enquanto que a vulnerabilidade explora a experiência humana. }\end{array}$ \\
\hline Resistência & $\begin{array}{l}\text { Christofoletti } \\
(1990)\end{array}$ & $\begin{array}{l}\text { Capacidade do sistema em permanecer sem ser afetado após distúrbios } \\
\text { externos }\end{array}$ \\
\hline Resiliência & $\begin{array}{l}\text { Christofoletti } \\
(1990)\end{array}$ & $\begin{array}{l}\text { Capacidade do sistema de retornar as condições originais após ser afetado } \\
\text { por distúrbios externos }\end{array}$ \\
\hline $\begin{array}{l}\text { Avaliação } \\
\text { de riscos }\end{array}$ & $\begin{array}{l}\text { UN-ISDR } \\
(2004)\end{array}$ & $\begin{array}{l}\text { Revisão das características inerentes aos processos envolvidos como } \\
\text { sejam a sua localização no espaço (suscetibilidade) e no tempo } \\
\text { (probabilidade), bem como a sua intensidade; além desta análise relativa } \\
\text { à severidade (que alguns autores designam de perigosidade) deve ser tida } \\
\text { em conta a vulnerabilidade, analisando os aspetos físicos, sociais, } \\
\text { econômicos e as dimensões ambientais. }\end{array}$ \\
\hline
\end{tabular}

Fonte: Adaptado de Souza e Lourenço (2015); Monte, Michel e Goldenfum (2018)

\subsubsection{Vulnerabilidade social e prejuízos diretos decorrentes de inundações urbanas}

O conceito de sociedade de risco está fundamentado na transformação das ameaças da natureza em ameaças sociais, econômicas e políticas, o que representa um desafio real no presente e no futuro (BECK, 2010). Por conta disso é que os problemas ambientais são, antes de tudo, problemas sociais advindos de uma determinada visão de mundo e de uma relação com a natureza.

Quando, nesta relação do homem com a natureza, uma ameaça hidrometeorológica, como a chuva, encontra uma vulnerabilidade socioambiental, temos um desastre. Assim, o 
desastre significa a disruptura da vida social (VALENCIO et al., 2009) e está ligado à uma conjuntura de processos sociais, ambientais e tecnológicos.

A abordagem quantitativa é uma metodologia que visa à quantificação do valor monetário associado aos danos provocados por uma inundação. Os prejuízos diretos são estimados com base no conteúdo e na estrutura dos imóveis e a profundidade de submersão é o fator determinante nesta avaliação. Há vários estudos no âmbito de realização desta quantificação, sendo a maior parte deles focada nos custos resultantes dos danos diretos (LEITÃO, 2009). No entanto, Ryu (2008) acredita que ainda não se chegou a um consenso em relação à metodologia a ser usada para quantificação desses danos.

A classificação do risco é efetuada por meio da elaboração de mapas de risco de inundação, que resultarão da aplicação de uma metodologia quantitativa, a qual classifica o risco de acordo com o custo resultante dos danos provocados por uma inundação.

Esse mapa de risco de inundação é diferente de um mapa de inundação, segundo definição proposta pela Comissão das Comunidades Européias (2006). Os mapas de inundação são plantas que mostram a área inundada e a profundidade de submersão para diferentes períodos de retorno; já os mapas de risco de inundação devem mostrar os riscos potenciais causados por inundações (em termos de prejuízos econômicos), além de informações sobre o histórico de inundações na região, população afetada e danos ao meio ambiente.

\subsection{Classificação dos danos causados por inundações}

De acordo com Smith (2010), os tipos dos danos causados por inundação podem ser distinguidos entre tangíveis e intangíveis. Aos danos intangíveis não é possível atribuir valores monetários diretos e a eles estão relacionados os danos pessoais, como a perda de vidas humanas, danos sobre a saúde e/ou efeitos relacionados ao estresse e à angústia, bem como mesmo à degradação de condições de saúde coletiva devido a condições sanitárias inadequadas.

Os danos tangíveis, por sua vez, são divididos em diretos e indiretos. Os danos econômicos diretos são aqueles que podem ser diretamente atribuídos à ocorrência de uma inundação e, em geral, são resultantes do contato físico da água com o bem atingido. Nessa categoria estão incluídos:

- os danos decorrentes da destruição ou degradação de propriedades públicas e privadas e a perda ou desgaste de bens públicos e privados, provenientes da ação física (pressão, empuxo), química e biológica (degradação) das águas e da deposição de sedimentos;

- custos de medidas de emergência tais como evacuação, salvamento, limpeza. 
Os danos indiretos são decorrentes de disrupturas da vida cotidiana provocada por uma inundação, e estão relacionados a prejuízos causados pela interrupção ou perturbação no meio (descontinuação do fluxo de tráfego e de serviços de comunicações, abastecimento de água, sistemas de esgoto etc.), ou pela cessão de atividades econômicas e de processos produtivos (perda de produção industrial, de renda e de lucros em negócios não realizados) [SMITH, 2010].

O valor do dano referente à inundação é afetado pelo emprego de sistemas de previsão e alerta, que podem reduzir significativamente a ocorrência de prejuízos, pois possibilita a remoção de bens móveis para um local seguro, além de diminuir a vulnerabilidade da população afetada.

As variáveis que afetam a vulnerabilidade da população propensa a inundações, são, principalmente: a profundidade, a duração da inundação e a velocidade da água.

\subsection{Curvas de danos por profundidade de submersão (DPS)}

$\mathrm{Na}$ avaliação dos danos por inundação usando o método direto, duas estratégias distintas podem ser aplicadas.

A primeira está relacionada à utilização de dados históricos, na qual a obtenção dos dados é baseada na identificação e diagnóstico dos prejuízos relacionados a um evento de inundação ocorrido e consiste na obtenção direta da relação de altura (nível) de inundação versus prejuízo total (GRIG e HELWEG, 1975).

Nesse caso, os dados são obtidos por levantamento local nas várias unidades atingidas (residências, atividades industriais, comerciais e de prestação de serviço). Essa estratégia retrata o prejuízo corrente, ou seja, o cenário da bacia estudada em um dado instante, representado por características socioeconômicas, condições da rede de drenagem, etc.

A segunda estratégia introduz o conceito de curvas de danos em função da profundidade de submersão (curvas DPS). Essas curvas podem ser derivadas de uma síntese de dados de danos reais ou de estimativas de danos hipotéticos, baseados na experiência acumulada de danos relacionados a eventos de inundação, os quais são sintetizados em padrões referentes à susceptibilidade dos vários bens ao contato com a água, para vários intervalos de profundidade e/ou duração da submersão (DUTTA, 2003).

Dado que a profundidade de inundação é a variável crítica para definição da quantificação das perdas, as curvas DPS são geralmente preparadas para diferentes tipos de edificação. 
A curva de danos por profundidade de submersão (DPS) é uma forma de apresentar os prejuízos individuais das empresas contidas na mancha de inundação. Os prejuízos são apresentados em termos de danos por área $\left(\mathrm{R} \$ / \mathrm{m}^{2}\right)$. De acordo com Green (2000), é usual ajustar ou modificar estas curvas diante de outros fatores para melhorar a acurácia de seus resultados.

Olivieri e Santoro (2000) também compartilham da mesma ideia, ao comentarem que o dano por inundação pode ser avaliado sob a suposição de que, observada uma condição socioeconômica ou financeira local semelhante, este pode ser considerado em função da profundidade da água.

De acordo com Smith (1994), as curvas de danos normalmente relatam uma classe específica de imóvel e apresentam informações inter-relacionadas entre os prejuízos da inundação pela profundidade de submersão, sendo assim importantes para construção dos cenários sobre os quais a avaliação dos danos da inundação é baseada. Essas curvas foram desenvolvidas para prever os danos causados pelas inundações ao reunir dados de eventos atuais e usá-los como guia para futuras ocorrências.

Porém, há um grande número de problemas ao realizar essa aproximação: extrapolações de uma região para outra colocam dificuldades para comparação da magnitude da inundação, como o tempo de aviso de um evento extremo e as diferenças do tipo de imóvel e de seu conteúdo. Além disso, é necessário decidir o número de classes e os tipos de construções a serem incluídos, o que representa o "trade-off" entre o tempo despendido com pesquisas de campo e a acurácia obtida.

$\mathrm{O}$ autor define a pesquisa de campo como aquela que seleciona uma amostra dos imóveis de cada classe e realiza um check-list do possível conteúdo. A informação da amostra de cada tipo de habitação é então normalizada e as curvas de danos são construídas. Os resultados das curvas são os danos provocados por um dado evento de inundação, que relacionam a profundidade de submersão com a área do imóvel atingida, sob uma vazão relacionada a uma dada probabilidade de excedência.

O desenvolvimento de curvas DPS apresenta uma capacidade potencial de generalização, que permite transferi-las no tempo ou no espaço, se atendidas determinadas condições. A transferência no tempo (para o mesmo local) pode ser necessária devido a modificações no uso do solo, por exemplo. 
Já a transferência das informações no espaço representa a possibilidade de utilização em outras regiões, cujas características socioeconômicas e de tecnologia de construção sejam semelhantes às das curvas desenvolvidas.

O método da curva nível-prejuízo consiste em quatro etapas (USACE, 1986):

(1) determinação da curva que relaciona a vazão com a probabilidade de ocorrência ou tempo de retorno, estimada por simulação hidrológica;

(2) determinação da curva que relaciona a vazão com o nível de inundação correspondente, estimada por simulação hidráulica do nível de inundação;

(3) determinação da curva que relaciona o nível de inundação com o prejuízo correspondente. Canholi (2005) e Tucci (2007) salientaram que a determinação desta curva representa a maior dificuldade de aplicação deste método;

(4) determinação da curva que relaciona o prejuízo com a probabilidade de ocorrência da vazão correspondente, ligada ao resultado da substituição das curvas (1) e (2) na curva (3);

Os dados das curvas padrões de dano x profundidade são aplicados à área inundada de acordo com a distribuição das profundidades de submersão nessa área, contando com informações relativas à cobertura e ocupação da terra, para gerar relações de dano em função da altura (nível) de inundação.

Este é um método bastante empregado para a estimativa dos prejuízos causados por inundações, também chamado de método da curva nível x prejuízo, graficamente ilustrado na Figura 2.3.

Figura 2.3 - Método da curva nível-prejuízo para estimativa dos prejuízos por inundação.

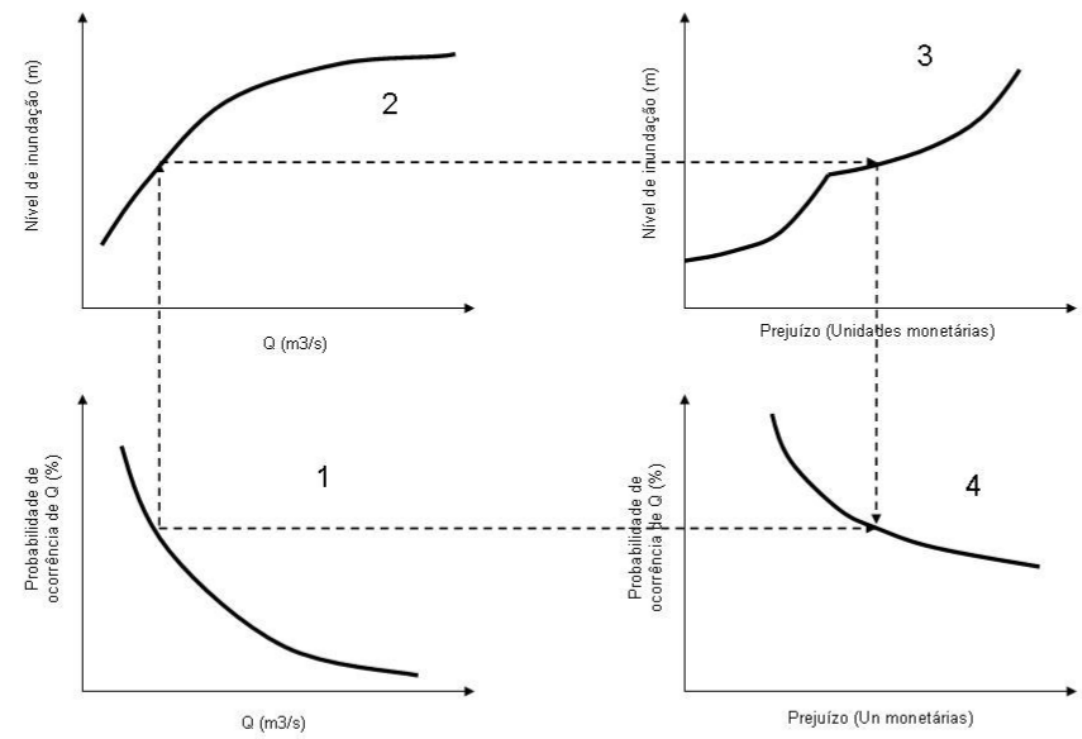

Fonte: Adaptado de TUCCI (1993) 


\subsection{Avaliação de sistemas de controle de inundações}

De acordo com USDA (1976) um plano de gerenciamento de inundações deve incluir:

$\checkmark$ inventário das características da bacia que afetam o escoamento;

$\checkmark$ formulação das alternativas de sistemas de controle, especificando os objetivos pretendidos e as dificuldades para implantação;

$\checkmark$ procedimento de avaliação da viabilidade econômica e financeira das várias alternativas;

$\checkmark$ procedimento para selecionar a melhor alternativa.

Para um dado projeto de controle de inundações, a curva de custo dos danos $\mathrm{x}$ a probabilidade de excedência é construída combinando-se informações disponibilizadas pelo desenvolvimento de outras relações, que envolvem as seguintes etapas:

$\checkmark$ obtenção da estimativa da probabilidade de excedência (ou do seu inverso, o período de retorno) relacionada às inundações de magnitudes distintas para estabelecer a relação vazão x probabilidade de excedência;

$\checkmark$ modelagem hidráulica para determinação dos níveis de inundação dos eventos considerados, determinando as relações cota de inundação x vazão;

$\checkmark$ estabelecimento dos danos causados em função de vários níveis de inundação, com o desenvolvimento da relação cota de inundação x custo dos danos.

Para projetos de controle de inundações, o benefício é igual ao valor dos danos evitados com a implantação do projeto. Dessa forma, os benefícios advindos com a construção de uma barragem para conter uma cheia de 100 anos, por exemplo, são iguais aos prejuízos que seriam causados por tal inundação e por outras de menor extensão e profundidade. Os custos a serem considerados incluem, basicamente, custos de implantação (planejamento, projeto, construção, terreno etc.) e custos de operação e manutenção (mão de obra, troca e reparo de equipamentos etc.). Estes são necessários para operar o sistema durante sua vida útil. Outros custos que também podem ser levados em consideração, como impacto social, impacto ambiental, dentre outros.

Quando observações de variáveis apropriadas para caracterizar as inundações (tais como vazão de pico, nível máximo de água, volume máximo) encontram-se disponíveis no local ou nas proximidades da região em que a informação é necessária, o uso de séries anuais dessas variáveis permite determinar a distribuição de frequência de inundações (YEVJEVICH, 
1994). A incerteza está associada aos eventos hidrológicos e pode ser quantificada em termos de distribuições de probabilidade.

Dados econômicos e estatísticos podem ser combinados na avaliação de sistemas de controle de inundações, como as relações hidrológicas entre vazões e probabilidade de excedência, vazões e cotas de inundação e através do estabelecimento dos danos causados em função dos vários níveis de inundação. Essas relações possibilitam determinar a correlação entre probabilidade e danos, a partir da qual é possível calcular o valor médio anual dos danos (DAVIS, 1988). Para projetos de controle de inundações, o valor médio anual dos danos evitados corresponde ao valor médio anual dos benefícios.

A Figura 2.4 apresenta o procedimento de determinação do valor médio anual dos benefícios, usado na análise custo-benefício para avaliação de sistemas de controle de inundações. Dessa forma, o Valor Médio Anual dos Benefícios é determinado como a diferença entre o Valor Médio Anual dos danos evitados (considerando que um dado sistema de proteção foi implantado) e o Valor Médio Anual dos danos residuais, que persistem mesmo após a implantação do sistema. Em cada caso, o Valor Médio Anual dos danos corresponde à área abaixo da curva custo dos danos x probabilidade de excedência. 
Figura 2.4 - Metodologia para avaliação de medidas mitigadoras em inundações

(A)

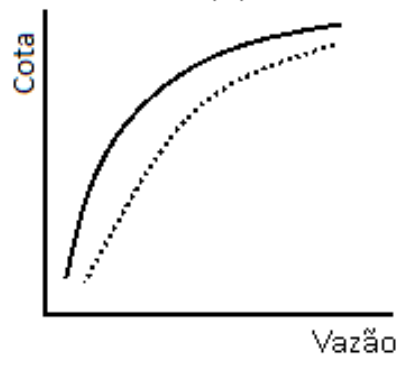

(B)

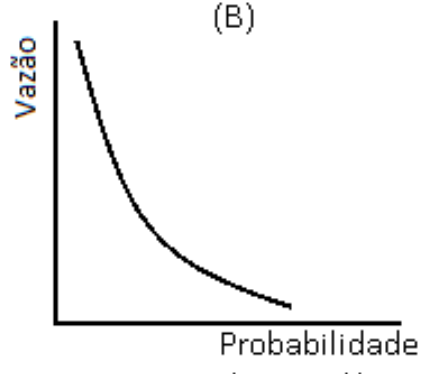

de excedência
(C)

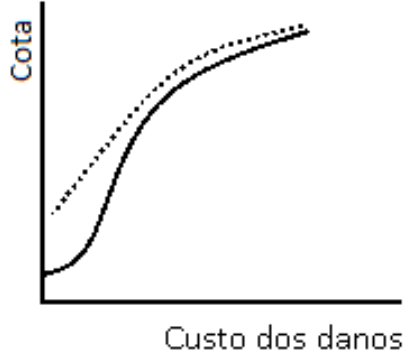

(D)

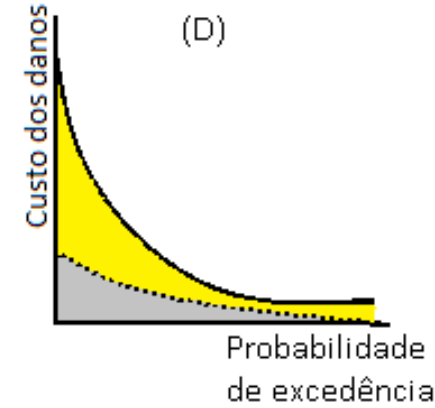

- Antes da implantação das medidas mitigadoras Após implantação das medidas mitigadoras

$\square$ Valor médio anual dos danos evitados pela mitigação

Valor médio anual dos danos residuais

Fonte: TORTEROTOT (1993) E PENNING-ROWSELL E CHATTERNON (1977)

A curva contínua da Figura 2.4-A é uma representação gráfica da relação cota-vazão em uma seção de um curso d'água, onde a curva pontilhada ilustra uma nova relação cota-vazão em que o aumento da capacidade de transporte de vazões é observado como resultado da adoção de uma medida mitigadora. Já a curva pontilhada da Figura 2.4-C ilustra a adoção de uma medida mitigadora ao reduzir a vulnerabilidade e os prejuízos, em que se pode observar a sensibilidade do prejuízo em relação à altura da inundação nos primeiros momentos de subida desta altura e a pouca eficácia da medida frente a maiores cotas na redução dos custos dos danos. A área do gráfico entre as curvas da Figura 2.4-D, que representam o quadro antes e após a implantação do sistema de mitigação, corresponde ao valor médio anual dos danos evitados pelo sistema de mitigação (representado pela cor amarela). A área mais próxima do cruzamento entre a abscissa e a ordenada do gráfico, representa o valor médio anual dos danos residuais (apresentado na cor cinza), considerados como aqueles que não foram evitados com a implantação da medida mitigadora. 
A maioria dos projetos de recursos hídricos é justificada com base na diferença (em termos monetários) entre benefícios e custos, quando os benefícios são medidos pelo aumento líquido no valor de bens e serviços que resultam de um projeto comparado à ausência deste (WANIELISTC e YOUSEF, 1992).

Após ter sido determinado o valor médio anual dos danos evitados, o benefício futuro e o custo real da implantação da solução estrutural são comparados, convertendo-os para uma base de tempo comum, utilizando o método do Valor Presente do Benefício Líquido (VPBL).

SALGADO (1995) realizou uma avaliação econômica de um projeto baseada em projeções do desempenho futuro do investimento, representado em termos de fluxo de caixa, (um demonstrativo das entradas e saídas de recursos) como consequência da decisão de implantar esse projeto. De acordo com o autor, os métodos mais utilizados são:

- valor presente do benefício líquido (VPBL)

- benefício líquido anual equivalente (BLAE)

- relação benefício/custo incremental (B/C) e

- taxa interna de retorno (TIR)

O autor esclarece que é consenso entre autores (FARO, 1971; CONTADOR, 1981; POMERANZ, 1985) a indicação do método VPBL na análise de investimentos ou na tomada de decisão entre alternativas. Esse método consiste em se obter o saldo entre o valor presente da série de benefícios anuais gerados pelo projeto $\left(\mathrm{B}_{\mathrm{t}}\right)$ e o valor presente da série de custos anuais desse projeto $\left(\mathrm{C}_{\mathrm{t}}\right)$ ao longo de sua vida útil, adotando uma taxa de desconto. $\mathrm{O}$ valor do VPBL é calculado pela Equação 2.1.

$V P B L=\sum_{t=1}^{n t} \frac{B_{t}-C_{t}}{\left(1-r_{d}\right)^{t}}$

Em que:

nt: número de períodos considerados, que deve corresponder à vida útil do projeto $\mathrm{r}_{\mathrm{d}:}$ a taxa de desconto.

Um VPBL maior que zero, sob a consideração de uma taxa de financiamento mínima aceitável, significa que o projeto é economicamente viável. Na avaliação de projetos alternativos, a escolha deverá recair sobre aquele que apresentar um maior VPBL.

\subsubsection{Técnicas compensatórias de drenagem urbana}

O conceito de tecnologias alternativas ou técnicas compensatórias de drenagem surgiu na Europa e na América do Norte com o propósito de minimizar a deficiência dos sistemas 
convencionais e neutralizar os efeitos da urbanização sobre os processos hidrológicos, com benefícios para a qualidade de vida e preservação ambiental.

De acordo com Baptista, Nascimento \& Barraud (2005), as técnicas compensatórias surgem para atuar na detenção e na infiltração das águas precipitadas, com o intuito de promover o rearranjo temporal das vazões e a diminuição do volume escoado, e assim reduzir a probabilidade de inundações e aumentar a possibilidade de ganhos na qualidade das águas pluviais.

Segundo Souza (2002), cada novo espaço a ser urbanizado deve compensar seu efeito de ocupação, pois isso representará uma manutenção e recuperação do ciclo hidrológico urbano, para que então a população perceba esse processo e participe de sua manutenção.

Segundo Urbonas \& Stahre (1993), as vantagens de se utilizar esses sistemas de drenagem são: diminuição dos riscos de inundação e melhoria da qualidade do meio urbano e da água; redução ou eliminação do uso da microdrenagem local; boa integração com espaços urbanos e valorização da água no meio urbano; melhoria da recarga de água subterrânea; minimização de intervenções a jusante decorrentes de novos loteamentos; e baixo custo de implantação.

Em relação às limitações, os autores citam: utilização de tecnologias limitadas às características do local, tais como: tipo de solo, uso e ocupação, topografia, lençol subterrâneo; manutenção frequente de modo a se evitar perdas e aumentar a vida útil das estruturas; dificuldade de avaliar seu desempenho a longo prazo devido a aplicação recente e falta de informações a respeito de seu funcionamento; e risco de contaminação do solo e do aquífero.

Alguns autores desenvolveram estudos acerca das técnicas compensatórias de drenagem. Serão apresentadas algumas características, vantagens e limitações de acordo com os seguintes autores: Baptista, Nascimento \& Barraud (2005); Almeida, Nascimento \& Baptista (2005); Deschene (2002); Matos, (2000); Cruz, Tucci \& Silveira, (1998); Barraud et al., (1999); Urbonas \& Stahre (1993); e Schueler (1987).

As técnicas compensatórias são classificadas em estruturais e não-estruturais, sendo as não-estruturais aquelas que incluem os princípios de prevenção, como as ações de educação ambiental. Já as estruturais são aquelas que atuam na detenção, retenção e infiltração do volume escoado e podem ser divididas em:

$\checkmark$ Técnicas de controle centralizado: bacias de detenção e retenção;

$\checkmark$ Técnicas de controle na fonte: valas e valetas de armazenamento e/ou infiltração; microreservatórios individuais; telhados armazenadores 
também conhecidos popularmente como telhados verdes; e poços de infiltração;

$\checkmark$ Técnicas lineares: pavimentos porosos, dotados ou não de dispositivos de infiltração; as valas de detenção e/ou infiltração e as trincheiras de infiltração.

No Brasil, as técnicas compensatórias têm sido estudadas, com maior ênfase, a partir da década 1990. Para Moura (2004), os benefícios das medidas estruturais e não estruturais, na compensação do processo de urbanização, são evitar os prejuízos e diminuir a vulnerabilidade social da população na área de risco. A seguir, são apresentadas algumas destas estruturas.

Bacias de detenção são estruturas de acumulação temporária das águas pluviais e dispositivos de armazenamento e regularização do escoamento pluvial afluente. As bacias são utilizadas para atender três funções principais relacionadas à drenagem urbana: o controle de inundações através do amortecimento de cheias geradas no contexto urbano; a redução do escoamento superficial (no caso de bacias de infiltração); e a redução da poluição difusa (URBONAS e STAHRE, 1993; DECHESNE, 2002).

As valas, valetas e planos de infiltração e/ou detenção são técnicas compensatórias constituídas por simples depressões escavadas no solo e possuem como finalidade armazenar temporariamente as águas pluviais, favorecendo eventualmente a infiltração. As diferenças entre as estruturas são percebidas em suas dimensões, sendo as valas e valetas com dimensões longitudinais maiores que transversais. Já os planos possuem pequenas profundidades e as dimensões longitudinais não muito maiores do que as transversais (ALMEIDA, NASCIMENTO e BAPTISTA, 2005).

Os microreservatórios ou reservatórios individuais são pequenas estruturas de amortecimento de cheia que permitem retardar o escoamento e atenuar os picos de cheia, possibilitando assim, a recuperação da capacidade de amortecimento da bacia perdida pelo processo de impermeabilização da superfície. Os reservatórios podem ser instalados ao ar livre (a céu aberto), enterrados ou dentro de uma edificação domiciliar. Estes são geralmente tanques pré-fabricados, estruturas em alvenaria ou concreto que permitem utilizar as águas pluviais para usos domésticos não potáveis, respeitando a concepção e os critérios adequados de projeto para a dupla função de amortecimento de cheias e reserva de águas de abastecimento (CRUZ, TUCCI \& SILVEIRA, 1998; BAPTISTA, NASCIMENTO \& BARRAUD, 2005).

No município de São Carlos foi sancionada uma lei municipal que dispõe sobre a construção de reservatório de detenção ou retenção de águas em conjuntos habitacionais, áreas 
comerciais e industriais, loteamentos ou parcelamentos em áreas urbanas aos loteamentos aprovados a partir dessa data (SÃO CARLOS, 2003). A lei prevê que sejam construídos reservatórios de detenção de $1 \mathrm{~m}^{3}$ (lotes de $250 \mathrm{~m}^{2}$ ) até $3,5 \mathrm{~m}^{3}$ (lotes de $600 \mathrm{~m}^{2}$ ) aos novos imóveis construídos no município. Cabe destacar também que foi sancionada uma lei municipal que cria o Sistema de Captação e Aproveitamento de água de chuva e institui a sua obrigatoriedade nos imóveis localizados no Município (SÃO CARLOS, 2016). Essa lei obriga os proprietários de imóveis que tenham construções residenciais ou comerciais, com área igual ou superior a $140 \mathrm{~m}^{2}$ (cento e quarenta metros quadrados) a instalar junto a tais construções o Sistema de Captação e Aproveitamento de água da chuva, com capacidade mínima de $2 \mathrm{~m}^{3}$ por lote.

Os telhados de armazenamento representam uma das possibilidades para redução do escoamento das águas das chuvas por meio do armazenamento provisório em sua própria estrutura, com limitação de descarga de vazão máxima por reguladores de vazão. Nesta técnica pode-se adotar tanto telhados planos como dotados de inclinação de 5\%, dependendo de instalação de compartimentos (BAPTISTA, NASCIMENTO \& BARRAUD, 2005).

Estas estruturas podem ser compostas por vegetação ou por britas e seixos. Os vegetalizados podem conter uma vegetação intensiva predominante (telhado jardim acessível) e/ou extensiva (cobertura vegetal simples). Além do aspecto hidrológico e urbanístico positivo, os telhados consistem ainda em proteção térmica contribuindo para o isolamento da edificação. Já os telhados com britas e seixos são utilizados quando não se prevê o acesso do usuário ao local, favorecendo uma proteção contra a impermeabilização, tanto na ação mecânica quanto sobre os raios ultravioletas em relação às variações bruscas de temperatura. Esta técnica se apresenta bastante atrativa por oferecer um grande potencial de integração aos projetos urbanísticos e arquitetônicos (BAPTISTA, NASCIMENTO \& BARRAUD, 2005; MATOS 2000).

As trincheiras de infiltração são técnicas compensatórias lineares implantadas na superfície do terreno a pequenas profundidades com a finalidade de recolher as águas pluviais e infiltrá-las no solo. Destaca-se também sua utilização na estabilização e atenuação de contaminantes provenientes do escoamento superficial (SCHUELER, 1987; BAPTISTA, NASCIMENTO \& BARRAUD, 2005).

O pavimento permeável consiste em uma parte da infraestrutura destinada à circulação de pessoas e de veículos, e dispõe de uma camada de base com elevado números de vazios no qual armazena e infiltra as águas pluviais. Essa estrutura é definida como o dispositivo de 
infiltração que desvia o escoamento superficial para dentro de reservatórios de pedras localizado sob a superfície do terreno (BAPTISTA, NASCIMENTO \& BARRAUD, 2005; URBONAS \& STAHRE, 1993).

Os pavimentos são classificados em pavimentos permeáveis e pavimentos porosos e podem ser identificados três níveis diferentes de atuação no controle do escoamento superficial, sendo estes:

Pavimentos com revestimento superficial permeável: possibilita a redução da velocidade do escoamento superficial, a retenção temporária de pequenos volumes de água na superfície do pavimento e infiltra parte da água;

$\checkmark$ Pavimentos com estrutura porosa de detenção: detém temporariamente a água pluvial amortecendo o pico de vazão e alterando o desenvolvimento temporal dos hidrogramas;

$\checkmark$ Pavimentos com estrutura porosa e com dispositivos de facilitação de infiltração: detém temporariamente a água e infiltra parte dela, amortecendo o pico de vazão, a alteração temporal dos hidrogramas e a redução dos volumes efetivamente escoados.

As vantagens e limitações das técnicas compensatórias de drenagem são apresentadas Tabela 2.6.

Tabela 2.6 - Vantagens e desvantagens das técnicas compensatórias de drenagem urbana

\begin{tabular}{|c|c|c|}
\hline $\begin{array}{l}\text { TÉCNICA } \\
\text { COMPEN- } \\
\text { SATÓRIA }\end{array}$ & VANTAGENS & LIMITAÇÕES \\
\hline $\begin{array}{l}\text { Valas, } \\
\text { Valetas e } \\
\text { Planos }\end{array}$ & $\begin{array}{l}\text { - Baixo custo de construção e manutenção; } \\
\text { - Redução das dimensões do sistema de drenagem } \\
\text { a jusante, ou eliminação do mesmo; } \\
\text { - Boa integração paisagística valorizando o espaço } \\
\text { urbano; } \\
\text { - Possibilidade de recarga do lençol freático; } \\
\text { - Possibilidade de melhoria da qualidade das águas } \\
\text { pluviais. }\end{array}$ & $\begin{array}{l}\text { - Necessidade de espaço específico } \\
\text { para sua implantação; } \\
\text { - Necessidade de manutenção } \\
\text { periódica; } \\
\text { - Restrição de eficiência em áreas de } \\
\text { fortes declividades; } \\
\text { - Possibilidade de estagnação das } \\
\text { águas com implicações ambientais. }\end{array}$ \\
\hline $\begin{array}{l}\text { Reservató- } \\
\text { rio } \\
\text { Individual }\end{array}$ & $\begin{array}{l}\text { - Utilização das águas pluviais para uso doméstico } \\
\text { e irrigação; } \\
\text { - Reserva de água de abastecimento quando } \\
\text { respeitados os critérios adequados; } \\
\text { - Redução dos picos de vazão à jusante; }\end{array}$ & $\begin{array}{l}\text { - Instalações da técnica geralmente } \\
\text { em áreas privadas; } \\
\text { - Dificuldade de manutenção; } \\
\text { - Risco de poluição do lençol e } \\
\text { colmatação da estrutura (no caso de } \\
\text { infiltração). }\end{array}$ \\
\hline $\begin{array}{l}\text { Trincheiras } \\
\text { de } \\
\text { Infiltração }\end{array}$ & $\begin{array}{l}\text { - Redução dos picos de vazão à jusante; } \\
\text { - Redução das dimensões dos sistemas de } \\
\text { drenagem convencionais ou eliminação deste; } \\
\text { - Boa integração com o fator paisagístico com } \\
\text { possibilidade de valorização do espaço urbano; } \\
\text { - Ganho ambiental, com possibilidade de recarga } \\
\text { do lençol freático e melhoria da qualidade das } \\
\text { águas pluviais; }\end{array}$ & $\begin{array}{l}\text { - Não podem ser utilizadas em áreas } \\
\text { de fortes declividades devido à } \\
\text { redução na sua eficiência; } \\
\text { - Necessitam de manutenção } \\
\text { constante e controle da colmatação; } \\
\text { - Risco de poluição das águas } \\
\text { subterrâneas. }\end{array}$ \\
\hline
\end{tabular}




\begin{tabular}{|c|c|c|}
\hline & $\begin{array}{l}\text { - Capacidade de retomar as características do } \\
\text { balanço hídrico e do ciclo hidrológico mais } \\
\text { próximo das condições naturais; } \\
\text { - Possibilidade de utilização de diversos tipos de } \\
\text { material, tais como: asfalto, concreto, grama ou } \\
\text { cascalho; } \\
\text { - Baixo custo. }\end{array}$ & \\
\hline $\begin{array}{l}\text { Bacias de } \\
\text { detenção e } \\
\text { infiltração }\end{array}$ & $\begin{array}{l}\text { - Controle de inundações através do } \\
\text { amortecimento de cheias geradas no contexto } \\
\text { urbano; } \\
\text { - No caso de bacias de infiltração há a redução do } \\
\text { escoamento superficial; } \\
\text { - Redução da poluição difusa de origem pluvial; } \\
\text { - Impactos sobre a qualidade de vida na região; } \\
\text { sobre a paisagem urbana; sobre a qualidade das } \\
\text { águas; e sobre o regime hidrológico; } \\
\text { - Pode ser usada de diferentes combinações e } \\
\text { arranjos; } \\
\text { - A água armazenada pode ser usada para diversos } \\
\text { fins, tais como: reserva para incêndios, ou } \\
\text { irrigação de jardins em bacias pequenas. } \\
\text { - Necessidade de pouco espaço, pois podem ser } \\
\text { associados à pavimentação tradicional; } \\
\text { - Reduções de 15\% a 30\% dos volumes escoados; } \\
\text { - Impactos positivos na mitigação de problemas de } \\
\text { inundação; } \\
\text { - Redução no custo de implantação em relação ao } \\
\text { custo de implantação do sistema tradicional; } \\
\text { - Recarga das águas subterrâneas; } \\
\text { - Melhoria da qualidade das águas por ação da } \\
\text { filtração no corpo do pavimento; } \\
\text { - Ganhos financeiros associados à redução das } \\
\text { dimensões do sistema de drenagem a jusante; } \\
\text { - Ganhos em termos de circulação viária, com } \\
\text { melhoria e conforto devido à redução de poças de } \\
\text { água e melhoria da aderência; } \\
\text { - Redução da aquaplanagem, além da redução de } \\
\text { ruídos. }\end{array}$ & $\begin{array}{l}\text { - Risco de segurança dos moradores } \\
\text { nas margens das bacias; } \\
\text { - Risco de poluição do lençol no caso } \\
\text { de bacias de infiltração; } \\
\text { - Risco de proliferação de insetos e } \\
\text { doenças de veiculação hídrica; } \\
\text { - Necessita de áreas grandes. } \\
\text { - O impacto sobre o lençol freático e } \\
\text { sobre o escoamento subterrâneo } \\
\text { devido à drenagem de águas } \\
\text { contaminadas; } \\
\text { - Entupimento dos dispositivos } \\
\text { devido à falta de controle na } \\
\text { construção e manutenção do sistema, } \\
\text { tornando-o ineficiente; } \\
\text { - A fragilidade dos revestimentos } \\
\text { asfálticos permeáveis em áreas } \\
\text { sujeitas a esforços de cisalhamento } \\
\text { significativos; } \\
\text { - Colmatação devido a finos. }\end{array}$ \\
\hline $\begin{array}{l}\text { Telhados } \\
\text { Armazena- } \\
\text { dores }\end{array}$ & $\begin{array}{l}\text { - Boa integração no meio urbano; } \\
\text { - Redução da vazão escoada a jusante; } \\
\text { - Diminuição do risco de inundação, com a } \\
\text { redução dos picos de vazões escoadas; } \\
\text { - Não necessita muitos investimentos; } \\
\text { - Ganho financeiro, com a redução das dimensões } \\
\text { das tubulações a jusante; } \\
\text { - Não há diferenças nas técnicas de construção em } \\
\text { relação aos telhados convencionais. }\end{array}$ & $\begin{array}{l}\text { - Necessidade de uma manutenção } \\
\text { regular; } \\
\text { - Dificuldade da utilização em } \\
\text { telhados com declividades elevadas; } \\
\text { - Necessidade de precauções } \\
\text { adicionais em relação à } \\
\text { estanqueidade; } \\
\text { - Necessidade de cuidados como } \\
\text { cálculos de estabilidade para a } \\
\text { utilização sobre telhados existentes. }\end{array}$ \\
\hline
\end{tabular}

Fonte: Urbonas \& Stahre, (1993); Araújo, Tucci \& Goldenfum, (2000); Baptista, Nascimento \& Barraud, (2005); Matos, (2000).

\subsubsection{Seguro-enchente}

Como breve histórico acerca da criação do seguro-enchente, tem-se, em 1936, nos Estados Unidos, a aprovação de uma lei federal que identificava a natureza pública dos 
programas de redução de enchentes e a implantação de medidas físicas ou estruturais como um meio de reduzir estes danos. Em 1966, o governo reconheceu que as medidas anteriores não eram adequadas e deu ênfase às medidas não estruturais, que permitiriam à população conviver com a cheia. (TUCCI, 2005)

De acordo com o autor, em 1973 foi aprovada uma lei sobre proteção contra desastres de enchentes, dando ênfase a medidas não estruturais, encorajando e exigindo o seguroenchente, regulamentação do uso do solo e proteção das novas construções para grandes cheias.

O seguro-enchente indeniza o segurado por eventuais danos decorrentes de sinistros hidrológicos. Apesar de sua importância, este tipo de seguro tem sido utilizado, principalmente, nos países desenvolvidos, em locais de alto risco onde a incidência de cheias é um evento comum, alcançando cifras de bilhões de dólares e milhares de mortes (RIGHETTO, 2005).

Como característica, o sistema de seguro aborda a transferência de risco à massa segurada, o fundo de seguro e a redistribuição das perdas (FENS, 1990). A implantação de fundos de seguros é uma tarefa complexa, tendo em vista que a concepção multidisciplinar necessária para valorar bens que não são diretamente quantificáveis e determinar curvas de prejuízo.

De acordo com Graciosa (2010), a composição do sistema se dá, basicamente, por quatro agentes:

$\checkmark \quad$ o segurador é a entidade que se compromete a ressarcir os prejuízos provocados pelo evento externo (sinistro) para o qual o seguro foi contratado, recebendo para isso um valor (prêmio);

$\checkmark \quad$ o segurado é a pessoa que receberá do segurador o ressarcimento parcial ou total pelos prejuízos sofridos em caso de sinistro;

$\checkmark \quad$ o ressegurador é a entidade que faz o seguro do segurador, pulverizando os riscos de desastre natural ao longo de uma área (geralmente é uma entidade que atua internacionalmente); $\checkmark \quad$ o regulador é aquele que dispõe sobre os termos da aplicação do seguro, como limite de prêmios, políticas de investimentos do segurador em mitigação dos danos, políticas de subsídio parcial, obrigatoriedade do seguro e abrangência da cobertura.

Segundo Righetto (2005), a quantificação do risco pode ser feita pela previsão de ocorrência de eventos hidrológicos extremos em função da probabilidade de ocorrência da inundação e das consequências sociais e/ou econômicas potenciais. Esse risco indica qual o mínimo necessário arrecadado para que a seguradora possa criar o fundo e assumir possíveis riscos. Dessa forma, o risco caracteriza-se como o prejuízo médio anual esperado a ser 
desembolsado a fim de cobrir eventuais prejuízos causados por enchentes, em um tempo de retorno máximo pré-determinado.

Nessa concepção de seguro, o valor do prejuízo médio anual esperado deve ser inferior ao valor anual a ser arrecadado pela seguradora com o prêmio pago pelos segurados. Essa é a situação que dará sustentabilidade de longo prazo ao sistema de seguro, de modo a evitar possíveis empréstimos para cobrir prejuízos significativos que possam ocorrer, principalmente, no início de implantação do sistema de seguro. [RIGHETTO, 2005]. 


\subsection{Monitoramento hidrológico}

As variáveis mais utilizadas nos modelos hidrológicos são a precipitação (entrada) e a vazão (saída), sendo que estas precisam ser monitoradas para serem representativas da realidade nos modelos aplicados.

Apesar da maior disponibilidade de dados ser proveniente da precipitação, a densidade de postos de monitoramento, a falta de dados em intervalo menor que um dia e o tamanho das séries monitoradas são as maiores limitações quanto a este parâmetro. Sendo assim, as incertezas existentes nas precipitações são uma das maiores fontes de erros dos modelos (TUCCI, 2005).

\subsubsection{Inundações bruscas}

De acordo com Goerl e Kobiyama (2005), as inundações bruscas são aquelas que ocorrem repentinamente, com pouco tempo de alarme e alerta para o local de ocorrência. $\mathrm{Na}$ língua inglesa é conhecida como flash flood, e no Brasil são conhecidas popularmente como enxurrada. Na Tabela 2.7 encontram-se algumas definições utilizadas para o termo inundação brusca.

Tabela 2.7 - Alguns conceitos utilizados para definir as inundações

\begin{tabular}{lll}
\hline Termo & Autor & Definição \\
\hline Flood & NFIP (2005) & $\begin{array}{l}\text { Uma condição geral ou temporária de parcial ou completa inundação de dois ou mais } \\
\text { acres de uma terra normalmente ou duas ou mais propriedades (uma das quais é a sua } \\
\text { propriedade), proveniente da inundação de águas continentais ou oceânicas. }\end{array}$ \\
\hline Flood & $\begin{array}{l}\text { NATIONAL } \\
\text { DISASTER } \\
\text { EDUCATION } \\
\text { COȦLITION }\end{array}$ & $\begin{array}{l}\text { Inundações ocorrem nas chamadas planícies de inundação, quando prolongada } \\
\text { precipitação por vários dias, intensa chuva em um curto período de tempo ou um } \\
\text { entulhamento de gelo ou de restos, faz com que um rio ou um córrego transbordem e } \\
\text { inundem a área circunvizinha. }\end{array}$ \\
\hline Flood & $\begin{array}{l}\text { NWS/NOAA } \\
\text { (2005) }\end{array}$ & $\begin{array}{l}\text { A inundação de uma área normalmente seca causado pelo aumento do nível das águas em } \\
\text { um curso d'água estabelecido, como um rio, um córrego, ou um canal de drenagem ou }\end{array}$ \\
um dique, perto ou no local onde a chuvas precipitaram.
\end{tabular}




\begin{tabular}{lll}
\hline $\begin{array}{l}\text { Inundações } \\
\text { Ribeirinhas }\end{array}$ & $\begin{array}{l}\text { Tucci e Bertoni } \\
(2003)\end{array}$ & $\begin{array}{l}\text { Quando a precipitação é intensa e o solo não tem capacidade de infiltrar, grande parte do } \\
\text { volume escoa para o sistema de drenagem, superando sua capacidade natural de } \\
\text { escoamento. O excesso de volume que não consegue ser drenado ocupa a várzea } \\
\text { inundando de acordo coma topografia áreas próximas aos rios. }\end{array}$ \\
\hline Flood & $\begin{array}{l}\text { OFFICE OF } \\
\text { TECNOLOGY } \\
\text { ASSESSMENT } \\
(1980)\end{array}$ & $\begin{array}{l}\text { Uma inundação de terra normalmente não coberta pela água e que são usadas ou } \\
\text { utilizáveis pelo homem. }\end{array}$ \\
\hline $\begin{array}{l}\text { River } \\
\text { Flood }\end{array}$ & Kron (2002) & $\begin{array}{l}\text { É o resultado de intensa e/ou persistente chuvas por alguns dias ou semanas sobre grandes } \\
\text { áreas algumas vezes combinadas com neve derretida. Inundações de rios elevam-se } \\
\text { gradualmente, ainda assim, algumas vezes dentro de um curto período }\end{array}$
\end{tabular}

Fonte: Adaptado de Goerl e Kobiyama (2005)

A partir da Tabela 2.7, observa-se que as inundações bruscas possuem características muito diferentes das inundações graduais. Como o próprio nome diz, elas são bruscas, ou seja, devem ocorrer no tempo próximo ao momento da ocorrência do evento que as causam. Outra característica particular deste tipo de inundação é o pouco ou nenhum tempo de alerta. Por elas se desenvolverem bruscamente, geralmente atingem as áreas susceptíveis a ela de surpresa, não tendo tempo hábil para os moradores tomar os devidos procedimentos para se protegerem ou salvar os seus bens.

\subsubsection{Tormentas padronizadas}

As precipitações intensas são as principais causas de cheias e prejuízos, por isso merecem destaque especial em hidrologia. Dentro do conceito de chuva intensa, deve ser lembrado que, quanto mais curta for a duração de uma precipitação, maior será a chance de que esta tenha sido muito intensa, e que, quanto mais frequente for uma chuva, maior será a probabilidade de sua ocorrência. Assim, na análise de uma chuva intensa, deve ser considerada a inter-relação entre as variáveis Intensidade, Duração e Frequência. Esse processo é possível com a utilização das chamadas curvas de intensidade-duração-frequência (IDF).

Canholi (2005) explica que as curvas IDF são construídas a partir de registros históricos de alturas de precipitação relacionadas à duração da chuva. Estas curvas são resultado da tabulação e processamento estatístico de tais dados. Cabe ressaltar que a composição de hietogramas a partir de curvas IDF pode ser bastante útil para o projetista. Contudo, a partir da adoção deste método, ocorre uma maximização das precipitações para cada duração, já que em raras ocasiões os totais precipitados máximos para cada duração ocorrerão em um único evento. 
A adoção de chuvas padronizadas é um dos métodos mais utilizados para a definição de chuva de projeto. É necessário que a chuva de projeto represente muitos eventos e tenha as mesmas características de intensidade, volume e duração de uma tormenta de igual frequência.

Ao se adotar chuvas de projetos padronizadas, devem ser consideradas algumas hipóteses: a tormenta de projeto tem um volume equivalente ao de uma chuva observada com a mesma recorrência; a distribuição temporal utilizada para a chuva de projeto representa uma tormenta ocorrida; a chuva é considerada uniformemente distribuída na bacia.

Tendo em vista a grande sensibilidade que a distribuição temporal das chuvas (variável aleatória e probabilística dependente das condições climáticas e topográficas locais) pode incorrer ao modelo econômico de prejuízos, esta deve ser analisada na região de estudo em questão, de modo a avaliar as probabilidades de excedência das vazões encontradas nos modelos chuva-vazão.

\subsubsection{Distribuição temporal das chuvas}

Diversos autores abordaram a importância de aspectos das precipitações nos estudos de hidrologia.

Rahman et al. (2002) afirmaram que os fatores primordiais a afetarem a geração de vazão são: a duração, a intensidade, os padrões temporais e de área da chuva, bem como as perdas da precipitação total, resultando na precipitação efetiva.

Loukas (2002) comentou sobre a relevância da variação temporal da precipitação e aplicou análises estatísticas, realizando comparações com dados observados para estimar esta importância.

Canholli (2005) discutiu a influência da distribuição temporal das precipitações nos projetos de drenagem urbana e realizou uma revisão bibliográfica sobre o assunto.

De acordo com Monteiro e Kobiyama (2014), a variação temporal detalhada se torna mais importante quanto menor for o tempo de concentração da bacia, mas este detalhamento não existe em grande parte dos bancos de dados de precipitação do Brasil. Desta forma, métodos alternativos são necessários para estimar a variação temporal da precipitação.

Nos estudos hidrológicos voltados à drenagem urbana, são adotados, normalmente, relações IDF e modelos matemáticos do tipo chuva-vazão na definição dos hidrogramas de projeto. É no processo de desagregação das precipitações para a determinação dos hietogramas de projeto que reside o grande problema do hidrólogo, visto que, para cada distribuição temporal das chuvas, tem-se hidrogramas diferentes (CANHOLI, 2005). 
A metodologia dos blocos alternados é caracterizada como uma solução simples e uma condição crítica para o obstáculo citado anteriormente. Este método propõe a desagregação dos totais de chuva em intervalos de tempo discretizados pela sua duração total. Desta forma, a partir dos incrementos totais acumulados de precipitação, transformados em altura de chuva, os blocos obtidos são rearranjados numa sequência tal que, no centro da duração da chuva, situese o bloco maior e, em seguida, os demais blocos, em ordem decrescente, um à direita e o outro à esquerda do bloco maior, alternadamente (TUCCI, 1995).

De acordo com Canholi (2005), a distribuição dos blocos no hietograma é arbitrária e pode conduzir a diversas configurações. Porém, há algumas regras empíricas que devem conduzir a picos mais elevados. Uma destas impõe que a parcela mais intensa da precipitação seja colocada entre 1/3 e 1/2 da duração da chuva e os outros blocos devem ser colocados alternadamente. Neste método, quanto menor for o passo de tempo empregado, maiores serão as intensidades de pico.

O método descrito por Huff (1967) classifica as precipitações em quatro grupos, divididas em durações com quatro partes iguais para cada, denominadas quartis. O autor analisou 261 eventos de chuva, com duração de 30 minutos a 48 horas, em 49 postos espalhados numa área de $1.000 \mathrm{~km}^{2}$, durante 11 anos de registro. A área considerada no estudo era rural, com terreno plano e com elevações de $200 \mathrm{~m}$ a $300 \mathrm{~m}$.

No modelo em questão, uma precipitação isolada foi definida como a chuva intensa, separada da precipitação que a antecede, por um intervalo de 6 horas ou mais. O critério adotado na classificação foi baseado no valor da chuva média observada na rede de postos pluviométricos utilizados no experimento. Apenas as precipitações que excederam $13 \mathrm{~mm}$ foram adotadas no estudo. As distribuições temporais foram expressas em termos de probabilidade, devido à grande variabilidade existente.

Assim, as precipitações foram classificadas e agrupadas de acordo com o quartil em que a chuva mais intensa ocorreu. Para os dados de chuva em cada quartil, fez-se uma análise estatística, com o objetivo de se obter as curvas adimensionais de distribuição temporal, associadas à uma probabilidade de excedência (probabilidade de a chuva exceder a curva adimensional de distribuição temporal no respectivo quartil). Essa subdivisão foi efetuada de acordo com a localização do pico da precipitação em cada um dos quatro quartis. As curvas de probabilidade de excedência de chuva descritas por Huff são apresentadas na Figura 2.5. 
Figura 2.5 - Curvas de probabilidade de excedência de chuva descritas por Huff

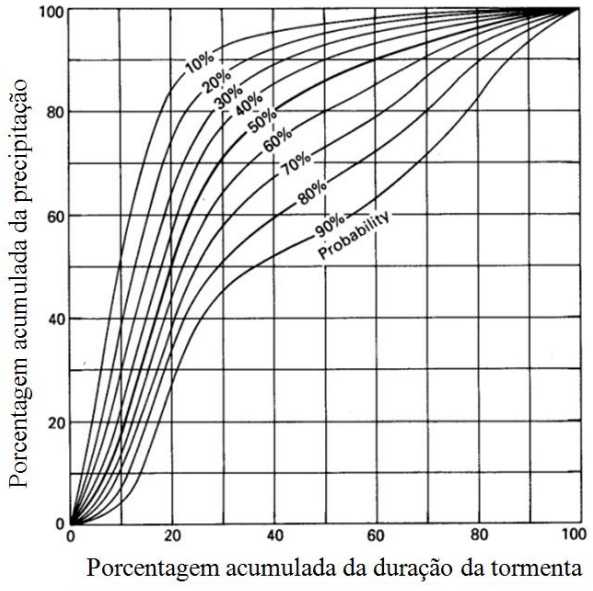

a. Huff $1^{\circ}$ quartil

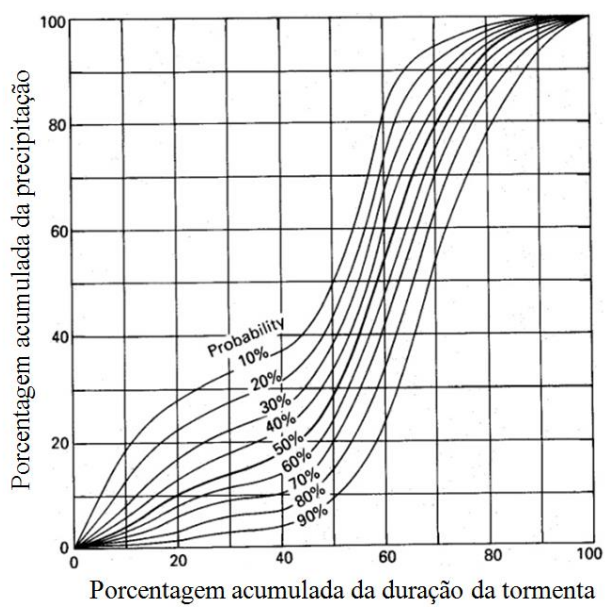

c. Huff $3^{\circ}$ quartil

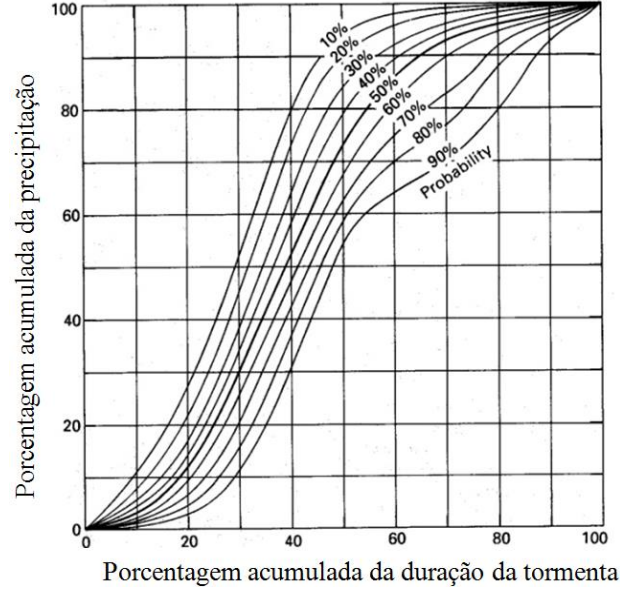

b. Huff $2^{\circ}$ quartil

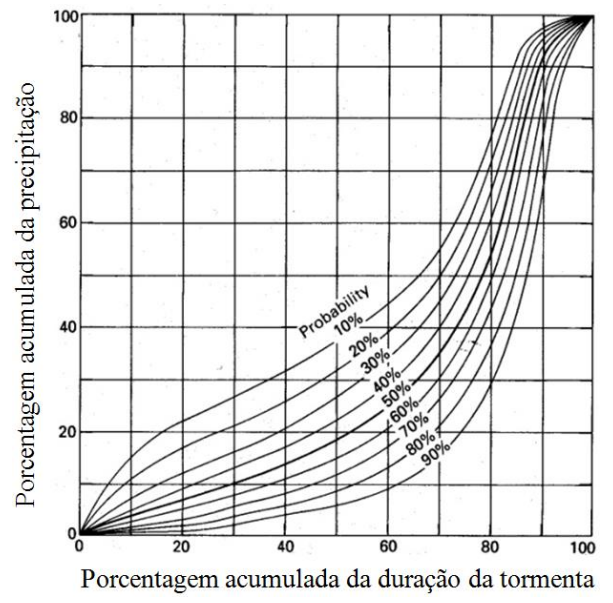

d. Huff $4^{\circ}$ quartil

Fonte: HUFF (1990)

Huff (1990) conclui que as curvas de cada tipo de tempestade (grupo quartil) verificadas em sua pesquisa fornecem estimativas das características de distribuição temporal, a níveis de probabilidade que variam de $10 \%$ a $90 \%$ do total de ocorrências de tempestade. Ainda que a curva mediana (50\% de probabilidade) seja a mais representativa dentre as observadas no estudo, as outras curvas permitem aos pesquisadores determinarem as relações na bacia para os vários tipos de distribuições que ocorrem na natureza, em cada um dos quartis. Sendo assim, as curvas de $10 \%$ e $90 \%$ poderão ser bastante úteis para estimar as relações de escoamento nos modelos mais extremos de distribuição temporal das chuvas.

Utilizando o gráfico de distribuição temporal de chuvas do $1^{\circ}$ quartil através do método de Huff (Figura 2.5a), é possível estabelecer, para cada percentual de duração de chuva, os percentuais de chuva acumulada total e o de chuva acumulada por intervalo de tempo. Como exemplo de aplicação, é apresentado na Erro! Fonte de referência não encontrada. 8 uma 
huva com duração de uma hora, em que o hietograma de projeto se enquadra no primeiro quartil com $50 \%$ de probabilidade de excedência (Figura 2.5a).

Tabela 2.8 - Percentual de chuva acumulada no tempo para a distribuição de Huff $1^{\circ}$ quartil com $50 \%$ de probabilidade de excedência

\begin{tabular}{cccc}
\hline $\begin{array}{c}\Delta \mathbf{t} \\
(\mathbf{m i n})\end{array}$ & $\begin{array}{c}\text { Duração } \\
(\boldsymbol{\%})\end{array}$ & $\begin{array}{c}\text { Chuva } \\
\text { acumulada }(\boldsymbol{\%})\end{array}$ & $\begin{array}{c}\text { Intervalo } \\
(\boldsymbol{\%})\end{array}$ \\
\hline 12 & 20 & 50 & 50 \\
\hline 24 & 40 & 78 & 28 \\
\hline 36 & 60 & 88 & 10 \\
\hline 48 & 80 & 95 & 7 \\
\hline 60 & 100 & 100 & 5 \\
\hline Total & & & 100
\end{tabular}

Fonte: TUCCI (1995)

Ao observar as durações das chuvas e seus respectivos quartis, Huff (1967) obteve as frequências associadas à estas chuvas, conforme a Tabela 2.9. É possível observar na tabela que as precipitações intensas de curta duração (menores do que $12 \mathrm{~h}$ e geralmente de maior interesse para os projetos de drenagem urbana) foram classificadas com maior frequência entre o $1^{\circ}$ e o $2^{\circ}$ quartis, sendo que $66 \%$ das chuvas analisadas enquadraram-se neles considerando durações menores do que 12 horas.

Tabela 2.9 - Relação duração da chuva - quartil - frequência

Duração da chuva (h) Quartil Frequência (\%)

\begin{tabular}{lll}
\hline Menor que 12 & $1^{\circ}$. & 30 \\
\hline Menor que 12 & $2^{\circ}$. & 36 \\
\hline Entre 12 e 24 & $3^{\circ}$. & 19 \\
\hline Maior que 24 & $4^{\circ}$. & 15 \\
\hline Fonte: adaptado de TUCCI (1995); CANHOLI (2005)
\end{tabular}

De acordo com o Manual de Drenagem e Manejo de Águas Pluviais de São Paulo (SÃO PAULO, 2012), o tipo de distribuição temporal das chuvas de projeto e a fixação da duração estão sujeitas a diversas orientações metodológicas, implicando em resultados de descargas máximas e volumes de cheias que podem ser bastante discrepantes.

Destaca também que, nos projetos de drenagem para bacias urbanas, tem sido adotada, na maioria das vezes, índices de chuvas com duração de 2 ou 3 horas, sendo que a distribuição é dada conforme o método dos blocos alternados ou o método de Huff $1^{\circ}$ quartil. Somente para bacias com áreas maiores de $100 \mathrm{~km}^{2}$ tem-se adotado índices de chuvas de 6 horas e distribuição dos blocos alternados ou de Huff $2^{\circ}$ quartil. 
Para a elaboração de hietogramas de projeto característicos em Portugal, Brandão et al. (2001) aplicaram o método de Huff (1967) em três postos pluviométricos, localizados nas cidades de Lisboa, Évora e Faro. Dentre as conclusões dos autores, verificou-se a predominância das chuvas analisadas de hietogramas do tipo Huff $1^{\circ}$ Quartil, ou seja, ocorrência de maior intensidade da precipitação no primeiro quarto da duração.

Os autores também realizaram análises das precipitações em relação à sua probabilidade de excedência, de modo a comparar os resultados com aqueles obtidos por Huff (1967). Os dados foram analisados estatisticamente, agrupados nos quartis e suas respectivas excedências definidas para probabilidade de $10 \%, 50 \%$ e $90 \%$. Os resultados mostraram boa correlação entre os dados observados e aqueles obtidos por Huff. As conclusões para os postos pluviométricos analisados com 10\% de probabilidade de excedência são apresentados na Figura 2.6.

Figura 2.6 - Resultados obtidos por Brandão et al. (2001) para os postos de Portugal e comparação destes com os obtidos por Huff (1967) com 10\% de probabilidade de excedência.

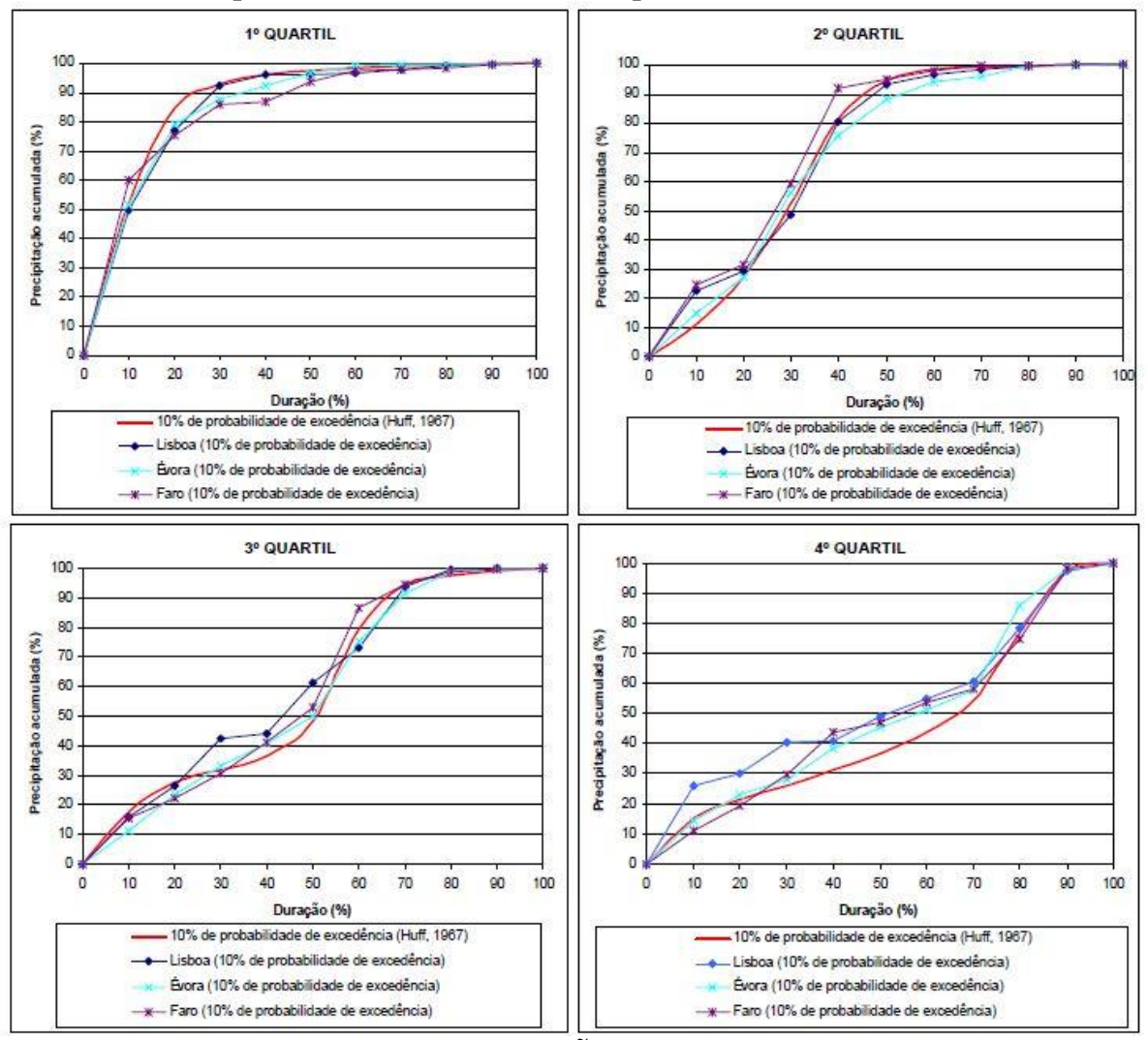

Fonte: BRANDÃO et al. (2001)

Vasconcelos et. al. (2007) realizaram análises estatísticas das chuvas baseada no método de Huff para a região do Córrego do Gregório em São Carlos/SP. Foram utilizados dados de uma estação hidrometeorológica próxima ao divisor de águas da bacia e de um pluviômetro às margens do Córrego do Gregório (próximo ao Fórum municipal de São Carlos - SP). 
Foram selecionados 71 eventos no período de janeiro de 2004 a dezembro de 2005, sendo considerados apenas os eventos com precipitação total superior a $10 \mathrm{~mm}$ e de duração entre 45min e 6 horas. Para caracterizar os eventos, foram elaborados gráficos adimensionais de precipitação no tempo para dividir as chuvas nos respectivos quartis.

A lâmina precipitada média foi de $22 \mathrm{~mm}$, com duração de $161 \mathrm{~min}$ e intensidade de 10 $\mathrm{mm} / \mathrm{h}$. As distribuições adimensionais das chuvas obtidas pelos autores são apresentadas nas Figuras 2.7 a 2.10. Nestes gráficos o eixo da abscissa corresponde a proporção do tempo em relação a duração total da chuva, e o eixo da ordenada a proporção da precipitação acumulada em relação ao total precipitado.

Figura 2.7 - Resultados dos eventos de precipitação com pico no $1^{\circ}$ quartil para chuvas localizadas no córrego do Gregório - São Carlos/SP

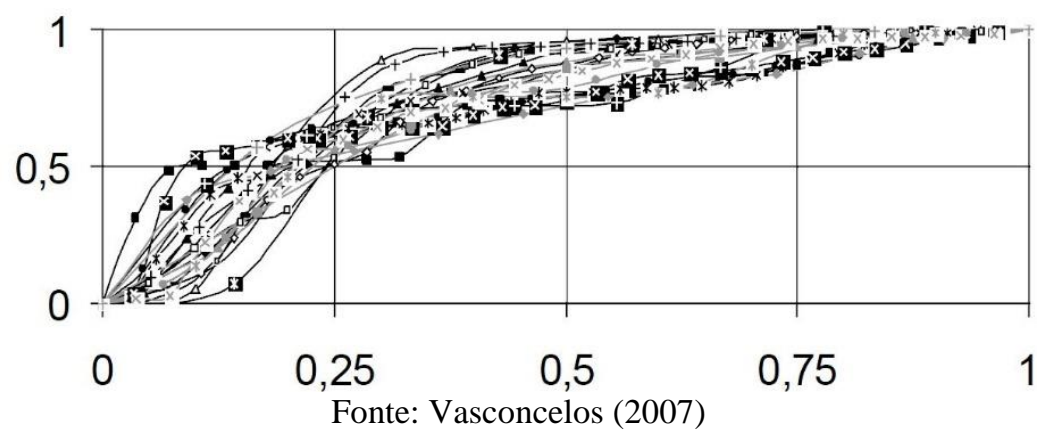

Figura 2.8 - Resultados dos eventos de precipitação com pico no $2^{\circ}$ quartil para chuvas localizadas no córrego do Gregório - São Carlos/SP

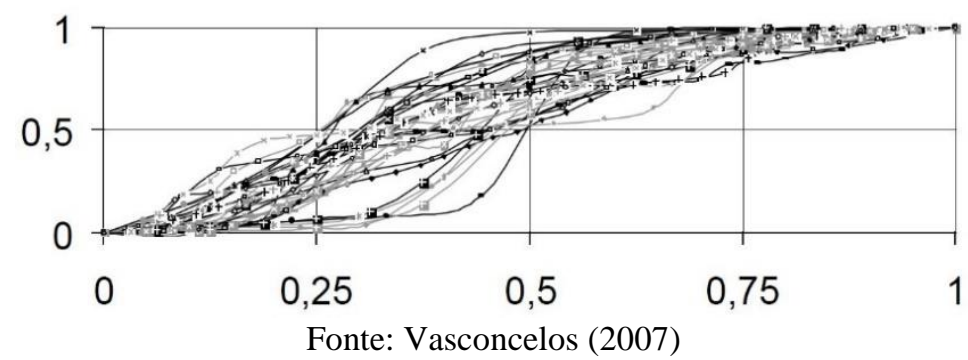


Figura 2.9 - Resultados dos eventos de precipitação com pico no $3^{\circ}$ quartil para chuvas localizadas no córrego do Gregório - São Carlos/SP

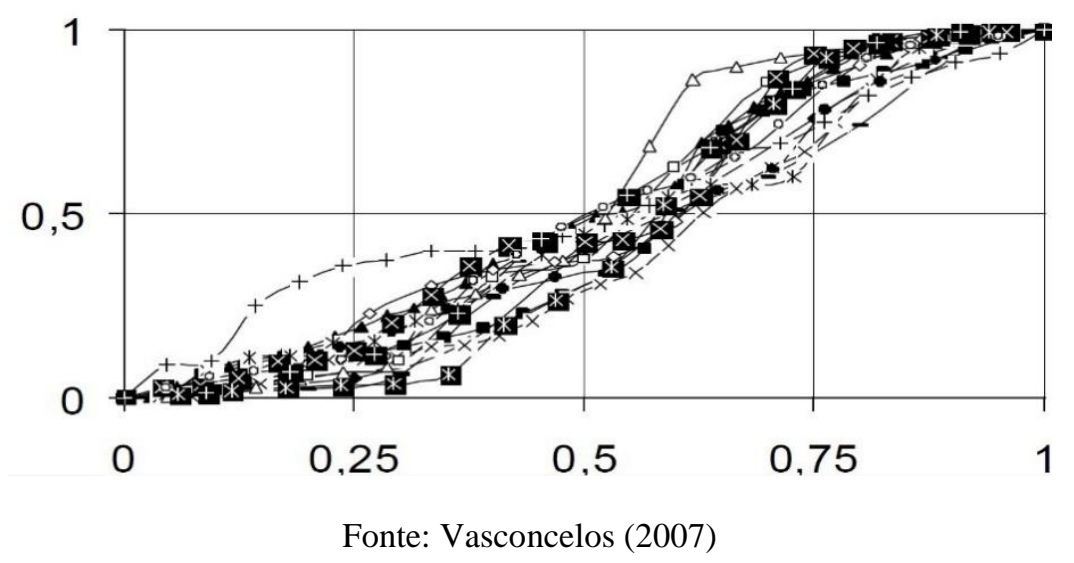

Figura 2.10 - Resultados dos eventos de precipitação com pico no $4^{\circ}$ quartil para chuvas localizadas no córrego do Gregório - São Carlos/SP

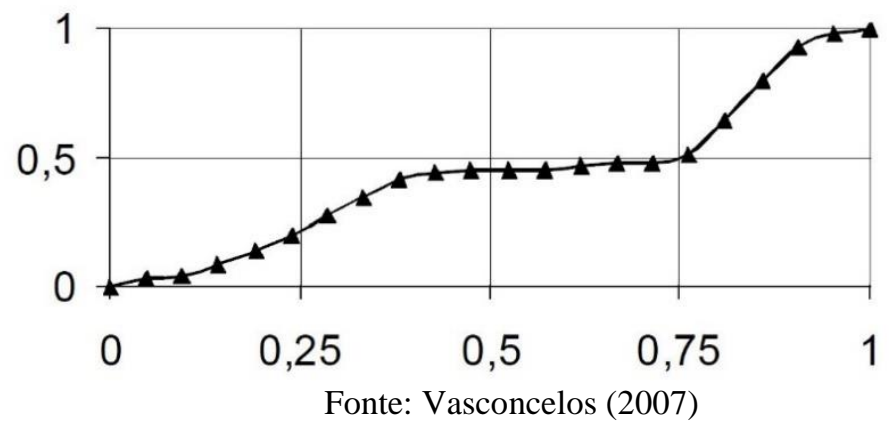

Os resultados mostraram que $31 \%$ das chuvas pertencem ao grupo do $1^{\circ}$ quartil, $45 \%$ ao grupo do $2^{\circ}$ quartil, $21 \%$ ao grupo $3^{\circ}$ quartil e $1 \%$ ao grupo $4^{\circ}$ quartil. Dessa forma, as chuvas na região puderam ser enquadradas, para o período analisado, com picos de intensidade que se situam entre o primeiro e o segundo quartil em $76 \%$ das ocorrências para região do córrego do Gregório.

Assim, em estudos de drenagem urbana em que os eventos de maior impacto são os de curta duração, as contribuições dos autores acerca das distribuições temporais de chuva apontam uma melhor representatividade dos resultados utilizando-se do método de Huff entre o $1^{\circ}$ quartil e o $2^{\circ}$ quartil, como evidenciado por Vanconcelos (2007) para o Córrego do Gregório em São Carlos - SP; Canholi (2005); Brandão et al. (2001) para cidades de Portugal.

\section{REFERÊNCIAS}

ACSELRAD, H. Justiça Ambiental e Construção Social do Risco. In: ENCONTRO NACIONAL DE ESTUDOS POPULACIONAIS, 13, 2002, Ouro Preto. Anais... Ouro Preto: ABEP, 2002. Disponível em: <http://www.abep.nepo.unicamp.br/docs/anais/pdf/2002/GT_MA_ST5_Acselrad_texto.pdf>. 
ALCÁNTARA-AYALA, I. Geomorphology, natural hazard, vulnerability and prevention of natural disasters developing countries. Geomorphology, v. 47, p.107-124, 2002.

ALEXANDER, D. (2000). Confronting Catastrophe: New perspectives on natural disasters. Harpenden, Oxford University Press/UK, 290 p.

ALMEIDA, L. Q.; DE, WELLE, T., BIRKMANN, J. (2016). "Disaster risk indicators in Brazil: A proposal based on the world risk index". International Journal of Disaster Risk Reduction, v.17, p.251-272.

ALMEIDA, V. A., NASCIMENTO, N., BAPTISTA, M. Avaliação da eficiência de sistemas alternativos de drenagem urbana de águas pluviais. In: VI Encontro Nacional de Águas Urbanas CREA-MG - Belo Horizonte, 18 a 20 de maio de 2005.

ALMEIDA, V. A., NASCIMENTO, N., BAPTISTA, M. Avaliação da eficiência de sistemas alternativos de drenagem urbana de águas pluviais. In: VI Encontro Nacional de Águas Urbanas CREA-MG - Belo Horizonte, 18 a 20 de maio de 2005.

ANGELINI SOBRINHA, L. Monitoramento e modelagem de um poço de infiltração de águas pluviais em escala real e com filtro na tampa. 148 p. (Dissertação de Mestrado em Engenharia Urbana). Universidade Federal de São Carlos. São Carlos - SP, 2012.

ARAÚJO, P. R.; TUCCI, C. E. M.; GOLDENFUM, J. A. Avaliação da eficiência dos pavimentos permeáveis na redução de escoamento superficial. Revista Brasileira de Recursos Hídricos, v.5, p.21-29, 2000.

ASSOCIAÇÃO BRASILEIRA DE NORMAS TÉCNICAS (ABNT). NBR 14653-1: avaliação de bens. Parte 1: procedimentos gerais. Rio de Janeiro, 2001.

BAPTISTA, M. B. e NASCIMENTO, N. O. - Sustainable development and urban stormwater management in the context of tropical developing countries.XXV Congreso Interamericano de IngenieriaSanitaria y Ambiental (Conferenceinteramericaine de géniesanitaireetevironnement), vol. IV, pp. 523 529, AIDIS, México. 1996

BAPTISTA, M. B.; NASCIMENTO, N.O. ; BARRAUD, S.. Técnicas compensatórias em Drenagem Urbana, Porto Alegre: ABRH, $1^{\circ}$ ed. 266p. 2005.

BARBASSA, A. P. Simulação do efeito da urbanização sobre a drenagem pluvial na cidade de São Carlos/SP. 1991. 327 f. Tese (Doutorado em Hidráulica e Saneamento) - Escola de Engenharia de São Carlos, Universidade de São Paulo, São Carlos, 1991.

BARRAUD, S.; AZZOUT, A.; CRES, F. N.; CHOCAT, B. Selection aid of alternative techniques in urban storm drainage - Proposition of an expert system. Water Science and Technology, v. 39, n.4, 1999.

BECK, U. Sociedade de risco: rumo a uma outra modernidade. São Paulo. ed. 34, 2010.

BRAGA, R. Plano Diretor Municipal: Três Questões para Discussão. In: Caderno do Departamento de Planejamento. Faculdade de Ciências e Tecnologia - UNESP - Presidente Prudente, vol. 1, n. 1, 1995.

BRANDÃO, C.; RODRIGUES, R.; COSTA, J. P. - Análise de fenómenos extremos precipitações intensas em Portugal continental - Direcção dos Serviços de Recursos Hídricos - Lisboa - 2001

BUTLER, D.; DAVIES, J. W. Urban Drainage. Londres: St Edmundsbury Press., 489 p., 2000.

CANÇADO, V. Consequências Econômicas das Inundações e Vulnerabilidade- Desenvolvimento de Metodologia para avaliação do Impacto nos Domicílios e na Cidade. MG. 2009. 1 v. Tese - (Área de concentração: recursos hídricos) - Escola de Engenharia, Universidade Federal de Minas Gerais, Belo Horizonte. 2009

CANÇADO, V. et. al. Consequências Econômicas das Inundações: Modelando o Impacto em Áreas Urbanas - XIX Simpósio Brasileiro de Recursos Hídricos - Maceió/AL - 2011.

CANHOLI, A. P. Drenagem Urbana e Controle de Enchentes. São Paulo: Oficina de textos, 302 p. 2005.

CARDONA, O.D. (2004). "The need for rethinking the concepts of vulnerability and risk from a holistic perspective: A necessary review and criticism for effective risk management", in Mapping vulnerability: Disasters, development and people. Org. por BANKOFF, G.; FRERKS, G.; HILHORST, D., ed. Earthscan, London/UK, pp. 37-51

CASTRO, A. L. C. (1996). Manual de Desastres: desastres naturais. Volume 1. Brasília: Ministério do Planejamento e Orçamento, 182 p. 
CHOUDHURY, N. Y.; POUL, A.; POUL, B.K. (2004). "Impact of costal embankment on the flash flood in Bangladesh: a case study”. Applied Geography v. 24, pp. 241-258.

CHOW, V. T.. Applied Hydrology. Mc-Graw-Hill Book. 1988.

CHRISTOFOLETTI, Antônio (1990). Modelagem de Sistemas Ambientais. Ed. Edgard Blucher, São Paulo, $256 \mathrm{p}$.

CRUZ, M. A. S.; TUCCI, C. E. M.; SILVEIRA, A. L. L. Controle do escoamento com detenção em lotes urbanos. In: Revista Brasileira de Recursos Hídricos - RBRH, v. 3, n. 4, 1998.

CRUZ, M. A. S.; TUCCI, C. E. M.; SILVEIRA, A. L. L. Controle do escoamento com detenção em lotes urbanos. In: Revista Brasileira de Recursos Hídricos - RBRH, v. 3, n. 4, 1998.

DAYWATER. Report 5.1. Review of the use of stormwater BMPs in Europe. Disponível em: <www.daywater.org> 98p. 2003.

DECHESNE, M. Connaissance et modélisation du fonctionnement des bassins d'infiltration d'eaux de ruissellement urbain pour l'évaluation des performances technique et environnement alesur le long terme. Thése. INSA de Lyon. Lyon, França. 275p. 2002.

DECHESNE, M. Connaissance et modélisation du fonctionnement des bassins d'infiltration d'eaux de ruissellement urbain pour l'évaluation des performances technique et environnement alesur le long terme. Thése. INSA de Lyon. Lyon, França. 275p. 2002.

DECINA, T. G. T. - Avaliação de medidas de controle de inundações na bacia hidrográfica do Córrego do Gregório, São Carlos, SP - Dissertação - Escola de Engenharia de São Carlos - EESC/USP - Maio 2012.

DUTTA, D.; HERATH, S.; MUSIAKE, K.A mathematical model for flood loss estimation. Journal of Hydrology. n.277, p.24-49, 2003.

EMA (2004). Emergency management in Australia concepts and principles. EMA, Dickson/AU.

FADEL, A. W. Incorporação do risco de prejuízo no Gerenciamento de medidas de controle de Inundação - Dissertaçao (Recursos Hídricos e Saneamento Ambiental) - Universidade Federal do Rio Grande do Sul. 108f., Porto Alegre, 2015.

FEMA - Federal Emergency Management Agency (1981). Design guidelines for flood damage reduction. (Disponível em www.fema.gov/hazards/floods/lib15.shtm).

FENS (1990). Fundação Escola Nacional de Seguros. Teoria Geral do Seguro. Rio de Janeiro: FUNENSEG, 274p.

GISSING, A.; RUSSELL, B. Accounting for Variability in Commercial Flood Damage Estimation. Australian Geographer, Vol. 35, No. 2, pp. 209-222, July 2004.

GOERL, R.F.; KOBIYAMA, M. Considerações sobre as Inundações no Brasil. XVI SIMPÓSIO BRASILEIRO DE RECURSOS HÍDRICOS, 2005, João Pessoa. Anais... Porto Alegre, ABRH, 2005.

GRACIOSA, M.C.P. Modelo de seguro para riscos hidrológicos com base em simulação hidráulicohidrológica como ferramenta de gestão do risco de inundações. 2010. 163 f. Tese (Doutorado em Engenharia Civil, Área de concentração: Hidráulica e Saneamento) - Escola de Engenharia de São Carlos, Universidade de São Paulo, São Carlos, 2010.

GRACIOSA, M.C.P. Modelo de seguro para riscos hidrológicos com base em simulação hidráulicohidrológica como ferramenta de gestão do risco de inundações. 2010. 163 f. Tese (Doutorado em Engenharia Civil, Área de concentração: Hidráulica e Saneamento) - Escola de Engenharia de São Carlos, Universidade de São Paulo, São Carlos, 2010.

GREENAWAY, M.A. \& SMITH, D.I. (1993). ANUFLOOD: programmer's guide and user's manual, Centre for Resource and Environmental Studies, Australian National University, Canberra.

GRIG, N. S., HELWEG, O. J. State of the art estimation flood damage in urban areas. Water Resources Bulletin, v.11, n.2, p.379-390, 1975.

HANDMER, J.W. ANUFLOOD in New Zealand: Part 2, Background to flood loss measurement. Centre for Resource and Environmental Studies, Australian National University, Canberra. 1986

HUFF, F. A. Time Distributionsof Heavy Rainstorms in Illinois. Illinois State Water Survey, Champaign, Circular 173, 1990. 
HUFF, F. A., Time distribution of rainfall in heavy storms. Water Resources Research, v.3, n.4, p. 10071019. 1967.

INSTITUTO BRASILEIRO DE GEOGRAFIA E ESTATÍSTICA - IBGE - Base de informações do Censo Demográfico 2010: Resultados do Universo por setor censitário - Documentação do Arquivo - Rio de Janeiro -2011 .

INSTITUTO BRASILEIRO DE GEOGRAFIA E ESTATÍSTICA - IBGE - Base de informações do Censo Demográfico 2010: Resultados do Universo por setor censitário - Documentação do Arquivo - Rio de Janeiro $-2011$.

INSTITUTO BRASILEIRO DE GEOGRAFIA E ESTATÍSTICA - IBGE. Estudos e Pesquisas Informação Demográfica e Socioeconômica.In: Tendências demográficas: Uma análise dos resultados da sinopse preliminar do censo demográfico 2000. Rio de Janeiro, 2001.

KRON, W. (2002). "Keynote leture: Flood risk = hazard x exposure x vulnerability". Proceedings of Second International Symposium of Flood Defense, Beijing, pp 82-97.

LEITÃO, J. P. C. Enhancement of digital elevation models and overland flow path delineation methods for advanced urban flood modelling. 366f. Tese (Doutorado em Engenharia Civil) - Department of Civil and Environmental Engineering, Imperial College, Londres, 2009.

LIMA, J. C. Avaliação dos riscos e danos de inundação e do impacto da adoção de medidas nãoestruturais em Itajubá-MG. Dissertação (Mestrado em Saneamento, Meio Ambiente e Recursos Hídricos) Universidade Federal de Minas Gerais, Minas Gerais, 180f. 2003.

LOUKAS, A. Flood frequency estimation by a derived distribution procedure. Journal of Hydrology, v.255, p. $69-89,2002$.

NICHOLAS, J., HOLT, G.D. \& PROVERBS, D.G. Towards standardizing the assessment of flood damaged properties in the UK, Structural Survey 19, pp. 163-72. 2001

MACHADO, M. L. Curvas de Inundação versus profundidade de submersão: Desenvolvimento de Metodologia - Estudo de caso da Bacia do Rio Sapucaí, Itajubá - MG - Tese - Universidade Federal de Minas Gerais - Belo Horizonte/MG- 2005

MARANDOLA, J. E.; HOGAN, J. D. (2005). Vulnerabilidade e Riscos: entre a geografia e a demografia. XIV Encontro Nacional de Estudos Populacionais da Abep. ABEP. São Paulo. p. 29-53.

MATOS, M. R. S. Gestão integrada de águas pluviais em meio urbano: visão estratégica e soluções para o futuro. Teses e Programas de Investigação LNEC. Laboratório Nacional de Engenharia Civil - LNEC. Lisboa, Portugal, 2000.

McBEAN, E. A.; GORRIE, J.; FORTIN, M.; DING, J.; MOULTON, R. Flood depth-damage curves by interview survey. Journal of Water Resources Planning and Management, v. 114, n. 6, p. 613-634, 1988.

MENDES, H. C.; MENDIONDO, E. M. Histórico da Expansão Urbana e Incidência de Inundações: o caso da Bacia do Gregório, São Carlos - SP. RBRH - Revista Brasileira de Recursos Hídricos. Volume 12 n.1, 17 27.Jan/Mar 2007

MENDES, H. C.; MENDIONDO, E. M. Histórico da Expansão Urbana e Incidência de Inundações: o caso da Bacia do Gregório- RBRH - Revista Brasileira de Recursos Hídricos. Volume 12 n.1, 17-27. Jan/Mar. 2007

MilogranA, J. Sistemática de Auxílio à decisão para a seleção de alternativas de Controle de inundação urbanas. Tese de doutorado em tecnologia ambiental e recursos hídricos, Publicação PTARH. TD 05/09, Departamento de engenharia civil e ambiental, Universidade de Brasília, DF, 316p. 2009.

MINISTÉRIO DAS CIDADES - Manual para apresentação de Propostas para sistemas de Drenagem urbana sustentável e de Manejo de águas pluviais - Secretaria nacional de saneamento ambiental - Brasília 2012.

MONTE, B. E. O.; MICHEL, G. P. GOLDENFUM, J. A. Reflexões sobre alguns conceitos relacionados a desastres naturais no brasil e no mundo. I Encontro Nacional de Desastres. Porto Alegre, RS/Brasil. 2018.

MONTEIRO, L. R.; KOBIYAMA, M. Influências da distribuição temporal de precipitação no mapeamento de inundação - REGA - Vol. 11, no. 2, p. 25-35, jul./dez. 2014. ISSN 2359-1919. 
MOURA, P. M. Contribuição para avaliação global de sistemas de drenagem urbana. Belo Horizonte: Escola de Engenharia da UFMG, 146p. (Dissertação, Mestrado em Saneamento Meio Ambiente e Recursos Hídricos). 2004.

NASCIMENTO, S. J. A. (2011). Vulnerabilidade a eventos climáticos extremos na Amazônia Ocidental: uma visão integrada na bacia do Rio Acre. Universidade Federal do Rio de Janeiro, Rio de Janeiro. 285 p.

NATIONAL DISASTER EDUCATION COALITION. (2004). Talking about disaster: Guide for standard messages. Washington, D.C. (Disponível em ww.disastereducation.org/guide.html)

NFIP - NATIONAL FLOOD INSURANCE PROGRAM. (2005). What is a Flood (Disponível em Www.floodsmart.gov/floodsmart/pages/whatflood.jsp.

NWS/NOAA - NATIONAL WEATHER SERVICE/NATIONAL OCEANIC ATMOSFERIC ADMINISTRATION. (2004). Glossary. (Disponível em http://www.nws.noaa.gov/glossary/)

OFFICE OF TECHNOLOGY ASSESSMENT. (1980). Issues and Options in Floodplain Management and Flood Insurance. Washington, D.C.

OLIVIERI, E.; SANTORO, M. Estimation of urban structural flood damages: the case study of Palermo. Urban Water2. p. 223-234, nov. 2000.

PENNINNG-ROWSELL, E.C. e CHATTERTON, J. B.The benefits of flood alleviation: A manual of assessment techniques. Gower Technical Press, Aldershot, Royaume-Uni, Inglaterra, 297p. 1977.

PMSC - Prefeitura Municipal de São Carlos. Lei no 13.691, de 25 de novembro de 2005. Disponível em: http://www.saocarlos.sp.gov.br/images/stories/pdf/Lei_13691_05_Plano_Diretor.pdf

PMSC - Prefeitura Municipal de São Carlos. Secretaria Municipal de Obras. SHS Consultoria e Projetos de Engenharia S/S Ltda. Plano Diretor de Drenagem Urbana Ambientalmente Sustentável. São Carlos: 2011. 213 p. Relatório Síntese. Volume II -Medidas Estruturais, Medidas Não Estruturais e Custos. Contrato nº 87/09 Processo ${ }^{\circ}$ 6.965/07. 2011

PORTO, R. L. L. Escoamento superficial direto. In: BARROS, M. T.; PORTO, R.L; TUCCI, C. E. M (Organizadores). Drenagem urbana. Cap. 4, p.107-165.Porto Alegre: ABRH, 1995

PRINCE GEORGE'S. Low Impact development design strategies: an integrated design approach. Prince George's: Department of Environmental Resource. Programs and Planning Division, 150 p. 1999.

RAHMAN, A.; WEINMANN, P.E.; HOANG, T.M.T; LAURENSON, E.M. Monte Carlo simulation of flood frequency curves from rainfall. Journal of Hydrology, v.256, p.196 - 210, 2002.

RIGHETTO, J. M.; MENDIONDO, E. M. Avaliação de riscos hidrológicos: principais danos e causas e proposta de seguro contra enchentes. In: III SIMPÓSIO DE RECURSOS HÍDRICOS CENTRO-OESTE, 2004, Goiânia. Anais. Goiânia, 2004.

RIGUETTO, J.M. Modelo de segero para riscos hidrológicos no contexto de manejo integrado de bacias hidrográficas. Dissertação (mestrado). Escola de Engenharia de São Carlos, Universidade de São Paulo, São Carlos, 2005.

RYU, J. Decision support for sewer flood risk management.Tese (Doutorado em Engenharia Civil) Department of Civil Engineering, Imperial College, 323 p.Londres, 2008.

SALGADO, J. C. M. Avaliação econômica de projetos de drenagem e de controle de inundações em bacias urbanas. Rio de Janeiro: Escola de Engenharia da UFRJ, 1995 113p. (Dissertação, Mestrado em Ciências em Engenharia Civil).

SANTOS, E. T. Avaliação dos Impactos econômicos de desastres naturais em megacidades: o caso dos alagamentos em São Paulo - Dissertação - Faculadade de Economia e Administração (FEA) - Universidade de São Paulo - São Paulo, 68p. 2013.

SANTOS, E. T. Avaliação dos Impactos econômicos de desastres naturais em megacidades: o caso dos alagamentos em São Paulo - Dissertação - Faculadade de Economia e Administração (FEA) - Universidade de São Paulo - São Paulo, 68p. 2013.

SANTOS, K.R. 2012. Inundações urbanas: um passeio pela literatura. Elisée - Revista de Geografia da UEG, 1(1): 177-190. 
SÃO CARLOS..Dispõe sobre a construção de reservatório de detenção ou retenção de águas em conjuntos habitacionais, áreas comerciais e industriais, loteamentos ou parcelamentos em áreas urbanas. Lei municipal no 13.246/2003. Câmara municipal de São Carlos, 6 de novembro de 2003

SÃO CARLOS.Cria o Sistema de Captação e Aproveitamento de água de chuva e institui a sua obrigatoriedade nos imóveis localizados no Município e dá outras providências. Lei municipal $\mathrm{n}^{\circ}$ 17.729/2016Diário Oficial de São Carlos, SP, de 01 de março de 2016.

SÃO PAULO. Secretaria Municipal de Desenvolvimento Urbano. Manual de Drenagem e Manejo de Águas Pluviais: Aspectos tecnológicos; diretrizes para projetos. 130p. São Paulo: SMDU, 2012

SCHMIDT, B.; FARRET, R.A questão urbana. Ed. Jorge Zahar: Rio de Janeiro, 1986.

SHUELER, T. R. Controlling urban runoff: A practical manual for planning and designing urban BMPs. Department of Environmental Programs. Washington Metropolitan Water Resources Planning Board. 1987.

SILVA, E. R. Um percurso na história através da água: passado, presente, futuro. In: XXVII Congresso Interamericano De Engenharia Sanitária E Ambiental.v. 1. Rio de Janeiro: ABES, 2000.

SMEC. Assessment of Potencial Flood Damage, River Torrents, Adelaide.Snowy Mountaisn Engeneering Corporantion for the South Australian Dept. of Engeneering and Water Supply.1980.

SMEC. Brisbane River Flood Investigations - Final Report. Snowy Mountain Engineering Corporation for Cities Commission, Canberra, 1975.

SMITH, D.I. Flood damage estimation - A review of urban stage-damage curves and loss functions Water AS Vol.20 No. 3 - Julho de 1994. ISSN 0378-4738.

SMITH, D.I. \& GREENAWAY, M.A. ANUFLOOD: a field guide, Centre for Resource and

Environmental Studies, Australian National University, Canberra. 1992

SMITH, K. \& TOBIN, G.A. (1979) Human adjustment to the flood hazard, Longman, London.

SOUZA, K. R. G.; LOURENÇO, L. A evolução do conceito de risco à luz das ciências naturais e sociais. Revista Territorium, n. ${ }^{\circ} 22$, 2015, p. 31-44, ISSN: 0872-8941. DOI: http://dx.doi.org/10.14195/1647-7723_22_1. Associação Portuguesa de Riscos, Prevenção e Segurança; Imprensa da Universidade de Coimbra, 2015

TACHINI, M. - Avaliação de danos associados às inundações no município de Blumenau.

Tese(Doutorado).Universidade Federal de Santa Catarina. UFSC. Programa De Pós-Graduação Em Engenharia Ambiental. Florianópolis/SC. 189p. 2010.

TOBIN, G. A; MONTZ, B. E. (1997). Natural hazards: explanation and integration. The Guilford Press, New York. 388p.

TORTEROTOT, J.-, Le Coût des Dommages dûs Aux Inondations: Estimations et Analyse des Incertitudes. Tese de doutorado, Ecole Nationale des Ponts et Chaussées, Paris, France. 1993 (apud LIMA, 2003).

TUCCI, C. E. M. Gerenciamento da drenagem urbana. In: RBRH: Revista Brasileira de Recursos Hídricos. Porto Alegre, RS Vol. 7, n. 1(2002 jan./mar). 2002.

TUCCI, C. E. M.- Gestão de Inundações Urbanas - Ministério das Cidades - Global Water Partnership World Bank - Unesco. 2005.

TUCCI, C. E. M. Inundações urbanas. In: TUCCI, C. E. M.; PORTO, R. L. L.; BARROS, M. T. Drenagem urbana. $1^{\text {a }}$ edição.cap. 1, p. 15-36.Porto Alegre: ABRH / Editora da Universidade / UFRGS, 1995

TUCCI, C. E. M., HESPANHOL, I. e CORDEIRO NETTO, O. M. Cenários da gestão da água no Brasil: Uma Contribuição Para a "Visão Mundial da Água". Bahia Análise e Dados, vol. 13 n. especial, 357-370 - 2003.

TUCCI, C.E M.; BERTONI, J.C. (2003) (orgs). Inundações Urbanas na América do Sul. Ed. Brasileira de Recursos Hídricos, p. 471.

UN-ISDR. UNITED NATIONS OFFICE FOR DISASTER RISK. REDUCTION (2004). Living with risk: a global review of disaster reduction initiatives. Geneva: Disponível em: http://www.unisdr.org/files/657_lwr1.pdf.

URBOnAS, B., STAHRE, P., 1993. Stormwater Best Management Practices and Detetion, New Jersey, Prentice Hall, Englewood Cliffs (apud TUCCI, 2005). 
USACE - U.S. ARMY CORPS OF ENGINEERS. A methodology for flood stage-damage calculations. Institute for Water Resources.California. 1986

USACE. United States Army Corps of Engineers. Risk-based analysis for flood damage reduction studies, United States Army Corps of Engineers, Engineer Manual 1110-2-1619. 1996

USDA (U.S. DEPARTMENT OF AGRICULTURE). Urban Hydrology for Small Watersheds. Natural Resouces Conservation Service. Technical Release 55. Washington: USDA, 1986.

VALENCIO, N. F. L. S. Da morte da quimera à procura de Pégaso: a importância da interpretação sociológica na análise do fenômeno denominado desastre. In: VALENCIO,N. F.L. S.; SIENA, M.;

MARCHEZINI, V.; GONÇALVES, J. C. (org.). Sociologia dos desastres: construção, interfaces e perspectivas no Brasil. VOLUME I. São Carlos: RiMA editora, 2009.

VASCONCELOS, A. F.; ANDRADE, J. P. M.; MENDIONDO, E. M. - Análise qualitativa de eventos de precipitação intensa na Bacia do Gregório, São Carlos - SP - Jornadas Internacionales sobre Gestión del Riesgo de Inundaciones y Deslizamientos de Laderas - Brasil - 2007

VEYRET, Y.; NANCY M. R. (2007). O risco, os risco. In: VEYRET, Yvette (org.) Os Riscos: o homem como agressor e vítima do meio ambiente. São Paulo: Contexto. P. 23-79.

VIESSMAN JUNIOR, W.; LEWIS, G. L.; KNAPP, J. K. Infiltration. In: Introduction to Hydrology. $3^{\circ}$ ed. New York: Harper e Row, p. 55-83. 1989.

WESTGATE, K.; O’KEEFE, P (1976). Occasional paper No.4. In: Some definitions of disasters. University of Bradford, Bradford/CA, $76 \mathrm{p}$

WHITE, G.F. Choice of adjustment to floods. University of Chicago, Department of Geography, University of Chicago Press.Research paper No. 93.1964.

YEVJEVICH, V. Floods and society. ln: ROSSI, G. et al: 1994. 
PARTE I -

Análise a priori 


\section{APRESENTAÇÃO}

A avaliação econômica dos prejuízos a inundação é uma tarefa complexa e interdisciplinar, tendo em vista a relação entre conhecimentos das áreas sociais, econômicas e hidráulico hidrológicas na composição de seu modelo.

Tendo em vista tal complexidade, é comum a adoção de funções que relacionam a profundidade de submersão com o prejuízo por área do imóvel para se atribuir o prejuízo final de um imóvel, seja ele um comércio ou uma residência. Tais funções, denominadas curvas de danos por profundidade de submersão (DPS), trazem em seu arcabouço a possibilidade de utilizá-las conhecendo apenas duas variáveis: a profundidade de submersão e a área do imóvel afetado.

Dessa forma, com o uso de modelos hidráulico-hidrológicos e com o uso de dados de saída de tais modelos em plataforma GIS, é possível gerar manchas de inundação e sobrepor a camada de cadastramento dos imóveis a profundidade verificada nesse meio.

Aplicando tais medidas a diversas configurações, alterando, dentre outros, o tempo de retorno do evento, é possível gerar funções que determinem o prejuízo em função do tempo de retorno e, com isso, determinar o valor do prejuízo médio anual do cenário escolhido. A Figura Ia representa, de maneira ampla, o arcabouço disciplinar necessário a implementação de tal metodologia. Já a Figura Ib apresenta, suscintamente, as etapas metodológicas atribuídas a parte 1 desta pesquisa.

Figura Ia - Interdisciplinaridade envolvida na quantificação de prejuízos

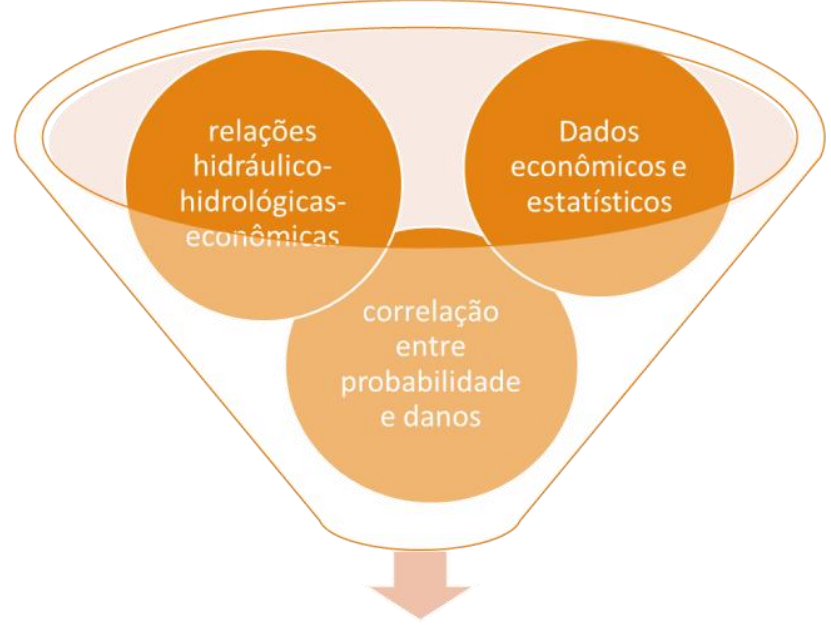


Figura $\mathrm{Ib}$ - Etapas do processo metodológico aplicado a parte 1 deste trabalho

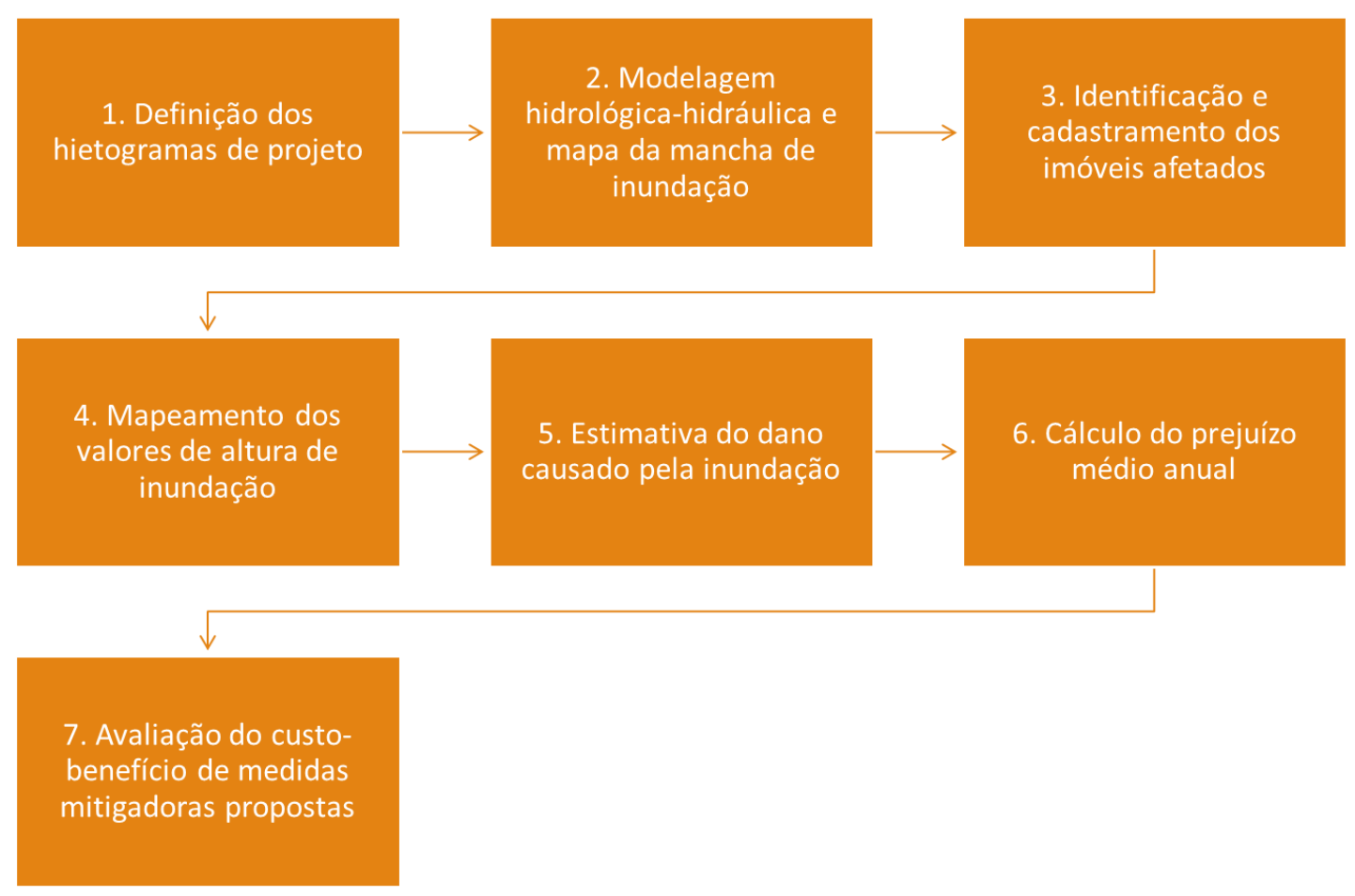

Dessa forma, no Capítulo 3 será apresentado os estudos desenvolvidos com relação as etapas 1 e 2 , relativo à modelagem hidráulico-hidrológico, enquanto que no capítulo 4 , os estudos relativos as etapas 3, 4, 5, 6 e 7, em que são acrescidas as variáveis econômicas àquelas hidráulico-hidrológicas.

Cabe frisar que, nesta primeira parte, como já dito anteriormente na apresentação geral do documento, a realização de tais etapas não envolve, necessariamente, a pesquisa de campo, sendo passível de ser realizada a distância do local foco do estudo. 


\section{CAPÍTULO 3 - ANÁLISE DA DISTRIBUIÇÃO TEMPORAL DAS CHUVAS EM EVENTOS HIDROLÓGICOS EXTREMOS}

\section{RESUMO}

O objetivo deste capítulo é apresentar a modelagem hidráulica hidrológico aplicados a essa pesquisa, os cenários propostos para análise de alternativas atuais e futuras de implantação de medidas mitigadoras e analisar as incertezas geradas pela influência da distribuição temporal das chuvas em eventos hidrológicos extremos na bacia do córrego do Gregório (São Carlos / SP). Desta forma, foram atribuídos 72 cenários distintos: 6 cenários de uso e ocupação do solo, 6 tempos de retorno aplicados e 2 configurações de distribuição temporal das chuvas de projeto. Dentre os resultados, verificou-se que a alteração do método de distribuição temporal das chuvas resultou em hidrogramas de cheia com diferenças de até $46 \%$ na vazão de pico, $57 \%$ nas áreas da mancha de inundação da região e 1,5 metros na altura de inundação no cenário atual. Além disso, as variáveis (vazão, área e profundidade) calculadas nos cenários em que foram aplicadas medidas mitigadoras estruturais foram semelhantes as encontradas nos cenários em que foram aplicadas técnicas não estruturais.

Palavras-chave: mancha de inundação, distribuição temporal das chuvas, simulação hidrológica

\subsection{INTRODUÇÃO}

As inundações urbanas no Brasil são decorrentes, principalmente, da alteração do uso do solo provocada pelo processo de urbanização, que se acentuou a partir da década de 50, e causam, além de perdas humanas, disrupção da vida cotidiana da população atingida, prejuízos econômicos e impactos ambientais.

No município de São Carlos - SP, ao analisar as notícias históricas de jornais com base nos anos de 1940 a 2004, foram encontrados 82 eventos de inundações ou alagamentos. Somente na bacia do córrego do Gregório, localizado no centro da cidade, foram constatados 64 casos de inundações e 38 intervenções e obras relacionadas à drenagem urbana; porém, o problema ainda persiste nesta região (MENDES e MENDIONDO, 2007).

O Plano Diretor de Drenagem Urbana Ambientalmente Sustentável do Município de São Carlos (PMSC, 2011) fornece diretrizes para auxiliar a prefeitura municipal no gerenciamento da drenagem urbana, de modo a subsidiar a tomada de decisão quanto à redução dos impactos causados pelas inundações.

$\mathrm{Na}$ elaboração do plano foram avaliadas as condições atuais da drenagem urbana e proposto a adoção de medidas mitigadoras de drenagem (estruturais e não estruturais). Como medidas estruturais, foram previstos 21 reservatórios de detenção in-line ao longo de diversas 
bacias hidrográficas do município. Em relação às medidas não estruturais, foram propostos: treinamento dos técnicos envolvidos na gestão da drenagem urbana; educação ambiental; orientação para projetos de engenharia e; elaboração de um manual de drenagem urbana.

Deve-se ressaltar que, normalmente, no Brasil e em diversos outros países subdesenvolvidos ou em desenvolvimento, as pequenas e médias bacias urbanas e rurais não contam com dados hidrometeorológicos que permitam a avaliação de chuvas de projeto para cada local específico. Dessa forma, é comum a aplicação de equações de chuvas intensas com base em relações I-D-F (Intensidade-Duração-Frequência), que fornecem o valor da intensidade máxima da precipitação ao longo de sua duração e período de retorno de um dado município.

A partir desse valor, é necessário definir o hietograma de projeto, que é o principal dado de entrada de chuva do modelo chuva-vazão, para então obter o hidrograma simulado. Para isso, é necessário distribuir os valores discretizados da chuva ao longo da duração escolhida para cada intervalo de tempo do hietograma.

O hietograma de projeto indica como um evento de precipitação é distribuído no tempo. O conhecimento da distribuição temporal da chuva é de extrema importância, já que esta pode influenciar significativamente na forma e no pico do hidrograma simulado.

Como, a priori, não se conhece essa distribuição temporal - que pode variar tanto no espaço como no tempo e também em relação ao tipo de precipitação - é comum adotar-se distribuições empíricas que procuram representar as condições mais críticas possíveis da desagregação temporal da chuva e assim definir um hidrograma igualmente crítico, a despeito do método dos blocos alternados, apresentado por Tucci (1995).

Uma precipitação com pico de intensidade concentrada no final do evento originará um escoamento superficial maior do que outra cuja intensidade máxima se concentra no início do evento (BRANDÃO et al., 2001).

De acordo com o autor, se o pico da intensidade da chuva ocorrer no final do evento, a precipitação efetiva será semelhante ao total precipitado, uma vez que as perdas iniciais já foram satisfeitas; ao contrário, se o pico da precipitação ocorrer no início do evento, só uma parte desta precipitação gerará escoamento superficial, sendo que o restante irá satisfazer as perdas iniciais e, dessa forma, irá provocar uma vazão menor quando comparado a primeira situação.

Essa correlação entre a variação do pico de intensidade da chuva e a respectiva precipitação efetiva gerada é explicada por Viessman Junior et al. (1989). Segundo o autor, o potencial do gradiente hidráulico do solo no início da chuva é elevado porque a frente de 
umedecimento permanece praticamente na superfície do solo. Entretanto, inicialmente, a velocidade de infiltração da água no solo é maior que a intensidade da precipitação e, com o fornecimento contínuo das águas precipitadas, a zona de umedecimento aumenta e a velocidade de infiltração é reduzida; neste momento ocorre a saturação da superfície do solo, gerando o escoamento superficial. Dessa forma, o comportamento da velocidade infiltração da água no solo pode ser representado por uma curva de decaimento, como apresentada na Figura 3.1, onde $\mathrm{K}_{\mathrm{s}}$ é o coeficiente de saturação do solo e $t_{\mathrm{p}}$ é o tempo a partir do qual ocorre um decaimento da velocidade de infiltração do solo.

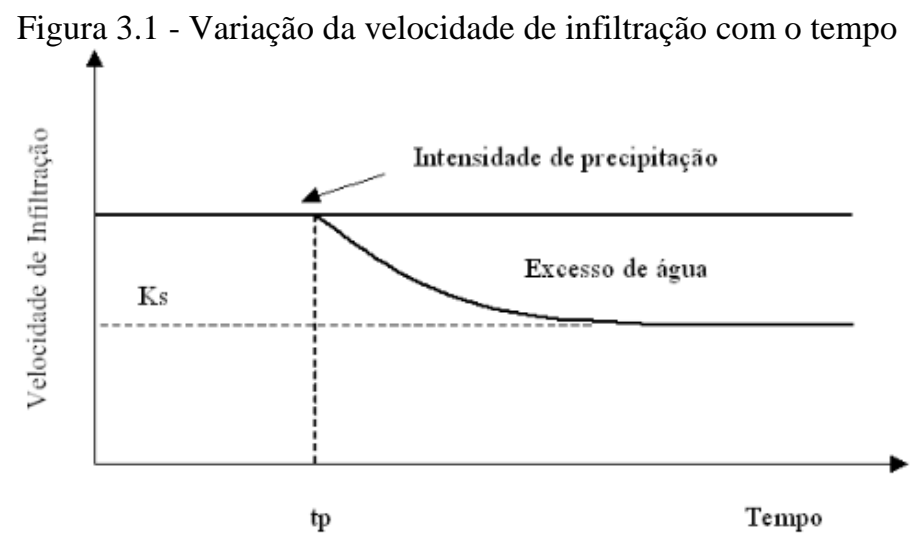

Fonte: Adaptado de MEIN e LARSON (1973)

Assim, com o intuito de analisar a influência da distribuição temporal das chuvas de modelos comumente utilizado em projetos de drenagem urbana (SÃO PAULO, 2012), essa pesquisa compara dois métodos de distribuição temporal da chuva para analisar o impacto da aplicação destes na geração dos hidrograma de cheia, do mapa da área da mancha de inundação e de sua respectiva altura de inundação. Como resultado foi verificada a alta sensibilidade destas variáveis à adoção do método de distribuição temporal.

Os métodos selecionados foram: a) desagregação da chuva com pico de intensidade no início da precipitação, denominado nessa pesquisa como "Huff $1^{\circ}$ quartil” (HUFF, 1967) e; b) desagregação das chuvas com pico de intensidade na metade da duração da chuva, denominado nesta pesquisa como "blocos alternados" (TUCCI, 1995). Dessa forma, o método "a" será chamado de "Huff $1^{\text {o }}$ quartil", enquanto o método "b" de "blocos alternados", devido a forma tradicional de se aplicar tal metodologia em análises hidrológicas de projetos de drenagem.

Foram utilizados os softwares de modelagem chuva-vazão HEC-HMS e o modelo hidrodinâmico HEC-RAS, que forneceram resultados para definição de manchas de inundação obtidas a partir do software ArcGIS e do suplemento HEC-GeoRAS. 


\subsection{METODOLOGIA}

O objetivo geral deste capítulo consiste em realizar modelagem hidráulica-hidrológica da bacia do córrego do Gregório e gerar manchas de inundação para a área de estudo (região do mercado municipal de São Carlos).

O método consiste nas seguintes etapas:

1. Apresentação da área de estudo;

2. Caracterização do uso e ocupação do solo e

3. Definição dos cenários de uso e ocupação da terra propostos nesta pesquisa;

4. Definição das variáveis hidrológicas e dos hietogramas de projeto (Huff $1^{\circ}$ quartil e blocos alternados);

5. Modelagem hidrológico-hidráulica;

6. Simulação hidráulica-hidrológica e elaboração dos mapas de mancha de inundação.

A Figura 3.2 apresenta o fluxograma simplificado da metodologia utilizada nesta pesquisa na elaboração da mancha de inundação.

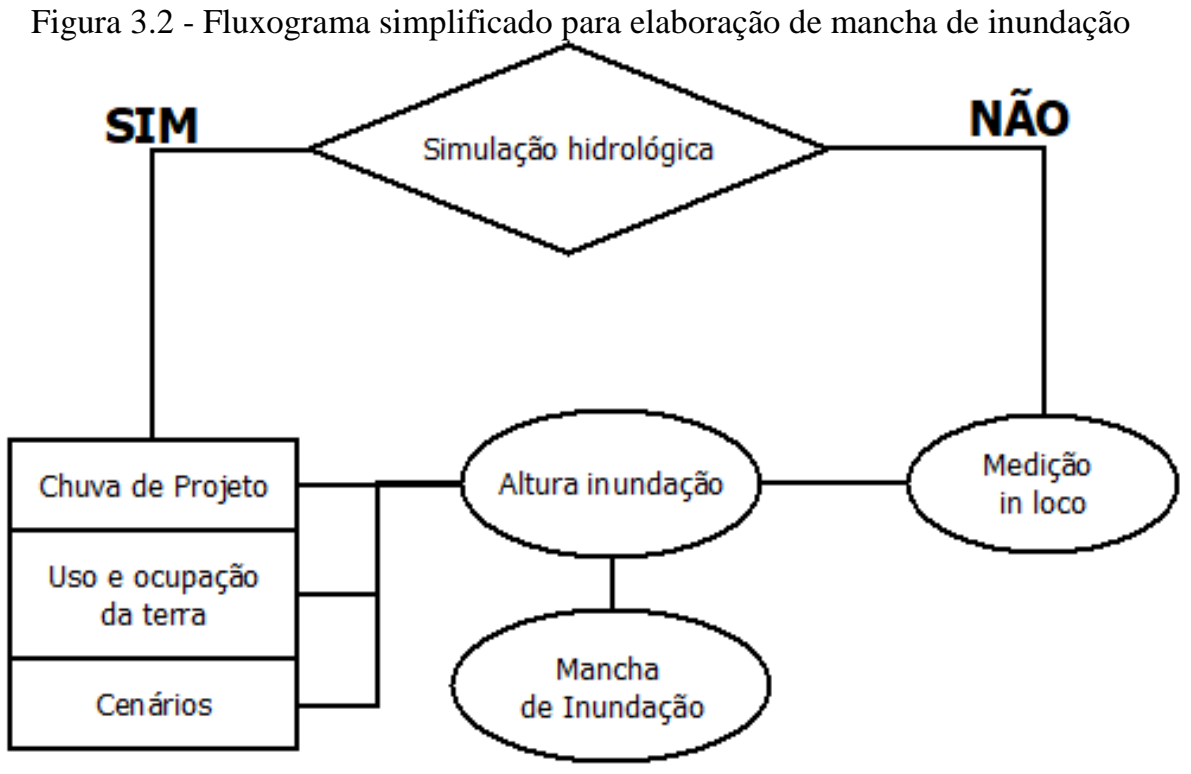

\subsection{1. Área de estudo}

A fim de quantificar os prejuízos decorrentes das inundações urbanas, foi selecionada uma área com elevada taxa de ocupação do solo, onde se localizam, em sua maioria, diversas 
empresas. Cabe frisar que local praticamente não se verifica a existência de residências no local, sendo apenas existentes sob elevados TR na mancha de inundação considerada.

Esta área, diretamente impactada, situa-se na bacia hidrográfica do córrego do Gregório, na cidade de São Carlos - SP. A região é considerada como centro econômico do município e sofre inundações frequentes.

A bacia hidrográfica do córrego do Gregório localiza-se na cidade de São Carlos - SP, e representa uma região que sofre inundações frequentes. Sua área é de $18,9 \mathrm{~km}^{2}$ e possui duas regiões com características distintas: uma urbanizada e outra em processo de urbanização. Esta parte da bacia apresenta características rurais, originalmente ocupada por vegetação de cerrado e atualmente possui sua mata ciliar bastante degradada. A jusante, cujo processo de urbanização é mais avançado, encontram-se fragmentos de mata ciliar. Contudo, o leito maior do córrego foi ocupado por avenidas marginais e edificações.

Na Figura 3.3 é apresentado o mapa com a delimitação da bacia do córrego do Gregório e nas Figuras 3.4 e 3.5 imagens de inundações ocorridas na região.

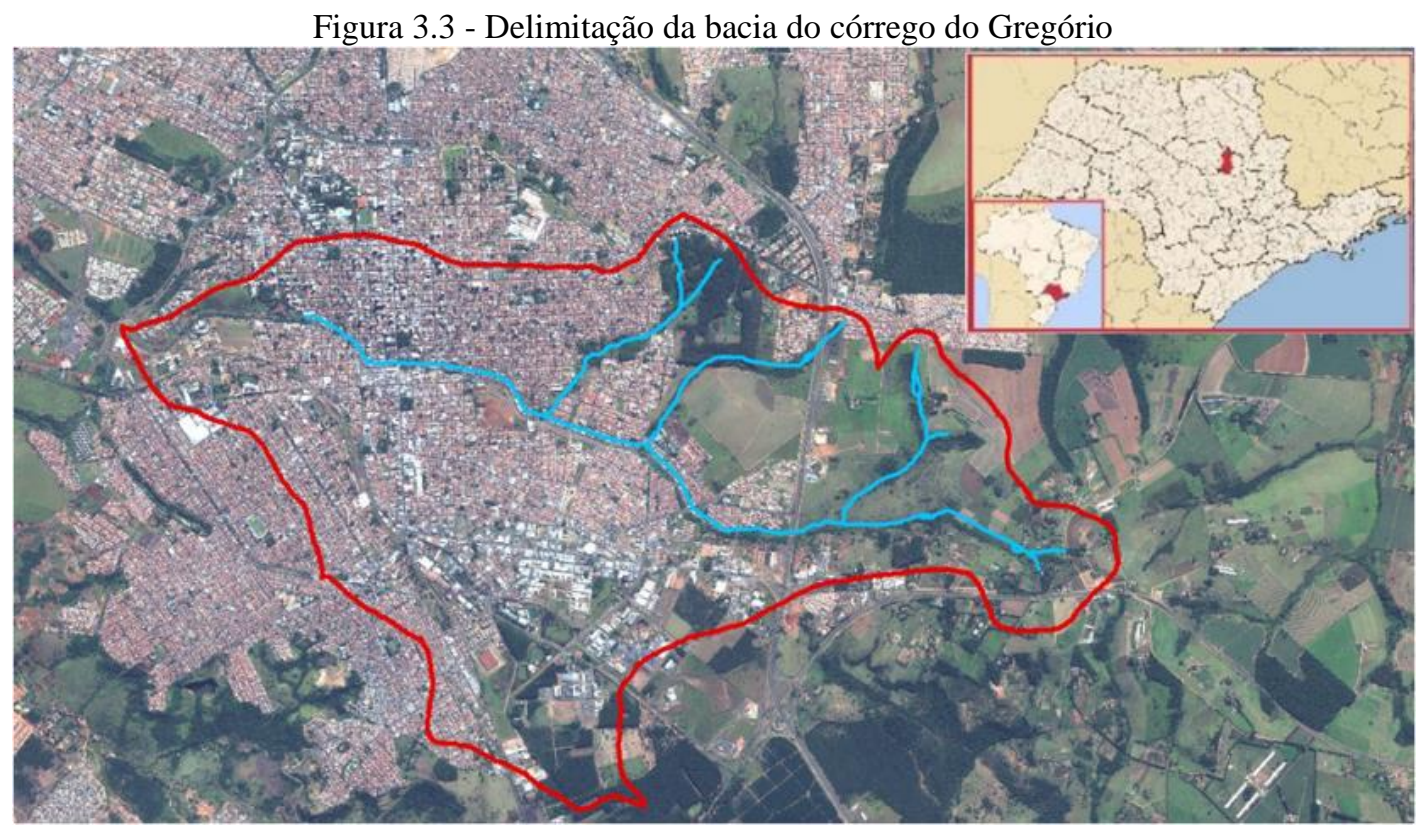


Figura 3.4 - Inundação ocorrida em 7 de outubro de 1975 na região do mercado municipal

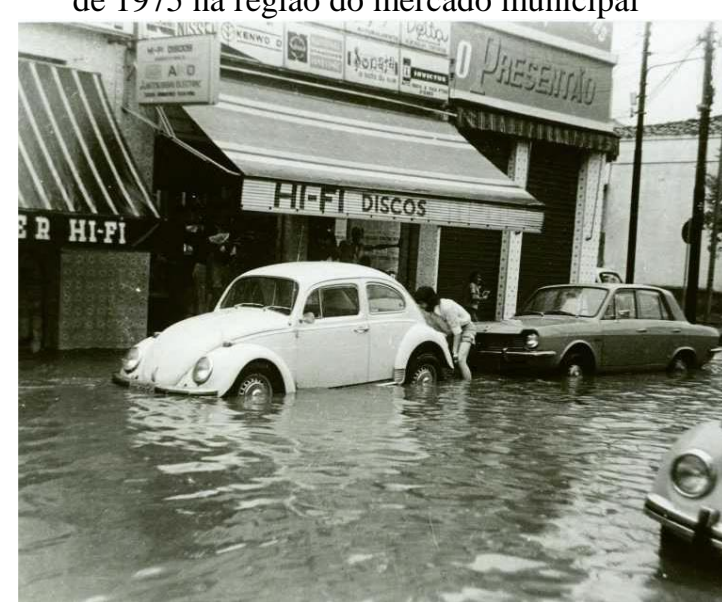

Fonte: Águas da memória (2011)
Figura 3.5 - Inundação ocorrida em 23 de novembro de 2015 na região do mercado municipal

A área de estudo está inserida na área urbanizada do córrego do Gregório e representa o maior centro econômico do município, com área de drenagem contribuinte de $10,4 \mathrm{~km}^{2}$. A delimitação das sub-bacias, utilizada na modelagem chuva-vazão é apresentada na Figura 3.6. Os dados obtidos nesta pesquisa, como área da mancha de inundação, vazão, profundidade e os mapas das manchas de inundação simuladas referem-se à área circulada na sub-bacia 12 (Figuras 3.6 e 3.7), referente a localização da área de estudo (região do mercado municipal de São Carlos). Os hidrogramas de cheia apresentados neste estudo referem-se aos dados de saída da sub-bacia 12.

\subsubsection{Cobertura e uso da terra}

O processo de classificação da cobertura e do uso da terra foi realizado por Decina (2012) de forma manual com base em uma imagem do satélite WorldView-II de 2 de junho de 2011. $\mathrm{O}$ arquivo da imagem contém uma banda pancromática (PAN) com resolução espacial de 0,5 m e quatro bandas multiespectrais (MS) com resolução espacial de 2 m: vermelho, verde, azul e infravermelho próximo. Foi aplicado o processo de fusão entre as bandas PAN e MS (composição RGB) a fim de aumentar a resolução espacial, que foi de 0,5 m. Esta etapa foi realizada com o software ArcGIS.

A partir da classificação da cobertura e do uso da terra é possível atribuir um valor de CN (Curve Number) médio para cada sub-bacia do sistema. O mapa da cobertura e do uso da terra da bacia do córrego do Gregório é apresentado na Figura 3.7 e a configuração das sub bacias na Figura 3.6. 
Figura 3.6 - Configuração das sub-bacias do córrego do Gregório para modelagem chuva-

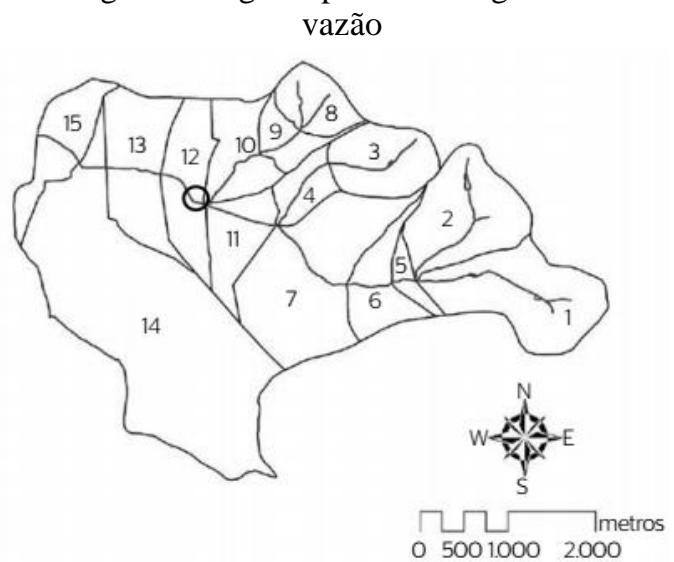

Fonte: Adaptado de Decina (2012)
Figura 3.7 - Cobertura e uso da terra classificados para a bacia do Córrego do Gregório

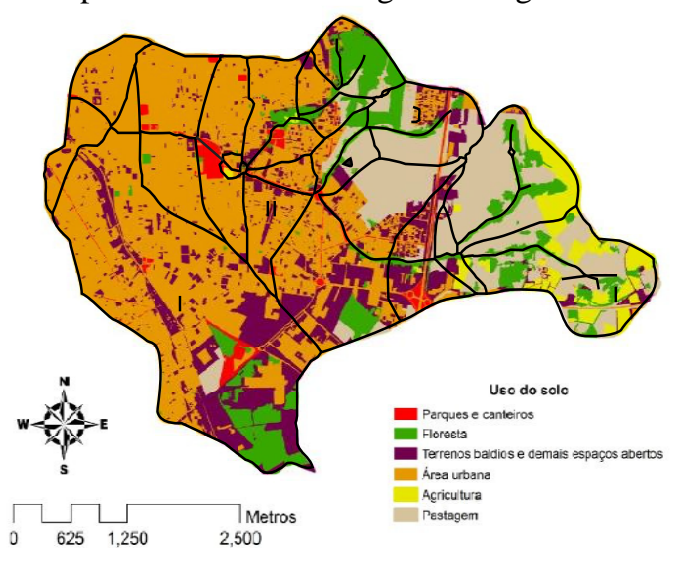

Fonte: Adaptado de DECINA (2012)

\subsubsection{Cenários de uso e ocupação do solo propostos}

A fim de modelar os impactos decorrentes da inundação, foram estabelecidos um cenário de cobertura e uso da terra para o momento atual e outro que simula a futura ocupação da bacia, adicionando as medidas mitigadoras propostas. Dessa forma, será possível avaliar as mudanças passíveis de ocorrem na bacia do ponto de vista hidráulico-hidrológico, para assim analisar o custo e o benefício da implantação de tais medidas mitigadoras no momento atual e ao final de sua vida útil, para verificar se tais medidas seriam ainda efetivas.

Tendo como parâmetro as relações hidráulico-hidrológica-econômica, propõe-se estipular o prejuízo decorrente de inundações nos seis cenários simulados seguintes, adaptados da pesquisa de Decina (2012): (1) cenário atual; (2) cenário atual com implantação dos reservatórios de detenção propostos no Plano de Drenagem de São Carlos (PMSC, 2011); (3) cenário futuro; (4) cenário futuro com a implantação dos reservatórios de detenção propostos no Plano de Drenagem de São Carlos (PMSC, 2011); (5) cenário futuro com a adoção de medidas mitigadoras não estruturais (PMSC, 2011); (6) cenário futuro com a implantação dos reservatórios de detenção e com a adocção de medidas mitigadoras não estruturais, conforme o Plano de Drenagem de São Carlos (PMSC, 2011).

No cenário futuro, considera-se a ocupação porvindoura da bacia do córrego do Gregório estabelecida de acordo com as premissas do zoneamento das macrozonas rural e urbana, previstas no Plano Diretor do Município de São Carlos (PMSC, 2005).

Destacam-se as alterações decorrentes das modificiações no uso do solo de zonas naturais para uso urbano, sob a nomenclatura de "zona de ocupação induzida", cuja alteração influencia o $\mathrm{CN}$ da bacia - as mudanças de uso do solo geraram um incremento de até 22 
unidades de $\mathrm{CN}$ em algumas sub-bacias. A Figura 3.8 apresenta as macrozonhas do plano diretor de acordo com as sub bacias modeladas para o córrego do Gregório. O círculo inserido na figura refere-se a área onde está localizada a mancha de inundação.

Figura 3.8 - Macrozonas do plano diretor de São Carlos para a bacia do córrego do Gregório

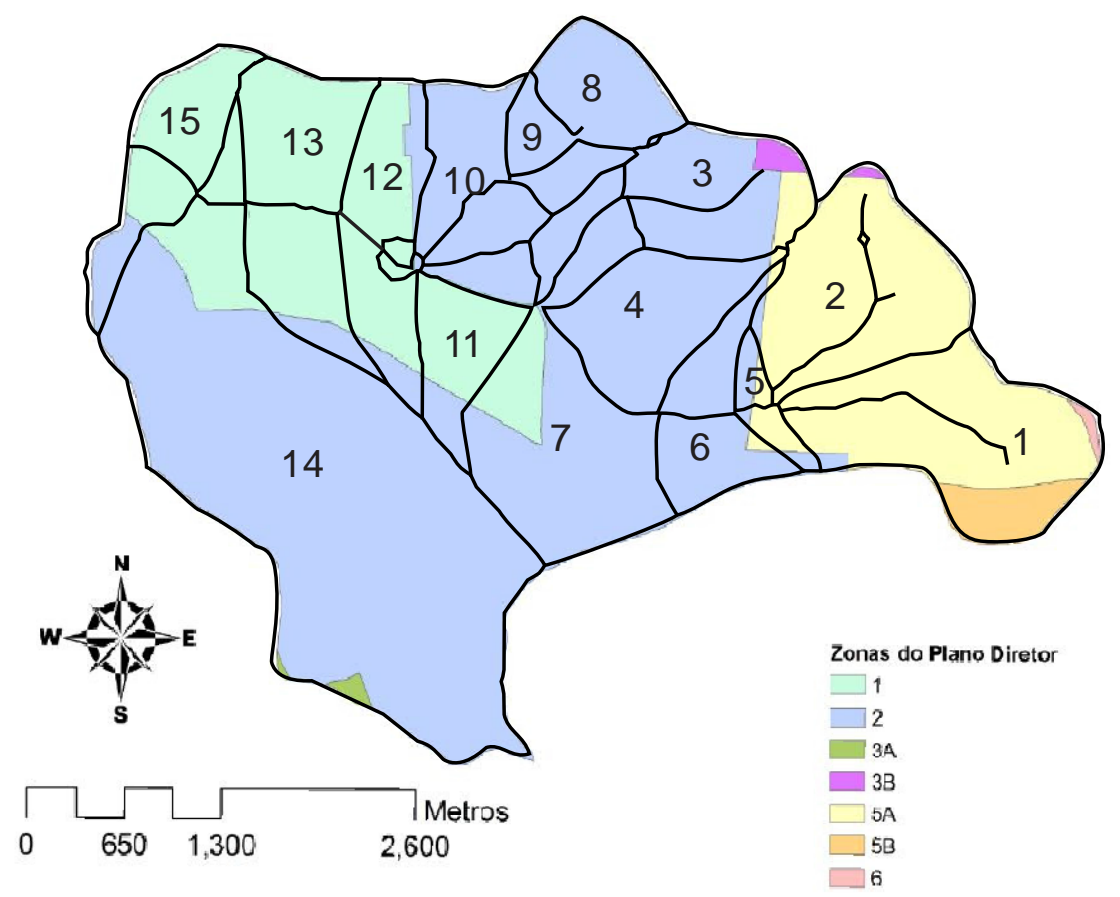

Fonte: adaptado de Decina (2012)

As medidas não estruturais deste estudo são baseadas no mesmo uso e ocupação do solo do cenário futuro, contemplando a averbação de reserva legal nas áreas ainda não ocupadas da bacia hidrográfica e a manutenção um terço das áreas públicas como área verde. [PMSC, 2011]

Com relação aos reservatórios de detenção, são propostos no PMSC (2011): a implantação de 5 reservatórios de detenção in-line localizados no córrego do Sorregotti (1 reservatório [B-84,5]), Lazarini (2 reservatórios [B-98,5 e B-97,5]) e no Gregório (2 reservatórios [B-93,5 e B-83,5]).

Para analisar o impacto dos reservatórios de detenção, foram inseridos no modelo as curvas cota-área-volume (PMSC, 2011) desses primeiros para avaliar o impacto de tais medidas nos cenários simulados.

Os reservatórios de detenção propostos são apresentados na Figura 3.9, na qual destacam-se também a localização do mercado municipal e da área de estudo em que ocorrem as inundações. No Anexo 2 são apresentadas as curvas cota-área-volume desses reservatórios. 
Figura 3.9 - Localização dos reservatórios de detenção na bacia do córrego do Gregório

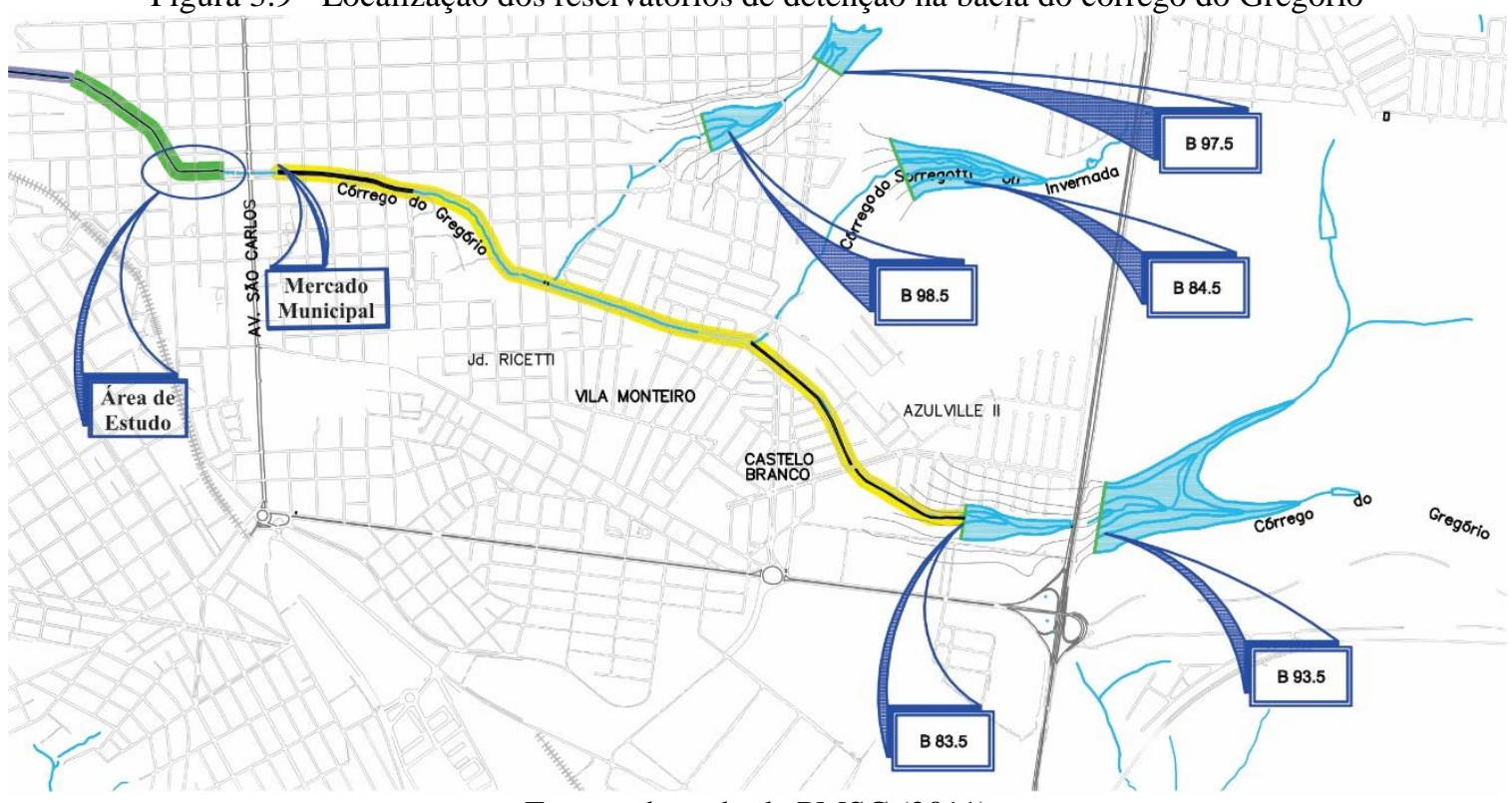

Fonte: adaptado de PMSC (2011)

As precipitações aplicadas pelos diferentes métodos, as áreas de cada sub-bacia e os valores de $\mathrm{CN}$ foram os principais dados de entrada do modelo chuva-vazão (HEC-HMS). Os três períodos de retorno de chuva associados aos dois hietogramas de projeto resultaram em seis simulações. A área de cada sub-bacia, o valor de $\mathrm{CN}$ médio atribuído e são apresentados na Tabela 3.1 e a média ponderada do $\mathrm{CN}$ de cada bacia para os diferentes cenários são apresentados na Tabela 3.2.

Tabela 3.1 - Valores de CN médio para cada sub-bacia nos respectivos cenários

\begin{tabular}{cccc}
\hline Sub-bacias & \multicolumn{3}{c}{ Cenários } \\
\cline { 2 - 4 } & $\mathbf{1}$ e 2 & $\mathbf{3 ~ e ~ 4}$ & $\mathbf{5}$ e 6 \\
\hline 1 & 66,51 & 77,73 & 72,88 \\
\hline 2 & 62,99 & 77,26 & 73,38 \\
\hline 3 & 68,97 & 88,68 & 82,60 \\
\hline 4 & 72,95 & 83,67 & 82,98 \\
\hline 5 & 65,55 & 84,09 & 77,71 \\
\hline 6 & 78,97 & 90,79 & 85,62 \\
\hline 7 & 78,98 & 93,29 & 88,70 \\
\hline 8 & 66,55 & 88,53 & 82,34 \\
\hline 9 & 80,17 & 90,93 & 87,38 \\
\hline 10 & 87,39 & 91,75 & 91,79 \\
\hline 11 & 90,50 & 94,34 & 93,56 \\
\hline 12 & 91,24 & 92,80 & 92,61 \\
\hline 13 & 93,11 & 94,50 & 94,43 \\
\hline 14 & 85,11 & 93,67 & 90,66 \\
\hline 15 & 93,32 & 94,95 & 94,73 \\
\hline
\end{tabular}

Fonte: Adaptado de DECINA (2012) 
Tabela 3.2 - Média ponderada do Curve Number $(\mathrm{CN})$ para os cenários simulados

\begin{tabular}{|c|c|}
\hline Cenário & $\mathbf{C N}$ \\
\hline $\begin{array}{l}\text { (1) cenário atual; } \\
\text { (2) cenário atual com implantação dos reservatórios de } \\
\text { detenção propostos no Plano de Drenagem (PMSC, 2011); }\end{array}$ & 80 \\
\hline $\begin{array}{l}\text { (3) cenário futuro; } \\
\text { (4) cenário futuro com a implantação dos reservatórios de } \\
\text { detenção propostos no Plano de Drenagem (PMSC, 2011) }\end{array}$ & 90 \\
\hline $\begin{array}{l}\text { (5) cenário futuro com a adoção de medidas mitigadoras } \\
\text { não estruturais (PMSC, 2011); } \\
\text { (6) cenário futuro com a implantação dos reservatórios de } \\
\text { detenção propostos no Plano de Drenagem (PMSC, 2011) } \\
\text { e com a adoção de medidas mitigadoras não estruturais. }\end{array}$ & 87 \\
\hline
\end{tabular}

\subsubsection{Distribuição temporal das chuvas}

Para a definição do hietograma de chuva, foi utilizada a curva intensidade-duraçãofrequência (IDF) proposta por Barbassa (1991) para o município de São Carlos-SP. Ela relaciona a intensidade da chuva com a duração e o tempo de retorno, ou seja, o período em que, em média, o evento é igualado ou superado. A curva IDF para São Carlos pode ser descrita pela Equação 3.1.

$i=\frac{1519 x T^{0,236}}{(t+16)^{0,935}}$

Em que:

i é a intensidade média da precipitação $(\mathrm{mm} / \mathrm{h})$

T é o tempo de retorno (anos)

t é a duração da chuva (min)

Foram abordados os seguintes métodos de distribuição de chuvas: i) método dos blocos alternados; ii) método de Huff (1967). No método dos blocos alternados, o pico de intensidade da chuva foi alocado na metade do tempo de sua duração, como comumente aplicado em projetos de drenagem. No método de Huff $1^{\circ}$ quartil, o pico da intensidade foi alocado no começo da precipitação, tendo em vista ser aplicado em regiões onde há predominância de chuvas do tipo convectivas para eventos extremos, típicas da região de estudo.

O hietograma da chuva de projeto utilizada nesta pesquisa, com duração de $120 \mathrm{~min}$, Tempo de Retorno (TR) de 3, 10, 25, 50, 75 e 100 anos, e discretização de 1 min são apresentadas na Figura 3.10. 
Figura 3.10 - Distribuição temporal da chuva pelo método de Huff $1^{\circ}$ quartil

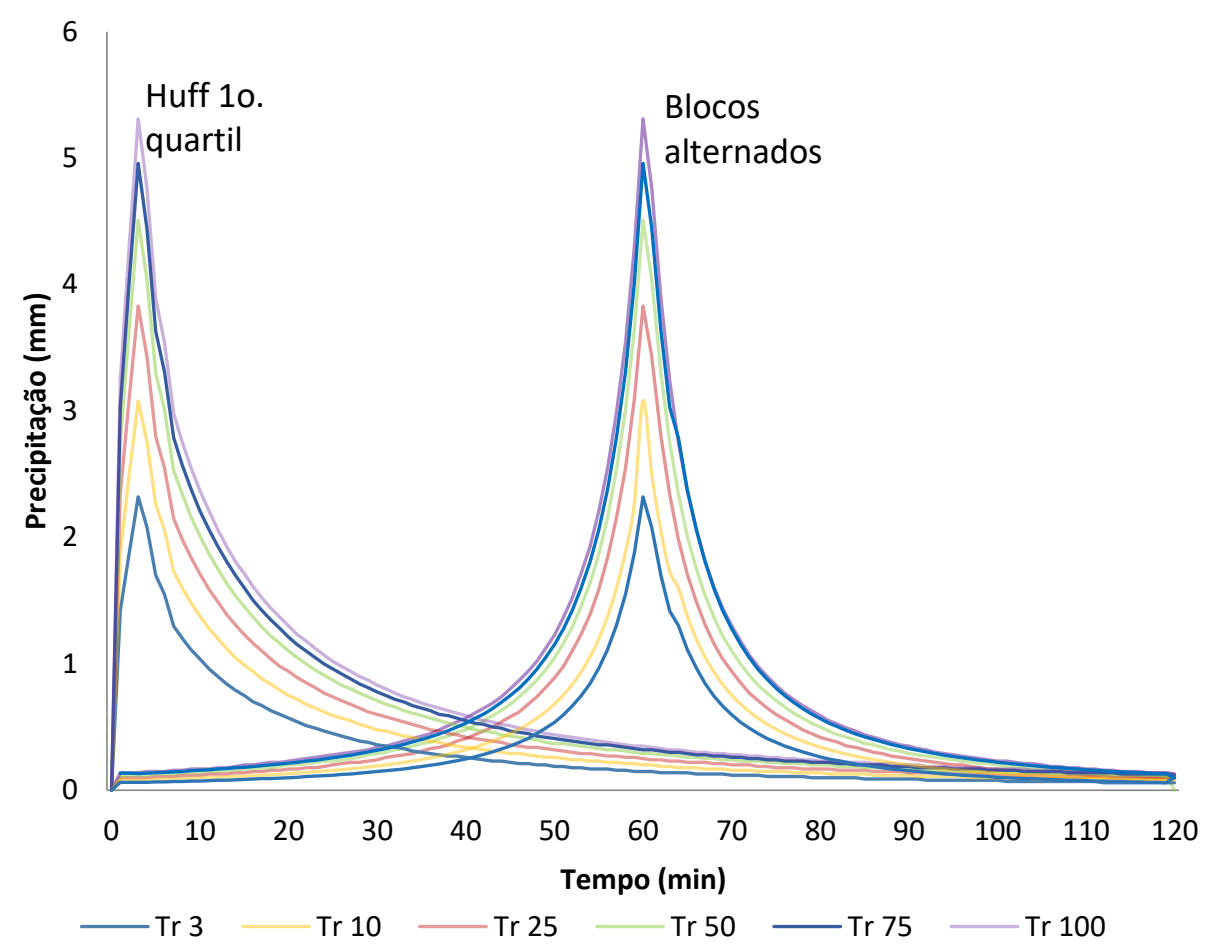

Para a desagregação das chuvas de projeto, foi aplicada o método dos blocos alternados para ambos hietogramas. Entretanto, os picos de intensidade foram alocados em diferentes durações da chuva. Os hietogramas das chuvas de projeto foram analisados de acordo os resultados obtidos por Huff (1967) para comparar o seu enquadramento nos respectivos quartis. Para isso, a chuva com o rearranjo dos blocos alternados e do Huff $1^{\circ}$ quartil (Figura 3.10) foi adimensionalisada quanto ao percentual da precipitação acumulada pelo percentual da duração e procedeu-se à comparação das mesmas de acordo com a probabilidade de excedência nos respectivos quartis.

Os hidrogramas de cheia gerados no HEC-HMS serviram como dados de entrada para o modelo hidrodinâmico HEC-RAS. Os arquivos contendo as simulações hidrodinâmicas foram exportados para o HECGeoRAS e elaborados os mapas contendo as manchas de inundação.

\subsubsection{Tempo de concentração da bacia}

O tempo de concentração das sub-bacias foi calculado pela equação proposta por George Ribeiro (RIBEIRO, 1961) expressa na Equação 3.2. Esta equação é adequada para região com bacias em processo de urbanização, tendo em vista considerar a permeabilidade da bacia e sua 
equação. Na Tabela 3.3 é apresentado o tempo de concentração das sub bacia do córrego do Gregório e área total de cada sua sub bacia.

$$
t_{c}=\frac{16 L_{t}}{(1,05-0,2 p)\left(100 S_{m}\right)^{0,04}}
$$

Em que:

$\mathrm{t}_{\mathrm{c}}$ : tempo de concentração (min)

$\mathrm{L}_{\mathrm{S}}$ : comprimento do talvegue $(\mathrm{km})$

$\mathrm{S}_{\mathrm{m}}$ : declividade média da bacia $(\mathrm{m} / \mathrm{m})$

p: fração da área da bacia coberta com vegetação (adimensional)

Tabela 3.3 - Tempo de concentração das sub bacias

\begin{tabular}{crrrrrrr}
\hline \multirow{2}{*}{$\begin{array}{c}\text { Sub- } \\
\text { bacia }\end{array}$} & Área $\left(\mathbf{m}^{\mathbf{2}}\right)$ & \multicolumn{6}{c}{ Tempo de Concentração $(\mathbf{m i n})$} \\
\cline { 3 - 8 } $\mathbf{1}$ & & $\mathbf{1}$ & $\mathbf{2}$ & $\mathbf{3}$ & $\mathbf{4}$ & $\mathbf{5}$ & $\mathbf{6}$ \\
\hline $\mathbf{2}$ & 1.597 .795 & 39,5 & 35,7 & 35,7 & 36,6 & 36,6 & 33,4 \\
\hline $\mathbf{3}$ & 1.349 .366 & 34,2 & 30,6 & 30,6 & 31,4 & 31,4 & 28,7 \\
\hline $\mathbf{4}$ & 865.454 & 21,2 & 18,9 & 18,9 & 19,5 & 19,5 & 18,6 \\
\hline $\mathbf{5}$ & 392.052 & 15,9 & 14,6 & 14,6 & 15,0 & 15,0 & 14,5 \\
\hline $\mathbf{6}$ & 188.991 & 5,0 & 4,4 & 4,4 & 4,6 & 4,6 & 4,3 \\
\hline $\mathbf{7}$ & 645.155 & 9,5 & 8,6 & 8,6 & 8,9 & 8,9 & 8,6 \\
\hline $\mathbf{8}$ & 2.214 .448 & 18,5 & 17,4 & 17,4 & 17,4 & 17,4 & 16,9 \\
\hline $\mathbf{9}$ & 538.384 & 11,5 & 10,1 & 10,1 & 10,4 & 10,4 & 10,0 \\
\hline $\mathbf{1 0}$ & 363.343 & 9,2 & 8,6 & 8,6 & 8,7 & 8,7 & 8,5 \\
\hline $\mathbf{1 1}$ & 718.825 & 14,3 & 13,9 & 13,9 & 14,0 & 14,0 & 13,9 \\
\hline $\mathbf{1 2}$ & 676.579 & 14,0 & 13,6 & 13,6 & 13,7 & 13,7 & 13,6 \\
\hline $\mathbf{1 3}$ & 899.996 & 10,3 & 10,2 & 10,2 & 10,2 & 10,2 & 10,1 \\
\hline $\mathbf{1 4}$ & 1.190 .867 & 9,7 & 9,6 & 9,6 & 9,6 & 9,6 & 9,6 \\
\hline $\mathbf{1 5}$ & 5.038 .564 & 58,4 & 54,8 & 54,8 & 54,9 & 54,9 & 54,6 \\
\hline & 765.842 & 9,4 & 9,3 & 9,3 & 9,3 & 9,3 & 9,3 \\
\hline
\end{tabular}

\subsection{RESULTADOS E DISCUSSÕES}

São apresentados neste tópico os resultados da análise dos hietogramas de chuva, dos hidrogramas gerados com o HEC-HMS e das áreas da mancha de inundação com as respectivas alturas atingidas pela água.

\subsubsection{Hietogramas das chuvas}

Para realizar a comparação entre os hietogramas propostos nessa pesquisa (Huff $1^{\circ}$ quartil e blocos alternados), são apresentadas na Figura 3.11 as curvas adimensionais das chuvas de projeto de São Carlos (linhas espessas) em comparação aos resultados obtidos por Huff (1967). 
Figura 3.11 - Comparação entre o percentual acumulado de chuva em relação ao tempo entre a chuva de projeto de São Carlos/SP e a distribuição de Huff $1^{\circ}$ quartil

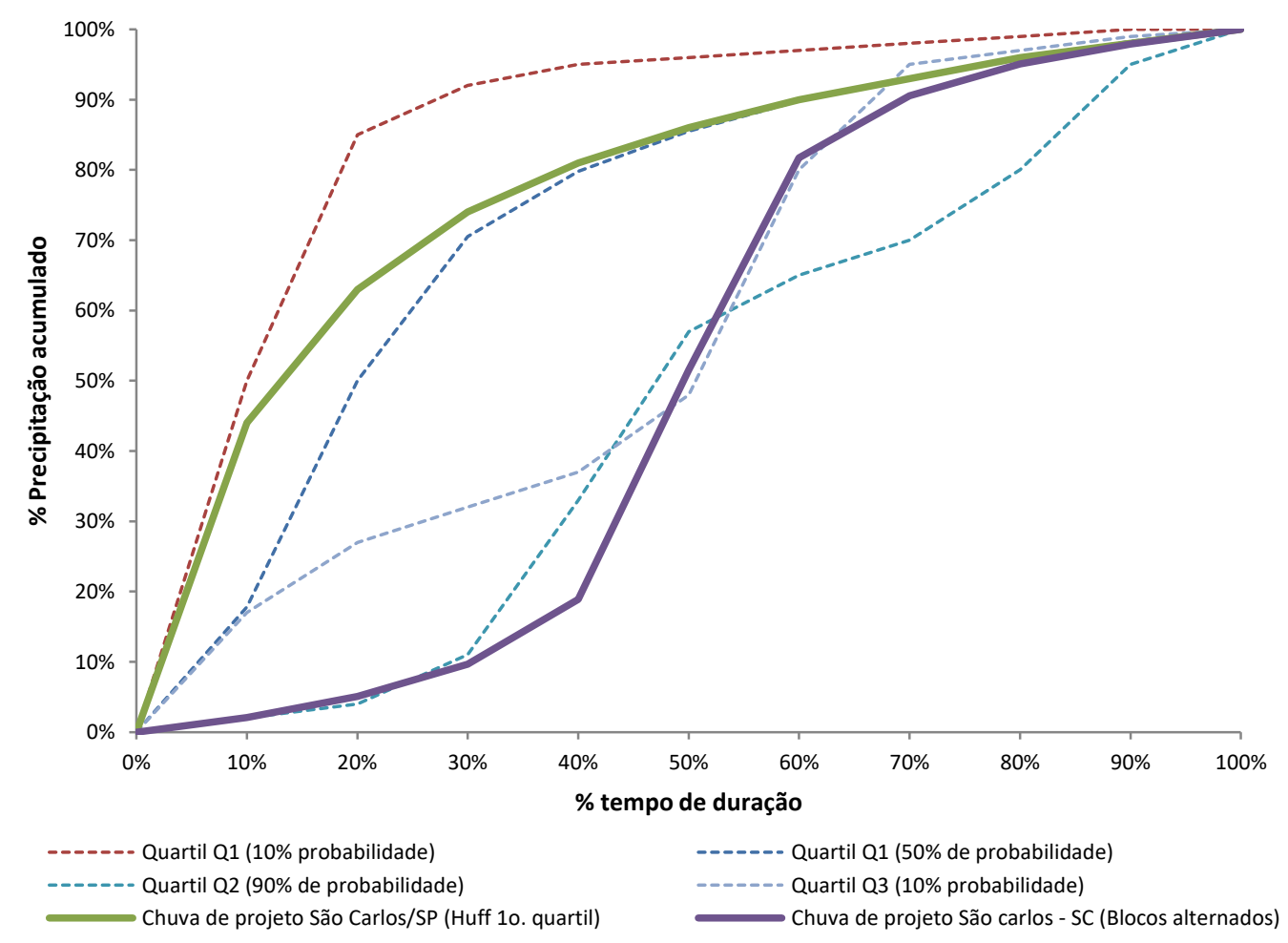

A análise da Figura 3.11 permite observar que o hietograma de projeto de São Carlos/SP, baseada no método Huff $1^{\circ}$ quartil, possui a máxima intensidade no início de sua duração, como observadas por Huff para o $1^{\circ}$ quartil entre $10 \%$ e $50 \%$ de probabilidade de excedência.

Para a chuva de projeto baseada no método dos blocos alternados com pico na metade da duração, percebe-se que em até $50 \%$ do tempo de duração da chuva (eixo x), a curva se assemelha à verificada por Huff para o $2^{\circ}$ quartil com $90 \%$ de probabilidade de excedência; e para o percentual da duração acima de $50 \%$ tem boa conformação com a curva do $3^{\circ}$ quartil com $10 \%$ de probabilidade de excedência. Esse resultado é decorrente do pico da chuva encontrar-se exatamente na metade do intervalo total da chuva, ou seja, entre o término do quartil Q2 e o início do quartil Q3.

\subsubsection{Hidrogramas de cheia}

Os hietogramas e hidrogramas de cheia para o TR de 100 anos pelos dois métodos de distribuição de chuva (blocos alternados e Huff $1^{\circ}$ quartil) elaborados com o software HECHMS são apresentados, respectivamente, nas Figuras 3.12 e 3.13. 
Figura 3.12 - Hidrograma de cheia obtido pelo software Hec-HMS com tempo de retorno de 100 anos sob método de distribuição temporal blocos alternados

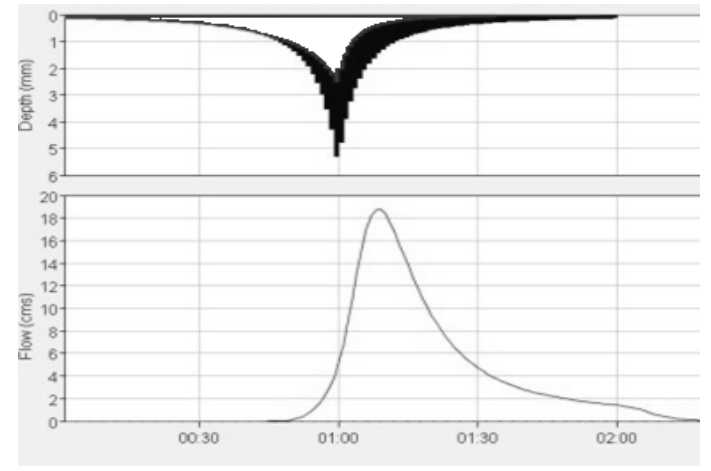

Figura 3.13 - Hidrograma de cheia obtido pelo software Hec-HMS com tempo de retorno de 100 anos sob método de distribuição temporal Huff $1^{\circ}$ Quartil

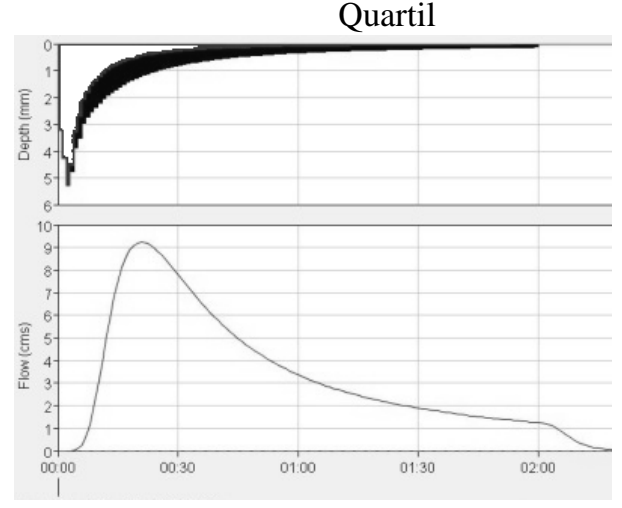

Nos gráficos apresentadas nas Figuras 3.12 e 3.13, a linha inferior refere-se ao hidrograma de escoamento superficial; na parte superior, a parte clara representa a parcela infiltrada e a parte escura a precipitação efetiva.

Pelas figuras, pode-se notar que, pelos hidrogramas gerados, o método dos blocos alternados produziu um pico significativamente maior de escoamento superficial. Dentre os fatores envolvidos à grande sensibilidade dessa variável, observa-se que o pico da vazão ocorreu 10 minutos após o pico da chuva (em 1 hora e 10 minutos) no método dos blocos alternados, enquanto que, pelo método de Huff $1^{\circ}$ quartil, o pico ocorreu 24 minutos após o início da precipitação (aos 27 minutos).

Verificou-se também, pelos hidrogramas gerados (Figuras 3.12 e 3.13), que tais discrepâncias (precipitation loss) são decorrentes da maior infiltração e perdas inicias (abstrações iniciais) observadas pelo método de Huff $1^{\circ}$ quartil.

Conclui-se que o solo infiltrou uma carga maior de água durante o pico da precipitação no método de Huff $1^{\circ}$ quartil, amortecendo o restante do escoamento gerado, de modo a gerar um hidrograma mais alongado e de menor pico em relação ao obtido pelos blocos alternados.

Percebe-se ainda pelas figuras que, pelo método de Huff $1^{\circ}$ quartil, o pico do hidrograma $\left(\approx 9 \mathrm{~m}^{3} \cdot \mathrm{s}^{-1}\right)$ corresponde a, aproximadamente, metade do valor do pico do hidrograma obtido pelo método dos blocos alternados $\left(\approx 19 \mathrm{~m}^{3} \cdot \mathrm{s}^{-1}\right)$. Essa discrepância entre os picos simulados pode ser explicada pela maior capacidade de infiltração do solo no começo da precipitação pelo método de Huff $1^{\circ}$ quartil 


\subsection{Modelagem Hidráulica-hidrológica}

\subsubsection{Vazão}

A modelagem hidráulica-hidrológica realizada para os 6 cenários simulados sob os dois picos de distribuição temporal das chuvas trouxe informações sobre a vazão máxima, observada na sub-bacia de estudo, próxima ao mercado municipal. Os resultados são apresentados nas Figuras 3.14 e $3.15^{1}$, que correspondem aos valores de vazão máxima nas simulações realizadas. Já a Figura $3.16^{1}$ apresenta o percentual de mitigação das medidas estruturais frente aos cenários estabelecidos, comparando-os com relação as distribuições temporais analisadas.

Dessa forma, para o cenário 2 são consideradas as medidas mitigadoras estruturais com a mesma configuração de uso e ocupação do solo do cenário 1 (atual), enquanto que os cenários 4,5 e 6 são consideradas medidas mitigadoras estruturais e não estruturais sob a mesma configuração de uso e ocupação do solo do cenário 3 (plano diretor), cenário sem as medidas mitigadoras propostas.

Figura 3.14 - Vazão máxima simulada nos cenários propostos para a distribuição temporal Huff $1^{\circ}$ quartil

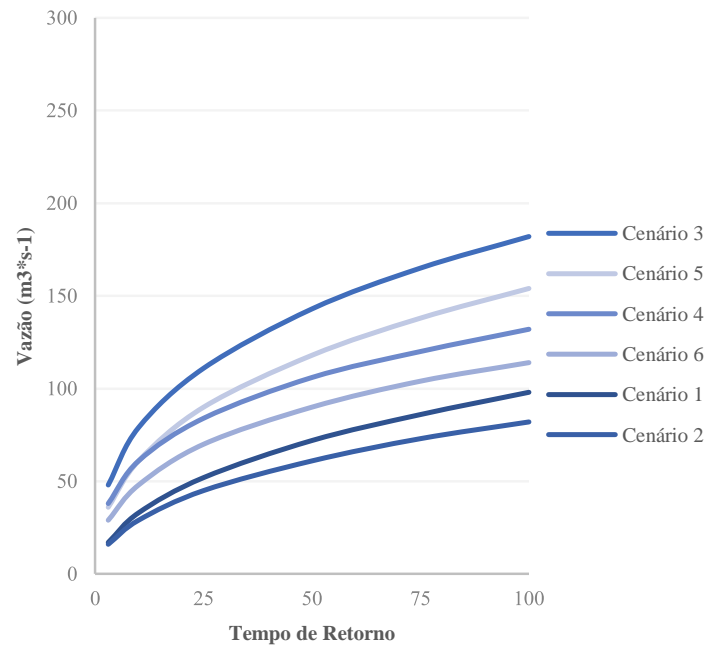

Figura 3.15 - Vazão máxima simulada nos cenários propostos e para a distribuição temporal blocos alternados

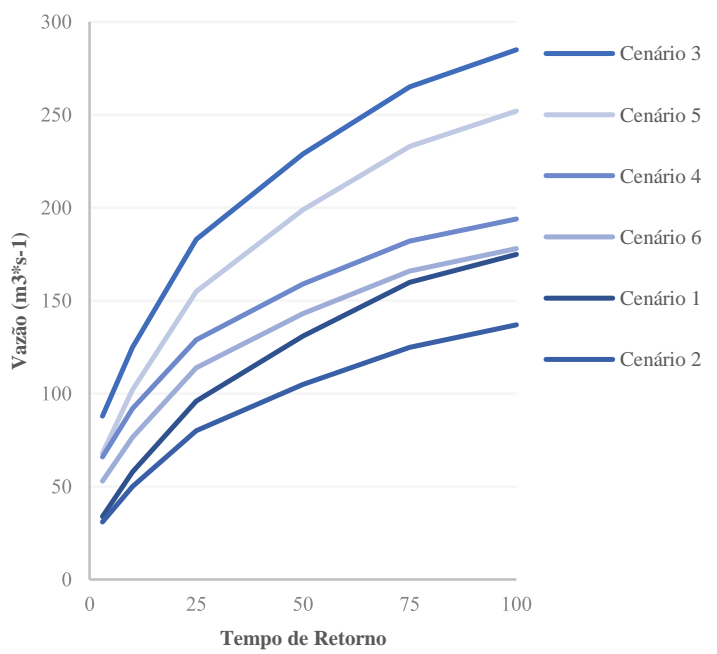

1 Cenário 1 - atual; Cenário 2 - atual + reservatórios de detenção; $\underline{\text { Cenário } 3}$ - futuro; Cenário 4 - futuro + reservatórios de detenção; Cenário $\underline{5}$ - futuro + medidas não estruturais; Cenário 6 - futuro + reservatórios de detenção e medidas não estruturais. 
Figura 3.16 - Percentual de mitigação da vazão máxima decorrente das medidas mitigadoras propostas para a distribuição temporal blocos alternados e Huff $1^{\circ}$ quartil

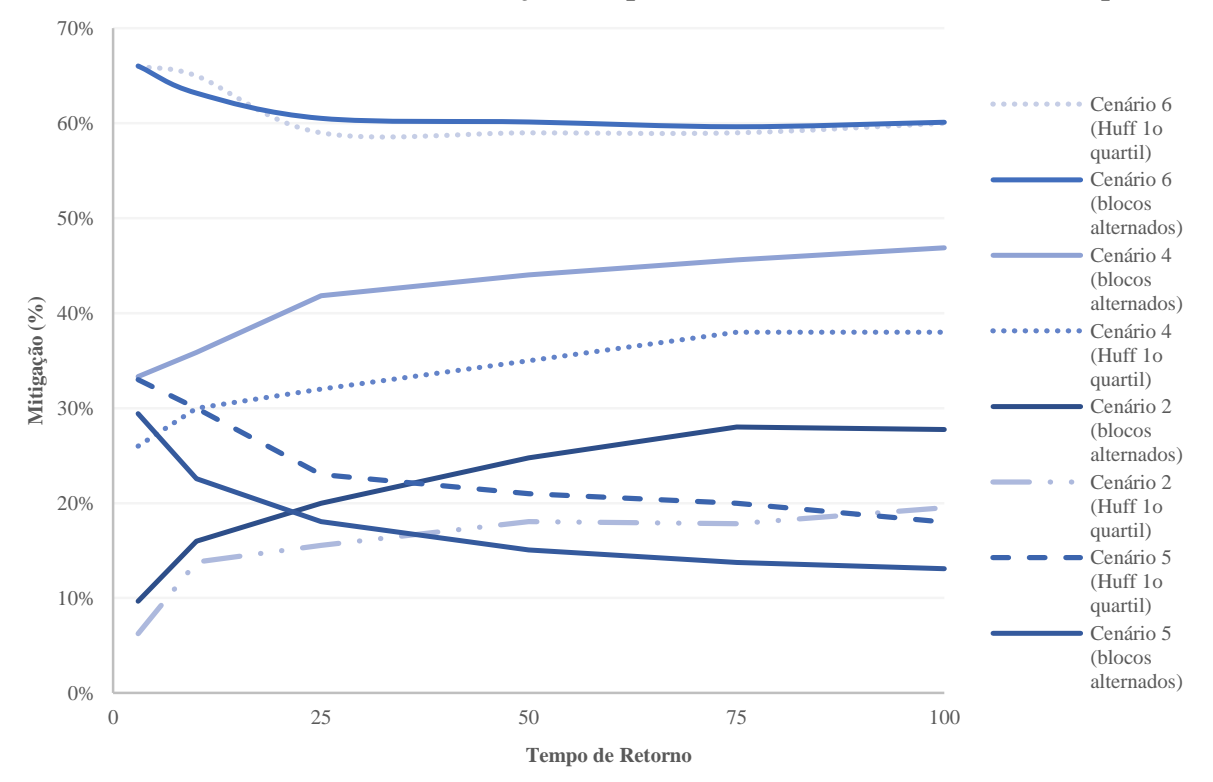

É possível constatar que no cenário futuro os reservatórios de amortecimento possuem maior impacto no amortecimento das vazões máximas do que no cenário atual. Essa questão está ligada ao fato de que os reservatórios de amortecimento são projetados para o amortecimento de maiores TR (maior vazão), observados no cenário futuro.

Porém, esse efeito não foi observado no cenário futuro, contemplando medidas não estruturais, observando-se que, com o aumento do TR, a capacidade de infiltração do solo tende a diminuir, já que a sua capacidade de campo é atingida mais rapidamente e, dessa forma, o escoamento superficial inicia-se mais aceleradamente, tornando-se mais acentuado.

Observa-se também que as medidas estruturais e não estruturais têm efeitos relativamente próximos no que tange à mitigação das vazões de pico, com valores da ordem de $18 \%$ a $38 \%$ de atenuação desta vazão para a distribuição blocos alternados e de $14 \%$ a $28 \%$ para a distribuição Huff $1^{\circ}$ quartil. Porém, quando essas medidas são implementadas em conjunto, a capacidade de atenuação da vazão de pico mantém-se na ordem de $60 \%$ em todos os TR.

O aumento da impermeabilização do solo simulada no cenário futuro sugere o aumento substancial da vazão nesse panorama, ao se observar que a vazão do cenário atual com os reservatórios de detenção e TR de 50 anos é a mesma para o cenário futuro com reservatórios e TR de 10 anos. Observa-se também que as medidas estruturais e não estruturais têm efeitos relativamente próximos no que tange à mitigação das vazões de pico, com valores da ordem de $18 \%$ a $38 \%$ de atenuação desta vazão. Porém, quando essas medidas são implementadas em 
conjunto, a capacidade de atenuação da vazão de pico mantém-se na ordem de $60 \%$ em todos os TR.

É possível perceber que os valores de vazão de pico dos hidrogramas de cheia simulados com base no método dos blocos alternados é praticamente o dobro do valor obtido pelo método de Huff $1^{\circ}$ quartil em todos os tempos de retorno simulados para TR acima de 25 anos (entre $46 \%$ e $44 \%$ superior). Esses dados corroboram o que foi anteriormente explicado por Viessman et al. (1989) e Brandão et al. (2011).

\subsection{2. Área de abrangência}

Como o modelo utilizado foi o modelo unidimensional sob regime permanente e uniforme, apenas a vazão de pico é considerada quando é gerado o mapa da mancha de inundação. Dessa forma, é possível estabelecer uma relação paralela entre o pico de vazão a máxima área de abrangência da mancha de inundação. As Figuras 3.17 e 3.18 apresentam as áreas de abrangência da mancha de inundação, respectivamente, para a distribuição Huff $1^{\circ}$ quartil e blocos alternados e a Figura 3.19 a evolução adimensional da área de abrangência em relação a vazão simulada.

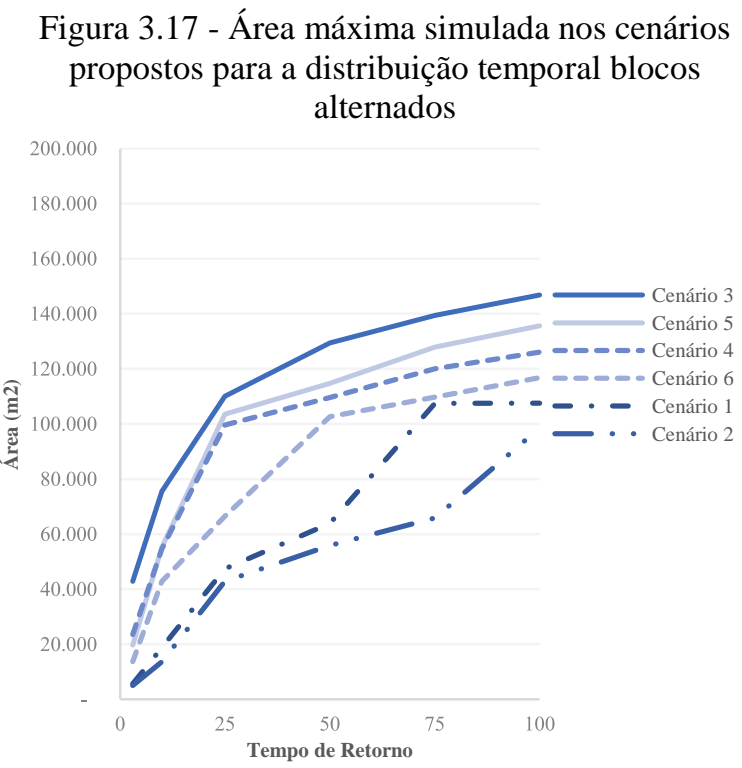

Figura 3.18 - Área máxima simulada nos cenários propostos para a distribuição temporal Huff $1^{\circ}$ quartil

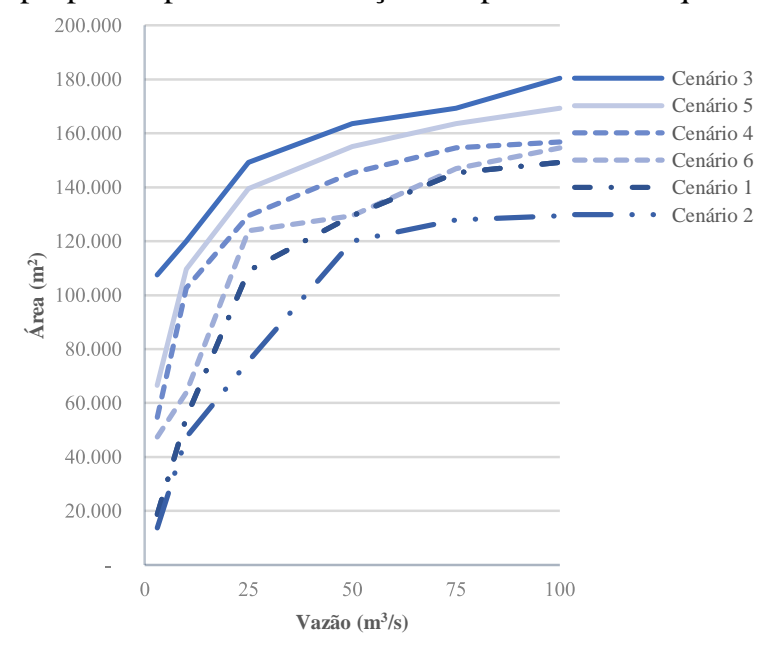


Figura 3.19 - Área de abrangência da mancha de inundação normalizado de acordo com a vazão simulada

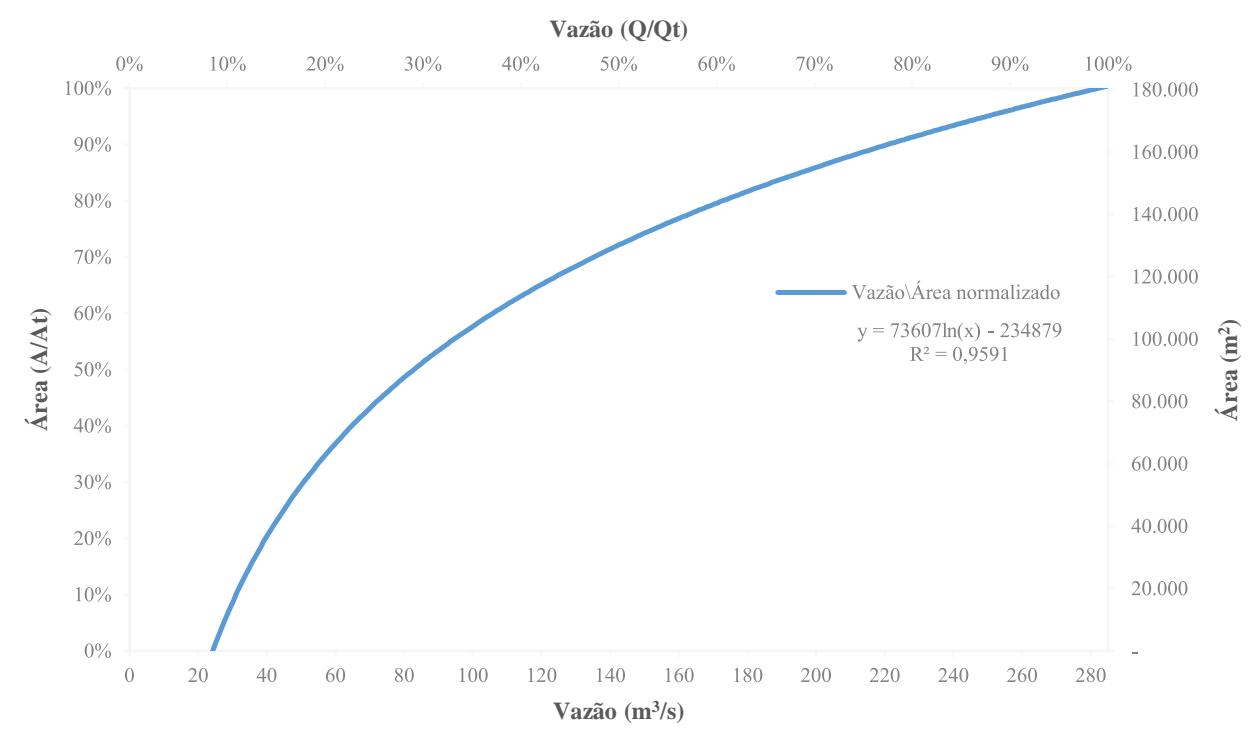

Com relação a área de abrangência, foi verificado que o maior potencial de mitigação ocorreu no TR de 75 anos para o cenário atual e de 3 e 10 anos para o cenário futuro.

A análise adimensional da área da mancha de inundação em relação a vazão máxima observada permite verificar que a relação entre ambas não é linear, já que ao atingir 30\% da vazão máxima (aproximadamente $80 \mathrm{~m}^{3} / \mathrm{s}$ ) a área da inundação atingiu aproximadamente $50 \%$ da área máxima verificada na bacia.

\subsubsection{Mancha de inundação}

As manchas de inundação foram geradas com a utilização da plataforma HEC, através do módulo RAS (HEC-RAS) e do HECGeoRAS, suplemento do ArcGIS.

Com o uso dessas ferramentas, foram mensuradas as áreas de abrangência da mancha de inundação em cada evento pelos dois métodos de distribuição temporal das chuvas para o cenário atual. As áreas das manchas de inundação são apresentadas, a título de exemplificação, nas Figuras 3.20 a 3.25 para o cenário atual com TR de 25, 50 e 100 anos. 
Figura 3.20 - Mancha de inundação para TR 25 anos sob o método de distribuição temporal de chuvas blocos alternados

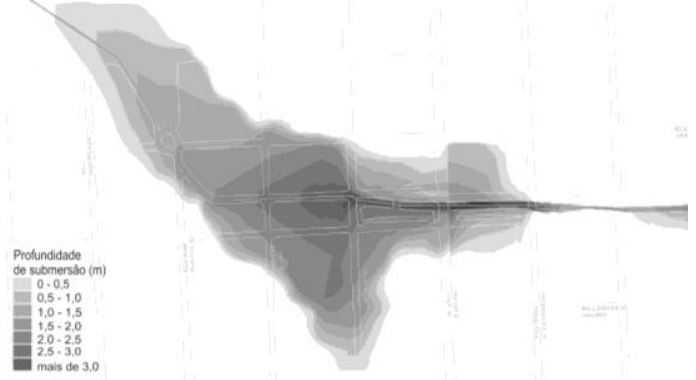

Figura 3.22 - Mancha de inundação para TR 50 anos sob o método de distribuição temporal de chuvas blocos alternados

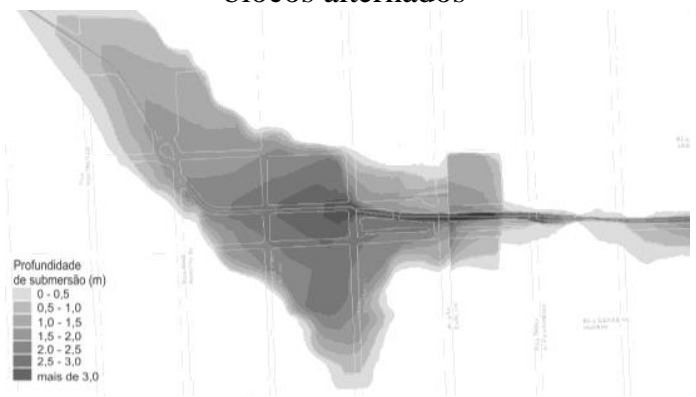

Figura 3.24 - Mancha de inundação para TR 100 anos sob o método de distribuição temporal de chuvas blocos alternados

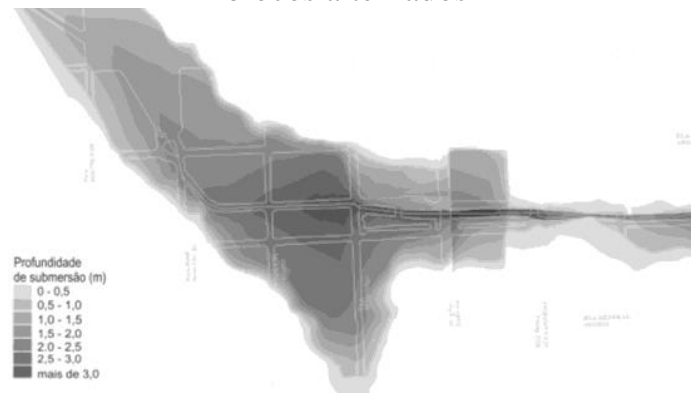

Figura 3.21 - Mancha de inundação para TR 25 anos sob o método de distribuição temporal de chuvas Huff $1^{\circ}$ quartil

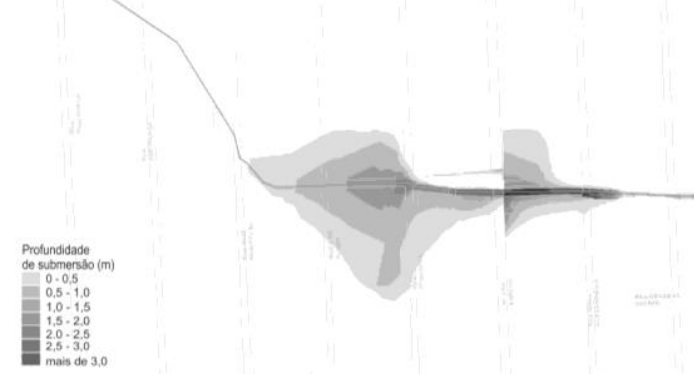

Figura 3.23 - Mancha de inundação para TR 50 anos sob o método de distribuição temporal de chuvas Huff $1^{\circ}$ quartil

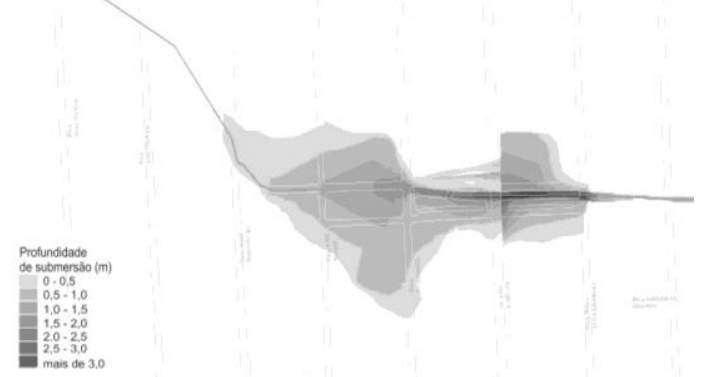

Figura 3.25 - Mancha de inundação para TR 100 anos sob o método de distribuição temporal de chuvas Huff $1^{\circ}$ quartil

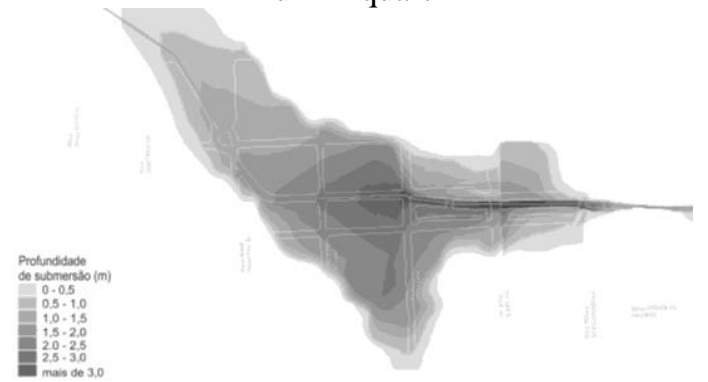

Os resultados obtidos pelo método de Huff $1^{\circ}$. quartil com relação a área das manchas de inundação para os eventos de TR de 25 e 50 anos mostraram-se entre $50 \%$ a $60 \%$ inferiores em comparação ao método blocos alternados. Apenas para o TR de 100 anos que essa diferença cai para $28 \%$. Este fato está associado às características topográficas da área sujeita a inundações, que se configura como um vale estreito com cotas altimétricas baixas. Em cotas mais elevadas o vale se alarga, e assim um significativo aumento na vazão não é necessariamente acompanhado por um correspondente acréscimo na área inundada. 
Observou-se que a vazão de pico e a área da mancha de inundação para o TR de 25 anos com blocos alternados são semelhantes às obtidas pelo método de Huff $1^{\circ}$ quartil com TR de 100 anos, fato que evidencia a grande sensibilidade das simulações quanto ao método de distribuição de chuva na avaliação da probabilidade de recorrência.

A distribuição temporal das chuvas pouco altera a proporção da vazão de escoamento superficial gerado entre os TR, que variou de $44 \%$ a $46 \%$ entre os TR na comparação entre os dois métodos de distribuição temporal propostos; porém, altera significativamente a área de abrangência da mancha de inundação, já que variou entre $57 \%$ e $28 \%$ a diferença entre as manchas de inundação entre os TR de 25 e 100 anos, respectivamente, demonstrando que as variáveis 'área de abrangência da inundação' e 'vazão gerada pelo escoamento superficial não possuem uma correlação diretamente proporcional, principalmente para maiores TR. Esses resultados estão de acordo com os argumentos explicitados anteriormente por Viessman et al. (1989).

\subsubsection{Profundidade de submersão}

Além da área da mancha de inundação, outra variável importante é a altura ou profundidade atingida pela água na mancha de inundação. Essa variável é essencial à avaliação de prejuízo de uma região, já que a profundidade de submersão é uma das principais variáveis utilizadas como dado de entrada na modelação de prejuízos diretos em imóveis, dentre outros. Para analisar essa questão, são apresentados nas Figuras 3.26 e 3.27 as profundidades máximas de submersão para, respectivamente, as distribuições temporais Huff $1^{\circ}$ quartil e blocos alternados. Já na Figura 3.28 é apresentada é apresentada uma relação adimensional das três variáveis de estudo: vazão, área de abrangência da mancha de inundação e profundidade. 
Figura 3.26 - Profundidade máxima simulada nos cenários propostos a distribuição temporal Huff $1^{\circ}$ quartil

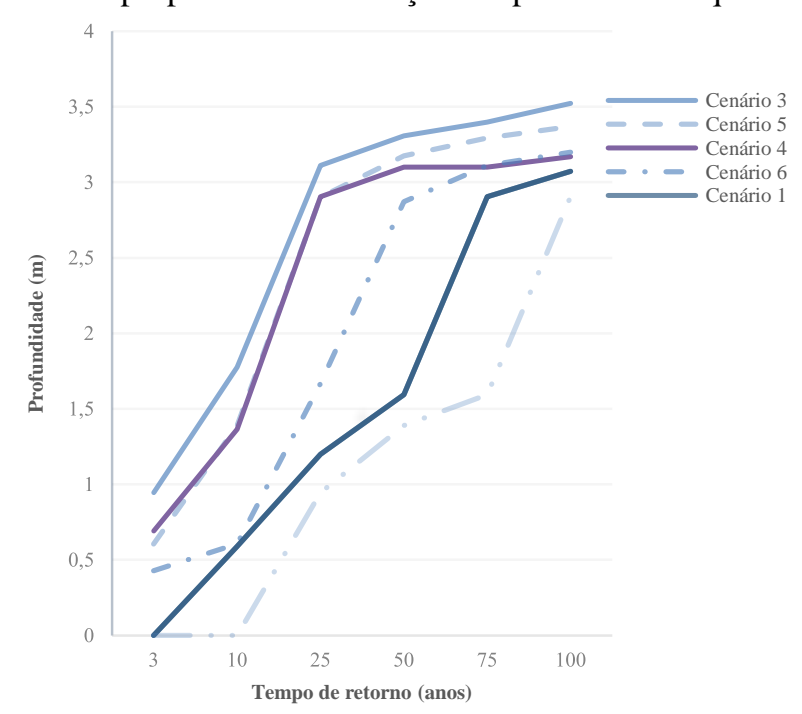

Figura 3.27 - Vazão máxima simulada nos cenários criados para a distribuição temporal blocos alternados

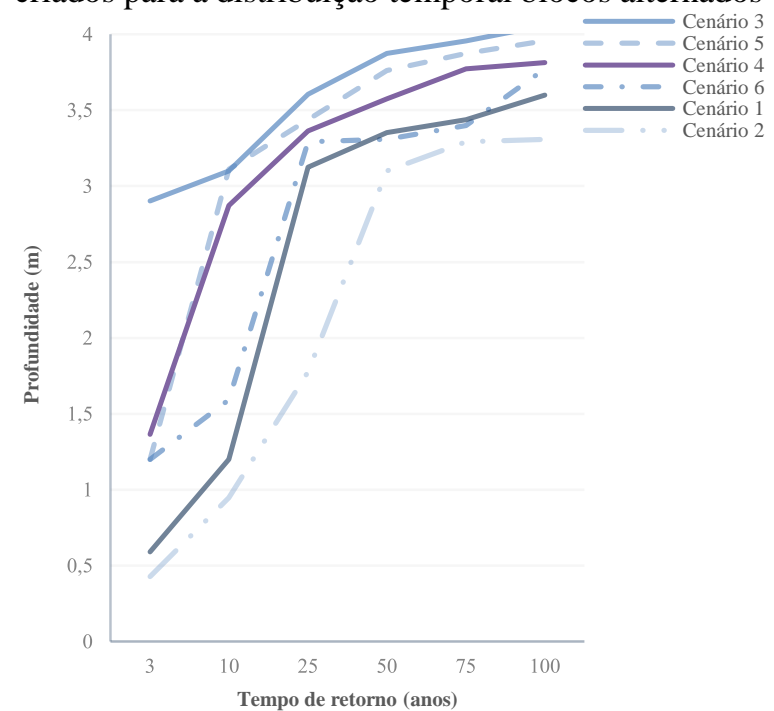

Figura 3.28 - Profundidade máxima e área da mancha de inundação normalizada em relação a vazão

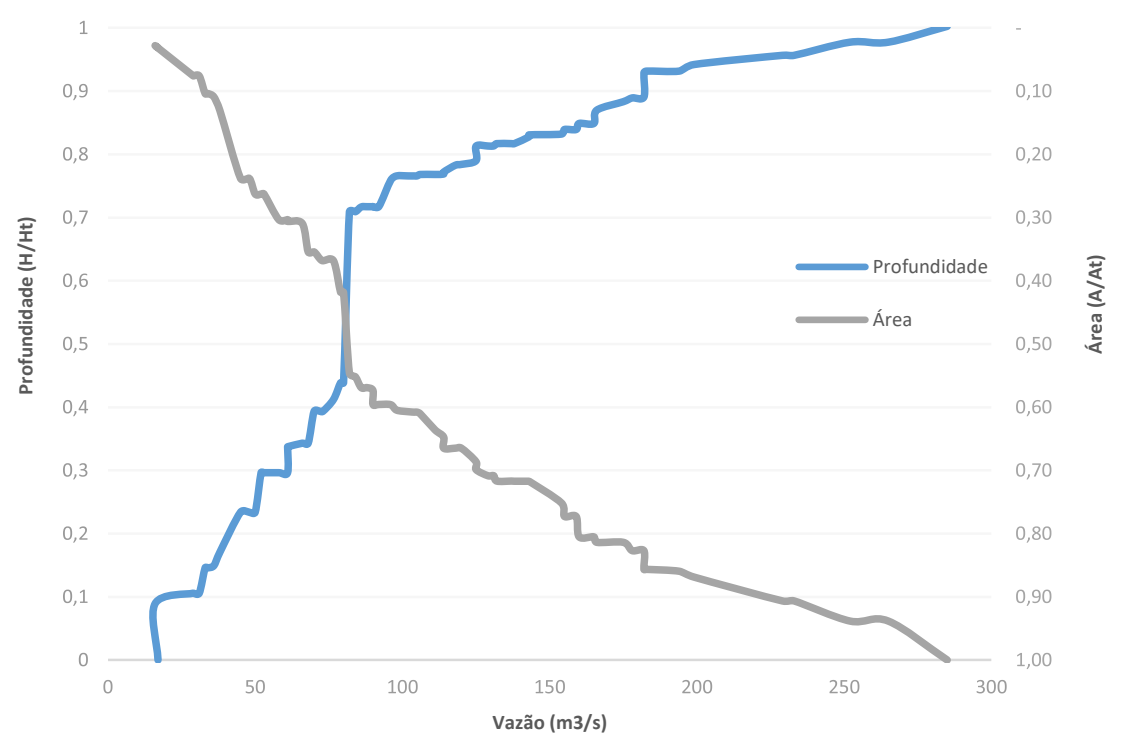

Pelo método de Huff, constata-se que, para os tempos de retorno de 25 e 50 anos, foi verificada altura da inundação com valores de até 1,5 $\mathrm{m}$ de profundidade na área da mancha de inundação, enquanto que, para os blocos alternados, essa altura superou os $3 \mathrm{~m}$.

A análise adimensional da profundidade de da área da mancha de inundação em relação a vazão permite verificar um ponto crítico entre essas variáveis. Esse ponto ocorre quando a vazão atinge $82 \mathrm{~m}^{3} / \mathrm{s}$, em que há um aumento substancial tanto da mancha de inundação quanto da profundidade. Pode-se observar esses fenômenos ao analisar as manchas de inundação do cenário atual entre TR de 50 e 100 anos pelo método de Huff $1^{\circ}$ quartil (Figuras 3.21 e 3.23), 
no qual um aumento de $26 \mathrm{~m}^{3} / \mathrm{s}$ gerou um incremento substancial (entre de 30 e $40 \%$ ) na profundidade e na área entre os TR analisados.

\subsection{CONSIDERAÇÕES FINAIS}

A geração dos hidrogramas de cheia utilizando as distribuições temporais de chuva de projeto pelos métodos dos blocos alternados e Huff $1^{\circ}$ quartil demonstraram profundas diferenças nos resultados com relação à vazão de pico, a área da mancha de inundação e a profundidade da água obtida em cada evento. Através da modelagem hidráulica-hidrológica e de um software de sistema de informação geográfica (SIG), foi possível comparar os dois métodos.

O uso de métodos que geram resultados mais críticos, como o método dos blocos alternados, pode ser útil para dimensionamento de projetos de grandes bacias hidrográficas. Além disso, o método dos blocos alternados na metade da duração da chuva, como é comumente aplicado, é arbitrário e carente de comprovação científica de sua aplicabilidade e deve ser aplicado apenas quando não se possui qualquer informação da área e da característica temporal da chuva. Por outro lado, podem-se aplicar diferentes formas de hietogramas e métodos de desagregação, como os apresentados nas Figura 3.10 e 3.11.

Nesta análise, foi possível constatar aumentos entre 32\% e $46 \%$ na vazão máxima entres os métodos dos blocos alternados e Huff $1^{\circ}$ quartil, o que gerou entre $28 \%$ e $57 \%$ de aumento de área na mancha de inundação e incremento de $1,5 \mathrm{~m}$ na profundidade da água.

Os resultados apresentados nas Figuras 3.14 e 3.19 demonstram que a vazão máxima e a área de abrangência da mancha de inundação não apresentam correlação direta com o percentual de mitigação das medidas. Para a vazão máxima simulada, houve aumento linear de acordo com a elevação do tempo de retorno, enquanto que a área de estudo não possui tal correlação: o aumento do TR não necessariamente provocou maior aumento da área de abrangência da mancha. Essa questão pode ser explicada pela grande declividade existente nesse local, em que um pequeno volume de água passa a ocupar uma nova cota da planície de inundação.

A análise hidrológica demonstrou a grande variabilidade dos resultados frente a distribuição temporal da chuva adotada e demonstra que tais valores podem ser extremamente discrepantes. Portanto, uma análise profunda sobre as características da distribuição temporal das precipitações deve ser avaliada ao se simular hidrogramas de cheia e manchas de inundação, 
tendo em vista a alta sensibilidade que a distribuição temporal das precipitações pode gerar aos resultados.

A análise da probabilidade de recorrência baseada em quartis por Huff (1967) traz subsídios à adoção de chuvas de projeto para múltiplas situações hidrometeorológica, variável essa incerta e influenciada pelas condições climáticas e atmosféricas locais.

Essa pesquisa demonstrou que a análise da distribuição temporal da tormenta de projeto é fundamental para se obter resultados confiáveis sobre os efeitos das inundações em bacias urbanas. Dessa forma, a falta de critérios quanto a correta desagregação das chuvas pode trazer incertezas significativas nos hidrograma simulados por modelos hidrológicas, já que podem sub ou superdimensionar seus efeitos e, por conseguinte, importar dados de entrada não condizentes com a realidade local, dificultando assim a elaboração de obras e projetos precisos.

Portanto, conclui-se que a alteração do método de distribuição temporal das chuvas pode trazer incertezas significativas à transformação da chuva em vazão e, dessa forma, introduzir diferenças consideráveis aos resultados. Porém, o método de Huff traz possibilidades de desagregação temporal de chuvas menos arbitrárias e possibilidade de adaptação quanto as características locais, podendo ser aplicado de acordo com a área e tempo de duração de chuva características da região, sendo assim importante ferramenta para a padronização de chuvas de projeto de acordo com o objetivo pretendido. Tais alterações podem trazer diferenças significativas para a modelagem de prejuízos, como será visto no próximo capítulo deste documento (capítulo 4). 


\section{REFERÊNCIAS}

BARBASSA, A. P. Simulação do efeito da urbanização sobre a drenagem pluvial na cidade de São Carlos/SP. Tese (Doutorado em Engenharia Hidráulica e Saneamento) Escola de Engenharia de São Carlos, Universidade de São Paulo, São Carlos, 1991, p. 327.

BRANDÃO, C.; RODRIGUES, R.; COSTA, J. P. Análise de fenómenos extremos precipitações intensas em Portugal continental - Direcção dos Serviços de Recursos Hídricos - Lisboa - 2001.

DECINA, T. G. T. Avaliação de medidas de controle de inundações na bacia hidrográfica do Córrego do Gregório, São Carlos, SP. Dissertação (mestrado em engenharia hidráulica e saneamento) - Escola de Engenharia de São Carlos, Universidade de São Paulo, 2012.

HUFF, F. A., Time distribution of rainfall in heavy storms. Water Resources Research, v.3, n.4, p. 1007-1019. 1967.

MEIN, R. G., LARSON, C. L. Modeling Infiltration during a steady rain. Water Resources Research, V. 9, n.2, p.384-394, 1973.

MENDES, H. C.; MENDIONDO, E. M. Histórico da Expansão Urbana e Incidência de Inundações: o caso da Bacia do Gregório, São Carlos - SP. In: RBRH - Revista Brasileira de Recursos Hídricos: 2007, Volume 12, n.1, p.17-27, Jan/Mar.

PMSC - Prefeitura Municipal de São Carlos. Secretaria Municipal de Obras. SHS Consultoria e Projetos de Engenharia S/S Ltda. Plano Diretor de Drenagem Urbana Ambientalmente Sustentável. São Carlos: 2011. 213 p. Relatório Síntese. Volume II Medidas Estruturais, Medidas Não Estruturais e Custos. Contrato $n^{\circ} 87 / 09$ - Processo ${ }^{\circ}$ 6.965/07. 2011

RIBEIRO, G. Acerca do cálculo da vazão de obras d'arte: tempo de concentração. Revista do Clube de Engenharia. Rio de Janeiro, 1961, n.291, p.16-19,

SÃO PAULO. Secretaria Municipal de Desenvolvimento Urbano. Manual de Drenagem e Manejo de Águas Pluviais: Aspectos tecnológicos; diretrizes para projetos. São Paulo: SMDU, 2012, p.130

TUCCI, C. E. M. Inundações urbanas. In: Drenagem urbana: Porto Alegre: ABRH / Editora da Universidade / UFRGS, $1^{a}$ edição. cap. 1, p. 15-36, 1995.

VIESSMAN JUNIOR, W.; LEWIS, G. L.; KNAPP, J. K. Infiltration. In: Introduction to Hydrology. $3^{\circ}$ ed. New York: Harper e Row, 1989, p. 55-83. 


\section{CAPÍTULO 4 - AVALIAÇÃO CUSTO-BENEFÍCIO DE MEDIDAS MITIGADORAS EM INUNDAÇÕES URBANAS}

\section{RESUMO}

As consequências de uma inundação dependem dos fatores hidrológicos e hidráulicos envolvidos, podendo vir a gerar danos econômicos. Apesar da importância do setor comercial para a economia no fornecimento de bens, serviços e empregos, as análises sobre danos causados pelas inundações têm se concentrado quase exclusivamente no setor residencial. Essa defasagem em relação aos demais setores pode gerar fatores como: alocações ineficientes de recursos para mitigação das inundações; exposição de companhias de seguros a seleções incorretas de recursos; criação de orçamento ineficiente e decisões políticas inapropriadas. Sendo assim, a avaliação dos danos é um sistema complexo, porém essencial na priorização de políticas públicas para proteção dos bens, tanto públicos como privados. Dentre as medidas utilizadas para mitigar esses prejuízos, as bacias de detenção estão entre as mais utilizadas em projetos de controle de drenagem no Brasil. Para analisar a influência dessas medidas estruturais na mitigação dos prejuízos ao comércio, foi estabelecida a seguinte sequência metodológica: (1) identificação e cadastramento dos imóveis afetados; (2) mapeamento dos valores de altura de inundação por meio de simulação hidráulica-hidrológica e pela mancha de inundação simulada; (3) estimativa do dano causado pela inundação; (4) cálculo do prejuízo médio anual esperado; (5) avaliação do custo-benefício das medidas mitigadoras propostas. Além disso, foram utilizados dois tipos de distribuição temporal das chuvas, para avaliar as incertezas referentes a essa análise. Como resultado, uma análise do custo-benefício dos reservatórios de detenção propostos para a bacia do córrego do Gregório - considerando apenas os prejuízos econômicos diretos dos comerciários - demonstrou que o custo econômico das obras é superior aos benefícios econômicos por ela geradas na maioria dos cenários. Além disso, a adoção de medidas mitigadoras não estruturais possui efetividade semelhante quando comparada às ações de cunho estrutural. Desta forma, a averiguação integrada de diversas técnicas compensatórias deve ser observada para que se tenha maior eficácia na redução dos prejuízos da região estudada, uma vez que esta se apresentou como a única alternativa capaz de manter a vazão de pico em cenários futuros de ocupação do solo.

Palavras-chave: inundações urbanas; simulações hidrológicas; prejuízos econômicos; medidas mitigadoras. Keywords: urban storm water; hydrological simulation; economical damage; mitigating measures.

\subsection{INTRODUÇÃO}

Os danos resultantes de uma inundação podem ser medidos através de vários parâmetros. Dentre eles, pode-se citar: o evento pluviométrico que deu origem à inundação; a profundidade de submersão; a velocidade do escoamento; e a duração da precipitação. Além dos fatores supracitados, deve-se considerar ainda características concernentes às próprias infraestruturas afetadas, tais como o tipo de uso do imóvel (residencial, comercial, industrial), o número de habitantes e à situação socioeconômica dos afetados. 
A avaliação dos danos permite priorizar políticas públicas de prevenção aos bens públicos e privados, como a retirada em definitivo de moradias, comércio e entidades públicas de áreas inundáveis, bem como ser uma importante ferramenta de análise "custo-benefício" na implantação de infraestrutura de contenção de cheias ou, ainda, lastrear coerentemente os bens e edifícios com apólices de seguros (TACHINI, 2010).

\subsection{METODOLOGIA}

A metodologia para análise é baseada no seguinte fluxograma:

1. Identificação e cadastramento dos imóveis afetados;

2. Mapeamento dos valores de altura de inundação das empresas cadastradas, baseado nas manchas de inundação geradas para as distribuições temporais das chuvas e cenários propostos (capítulo 3);

3. Estimativa do dano causado pela inundação, baseada nas funções de custo que relacionam a altura de água com os prejuízos causados e posterior cálculo das probabilidades de recorrência (tempo de retorno), fundamentado nas curvas DPS elaboradas por Machado (2005);

4. Cálculo do prejuízo médio anual esperado para a região de acordo com as probabilidades de excedência simuladas e os cenários propostos;

5. Avaliação do custo-benefício das medidas mitigadoras propostas;

A Figura 4.1 apresenta o fluxograma simplificado da metodologia proposta neste estudo para avaliar o custo-benefício de medidas mitigadoras. 
Figura 4.1 - Fluxograma simplificado para elaboração do custo-benefício de medidas mitigadoras

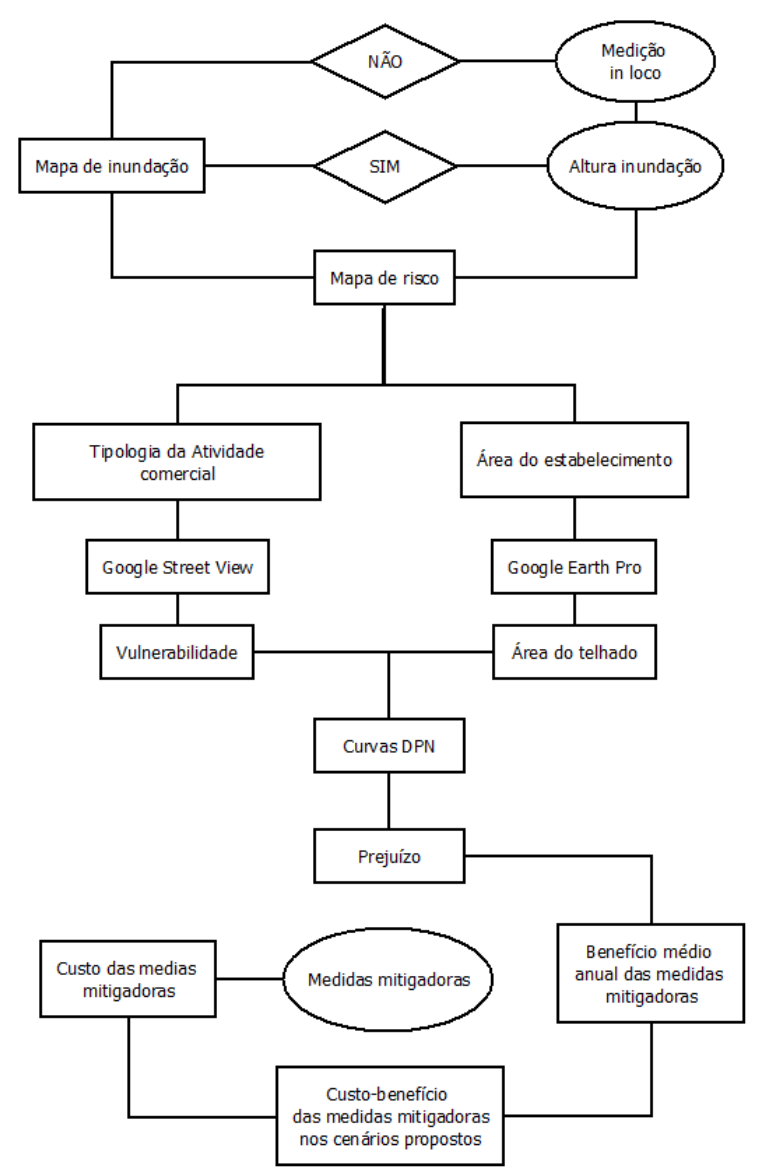

\subsubsection{Identificação e cadastramento dos imóveis afetados}

Os imóveis foram cadastrados com o uso de ferramentas de sistemas de informações geográficas (SIG). Para iniciar o cadastro dos imóveis, foi utilizado um mapa com informações sobre logradouros municipais disponíveis no SIGA SC (Sistemas de Informações Geográficas de São Carlos) $)^{2}$, o qual se encontra no portal da prefeitura de São Carlos, sendo de livre acesso na internet. Por meio do portal, foi possível discriminar os logradouros presentes na área em estudo, a partir da sobreposição deste mapa ao da mancha de inundação.

Os dados cadastrais das empresas foram obtidos na Associação Comercial e Industrial de São Carlos (ACISC), que disponibiliza, sob pagamento de taxa, uma planilha digital contendo informações com a razão social e endereço das empresas cadastradas na associação. Com essas informações e as obtidas no SIGA SC (sobre logradouros municipais), foi possível

\footnotetext{
${ }^{2}$ Prefeitura Municipal de São Carlos. Sistemas de Informações Geográficas de São Carlos. Disponível em: http://geo.saocarlos.sp.gov.br/index.php?. Acesso em 17.08.2016
} 
delimitar as empresas contidas nas manchas de inundações e realizar o cadastramento. O mapa dos logradouros disponível no portal do SIGA SC é apresentado na Figura 4.2.

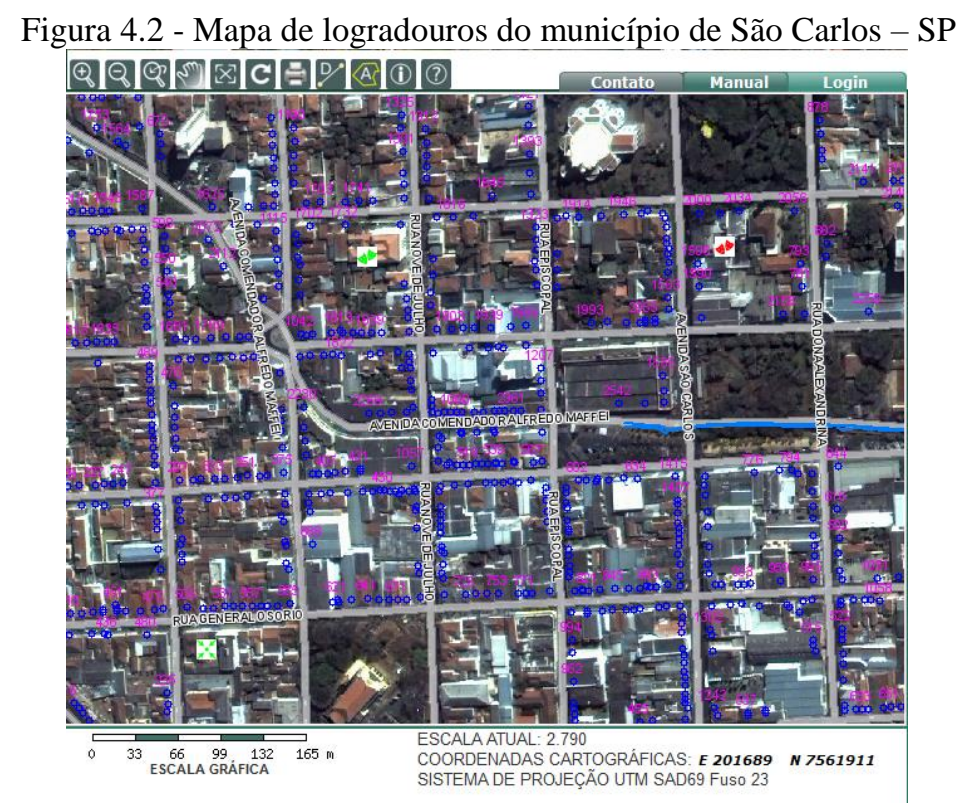

Fonte: Sistema de Informações Geográfica de São Carlos - SIGA SC

Através da localização dos imóveis importaram-se os dados cadastrados para a plataforma do ArcGIS. Foram atribuídas coordenadas para cada empresa em uma tabela, sendo que, a cada imóvel, foi associado um número de identificação (ID) e sua respectiva localização utilizada na importação para o ArcGIS.

Em relação ao tipo de atividade comercial exercida nestes locais, utilizou-se o Google Street View, com imagem da cidade de São Carlos do ano de 2015, apontando o tipo de atividade comercial por meio da observação das fachadas comerciais.

Para mensurar a área construída, foi utilizado o software Google Earth Pro para vetorização manual de polígonos dos telhados dos imóveis atingidos. A resolução obtida foi suficiente para distinguir os telhados e fornecer a área de cada imóvel. A Figura 4.3 apresenta exemplos vetorização de polígonos relativos aos telhados dos imóveis inseridos na mancha de inundação. 
Figura 4.3 - Exemplo de vetorização dos polígonos dos telhados dos imóveis inseridos na área sujeita a

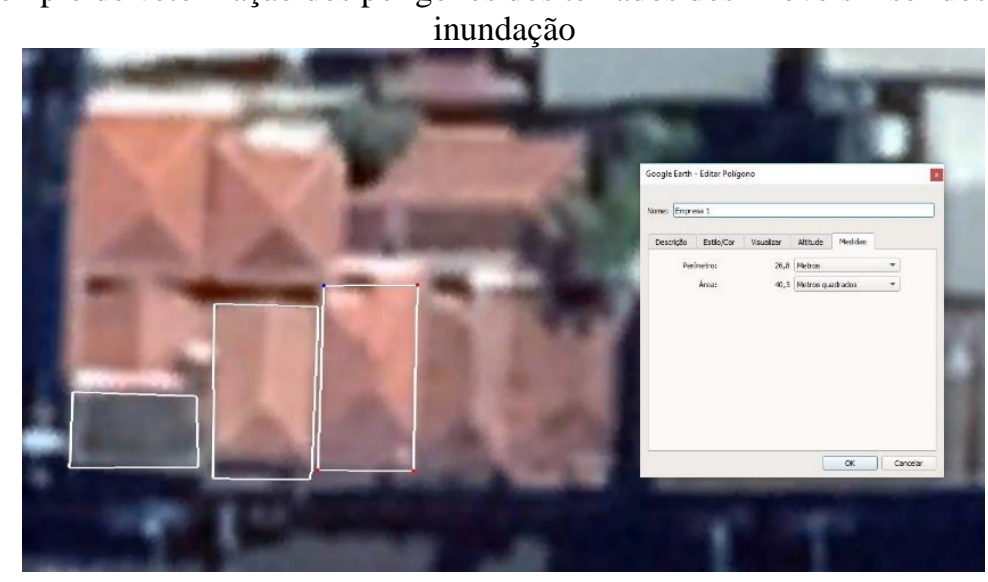

Para delimitar a área de abrangência deste cadastro, foi utilizada como referência a mancha de inundação obtida a partir da modelagem com o software HEC-GeoRAS. Por meio deste mapeamento manual, foram cadastradas 90 empresas presentes na área sujeita à inundação e importaram-se os dados cadastrados para a plataforma GIS, associando cada empresa às seguintes informações:

- número de identificação (ID);

- coordenada;

- tipo de atividade comercial;

- área do estabelecimento;

Assim, a sobreposição do mapa da mancha de inundação com o mapa de cadastramento dos imóveis afetados possibilitou delimitar os locais comerciais potencialmente afetados nesta área, além de obter as respectivas profundidades de submersão de cada um deles para os cenários e distribuições temporais de chuvas propostos. Sendo assim, foram gerados dados para 6 cenários, sob 6 tempos de retorno distintos e, duas distribuições temporais de chuvas, gerando um total de 72 cenários com dados hidráulico-hidrológicos e econômicos. Tais informações formaram a base de dados para a quantificação dos prejuízos de decorrentes das inundações.

O mapeamento dos valores de altura de inundação foi realizado por meio de simulação hidráulica-hidrológica na plataforma HEC, gerando mapas de mancha de inundação simulados por meio de SIG (capítulo 3). Os imóveis comerciais foram caracterizados de acordo com a área construída e o tipo de atividade comercial. 
Com isso, foi possível correlacionar a altura de inundação em que o imóvel está inserido com o prejuízo ocasionado, formando assim, as curvas de benefícios necessárias à avaliação dos danos e ao custo benefício das medidas mitigadoras propostas.

\subsubsection{Análise dos custos das medidas mitigadoras propostas}

As medidas mitigadoras selecionadas foram apresentadas e modeladas do ponto de vista hidráulico-hidrológico no capítulo 3, e formarão a base de dados para as análises posteriores deste capítulo. Com relação aos custos, serão analisadas apenas medidas mitigadoras de cunho estrutural, tendo em vista que as de cunho não estrutural envolveriam, principalmente, as despesas - ou a não geração de benefícios para o município - da não conversão de áreas verdes em áreas construídas, de difícil quantificação.

Os custos das medidas mitigadoras estruturais a serem considerados incluem: i) o custo de implantação (planejamento, projeto, construção, terreno, etc.); ii) gastos com operação e manutenção (mão de obra, troca e reparo de equipamentos, etc.) para operar o sistema durante sua vida útil e; iii) os custos de financiamento, relativos aos juros de empréstimos necessários para a implantação da obra. Os juros foram transformados em valores presentes através da metodologia do Valor Presente Líquido (VPL).

Sendo assim, o benefício das ações adotadas será a diferença entre os prejuízos observados nos cenários pesquisados para uma mesma chuva de projeto nos cenários previstos. Os custos serão baseados nos orçamentos apresentados no Plano Municipal de Drenagem de São Carlos (PMSC, 2011), elencados na Tabela 4.1, cujo volume refere-se ao nível máximo de projeto dos respectivos reservatórios de detenção. A localização de cada reservatório foi apresentada anteriormente na Figura 3.9.

\begin{tabular}{|c|c|c|c|}
\hline BARRAGEM & LOCAL & $\begin{array}{r}\text { VOLUME } \\
\left(\mathbf{m}^{3}\right)\end{array}$ & $\begin{array}{r}\text { VALOR }(\mathbf{R} \$) \\
\text { [base 2010] }\end{array}$ \\
\hline Barramento B93.5 & $\begin{array}{l}\text { Córrego do Gregório } \\
\text { Rod. Washington Luiz }\end{array}$ & 339.878 & 7.194 .634 \\
\hline Barramento B98.5 & Córrego do Lazarini & 24.913 & 2.035 .772 \\
\hline Barramento B84.5 & Córrego do Sorregotti & 64.123 & 5.513 .737 \\
\hline Barramento B97.5 & Córrego do Lazarini & 32.232 & 1.869 .939 \\
\hline Barramento B83.5 & $\begin{array}{l}\text { Córrego do Gregório } \\
\text { Rua Roberto Martinez }\end{array}$ & 48.343 & 1.972 .224 \\
\hline TOTAL & & 509.489 & 18.586.306 \\
\hline
\end{tabular}


Os valores apresentados na Tabela 4.1 representam o somatório, para cada reservatório, dos seguintes itens:

- canteiro de obras e serviços técnicos (topografia, estudos complementares e serviços gerais); - serviços preliminares (preparação, limpeza do terreno e transporte de maquinário);

- obras de contenção para desvio do curso d'água;

- barragem (movimentação de terra [execução do maciço], descarga de fundo, vertedouro e proteção do maciço);

- drenagem e pavimentação da crista da barragem;

- desapropriações.

Cabe destacar que, do valor de implantação das barragens (R \$ 18.586.306,00), 23\% do total, equivalente a $\mathrm{R} \$ 4.226 .077,00$, correspondem à verba para desapropriação das áreas inundadas, com valores entre $\mathrm{R} \$ 10,85$ a $\mathrm{R} \$ 29,20$ por metro quadrado de área desapropriada.

Para atualizar os valores e aplicá-los à pesquisa, o montante foi corrigido pelo Índice Nacional de Preços da Construção Civil (INCC). O INCC, acumulado de janeiro de 2011 a maio de 2018 , resultou em $47,1 \%$. Sendo assim, o valor atualizado considerado é de $\mathrm{R} \$$ $27.340 .456,12$.

Para realizar a análise financeira inicial dos reservatórios foi definido o período de 30 anos, que corresponde ao prazo provável de vida útil da obra, adotando maio de 2018 como data base para comparação dos custos e benefícios. As despesas com financiamento de juros foram realizadas com a metodologia adotada pela tabela Price de financiamento, com índice de juros anuais de 6\%, valor adotado atualmente em financiamentos pelo Banco Nacional de Desenvolvimento Social (BNDES) e transformados em VPL. Assim, o custo total dos juros resultou em $\mathrm{R} \$ 71.217 .922,00$ para os 30 anos considerados, os quais correspondem, em valores presentes, a R \$ 20.739.777,93, uma prestação anual de $\mathrm{R} \$ 3.245 .318,73$.

Tendo em vista o alto valor dos custos financeiros das obras para 30 anos, propõem-se a avaliação custo-benefício para tempos de aplicação menor, sendo aqui adotado o prazo de 5 anos para pagamento. Com isso, o valor dos juros do financiamento, aqui chamados de custo financeiro, resultou em $\mathrm{R} \$ 3.570 .891,00$, com 60 parcelas mensais de $\mathrm{R} \$ 406.824,00$.

Para o cálculo dos juros foi excluído o montante relativo à desapropriação de terrenos, considerando apenas a quantia referente à construção dos reservatórios, totalizando $\mathrm{R} \$$ 21.123.895,00. Da mesma maneira, retirou-se o custo de desapropriação dos terrenos utilizados para os reservatórios de detenção do cálculo de operação e manutenção, uma vez que não se 
enquadram de maneira direta na construção dos reservatórios, que é a base para este cálculo financeiro.

$\mathrm{Na}$ falta de informações mais precisas relativas aos custos supracitados, foi adotado como referência o estudo elaborado por Moura (2004), que verificou que o valor anual destas despesas representa cerca de 3 a 5\% dos gastos com a implantação desses sistemas. Assim, foi adotado um valor anual para manutenção e operação dos 5 reservatórios igual a $R \$ 633.716,87$ (3\% do custo de implantação do sistema). Dessa forma, o custo total de operação e manutenção, para 30 anos, corresponde ao valor de $\mathrm{R} \$ 19.011 .506,02$.

Portanto, a soma do custo total de implantação dos reservatórios, considerando construção ( $\mathrm{R}$ \$ 21.123.895,00), desapropriação ( $\mathrm{R}$ \$ 6.216.560,00) financiamento (R\$ 3.570.891,00) e manutenção ( $\mathrm{R}$ \$ 19.011.506,02) resultaram no valor de $\mathrm{R} \$ 49.922 .163,00$ para os 30 anos de vida útil do sistema. A Tabela 4.2 apresenta um resumo dos custos de implantação, operação e manutenção e os custos financeiros da obra. No Apêndice 1 é apresentado o demonstrativo de cálculo financeiro das obras.

\begin{tabular}{|c|c|c|c|c|c|c|}
\hline \multirow[t]{2}{*}{ Descrição } & \multirow{2}{*}{$\begin{array}{l}\text { Construção } \\
\text { (R\$) }\end{array}$} & \multirow{2}{*}{$\begin{array}{l}\text { Desapropriação } \\
\text { (R\$) }\end{array}$} & \multicolumn{2}{|c|}{ Operação e manutenção } & \multirow{2}{*}{$\begin{array}{c}\text { Custos } \\
\text { financeiros } \\
(\mathbf{R} \$)\end{array}$} & \multirow{2}{*}{$\begin{array}{c}\text { CUSTO } \\
\text { TOTAL } \\
(\mathbf{R} \$)\end{array}$} \\
\hline & & & Anual & 30 anos & & \\
\hline $\begin{array}{l}\text { Barramentos previstos (5) } \\
\text { pelo PMSC (2011) para o } \\
\text { córrego do Gregório }\end{array}$ & 21.123 .895 & 6.216 .560 & 633.716 & 19.011 .506 & 3.570 .891 & 49.922.163 \\
\hline
\end{tabular}

\subsubsection{Análise dos danos (benefícios) causados pela inundação}

Para estimar os prejuízos decorrentes de eventos de inundação, foram utilizadas curvas regionais de danos por profundidade de submersão (DPS) elaboradas por Machado (2005), que equacionam diversas categorias de atividade de estabelecimentos comerciais, relacionando o prejuízo do imóvel por metro quadrado de área com a profundidade de submersão.

Tal relação parte da hipótese de que, em lojas de varejo, a área útil do imóvel é utilizada intensamente para o armazenamento de produtos em estoque. Assim, quanto maior a área, maior o potencial de estoque de produtos e, portanto, maiores serão as perdas decorrentes de eventos de inundação.

As empresas foram divididas de acordo com as atividades comerciais propostas pela autora para aplicar a relação das curvas DPS à área de estudo. Tais curvas foram aplicadas à região de estudo e são apresentados na Figura 4.4; as equações referentes as categorias de estabelecimento comercial são apresentadas na Tabela 4.3. 
Figura 4.4 - Curvas de Danos por Profundidade de Submersão (DPS) por categoria de atividade comercial

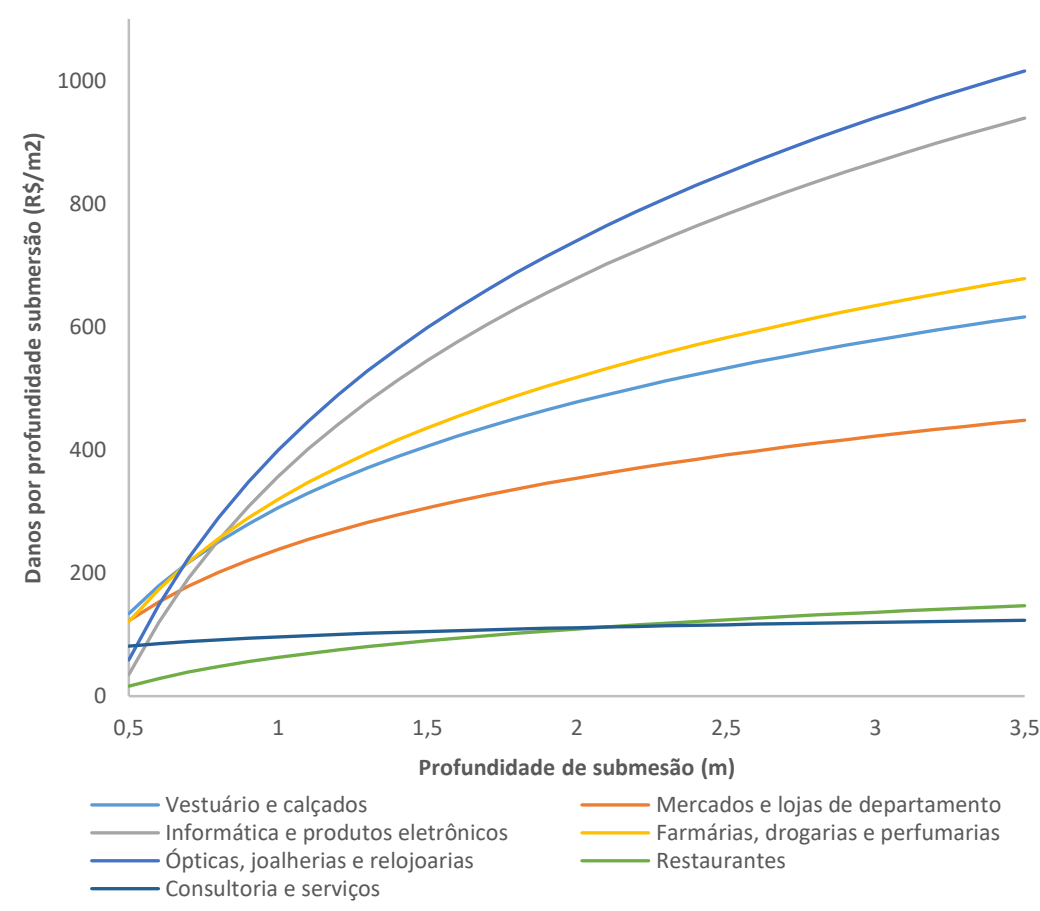

Fonte: Adaptados de Machado (2005)

Tabela 4.3 - Classificação do tipo de atividade e equação utilizada para calcular os danos por profundidade de submersão das empresas contidas na mancha de inundação

\begin{tabular}{ll}
\hline Tipo de atividade & Equação \\
\hline $\begin{array}{l}\text { Lojas de departamento, artigos de armarinho, vestuário e } \\
\text { tecidos, sapatarias e produtos de couro }\end{array}$ & $\mathrm{y}=305,919+247,666 * \ln (\mathrm{x})$ \\
\hline Mercados e lojas de departamento & $\mathrm{y}=238,37+167,267 * \ln (\mathrm{x})$ \\
\hline Móveis, eletrodomésticos, equipamentos de informática & $\mathrm{y}=357,015+464,437 * \ln (\mathrm{x})$ \\
\hline Produtos farmacêuticos, perfumaria e cosméticos & $\mathrm{y}=319,796+286,196 * \ln (\mathrm{x})$ \\
\hline Joalherias, relojoarias e óticas & $\mathrm{y}=399,57+491,238 * \ln (\mathrm{x})$ \\
\hline Restaurantes, lanchonetes, bares e cafés & $\mathrm{y}=62,979+66,847 * \ln (\mathrm{x})$ \\
\hline Escritórios de serviços e consultoria & $\mathrm{y}=96,339+21,628 * \ln (\mathrm{x})$ \\
\hline \multicolumn{2}{c}{ Fonte: Adaptado de Machado $(2005)$}
\end{tabular}

Analisando a Figura 4.4 percebe-se que escritórios e lanchonetes são os tipos de estabelecimento que sofrem um menor prejuízo por metro quadrado de área, da ordem de $\mathrm{R} \$$ $100 / \mathrm{m}^{2}$, enquanto joalherias, lojas de móveis e eletrodomésticos são as que sofrem os maiores danos, com valores que podem ultrapassar $\mathrm{R} \$ 1.000 / \mathrm{m}^{2}$. A categoria de vestuário e produtos farmacêuticos - que engloba predominantemente o número de empresas observadas na região possui curvas que se localizam em posição mediana entre os grupos citados anteriormente, com 
valores de prejuízo de até $\mathrm{R} \$ 600 / \mathrm{m}^{2}$. Essa análise permite verificar a vulnerabilidade a que uma determinada categoria de atividade comercial está exposta.

Dentre as empresas presentes potencialmente atingidas por eventos de inundação, destaca-se a presença de lojas de vestuários (55), seguida das de móveis e eletrodomésticos (22) e, por fim, farmácias e drogarias (13).

\subsubsection{Prejuízo médio anual esperado}

Para elaborar a curva de danos em função da frequência de excedência (curva probabilidade $\mathrm{x}$ dano), o levantamento do montante dos custos econômicos dos prejuízos foi realizado para enchentes de 6 magnitudes sob os dois tipos de distribuição temporal das chuvas propostos nesta pesquisa (capítulo 3). Os valores de frequência de excedência utilizados foram 0,$33 ; 0,1 ; 0,04 ; 0,02 ; 0,0133 ; 0,01$; correspondentes, respectivamente, aos TR de 3, 10, 25, 50, 75 e 100 anos.

De acordo com os valores apurados para o custo total dos danos (correspondente a cada período de retorno), foram estabelecidas as respectivas curvas do valor médio anual dos danos para cada cenário proposto, que corresponde a área abaixo da curva do valor médio anual dos danos (Figura 2.11), por meio da regra do trapézio. Para o cálculo dessa área representativa do gráfico, é calculada a integral determinada entre esses dois pontos, correspondente à probabilidade de recorrência entre 0 e 1.

A equação integral que define a curva a ser obtida é apresentada na equação 4.1.

$$
P_{f, c}=P_{\max (c)} \int_{0}^{1} e^{-r * f}=\frac{P_{\max (c)}}{r} *\left|e^{-r * f}\right|_{0}^{1}
$$

Em que:

$\mathrm{P}$ = prejuízo para um determinado cenário e período de retorno

$\mathrm{f}=$ frequência de excedência

$\mathrm{c}=$ cenário

$\mathrm{P}_{\max }=$ Prejuízo máximo em um determinado cenário para a máxima frequência de excedência simulada (definido nessa pesquisa como $\mathrm{TR}=200$ anos)

$\mathrm{r}=$ fator de ajuste da curva

No cálculo da área sob a curva, o limite superior (1) e inferior (0) foram considerados como:

- Custo mínimo, quando a frequência de excedência se aproximar de 1;

- Custo máximo, quando a frequência de excedência tender a 0.

Os valores obtidos pelo modelo foram ajustados sob a curva da equação $4.1 \mathrm{com}$ otimização do fator de ajuste desta pelo método de Nash e pelo método volumétrico para a variável "r" (Criss; Winston, 2008). Com as curvas ajustadas e os coeficientes definidos, é 
possível calcular o valor anual médio dos danos conforme a frequência de excedência dos eventos.

Este valor é representado pela área do gráfico inerente à curva de danos entre os períodos de recorrência extremos (entre 0 e 1). O cálculo das funções integrais resulta em equações analíticas que representam o valor médio anual dos danos decorrente de inundações.

\subsection{RESULTADOS}

Na presente pesquisa, foi desenvolvido um estudo de caso que contempla a avaliação custo-benefício da implantação de medidas mitigadoras aplicadas às inundações urbanas. Para calcular o valor dos benefícios, foram utilizadas curvas de danos por profundidade de submersão (DPS) sintéticas, tendo como base a pesquisa de Machado (2005). A avaliação do custo-benefício das obras de mitigação de inundações foi realizada calculando-se o valor anual dos benefícios (prejuízos) decorrentes das inundações - para cada cenário e distribuição temporal proposto -, multiplicado pela vida útil dos reservatórios (30 anos). Desta forma, foi possível compará-los com o valor presente de implantação das obras (custo) e verificar a viabilidade do projeto.

\subsubsection{Mapeamento dos valores de altura de inundação}

A profundidade de submersão para cada imóvel foi obtida com uso do software $H E C$ GeoRas (suplemento do ArcGIS) a partir das coordenadas geográficas de cada imóvel. As informações foram exportadas com a ferramenta Spacial Analist, suplemento do ArcGIS, para planilha contendo a identificação do imóvel e a respectiva profundidade de submersão. Assim, foram geradas planilhas para cada evento contendo as informações das empresas junto à sua respectiva profundidade de submersão.

A profundidade de submersão serviu de base para o cálculo dos prejuízos dos imóveis. O mapa com os imóveis cadastrados é apresentado na Figura 4.5. Nesta figura, a mancha de inundação refere-se ao TR de 25 anos no cenário atual, enquanto a borda externa refere-se a área máxima ocupada pela mancha nos cenários simulados, referente ao TR de 100 no cenário futuro. 
Figura 4.5 - Mapa da mancha de inundação com os imóveis cadastrados para o tempo de retorno de 25 anos em um cenário atual e limite da área atingida pela mancha de inundação (cenário futuro com TR 100 anos)

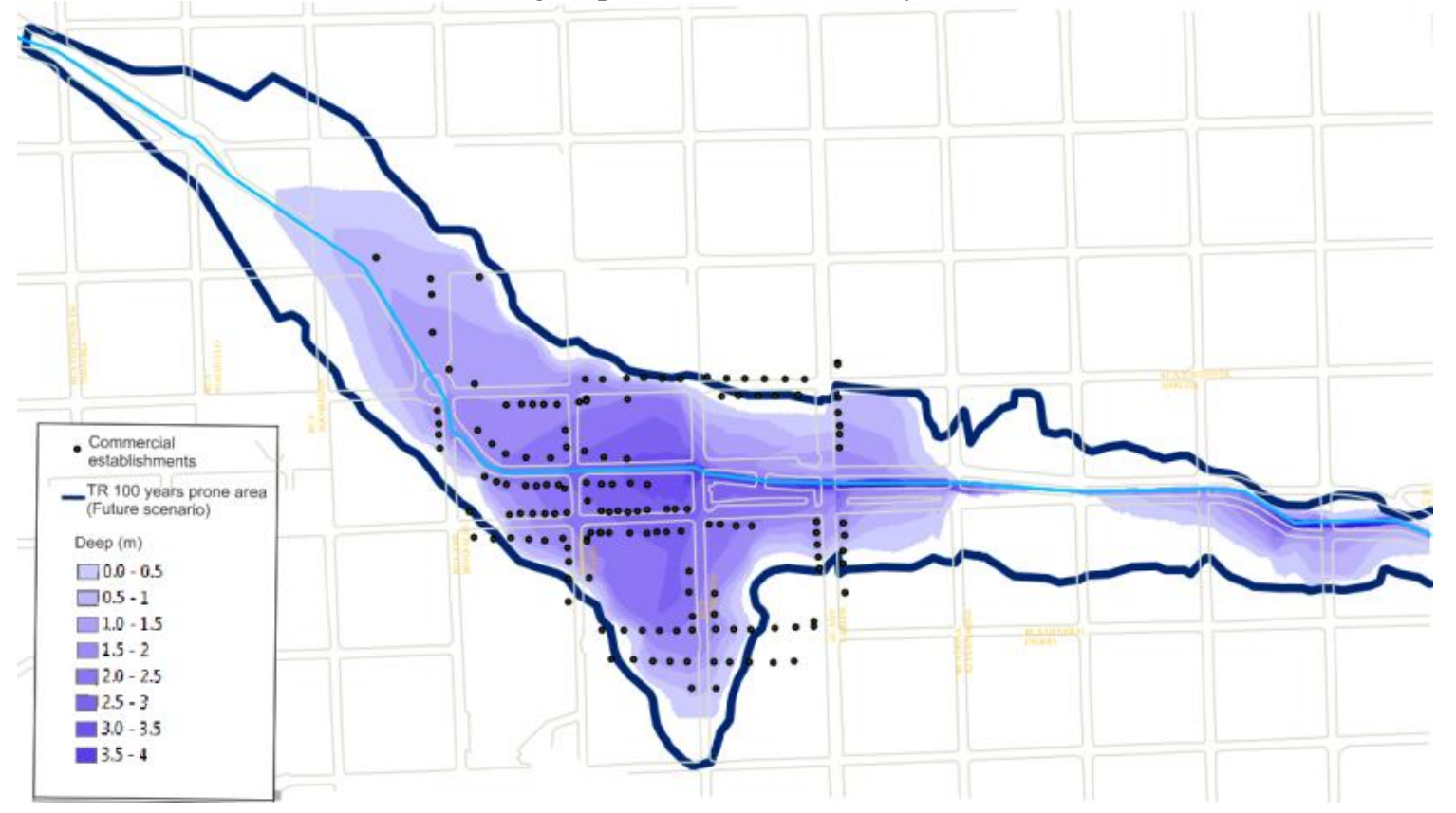

\subsubsection{Análise econômica das medidas mitigadoras}

A fim de comparar a eficácia das medidas propostas pelo plano diretor de São Carlos (PMSC, 2005) e pelo plano de drenagem ambientalmente sustentável do município de São Carlos (PMSC, 2011) quanto à mitigação dos prejuízos econômicos, foram elaboradas simulações econômicas para cada cenário e TR, apresentados nas Figuras 4.6 e 4.7.

As linhas apresentadas nas Figuras 4.8 e 4.9 mostram as variações do potencial de mitigação decorrente da implantação das medidas mitigadoras com relação aos cenários atual e futuro. 
Figura 4.6 - Prejuízo total nos cenários propostos com distribuição Huff $1^{\circ}$ quartil ${ }^{3}$

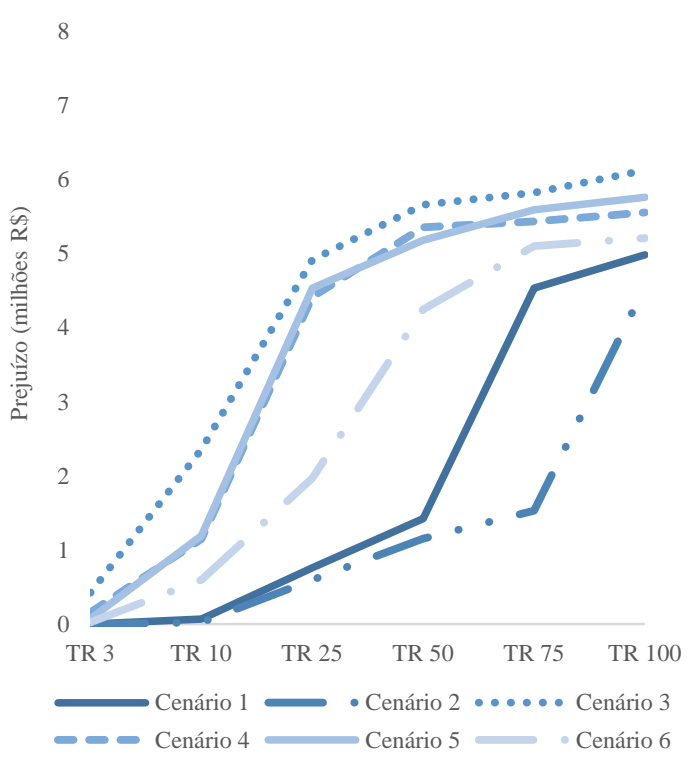

Figura 4.8 - Percentual de redução do prejuízo das medidas mitigadoras com a distribuição Huff $1^{\circ}$ quartil

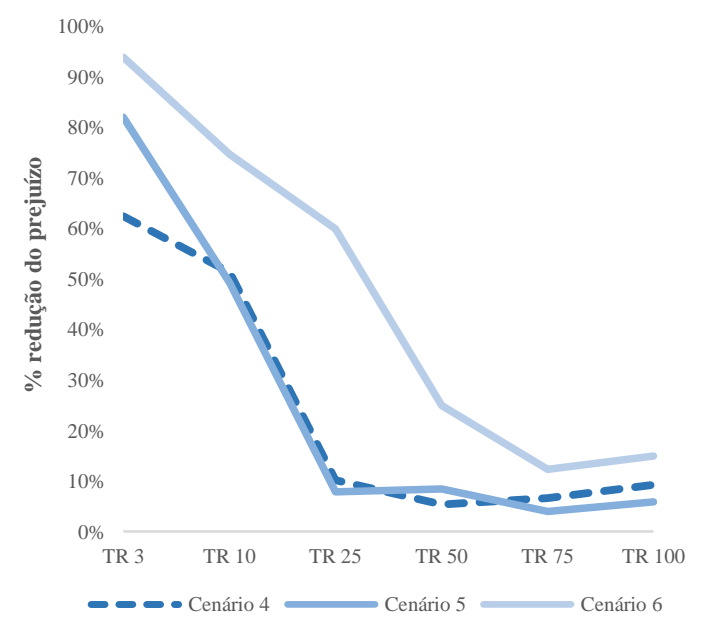

Figura 4.7 - Prejuízo total nos cenários propostos com distribuição blocos alternados

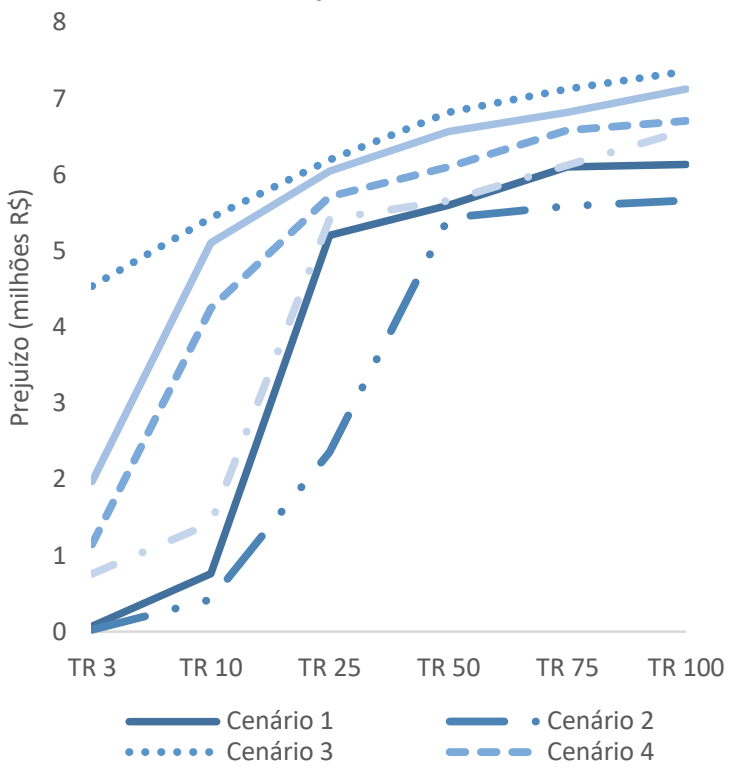

Figura 4.9 - Percentual de redução do prejuízo das medidas mitigadoras com a distribuição temporal blocos alternados

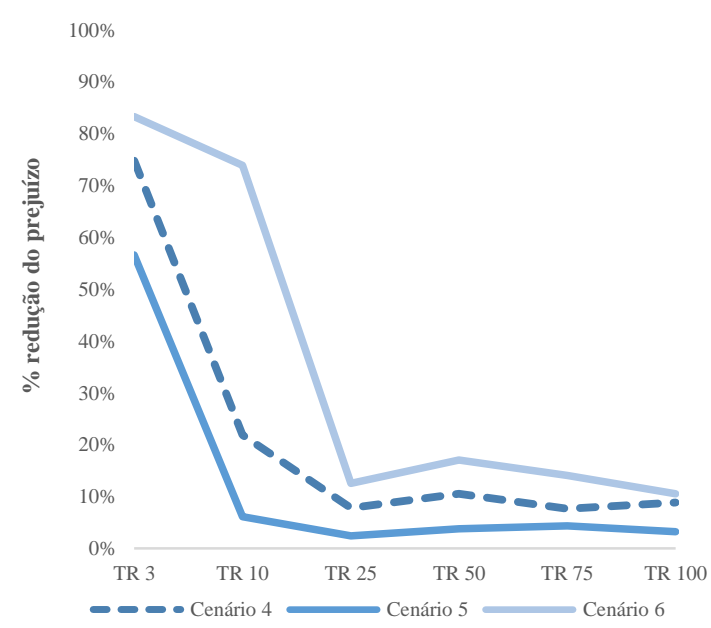

As simulações sugerem que as medidas estruturais propostas pelo plano diretor de drenagem de São Carlos, de forma isolada, não serão suficientes para conter os prejuízos em cenários futuros, principalmente para TR acima de 10 anos na distribuição blocos alternados e TR acima de 25 anos na distribuição Huff $1^{\circ}$ quartil, já que o prejuízo observado no cenário

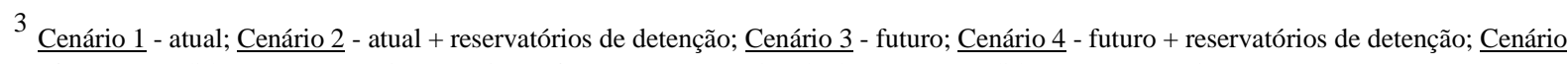
$\underline{5}$ - futuro + medidas não estruturais; Cenário 6 - futuro + reservatórios de detenção e medidas não estruturais. 
modelado com medidas estruturais aproximou-se daquele em que não houve a implementação dessas; porém serão capazes de mitigá-los

Já para o cenário atual, o maior potencial de mitigação foi para o TR de 75 anos distribuição Huff $1^{\circ}$ quartil - e TR 25 anos para a distribuição blocos alternados. Neste cenário, os maiores aumentos ocorrem próximos ao tempo de retorno de 75 anos, com aumento do prejuízo ocorrido no cenário atual entre os TR de 50 e 75 anos da ordem de R \$1,4 milhão para R \$ 4,5 milhões. Aumentos do valor de prejuízos semelhantes são observados no cenário atual com medidas estruturais; porém, essa situação é observada entre os TR de 75 a 100 anos, demonstrando assim o efeito do amortecimento da vazão com relação ao prejuízo.

Para o cenário futuro (3), cenário futuro com medidas estruturais (4) e cenário futuro com medidas não estruturais (5), esse efeito é observado entre os TR de 10 a 25 anos e verificase o dobro do valor do prejuízo no TR de 10 anos - quando não são implementadas as medidas mitigadoras.

Além disso, percebe-se que nesses cenários, a eficácia das medidas compensatórias tem efeito desprezível a partir do TR de 25 anos. Para o cenário futuro com medidas estruturais e não estruturais, verifica-se que o aumento mais substancial ocorre entre os TR 25 a 50 anos, demonstrando assim a eficácia da implementação conjunta das medidas na mitigação dos prejuízos.

Para os blocos alternados, observa-se uma linearidade dos prejuízos acumulados ocorridos nos cenários 1 (atual) a 3 (futuro) para eventos com TR acima de 25 anos, com uma variação de 26,2\% entre os prejuízos do cenário 2 para TR de 25 anos e cenário 3 com TR de 100 anos.

Observa-se a grande influência que as medidas estruturais exercem no TR 25 anos, já que os danos verificados com as medidas mitigadoras neste cenário representaram $54 \%$ do prejuízo sem as medidas, com uma redução de vazão de apenas $16 \mathrm{~m}^{3} / \mathrm{s}$ entre os métodos. Porém, conforme apresentado na Figura 3.28, a região próxima da vazão de $80 \mathrm{~m}^{3} / \mathrm{s}$ é um divisor quantitativo da profundidade de submersão e da área da mancha de inundação, o que provoca tamanho impacto em relação a mitigação do prejuízo.

Para os cenários futuros, percebe-se que as medidas mitigadoras de forma isolada (cenário 4) apresentam maior eficácia entre os menores tempos de retorno (entre 3 e 10 anos). Porém, quando implantadas em conjunto com as medidas não estruturais, sua eficácia é estendida para até 25 anos, sendo que a partir desta frequência, os prejuízos entre este cenário e o atual ficam equiparados nos TR subsequentes. 
O custo máximo adotado para os cenários pesquisados com TR de 100 anos (probabilidade de 0,01) possuem valores muito próximos de prejuízo. A proximidade dos valores sugere que a sensibilidade do modelo econômico é baixa para altos TR, tendo em vista a alta profundidade de submersão a que os imóveis estão submetidos nessa situação.

Para analisar o conjunto das variáveis aplicadas a análise econômica dos prejuízos, são apresentados um conjunto de gráficos que inter-relacionam a frequência de excedência, vazão, profundidade e prejuízo. Nas Figuras 4.10 a 4.15 são relações tais valores para a distribuição temporal Huff $1^{\circ}$ quartil (curva azul) e blocos alternados (curva vermelha) nos respectivos cenários analisados, sendo que as linhas pontilhadas entre os gráficos representam a análise de dados para o TR 25 anos.

Figura 4.10 - Método da curva nível-prejuízo para estimativa dos prejuízos por inundação aplicado a região de estudo para o cenário 1 (atual)

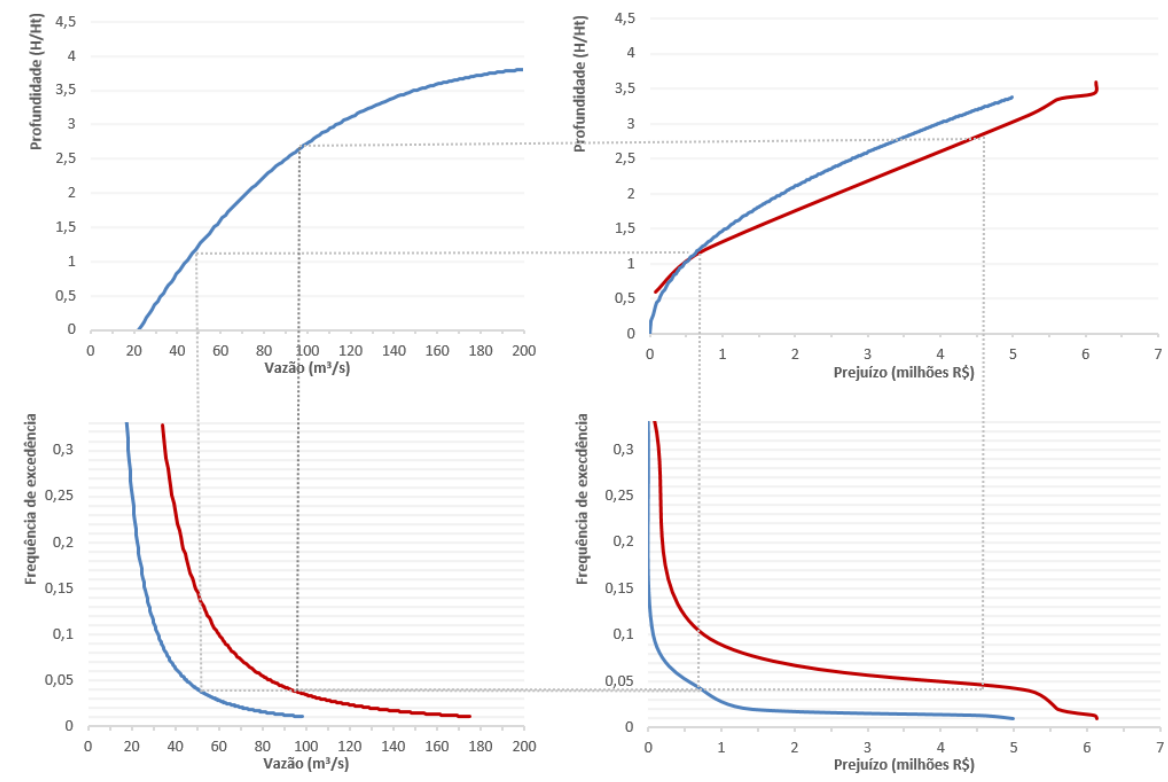


Figura 4.11 - Método da curva nível-prejuízo para estimativa dos prejuízos por inundação aplicado a região de estudo para o cenário 2 (atual com medidas mitigadoras)

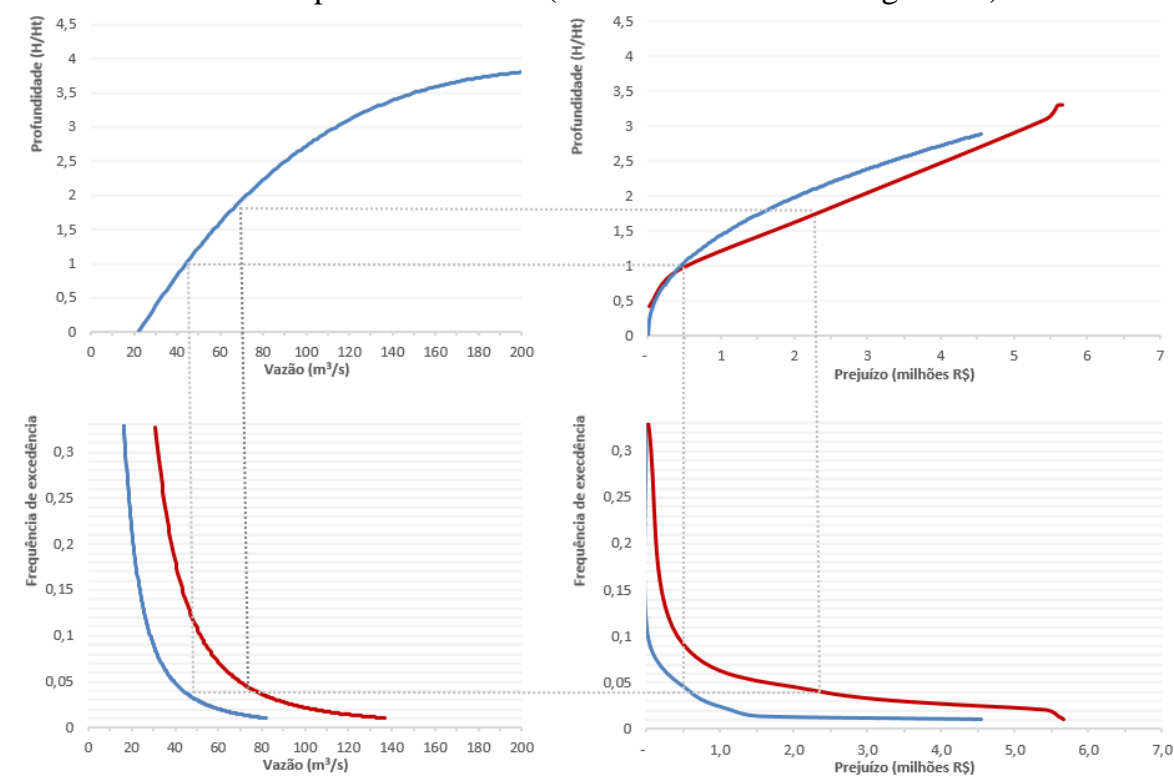

Figura 4.12 - Método da curva nível-prejuízo para estimativa dos prejuízos por inundação aplicado a região de estudo para o cenário 3 (Futuro)

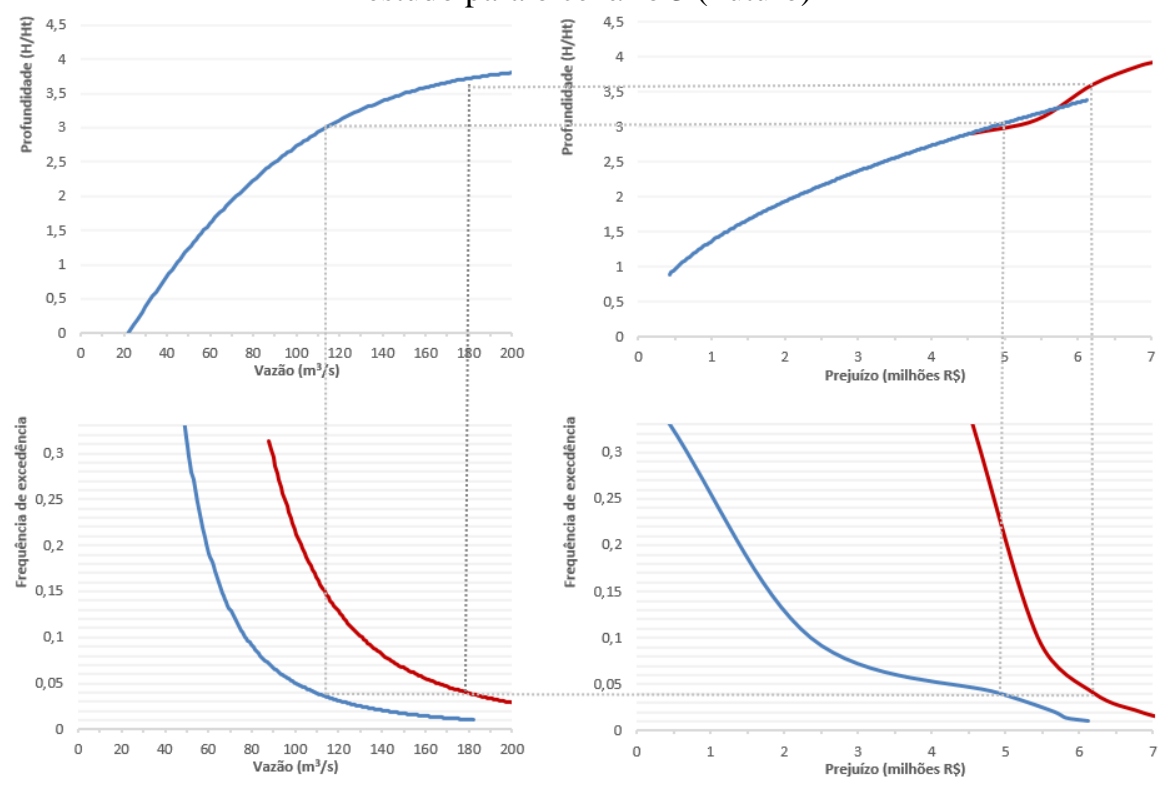


Figura 4.13 - Método da curva nível-prejuízo para estimativa dos prejuízos por inundação aplicado a região de estudo para o cenário 4 (Futuro com medidas estruturais)

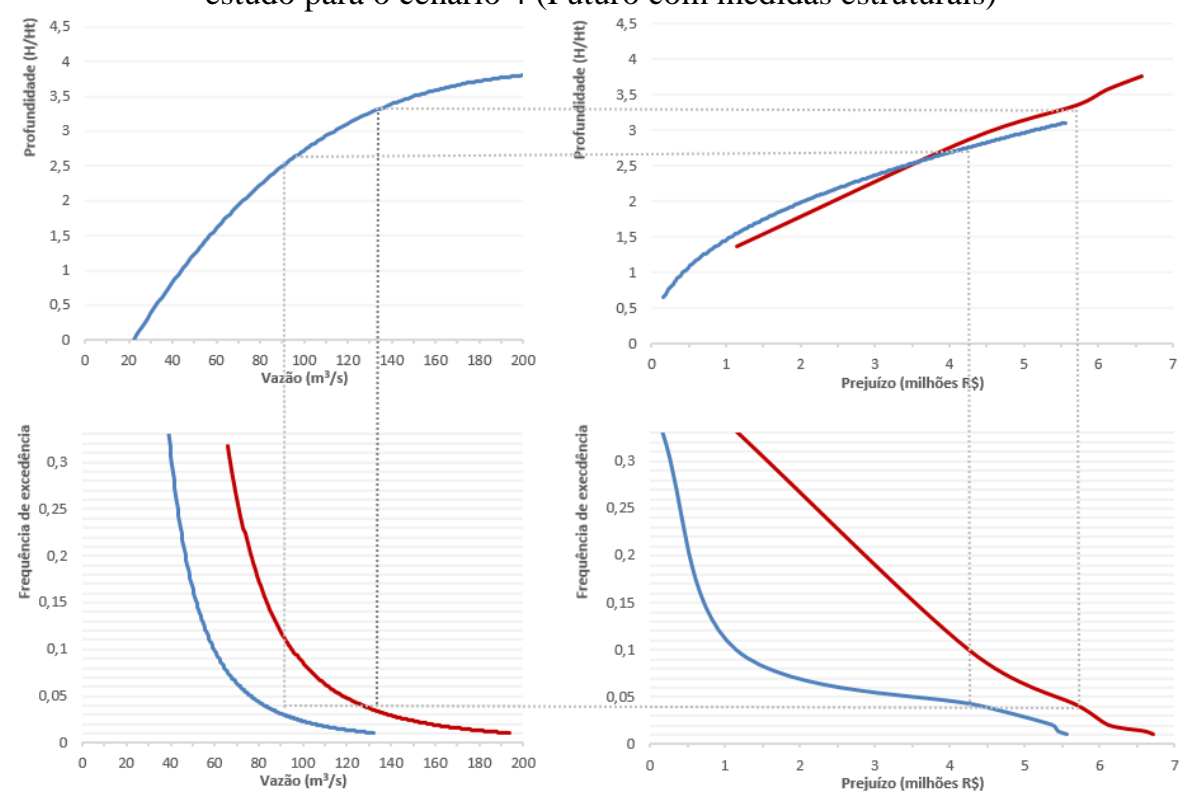

Figura 4.14 - Método da curva nível-prejuízo para estimativa dos prejuízos por inundação aplicado a região de estudo para o cenário 5 (Futuro com medidas não estruturais)
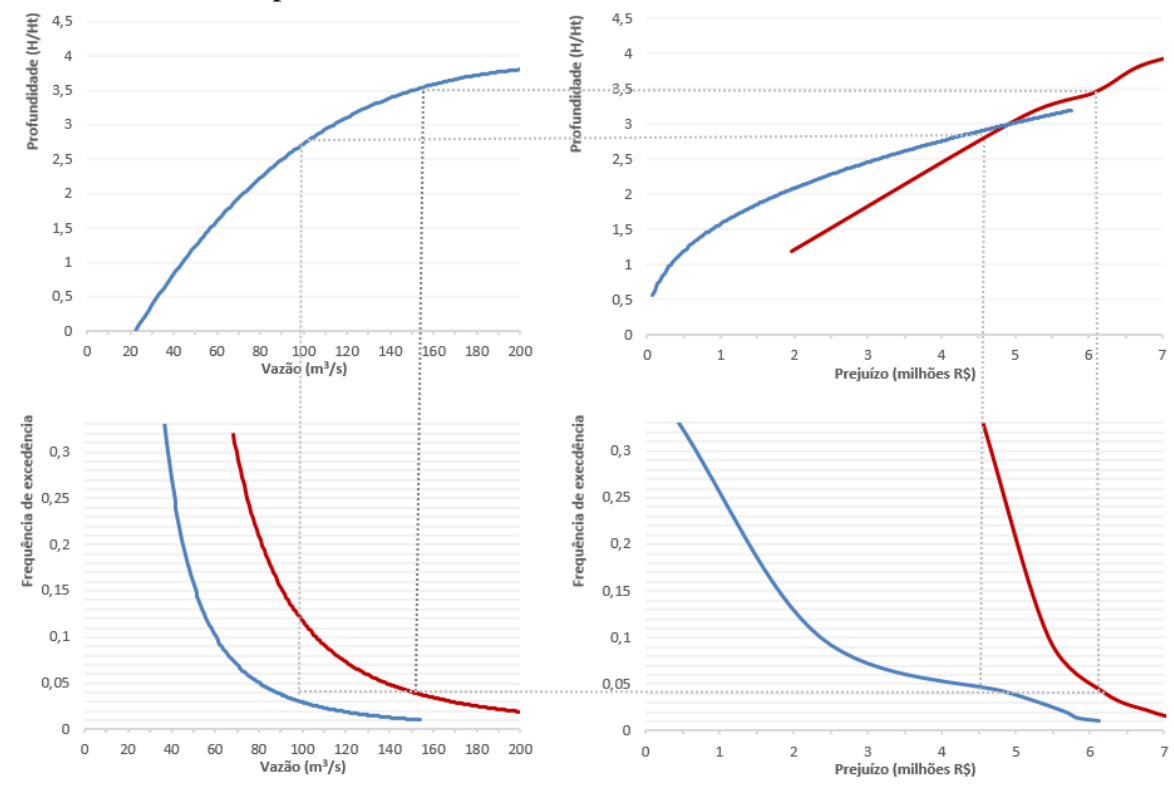
Figura 4.15 - Método da curva nível-prejuízo para estimativa dos prejuízos por inundação aplicado a região de estudo para o cenário 6 (Futuro com medidas estruturais e não estruturais)

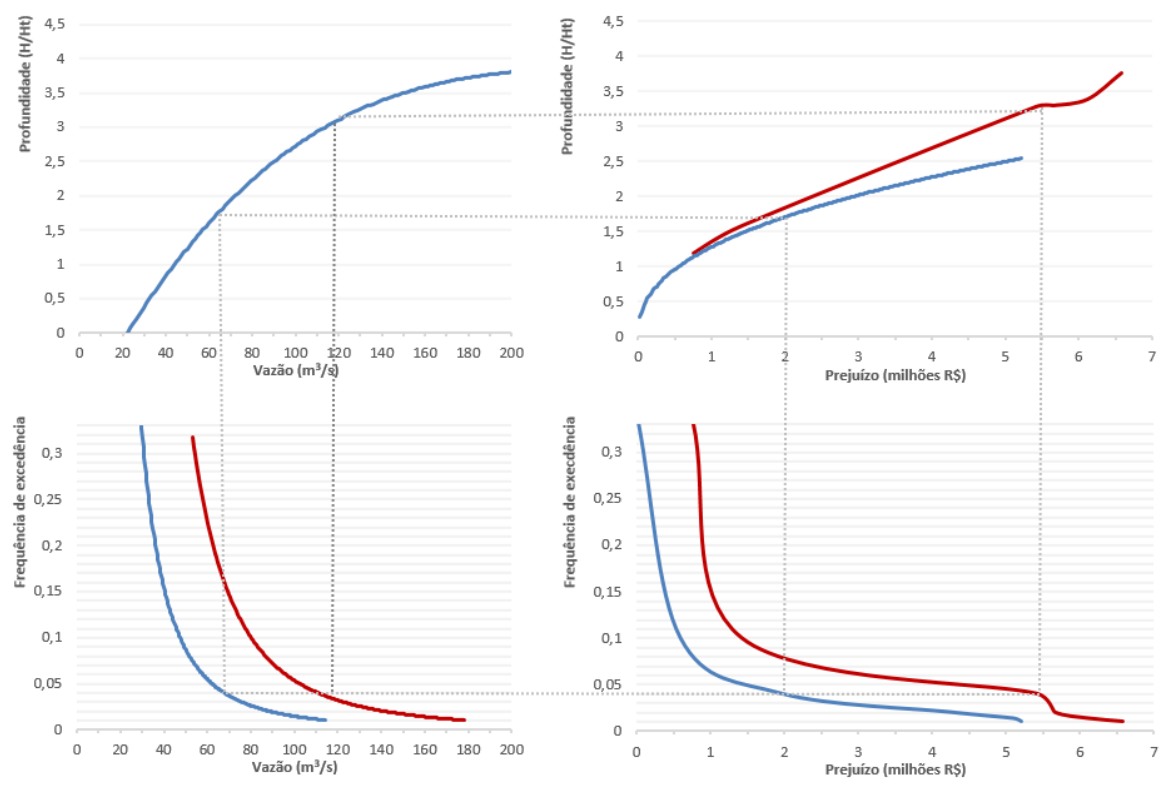

As diferenças obtidas entre as curvas podem ser consideradas como incertezas referentes quanto ao método de distribuição temporal de chuvas adotado, demonstrando que a utilização da frequência de excedência como única forma de análise pode trazer incertezas consideráveis na análise econômica dos prejuízos.

\subsubsection{Valor do prejuízo médio anual esperado}

Os valores de prejuízo totais nos cenários e respectivos TR são apresentados num gráfico que relaciona a frequência de excedência e o prejuízo simulado. Os valores obtidos pelo modelo foram ajustados sob a curva exponencial com melhor ajuste dos dados.

Os gráficos com as curvas obtidas pelos modelos e as curvas de ajuste exponencial são apresentadas nas Figuras 4.16 a 4.21 para a distribuição temporal Huff $1^{\circ}$ quartil e as Figuras 4.22 a 4.27 para a distribuição blocos alternados. Para realizar o alinhamento das equações, foi feita a otimização com o suplemento "Solver" do Excel por dois métodos: Nash e volumétrico (Criss; Winston, 2008), de forma a maximizar a soma de seus resultados. Os resultados obtidos pela otimização são apresentados na Tabela 4.4. 
Figura 4.16 - Curva prejuízo por probabilidade de excedência para o cenário atual sob distribuição

Huff $1^{\circ}$ quartil

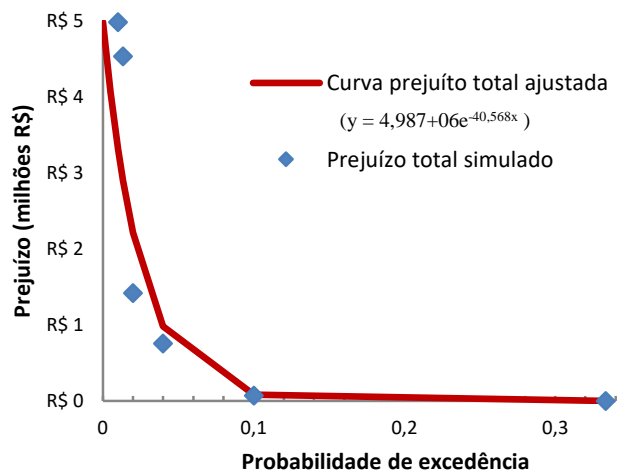

Figura 4.18 - Curva prejuízo por probabilidade de excedência para o cenário futuro sob distribuição Huff $1^{\circ}$ quartil

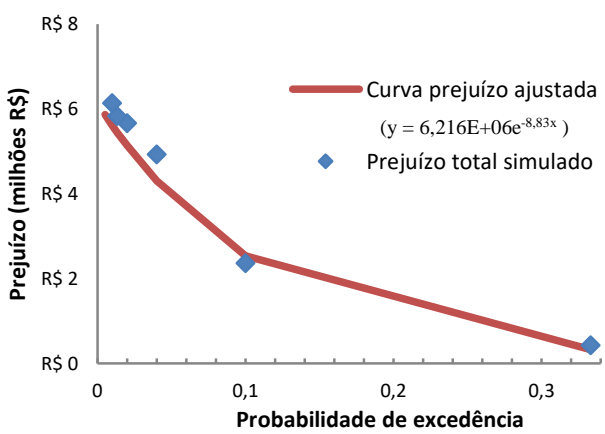

Figura 4.20 - Curva prejuízo por probabilidade de excedência para o cenário futuro com medidas não estruturais sob distribuição Huff $1^{\circ}$ quartil

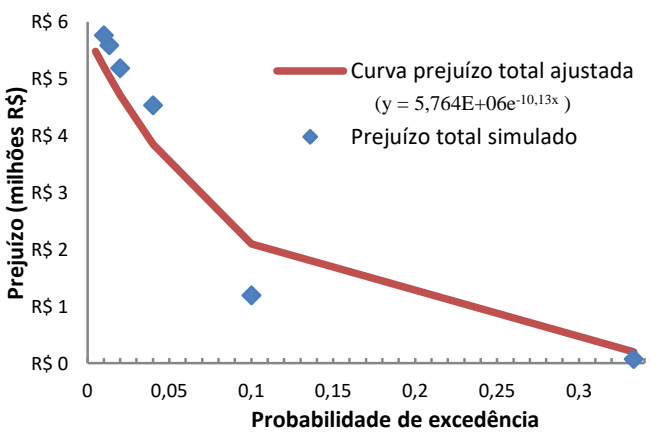

Figura 4.17 - Curva prejuízo por probabilidade de excedência para o cenário atual com medidas estruturais sob distribuição Huff $1^{\circ}$ quartil

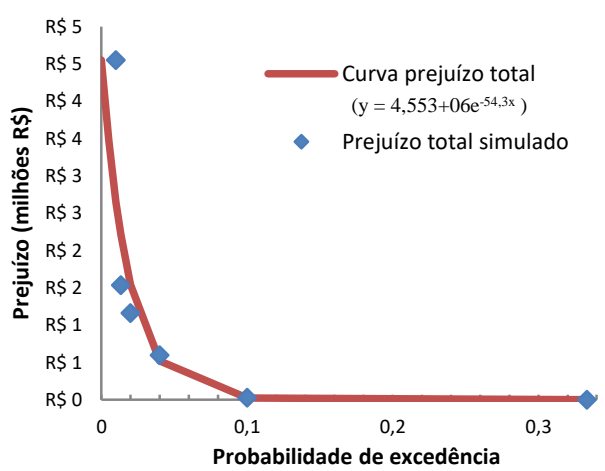

Figura 4.19 - Curva prejuízo por probabilidade de excedência para o cenário futuro com medidas estruturais sob distribuição Huff $1^{\circ}$ quartil

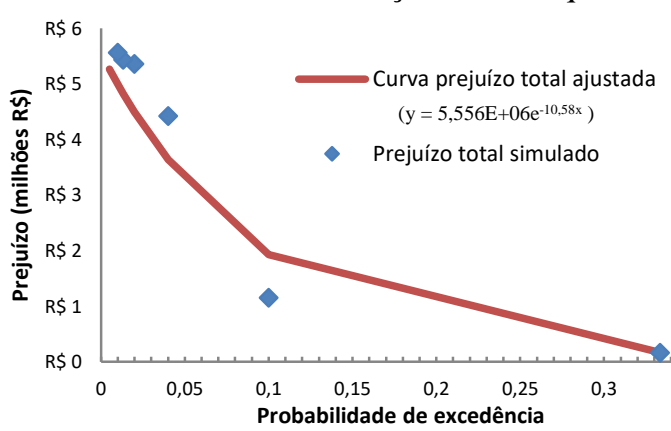

Figura 4.21 - Curva prejuízo por probabilidade de excedência para o cenário futuro com medidas estruturais e não estruturais sob distribuição Huff $1^{\circ}$ quartil

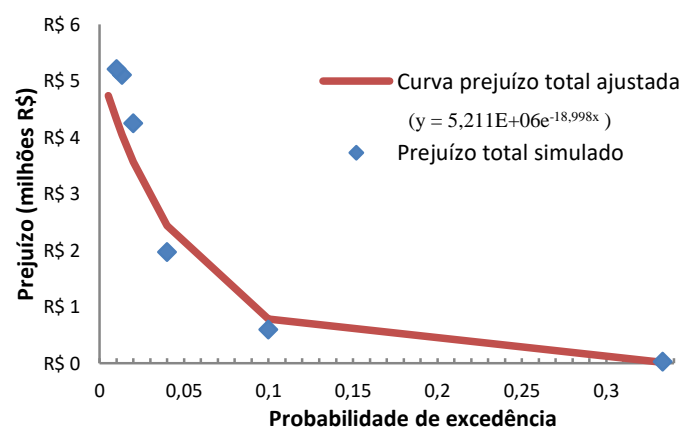


Figura 4.22 - Curva prejuízo por probabilidade de excedência para o cenário atual sob distribuição blocos alternados

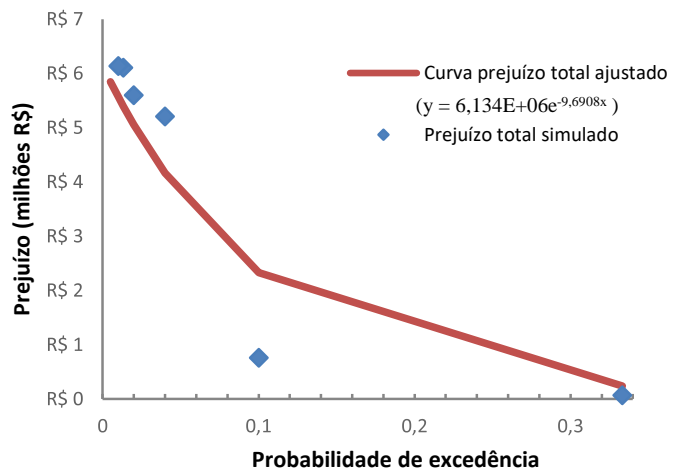

Figura 4.24 - Curva prejuízo por probabilidade de excedência para o cenário futuro sob distribuição blocos alternados

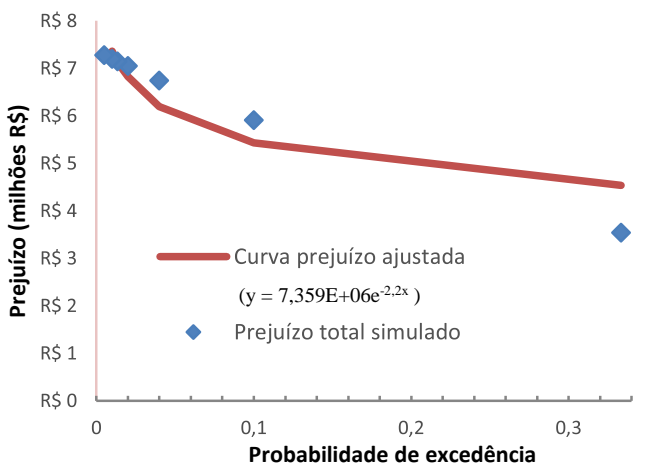

Figura 4.26 - Curva prejuízo por probabilidade de excedência para o cenário futuro com medidas não estruturais sob distribuição blocos alternados

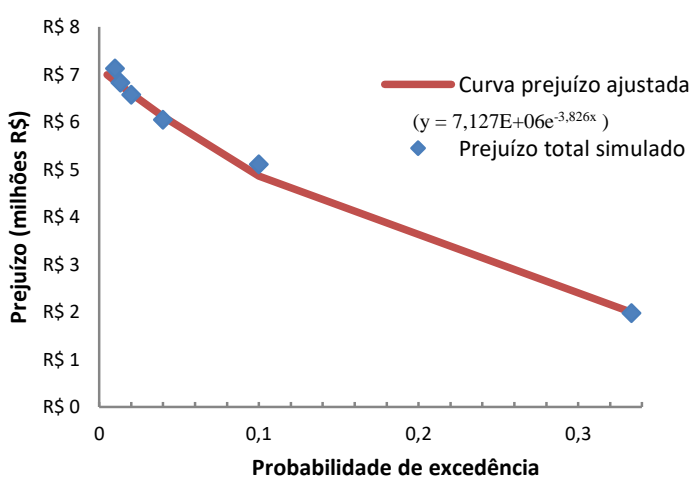

Figura 4.23 - Curva prejuízo por probabilidade de excedência para o cenário atual com medidas estruturais sob distribuição blocos alternados

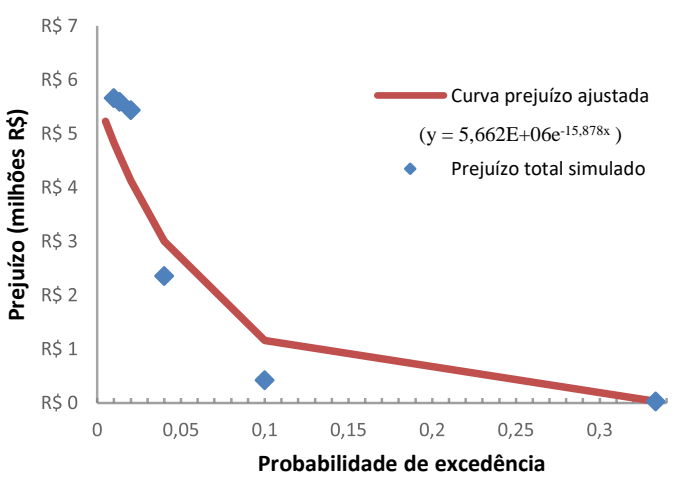

Figura 4.25 - Curva prejuízo por probabilidade de excedência para o cenário futuro com medidas estruturais sob distribuição blocos alternados

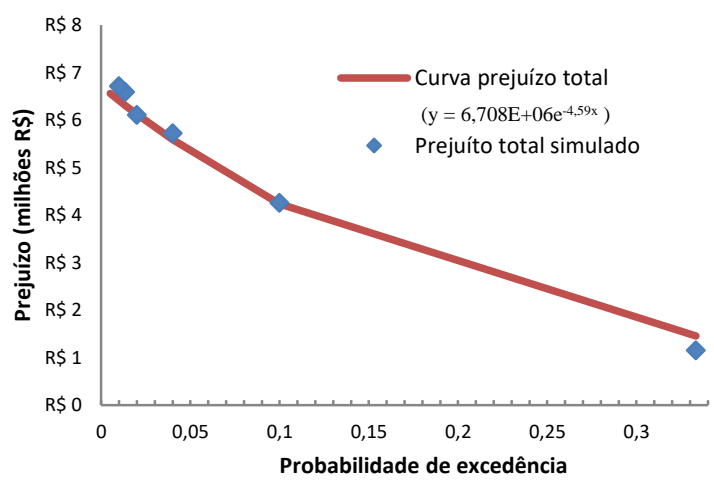

Figura 4.27 - Curva prejuízo por probabilidade de excedência para o cenário futuro com medidas estruturais e não estruturais sob distribuição blocos alternados

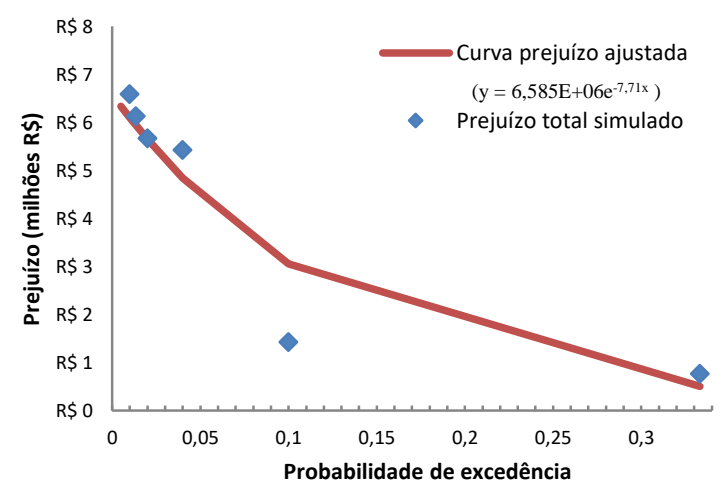

Tabela 4.4 - Coeficientes obtidos com a otimização pelos métodos de Nash e volumétrico

\begin{tabular}{lcccccc}
\hline & \multicolumn{3}{c}{ Huff 1 $^{\mathbf{0}}$ quartil } & \multicolumn{3}{c}{ Blocos alternados } \\
\hline \multirow{2}{*}{ Cenário } & Otimizador & & & Otimizador & \\
\cline { 2 - 7 } & Nash & Volumétrico & Soma & Nash & Volumétrico & Soma \\
\hline Cenário 1 & 0,75 & 0,63 & 1,39 & 0,88 & 0,81 & 1,69 \\
\hline Cenário 2 & 0,71 & 0,61 & 1,32 & 0,88 & 0,77 & 1,64 \\
\hline Cenário 3 & 0,96 & 0,91 & 1,87 & $-0,84$ & 0,94 & 0,09 \\
\hline Cenário 4 & 0,91 & 0,84 & 1,75 & 0,99 & 0,97 & 1,95 \\
\hline Cenário 5 & 0,93 & 0,85 & 1,78 & 0,99 & 0,98 & 1,97 \\
\hline
\end{tabular}




\begin{tabular}{lllllll}
\hline Cenário 6 & 0,90 & 0,81 & 1,71 & 0,90 & 0,82 & 1,71 \\
\hline
\end{tabular}

O valor anual dos danos é representado pela área do gráfico inferior à curva de danos e representa a quantia do prejuízo médio anual esperado entre as frequências de excedência extremas (entre 0 e 1). Para o cálculo dessa área representativa do gráfico, foi utilizada a regra do trapézio, efetuando o cálculo da integral determinada entre esses dois pontos (com frequência de excedência entre 0 e 1 ).

A integral que representa esse cálculo para os cenários simulados sob a distribuição Huff $1^{\circ}$ quartil é apresentada na Tabela 4.5 pelas Equações 4.2 a 4.7, que representam o valor médio anual dos danos decorrente de inundações para, respectivamente: i) cenário atual (Equação 4.2); ii) cenário atual com reservatórios de detenção (Equação 4.3); iii) cenário futuro (Equação 4.4); iv) cenário futuro com reservatórios de detenção (Equação 4.5); v) cenário futuro com medidas não estruturais (Equação 4.6); vi) cenário futuro com medidas estruturais e não estruturais (Equação 4.7). Já na Tabela 4.6 são apresentadas tais equações sob a distribuição temporal blocos alternados pelas Equações 4.8 a 4.13, seguindo a mesma sequência de cenários anterior.

Tabela 4.5 - Valor médio anual dos danos para a distribuição temporal Huff $1^{\circ}$ quartil

\begin{tabular}{|c|c|c|c|}
\hline$y=5566671 \int_{0}^{1} e^{-40,568 * x}$ & $=\frac{5566671}{40,568}\left|e^{-40,568 * x}\right|_{0}^{1}$ & $=137.217$ & $(4.2)$ \\
\hline$y=5235682 \int_{0}^{1} e^{-54,304 * x}$ & $=\frac{5235682}{54,304}\left|e^{-54,3045 * x}\right|_{0}^{1}$ & $=96.414$ & $(4.3)$ \\
\hline$y=6757150 \int_{0}^{1} e^{-8,833 * x}$ & $=\frac{6757150}{8,83}\left|e^{-8,83 * x}\right|_{0}^{1}$ & $=764.959$ & $(4.4)$ \\
\hline$y=5897751 \int_{0}^{1} e^{-10.583 * x}$ & $=\frac{5897751}{10.583}\left|e^{-10.583 * x}\right|_{0}^{1}$ & $=557.286$ & $(4.5)$ \\
\hline$y=6350484 \int_{0}^{1} e^{-10.135 * x}$ & $=\frac{6350484}{10.135}\left|e^{-10.135 * x}\right|_{0}^{1}$ & $=595.623$ & $(4.6)$ \\
\hline$y=5743034 \int_{0}^{1} e^{-18.998 x}$ & $=\frac{5743034}{18.998}\left|e^{-18.998 * x}\right|_{0}^{1}$ & $=274.903$ & (4.7) \\
\hline
\end{tabular}

Tabela 4.6 - Valor médio anual dos danos para a distribuição temporal blocos alternados

\begin{tabular}{|c|c|c|c|}
\hline$y=6134598 \int_{0}^{1} e^{-9,691 * x}$ & $=\frac{6134598}{9,691}\left|e^{-9,691 * x}\right|_{0}^{1}$ & $=632.992$ & (4.8) \\
\hline$y=5662889 \int_{0}^{1} e^{-15,878 * x}$ & $=\frac{5662889}{15,878}\left|e^{-15,878 * x}\right|_{0}^{1}$ & $=356.694$ & (4.9) \\
\hline$y=7359338 \int_{0}^{1} e^{-2,2 * x}$ & $=\frac{7359338}{40,568}\left|e^{-2,2 * x}\right|_{0}^{1}$ & $=2.974 .500$ & (4.10) \\
\hline$y=6708223 \int_{0}^{1} e^{-4,595 * x}$ & $=\frac{6708223}{4,595}\left|e^{-4,595 * x}\right|_{0}^{1}$ & $=1.445 .868$ & (4.11) \\
\hline$y=7127393 \int_{0}^{1} e^{-3,826 * x}$ & $=\frac{7127393}{3,826}\left|e^{-3,826 * x}\right|_{0}^{1}$ & $=1.822 .074$ & (4.12) \\
\hline$y=6585279 \int_{0}^{1} e^{-7,7007 * x}$ & $=\frac{6585279}{7,7007}\left|e^{-7,7007 * x}\right|_{0}^{1}$ & $=791.414$ & (4.13) \\
\hline
\end{tabular}

Em que:

y é o prejuízo anual médio decorrente de inundações entre probabilidade de excedência de 0 a 1; $\mathrm{x}$ é a frequência de excedência 
Ressalta-se também que as medidas estruturais e as medidas não estruturais obtiveram praticamente a mesma eficácia na mitigação das consequências das inundações, que mostram que obras hidráulicas e medidas de controle de uso e ocupação do solo podem ter o mesmo efeito quanto à contenção de enchentes.

A análise dos benefícios anuais das obras para cenários atuais apresentou valor anual de $\mathrm{R} \$$ 137.217. O valor com presença de medidas mitigadoras foi de $\mathrm{R} \$ 96.414$, representado benefícios anuais da ordem de 35 mil reais, em relação apenas aos prejuízos dos imóveis comerciais presentes na mancha de inundação, que estão localizados no entorno do mercado municipal.

A análise dos benefícios anuais das obras para cenários futuros demonstrou que os reservatórios de detenção terão influência significativa na redução dos danos em cenários futuros.

Porém, considerando apenas essa variável, - tendo em vista que o valor anual dos prejuízos para cenários futuros foi de $\mathrm{R} \$ 764.959,00$ - esse valor com presença de medidas mitigadoras cai para $\mathrm{R} \$ 557.286,00$.

A análise dos resultados das obras estruturais, propostas no PMSC (2011), apresentam benefícios anuais da ordem de $\mathrm{R} \$ 207.579,00$. Assim, para os 30 anos de implantação da obra, o benefício no cenário atual seria de 1 milhão de reais, com sua realização, enquanto em cenários futuros atingiria $\mathrm{R} \$ 5$ milhões. Apesar da diminuição dos efeitos, o custo das obras estruturais ainda seria muito menor do que o custo de implantação do reservatório, com valor presente da ordem de $\mathrm{R} \$ 49$ milhões.

\subsubsection{Avaliação dos benefícios das medidas mitigadoras propostas}

O Valor Médio Anual dos Benefícios é determinado como a diferença entre o Valor Médio Anual dos danos evitados (considerando que um dado sistema de proteção foi implantado) e o Valor Médio Anual dos danos residuais, que persistem mesmo após a implantação do sistema. Em cada caso, o Valor Médio Anual dos danos corresponde à área abaixo da curva custo dos danos x probabilidade de excedência.

Os valores dos benefícios foram calculados de acordo com a vida útil provável das obras (30 anos), para o cenário atual e futuro, nas duas distribuições temporais de chuvas propostas. Para o cenário atual, foi avaliado o benefício da implantação das medidas mitigadoras (cenário 2) sob o uso e ocupação atual (cenário 1). Já para o cenário futuro, foram consideradas três análises, todas tendo como valor base de prejuízo o cenário futuro sem a implantação de 
medidas mitigadoras (cenário 3): o benefício da implantação das medidas mitigadoras estruturais (cenário 4); o benefício da implantação das medidas mitigadoras não estruturais (cenário 5) e o benefício da implantação das medidas mitigadoras estruturais e não estruturais (cenário 6).

\section{4..3.1.1. Huff $1^{\circ}$ quartil}

Para a distribuição Huff $1^{\circ}$ quartil, são apresentadas na Figura 4.28 as curvas do valor médio anual do prejuízo nos respectivos cenários. A análise da Figura 4.28 permite traçar um comparativo visual do valor anual dos prejuízos para as respectivas probabilidades de excedência.

Figura 4.28 - Curva prejuízo por probabilidade de excedência para os cenários propostos sob a distribuição Huff $1^{\circ}$ quartil $4^{4}$

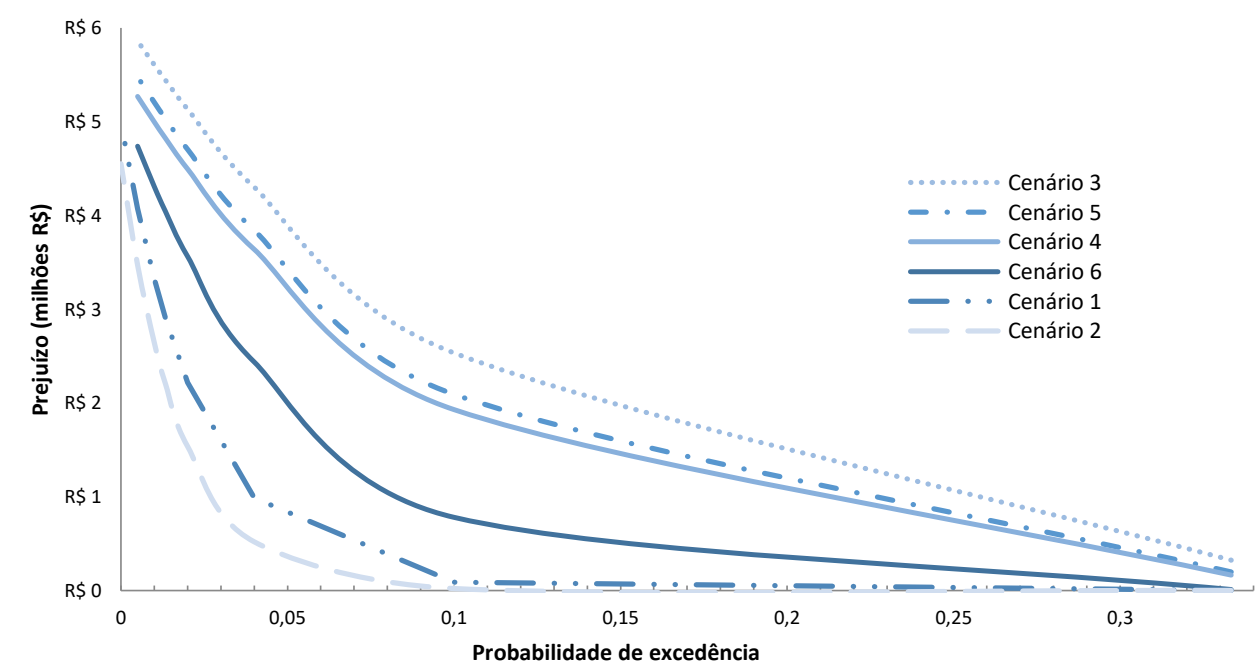

O valor total do custo-benefício das medidas mitigadoras adotadas para o período de implantação das obras (30 anos) e o valor anual deste para o mesmo período nos cenários propostos são apresentados na Tabela 4.7. Os dados são comparativos em relação ao cenário atual e ao cenário futuro com as respectivas medidas mitigadoras.

\footnotetext{
${ }^{4}$ Cenário 1 - atual; Cenário 2 - atual + reservatórios de detenção; Cenário 3 - futuro; Cenário 4 - futuro + reservatórios de detenção; Cenário $\underline{5}$ - futuro + medidas não estruturais; Cenário 6 - futuro + reservatórios de detenção e medidas não estruturais.
} 
Tabela 4.7 - Benefício das medidas mitigadoras para a distribuição Huff $1^{\circ}$ quartil

\begin{tabular}{lrrr}
\hline Cenário & $\begin{array}{r}\text { Prejuízo } \\
(\mathbf{3 0} \text { anos })\end{array}$ & $\begin{array}{r}\text { Benefício } \\
(\mathbf{3 0} \text { anos) }\end{array}$ & $\begin{array}{r}\text { Benefício } \\
\text { (anual) }\end{array}$ \\
\hline Atual (1) & 3.688 .076 & - & - \\
\hline $\begin{array}{l}\text { Atual com medidas } \\
\text { Estruturais (2) }\end{array}$ & 2.515 .765 & 1.172 .310 & 39.077 \\
\hline Futuro (3) & 19.766 .292 & - & - \\
\hline $\begin{array}{l}\text { Futuro com medidas } \\
\text { Estruturais (4) }\end{array}$ & 15.756 .600 & 4.009 .691 & 133.656 \\
\hline $\begin{array}{l}\text { Futuro com medidas } \\
\text { não estruturais (5) }\end{array}$ & 16.448 .045 & 3.318 .246 & 110.068 \\
\hline $\begin{array}{l}\text { Futuro com medidas } \\
\text { estruturais e não estruturais (6) }\end{array}$ & 8.230 .051 & 11.536 .240 & 384.541 \\
\hline
\end{tabular}

Na Tabela 4.7 é possível observar que os efeitos das medidas mitigadoras no cenário atual são bastante irrisórios, com benefícios da ordem de 1 milhão de reais no decorrer do período analisado. Porém, caso se concretize o uso e ocupação do solo proposto no plano diretor de São Carlos (PMSC, 2005), os prejuízos na região objeto desta pesquisa serão de 5 a 6 vezes maiores, sendo que apenas com a implantação conjunta de medidas mitigadoras estruturais e não estruturais propostas no plano de drenagem de São Carlos (PMSC, 2011) é que haverá efeito considerável de mitigação dos danos. Mesmo assim, os prejuízos ainda serão consideráveis: duas vezes maior que os prejuízos observados em um cenário atual.

\subsubsection{Blocos alternados}

Para a distribuição blocos alternados, são apresentadas na Figura 4.29 as curvas do valor médio anual do prejuízo nos respectivos cenários. A análise da Figura 4.29 permite traçar um comparativo visual do valor anual dos prejuízos para as respectivas probabilidades de excedência. 
Figura 4.29 - Curva prejuízo por probabilidade de excedência para os cenários propostos sob a distribuição blocos alternados

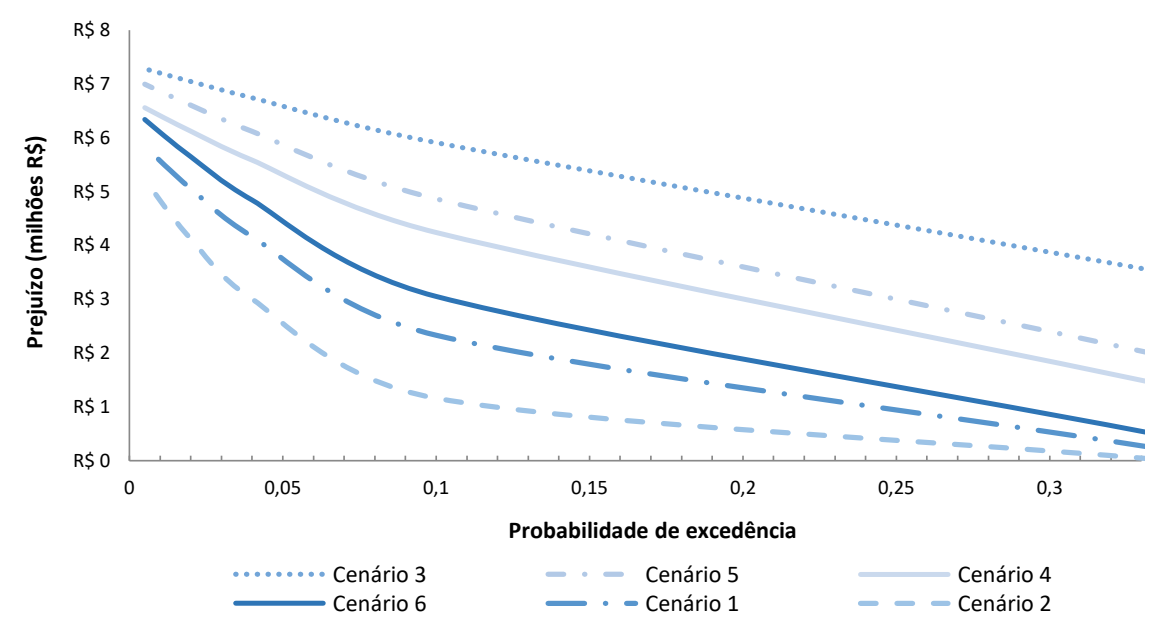

O valor total do custo-benefício das medidas mitigadoras adotadas para o período de implantação das obras (30 anos) e o valor anual deste para o mesmo período nos cenários propostos são apresentados na Tabela 4.8. Os dados são comparados em relação ao cenário atual e ao cenário futuro com as respectivas medidas mitigadoras.

Tabela 4.8 - Benefício das medidas mitigadoras para a distribuição blocos alternados

\begin{tabular}{lrrr}
\hline Cenário & $\begin{array}{r}\text { Prejuízo } \\
(\mathbf{3 0} \text { anos) }\end{array}$ & $\begin{array}{r}\text { Benefício } \\
(\mathbf{3 0} \text { anos) }\end{array}$ & $\begin{array}{r}\text { Benefício } \\
\text { (anual) }\end{array}$ \\
\hline Atual (1) & 18.989 .770 & - & - \\
\hline $\begin{array}{l}\text { Atual com medidas } \\
\text { Estruturais (2) }\end{array}$ & 10.669 .478 & 8.290 .291 & 276.343 \\
\hline Futuro (3) & 89.235 .001 & - & - \\
\hline $\begin{array}{l}\text { Futuro com medidas } \\
\text { Estruturais (4) }\end{array}$ & 43.353 .643 & 45.881 .358 & 1.529 .378 \\
\hline $\begin{array}{l}\text { Futuro com medidas } \\
\text { não estruturais (5) }\end{array}$ & 54.662 .223 & 34.572 .777 & 1.152 .425 \\
\hline $\begin{array}{l}\text { Futuro com medidas } \\
\text { estruturais e não estruturais (6) }\end{array}$ & 23.742 .440 & 65.492 .560 & 2.183 .085 \\
\hline
\end{tabular}

Na Tabela 4.8 é possível observar que os efeitos das medidas mitigadoras no cenário atual são elevados, correspondendo a praticamente metade do valor dos danos sem as medidas mitigadoras estruturais (cenário 1). Porém, mesmo que se concretize o ordenamento do uso e ocupação do solo proposto no plano diretor de São Carlos (PMSC, 2005), os prejuízos na região objeto desta pesquisa serão de 2 a 3 vezes maiores, sendo que apenas com a implantação conjunta de medidas mitigadoras estruturais e não estruturais propostas no plano de drenagem de São Carlos (PMSC, 2011) é que haverá efeito considerável de mitigação dos danos, aproximando-se dos prejuízos verificados no cenário atual 


\subsection{DISCUSSÃO}

\subsubsection{Análise custo-benefício}

Para projetos de controle de inundações, o benefício é igual ao valor dos danos evitados com a implantação do projeto. Dessa forma, os benefícios advindos com a construção de uma barragem para conter uma cheia de 100 anos, por exemplo, são iguais aos prejuízos que seriam causados por tal inundação e por outras de menor extensão e profundidade.

Os custos a serem considerados incluem, basicamente: custos de implantação (planejamento, projeto, construção, terreno etc.); e custos de operação e manutenção (mão de obra, troca e reparo de equipamentos etc.) - que são necessários para operar o sistema durante sua vida útil; custos financeiros, relativo ao pagamento de juros aos credores ${ }^{5}$. Custos que também podem ser levados em consideração são: impacto social, impacto ambiental, dentre outros.

A maioria dos projetos de recursos hídricos é justificada com base na diferença (em termos monetários) entre benefícios e custos, quando os benefícios são medidos pelo aumento líquido no valor de bens e serviços que resultam de um projeto comparado à ausência deste (WANIELISTC e YOUSEF, 1992).

Após ter sido determinado o valor médio anual dos danos evitados, o benefício futuro e o custo real da implantação da solução estrutural são comparados, convertendo-os para uma base de tempo comum.

Graficamente é possível observar tais incrementos de danos utilizando a metodologia proposta por Torterot (1993) e Penning-Rowsell \& Chatternon (1977) ${ }^{6}$. Buscou-se aplicar essa metodologia a área de estudo para, com uso de curvas sintéticas, apresentar o valor dos benefícios das medidas mitigadoras propostas nesta pesquisa, sob duas distribuições temporais aplicadas a esses cenários. Por meio das Figuras 4.30 a 4.37, são apresentados graficamente os valores dos benefícios das medidas mitigadoras (representadas pela área escura do gráfico) e o valor residual dos danos (representado pela parte clara do gráfico).

\footnotetext{
${ }^{5}$ Considerado aqui a utilização de verba pública, tendo como parâmetro o valor módico de juros aplicado pelo BNDS em investimentos de infraestrutura.

${ }^{6}$ Ver item 2.10 e Figura 2.11
} 
Figura 4.30 - Método da curva nível prejuízo para avaliação econômica de projetos de drenagem para o cenário 4 (atual com medidas mitigadoras) e distribuição Huff $1^{\circ}$ quartil
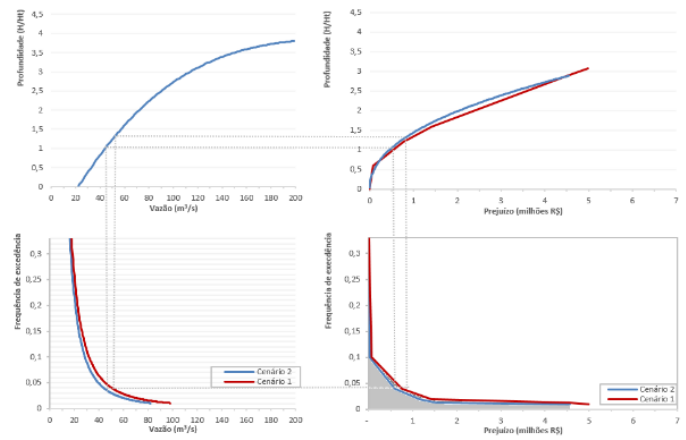

Figura 4.32 - Método da curva nível prejuízo para avaliação econômica de projetos de drenagem para o cenário 4 (atual com medidas mitigadoras) e distribuição Huff $1^{\circ}$ quartil
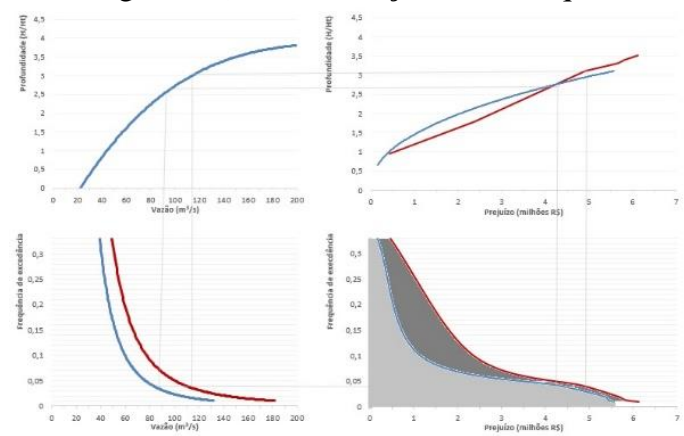

Figura 4.34 - Método da curva nível prejuízo na avaliação econômica de projetos de drenagem para cenário 5 (futuro com medidas não estruturais) e distribuição Huff $1^{\circ}$ quartil
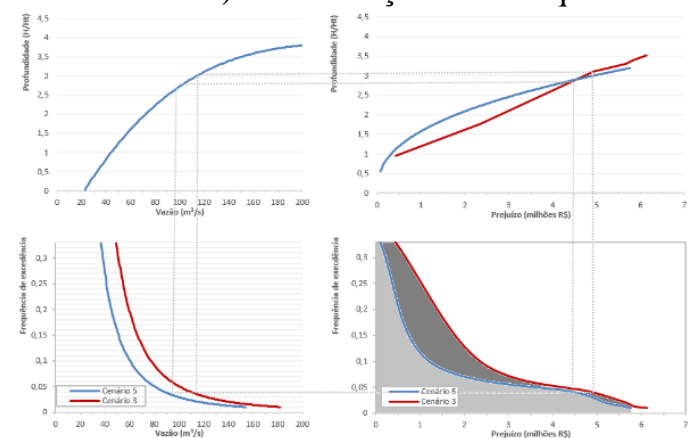

Figura 4.31 - Método da curva nível prejuízo para avaliação econômica de projetos de drenagem para o cenário 4 (atual com medidas mitigadoras) e distribuição blocos alternados
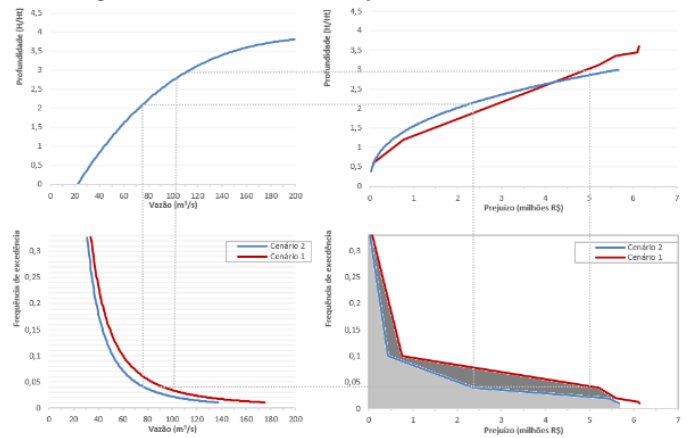

Figura 4.33 - Método da curva nível prejuízo para avaliação econômica de projetos de drenagem para o cenário 4 (atual com medidas mitigadoras) e distribuição blocos alternados

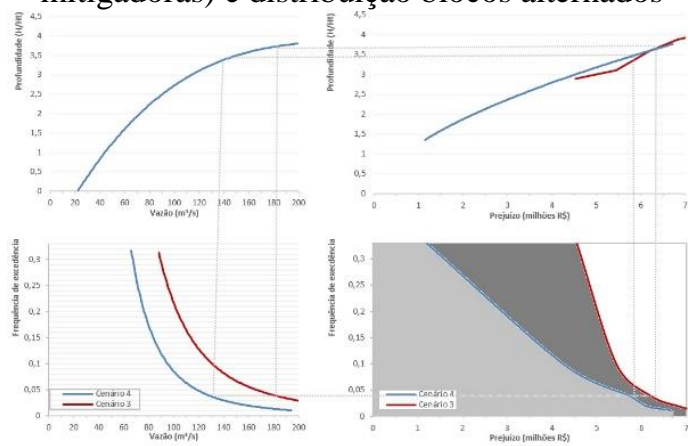

Figura 4.35 - Método da curva nível prejuízo na avaliação econômica de projetos de drenagem para cenário 5 (futuro com medidas não estruturais) e distribuição blocos alternados

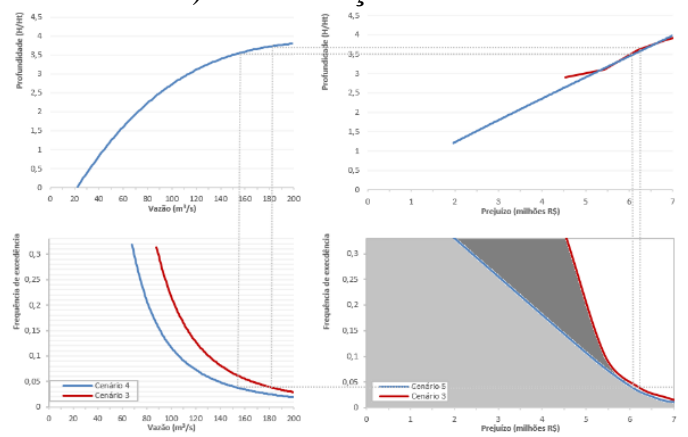


Figura 4.36 - Método da curva nível prejuízo na avaliação econômica de projetos de drenagem para cenário 6 (futuro com ambas medidas) e distribuição Huff $1^{\circ}$ quartil

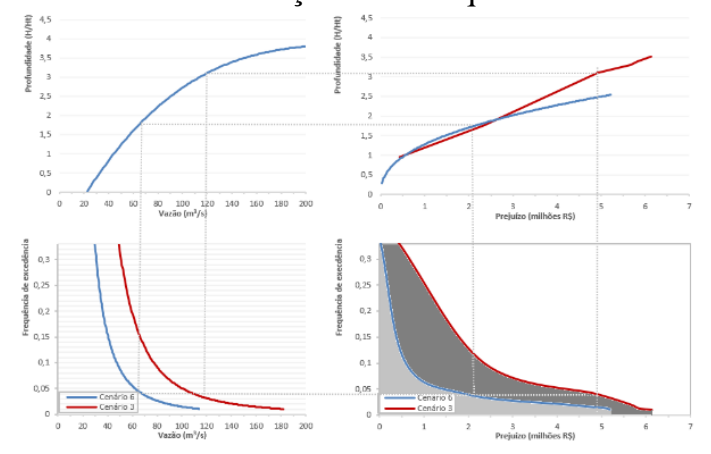

Figura 4.37 - Método da curva nível prejuízo na avaliação econômica de projetos de drenagem para cenário 6 (futuro com ambas medidas) e distribuição blocos alternados

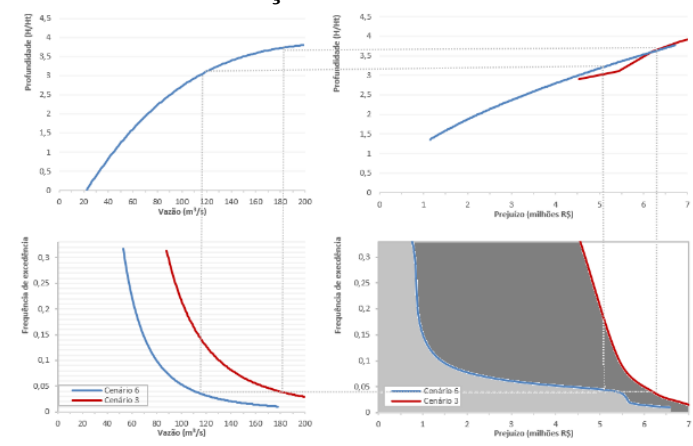

Por meio das figuras é possível observar o valor dos danos evitados com as respectivas medidas mitigadoras propostas (área cinza escura), assim como analisar os danos residuais em cada cenário (área cinza clara do gráfico). Essa abordagem facilita a análise, tendo em vista a possibilidade de estimar de forma didática tais valores.

Por meio da Figura 4.30 é possível averiguar que as medidas mitigadoras estruturais para o cenário atual sob distribuição temporal Huff $1^{\circ}$ quartil possuem eficácia quase nula, já que os danos residuais são praticamente os mesmos, tendo em vista as curvas de valor anual dos prejuízos estarem posicionadas praticamente na mesma região. Já para os blocos alternados, a mitigação é mais relevante.

Tal observação também foi verificada por Martins (2018), que avaliou a implantação de medidas mitigadoras na região por meio de modelagem com uso do software SWMM.

De acordo com o autor, "curiosamente, as bacias de detenção obtiveram melhores resultados de redução de
vazão de pico para os maiores eventos. Dalmodaram et al. (2010) afirmam que bacias
de detenção, por serem geralmente dimensionadas para tempos de retorno iguais ou
superiores a 100 anos, costumam não surtir grandes efeitos na redução de vazões de
pico de eventos menores. Além disso, Emerson, Welty e Traver (2006) afirmam que
estes dispositivos de detenção de grande porte podem ser prejudiciais ao sistema de
drenagem durante eventos de grande frequência anual pois, além de serem pouco
eficientes nestes casos, ainda prolongam demasiadamente as altas vazões, elevando o
risco de erosão nos canais." Com relação aos resultados de sua análise, referente a mesma área de estudo e bacia de contribuição, Martins (2018) afirma que, apesar dos resultados positivos, por se tratarem de cinco bacias de detenção em uma única bacia hidrográfica urbana, os valores de redução de vazão de pico inferiores a $10 \%$ podem ser considerados baixos, ainda mais se os dispositivos forem instalados isoladamente ou sem um planejamento mais amplo de regulação de uso do 
solo, principalmente por terem como áreas de drenagem regiões predominantemente rurais. Entretanto, como combatem o escoamento gerado apenas nas áreas menos desenvolvidas e mais permeáveis, o escoamento gerado nas regiões mais urbanizadas não passa pelos dispositivos, o que limita o potencial dos reservatórios de amortecer hidrogramas em nível de bacia hidrográfica e, consequentemente, diminui seu potencial de combate a inundações.

Esses resultados vêm de encontro com o que afirmam Emerson, Welty e Travor (2006). De acordo com os autores, apesar de o dimensionamento de bacias de detenção ocorrer caso-acaso e em escala local, a decisão de construção de uma bacia deve ocorrer depois de se averiguar a eficiência do dispositivo na escala de bacia hidrográfica, principalmente se houverem outros dispositivos de detenção na mesma bacia hidrográfica. Além disso, em um estudo realizado em uma bacia hidrográfica com mais de 100 bacias de detenção (todas entre 2 e 100 anos de tempo de retorno), os autores afirmam que, trabalhando em conjunto e de forma desordenada, as bacias de detenção podem até mesmo aumentar a vazão de pico de eventos de baixo tempo de retorno.

Por meio dessas Figuras, pode-se concluir que os dispositivos de drenagem propostos no plano diretor são eficientes sob altos valores de vazão, sendo assim congruente a análise dos hidrograma.

Analisando as Figuras 4.32 a 4.35 percebe-se que as medidas mitigadoras estruturais e não estruturais, aplicadas isoladamente, possuem eficácia semelhante frente a diminuição da vazão e, consequentemente, a mitigação dos prejuízos.

Já pela Figura 4.36 observa-se valores consideráveis de mitigação do prejuízo, tendo em vista o valor de vazão e prejuízo se aproximar daqueles verificados no cenário atual, premissa de um plano de drenagem eficiente. Além disso, ao observar a Figura 4.37, percebe-se que os a mitigação dos danos é maior que que os danos residuais.

Para avaliar o custo benefício das medidas mitigadoras propostas e as incertezas entre os métodos de distribuição propostos, são apresentados na Tabela 4.9 os benefícios das medidas mitigadoras para as distribuições propostas e as incertezas entre os métodos de distribuição. Já na Tabela 4.10 é apresentado a diferença entre os custos e os benefícios das medidas mitigadoras propostas. Para os custos, foi considerado o valor de $\mathrm{R} \$ 49.922 .163,00$, conforme calculado anteriormente no item 4.2.2 deste capítulo, referente aos custos de implantação, manutenção e operação e custos financeiros referente aos juros para pagamento das obras de implantação dos 5 reservatórios de detenção propostos (PMSC, 2011). 
Tabela 4.9 - Incerteza entre os métodos de distribuição avaliados para a distribuição Huff $1^{\circ}$ quartil

\begin{tabular}{lrrr}
\hline Cenário & $\begin{array}{r}\text { Blocos } \\
\text { alternados }\end{array}$ & $\begin{array}{r}\text { Huff 10 } \\
\text { quartil }\end{array}$ & Incertezas \\
\cline { 2 - 3 } & $\begin{array}{r}\text { Benefício } \\
(30 \text { anos })\end{array}$ & $\begin{array}{r}\text { Benefício } \\
(30 \text { anos })\end{array}$ & \\
\hline $\begin{array}{l}\text { Atual com medidas } \\
\text { estruturais (2) }\end{array}$ & 8.290 .478 & 1.172 .310 & 7.118 .168 \\
\hline $\begin{array}{l}\text { Futuro com medidas } \\
\text { estruturais (4) }\end{array}$ & 45.881 .358 & 4.009 .691 & 41.871 .667 \\
\hline $\begin{array}{l}\text { Futuro com medidas } \\
\text { não estruturais (5) }\end{array}$ & 34.572 .777 & 3.318 .246 & 31.254 .531 \\
\hline $\begin{array}{l}\text { Futuro com medidas } \\
\text { estruturais e não estruturais (6) }\end{array}$ & 63.492 .560 & 11.536 .240 & 51.956 .320 \\
\hline
\end{tabular}

\begin{tabular}{|c|c|c|c|}
\hline \multirow[t]{2}{*}{ Cenário } & $\begin{array}{l}\text { Blocos } \\
\text { alternados }\end{array}$ & $\begin{array}{l}\text { Huff 10 } \\
\text { quartil }\end{array}$ & \multirow[t]{2}{*}{ Incertezas } \\
\hline & $\begin{array}{l}\text { Custo-Benefício } \\
\quad(30 \text { anos })\end{array}$ & $\begin{array}{l}\text { Custo-Benefício } \\
\quad(30 \text { anos })\end{array}$ & \\
\hline $\begin{array}{l}\text { Atual com medidas } \\
\text { estruturais (2) }\end{array}$ & $41.631 .685,000$ & $48.749 .853,000$ & $7.118 .168,000$ \\
\hline $\begin{array}{l}\text { Futuro com medidas } \\
\text { estruturais (4) }\end{array}$ & $4.040 .805,000$ & $45.912 .472,000$ & $41.871 .667,000$ \\
\hline $\begin{array}{l}\text { Futuro com medidas } \\
\text { não estruturais (5) }\end{array}$ & $15.349 .386,000$ & $46.603 .917,000$ & $31.254 .531,000$ \\
\hline $\begin{array}{l}\text { Futuro com medidas } \\
\text { estruturais e não estruturais (6) }\end{array}$ & $-13.570 .397,000$ & $38.385 .923,000$ & $51.956 .320,000$ \\
\hline
\end{tabular}

A análise da Tabela 4.9 permite verificar que, utilizando a distribuição Huff $1^{\circ}$ quartil, os custos dos benefícios são irrisórios frente ao custo da implantação das medidas mitigadoras estruturais, enquanto que para a distribuição blocos alternados o benefício das medidas mitigadoras estruturais é muito próximo dos custos de sua execução. Porém, deve-se ressaltar o benefício gerado pelas medidas não estruturais na distribuição Huff $1^{\circ}$ quartil, já que na aplicação de tal cenário não estão envolvidos custos de obras e possui eficácia próxima à verificada com as medidas estruturais.

Para o cenário com a distribuição blocos alternados (Tabela 4.10), essas medidas têm proporcionalmente menor eficácia em relação as medidas estruturais, já que os reservatórios de detenção têm maior eficiência na mitigação de vazão mais elevadas. Como era de se esperar, a implantação das medidas estruturais em conjunto com as medidas não estruturais trouxe o melhor custo-benefício dentre os cenários analisados, sendo que o cenário para a distribuição blocos alternados foi o único em que se obteve um benefício superior aos custos envolvidos com as medidas mitigadoras.

Cabe salientar que a incerteza entre os métodos se mostrou elevada, principalmente para os cenários futuros, frente ao substancial aumento dos prejuízos verificados na distribuição blocos alternados. Entretanto, tais incertezas relativas ao método de distribuição temporal de 
chuva adotado pode ser considerado como o espectro de incerteza dos métodos, podendo assim se estabelecer valores intermediários de prejuízo frente as incertezas das chuvas da região, tornando possível concluir que tais valores sejam considerados como valores mínimos e máximos de prejuízos frente as distintas distribuições temporais de chuvas para a região.

A análise do custo-benefício das medidas mitigadoras foi realizada considerando apenas os prejuízos diretos dos comerciários da região afetada e novas análises devem incluir outros fatores que provocam prejuízos à região - como os danos estruturais à cidade e os indiretos causados pela inundação - nas funções de prejuízo para avaliar com maior acurácia a implantação de tais medidas.

\subsubsection{Análise unitária dos dados}

Para correlacionar os dados de custo com os dados de vazão, foram elaborados gráficos para adimensionalisar essas duas variáveis, possibilitando a análise das relações entre custo e vazão da bacia em detrimento da área da mancha de inundação e da área de contribuição da bacia, em seus respectivos tempos de retorno e cenários propostos. Com esta finalidade, nas Figura 4.38 e 4.39 é apresentado o custo unitário em relação ao tempo de retorno nos cenários concernentes para as duas distribuições temporais de chuvas propostas, enquanto que, nas Figuras 4.40 a 4.43, estão expostas as relações custo-unitário por vazão unitária para toda a área de contribuição da bacia e para a área inundada. 
Figura 4.38 - Prejuízo Unitário (R \$unidade de área inundada) x Tempo de retorno para a distribuição Huff $1^{\circ}$

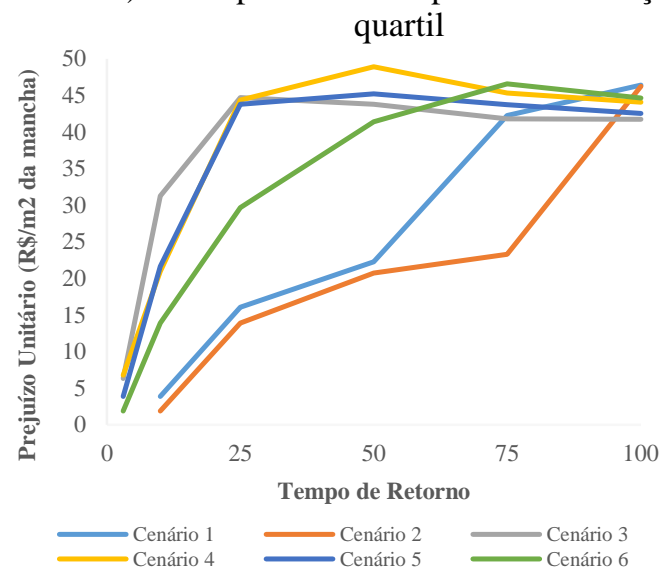

Figura 4.40 - Relação custo unitário (Custo/unidade de área inundada) x Vazão Unitária (Vazão/área) para

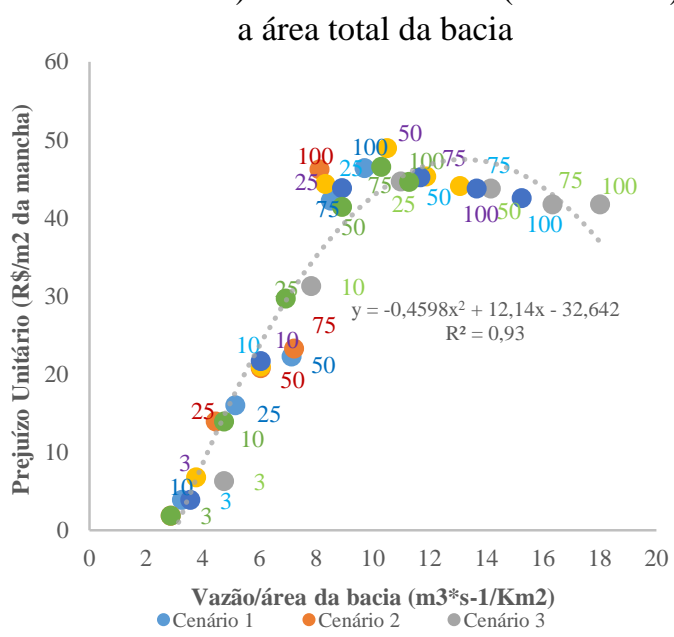

Figura 4.42 - Relação custo unitário x vazão unitária para a área da mancha de inundação

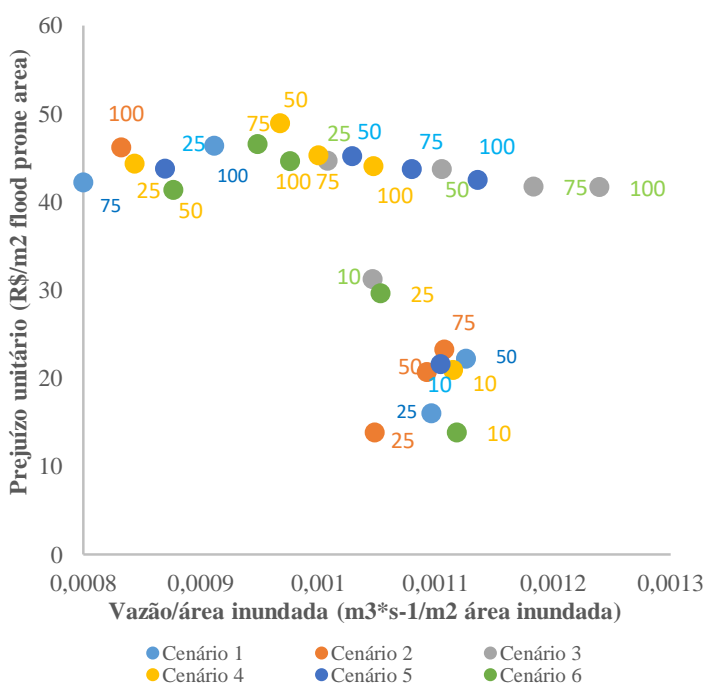

Figura 4.39 - Prejuízo Unitário (R\$/unidade de área inundada) x Tempo de retorno para

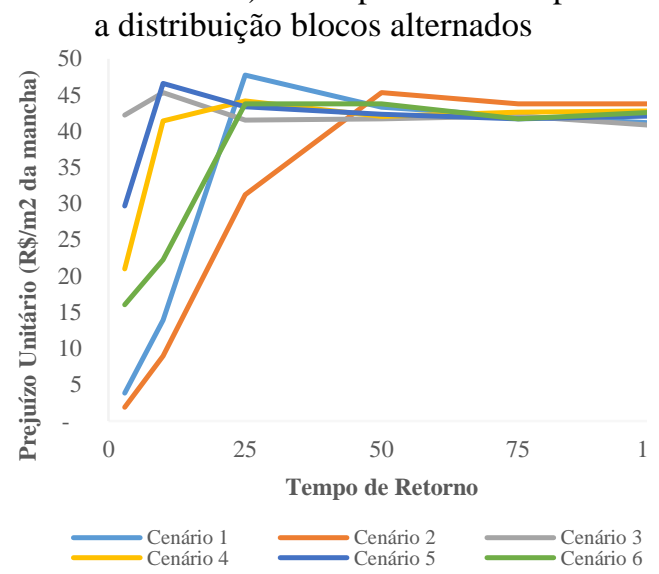

Figura 4.41- Relação custo unitário (Custo/unidade de área inundada) x Vazão Unitária (Vazão/área) para a área total da bacia

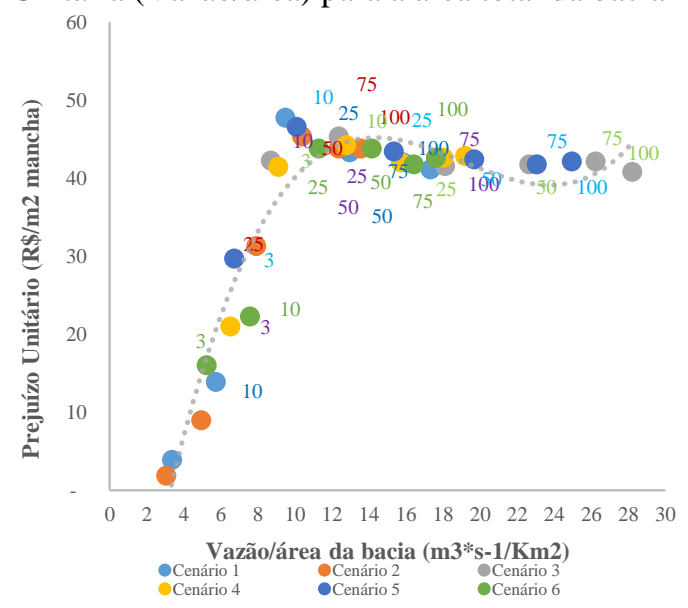

Figura 4.43 - Relação custo unitário x vazão unitária para a área da mancha de inundação

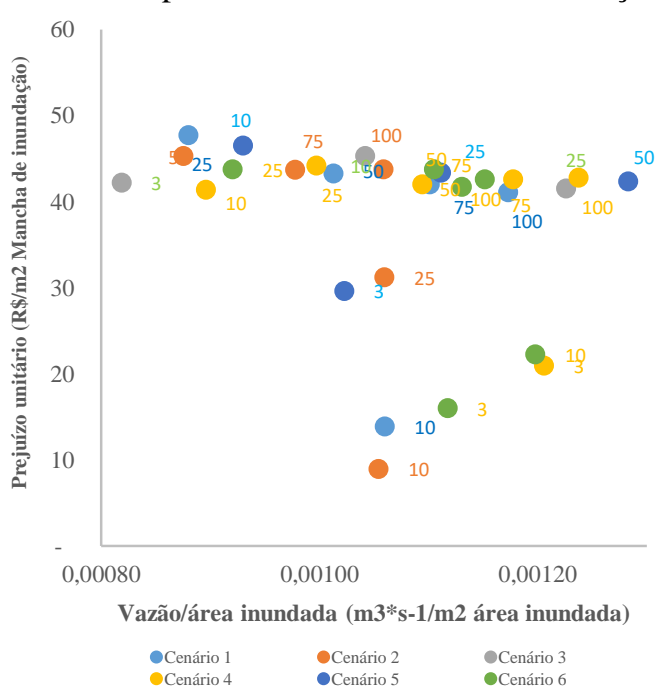


Pela Figura 4.38, percebe-se que a relação entre o custo unitário pelo tempo de retorno tem semelhança com a relação custo total. Já na Figura 4.39, percebe-se uma linearidade do custo unitário após o TR 50 anos.

Já com as Figura 4.40 e 4.41 pode-se constatar que altos valores de vazão têm relação horizontal de custo unitário tendo em vista a vazão unitária por área inundada, não possuindo correspondência quando se analisa tal custo pela vazão unitária por área de contribuição total da bacia; esta última, mantém-se horizontal a partir da vazão unitária de $8 \mathrm{~m}^{3} / \mathrm{s}^{*} \mathrm{~km}^{2}$. Tais Figuras explicitam o valor do prejuízo com o incremento de vazão unitária.

Dessa forma, analisando as Figuras 4.40 e 4.41, verifica-se uma relação peculiar dos prejuízos unitários (danos por área da área inundada), pois se estabelece uma relação crescente para eventos de baixa magnitude e uma relação praticamente constante para eventos de maior magnitude.

Neste estudo, os danos unitários mantiveram-se praticamente constantes a partir do período de retorno de 50 anos do cenário 6 para a distribuição Huff $1^{\circ}$ quartil, que corresponde a vazão de $90 \mathrm{~m} 3 / \mathrm{s}$ e obtiveram seu máximo valor com tempo de retorno de 50 anos do cenário 4, que corresponde a vazão de $106 \mathrm{~m} 3 / \mathrm{s}$.

De maneira geral, altos valores obtidos com relação a vazão por $\mathrm{m}^{2}$ da área da mancha de inundação com relação a vazão pela área de inundada, foram obtidos por vazões superiores a $80 \mathrm{~m}^{3} / \mathrm{s}$, sendo que, a partir dessa vazão, tal relação manteve-se praticamente constante (entre 40 e $50 \mathrm{R} \$ / \mathrm{m}^{2}$ de área da mancha).

Nestes eventos, o potencial de danos já foi praticamente atingido e um aumento na vazão reflete não um crescimento acentuado na área inundada. Contudo, esse aumento é maior do que a expansão dos danos, uma vez que o potencial de danos já foi atingido e, assim, não se observa aumento dos danos unitários após um determinado limite de vazão.

\subsubsection{Análise das incertezas baseada na escala de análise (micro e meso escala)}

O objetivo desta análise é comparar os dados obtidos na pesquisa de Graciosa (2010) com aqueles obtidos nesta pesquisa. Essa comparação é válida pelo fato das escalas de análise serem distintas: enquanto Graciosa (2010) utilizou uma análise em meso escala para atribuição de prejuízo (escala de lote [quadra]), nesta pesquisa foram verificados os prejuízos em escala de imóvel (microescala).

Dessa forma, a análise de meso escala utilizada pela autora entende que toda a mancha de inundação simulada está totalmente (100\% de ocupação do solo) preenchida por imóveis, ou 
seja, correspondente aos prejuízos potenciais da região, enquanto na presente pesquisa faz-se uma micro análise desses dados, considerando apenas a área dos imóveis (baseado na área dos telhados) presentes na mancha de inundação, retirando assim os vazios urbanos, ruas, praças, etc. A Tabela 4.10 explica as diferenças em termos de vulnerabilidade e risco de inundação das análises realizadas em microescala e em meso escala.

Tabela 4.10 - Características relevantes a serem consideradas relacionadas a vulnerabilidade e ao risco de inundação nas escalas de análise micro e meso.

\begin{tabular}{cll}
\hline Escala & Vulnerabilidade & Riscos de inundação \\
\hline \multirow{3}{*}{ Micro } & $\begin{array}{l}\text { São analisadas as variáveis a nível } \\
\text { elementar (como prédios, } \\
\text { infraestrutura, conteúdo, etc.). É } \\
\text { dada atenção aos detalhes de } \\
\text { construção e ocupação de cada local } \\
\text { para determinar sua vulnerabilidade } \\
\text { individual. }\end{array}$ & $\begin{array}{l}\text { Modelos hidrodinâmicos eficientes } \\
\text { são usados com descrição detalhada } \\
\text { das vazões dos rios, como canais e } \\
\text { planície de inundação, além das } \\
\text { estruturas hidráulicas existentes. É } \\
\text { dado foco nas características } \\
\text { hidráulicas de eventos extremos de } \\
\text { inundação. }\end{array}$ \\
\hline \multirow{3}{*}{ Meso } & $\begin{array}{l}\text { São utilizados blocos homogêneos } \\
\text { com escalas baseadas no uso do } \\
\text { solo (residencial, industrial, } \\
\text { comercial). A maior foco está nas } \\
\text { características das construçães, } \\
\text { sendo necessária a agregação de } \\
\text { valores entre os conjuntos. }\end{array}$ & $\begin{array}{l}\text { Modelos hidrodinâmicos descrevem } \\
\text { superficialmente as inundações } \\
\text { relativas a canais e mediana } \\
\text { descrição dos detalhes da planície } \\
\text { de inundação. É dada ênfase a área } \\
\text { inundável de eventos extremos de } \\
\text { inundação }\end{array}$ \\
\hline
\end{tabular}

Fonte: Adaptado de Eleutério et al. (2014)

De acordo com Graciosa (2010), para a obtenção do potencial de prejuízo na bacia hidrográfica em sua pesquisa foi utilizada a metodologia de BWK (2001). Este método tem por objetivo obter, para a bacia hidrográfica, o prejuízo associado à cheia de projeto, por período de retorno, que é o chamado prejuízo potencial ou também o prejuízo associado a um determinado evento. No trabalho de Graciosa (2010), foi obtida por simulação uma área de risco de $268.068 \mathrm{~m}^{2}$, com aproximadamente 75 quarteirões para período de retorno $\mathrm{TR}=100$ anos, o que corresponde a, aproximadamente, 1800 usuários (lotes) e área de $268.000 \mathrm{~m}^{2}$.

Para tanto, foram utilizadas as seguintes informações: níveis de inundação simulados por modelagem hidráulico-hidrológica; modelo de elevação digital do terreno; mapas de uso e ocupação do solo detalhados em escala de lote, por categorias; parâmetros das curvas de prejuízo por categoria avaliada de uso e ocupação do solo conforme o modelo adotado.

Na presente pesquisa foi considerada apenas a área mais crítica com relação ao prejuízo, com área de drenagem de até $180.000 \mathrm{~m}^{2}$ no cenário de maior perigo. Porém, a análise foi considerada sob o âmbito da microescala, considerando apenas a área dos telhados dos imóveis contidos na mancha de inundação. As Figura 4.29 e 4.30 apresentam, respectivamente, o mapa de risco de inundação apresentado por Graciosa (2010) e o mapas da mancha de inundação simulado nesta pesquisa, ambas para o cenário futuro com tempo de retorno de 100 anos. Cabe 
destacar que nas duas pesquisas foram utilizadas as curvas DPS de Machado (2005) para quantificação dos prejuízos.

Figura 4.29 - Mapa de risco de inundação obtidas por Graciosa (2010) para o cenário Futuro com TR de 100 anos

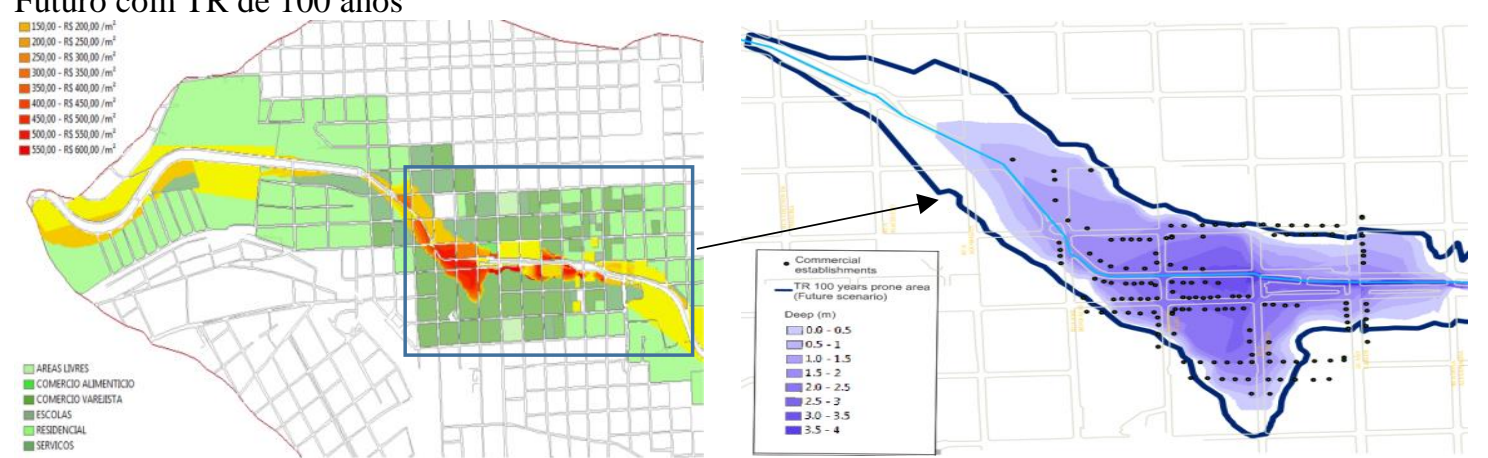

Fonte: Adaptado de Graciosa (2010)
Figura 4.30 - Mapa mancha de inundação para o cenário Futuro com TR 100 anos

Ao comparar as Figuras 4.29 e 4.30, observa-se que, apesar da área da mancha de inundação ser distinta entre as pesquisas, os locais fora da área do mercado municipal apresentam valores muito baixos de prejuízo por altura de inundação, marcadas pelas cores de risco amarelas e laranja. Contudo, esta é praticamente a única escala de valores para prejuízo fora da área do mercado municipal (em que se verificou valores muito maiores de prejuízo por área), com perdas da ordem de $\mathrm{R} \$ 50$ a $\mathrm{R} \$ 100 / \mathrm{m}^{2}$.

Portanto, tal área, apesar de maior em termos absolutos, deve apresentar pouca diferença em termos de prejuízo. A Tabela 4.11 apresenta os valores da área da mancha de inundação obtidos nesta pesquisa e na de Graciosa (2010). Além disso, são apresentados valores considerados de área impactada nesta pesquisa, relativo ao somatório área dos telhados dos imóveis contidos na mancha de inundação.

\begin{tabular}{|c|c|c|c|c|c|c|c|c|}
\hline & \multicolumn{4}{|c|}{ Cenário atual } & \multicolumn{4}{|c|}{ Cenário futuro } \\
\hline & & rea total $\left(\mathbf{m}^{2}\right)$ & & Área considerada $\left(\mathrm{m}^{2}\right)$ & & rea total $\left(\mathrm{m}^{2}\right)$ & & Área considerada $\left(\mathrm{m}^{2}\right)$ \\
\hline TR & $\begin{array}{l}\text { Huff } 1^{\circ} \\
\text { quartil }\end{array}$ & $\begin{array}{l}\text { Blocos } \\
\text { alternados }\end{array}$ & $\begin{array}{r}\text { Graciosa } \\
(2010)\end{array}$ & $\begin{array}{r}\text { Blocos } \\
\text { alternados }\end{array}$ & $\begin{array}{l}\text { Huff } 1^{\circ} \\
\text { quartil }\end{array}$ & $\begin{array}{r}\text { Blocos } \\
\text { alternados }\end{array}$ & $\begin{array}{r}\text { Graciosa } \\
(2010)\end{array}$ & $\begin{array}{r}\text { Blocos } \\
\text { alternados }\end{array}$ \\
\hline
\end{tabular}

\begin{tabular}{crrrrrrrrrr}
\hline $\mathbf{1 0}$ & 18.753 & 54.731 & 218.908 & 626 & 5.200 & 75.510 & 119.976 & 243.932 & 7.886 & 11.476 \\
\hline $\mathbf{2 5}$ & 47.435 & 109.113 & 224.460 & 3.898 & 10.877 & 110.129 & 149.250 & 254.196 & 10.771 & 11.930 \\
\hline $\mathbf{5 0}$ & 63.954 & 129.367 & 239.600 & 5.592 & 11.398 & 129.414 & 163.584 & 263.640 & 11.574 & 12.285 \\
\hline $\mathbf{1 0 0}$ & 107.557 & 149.230 & 246.596 & 10.636 & 11.768 & 146.862 & 180.458 & 268.068 & 11.950 & 12.879 \\
\hline
\end{tabular}

São consideradas nesta tabela a área total da mancha de inundação, a área dos telhados aplicados nesta pesquisa (área essa que, de fato, foi considerada para a quantificação dos prejuízos), a diferença entre a área total e área de abrangência verificada, além da área da 
mancha de inundação considerada por Graciosa, que corresponde a mesma área considerada para quantificação dos prejuízos.

A análise da Tabela 4.12 permite verificar que as áreas das manchas de inundação consideradas por Graciosa (2010) são substancialmente maiores que as obtidas nesta pesquisa, principalmente sob baixos TR, apesar da área da mancha de inundação na região de estudo (proximidades do mercado municipal de São Carlos), obterem formatos semelhantes. Porém, na pesquisa da autora foi considerada a área da mancha para toda bacia do córrego do Gregório, como observado na Figura 4.29, o que justifica as diferenças verificadas entre as pesquisas.

A análise das diferenças verificadas entre as pesquisas aponta profundas diferenças entre os prejuízos verificados, sendo que para o cenário atual sob distribuição Huff $1^{\circ}$ quartil as discrepâncias foram mais significativas.

Ao comparar os cenários pela distribuição temporal de blocos alternados, foram verificadas diferenças entre as áreas da mancha de inundação de cerca de $75 \%$ e $40 \%$ para o cenário atual e de 51 e 33\% para o cenário futuro. Já para a distribuição temporal Huff $1^{\circ}$ quartil as diferenças foram mais significativas, entre $91 \%$ e $56 \%$ para o cenário atual e $69 \%$ a $45 \%$ para o cenário futuro.

A análise da área dos imóveis susceptíveis a inundação demonstrou que área, de fato, impactada corresponde a aproximadamente 5\% da área total da mancha de inundação, sendo o restante correspondente a praças, ruas, calçadas, etc., as quais não possuem danos diretos em relação a conteúdo.

Assegura-se também que, apesar de ambas as pesquisas terem utilizado as curvas propostas por Machado (2005), não foi caracterizado o tipo de estabelecimento comercial pela autora. A curva média dos danos obtidos por Machado (2005) para elaboração dos prejuízos foi utilizada. Contudo, a metodologia adotada pela autora está de acordo com a análise do tipo meso escala, em que se estabelece os lotes como unidade de análise.

Quando se apenas a área suscetível aos danos, ou seja, a área dos telhados dos imóveis contidos na mancha de inundação, a relação entre tais áreas e área adotada por Graciosa varia de $99 \%$ a $95 \%$ entre os cenários simulados.

Para quantificar tais diferenças em termos de prejuízo, na Tabela 4.12 são apresentados os valores de prejuízo total obtidos nesta pesquisa para as duas distribuições temporais de chuvas e os valores obtidos por Graciosa (2010) e nas Figuras 4.44 e 4.45 tais valores apresentados graficamente para, respectivamente, o cenário atual e o futuro (cenários 1 e 3). Essa relação permite verificar as diferenças entre uma análise sob os âmbitos da micro e meso 
escala, em relação aos prejuízos simulados. Nesta análise foram considerados apenas os TR de $10,25,50$ e 100 anos, tendo em vista serem esses os apresentados pela autora.

Tabela 4.12 - Prejuízo calculado nesta pesquisa e prejuízo calculado por Graciosa (2010)

\begin{tabular}{crrc|ccc}
\hline \multicolumn{3}{c|}{ Cenário atual } & \multicolumn{3}{c}{ Cenário futuro } \\
\hline TR & $\begin{array}{c}\text { Huff } \\
\text { 10 quartil }\end{array}$ & $\begin{array}{c}\text { Blocos } \\
\text { alternados }\end{array}$ & $\begin{array}{c}\text { Graciosa } \\
\mathbf{( 2 0 1 0 )}\end{array}$ & $\begin{array}{c}\text { Huff } \\
\mathbf{1}^{\mathbf{0}} \text { quartil }\end{array}$ & $\begin{array}{c}\text { Blocos } \\
\text { alternados }\end{array}$ & $\begin{array}{c}\text { Graciosa } \\
(\mathbf{2 0 1 0})\end{array}$ \\
\hline $\mathbf{1 0}$ & 72.411 & 759.922 & 11.774 .764 & 2.359 .153 & 5.434 .835 & 20.103 .234 \\
\hline $\mathbf{2 5}$ & 759.922 & 5.208 .084 & 14.029 .124 & 4.918 .823 & 6.197 .054 & 20.625 .232 \\
\hline $\mathbf{5 0}$ & 1.423 .325 & 5.601 .334 & 18.436 .854 & 5.662 .890 & 6.822 .773 & 26.183 .044 \\
\hline $\mathbf{1 0 0}$ & 4.987 .263 & 6.134 .598 & 20.430 .260 & 6.126 .754 & 7.359 .338 & 28.017 .029 \\
\hline
\end{tabular}

Figura 4.44 - Comparação entre o prejuízo obtido nas pesquisas de Graciosa e na presente para o cenário atual

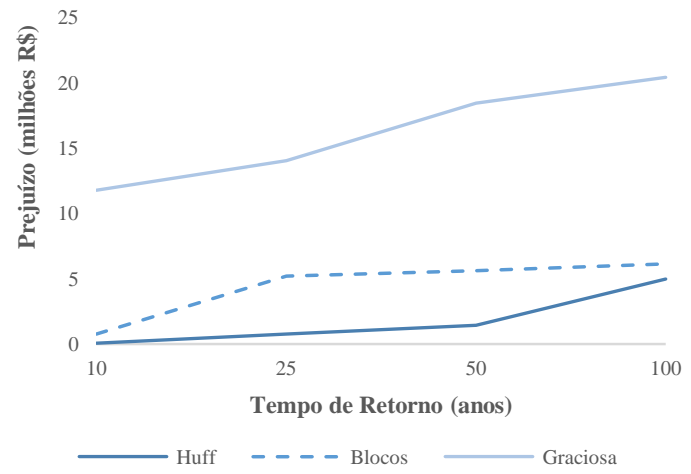

Figura 4.45 - Comparação entre o prejuízo obtido nas pesquisas de Graciosa e na presente para o cenário atual

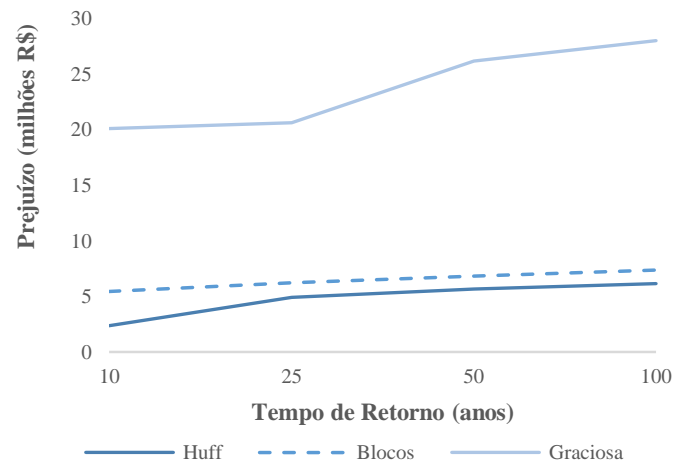

Por meio das Figuras 4.44 e 4.45 é possível averiguar que, com relação aos prejuízos, se observa que, para o cenário atual com distribuição Huff $1^{\circ}$ quartil, se obteve as maiores diferenças verificadas de prejuízo entre os métodos de distribuição de chuvas, o qual variou de 99 a 70\%. Por outro lado, para a distribuição blocos alternados essa variação foi de 88 a $70 \%$. Sendo assim, a escala de análise tem influência muito significativa na avaliação de prejuízos de inundações, podendo gerar incertezas extremas na quantificação dos prejuízos.

\subsection{CONCLUSÕES}

A partir da metodologia proposta, buscou-se trazer avanços na quantificação dos danos causados aos imóveis, com a análise custo-benefício de medidas mitigadoras. Para tal, o cadastramento dos imóveis foi uma ferramenta importante na análise das variáveis econômicas destes primeiros, que estão contidos na mancha de inundação.

Através da incorporação dos imóveis em um Sistema de Informações Geográfica (SIG), com dados de altura de submersão, foi possível exportar os valores gerados na mancha de 
inundação e atrelar essas informações a Identificadores (ID) vinculados a cada propriedade, de forma automática, através da ferramenta Spacial analyst.

As profundidades de submersão de cada imóvel foram dados relevantes para a quantificação dos prejuízos decorrentes das inundações. Assim, foi possível correlacionar a altura de inundação em que o imóvel está inserido com o prejuízo ocasionado, formando a curva de danos por profundidade de submersão (DPS) por meio de curvas por tipo de atividade, propostas por Machado (2005).

Com relação aos cenários, os benefícios das medidas não estruturais se equipararam ao das medidas estruturais (construção de obras de detenção de águas pluviais), ou seja, a construção de barragens de acumulação de água pluvial se equipara ao adequado disciplinamento do uso do solo, com a manutenção de áreas verdes na bacia.

A alteração do uso do solo pode provocar diferenças significativas nas alturas de submersão e, consequentemente, aos prejuízos observados pelo comércio, pois foi verificada a grande sensibilidade frente ao uso do solo no futuro. As simulações demonstraram que, para um TR de 25 anos, observa-se pouca efetividade dos reservatórios do PMSC (2011) frente à alteração do uso e ocupação da terra na mitigação dos prejuízos aos comerciantes em cenários futuros. Já para o cenário atual, a maior efetividade das medidas estruturais deu-se para o TR de 75 anos para a distribuição Huff $1^{\circ}$ quartil e TR 25 para a distribuição blocos alternados. Tais alterações são decorrentes da mudança da cobertura da terra de zonas naturais para uso urbano, com incremento de valores de até 22 unidades de $\mathrm{CN}$ nas sub-bacias.

É possível verificar que para eventos com TR de 100 anos, as medidas mitigadoras possuem baixa eficácia, já que, em todas as variáveis analisadas (área da mancha de inundação, vazão de pico e prejuízo), os valores encontrados não demonstraram grandes variações.

Assim, uma análise preliminar do custo-benefício das obras estruturais de mitigação com efeitos decorrentes de inundação na bacia do córrego do Gregório, considerando apenas os prejuízos dos comerciários, mostrou maior eficácia na mitigação dos prejuízos com TR da ordem 75 anos, no cenário de ocupação atual. Considerando o cenário de ocupação futura, a ordem de 3 a 10 anos se mostra mais eficiente.

Cabe salientar que, mesmo que tais medidas tenham capacidade de atenuar os efeitos, não serão suficientes se aplicadas isoladamente, competindo ao poder público considerar a implantação de medidas mitigadoras, tanto estruturais como não estruturais, para contenção das cheias e dos prejuízos dela oriundos. 
Novas análises devem incluir outros fatores que provocam prejuízos à região - como os danos estruturais à cidade e os danos indiretos, causados pela inundação - nas funções de prejuízo para avaliar com maior acurácia a implantação de tais medidas.

Com relação as escalas de análise, na análise em meso escala, uma base de dados importante é a vazão contribuinte para o prejuízo, ou seja, a análise unitária da vazão em detrimento do prejuízo.

Tal análise foi realizada na seção anterior (item 4.4.3), que demonstrou que a vazão unitária não excede o valor de $50 \mathrm{R} \$ / \mathrm{m} 2$ de área contribuinte em nenhum dos cenários. Portanto a utilização de curvas DPS sob uma análise meso escala pode trazer superdimensionamento dos prejuízos na medida que considera a área total na análise de prejuízos, sendo assim sugerido escalas unitárias para aplicação nesta escala de análise. 


\section{REFERÊNCIAS}

ÁGUAS DA MEMÓRIA: um percurso pelos córregos esquecidos de São Carlos. 23 de novembro de 2015. Disponível em: <https://aguasdamemoria.wordpress.com/2015/11/24/23-novembro-2015/> Acesso em: 21/07/2016.

ÁGUAS DA MEMÓRIA: um percurso pelos córregos esquecidos de São Carlos. ... e as chuvas chegaram. Disponível em: $<$ https://aguasdamemoria.wordpress.com/2011/06/08/e-as-chuvas-chegaram-a-folha19-de-setembro-1966/>. Acesso em 04/08/2016.

BARBASSA, A. P. Simulação do efeito da urbanização sobre a drenagem pluvial na cidade de São Carlos/SP. Tese (Doutorado em Engenharia Hidráulica e Saneamento) - Escola de Engenharia de São Carlos, Universidade de São Paulo, São Carlos, 1991, p. 327.

CRISS, R. E., WINSTON, W. E. (2008). "Do Nash Values have value? Discussion and alternate proposals." Hydrological Processes, 22(14), 2723-2725.

DECINA, T. G. T. Avaliação de medidas de controle de inundações na bacia hidrográfica do Córrego do Gregório, São Carlos, SP. Dissertação (mestrado em engenharia hidráulica e saneamento) - Escola de Engenharia de São Carlos, Universidade de São Paulo, 2012.

ELEUTÉRIO, J.; PAYRAUDEAU, MOSÉ, S. R.; ROZAN, A. - Cascade of uncertainties in flood damage estimations. 6th International Conference on Flood Managment (ICFM6). São Paulo/SP, Brazil. Setembro de 2014.

EMERSON, C.H.; WELTY, C.; TRAVER, R.G. Watershed-Scale Evaluation of a System of Storm Water Detention Basins. Journal of Hydrologic Engineering, v.10, n.3, 2005.

MACHADO, M. L. Curvas de Inundação versus profundidade de submersão: Desenvolvimento de Metodologia - Estudo de caso da Bacia do Rio Sapucaí, Itajubá - MG - Tese (doutorado) - Universidade Federal de Minas Gerais - Belo Horizonte/MG- 2005

MARTINS, L. G. B. Avaliação do potencial de aplicação de técnicas compensatórias em áreas urbanas consolidadas. 191f. Tese (Doutorado) - Escola de Engenharia de São Carlos, Universidade de São Paulo, São Carlos, 2018.

MONTEIRO, L. R.; KOBIYAMA, M. - Influências da distribuição temporal de precipitação no mapeamento de inundação - REGA - Vol. 11, no. 2, p. 25-35, jul./dez. 2014. ISSN 2359-1919.

PENNINNG-ROWSELL, E.C. e CHATTERTON, J. B. The benefits of flood alleviation: A manual of assessment techniques. Gower Technical Press, Aldershot, Royaume-Uni, Inglaterra, 297p. 1977.

PMSC - Prefeitura Municipal de São Carlos. Plano Diretor de desenvolvimento urbanao. Lei no 13.691 , de 25 de novembro de 2005. Disponível em:

http://www.saocarlos.sp.gov.br/images/stories/pdf/Lei_13691_05_Plano_Diretor.pdf

PMSC - Prefeitura Municipal de São Carlos. Secretaria Municipal de Obras. SHS Consultoria e Projetos de Engenharia S/S Ltda. Plano Diretor de Drenagem Urbana Ambientalmente Sustentável. São Carlos: 2011. 213 p. Relatório Síntese. Volume II - Medidas Estruturais, Medidas Não Estruturais e Custos. Contrato no 87/09 - Processo no 6.965/07. 2011

TACHINI, M. - Avaliação de danos associados às inundações no município de Blumenau. Tese (Doutorado). Universidade Federal de Santa Catarina. UFSC. Programa De Pós-Graduação Em Engenharia Ambiental. Florianópolis/SC. 189p. 2010.

TORTEROT. J. Le coût dês dommages dûs aux inondations: estimatitions et anlyses dês incertitudes . Tese (doutorado). Ecole Nationale de Ponts et Chaussés. Paris. 283 p. 1993. 
PARTE II -

Análise a posteriori 


\section{CAPÍTULO 5 - INCERTEZAS DO USO DE MODELOS CONCEITUAIS UNIDIMENSIONAIS NA VALIDAÇÃO DE ALTURAS DE SUBMERSÃO}

\section{Resumo}

Essa pesquisa busca analisar as incertezas do uso de um modelo conceitual unidimensional na obtenção de alturas de submersão de imóveis. Para isso, foi analisado o modelo conceitual unidimensional de uma área de estudo densamente ocupada por imóveis comerciais e com alta recorrência de eventos de inundação (capítulo 3). Foram utilizados três hietogramas observados de chuva, relativos a eventos de inundação ocorridos em 2013, 2015 e 2018, que ocasionaram grandes danos na região do mercado municipal de São Carlos. Na sequência, foram traçadas as manchas de inundação resultantes por meio do software de ArcGIS e do suplemento HECGeoRAS. No dia seguinte ao evento de inundação, foram realizadas medidas em 40 pontos as alturas de inundação por meio das marcas de sedimentos deixadas nas paredes dos estabelecimentos. As alturas de inundação obtidas na modelagem foram comparadas com aquelas obtidas em campo (reais) para 40 estabelecimentos comerciais afetados pelas chuvas. Com relação a profundidade de submersão verificou-se uma diferença média de $59 \%$ entre o modelo e as medidas reais para todos os imóveis analisados. Conclui-se que as questões hidrodinâmicas bidimensionais provocadas pelas construções e ruas geram um efeito gradualmente variado não verificado no modelo unidimensional utilizado e, portanto, diferenças significativas nas alturas de inundação.

\subsection{INTRODUÇÃO}

A inundação urbana é um desastre ambiental que causa prejuízos econômicos da ordem de bilhões por ano no Brasil. A avaliação dos danos provocados pelas inundações é um processo inerente a gestão de riscos por inundação, pois traz maiores subsídios ao tomador de decisão quanto ao custo benefício das políticas a serem aplicadas.

De acordo com Barros et al. (2003), dados da defesa civil do município de São Carlos indicam que a região do Mercado Municipal de São Carlos sofre em média de quatro a cinco enchentes por ano, com prejuízos em torno de até $\mathrm{R} \$ 90.000$ em cada um desses eventos. De acordo com Riguetto, Barros e Mendiondo (2003), em relação ao histórico das piores inundações, essas encontram-se na ordem de $50 \mathrm{~cm}$ na Avenida Comendador Maffei, entre 100 a $150 \mathrm{~cm}$ na 9 de julho, em torno de $30 \mathrm{~cm}$ na Geminiano Costa e em torno de $100 \mathrm{~cm}$ na Episcopal.

Para isso, a modelagem computacional se faz ferramenta importante para a análise e avaliação das ações a serem tomadas, já que possibilita a elaboração de cenários de uso e ocupação do solo bem como do tempo de recorrência dos eventos, possibilitando assim proceder com avaliações custo-benefício e disponibilizar um maior leque de opções ao tomador 
de decisão. Entretanto, o nível de exigência do modelo é um trade-off entre a complexidade computacional e o tempo demandado para sua elaboração.

Em vista disso, a maior parte dos modelos tem se baseado na modelagem hidrodinâmica unidimensional para obter valores de vazão de pico e elaborar as respectivas manchas de inundação para a bacia.

Os modelos unidimensionais usam as equações de Saint-Venant, completas ou simplificadas, para realizar simulação através do tempo e do espaço. São modelos adequados para o fluxo de longo alcance e longos períodos de tempo, cujos vetores velocidade podem ser assumidos como aproximadamente paralelos à direção do fluxo. Por isso são modelos adequados para simular rios, em que o escoamento é praticamente em uma única direção. Podemos subdividir os modelos 1D em modelos com escoamento permanente, quando consideramos que a vazão do rio modelado não varia no tempo e modelos hidrodinâmicos, quando consideramos a variação da vazão do rio modelado. [SOUZA, 2010].

Para realizar a correlação entre os valores observados de altura de inundação com os obtidos por meio de simulação, foi utilizado como software de processamento de dados e modelagem hidráulica-hidrológica a plataforma HEC, apresentado no capítulo 3.

Portanto, o objetivo desta pesquisa consiste em comparar as alturas de inundação geradas por um modelo de simulação com as alturas reais observadas.

\subsection{METODOLOGIA}

A metodologia para análise é baseada no seguinte fluxograma:

1. Definição do hietograma da chuva observada para os eventos de 22 de outubro de 2013 , 23 de novembro de 2015 e 20 de março de 2018 em pluviógrafo situado no córrego do Gregório, São Carlos;

2. Simulação hidráulica-hidrológica;

3. Identificação e cadastramento dos imóveis afetados

4. Verificação em campo das marcas de sedimentos deixadas nas partes dos estabelecimentos para definição das alturas de submersão observadas

5. Comparação das marcas observadas em campo com as obtidas pela simulação.

A Figura 5.1 apresenta o fluxograma simplificado da metodologia proposta neste capítulo. 
Figura 5.1 - Fluxograma simplificado da metodologia para comparação entre os valores de altura simulada e

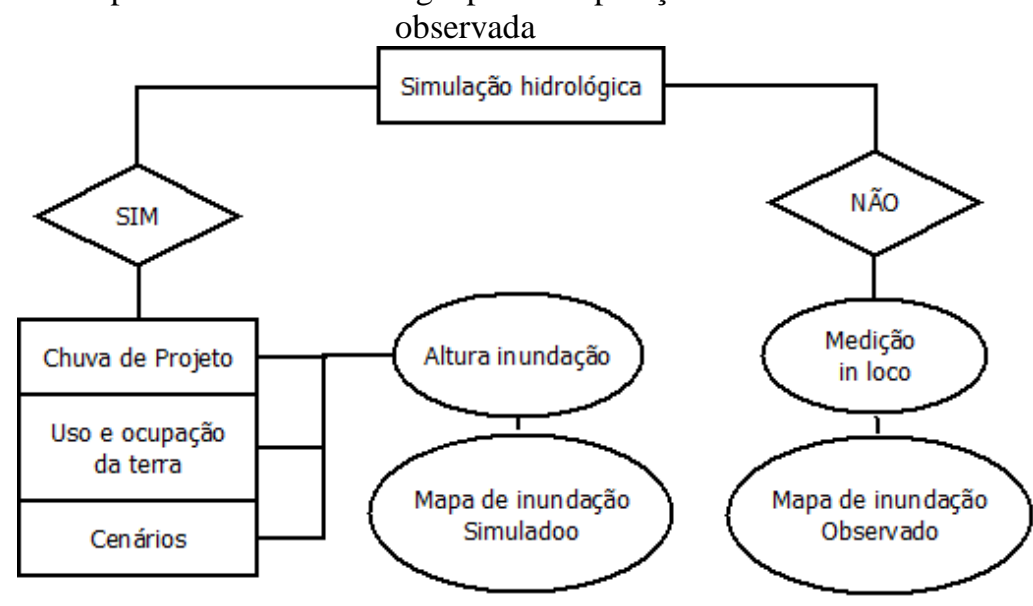

\subsubsection{Definição dos hietogramas de projeto e simulação hidráulica-hidrológica}

O hietograma de projeto foi obtido pelos dados obtidos de pluviógrafo no córrego do Gregório para os eventos de 22 de outubro de 2013, 23 de novembro de 2015 e 20 de março de 2018. As Figuras 5.2 a 5.4 apresentam o hietograma de tais chuvas observadas no córrego do Gregório e na Figura 4 é apresentado o hidrograma de saída da chuva simulado pelo software HEC-HMS.

Figura 5.2 - Hietograma das chuvas estudadas de 23 de novembro de 2013

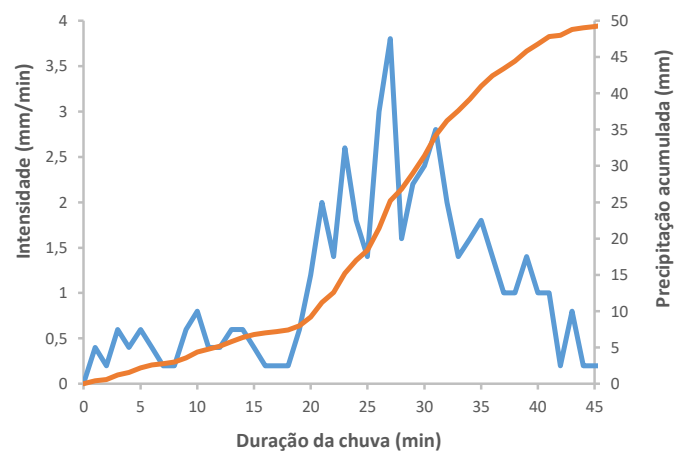

intensidade $\longrightarrow$ acumulado
Figura 5.3 - Hietograma das chuvas estudadas de 23 de novembro de 2015

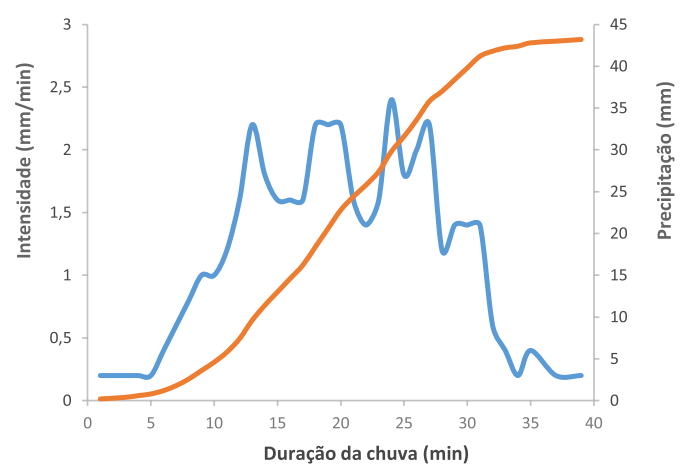


Figura 5.4 - Hietograma das chuvas estudadas de 20 de março de 2018

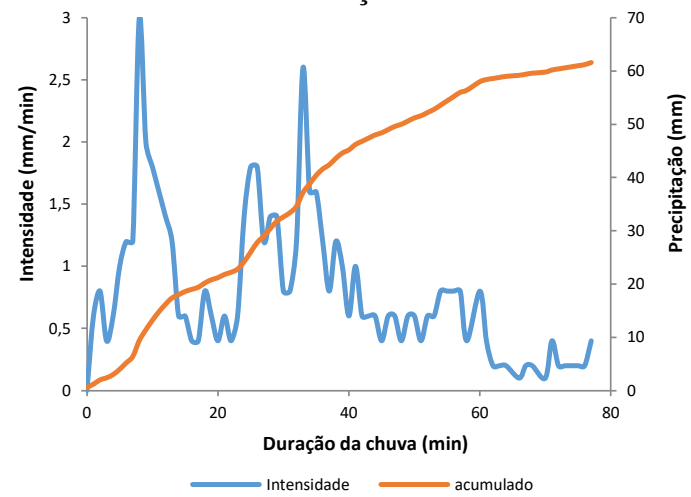

Para a precipitação de 2013, foi verificado que a intensidade média foi de $1,07 \mathrm{~mm} / \mathrm{min}$, com total precipitado de 49 mm em 45 min, o que, de acordo com a equação de Barbassa (1991) corresponde ao TR de 20 anos.

Para o evento de 2015, a intensidade média da chuva observada foi de $1,11 \mathrm{~mm} / \mathrm{min}$, sendo o total precipitado de $43 \mathrm{~mm}$. Considerou-se apenas a parcela de maior intensidade da chuva, com duração de 39 minutos e que corresponde ao tempo de retorno de 14 anos.

Para o evento de 2018, a intensidade média foi de $0,8 \mathrm{~mm} / \mathrm{min}$, sendo o total precipitado de $62 \mathrm{~mm}$ em $76 \mathrm{~min}$, que corresponde ao TR de 32 anos.

Com o uso desse hietogramas, foram elaboradas manchas de inundações por meio de modelo de simulação hidráulica-hidrológica (capítulo 3) para verificar as alturas obtidas no modelo e comprar com as obtidas por meio de medição in loco para os eventos de 2015 e 2018.

\subsubsection{Identificação e cadastramento dos imóveis afetados}

Foram cadastrados locais onde foi possível verificar a altura de inundação pelas mercas de sedimentos deixadas em suas paredes. Tendo em vista que as obtenções das marcas muitas vezes eram distantes umas das outras, buscou-se traçar retas entre os pontos de verificação para verificar as alturas das empresas entrevistadas.

Foi realizada a verificação em campo das marcas de sedimentos deixadas nas partes dos estabelecimentos para definição das alturas de submersão observadas $24 \mathrm{~h}$ após o evento de inundação. As marcas deixadas foram utilizadas para verificar a altura máxima atingida pela inundação nos respectivos eventos. Os locais coletados são apresentados na Figura 5.5. 
Figura 5.5 - Pontos de obtenção das alturas de submersão

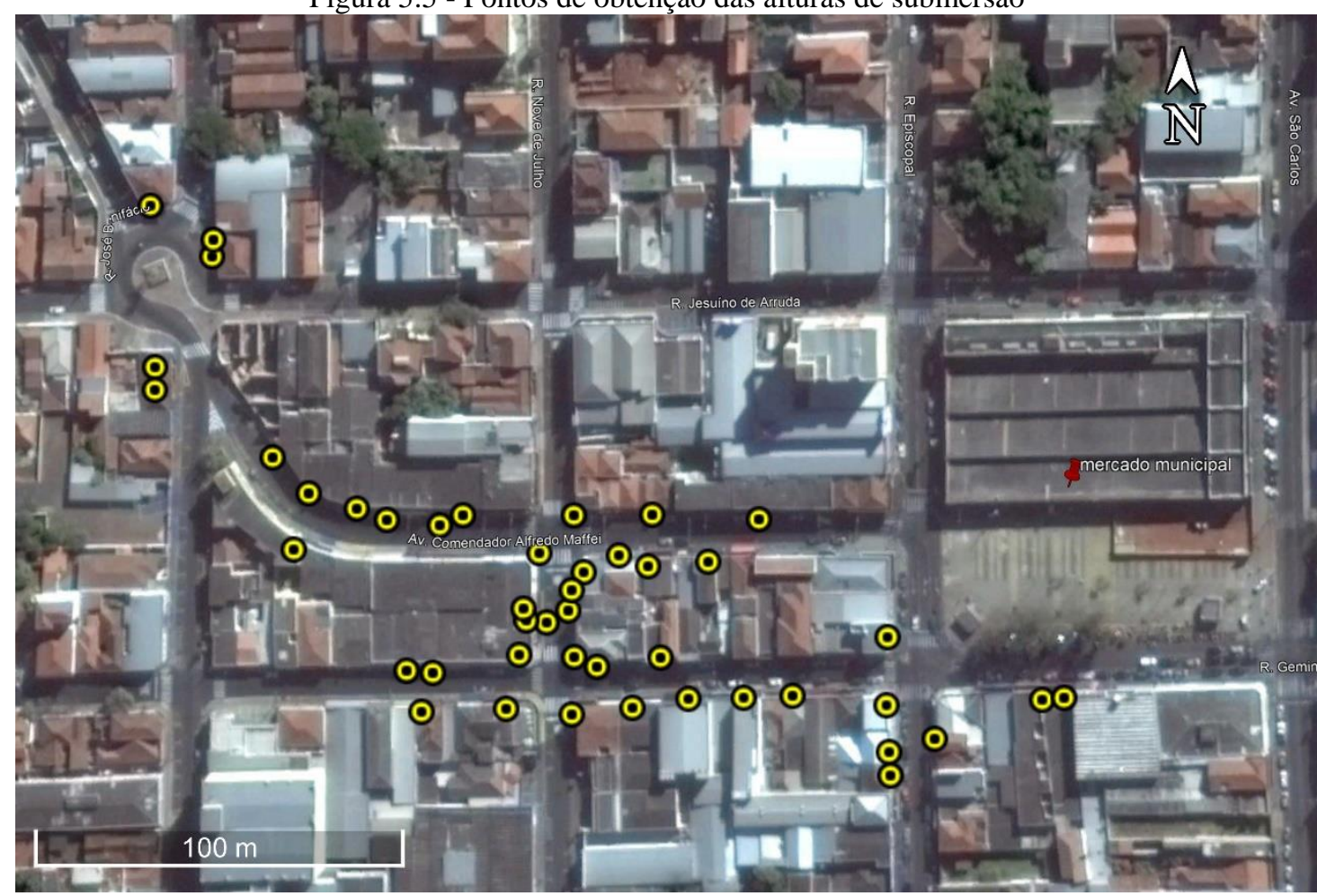

\subsection{RESULTADOS}

\subsubsection{Análise adimensional dos hietogramas dos eventos}

Para analisar os hietogramas de chuvas dos eventos propostos, estes formam adimensionalizados em relação a precipitação e o tempo de duração da chuva. Desta forma, foi possível estabelecer relação entre as chuvas observadas utilizadas neste estudo com o observado por Huff (1967). A Figura 5.6 apresenta as chuvas adimensionalisadas para os eventos de 2013, 2015 e 2018 e os quartis observados por Huff (1967) 
Figura 5.6 - Curvas adimensionais precipitação x tempo dos eventos simulados e comparação com os quartis observados por Huff (1967)

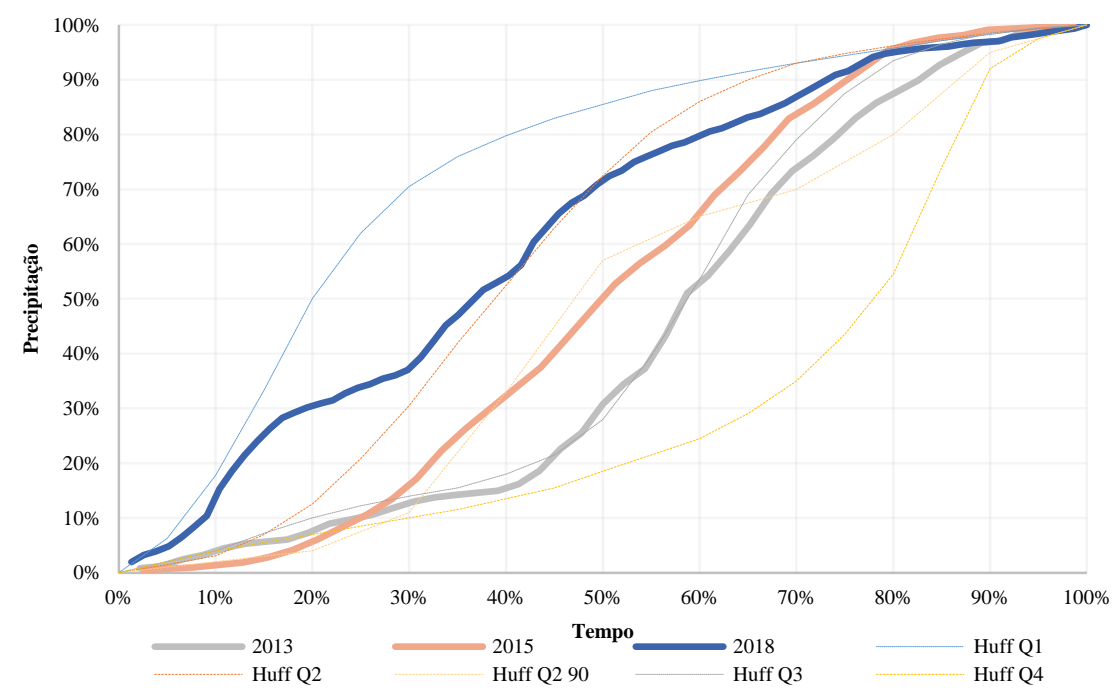

Analisando a Figura 5.5 percebe-se que a chuva observada de 2013 situou-se próximo do quartil Q3 de Huff, a de 2015 ficou situadas no segundo quartil com 90\% de excedência e a de 2018 situou-se entre o primeiro quartil (até $20 \%$ da duração da chuva) e o segundo quartil. Destaca-se que quando mais tarde ocorrer o pico da inundação, maiores serão os picos de inundação no hidrograma de cheia.

\subsubsection{Simulação hidrológica}

Na Figura 5.7 é apresentado o hidrograma de saída da chuva simulado pelo software HEC-HMS.

Figura 5.7 - Vazão simulada para os eventos considerados

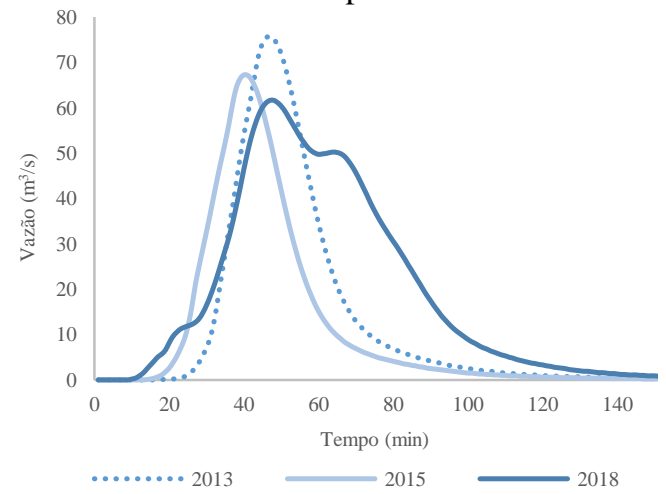

Por meio da Figura 5.7 é possível comparar a vazão de entrada da sub bacia 12 (Figura 3.6) para os eventos analisados. É possível perceber que as vazões de entrada da sub-bacia tiveram valores próximos, variando de $61 \mathrm{~m} 3 / \mathrm{s}$ (2018) a $74 \mathrm{~m} 3 / \mathrm{s}$ (2013), apesar da diferença 
significativa em termos de tempo de retorno entre os eventos, sendo que o evento de 2018 foi de TR 32 anos e o evento de 2013 de TR 20 anos, ou seja, apesar do maior tempo de retorno da precipitação em 2018, a mesma obteve vazão de saída menor. Esse fato se deu em decorrência da distribuição temporal de chuva que cada evento apresentou, já que, em 2013, o hietograma se situou próximo do terceiro quartil, enquanto que em 2018 entre o primeiro e o segundo quartil. Assim, a distribuição temporal de chuva pode trazer diferenças significativas na vazão de saída.

\subsubsection{Análise das alturas de inundação}

A partir do modelo hidráulico-hidrológico (capítulo 3) e dos dados de campo de altura de inundação decorrente do evento dos eventos de precipitação de 23 de novembro de 2015 e 20 de março de 2018, foram comparadas as alturas reais com aquelas simuladas na plataforma HEC.

As alturas foram obtidas por meio da medição com trena das marcas deixadas pelo rio nas paredes dos imóveis 24 horas após a ocorrência do evento para os dois eventos. Foram comparadas as alturas de submersão da chuva simulada com aquelas verificadas nas medições de campo. Para a chuva de 20 de outubro de 2013 não será realizada esta análise, tendo em vista que não foram obtidas informações de altura de inundação deste evento.

Para demonstrar as diferenças, os dados foram plotados em gráficos que relacionam a altura observada com a altura simulada. Nos gráficos elaborados, quanto mais distante os pontos encontram-se da reta, maior a diferença encontrada entre a simulação e os dados reais. Os resultados das alturas observadas e simuladas são apresentados nas Figuras 5.8 a 5.16. 
Figura 5.8 - Altura de submersão observada e simulada na Rua Comendador Maffei (2015)

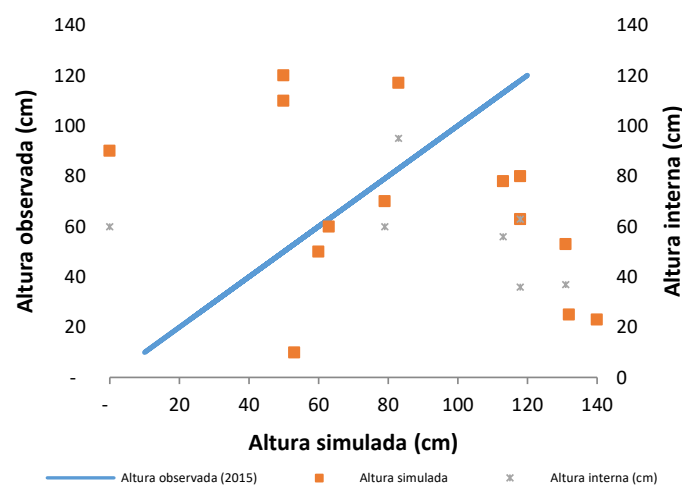

Figura 5.10 - Altura de submersão observada e simulada na Rua Episcopal (2015)

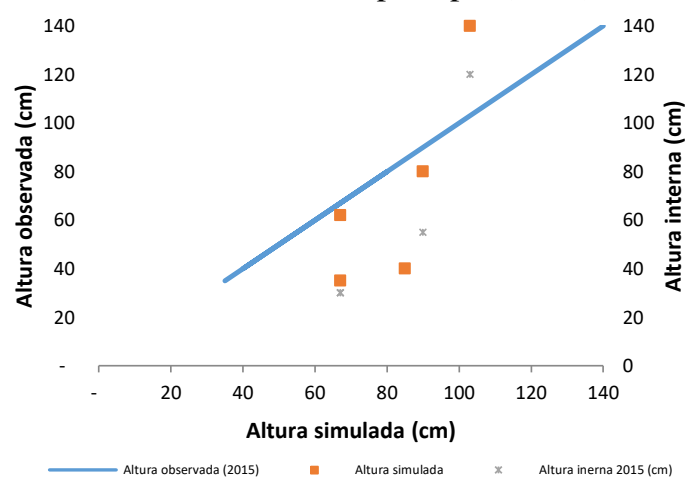

Figura 5.12 - Altura de submersão observada e simulada na Rua Geminiano Costa (2015)

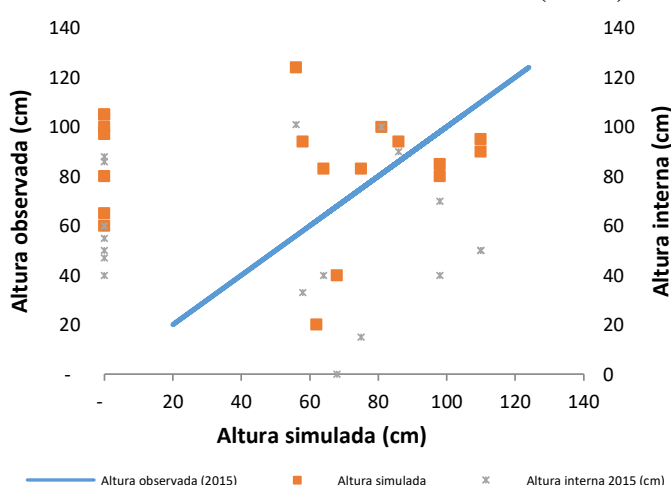

Figura 5.9 - Altura de submersão observada e simulada na Rua Comendador Maffei (2018) 140

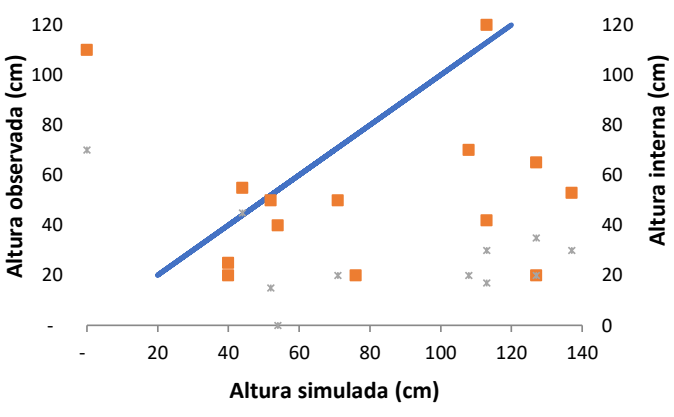

Figura 5.11 - Altura de submersão observada e simulada na Rua Episcopal (2018)

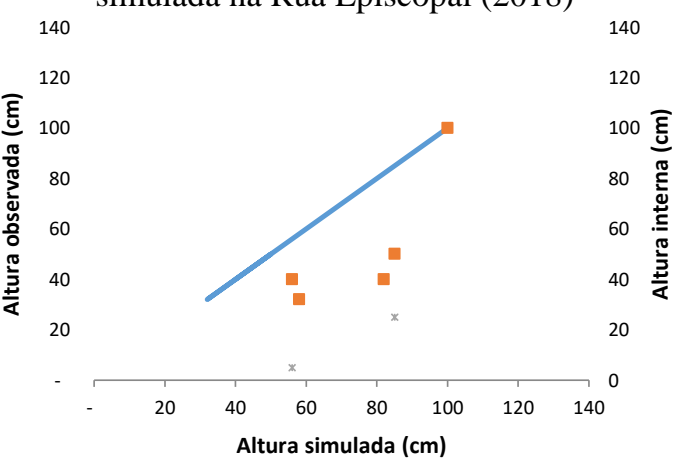

Figura 5.13 - Altura de submersão observada e simulada na Rua Geminiano Costa (2018)

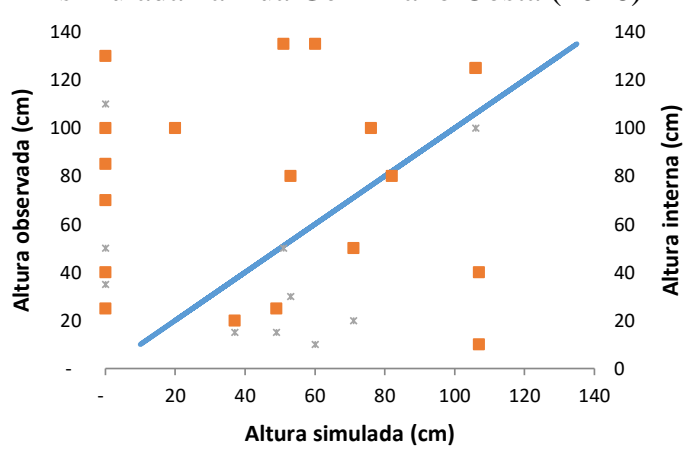


Figura 5.14 - Altura de submersão observada e simulada na Rua Nove de Julho (2015)

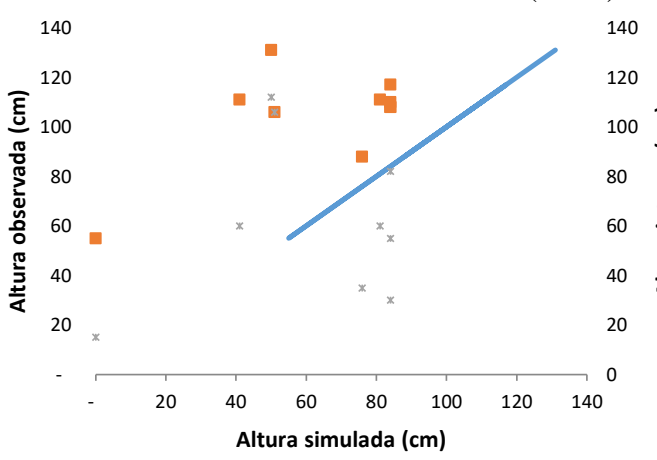

Figura 5.16 - Altura de submersão observada e simulada total (2015)

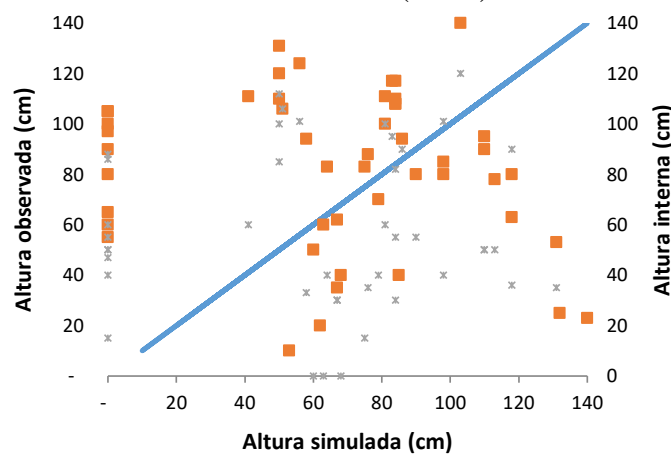

Figura 5.15 - Altura de submersão observada e simulada na Rua Nove de Julho (2018)

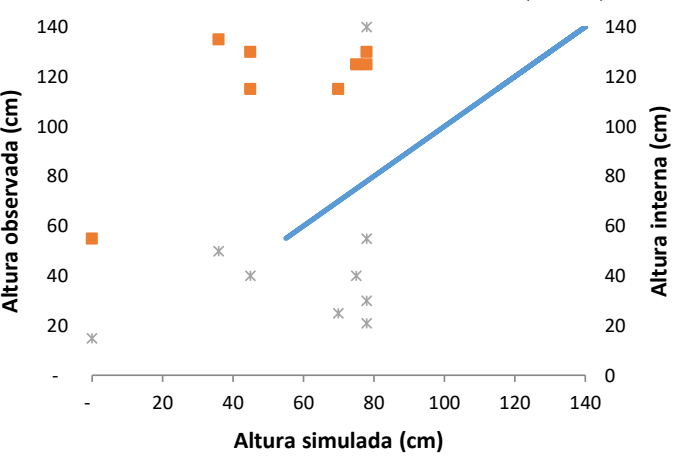

Figura 5.17 - Altura de submersão observada e simulada total (2018)

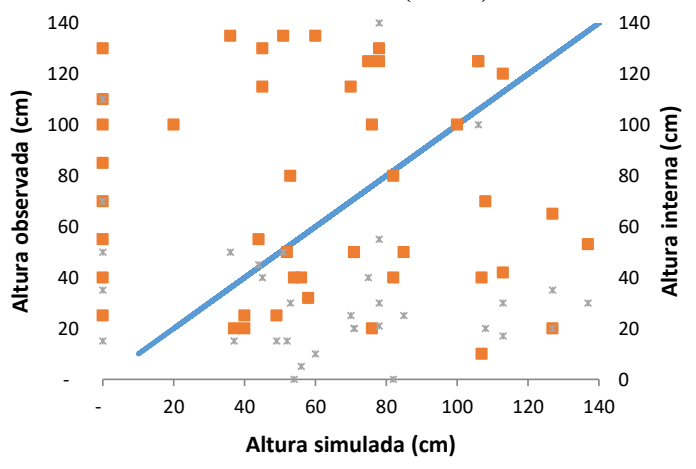

É possível concluir pelas figuras que nas ruas Geminiano Costa e Nove de Julho as alturas observadas foram maiores que as alturas simuladas, notadamente na Rua Geminiano Costa, em que seis pontos com alturas observadas entre 60 e $110 \mathrm{~cm}$ estavam fora da mancha de inundação. Esses dados podem ser explicados pelo comportamento unidimensional da mancha simulada, já que no modelo o fluxo de água ocupa os espaços de acordo com a declividade do terreno, enquanto que, na realidade, o fluxo possui características bidimensionais, ocupando as ruas como verdadeiros canais momentâneos de cursos de água.

Além disso, todo o espaço entre os quarteirões é considerado como espaço vazio pelo modelo, aumentando ainda mais o erro. Na Rua Comendador Maffei, onde localiza-se o córrego do Gregório (tamponado), verifica-se que a altura observada é menor que a altura simulada pois, em um modelo unidimensional, a maior altura de água certamente será na própria calha do rio.

Para avaliar estatisticamente as discrepâncias entre os valores reais e simulados, é apresentado na Tabela 5.1 as comparações estatísticas entre os valores reais e os simulados. Cabe salientar que houveram locais em que se observou altura de submersão reais, porém essas 
não foram observadas no modelo simulado. Esses pontos foram considerados igual a zero e tiveram assim impacto significativo estatisticamente. As Figuras 5.18 a 5.22 apresentam esses valores estatisticamente com uso de gráficos boxplot.

Tabela 5.1 - Comparação estatística entre os valores reais de altura de simulação reais e simulados

\begin{tabular}{|c|c|c|c|c|c|c|c|}
\hline \multicolumn{8}{|c|}{ Evento } \\
\hline \multicolumn{4}{|c|}{$23 / 11 / 2015$} & \multicolumn{4}{|c|}{$20 / 03 / 2018$} \\
\hline \multicolumn{4}{|c|}{ Rua Comendador Maffei } & \multicolumn{4}{|c|}{ Rua Comendador Maffei } \\
\hline & Observado & Simulado & Erro & & vado & Simulado & Erro \\
\hline Média & 68 & 85 & 17 & Média & 53 & 79 & 26 \\
\hline Mediana & 67 & 81 & 15 & Mediana & 50 & 74 & 24 \\
\hline Q1 & 51 & 55 & 4 & Q1 & 29 & 46 & 17 \\
\hline Q3 & 88 & 118 & 31 & Q3 & 63 & 113 & 51 \\
\hline Desv Pad & 35 & 41 & 7 & Desv Pad & 31 & 42 & 11 \\
\hline Máximo & 120 & 140 & 20 & Máximo & 120 & 137 & 17 \\
\hline Mínimo & 10 & 0 & 10 & Mínimo & 20 & 0 & 20 \\
\hline \multicolumn{4}{|c|}{ Rua Nove de Julho } & \multicolumn{4}{|c|}{ Rua Nove de Julho } \\
\hline & Observado & Simulado & Erro & & vado & Simulado & Erro \\
\hline Média & 105 & 64 & 41 & Média & 125 & 58 & 66 \\
\hline Mediana & 109 & 79 & 31 & Mediana & 128 & 73 & 55 \\
\hline Q1 & 107 & 50 & 56 & Q1 & 118 & 45 & 73 \\
\hline Q3 & 111 & 84 & 27 & Q3 & 134 & 78 & 56 \\
\hline Desv Pad & 20 & 28 & 8 & Desv Pad & 29 & 26 & 3 \\
\hline Máximo & 131 & 84 & 47 & Máximo & 165 & 78 & 87 \\
\hline Mínimo & 55 & 0 & 55 & Mínimo & 55 & 0 & 55 \\
\hline \multicolumn{4}{|c|}{ Geminiano Costa } & \multicolumn{4}{|c|}{ Geminiano Costa } \\
\hline & Observado & Simulado & Erro & & vado & Simulado & Erro \\
\hline Média & 84 & 50,8 & 33 & Média & 78 & 49 & 29 \\
\hline Mediana & 90 & 62,0 & 28 & Mediana & 80 & 51 & 29 \\
\hline Q1 & 80 & 0,0 & 80 & Q1 & 40 & 0 & 40 \\
\hline Q3 & 98 & 83,5 & 15 & Q3 & 113 & 79 & 34 \\
\hline Desv Pad & 24 & 42,8 & 19 & Desv Pad & 42 & 42 & 1 \\
\hline Máximo & 124 & 110 & 14 & Máximo & 135 & 107 & 28 \\
\hline Mínimo & 20 & 0 & 20 & Mínimo & 10 & 0 & 10 \\
\hline \multicolumn{4}{|c|}{ Rua Episcopal } & \multicolumn{4}{|c|}{ Rua Episcopal } \\
\hline & Observado & Simulado & Erro & & vado & Simulado & Erro \\
\hline Média & 71 & 82 & 11 & Média & 52 & 76 & 24 \\
\hline Mediana & 62 & 85 & 23 & Mediana & 40 & 82 & 42 \\
\hline Q1 & 40 & 67 & 27 & Q1 & 40 & 58 & 18 \\
\hline Q3 & 80 & 90 & 10 & Q3 & 50 & 85 & 35 \\
\hline Desv Pad & 42 & 16 & 27 & Desv Pad & 27 & 19 & 9 \\
\hline Máximo & 140 & 103 & 37 & Máximo & 100 & 100 & 0 \\
\hline Mínimo & 35 & 67 & 32 & Mínimo & 32 & 56 & 24 \\
\hline \multicolumn{4}{|c|}{ Total } & \multicolumn{4}{|c|}{ Total } \\
\hline & Observado & Simulado & Erro & & vado & Simulado & Erro \\
\hline Média & 82 & 67 & 16 & Média & 78 & 62 & 15 \\
\hline Mediana & 87 & 72 & 15 & Mediana & 70 & 65 & 5 \\
\hline Q1 & 62 & 50 & 12 & Q1 & 40 & 40 & 0 \\
\hline Q3 & 107 & 87 & 20 & Q3 & 121 & 83 & 39 \\
\hline Desv Pad & 31 & 40 & 9 & Desv Pad & 44 & 39 & 5 \\
\hline Máximo & 140 & 140 & 0 & Máximo & 165 & 137 & 28 \\
\hline
\end{tabular}




\begin{tabular}{llll|llll}
\hline Mínimo & 10 & 0 & 10 & Mínimo & 10 & 0 & 10 \\
\hline
\end{tabular}

Figura 5.18 - Boxplot referente a altura observada $\mathrm{x}$ simulada para a Rua Comendador Maffei

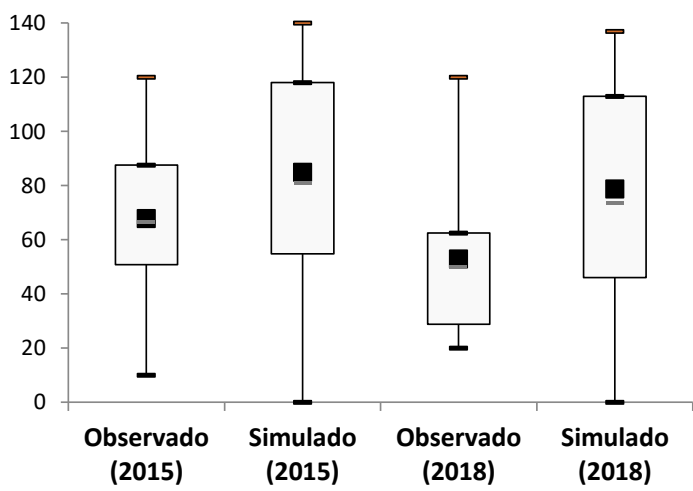

Figura 5.20 - Boxplot referente a altura observada $\mathrm{x}$ simulada para a Rua Episcopal

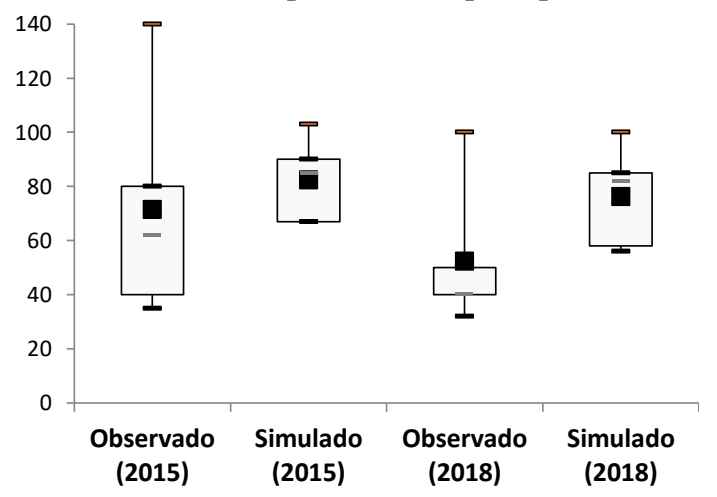

Figura 5.19 - Boxplot referente a altura observada $\mathrm{x}$ simulada para a Rua Nove de Julho

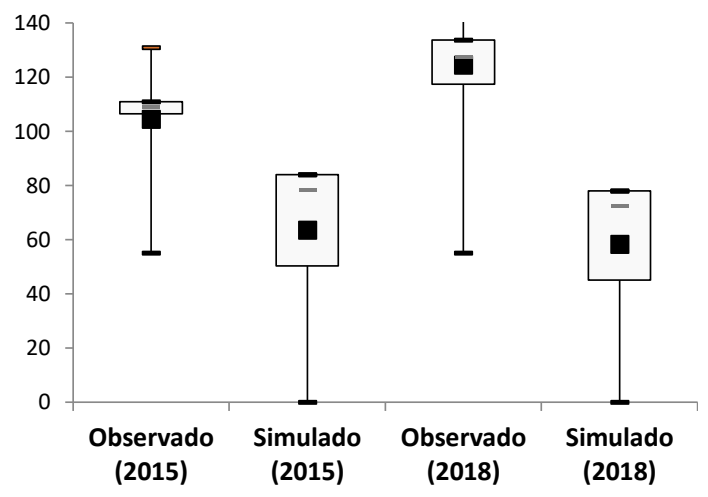

Figura 5.21 - Boxplot referente a altura observada x simulada para a Rua Geminiano Costa

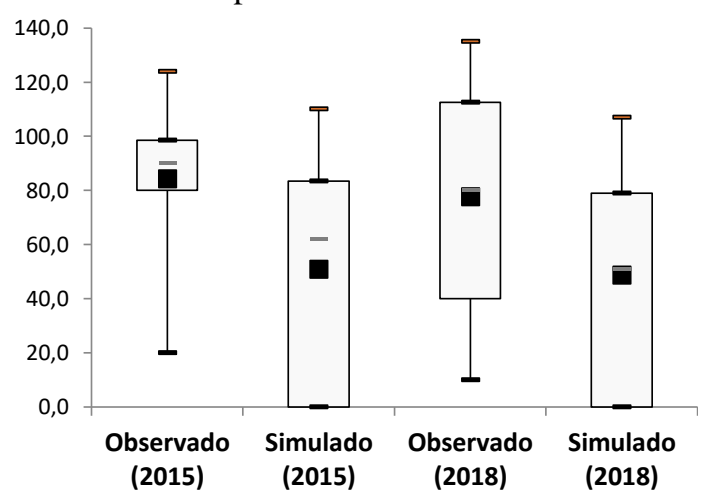

Figura 5.22 - Boxplot referente a altura observada x simulada total

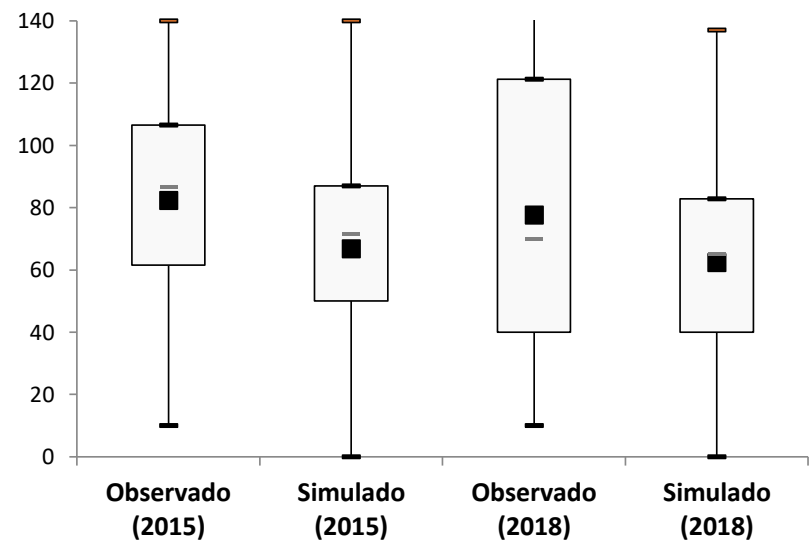

\subsection{CONCLUSÃO}

A modelagem unidimensional utilizando a plataforma HEC é amplamente utilizada devido a relativa facilidade de se realizar simulações e pouca necessidade de dados de entrada 
em relação a outros softwares. Porém, em situações em que o tempo de concentração é baixo, a declividade da região é alta e a área da mancha de inundação encontra-se intensamente ocupada por edificações e ruas, é necessário que se escolha modelos mais complexos para realizar a modelagem da região, notadamente quando a altura de inundação for a variável desejada, tendo em vista que os efeitos bi dimensionais dos fluxos de água, as transformações de energias cinética e potencial e o preenchimento dos espaços pelas edificações tornam a análise desses fatores imprescindíveis na obtenção de resultados satisfatórios.

Porém, devido à alta dispersão dos dados, a análise dos valores médios e medianos e das alturas simuladas e observadas (Figura 5.22) permite verificar que tais alturas passaram a ser similares e, caso fosse utilizada uma análise em meso escala dos danos, tal efeito dispersivo poderia ser diminuído nessa escala de análise. 


\section{REFERÊNCIAS BIBLIOGRÁFICAS}

BARROS, R. M.; ESTEVES, R. L.; MENDIONDO, E. M.; WENDLAND, E. Cálculo de vazões em eventos críticos para mapeamento de inundações na sub-bacia do Córrego do Gregório, São Carlos - SP. XV Simpósio Brasileiro de Recursos Hídricos, Curitiba/PR, Brasil, 2003.

HUFF, F. A., Time distribution of rainfall in heavy storms. Water Resources Research, v.3, n.4, p. 1007-1019. 1967.

RIGHETTO, J.M.; BARROS, R.M.; MENDIONDO, E.M. Avaliação da seguridade e percepção pública sobre riscos de enchentes em várzeas urbanizadas: o caso do microcentro da cidade São Carlos-SP. XV Simpósio Brasileiro de Recursos Hídricos. CuritibaPR. 2003

SOUZA, M. M. Comparação Entre Ferramentas de Modelagem Unidimensional e Quasi-Bidimensional, Permanente e Não- Permanente, em Planejamento e Projetos de Engenharia Hidráulica -: Dissertação (mestrado) - UFRJ/ COPPE/ Programa de Engenharia Civil, Rio de Janeiro. 2010. 


\section{CAPÍTULO 6 - ANÁLISE QUALI-QUANTITATIVA DO EFEITOS DAS INUNDAÇÕES URBANAS AOS IMÓVEIS COMERCIAIS LOCALIZADOS NA REGIÃO DO MERCADO MUNICIPAL}

\section{RESUMO}

O objetivo deste capítulo é abordar as questões quali-quantativas dos impactos das inundações relacionados aos prejuízos. Para isso, foram analisados dois eventos de inundação em que ocorram severos prejuízos na região, por meio de entrevistas junto aos comerciantes impactados locais. Assim, foi possível diagnosticar a resistência desses comerciantes ao enfrentamento desse perigo, juntamente em como a memória desses é utilizada para se analisar tal resistência. Além disso, as entrevistas foram estruturadas para se avaliar os prejuízos diretos e indiretos desses comerciantes.

\subsection{INTRODUÇÃO}

A Lei 12.608, de 10 de abril de 2012, que institui a Política Nacional de Proteção e Defesa Civil, prevê que é dever da União, dos Estados, do Distrito Federal e dos Municípios adotar as medidas necessárias à redução dos riscos de desastre, com a colaboração de entidades públicas ou privadas e da sociedade em geral.

Dentre as medidas necessárias para a redução dos riscos, diagnosticar as áreas de perigo, buscando conhecer os impactos provocados pelas inundações, é uma ação inerente às atividades de resposta e mitigação desses efeitos. Tal procedimento colabora com os tomadores de decisão, dentre outros, em análises sobre custo-benefício de medidas mitigadoras.

Outra providência a ser aplicada é a averiguação de alturas de inundação a partir de dados coletados por meio de voluntários da população afetada. Esta é uma importante ferramenta para a calibração de modelos hidráulico-hidrológicos, tornando-se um recurso essencial à resposta de eventos de cheia e sistemas de previsão de alerta - elementos imprescindíveis para a mitigação dos prejuízos e análise sócio hidrológica dos desastres.

Para avaliar as consequências de eventos de inundações em bacias urbanas - baseado nos acontecimentos ocorridos entre 2015 e 2018, no município de São Carlos - foram realizadas entrevistas junto aos comerciários do entorno do mercado municipal da cidade, região que sofre com inundações frequentes e representa o centro comercial.

Com base nessas informações é possível estabelecer um panorama relativo às perdas dos comerciantes da localidade selecionada e realizar um diagnóstico da situação. Tais dados auxiliam os tomadores de decisão a avaliar o custo-benefício de medidas mitigadoras, estipular o valor do prêmio ótimo junto aos segurados e colaborar para futuras pesquisas com dados. 


\subsection{METODOLOGIA}

Nesta metodologia foram abordados os prejuízos diretos e indiretos considerados mais significativos na caracterização dos impactos das cheias no meio urbano. São eles:

- Danos a propriedades: conteúdo e edificação;

- Limpeza dos imóveis;

- Lucro cessante;

- Estragos a veículos;

- Custos de infraestrutura

A metodologia é constituída pelas seguintes etapas:

1. Identificação e cadastramento dos imóveis afetados;

2. Elaboração de questionário aplicado ao setor comercial;

3. Aplicação do questionário aos comerciantes da região diretamente impactados pelas inundações;

4. Análise das variáveis de estudo baseadas nas respostas dos comerciantes e nas alturas de inundação obtidas in loco;

5. Análise dos custos diretos e indiretos das inundações;

6. Estudo comparativo estatístico dos dados obtidos nas entrevistas com os auferidos por Machado (2005) e Riguetto (2005).

A Figura 6.1 apresenta o fluxograma simplificado deste capítulo

Figura 6.1 - Fluxograma simplificada da obtenção do prejuízo total dos danos provocados pela inundação

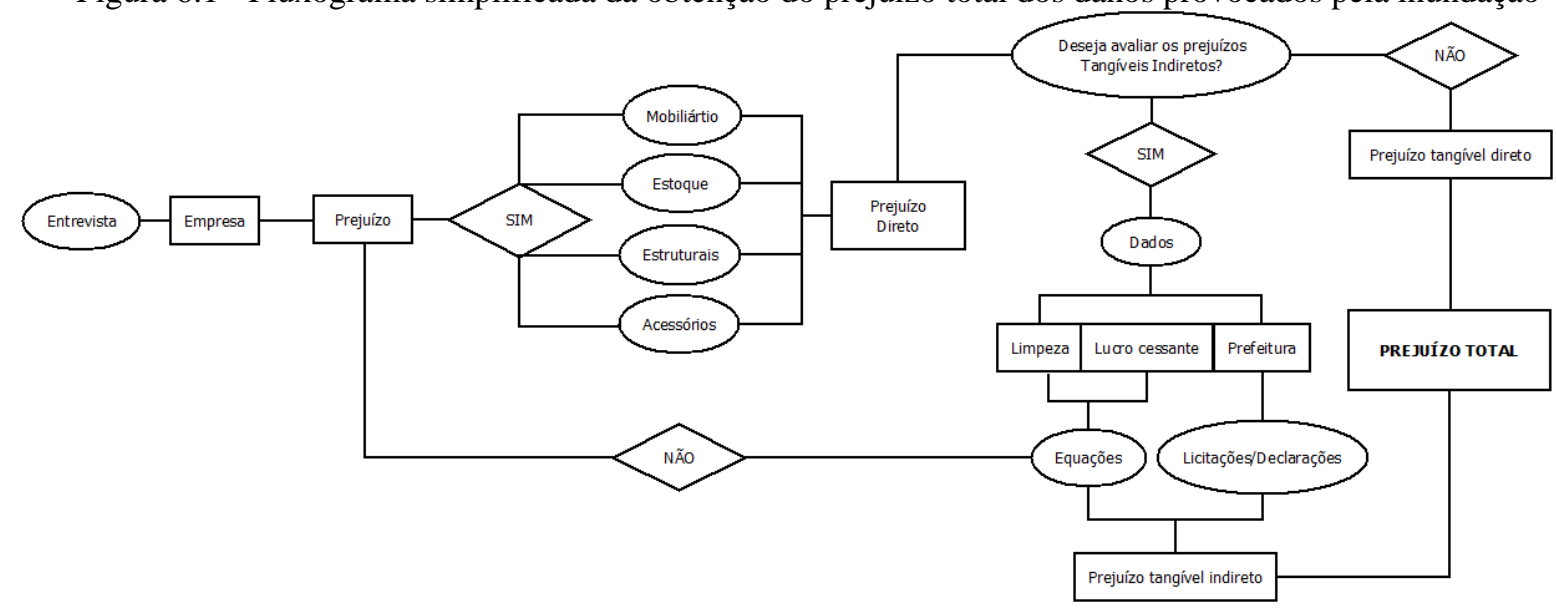

\subsubsection{Identificação e cadastramento dos imóveis afetados}

O processo de entrevistas ocorreu em duas etapas: foram realizadas 28 entrevistas, realizadas entre $24 \mathrm{~h}$ e $72 \mathrm{~h}$ após o evento de 23 de novembro de 2015; e 51 entrevistas realizadas 
entre maio e junho de 2019, em que se obtiveram informações relativas à inundação de 23 de novembro de 2015 e de 21 de março de 2018, ambas com comerciários do entorno do mercado municipal. O critério estabelecido para iniciar a entrevista foi a água ter adentrado seu imóvel, sendo a primeira questão abordada junto aos comerciantes após as apresentações iniciais. Assim, buscou-se traçar as bordas da área que continham imóveis impactados (aqueles em que a água adentrou o imóvel), já que, quando o comerciante informava que a água não havia adentrado seu imóvel, buscava-se entrevistar o imóvel adjacente a esse. Portanto, os limites dos imóveis junto às ruas condizem, com razoável aproximação, aos limites dos imóveis impactados com as inundações.

Fora realizada rápida abordagem junto aos comerciantes localizados dentro do mercado municipal, porém não foram realizadas entrevistas individuais com esses, tendo em vista informarem que suas lojas não sofreram prejuízo, apenas necessidade de higienização do local. De acordo com os lojistas do mercado municipal, a comporta (de $53 \mathrm{~cm}$ de altura) instalada em frente à entrada do mercado foi suficiente para conter a inundação e impedir que a maior parte do fluxo de água adentrasse o local: verificou-se apenas sedimentos oriundos da enchente que atravessaram pelos vãos do tapume, havendo a limpeza do local posteriormente.

Foi realizado também o levantamento das coordenadas de cada estabelecimento comercial entrevistado para especialização em sistema GIS. A localização dos locais visitados na mancha de inundação é apresentada na Figura 6.2. 


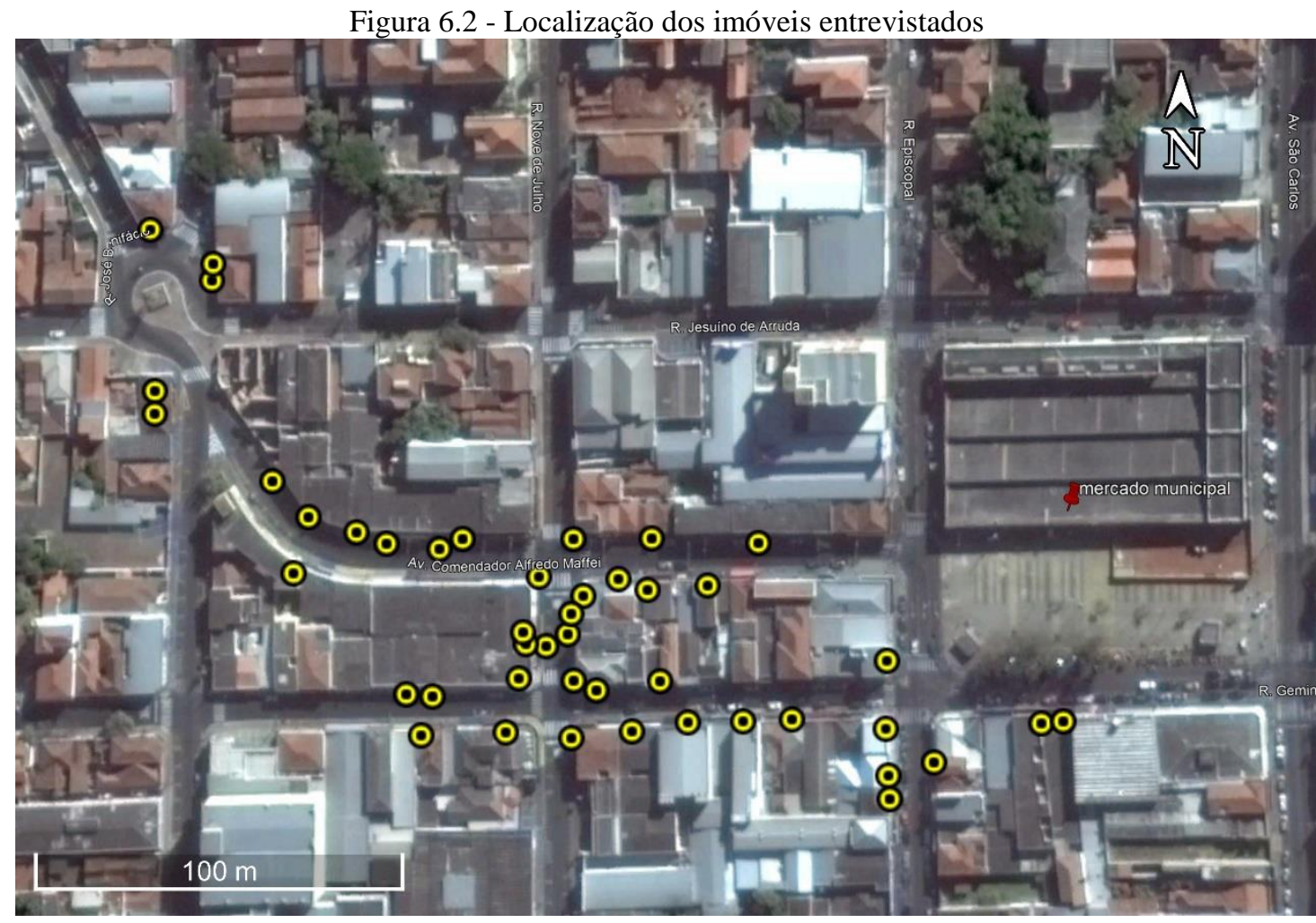

\subsubsection{Elaboração de questionário aplicado ao setor comercial}

O questionário aplicado nas propriedades comerciais (Apêndice 2) contém informações relacionadas:

- à empresa: nome, endereço, categoria do comércio ou serviços, número de empregados e área de exposição dos produtos;

- ao levantamento de dados sobre o conteúdo das propriedades considerando: estoque, equipamentos, móveis de escritório, unidades de exposição e armazenamento, estimativa dos prejuízos sofridos e do valor dos bens expostos, altura das comportas (se existente);

- às informações gerais sobre a inundação, compreendendo as profundidades de submersão (interna e externa) da construção, a duração, a antecedência com a qual a empresa foi alertada sobre iminência do evento e as atitudes adotadas após o alerta;

- a dados relacionados a danos indiretos: estimativa de tempo de interrupção das atividades, estimativa de perdas de negócio, estimativa do tempo de limpeza dos imóveis, números de pessoas envolvidas do processo de higienização e limpeza;

- a seguros, ajudas e indenizações;

No momento das entrevistas, era perguntado ao entrevistado qual a função exercida por ele: proprietário, gerente ou funcionário da loja. Essa informação é importante uma vez que o 
proprietário possui maior conhecimento sobre a loja do que os demais funcionários. Verificouse que, quando os superiores eram entrevistados, perguntas relacionadas às questões financeiras, como valor do estoque, dimensão do prejuízo e disposição a pagar por prejuízos eram respondidas detalhadamente, fato que não ocorria quando o funcionário era entrevistado. Do total das entrevistas, 8 foram respondidas por funcionários, 8 por gerente do estabelecimento e 34 pelos proprietários da loja.

\subsubsection{Aplicação de questionário aos comerciantes da região diretamente impactados pelas inundações}

Nesta etapa do trabalho, foi utilizado tablet com aplicativo DoForms ${ }^{\odot}$, no qual plotaram-se as questões para realização das entrevistas. O software foi de grande ajuda, já que é capaz de gerar relatórios com os dados coletados, apresentando cálculos automáticos prédeterminados, a possibilidade de incluir fotografias do local, assim como a coleta de coordenadas geográficas e a facilidade de exportação para o Excel.

Antes disso, foram realizadas visitas na ACISC (Associação Comercial de São Carlos) para realização de apoio institucional. Esta entidade divulgou diversas notícias de jornais ${ }^{7}$ relatando que seriam realizadas tais entrevistas com o intuito de conhecer melhor os danos sofridos na região, bem como divulgando em suas reuniões a presença futura do pesquisador no local.

Tal abordagem foi de fundamental importância para estabelecer elo de confiança entre o entrevistador e os entrevistados, visto que foram solicitadas, além de informações hidrológicas, outras de caráter financeiro acerca de seus estabelecimentos. Um exemplo de relatório gerado pelo sistema contendo as questões abordadas na entrevista está apresentado no Apêndice 2.

\footnotetext{
7 São Carlos Agora:

http://www.saocarlosagora.com.br/cidade/acisc-realizara-pesquisa-com-comerciantes-da-regiao-central/100706/

São Carlos em Rede:

https://saocarlosemrede.com.br/acisc-fara-pesquisa-sobre-prejuizos-das-enchentes-em-sao-carlos/

Região em Destaque:

http://www.regiaoemdestake.com.br/site/2018/04/13/estudo-acisc-realizara-pesquisa-com-comerciantes-da-regiao-central/

São Carlos Mais:

http://www.saocarlosmais.com.br/2018/04/16/acisc-realizara-pesquisa-com-comerciantes-da-regiao-central/

Jornal Primeira Página:

https://www.jornalpp.com.br/cidades/item/129675-acisc-realizara-pesquisa-com-comerciantes

São Carlos Alerta:

https://www.saocarlosalerta.com.br/noticia/acisc-realizara-pesquisa-com-comerciantes-da-regiao-central

Diário São Carlos:

http://www.diariosaocarlos.com.br/diario/index.php/cidade/item/3506-acisc-realizara-pesquisa-com-comerciantes-da-regiao-central

São Carlos Dia e Noite:

https://www.saocarlosdiaenoite.com.br/cidade/58028-acisc-realizara-pesquisa-com-comerciantes-da-regiao-central
} 
A entrevista foi estruturada para durar de 3 a 5 minutos; porém a abordagem foi muito positiva junto a alguns comerciantes: houve conversas de até 40 minutos sobre a problemática da inundação. Cabe salientar que, ao entrar no estabelecimento, era solicitado ao comerciante que preenchesse um termo de livre consentimento do uso das informações obtidas na entrevista, elaborado pelo corpo jurídico da ACISC (Apêndice 3), assim como uma carta de apresentação assinada pelo presidente da ACISC (Apêndice 4), que era cedida ao comerciante.

Esse ponto foi fundamental para melhorar a relação interpessoal estabelecida, possibilitando abertura a respeito das questões ocorridas em seu estabelecimento relativas à inundação, já que demonstrou maior preparo do entrevistador para com o entrevistado. Este fato foi percebido em comparação às entrevistas de 2015: havia menos preparo do ponto de vista do pesquisador/entrevistador, logo, não se obteve tanta abertura nas respostas como em 2018, com o órgão de apoio. No Apêndice 5 são apresentados, resumidamente, os principais pontos apresentados pelos comerciantes, relacionados às suas experiências em eventos de inundação.

Além das entrevistas, foram tiradas fotos internas e externas das lojas, com o intuito de se verificar a altura mínima acima do piso em que estavam os produtos e a densidade de ocupação destes no recinto.

\subsubsection{Medição das variáveis obtidas in loco}

Foram medidas, em cada estabelecimento, as seguintes características:

- área do estabelecimento;

- altura da planta baixa em relação a rua;

- altura da comporta;

- altura de submersão interna.

A medição das alturas da lâmina fora realizada com trena a laser, com alcance de até $15 \mathrm{~m}$, tendo como base as marcações oriundas dos sedimentos nas paredes dos estabelecimentos e a memória das pessoas com relação aos eventos. Tais informações mostraram que lâmina d'água interna atingiu até 1,5 metro na inundação de 2015 e 1,4 metro na inundação de 2018, ambas verificadas no mesmo local (esquina da Rua Nove de Julho com a Geminiano Costa). As marcas puderam ser percebidas em alguns estabelecimentos pelo sedimento ainda exposto no papel de parede de uma das lojas (Figura 6.3). 
Figura 6.3 - Exemplo de marca causada pelo sedimento das paredes do imóvel

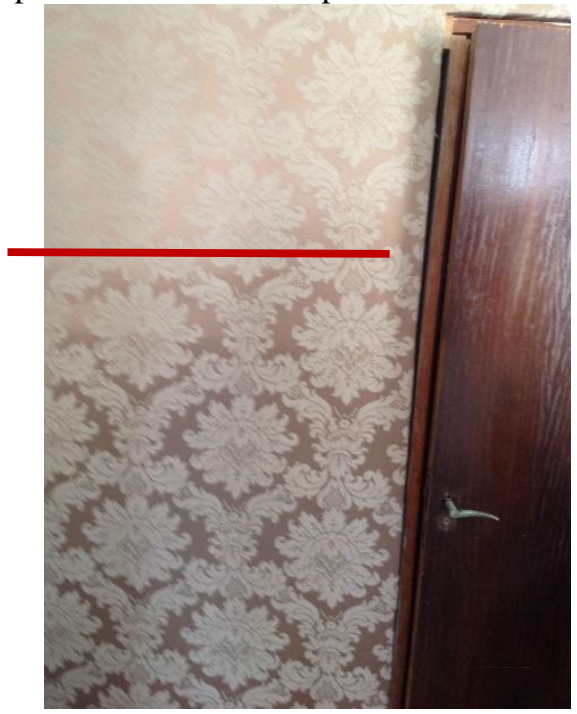

Dentre as questões abordadas nas entrevistas, foi solicitado que os entrevistados apontassem o nível d’água atingido pelas inundações em 2015 e 2018 e se houve alterações nas estruturas das comportas em decorrência desses eventos. A Figura 6.4 apresenta as marcas deixadas pela água causadas pela da inundação ou a percepção das pessoas com relação ao seu nível máximo atingido.

Figura 6.4 - Apontamento das marcas atingidas na inundação pelos afetados

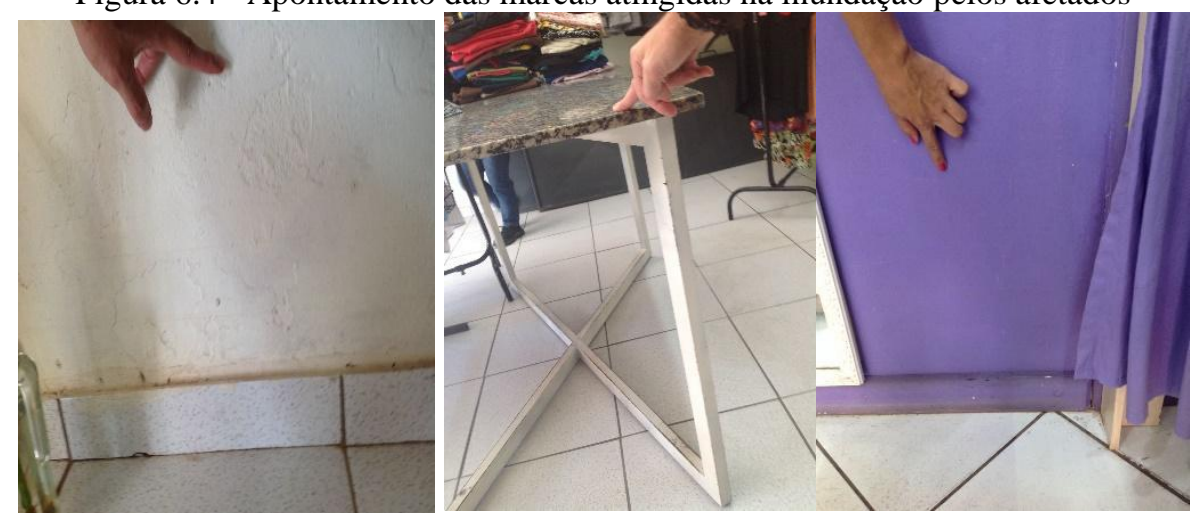

Com relação às comportas, tomou-se como base a altura da haste de suporte existente entre as paredes dos imóveis, tendo em vista que a comporta é projetada para atingir até esta altura. A altura considerada foi aquela existente entre o topo da comporta e o piso da loja.

Além disso, foi verificado a altura do piso em relação à calçada, para assim se averiguar a altura de submersão que cada estabelecimento está resistente à ameaça. Essa informação é importante pois, em um modelo de inundação, tal variável pode trazer diferenças significativas a respeito da altura interna de inundação, sendo o fator mais importante na averiguação do 
prejuízo. Como o local de estudo possui historicamente recorrência de eventos de inundação, é fato que os comerciantes possuem piso elevado em relação à calçada.

Um exemplo da medição da comporta e da altura da planta baixa da loja em relação a calçada é apresentado, respectivamente, na Figura 6.5.

Figura 6.5 - Medição da altura da comporta e da altura da planta baixa em relação a calçado dos imóveis

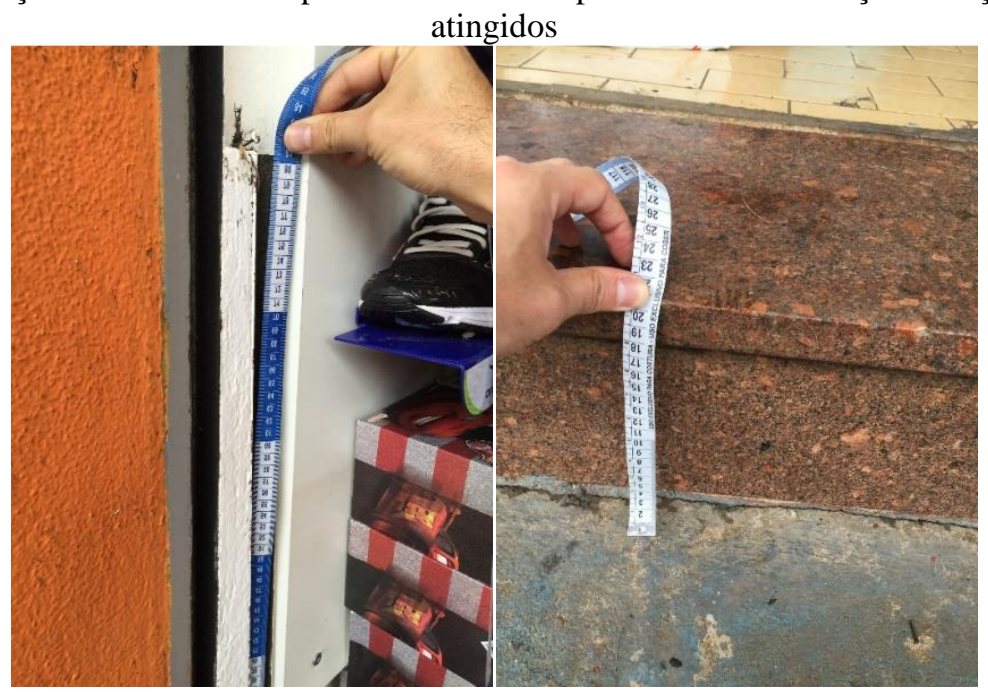

Com relação à área do estabelecimento, buscou-se medir apenas a área com exposição de produtos, não sendo assim consideradas as áreas de escritório, banheiros, ou outras não expostas ao público.

Com o uso das informações de altura interna obtidas pelos entrevistados, da área do estabelecimento e dos valores de prejuízo e estoque, foi possível realizar análises com o intuito de relacionar tais variáveis. Além disso, ao relacionar tais variáveis, foi possível também comparar os resultados com outras pesquisas similares.

\subsubsection{Análise dos custos diretos e indiretos das inundações}

\subsubsection{Custos diretos}

Para quantificação dos custos diretos, foram solicitadas informações referente ao valor do prejuízo e ao valor do estoque. As informações foram obtidas para os dois eventos de inundação analisados nesta pesquisa.

Com relação ao prejuízo, esses foram classificados em 4 categorias: estoque; acessórios; estruturais e móveis.

Os danos ao estoque referem-se as mercadorias atingidas pela inundação. Cabe salientar que, notadamente para o setor de calçados, muitos são revendidos a preço reduzido para mitigar 
as perdas, o que não foi computado nessa pesquisa, sendo assim não considerada tal recomposição do valor.

Para os móveis, foi considerada a perda daqueles atingidos pela inundação e que de fato sofreram depreciação, decorrente, por exemplo, do estufamento da madeira. Muitas vezes, apesar do mobiliário ter sido atingido, esse não foi impactado e o comerciante informava que tais não seriam substituídos. Nesse caso, o mobiliário não foi considerado no montante do prejuízo.

Para os aos acessórios, considerou-se equipamentos como computadores e outros eletrônicos, objetos que fazem parte das vendas da loja, porém não representam estoque, como sacolas, cartões, brindes, etc. Para os danos físicos, além dos danos propriamente ditos, como alvenaria e pintura, considerou-se também os valores declarados com medidas mitigadoras, como comportas e muros.

Com relação ao valor do estoque, como existe a dificuldade de estimar o estoque em cada período, foi solicitado que cada comerciante declarasse um valor médio de estoque de mercadorias em seus estabelecimentos ao longo do ano. Tais valores referem-se apenas ao estoque existente no primeiro pavimento do imóvel.

\subsubsection{Custos indiretos}

Foram considerados os seguintes custos indiretos:

- Custos de infraestrutura

- Lucro cessante;

- Danos aos veículos;

- Limpeza dos estabelecimentos;

\section{Custos de infraestrutura}

Com relação aos custos da infraestrutura, foram utilizados, para o ano de 2018, informações solicitadas à prefeitura relativas aos danos provocadas pela inundação, por meio de processo para solicitação de informações via plataforma GIAP da prefeitura sob número de processo 6.025/2018. Apesar do pedido ser referente aos prejuízos de 2015 e 2018, apenas os valores de obras e serviços do ano de 2018 foram informados.

Em vista desta limitação, foram utilizados, para o ano de 2015, dados da Defesa Civil para a mensuração dos custos atribuídos a prefeitura para conserto e reparação dos danos provocados pelas enchentes. 


\section{Lucro cessante}

O lucro cessante é o lucro que o comerciante deixa de adquirir em detrimento do evento hidrológico causador da inundação.

Para estimar o lucro cessante, desenvolveu-se metodologia baseada no valor do estoque declarado pelos comerciantes, e no tempo que o estabelecimento ficou fechado para vendas, varáveis estas contidas na entrevista. Para quantificar essa análise, o tempo que o comércio ficou fechado e a receita anual do estabelecimento são variáveis fundamentais para se determinar esse valor.

Para isso, fora estimada e dividida a receita líquida de revenda anual dos comércios entrevistados pela quantidade de horas trabalhadas no ano para se obter a receita líquida anual horária, sendo esse valor multiplicado pela duração que o comércio ficou fechado.

Com relação ao tempo que o estabelecimento ficou fechado, foi solicitado aos entrevistados informarem tal dado.

Já a estimativa da receita líquida de revenda foi realizada tendo como base a pesquisa anual de comércio (IBGE, 2016) na Tabela 5B (Receita líquida de revenda, compras, estoques, margem e taxa de margem de comercialização das empresas comerciais, segundo divisões, grupos e classes das atividades - Brasil - 2016), localizada no anexo do documento, que informa a Receita Líquida de revenda no ano de 2015 e o estoque em 31.12.2015 para cada classe de atividade (Anexo 1).

De acordo com o glossário do documento (IBGE, 2016), a receita líquida de revenda corresponde à receita bruta proveniente da atividade comercial exercida pela empresa, com deduções dos impostos e contribuições (ICMS, IPI, ISS, PIS, COFINS etc.) das vendas canceladas, abatimentos e descontos incondicionais relativos à comercialização de mercadorias. Já a receita bruta de revenda é a receita bruta proveniente da atividade comercial exercida pela empresa, sem deduções dos impostos e contribuições (ICMS, IPI, ISS, PIS, COFINS etc.) das vendas canceladas, abatimentos e descontos incondicionais relativos à comercialização de mercadorias (IBGE, 2016).

Assim, na falta de informações sobre relação de receita bruta de revenda e estoque, adotou-se o índice referente a receita líquida de revenda pelo estoque como aproximação para esta variável.

A relação entre as variáveis (receita líquida de revenda; estoque em 31.12.2015; tipo de atividade) foi importada para as empresas de São Carlos. Dessa forma, de acordo com o tipo de 
atividade comercial de cada empresa, estimou-se sua respectiva receita anual líquida. $\mathrm{O}$ percentual da receita pelo estoque $(\mathrm{R} / \mathrm{E})$ relacionado com o tipo de atividade comercial é apresentado na Tabela 6.1.

Tabela 6.1 - Tipo de atividade comercial e média nacional do faturamento e do estoque em 31.12.2015

\begin{tabular}{|c|c|c|c|}
\hline Tipo de atividade & $\begin{array}{r}\text { Receita Anual } \\
\text { Líquida (R) } \\
(\mathbf{R} \$)\end{array}$ & $\begin{array}{r}\text { Estoque (E) em } \\
31 / 12 / 2015 \\
(\mathbf{R} \$)\end{array}$ & $(\mathbf{R} / \mathbf{E})$ \\
\hline Hipermercados e supermercados & 461.103 .020 & 68.547 .800 & 6,73 \\
\hline $\begin{array}{l}\text { Outros tipos de comércio não especializado com } \\
\text { predominância de produtos alimentícios (1) }\end{array}$ & 340.228 .491 & 21.043 .620 & 16,17 \\
\hline $\begin{array}{l}\text { Comércio não especializado sem predominância } \\
\text { de produtos alimentícios (2) }\end{array}$ & 37.782 .347 & 11.348 .998 & 3,33 \\
\hline Tecidos e artigos de armarinho & 15.002 .653 & 6.127 .731 & 2,45 \\
\hline Artigos do vestuário e complementos & 96.494 .079 & 25.746 .300 & 3,75 \\
\hline Calçados, artigos de couro e viagem & 29.910 .176 & 9.800 .939 & 3,05 \\
\hline $\begin{array}{l}\text { Produtos farmacêuticos, perfumaria e cosméticos } \\
\text { e artigos médicos, ortopédicos e de óptica }\end{array}$ & 121.676 .232 & 27.878 .870 & 4,36 \\
\hline Comercio não especializado & 173.220 .529 & 23.013 .593 & 7,53 \\
\hline Outros produtos novos (3) & 24.825 .718 & 5.091 .168 & 4,88 \\
\hline
\end{tabular}

(1) - Lojas com menos de $300 \mathrm{~m}^{2}$ (minimercados, mercearias, armazéns, empórios, etc.

(2) - Lojas de departamentos e variedades

(3) - Artigos de joalheria, relojoaria, metais preciosos; artigos de suvenires, de bijuterias e de artesanatos objetos de arte; Fonte: Adaptado de IBGE (2016)

Para aplicar os valores de receita anual, estes valores foram transformados em horas, tendo em vista a variável tempo que o estabelecimento ficou fechado estar nessa unidade. Foram consideradas 12 meses de trabalho, 22 dias úteis por mês e 8 por dia de trabalho, totalizando assim 2.112 horas de trabalho. Não foram somadas as horas referentes aos sábados, tendo em vista que nem todas as empresas abrem neste período e nem horários especiais, como natal, etc., por ser de difícil quantificação.

Em posse dessas informações, a equação 6.1 apresenta a equação utilizada para estimar a receita bruta horária e a Equação 6.2 a equação aplicada para estimar o lucro cessante.

$$
\begin{aligned}
& R_{h}=\frac{V_{e} *\left(\frac{R}{E}\right)}{H_{\text {ano }}} \\
& L C=T_{f} * R_{h}
\end{aligned}
$$

Em que:

$\mathrm{R}_{\mathrm{h}}=$ Receita líquida de revenda horária;

$\mathrm{V}_{\mathrm{e}}=$ Valor médio do estoque no ano;

$\mathrm{R} / \mathrm{E}=$ Relação entre Receita e Estoque;

$\mathrm{H}_{\mathrm{ano}}=$ Número de horas de trabalho em um ano;

$\mathrm{LC}=$ Lucro Cessante;

$\mathrm{T}_{\mathrm{f}}=$ Tempo que o estabelecimento se manteve fechado em detrimento das inundações;

Esta abordagem traz uma nova forma de levantamento de dados de empresas, já que busca atribuir valores de receita das empresas de forma indireta. Foram consideradas 44 
empresas nessa análise, referente àquelas que responderam à questão relacionada ao valor médio anual do estoque.

\section{Limpeza dos estabelecimentos}

Os estabelecimentos comerciais que são invadidos pelas águas de inundação necessitam de limpeza e higienização de seus estabelecimentos. Essa limpeza pode ser realizada por empresas externas terceirizadas ou pelos próprios funcionários do estabelecimento.

O custo relacionado a perda de horas de trabalho devido à limpeza do comércio foi adaptado, tendo como base a metodologia de Nagem (2008), que a definiu para a limpeza de residências, para ser incorporada à limpeza do comércio. Dessa forma, o custo da limpeza do comércio pode ser regido pela equação (6.3):

$C L C=\sum\left(\frac{R M T * E S}{N H}\right) * T L * N P$

Em que:

CLR $=$ Custo de Limpeza do comércio

$\mathrm{RMF}=$ Renda média do empregado $(\mathrm{R} \$)$

$\mathrm{ES}=$ Encargos Sociais $(95 \%)=1,95$

$\mathrm{NH}=$ Número de horas de trabalho por mês $=168$ horas

$\mathrm{TL}=$ Tempo de limpeza (horas/pessoa)

$\mathrm{NP}=$ Número de pessoas envolvidas na limpeza

Para a variável renda média do empregado, foi utilizado como fonte o instituto SalárioBR ${ }^{8}$, que se fundamentado em dados extraídos do Banco Nacional de Empregos ${ }^{9}$, empresa que com mais de 20 milhões de currículos cadastrados, para filtrar a pesquisa e definir a média salarial por categoria de trabalho. Neste caso, foi utilizada a categoria "vendedor de loja" e adotada a média salarial do trabalhador pleno, que considera aqueles com experiência entre 4 a 6 anos na função, sendo assim estipulado o salário médio de $\mathrm{R} \$ 1.793,98$. A Figura 6.6 expõe a média salarial dessa categoria de trabalho para diferentes classes de experiência profissional.

\footnotetext{
${ }^{8} \mathrm{https://www.salariobr.com/}$

${ }^{9}$ https://www.bne.com.br/
} 
Figura 6.6 - Valor médio salarial da categoria "vendedor de loja" de acordo com a experiência profissional

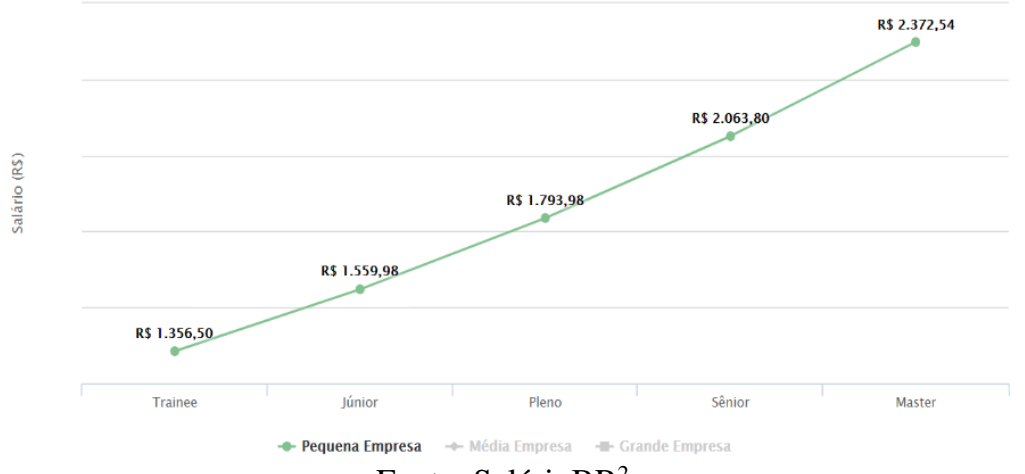

Fonte: SalárioBR ${ }^{2}$

Durante a entrevista, três questões foram abordadas com intuito de quantificar esse ponto: i) tempo necessário para realizar a limpeza do estabelecimento; ii) número de pessoas envolvidas no processo de limpeza; iii) se a limpeza do estabelecimento foi realizada pelos próprios funcionários ou empresas terceirizadas. As duas variáveis foram abordadas apenas para a entrevista de 2018, sendo que, dessa forma, o custo de limpeza está associado a este evento. Foram obtidas informações relativas a estas variáveis para 40 estabelecimentos comerciais. Dessas empresas, 37 utilizaram os funcionários de suas lojas para realizarem a limpeza dos estabelecimentos, e apenas 3 contrataram serviços terceirizados para essa finalidade.

As despesas das empresas que usaram serviços terceirizados para realizar a limpeza não estão embutidas nos custos aqui expostos, sendo incluídos na categoria de prejuízo "danos físicos". As informações relativas a essas questões podem ser observadas no anexo x. Para responder a equação 6.3, será utilizado o número de pessoas envolvidas no processo e o somatório de horas gasta pelas empresas para realizar a limpeza dos estabelecimentos.

\section{Danos aos veículos}

De acordo com o relatório da Defesa Civil, 63 carros e 32 motos $^{10}$ foram afetados. Em 2018, o órgão contabilizou 25 veículos danificados pelas águas ${ }^{11}$.

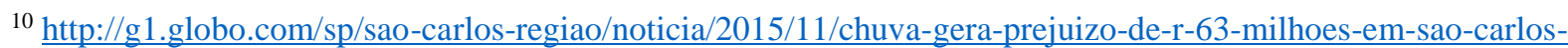
aponta-defesa-civil.html

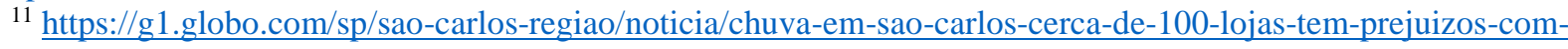
alagamentos-no-centro.ghtml
} 
Para realizar a quantificação desses danos, inicialmente foi levado em consideração o tempo médio da frota nacional em circulação, considerada nessa análise como sendo de 9 anos e 3 meses. ${ }^{12}$

A partir deste dado, foram verificados os preços dos veículos mais vendidos no Brasil ${ }^{13}$ para se estabelecer uma média de preço, buscando automóveis com tempo de uso aproximado da média de frotas dos veículos e seus valores de mercado. Dessa forma, os seguintes veículos e valores selecionados estão apresentados na Tabela 6.2. Para as motocicletas, foi considerado o valor de R \$ 4.500, preço médio de uma Honda CG 125, ano 2008, veículo mais vendido no Brasil.

\begin{tabular}{|c|c|c|}
\hline Veículo & Ano & Valor (R\$) \\
\hline Gol & 2008 & $16.392,00$ \\
\hline Fiat Uno & 2012 & $20.768,00$ \\
\hline Fiat Palio & 2010 & $17.686,00$ \\
\hline Celta & 2008 & $15.483,00$ \\
\hline Corsa & 2005 & $15.517,00$ \\
\hline Ford Fiesta & 2008 & $18.426,00$ \\
\hline Fox & 2010 & $21.849,00$ \\
\hline Fiat Siena & 2010 & $23.151,00$ \\
\hline Corsa Sedan & 2005 & $14.393,00$ \\
\hline Ford Ka & 2008 & $16.320,00$ \\
\hline Média & 2008 & $17.998,50$ \\
\hline
\end{tabular}

Desse modo, a equação utilizada para quantificar os danos dos veículos impactados pelas chuvas é apresentado na Equação 6.4

$D_{v}=\sum N_{v} * \bar{P}_{v}$

Em que:

$\mathrm{D}_{\mathrm{v}}=$ Danos aos veículos;

$\mathrm{N}_{\mathrm{v}}=$ Número de veículos;

$\bar{P}_{v}=$ Preço médio dos veículos usados no Brasil.

\subsubsection{Análise comparativa estatística dos dados obtidos nas entrevistas com aqueles obtidos por Machado (2005) e Riguetto (2005)}

Com relação a Machado (2005), as informações relativas as curvas DPS foram tabuladas de acordo com a autora para se estabelecer comparação de tais curvas com as objeto

\footnotetext{
${ }^{12}$ https://economia.estadao.com.br/noticias/geral,efeito-crise-faz-idade-media-de-frota-de-carros-no-pais-ser-amais-alta-em-10-anos, 70001790741

${ }^{13}$ https://exame.abril.com.br/seu-dinheiro/os-precos-dos-carros-usados-mais-vendidos-do-brasil/
} 
desse estudo. As curvas DPS de Machado (2005) para as distintas tipologias de comércio são apresentados no Anexo 1. Além disso, verificou-se as diferenças em termos de prejuízo total entre as metodologias, para se avaliar a diferença entre as metodologias na obtenção do prejuízo total.

Com relação ao estudo de Riguetto (2005), é possível estabelecer comparações relativas as variáveis disponibilidade a pagar, prejuízo e estoque, dessa vez oriunda da área de estudo.

\subsection{RESULTADOS}

\subsubsection{Aspectos qualitativos}

Com relação aos aspectos qualitativos, serão analisadas a memória da população de modo a correlacionar sua preparação para esses eventos. Para isso, será inicialmente exposto um histórico dos relatos dos comerciários da região, para depois avaliar quantitativamente tais informações.

\subsubsection{Declarações dos comerciários acerca dos problemas da inundação}

Por meio das entrevistas, percebeu-se que um fator preponderante quanto à magnitude dos prejuízos é o tempo que os comerciantes possuem para deslocar seus produtos a um lugar seguro.

Os comerciantes declararam que o fator preponderante ao nível de prejuízo do evento de 2015 foi a altura da água. No caso do evento de 2018 foi a velocidade da água, considerada mais rápida que a do evento de 2015 (maior enxurrada). Também foi declarado que o tempo entre o início da chuva e a ocorrência da inundação foi de 10 a 15 minutos para ambos os eventos.

O gerente de uma loja de produtos ópticos declarou que, devido a essa velocidade, não foi possível fechar o sistema de janelas de metal da sua vitrine - que funciona como segurança em dias normais -, pois este é elétrico e realizado por motores de forma lenta; desta forma a água atingiu os produtos por completo antes do fechamento total das janelas, quebrando as vidraças e levando os produtos para fora de seu estabelecimento. Como medida de proteção, após a inundação de 2018, o comerciante construiu paredes de alvenaria no local onde antes eram as vitrines da loja. $\mathrm{O}$ comerciante ainda relatou que diversas pessoas se aproveitaram da 
situação logo após a inundação ao se apossar de suas mercadorias que estavam espalhadas pela rua.

Cabe pontuar que o proprietário de um estabelecimento em que a água atingiu $1,2 \mathrm{~m}$ em 2015, que está no local há 10 anos, disse que nunca havia tido prejuízo com inundações. Nesse imóvel foi verificado que as vidraças da vitrine foram destruídas com a força da enxurrada, além de sua comporta ter cedido pelo impacto da água, ocasionando inundação no local, danificando produtos de vestuário, além de grande prejuízo pelo contato da água com sedimentos nos móveis. O comerciante relatou que, em eventos passados, a comporta instalada na entrada da loja foi suficiente para conter o avanço da água em seu estabelecimento.

Os comerciantes relataram que, há 5 anos, existia um sistema de alerta por meio de WhatsApp, no qual recebiam informes da defesa civil quanto à possibilidade de ocorrência de eventos extremos de precipitação. De acordo com a defesa civil de São Carlos, os eventos de 2015 e 2018 decorreram de uma rápida formação de nuvem do tipo cumullus nimbus, dificultando assim o lançamento de alerta aos comerciantes. A defesa civil ainda informou que envia alertas de inundação, porém não tem como prever a magnitude do evento devido à rápida formação das nuvens, pois afirma que as imagens de radar não são instantâneas, já que possuem um tempo de atraso de 8 minutos e a chuva possui tempo de formação não tão distante deste atraso, impossibilitando que o alarme seja emito com esse meio.

Porém, muitos comerciantes, principalmente aqueles instalados há menos de 1 ano na região, não possuíam qualquer dispositivo de mitigação, declarando-se surpresos com a força e a altura que água atingiu, muitos alegando que iriam desocupar o imóvel e abrir o comércio em outra região.

O proprietário de uma loja informou que foram necessários 2 dias para a limpeza completa do estabelecimento para retorno às atividades normais, sendo que o seguro do imóvel (SINISEG - ALLIANZ seguros) encaminhou uma equipe em 24 horas para auxiliar na limpeza do local.

Os comerciantes informaram que uma equipe da prefeitura realizou a limpeza do local no dia posterior a inundação; porém, não obtiveram qualquer auxílio financeiro por parte da prefeitura para reparar os danos causados pelas inundações e não tinham esperanças em obter. Entretanto, a ACISC (Associação de comércio de São Carlos), por meio de sua cooperativa de crédito, disponibilizou linha de crédito a juros reduzidos (18\% ao ano) para que os comerciantes pudessem retomar suas atividades e cobrir o prejuízo ao conteúdo (estoque e mobiliário). 
Porém, em recente medida judicial, foi julgada procedente ação de cunho indenizatório por comerciante local, referente a prejuízos em seu estabelecimento. Foi determinado em juízo que a prefeitura deveria indenizar o proprietário em $\mathrm{R} \$ 36.000$, referente aos prejuízos decorrentes da inundação de 2013 em seu imóvel ${ }^{14}$, apesar do comerciante ter solicitado mais de R\$ 90 mil para reparação dos danos.

A decisão, após todos os recursos possíveis em $1^{\text {a }}$ estância por parte de prefeitura, foi protocolada em 29 de maio de 2019 para que a prefeitura cumpra a ordem judicial, referente ao processo número 0003832-31.2019.8.26.0566 do foro de São Carlos. De acordo com o acórdão do juiz (processo número 1009905-41.2015.8.26.0566 da comarca de São Carlos), ao julgar recurso de defesa da prefeitura relativo à sua responsabilidade de indenizar os danos, declarou que "Reside a controvérsia na responsabilização do Município pelos danos sofridos pela autora; se os fatos ocasionaram abalo a justificar indenização por dano extrapatrimonial; e o valor pleiteado a título de indenização.”.

A alegação da empresa afirma que "o córrego que corta o centro de São Carlos transbordou e a força da água chegou a derrubar a mureta de proteção, tendo sido noticiado em jornais da época que a Prefeitura assumiu a necessidade de novas obras e disse que pagaria parte do prejuízo dos lojistas. Contudo, não foi o que aconteceu, pois alagamentos constantes se sucedem nos mesmos locais e seu pedido administrativo foi indeferido."

De acordo com a decisão, "a responsabilidade do Estado poderá ocorrer se, aliada à força maior, ocorrer omissão do Poder Público na realização de um serviço. Por exemplo, quando as chuvas provocam enchentes na cidade, inundando casas e destruindo objetos, o Estado responderá se ficar demonstrado que a realização de determinados serviços de limpeza dos rios ou dos bueiros e galerias de águas pluviais teria sido suficiente para impedir a enchente. O dano não decorreu de atuação de agente público, mas de omissão do poder público",

É interessante observar que, após uma enchente, muitos dos produtos atingidos pela água são colocados à venda por preços reduzidos, diminuindo assim o seu prejuízo. Essa situação é comum, principalmente entre os comerciantes do setor calçadista. Cabe aqui uma observação de que, relativa ao evento de 23 de novembro de 2015, os comerciários estavam com estoque elevado devido a promoção "Black Friday", que iria ocorrer 4 dias após esse evento de inundação.

\footnotetext{
${ }^{14} \leq$ https://www.acidadeon.com/saocarlos/divirtase/NOT,0,0,1347335,prefeitura+e+condenada+a+pagar+r36+mil +a+empresa+por+causa+de+enchente.aspx $>$ Acesso em 07 de junho de 2019
} 
Assim, para diminuir seus prejuízos e fazer desse evento trágico de inundação uma fonte de propaganda para venda dos produtos atingidos, vendedores criativos adotaram o slogan "Black Enchente" para a venda de seus produtos (Figura 6.7). O mesmo ocorreu em 2018, sob o slogan "liquida enchente" (Figura 6.8), demonstrando ser essa uma prática recorrente entre os lojistas
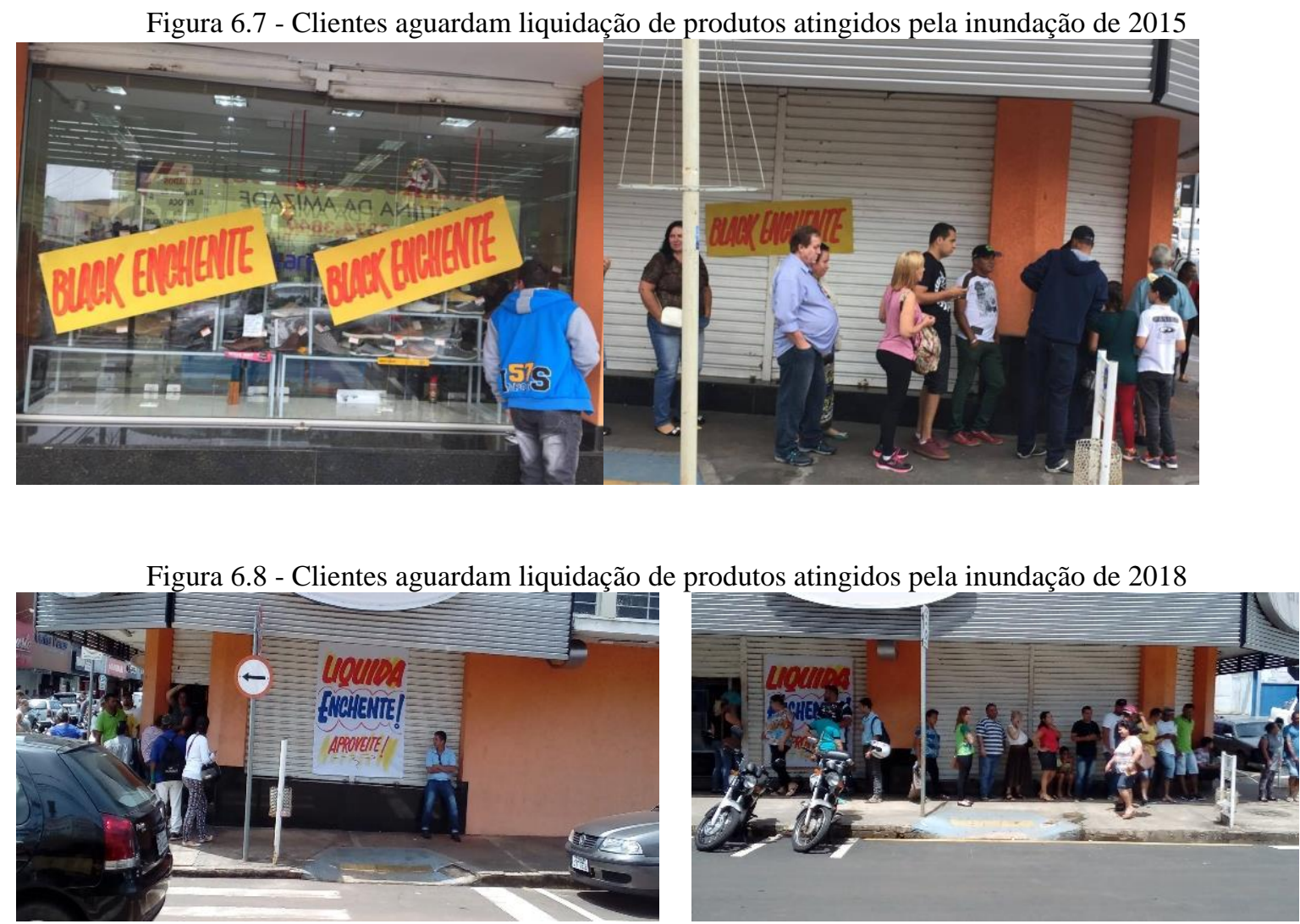

Com relação ao prejuízo de 2015, 25 dos 28 comerciantes entrevistados relataram prejuízos em suas lojas, que variaram de $\mathrm{R} \$ 500,00$ a $\mathrm{R} \$ 280.000,00$, sendo que a média dos danos foi em torno de $\mathrm{R} \$ 30$ mil, e a mediana de $\mathrm{R} \$ 10$ mil. Foi solicitado também que os comerciantes informassem uma estimativa dos prejuízos com relação ao estoque. Alguns deles não obtiveram prejuízo no estoque e conteúdo, mas relataram que houve a perda de sacolas e embalagens para presentes que se encontravam próximo ao solo.

Foi averiguada a disposição a pagar dos comerciantes por um seguro que cobrisse os prejuízos ocasionados pela inundação, porém o desconhecimento sobre o assunto fez com que apenas 4 deles se pronunciassem a respeito de um valor estipulado para esse seguro em 2015, que foi de $\mathrm{R} \$ 1.500, \mathrm{R}$ \$2.000, R \$ 2.500 e R \$ 3.500. Já com relação as entrevistas de 2018, 39 comerciantes informaram tal valor, sendo posteriormente apresentado. 
Com relação a existência de segundo piso na loja, poucos estabelecimentos possuíam um andar superior para estoque de seus produtos. Entretanto, mesmo para aqueles que possuíam piso superior, não foi possível o deslocamento dos produtos devido ao pouco tempo que tiveram para transportar a mercadoria (em torno de 5 a 10 minutos). Assim, o estoque de mercadorias considerado foi apenas aquele que estava inserido no primeiro pavimento do imóvel.

\subsubsection{Memória da população afetada}

De acordo com Folke (2006), o conceito de memória é descrito como a experiência acumulada baseada no histórico de um sistema, que fornece a base para identificar fontes de renovação, inovação, recombinação, auto-organização e inovação após condições de estresse.

A memória da população afetada com relação aos eventos passados é relevante para análise da vulnerabilidade dos estabelecimentos, tendo em vista sua preparação para eventos de inundação.

Para isso, inicialmente verificou-se quantos estabelecimentos estavam presentes nas duas inundações. Como resultado, dos 51 estabelecimentos visitados, 37 permaneciam no mesmo local desde a inundação de 2015 (73\%) e, 14 deles estavam presentes após esse evento, ou seja, há menos de 2 anos e meio no local, verificando assim rotatividade de $24 \%$ dentre as empresas visitadas.

De acordo com relatos, tal rotatividade advém, além dos problemas relacionados as frequentes inundações, ao fraco desempenho econômico do país, já que foi frequente as queixas relacionadas a diminuição das vendas em seus negócios.

Com relação aos comerciários do entorno do mercado municipal, alguns deles instalados há mais tempo na região, que informaram estar há mais de 30 anos no local, relataram que essa foi a terceira vez que a inundação atinge seu estabelecimento, comparando magnitude da inundação somente a um evento ocorrido há 10 anos.

Dentre esses comerciantes, o proprietário de uma loja declarou que a inundação de 2015 foi a primeira em que o nível de água atingiu seu imóvel - há 38 anos no local - causando prejuízos. Não havia comporta instalada até esse incidente, sendo instalada, o que atenuou completamente a entrada de água no local, não havendo prejuízos causados pela inundação de 2018, apenas necessidade de limpeza do imóvel.

Tais informações demonstram a magnitude dos eventos. Contudo, apesar da área sob risco de inundação possuir poucas quadras, a susceptibilidade de danos dos imóveis teve grande variação: houve comerciantes que declararam ter sido esse o primeiro evento de inundação que 
lhes trouxe prejuízo em 38 anos e, outros que declararam que isso ocorre anualmente, chegando até a 3 vezes por ano. Para avaliar a frequência com que os estabelecimentos são afetados pelas inundações, a Figura 6.9 apresenta a frequência de inundações presenciadas pelo comerciante com relação ao tempo em que este se encontra no local.

Figura 6.9 - Relação entre a frequência de eventos de inundação e o tempo de permanência do comerciante no local

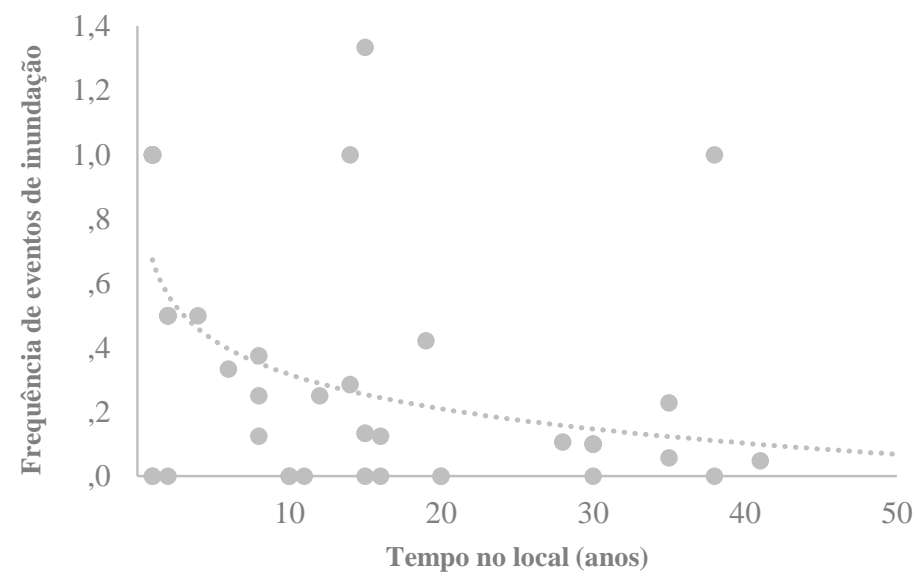

A análise da Figura 6.9 permite avaliar a frequência com o estabelecimento comercial é prejudicado pelas inundações. É possível perceber que tais eventos ocorreram com maior frequência nos últimos 10 anos, pois a relação entre o tempo que o comerciante está no local e o número de eventos de inundação sofrido é maior nesse período. Para comerciantes que estavam no local há mais de 20 anos, essa relação é menor de 0,2 para a maioria dos estabelecimentos entrevistados.

Tal relação afeta a forma como os comerciantes se preparam para mitigar seus prejuízos em eventos de inundação. De acordo com Machado (2005), as principais medidas de mitigação individuais são:

- utilização de materiais de construção não porosos;

- elevação do piso com relação a calçada;

- a proteção das edificações, por meio da construção de muros e instalação de comportas;

- a vedação de esgotos e tubulações de águas pluviais para impedir refluxo, por meio da utilização de válvulas de retenção e tampões rosqueáveis nos ralos internos;

- a instalação de bombas para esgotamento de áreas internas.

Na região de estudo, as principais medidas mitigadoras encontradas foram a elevação do piso com relação a calçada e utilização de comportas. A análise da elevação das comportas permite verificar o comportamento da população frente a eventos de inundação, visto que as comportas tendem a serem elevadas caso se verifique um incremento na magnitude das 
inundações, baseado na altura que esta atingiu nos imóveis para o evento, conforme já observado por DiBaldassare (2015).

De acordo com DiBaldassare (2015), na avaliação do risco de inundação, verifica-se um efeito adaptativo relacionado a observação de que a maior frequência de inundações é também associada com o decréscimo da vulnerabilidade.

$\mathrm{O}$ autor constatou empiricamente que os impactos de um evento de inundação são menores quando tais eventos, de mesma magnitude, ocorrem em espaços curto de tempo. Para o autor, esse efeito pode ser atribuído à capacidade de adaptação aos eventos adquiridas durante tais eventos de inundação.

Dessa forma, considera-se que projeções futuras relacionadas a risco de inundação podem trazer informação pouco realistas da situação. A Figura 6.10 exemplifica essa relação baseada na sociohidrologia dos desastres, baseado na relação entre os eventos de inundação e as adaptações realizadas pela sociedade para sua proteção.

Figura 6.10 - Relação sócio hidrológica adaptativa entre as inundações e a população atendida

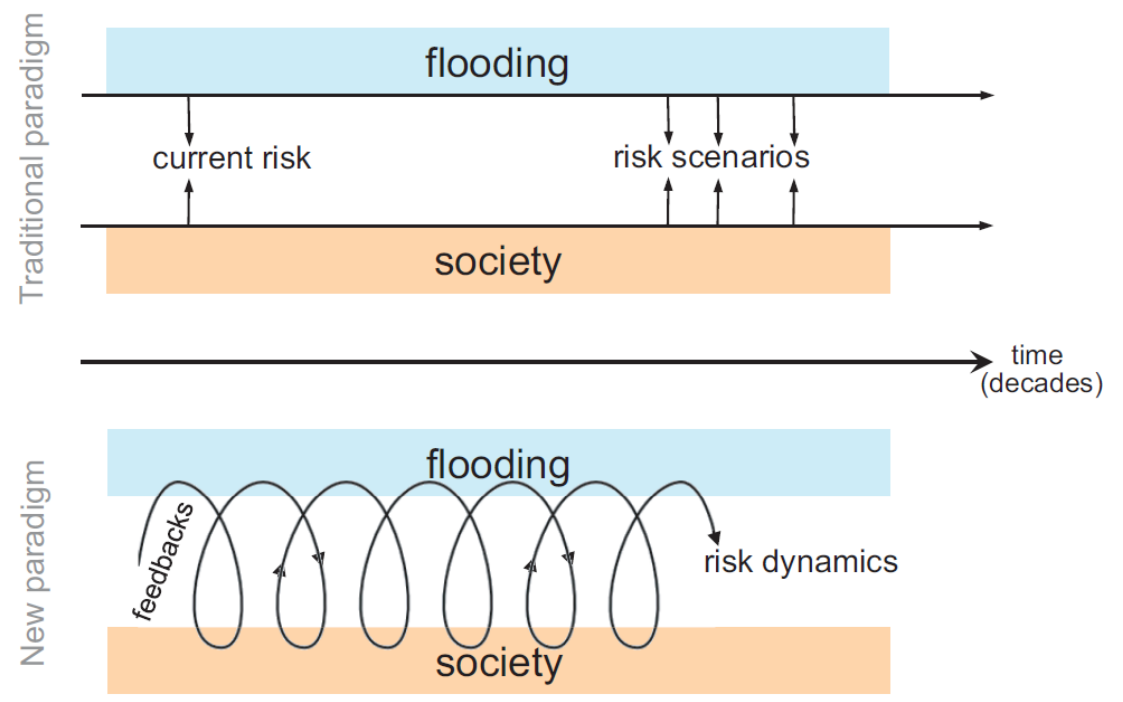

Fonte: DiBaldassare (2015)

A Figura 6.10 apresenta um novo paradigma na avaliação de danos de inundação: enquanto a visão tradicional apresenta apenas a relação entre inundação e a população afetada de uma maneira não relacionada, verificando os riscos presentes e avaliando cenários futuros para compor curvas de danos, o novo paradigma apresentado estabelece um feedback entre os eventos naturais e capacidade humana de se adaptar, em um constante feedback entre os eventos. 
Dessa forma, a avaliação das medidas mitigadoras localizadas utilizadas pela população não é considerada na abordagem tradicional, podendo assim inferir avaliações de prejuízo não realistas.

$\mathrm{Na}$ tentativa de quantificar as observações de DiBaldassare (2015) a Figura 6.11 apresenta a relação entre a altura interna externa e externa observada nos eventos de 2015 e 2018 .

Figura 6.11 - Relação altura externa x interna em 2015 e 2018

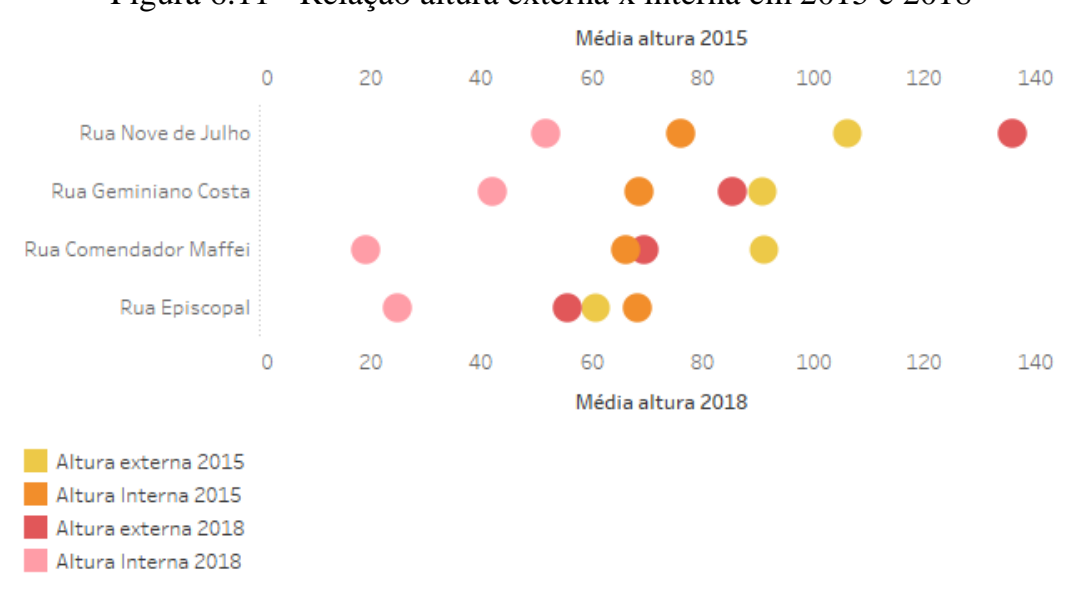

A análise da Figura 6.11 permite verificar que, mesmo com a área sujeita a inundação inserida em algumas poucas quadras, a variância das medidas é bastante elevada, já que é possível verificar alturas entre $140 \mathrm{~cm}$ e $57 \mathrm{~cm}$ para o evento de 2018 e $110 \mathrm{~cm}$ a $60 \mathrm{~cm}$ para o evento de 2015.

Ao se analisar as alturas internas de submersão, também se verifica uma diferença acentuada para o evento de 2018 , entre 20 a $55 \mathrm{~cm}$, sendo a mesma entre 75 e $85 \mathrm{~cm}$ para o evento de 2015.

Porém, é possível verificar que, na Rua Nove de Julho, zona crítica em relação aos prejuízos, a diferença entre as alturas internas e externas nos eventos foi a mais acentuado, em torno de $30 \mathrm{~cm}$ para o evento de 2015 e $85 \mathrm{~cm}$ para o evento de 2018. Pode-se inferir que isso se deve a melhor preparação para os eventos de inundação dos comerciantes dessa rua, podendo ser analisada com relação as comportadas instaladas nas lojas: dos 10 estabelecimentos visitados, 7 possuíam comportas em 2015, sendo que após esse evento, todas as lojas instalaram comportas ou as elevaram.

Porém, mesmo com tal preparação, essa foi a rua em que a altura de submersão interna foi maior, tendo em vista a altura externa ter sido maior nesse evento, diminuindo assim a 
eficácia das comportas quanto a atenuação da entrada de água em seus estabelecimentos. Portanto, nesta rua, que se encontra sob maior perigo dos efeitos das inundações, verifica-se que, apesar da altura externa de inundação ter sido maior no evento de 2018 em relação a 2015, a altura interna foi menor naquele evento, fato que pode ser explicado pela maior preparação da população em relação a ameaça de inundação.

Com relação a Rua Comendador Maffei, cabe destacar que, dos 9 estabelecimentos entrevistados na Av. Comendador Antônio Maffei localizados entre a Rua Episcopal, nenhum possuía comporta em 2015. Um dos prováveis motivos é o fato de que, de acordo com os comerciantes, os eventos de inundação raramente atingirem esse local em eventos anteriores aos de 2015, apesar desses imóveis estarem exatamente acima do córrego do Gregório, em sua porção tamponada. Após esse evento, foram instaladas comportas em outros 5 estabelecimentos e elevadas nos estabelecimentos que á a possuíam, sendo que os demais estudavam a sua instalação.

Para quantificar tal compreensão relacionada à preparação da população afetada frente a um novo nível de perigo a que está exposta, é apresentado na Figura 6.12 a soma das alturas das comportas dos imóveis entrevistas para os eventos de 2015 e 2018. E na Figura 6.13 o gráfico boxplot referente à altura da comporta verificada nesses eventos.

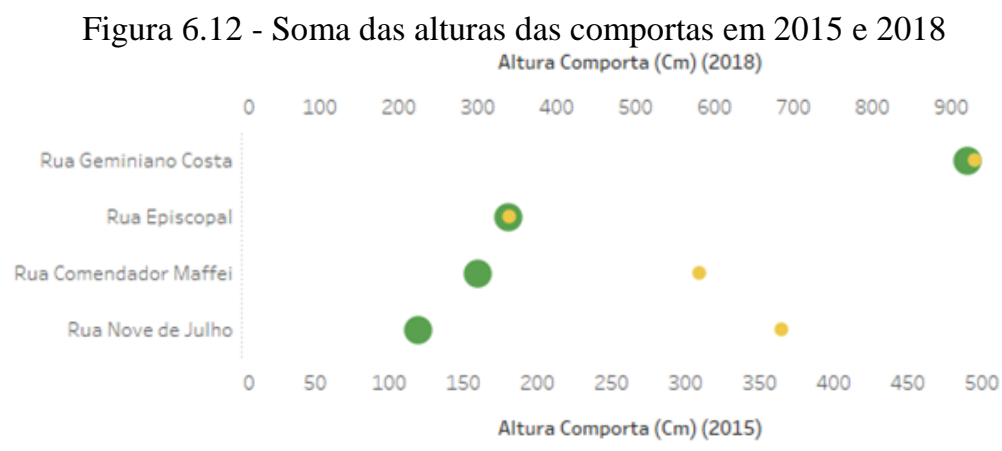


Figura 6.13 - Gráfico boxplot da altura da comporta nos eventos de 2015 e 2018

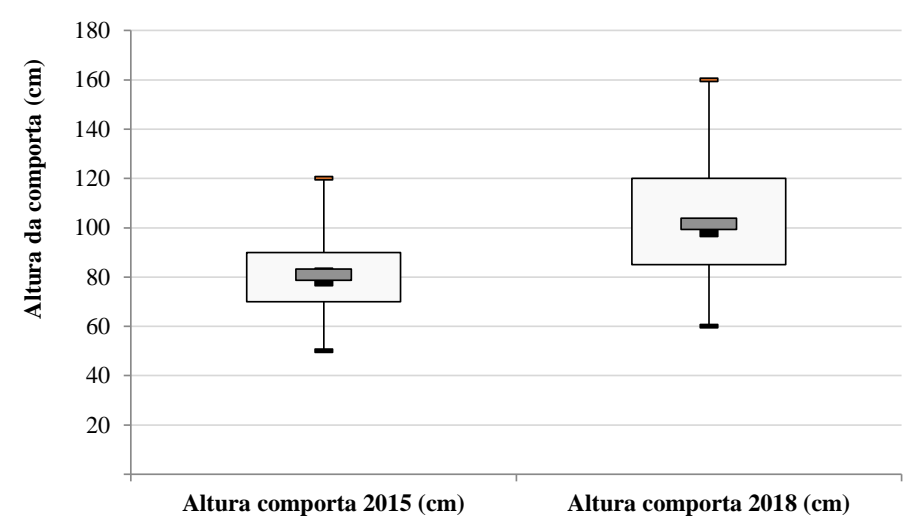

Analisando a Figura 6.12 verifica-se que a altura das comportas em 2015 eram substancialmente menores do que as verificadas no evento de 2018 , sendo a soma total da altura das comportas em 2015 ser de $990 \mathrm{~cm}$ e em 2018 de $2.325 \mathrm{~cm}$, ou seja, percebeu-se que, como medida de mitigação, muitos instalaram ou realizaram elevação do nível de suas comportas; porém, em muitos casos não foi suficiente para que a enxurrada não entrasse no imóvel, apesar dessa medida ter evitado maiores prejuízos.

Com relação a Figura 6.13, percebe-se que a mediana possui valores muito próximos da média, inferindo uma simetria na distribuição dos dados, as quais localizam-se próximo de 80 cm para o evento de 2015 e $100 \mathrm{~cm}$ para o evento de 2018. Percebe-se que há um aumento em torno de 15 a $20 \mathrm{~cm}$ para o $1^{\circ}$ e $3^{\circ}$ quartil e o valor mínimo, e um aumento de $40 \mathrm{~cm}$ para o máximo verificado, atingindo $160 \mathrm{~cm}$ em 2018. Assim, conclui-se que o aumento da comporta foi uma medida adaptativa da população frente ao evento de inundação. A Figura 6.14 apresenta dois exemplos de comportas instaladas na região, exemplificando propriedades onde foram elevadas as comportas frente ao evento de 2015.

Figura 6.14 - Exemplos de comportas instaladas nos imóveis afetados pelas inundações

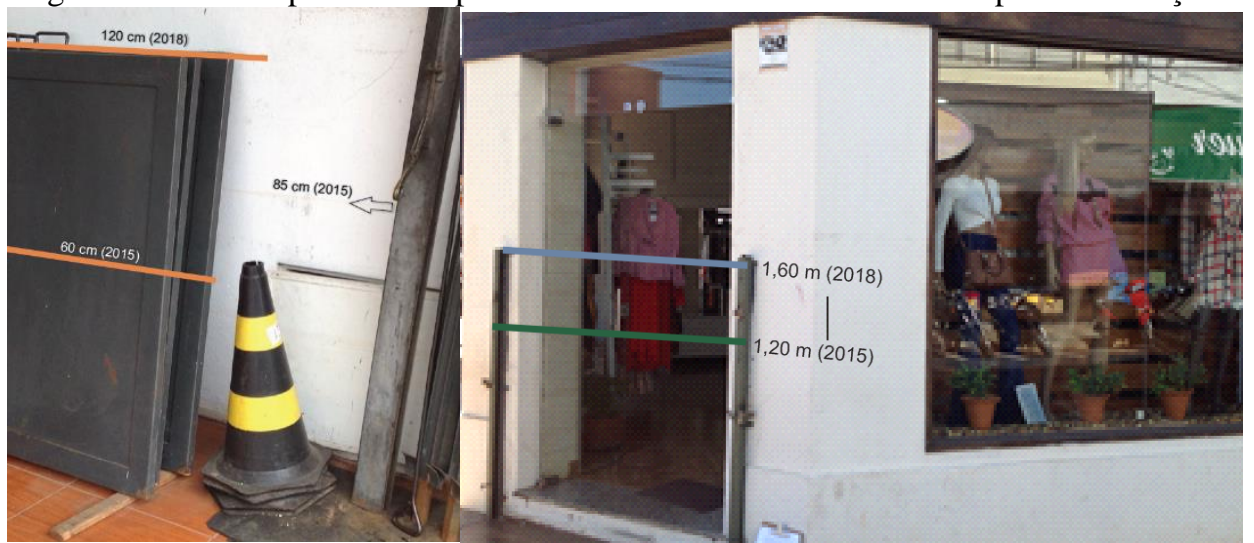


Nos dois casos, os comerciantes da região elevaram suas comportas devido às experiências passadas, o que ocasionou menores prejuízos em seus comércios, ainda que, em ambos os casos, essa medida somente não foi suficiente para conter o avanço da cheia em suas dependências.

Com relação às comportas, verificou-se que algumas não suportaram a força da enxurrada e cederam, causando prejuízo a esses imóveis. Também foi percebido no local que muitos comerciantes estavam instalando comportas em seus imóveis, ficando até mesmo constrangidos com a entrevista e solicitando que não fosse registrada por meio de fotografia a sua instalação.

Mesmo para os imóveis que possuíam comportas, alguns comerciantes relataram que, em 2015, apesar de possuírem o dispositivo em seus estabelecimentos, a mesma não foi colocada no local devido ao curto período entre o início da chuva e a inundação, fato não relatado no evento de 2018, evidenciando mais uma vez melhor preparação frente ao evento.

Assim, as comportas, mesmo que não tenham altura suficiente para evitar por completo a entrada de água no estabelecimento, mostraram-se importantes para diminuir a passagem de água, bem como aumentar o tempo para deslocamento dos produtos.

Portanto, a memória a respeito das inundações passadas colaborou para a mitigação dos prejuízos, seja pela melhor preparação dos afetados, seja pela incorporação de estruturas que atenuassem os efeitos das inundações.

\subsubsection{Aspectos quantitativos}

\subsubsection{Prejuízos individuais}

Por meio das entrevistas, buscou-se quantificar os prejuízos causados pelos eventos de inundação ocorridos em 23 de novembro de 2015 e 21 de março de 2018. Das 51 empresas entrevistadas, 32 declaram apresentar prejuízos em 2015 (64\%) e 23 em 2018 (45\%), sendo que apenas 14 delas declararam prejuízo nos dois eventos (29\%).

Ressalta-se que, apesar de tais empresas não declararem prejuízos, a água adentrou seus imóveis e sua atividade comercial foi suspensa para reorganização do negócio, incorrendo assim, ao menos, em prejuízos indiretos, apresentados posteriormente. Com relação a esses eventos, a Figura 6.15 apresenta os valores individuais de prejuízo pelos comerciantes entrevistados nesses eventos. 
Figura 6.15 - Prejuízo individual por altura de submersão sofrido pelas empresas entrevistas

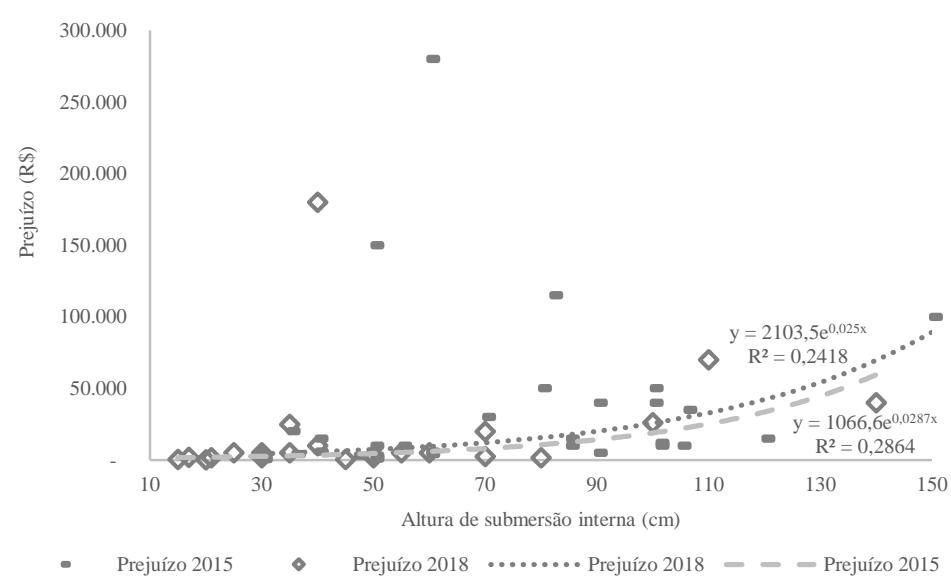

O prejuízo sofrido pelas empresas possui uma grande dispersão de dados, incluindo outliers bastante discrepantes da tendência central. Porém, ao analisar os dois períodos, percebe-se que os eventos de 2015 e 2018 tiveram uma correlação em relação a linha de tendência: essa similaridade entre os eventos ocorre no que tange ao prejuízo individual de cada empresa em suas respectivas alturas de submersão interna.

Para melhor apresentar os dados, na Figura 6.16 foram retirados os outliers, onde foram removidos os 4 maiores valores para o ano de 2015 e os 2 maiores para o ano de 2018, seguindo a metodologia boxplot. O gráfico boxplot representativo desses dados é apresentado na Figura 6.17 .

Figura 6.16 - Prejuízo individual por altura de submersão sofrido pelas empresas entrevistas com exclusão de outliers

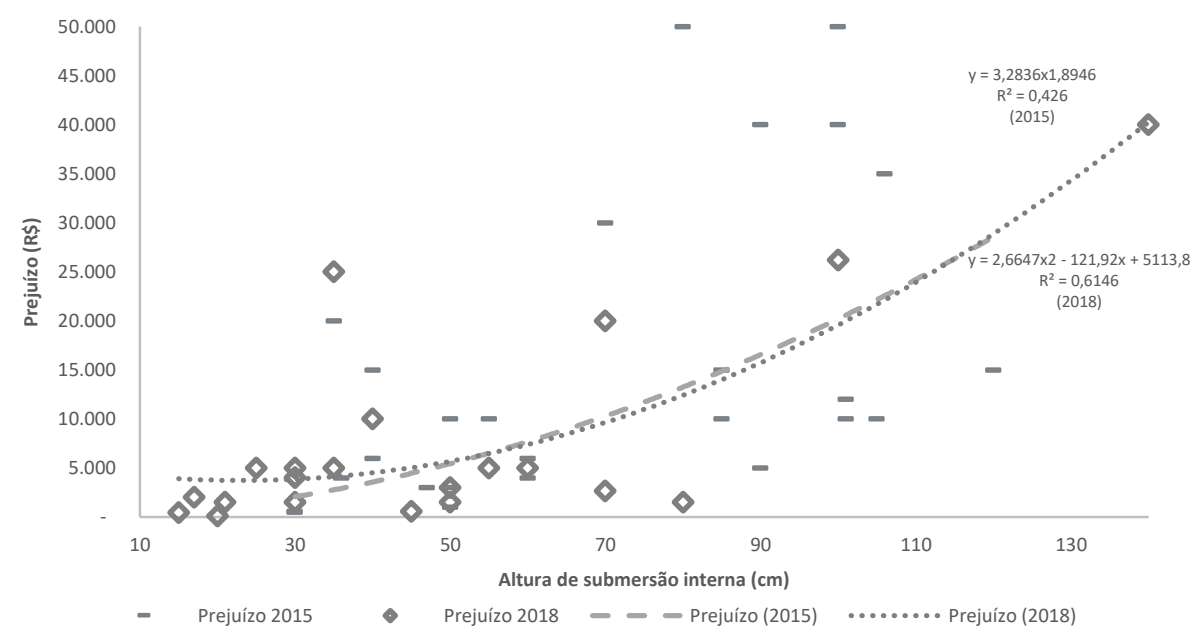


Figura 6.17 - Prejuízo individual por altura de submersão sofrido pelas empresas entrevistas

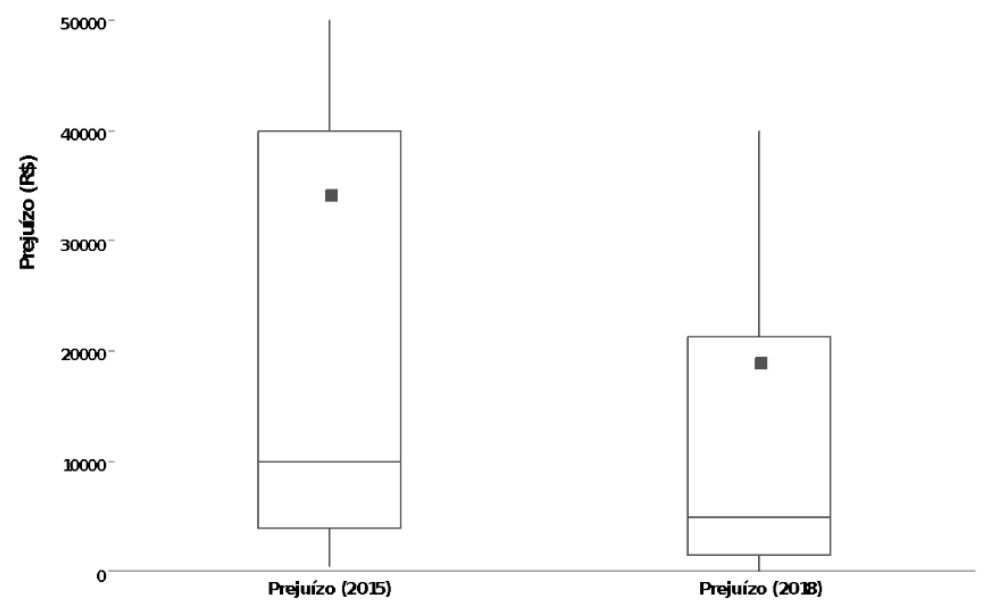

Os valores de prejuízo para os eventos de 2015 e 2018 (sem a presença de outliers) demonstram que o valor do prejuízo na região interquartil variou de $\mathrm{R} \$ 10.000$ a $\mathrm{R} \$ 40.000$ para o evento de 2015 e de $\mathrm{R} \$ 2.000$ a $\mathrm{R} \$ 22.000$ para o evento de 2018 . A região do $3^{\circ}$ quartil apresentou o dobro do valor para o evento de 2015 em relação ao de 2018, sendo a média também próxima desse número.

Tendo em vista a média estar próxima do terceiro quartil, percebe-se que poucas empresas apresentam alto valor de prejuízo e/ou prejuízo total verificado alto, porém foram representativas quanto ao prejuízo total verificado. Já a mediana está próxima ao $1^{\circ}$ quartil em ambos os eventos, corroborando para que a maior parte das empresas apresente valores baixos de prejuízo, assim como a assimetria dos dados ser considerada alta.

Dessa forma, a análise individual dos outliers se faz necessária para melhor entender a colaboração individual destas no total do prejuízo verificado nos eventos. Para isso, algumas possibilidades são possíveis ${ }^{15}$ :

- $\quad$ excluir as observações discrepantes da amostra de dados: quando o dado discrepante é fruto de um erro de input dos dados, então ele precisa ser removido da amostra;

- realizar uma análise separada apenas com os outliers: esta abordagem é útil quando se quer investigar casos extremos.

- utilizar métodos de clusterização para encontrar uma aproximação que corrige e dá um novo valor aos dados outliers

15 Jean Prado. Tecnoblog, 2018. Como fazer referência de site na ABNT em trabalhos acadêmicos. Disponível em: < https://tecnoblog.net/247956/referencia-site-abnt-artigos/>. Acesso em: 08 de junho de 2019. 
Dessa forma, buscou-se incialmente avaliar o impacto dos outliers no montante de prejuízo total, principal variável em um projeto de análise econômica de prejuízos.

Para isso, é apresentado na Figura 6.18 os incrementos crescentes de prejuízo declarado dos valores individuais acumulados de forma empilhada.

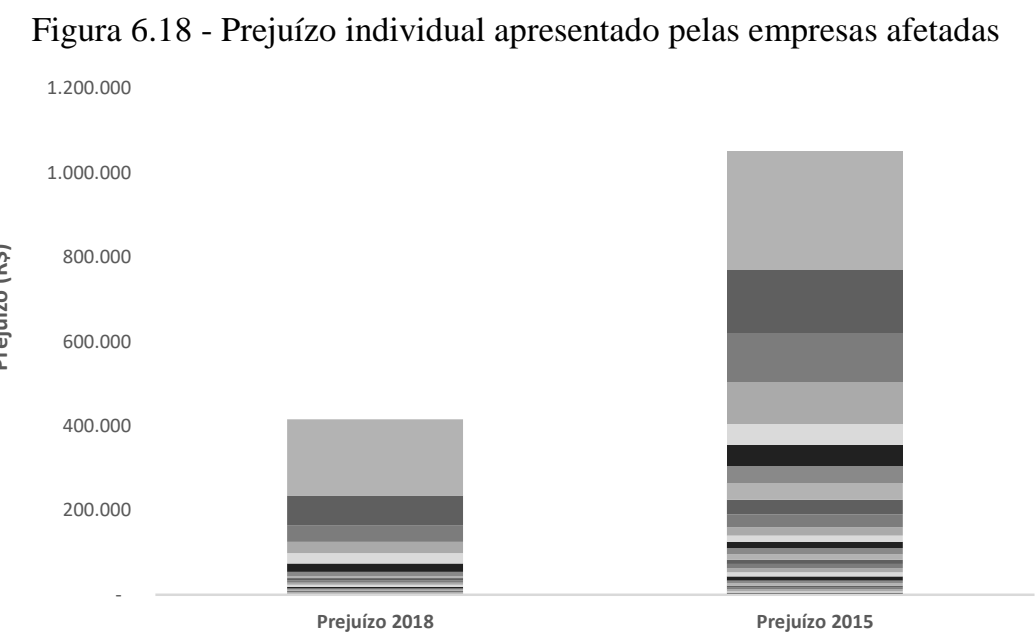

A análise da Figura 6.18 apresenta o valor total do prejuízo ocorrido nos dois eventos de inundação para os eventos de 2018 e 2015, sendo, respectivamente, R\$ 414.950 e R\$ 1.050.100. Com relação às empresas, percebe-se o alto valor que os outliers dos eventos de 2018 e 2015 ( 2 empresas em 2018 e 4 empresas em 2015) representam no montante total dos prejuízos, sendo respectivamente de R 645.000 (61,4\%) e R 250.000 (60,3\%). Sendo assim, dada sua representatividade aos valores de prejuízo total declarados, deve-se analisá-los individualmente antes de excluí-los para que se possa compreender os motivos pelos quais tais empresas apresentam-se tão discrepantes das demais.

\subsubsection{Análise dos outliers}

Para realizar a análise dos outliers, serão apresentadas de forma individual as seguintes características relacionadas: à memória dos comerciantes, ao estoque médio de produtos e ao prejuízo total declarado pelos comerciantes (Tabela 6.3). Tal demonstração se faz particularmente necessária, tendo em vista o forte impacto que os outliers possuem no montante total do valor da inundação.

Será tomada a precaução de não se apresentar dados que possam identificar tais empresas de modo a preservar sua individualidade, conforme declarado no termo de compromisso de confidencialidade assinado por todos os entrevistados (Apêndice 4 e 5). 
Tabela 6.3 - Memória das empresas outliers aos eventos de inundação

\begin{tabular}{lccccccc}
\hline Empresa & $\begin{array}{c}\text { Evento em } \\
\text { considerado }\end{array}$ & $\begin{array}{c}\text { Tempo do } \\
\text { estabelecimento } \\
\text { (anos) }\end{array}$ & $\begin{array}{c}\text { Número de } \\
\text { eventos de } \\
\text { inundação }\end{array}$ & $\begin{array}{c}\text { Altura da } \\
\text { planta } \\
\text { baixa }\end{array}$ & $\begin{array}{c}\text { Altura } \\
\text { comporta } \\
\text { (cm) } \\
(\mathbf{2 0 1 5})\end{array}$ & $\begin{array}{c}\text { Altura } \\
\text { comporta (cm) } \\
\text { [2018] }\end{array}$ & $\begin{array}{c}\text { Aumentou após } \\
\text { inundação de } \\
\text { 2015? }\end{array}$ \\
\hline Empresa 1 & 2015 e 2018 & 28 & 3 & 30 & - & - & $\operatorname{sim}^{16}$ \\
\hline Empresa 2 & 2018 & 2 & 1 & 20 & - & - & - \\
\hline Empresa 3 & 2015 & 14 & 14 & 25 & 120 & 160 & sim \\
\hline Empresa 4 & 2015 & 41 & 2 & 50 & - & 60 & sim \\
\hline Empresa 5 & 2015 & 19 & 8 & 30 & - & 100 & sim \\
\hline
\end{tabular}

A análise da Tabela 6.3 permite compreender os efeitos da memória dos proprietários das empresas outliers com relação aos eventos de inundação da região. Percebe-se que a maioria dessas empresas está presente há mais de 14 anos na região. Porém, dessas empresas, apenas uma possuía comporta na entrada do estabelecimento antes do evento de 2015.

Tais comerciantes foram unânimes em afirmar que os eventos de 2015 e 2018 foram os maiores eventos que já presenciaram desde que possuem os estabelecimentos, o que evidencia a magnitude dos eventos ocorridos.

A altura da comporta é outro elemento que corrobora essa afirmação: os estabelecimentos há mais tempo no local elevaram suas comportas nesses períodos. Essas pessoas afirmaram que, em eventos passados, a inundação não atingia o interior de seus estabelecimentos, sendo que apenas em 2015 esse fato ocorreu.

Com relação à empresa 1, a única empresa considerada outliers nos dois eventos, verificou-se que essa não possuía comporta durante os eventos de 2015 e 2018, porém instalou muros de alvenaria com $120 \mathrm{~cm}$ onde antes era o espaço das vitrines após o evento de 2018 . Essa protegia seu estabelecimento com portas de aço; porém, no evento de 2015, tais portas, de fechamento motorizado, não foram completamente fechadas pois, segundo o entrevistado, a água invadiu o estabelecimento muito rapidamente e entraram em contato com os motores de fechamento das portas, danificando-os e promovendo seu não funcionamento.

Já a empresa 2 ainda estava de portas fechadas, mesmo após o encerramento das entrevistas (junho de 2018). O estabelecimento há menos tempo na região, empresa 2, - presente há apenas 2 anos no local, não sendo proprietária do local (alugado) - informou que o proprietário lhe garantiu que, em eventos de inundação, a água não atingiria sua loja, por isso não instalou comportas. Afirmou ainda que não estava no estabelecimento durante o evento de inundação, que sua loja estava fechada e que havia sido reformada há pouco tempo. Afirmou ainda que os danos mais graves foram decorrentes da entrada de água pela loja vizinha, que

\footnotetext{
${ }^{16}$ Instalou paredes de alvenaria onde antes era sua vitrine, elevando-a.
} 
estava desocupada. Segunda a entrevistada, a parede da loja vizinha foi destruída pela velocidade da água, o que colaborou para que praticamente todo seu estoque fosse danificado, além de móveis e da estrutura física, composta principalmente por material de gesso recentemente instalado.

A empresa 3 obteve alto prejuízo em ambas as inundações, apesar de ser considerada outliers apenas na inundação de 2015. Nesta empresa, a comporta não foi suficiente para conter o avanço da inundação no evento de 2018, pois os vidros laterais da loja cederam e a água adentrou com muita intensidade. De acordo com o comerciante, a "força" da água foi muito maior nesse ano em seu estabelecimento em relação ao evento de 2015, em que a considerou que, apesar da lâmina ser maior no evento de 2015, as vidraças, assim como a comporta, não cederam e assim obteve menor prejuízo.

No que concerne à altura da planta baixa em relação a calçada, as empresas 4 e 5, apesar de não possuírem comportas instaladas em seus estabelecimentos, possuíam degrau elevado para se proteger das inundações, o que, segundo os entrevistados, foi suficiente para que a água não penetrasse nos estabelecimentos até o evento de 2015. Para realizar a análise quantitativa dos danos, Tabela 6.4 apresenta os valores de estoque e prejuízo das empresas consideradas outliers.

Tabela 6.4 - Valores de estoque e prejuízo das empresas consideradas outliers

\begin{tabular}{|c|c|c|c|c|c|c|c|c|}
\hline Empresa & $\begin{array}{c}\text { Valor do } \\
\text { estoque } \\
(\mathbf{R} \$)\end{array}$ & $\begin{array}{c}\text { Prejuízo } \\
\text { (2015) } \\
\text { [R\$] }\end{array}$ & $\begin{array}{c}\text { Prejuízo } \\
\text { (2018) } \\
{[R \$]}\end{array}$ & $\begin{array}{l}\text { Prejuízo/ } \\
\text { área } \\
(\mathbf{2 0 1 5}) \\
{[\mathbf{R} \$ / \mathbf{m} 2]}\end{array}$ & $\begin{array}{l}\text { Prejuízo/ } \\
\text { área } \\
(\mathbf{2 0 1 8}) \\
{[\mathbf{R} \$ / \mathbf{m} 2]}\end{array}$ & $\begin{array}{l}\text { Prejuízo/ } \\
\text { estoque } \\
(2015)\end{array}$ & $\begin{array}{l}\text { Prejuízo/ } \\
\text { estoque } \\
(2018)\end{array}$ & $\begin{array}{c}\text { Área do } \\
\text { estabeleci } \\
\text { mento } \\
\left(\mathbf{m}^{2}\right)\end{array}$ \\
\hline Empresa 1 & 250.000 & 280.000 & 180.000 & 3.500 & 2.250 & 1,12 & 0,72 & 80 \\
\hline Empresa 2 & 30.000 & 0 & 70.000 & - & 1.750 & - & 2,33 & 40 \\
\hline Empresa 3 & 70.000 & 100.000 & 40.000 & 3.333 & 1.333 & 1,43 & 0,57 & 30 \\
\hline Empresa 4 & 1.000 .000 & 150.000 & 0 & 600 & - & 0,15 & - & 250 \\
\hline Empresa 5 & 200.000 & 115.000 & 1.500 & 2.300 & 30 & 0,58 & 0,01 & 50 \\
\hline
\end{tabular}

Considerando tais empresas, apenas a empresa 1 foi apontada como outliers nos dois eventos de inundação, sendo a única, também, a não possuir comporta em ambos os eventos. As empresas 4 e 5 obtiveram altos valores de prejuízo no evento de 2015 e prejuízo praticamente nulo no evento de 2018, fruto da melhor preparação desses estabelecimentos com a instalação das comportas.

O valor do prejuízo em relação a área desses estabelecimentos apontou valores muito maiores que os obtidos pelas demais empresas, que foi de até $\mathrm{R} \$ 800 / \mathrm{m}^{2}$. Para a relação entre 
o prejuízo e o estoque, tais empresas obtiveram prejuízos de até 2,33 vezes o valor de seu estoque.

Tais índices elevados, os quais excedem o valor total de estoque de mercadorias do estabelecimento, foram provocados principalmente pelos danos físicos provocados aos imóveis e ao com o conteúdo das lojas, como móveis e acessórios. Assim uma análise detalhada de seus prejuízos com relação ao tipo de perda de cada imóvel se faz necessária.

A Tabela 6.5 apresenta os valores declarados de prejuízo nas quatro categorias consideradas e o percentual que cada categoria representa com relação ao total dos danos.

Tabela 6.5 - Prejuízos por categoria dos comerciantes outliers

\begin{tabular}{|c|c|c|c|c|c|c|c|c|c|c|}
\hline Empresa & $\begin{array}{r}\text { Perdas } \\
\text { estoque } \\
(2018) \\
{[R \$]}\end{array}$ & $\begin{array}{r}\text { Perdas } \\
\text { móveis } \\
(2018) \\
{[R \$]}\end{array}$ & $\begin{array}{r}\text { Perdas } \\
\text { acessórios } \\
(2018) \\
{[R \$]}\end{array}$ & $\begin{array}{r}\text { Perdas } \\
\text { estruturais } \\
(2018) \\
{[R \$]}\end{array}$ & $\begin{array}{r}\text { Prejuízo } \\
\text { total } \\
(2018) \\
{[R \$]}\end{array}$ & $\begin{array}{r}\text { Perdas } \\
\text { estoque } \\
(2015) \\
{[R \$]}\end{array}$ & $\begin{array}{r}\text { Perdas } \\
\text { móveis } \\
(2015) \\
{[R \$]}\end{array}$ & $\begin{array}{r}\text { Perdas } \\
\text { acessórios } \\
(2015) \\
{[R \$]}\end{array}$ & $\begin{array}{r}\text { Perdas } \\
\text { estruturais } \\
(2015) \\
{[R \$]}\end{array}$ & $\begin{array}{r}\text { Prejuízo } \\
\text { total } \\
(2015) \\
{[R \$]}\end{array}$ \\
\hline Empresa 1 & $\begin{array}{r}54.000 \\
(30 \%)\end{array}$ & $\begin{array}{r}50.000 \\
(28 \%)\end{array}$ & $\begin{array}{r}10.000 \\
(6 \%)\end{array}$ & $\begin{array}{r}66.000 \\
(37 \%)\end{array}$ & $\begin{array}{r}180.000 \\
(100 \%)\end{array}$ & $\begin{array}{r}180.000 \\
(64 \%)\end{array}$ & $\begin{array}{r}20.000 \\
(7 \%)\end{array}$ & - & $\begin{array}{r}80.000 \\
(29 \%)\end{array}$ & $\begin{array}{r}280.000 \\
(100 \%)\end{array}$ \\
\hline Empresa 2 & $\begin{array}{r}30.000 \\
(43 \%)\end{array}$ & $\begin{array}{r}18.000 \\
(26 \%)\end{array}$ & $\begin{array}{r}10.000 \\
(14 \%)\end{array}$ & $\begin{array}{r}12.000 \\
(17 \%)\end{array}$ & $\begin{array}{r}70.000 \\
(100 \%)\end{array}$ & - & - & - & - & - \\
\hline Empresa 3 & $\begin{array}{r}20.000 \\
(50 \%) \\
\end{array}$ & $\begin{array}{r}10.600 \\
(27 \%) \\
\end{array}$ & $\begin{array}{r}800 \\
(2 \%) \\
\end{array}$ & $\begin{array}{r}8.600 \\
(22 \%) \\
\end{array}$ & $\begin{array}{r}40.000 \\
(100 \%)\end{array}$ & $\begin{array}{r}60.000 \\
(60 \%)\end{array}$ & $\begin{array}{r}10.000 \\
(10 \%) \\
\end{array}$ & $\begin{array}{r}5.000 \\
(5 \%) \\
\end{array}$ & $\begin{array}{r}25.000 \\
(25 \%) \\
\end{array}$ & $\begin{array}{r}100.000 \\
(100 \%)\end{array}$ \\
\hline Empresa 4 & - & - & - & - & - & $\begin{array}{r}150.000 \\
(100 \%)\end{array}$ & - & - & - & $\begin{array}{r}150.000 \\
(100 \%)\end{array}$ \\
\hline Empresa 5 & $\begin{array}{r}1.500 \\
(100 \%)\end{array}$ & - & - & - & $\begin{array}{r}1.500 \\
(100 \%)\end{array}$ & $\begin{array}{r}80.000 \\
(70 \%)\end{array}$ & $\begin{array}{r}25.000 \\
(25 \%)\end{array}$ & $\begin{array}{r}3.000 \\
(3 \%)\end{array}$ & $\begin{array}{r}7.000 \\
(6 \%)\end{array}$ & $\begin{array}{r}115.000 \\
(100 \%)\end{array}$ \\
\hline
\end{tabular}

A Tabela 6.5 apresenta os valores de danos por categoria de prejuízo. A partir desta tabela percebe-se que, no ano de 2015 , os maiores danos foram provocados pela perda do estoque, enquanto em 2018 pelas perdas de móveis e perdas estruturais. Verificou-se que para a elevada perda de móveis em 2018, fato marcante foi o contato cumulativo das inundações, já que houve necessidade de troca do mobiliário após o segundo contato desses com a água, sendo assim computado apenas em 2018 seu prejuízo.

Isso corrobora com declarações dos entrevistados, que afirmaram que em 2018 a velocidade da água (enxurrada) foi maior que em 2015, assim como a quantidade de sedimentos. Também evidencia que a análise de outras categorias do conteúdo dos imóveis (além do estoque) é fundamental para formular o prejuízo total, tendo em vista a proporção significativa dessas categorias de prejuízo no incremento total dos danos.

Portanto, verifica-se que tais empresas discrepantes das demais possuem particularidades que podem não se evidenciar em todos os eventos de inundação e trazer dificuldade na análise global dos valores de inundação. Sendo assim, a análise dos outliers é fundamental para o entendimento dos prejuízos significativos no montante total de danos, uma vez que forem enquadrados neste critério, serão desconsiderados das análises posteriores para 
não influenciarem estatisticamente. Assim, para uma análise a posterior dos danos (utilizando curvas DPS), serão ser analisados tais dados sem a presença dos outliers.

\subsubsection{Prejuízo unitário}

Para apresentar os dados de prejuízo por altura de submersão, Penning-Roswell \& Chatternon (1977) para a Inglaterra e Machado (2005) adotaram uma metodologia de apresentar os dados de forma unitária, estabelecendo para isso a variável prejuízo por metro quadrado de área. Essa função se justifica já que o espaço de cada loja é ocupado por produtos de maneira intensa e, dessa forma, podem-se atribuir valores de prejuízo por unidade de área de cada imóvel em suas respectivas alturas de inundação.

A dificuldade desta metodologia encontra-se na heterogeneidade das lojas, mesmo que estas ocupem um mesmo local e comercializem produtos relativamente semelhantes. As curvas DPS que representam os danos por profundidade de submersão para os eventos de 2015 e 2018, sem a presença de outliers, é apresentado na Figura 6.19.

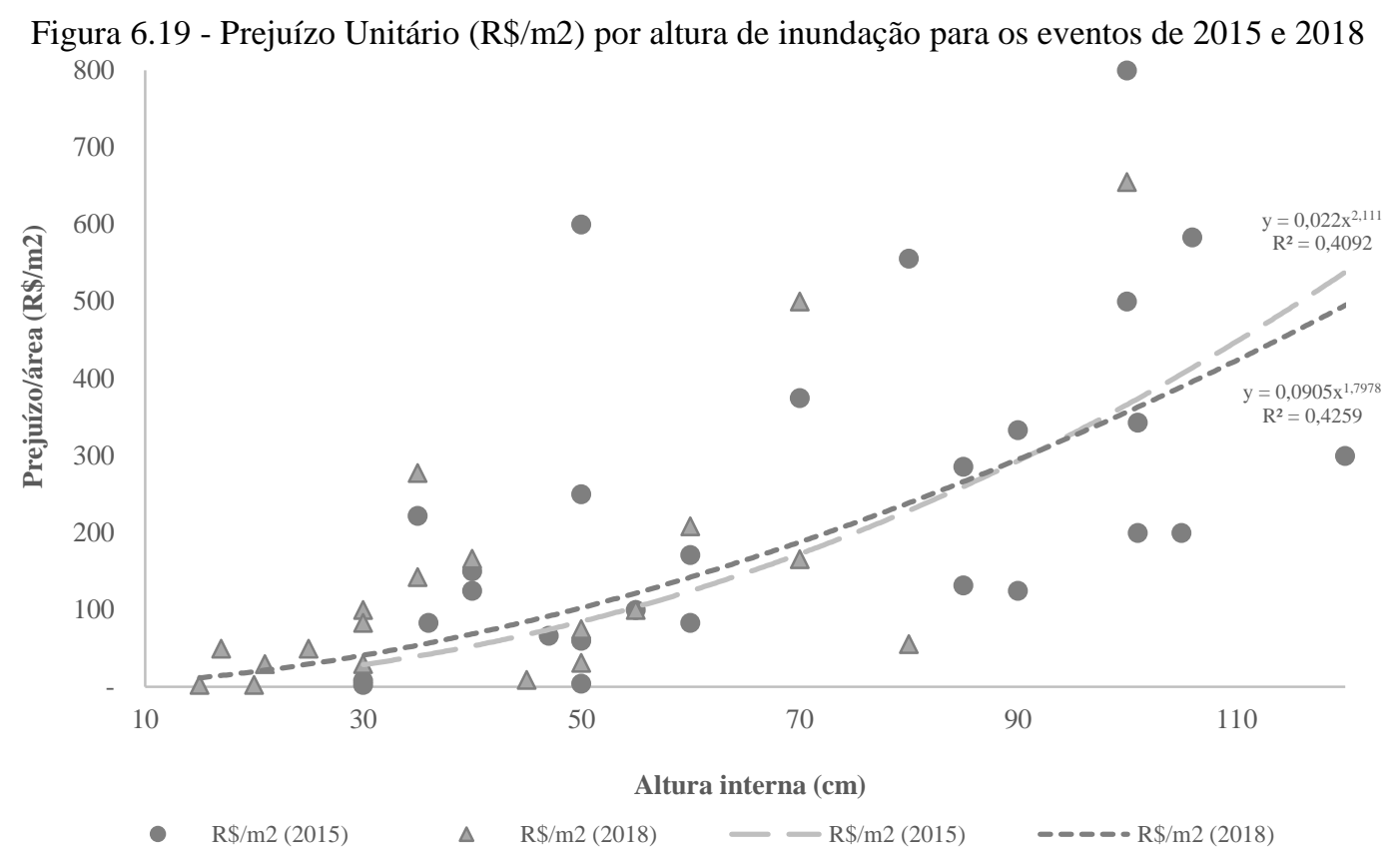

Apesar da alta dispersão dos dados, as linhas de tendência apresentaram formato semelhante. Para melhor representatividade dos dados, estes foram normalizados para se perceber os incrementos de altura em cada etapa do crescimento da altura de submersão e avaliar a normalidade dos dados.

Para avaliar a normalidade da função em relação aos dados, foi aplicado o teste de Anderson-Darling. Com relação variável Valor- $P$, o valor maior de 0,05 considera que os dados 
possuem normalidade, enquanto que para valores menores não possui normalidade. As Figuras 6.20 e 6.21 apresentam os testes para os dos normalizados em relação ao prejuízo unitário e a Figura 6.22 o gráfico boxplot relativo às curvas DPS para a região.

Figura 6.20 - Prejuízo unitário normalizado, análise estatística e teste de Anderson para o evento de 2015

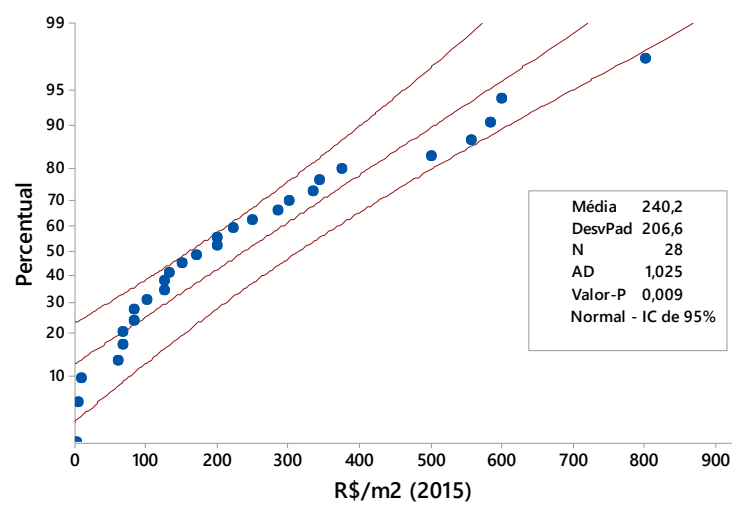

Figura 6.21 - Prejuízo unitário normalizado, análise estatística e teste de Anderson para o evento de 2018

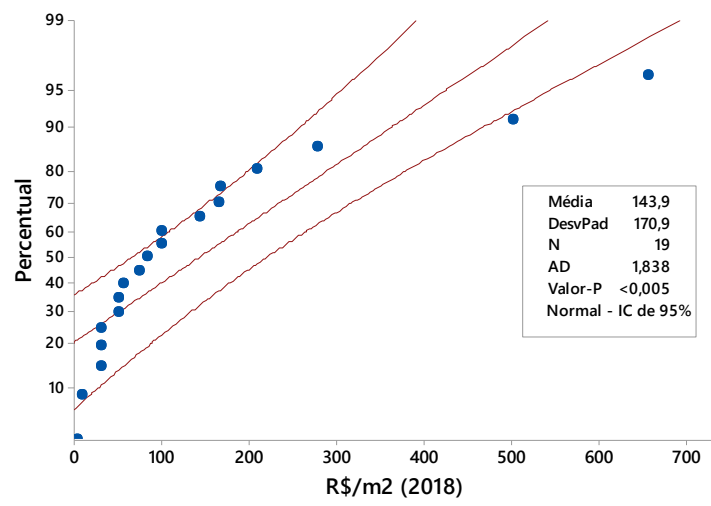

Figura 6.22 - Boxplot da variável prejuízo por área do estabelecimento para os eventos de 2015 e 2018

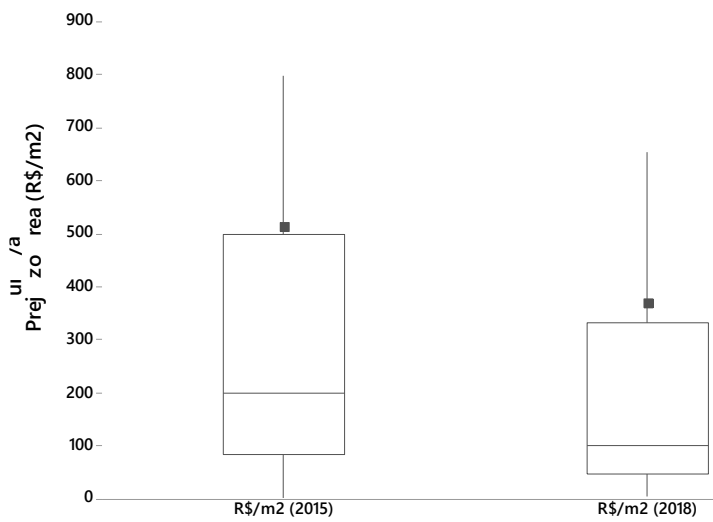


Verifica-se pelo gráfico boxplot da Figura 6.22 que a média dos prejuízos se encontra próxima do terceiro quartil, enquanto que a mediana se encontra próxima do primeiro quartil, evidenciando que poucas empresas possuem valores elevados de prejuízo unitário enquanto a maioria das empresas possui baixos valores para essa variável.

Já pelas Figuras 6.19 e 6.20 verifica-se que o valor do teste de normalidade está abaixo de 0,05, o que conclui que os dados não possuem normalidade. Além disso, a análise adimensional permite verificar que, para o evento de 2018, 60\% estavam abaixo de $\mathrm{R} \$ 100 / \mathrm{m}^{2}$, enquanto que para o evento de 2015 esse percentual é de $30 \%$, evidenciando maiores perdas relativas nesse ano. Outra variável a ser analisada é a frequência dos estabelecimentos em relação a esta variável, apresentadas na Figura 6.23.

Figura 6.23 - Frequência de empresas por categoria de danos por profundidade de submersão par os eventos considerados

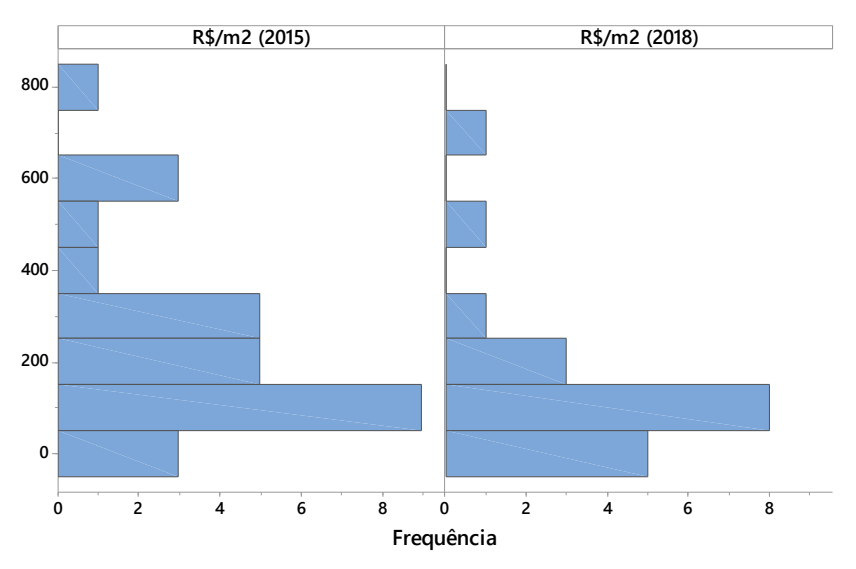

Por meio da Figura 6.23 é possível averiguar uma quantidade maior de empresas com valores de prejuízo igual ou superior a $\mathrm{R} \$ / \mathrm{m}^{2} 300$, fato que ocorreu raramente em para o evento de 2018.

\subsubsection{Relações entre prejuízo, estoque e altura de submersão}

Outra variável obtida por meio das entrevistas foi o estoque médio declarado de cada comerciante. Com isso, foi possível estabelecer uma relação entre o estoque e o prejuízo por altura de submersão para cada estabelecimento. Os resultados dessa análise para os dois eventos são apresentados na Figura 6.24. 
Figura 6.24 - Relação prejuízo/estoque por altura de inundação

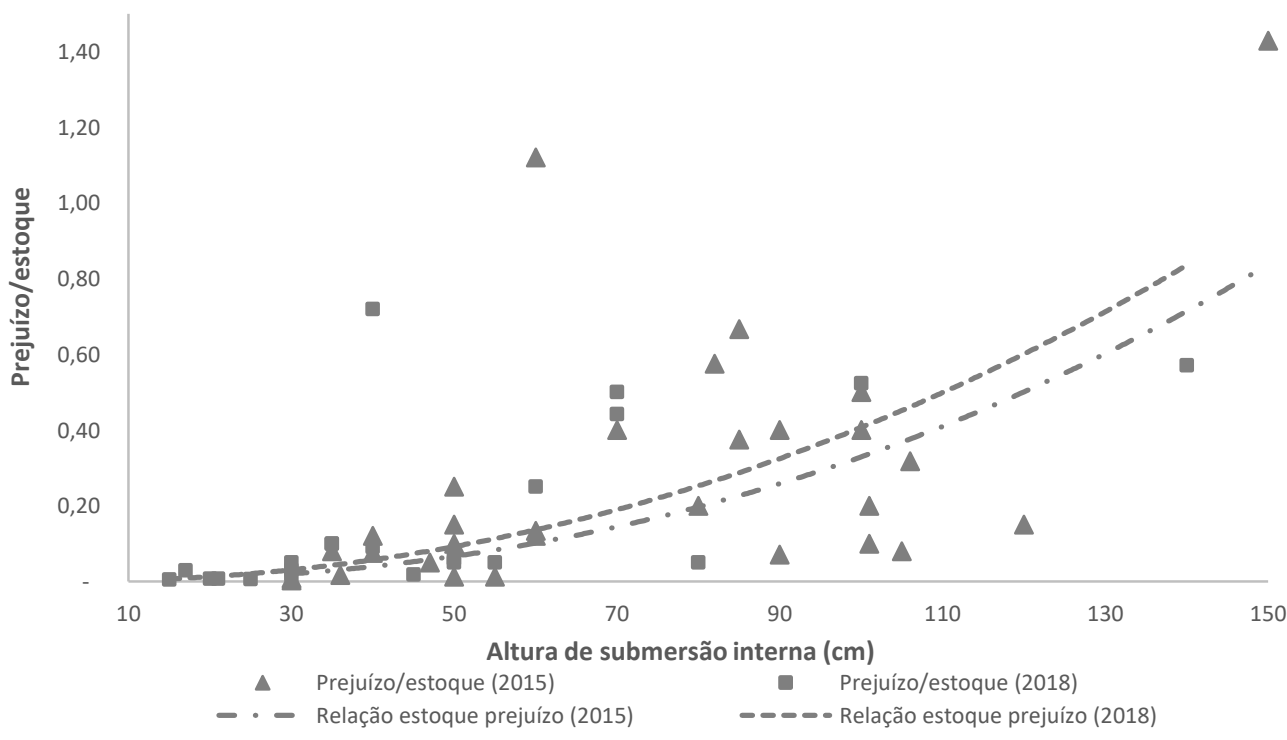

A relação prejuízo/estoque permite analisar o percentual de prejuízo em detrimento da altura de inundação atingida e comparar com outras metodologias. Percebe-se que as curvas de tendência exponencial para os dois eventos possuem proximidade, além de serem similares aos dados de Cançado (2009) ${ }^{17}$, conforme apresentado na Tabela 6.6 e na Figura 6.25.

Tabela 6.6 - Índice de amaça a inundação obtidos por Cançado (2009) para a área de estudo de São Carlos Prejuízo/estoque

\begin{tabular}{ccc}
\hline $\begin{array}{c}\text { Profundidade } \\
(\mathbf{m})\end{array}$ & $\begin{array}{c}\text { Cançado } \\
(2009)\end{array}$ & $\begin{array}{c}\text { São Carlos } \\
(2015)\end{array}$ \\
\hline 0,35 a 0,45 & 0,05 & 0,05 \\
\hline 0,45 a 0,55 & 0,21 & 0,12 \\
\hline 0,55 a 0,70 & 0,31 & 0,20 \\
\hline 0,70 a 0,85 & 0,41 & 0,28 \\
\hline 0,85 a 0,95 & 0,54 & 0,36 \\
\hline 0,95 a 1,05 & 0,67 & 0,44 \\
\hline 1,05 a 1,15 & 0,79 & 0,56 \\
\hline 1,15 a 1,45 & 0,94 & 0,84 \\
\hline
\end{tabular}

\footnotetext{
17 Ver item 2.8.
} 
Figura 6.25 - Comparação entre os percentuais de prejuízo em relação ao estoque por altura de submersão obtidos por Cançado (2009) e nesta pesquisa

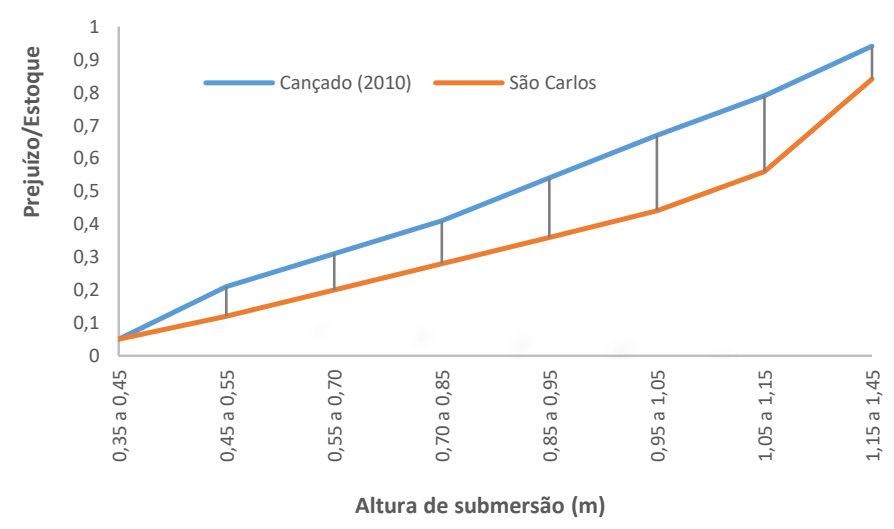

Para analisar os tipos de perdas ocorridos no comércio em cada evento, foi solicitado aos comerciantes que listassem os itens perdidos nessas ocasiões. Os danos foram assim discretizados em 4 categorias: conteúdo, móveis, acessórios e estruturais (físicos). Os resultados da amostragem são apresentados na Figura 6.26.

Figura 6.26 - Quantificação por categoria de perdas observados pelos comerciantes

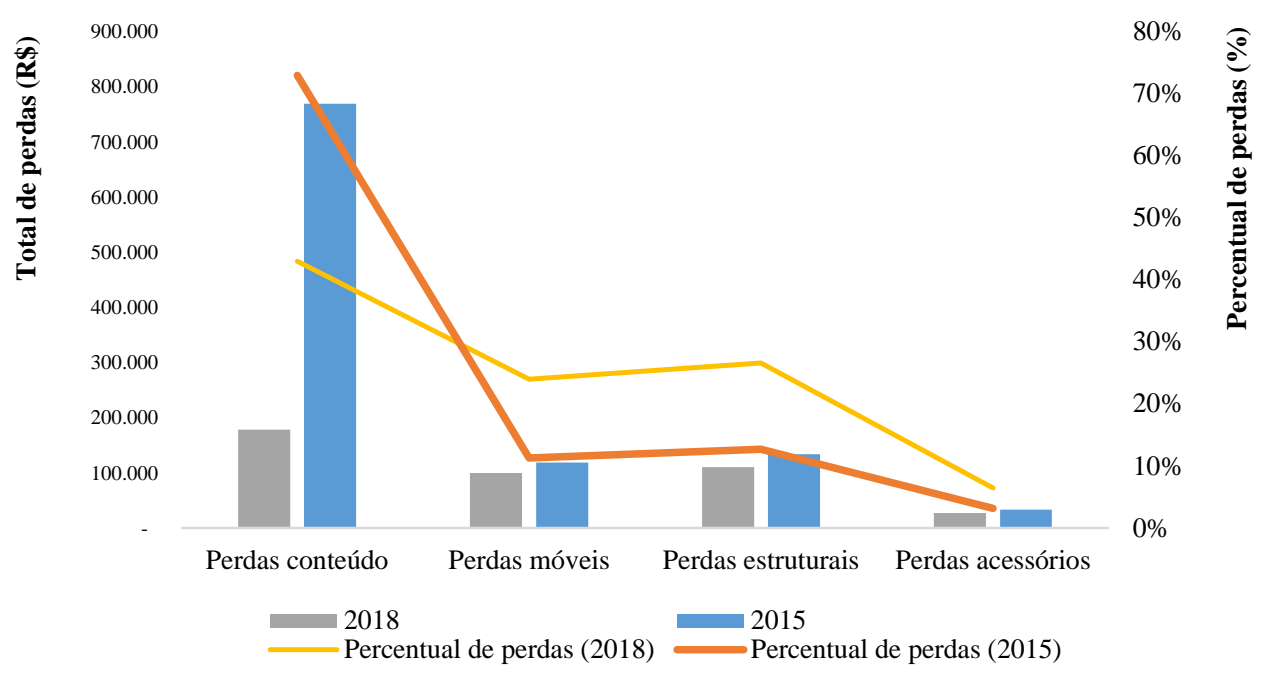

É possível observar que, em 2015, mais de 70\% dos danos foram decorrentes de perdas de conteúdo, enquanto em 2018 essas perdas atingiram apenas 42\%. Esse fato pode ser correlacionado à memória da população, que presenciou um evento semelhante há poucos anos e estava mais preparada, tanto pelo maior número de comportas quanto pela agilidade de locomover as peças para locais mais elevados.

Além disso, o contato dos imóveis as duas inundações foi fator que colaborou para a maior perda de imóveis em 2018, tendo em vista que, mesmo com baixas alturas de submersão 
internas, esses são afetados em seus rodapés, estufando-os e danificando permanentemente suas estruturas.

As perdas estruturais em 2018, em danos relativos, também foram superiores aos presenciados no ano de 2015. Dentre os fatores, destaca-se as instalação e elevação das comportas (computadas neste estudo como danos estruturais), quebra de vidraças, pisos e pintura de paredes.

Outra abordagem se dá com relação ao número de funcionários em detrimento do estoque. Como o número de funcionários é função da eficiência do processo, um alto valor de estoque também deve estar atrelado ao maior número de funcionários, já que o valor do estoque tem relação direta com a receita obtida pela empresa. Esta relação é apresentada na Figura 6.27.

Figura 6.27 - Número de funcionários em relação ao estoque

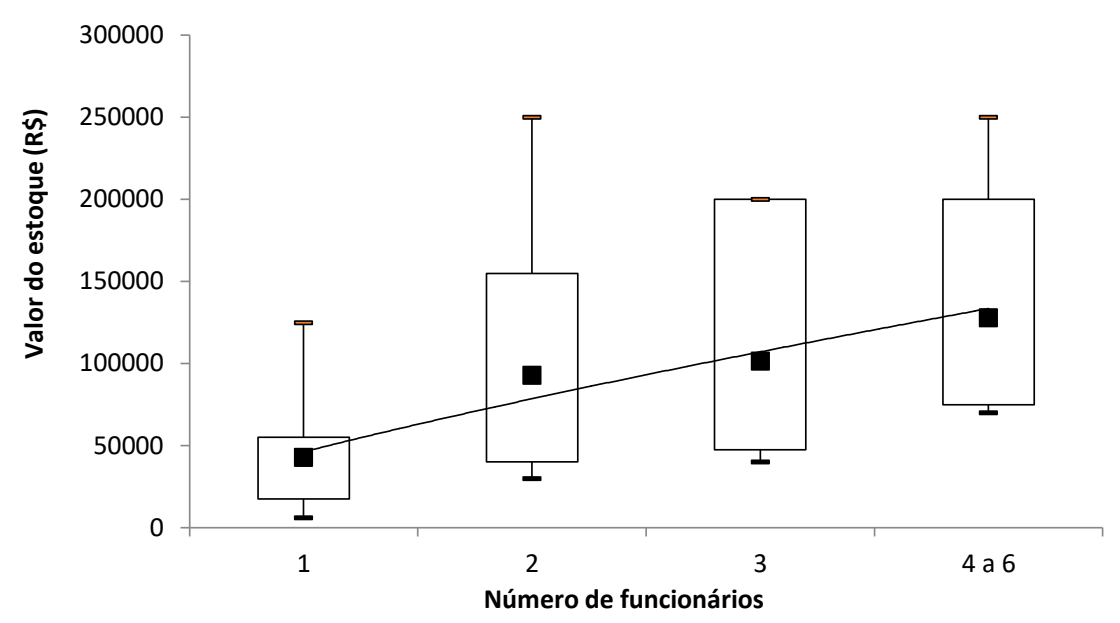

O dado relativo ao número de funcionários nos permite inferir que o valor do estoque tem relação progressiva ao número de funcionários, podendo se estabelecer relação entre ambos para inferir o valor do estoque com relação ao número de funcionários, já que o valor médio do estoque passou de $\mathrm{R} \$ 43.000$ para empresas com apenas 1 funcionário para $\mathrm{R} \$ 130.000$ para empresas com 4 a 6 funcionários, sendo que a área interquartil também apresenta tendência crescente.

\subsubsection{Prejuízos indiretos}

\subsubsection{Custos de infraestrutura}

No que diz respeito aos danos, a defesa civil do município de São Carlos informou que foram removidas 18 toneladas de entulho, lixo e material orgânico, como árvores. O órgão estima prejuízos da ordem de $\mathrm{R} \$ 6,3$ milhões em decorrência do evento, sendo que R 3,8 
milhões foram gastos com despesas emergenciais, como conserto de ruas, limpeza da área afetada e reparo de estruturas públicas. O restante, $\mathrm{R} \$ 2,5$ milhões, foram gastos com danos aos $\operatorname{comerciários~}^{18}$. Cabe salientar que o custo dos danos aos comerciários refere-se a uma avaliação rápida e simplificada dos danos pela defesa civil, porém não refletem desembolsos reais por parte da prefeitura.

Cabe apontar que, para ambos os eventos foram decretados estado de emergência no município $^{19,20}$, o permite ao município a abertura de gastos sem processo licitatório para os gastos emergenciais, o que pode acarretar em valores superiores aos módicos praticados pelo mercado devido à falta de concorrência no processo.

Além disso, foi aberto pelo pesquisador processo para solicitação de informações via plataforma GIAP da prefeitura sob número 6.025/2018 ${ }^{21}$, sendo intitulado no pedido ofício resumido pela prefeitura como "solicita informações ref. a valores despendidos pela PMSC e órgãos públicos referente as obras de reparo e serviços executados na região do mercado municipal, nas inundações de 23/11/2015 e 20/03/2018, bem como outras que teriam sido realizadas durante este período, para fins de pesquisa em tese de doutorado."

O processo encontra-se na seção de arquivos da prefeitura municipal sob o número de processo supracitado. Ressalta-se que, apesar do pedido se referir aos períodos de 2015 e 2018 , as informações obtidas referem-se apenas aos dados de $2018^{22}$. Como resposta, obteve-se cinco tipos de obras, sendo que apenas três aparentemente estavam de fato estabelecidos com o processo de inundação, apresentadas na Tabela 6.7. A página do processo contendo o descritivo completo das obras e serviços no Apêndice 7.

Tabela 6.7 - Valores declarados pela Prefeitura Municipal de São Carlos referente as obras de reparo e serviços executados

\begin{tabular}{lr}
\hline Tipo de contrato & Valor $(\mathbf{R} \$ \mathbf{)}$ \\
\hline $\begin{array}{l}\text { Contratação emergencial de conserto } \\
\text { e manutenção de galerias de águas pluviais }\end{array}$ & 265.584 \\
\hline $\begin{array}{l}\text { Contratação emergencial de reparos e } \\
\text { manutenção dos leitos e córregos }\end{array}$ & 734.683 \\
\hline $\begin{array}{l}\text { Contratação emergencial de limpeza } \\
\text { de córrego e galerias }\end{array}$ & 411.180 \\
\hline TOTAL & $\mathbf{1 . 4 2 0 . 4 4 7}$ \\
\hline
\end{tabular}

\footnotetext{
${ }^{18}$ Chuva gera prejuízo de R \$ 6,3 milhões em São Carlos, aponta Defesa Civil. Disponível em: < http://g1.globo.com/sp/sao-carlos-regiao/noticia/2015/11/chuvagera-prejuizo-de-r-63-milhoes-em-sao-carlos-aponta-defesa-civil.html>. Acesso em: 08 de agosto de 2016.

${ }^{19}$ Após destruição com temporal, São Carlos decreta estado de emergência. Disponível em: <http://g1.globo.com/sp/sao-carlosregiao/noticia/2013/10/apos-destruicao-com-temporal-sao-carlos-decreta-estado-de-emergencia.html>. Acesso em 06.08.2016.

${ }^{20}$ URGENTE: Após chuva, Airton decreta situação de emergência em São Carlos. Disponível em: < https://saocarlosemrede.com.br/urgenteapos-chuva-airton-decreta-situacao-de-emergencia-em-sao-carlos> Acesso em 06.08.2016

${ }^{21}$ Prefeitura municipal. Serviço Integrado do município. Disponível em:

<https://cidadaoscarlos.giap.com.br/apex/trib/f?p=231:1:0::NO::P0_CERT_INSCRICAO:I > Acesso em: 13/06/2019

${ }^{22}$ Possivelmente por dificuldade de acesso de informações do ano de 2015, decorridos de alteração de partidos políticos.
} 
Cabe salientar que as obras apresentadas acima referem-se apenas as realizadas em decorrência do evento de 2018, sendo que a referente ao evento de 2015 não foram informadas ${ }^{20}$.

Sendo assim, para efeito da contabilização dos prejuízos nesta pesquisa será considerado o valor decretado pela defesa civil para as obras de reparos ( $\mathrm{R} \$ 3,8$ milhões) para o evento de 2015 e os gastos declarados pela prefeitura para o evento 2018 ( $\mathrm{R} \$ 1.420 .447)$.

\subsubsection{Lucro cessante}

De acordo com as entrevistadas, o tempo médio que o estabelecimento ficou fechado foi de 12 horas e com a mediana em 6 h, totalizando 416 horas para os 39 estabelecimentos que responderam a esta questão. Para os estabelecimentos que não responderam à questão, foi considerada o tempo de $6 \mathrm{~h}$, relativo a mediana dos valores observados.

Com relação à receita das empresas, realizou-se estimativa baseada no estoque das empresas, metodologia desenvolvida nesta pesquisa e apresentada no item 6.2.5.2. Com isso, a partir do o valor do estoque presente em cada empreendimento estimou-se a receita anual das empresas.

Desta forma, aplicou-se os percentuais de receita em relação ao estoque às empresas pesquisas para estimar a receita que das empresas, tendo em vista as informações de estoque foram declaradas pelos entrevistados. Foram consideradas 44 empresas nessa análise, referente àquelas que responderam à questão relacionada ao valor médio anual do estoque. $\mathrm{O}$ valor médio da receita estimada para as empresas pesquisadas foi de $\mathrm{R} \$ 558.000$, enquanto que o total foi estimado em $\mathrm{R} \$ 24.548 .750$.

Dessa forma, o lucro cessante total das empresas impactadas totalizou $\mathrm{R} \$ 128.599,59$. Os valores de estoque, tempo que o comércio ficou fechado, receita estimada e lucro cessante é apresentado no Apêndice 6.

\subsubsection{Limpeza dos estabelecimentos}

De acordo com os comerciários da região, foram gastos 535 horas com a limpeza dos seus estabelecimentos, com 208 pessoas envolvidas neste processo; assim, o custo de limpeza total, contando todos os entrevistados, resultou em $\mathrm{R} \$ 121.223$. Os custos com limpeza de cada estabelecimento podem ser verificados no Apêndice 8. 
A Tabela 6.8 apresenta a relação de tempo para limpeza por pessoa por metro quadrado, de acordo com a altura de inundação - baseados nos valores sugeridos por Penning-Roswell \& Chatterton (1977) e adaptados para o Brasil por Nagem (2008), com os dados obtidos por meio das entrevistas em São Carlos. Cabe salientar que na pesquisa de Nagem (2008), os dados referem-se ao tempo de limpeza das residências.

\begin{tabular}{|c|c|c|c|}
\hline \multicolumn{4}{|c|}{ Tabela 6.8 - Tempo de limpeza } \\
\hline \multicolumn{2}{|c|}{ Nagem (2008) } & \multicolumn{2}{|c|}{ São Carlos } \\
\hline $\begin{array}{c}\text { Altura de } \\
\text { inundação (m) }\end{array}$ & $\begin{array}{c}\text { Horas } / \mathrm{m}^{2} / \\
\text { pessoa }\end{array}$ & $\begin{array}{c}\text { Altura de } \\
\text { inundacão (m) }\end{array}$ & $\begin{array}{c}\text { Horas } / \mathrm{m}^{2} / \text { pessoa } \\
\text { (São Carlos) }\end{array}$ \\
\hline 0,50 a 0,75 & 0,25 & até 0,50 & 0,58 \\
\hline 0,75 a 1,00 & 0,50 & 0,50 a 1,00 & 1,59 \\
\hline 1,00 a 1,50 & 1,00 & 1,00 a 1,50 & 3,81 \\
\hline 1,50 a 2,00 & 3,00 & & \\
\hline 2,00 a 3,00 & 5 & & \\
\hline
\end{tabular}

\subsubsection{Danos aos veículos}

Os danos aos veículos foram computados de acordo com dados da defesa civil para os dois eventos de inundação, referente ao número de veículos danificados nesses eventos (item 6.2.5.2). De acordo com esses dados, a somatória dos para os carros foi de $\mathrm{R} \$ 1.133 .905,50 \mathrm{e}$ para as motocicletas de $\mathrm{R} \$ 144.000,00$ em 2015, totalizando $\mathrm{R} \$ 1.277 .905,50$. Já para o ano de 2018, o somatório dos danos aos veículos foi de $\mathrm{R} \$ 449.962,50$, sendo que não foram divulgadas informações sobre as motocicletas nesse evento. Dessa forma, para os dois eventos considera-se o valor de danos aos veículos igual a $\mathrm{R} \$ 1.727 .868$, conforme apresentado na Tabela 6.9.

Tabela 6.9 - Valores dos danos aos veículos para as inundações de 2015 e 2018

\begin{tabular}{lrcr}
\hline Ano & Carros & Motocicletas & \multicolumn{1}{c}{ Total } \\
\hline 2015 & $1.133 .905,50$ & $144.000,00$ & $1.277 .905,50$ \\
\hline 2018 & $449.962,50$ & & $449.962,50$ \\
\hline Total & & & $\mathbf{1 . 7 2 7 . 8 6 8 , 0 0}$ \\
\hline
\end{tabular}

\subsection{DISCUSSÕES}

De acordo com Eleutério (2014), a análise do risco de inundação pode ser realizada por diferentes atores e com diferentes propostas para tal. Porém, estimar os danos de uma inundação requer a junção de diversas áreas do conhecimento relativo ao risco de inundação. 
Dessa forma, diversos métodos podem ser aplicados para avaliar tal fenômeno; porém, qualquer que seja, o conhecimento do fenômeno que provocou a inundação é tão importante quanto o conhecimento da vulnerabilidade a que a comunidade da zona de risco está exposta.

Portanto, buscou-se incorporar diversos aspectos acerca do prejuízo: a memória da população frente a preparação de eventos de inundação; o prejuízo das empresas contidos na área de inundação; os danos indiretos provocados pelas inundações e a comparação com outros trabalhos acerca da temática de prejuízos para validação dos resultados.

\subsubsection{Memória da população}

Acerca da memória da população, tal análise trouxe informações gerais sobre a problemática da inundação, trazendo informações gerais relacionadas a inundação. Verificouse que, dos 52 estabelecimentos entrevistados, 38 (73\%) estavam no local nos dois eventos de inundação, sendo a média que tais comerciantes estavam instalados nesta região de 21 anos e, também em média, terem evidenciado 6 eventos de inundação em seus estabelecimentos.

Porém, devido a tal experiência, foi possível constatar que as inundações analisadas neste estudo foram as que trouxeram maior impacto aos comerciários da região, já que alguns comerciantes instalados a mais de 30 anos no local nunca haviam sofrido danos significativos em seus estabelecimentos.

Apesar dos eventos de inundação, a maioria destes comerciantes instalados a mais tempo na região declararam que não pretendiam sair do local, tendo em vista o local ser um importante ponto comercial da cidade.

Esse fato foi corroborado ao se analisar as comportas instaladas nos estabelecimentos. Das 14 lojas instaladas a menos de 2 anos, 6 (43\%) possuíam comportas instaladas, enquanto que das 38 lojas instaladas a mais de 3 anos na região, 24 (63\%) possuíam comportas em seus estabelecimentos. Destes comerciantes, 16 (42\%) instalaram suas comportas apenas no ano de 2018, com média de $95 \mathrm{~cm}$ de altura e apenas 3 aumentaram suas comportas nesse período. Ao se verificar a soma da altura das comportas, verificou-se que no ano de 2018 a soma da altura foi o dobro da verificada em 2015, evidenciando o feed back da população frente a um novo nível de ameaça.

Com relação ao número de eventos sofridos, realizou-se a análise da relação entre o tempo que o imóvel está inserido no local em relação ao número de eventos de inundação (frequência de eventos de inundação). Constatou-se que, para as lojas presentes a mais de 20 anos no local, a essa relação foi menor de 0,2 para a maioria dos estabelecimentos, ou seja, em 
$20 \%$ dos anos tais lojas presenciaram eventos de inundação. Já para as lojas com menos de 10 anos no local, essa relação foi de 0,6 , evidenciando assim maior recorrência desses eventos nesse período.

\subsubsection{Prejuízo das empresas contidos na área de inundação}

Os prejuízos foram obtidos por meio de entrevistas aos comerciantes (auto declaração). Como critério para realização das entrevistas, abordava-se inicialmente se a empresa foi atingida pela água dentro de seu estabelecimento. Porém, muitas das empresas atingidas declararam que não sofreram danos diretos ao conteúdo.

Do total de empresas presente nos dois eventos (38), 27 (71\%) declararam ter sofrido prejuízo em 2015, 17 (44\%) em 2018, sendo que 13 delas (34\%) declaram que sofreram prejuízo em ambos os eventos.

Verificou-se que as empresas outliers (seguindo metodologia boxplot) possuem considerável participação no montante total de prejuízos: em torno de $60 \%$ em ambos os eventos. Verificou-se que questões peculiares descrevem o porquê dessa situação, como: o não fechamento das portas da loja; a entrada de água por meio loja vizinha (força da água destruiu as paredes); a falta de conhecimento sobre a problemática da inundação (proprietário informou que a água não atingiria o imóvel ao locatário); e a falta de estruturas de contenção nesses estabelecimentos.

As curvas de danos por profundidade de submersão possuem boa correlação com relação entre as linhas de tendência entre os dois eventos de inundação, tanto para o prejuízo total quanto para o prejuízo unitário, apesar da alta dispersão dos dados e sua não normalidade.

Verificou-se, pelas análises boxplot (retirados os outliers), que a média dos dados se encontra próxima do terceiro quartil, o que demonstra que poucas empresas foram responsáveis pela maior parte dos prejuízos verificados no local, assim como a mediana dos dados encontrase próxima do terceiro quartil, dada a alta dispersão dos dados para a metodologia DPS, fato também verificado por Machado (2005) para os dados do comércio.

\subsubsection{Danos indiretos}

Os danos indiretos considerados nesta pesquisa foram:

- Custo da infraestrutura

- Danos aos veículos 
- Lucro cessante

- Limpeza dos estabelecimentos

Além desses prejuízos, é possível ainda considerar nas análises dos custos tangíveis indiretos aqueles relacionados a paralização do tráfego de veículos, porém não fora considerado nesta análise.

Com relação aos danos considerados, é possível imputar tais danos aos diferentes atores afetados pelas inundações: ao custo da infraestrutura, o valor é despendido pela prefeitura, com reparo e manutenção dos estragos provocados pelas inundações; ao custo dos veículos, são afetados os munícipes que estavam na região, assim como os comerciantes que possuíam seus veículos estacionados no local; ao lucro cessante e a limpeza dos estabelecimentos, os prejuízos são absorvidos pelos comerciantes.

Com relação ao lucro cessante e ao custo de limpeza dos estabelecimentos, foram obtidas informações apenas do evento de 2018 , face as pessoas terem dificuldade de recordarem de detalhes de informações referente ao ano de 2015 necessário a essa análise. Porém, é provável que tais variáveis, como tempo que o comércio ficou fechado, o número de horas de limpeza e o número de pessoas que participaram do processo de limpeza, não terem variado substancialmente entre os eventos e, dessa forma, foi considerado o mesmo valor de dano para ambos os eventos. A Tabela 6.10 apresenta um resumo dos danos indiretos analisados nesta pesquisa. Já a Tabela 6.11 apresenta a soma dos danos diretos e indiretos apresentados nos eventos analisados absorvidos pelos comerciantes (prejuízos ao conteúdo e estruturas [diretos], e perdas relativas ao lucro cessante e limpeza dos imóveis [prejuízo indireto].

Tabela 6.10 - Resumo dos danos indiretos analisados

\begin{tabular}{lrr}
\hline Tipo de dano & $\mathbf{2 0 1 5}(\mathbf{R} \$)$ & $\mathbf{2 0 1 8}(\mathbf{R} \$)$ \\
\hline Custo da infraestrutura & 3.800 .000 & 1.420 .447 \\
\hline Danos aos veículos & 1.277 .905 & 449.962 \\
\hline Lucro cessante & 128.600 & 128.600 \\
\hline Limpeza dos estabelecimentos & 121.223 & 121.223 \\
\hline Total & $\mathbf{5 . 3 2 7 . 7 2 8}$ & $\mathbf{2 . 1 2 0 . 2 3 3}$ \\
\hline
\end{tabular}

Tabela 6.11 - Danos diretos e indiretos provocados nos eventos analisados

\begin{tabular}{lrr}
\hline Tipo de dano & $\mathbf{2 0 1 5}(\mathbf{R} \mathbf{)}$ & $\mathbf{2 0 1 8}(\mathbf{R} \mathbf{)}$ \\
\hline Direto & 1.050 .100 & 414.950 \\
\hline Indireto & 249.853 & 249.853 \\
\hline TOTAL & $\mathbf{1 . 2 9 9 . 9 5 3}$ & $\mathbf{6 6 4 . 8 0 3}$
\end{tabular}


Com relação ao custo de infraestrutura, verifica-se ser muito superior ao custo absorvido pelos comerciantes, em torno de 3 vezes em ambos os eventos. Ressalta-se que as licitações para essa finalidade podem ser realizadas em caráter emergencial, sem a necessidade de concorrência, tendo em vista o município ter decretado estado de emergência em ambos eventos, o que pode encarecer o serviço.

Com relação aos danos dos veículos, este pode ter duas consequências diretas: a diminuição dos gastos dos impactados pela necessidade de adquirir um novo veículo, assim como o aquecimento das vendas de veículos por parte de concessionárias. Ou ainda à não execução de compra de novo veículo, reflexo do menor poder de compra do momento atual de crise. Assim, questões intangíveis são verificadas nessa análise, de difícil quantificação

De qualquer forma, considerando os danos totais relativos aos dois eventos, a soma dos danos resultaria em $\mathrm{R} \$$ 8.913.011, que representaria 18\% do custo total das obras de contenção, ou $42 \%$ do custo do reservatório quando se considera apenas a execução da obra. Considerando apenas os custos relacionados a infraestrutura, gastos diretamente pela prefeitura, esse percentual seria de, respectivamente, $11 \%$ e $25 \%$.

Portanto, a análise dos danos indiretos traz valores embutidos não aferidos pela entrevista de maneira direta, já que os comerciantes computam apenas os prejuízos diretos em sua análise. Porém, tais custos refletem um elevado valor de danos verificado nos eventos, os quais devem ser considerados em análises de danos sob pena de subdimensionar os danos de forma significativa.

Por meio da Tabela 6.11, verifica-se que o valor dos danos indiretos relativo apenas aos comerciantes é de $\mathrm{R} \$ 249.853$ para os eventos analisados, que corresponde a $24 \%$ dos danos diretos para o evento de 2015 e $60 \%$ para o evento de 2018.

\subsubsection{Análise comparativa estatística dos dados obtidos nas entrevistas com aqueles obtidos por Machado (2005) e Riguetto (2005)}

\subsubsection{Prejuízo das empresas}

Para comparar os valores obtidos com a literatura consultada com os valores de altura de submersão interna obtidos por meio das entrevistas com os comerciantes foram aplicadas as curvas de prejuízo desenvolvida por Machado (2005) aos imóveis da região, de acordo com os dados obtidos no evento. Para isso, foram aplicados os dados relativos à altura de submersão 
interna, tipologia de venda do comércio e área medida do estabelecimento. Os resultados são apresentados na Figura 6.28.

Figura 6.28 - Comparação entre os prejuízos sofridos pelas empresas entrevistas e os obtidos por Machado (2005)

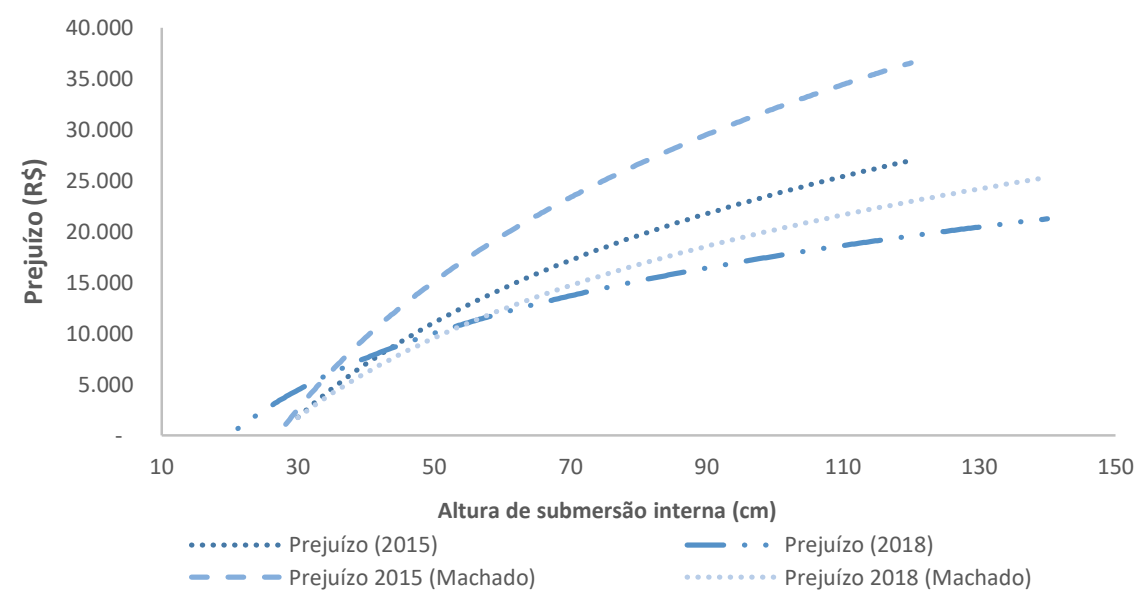

Ainda com o intuito de apresentar as relações entre as variáveis prejuizo e altura de inundação, os dados de prejuízo por empresa foram acumulados para avaliação dos incrementos de dano com relação à altura de inundação. As curvas representativas do prejuízo acumulado por empresa são apresentadas na Figura 6.29.

Figura 6.29 - Comparação entre os valores de prejuízo utilizando as curvas elaboradas por Machado (2005) e as elaboradas nesta pesquisa.

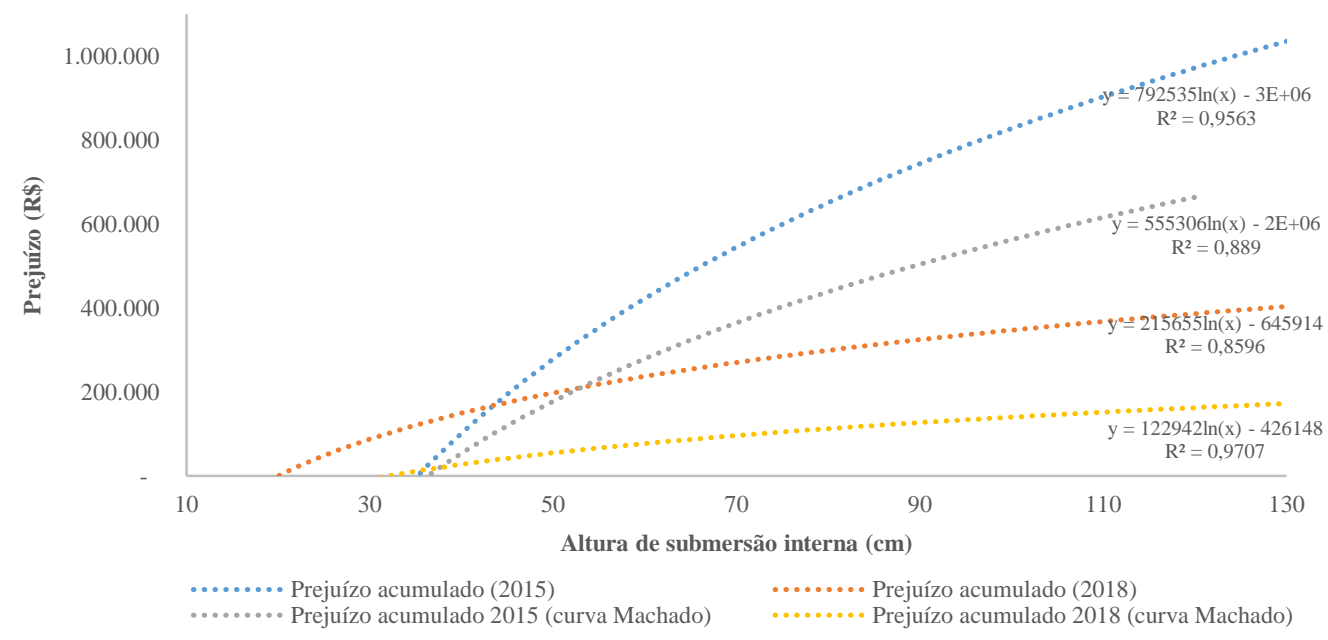

A análise do prejuízo total demonstra que os valores declarados pelos comerciantes de São Carlos por meio das entrevistas são aproximadamente o dobro daqueles que seriam obtidos pelas equações apresentadas por Machado e aplicadas nesta região. Contudo, há baixa correlação com os dados obtidos, tanto por Machado quanto por meio das entrevistas na região do mercado municipal de São Carlos/SP. 
Outra pesquisa realizada na mesma região foi elaborada por Riguetto (2005) com amostra de 14 empresas do local. Riguetto apresentou seus resultados analisando as relações entre prejuízo e estoque nas empresas entrevistas. Além disso, foi averiguado a disponibilidade a se pagar por seguro inundação. Dessa forma, foi possível comparar os valores obtidos pelo autor com os alcançados na presente pesquisa e os atingidos por Machado no mesmo local para a variável prejuízo. Os valores de prejuízo por empresa para as três pesquisas são apresentados na Figura 6.30.

Figura 6.30 - Comparação do prejuízo dos imóveis comercias nas pesquisas de Riguetto (2005), Machado (2005) e na presente pesquisa.

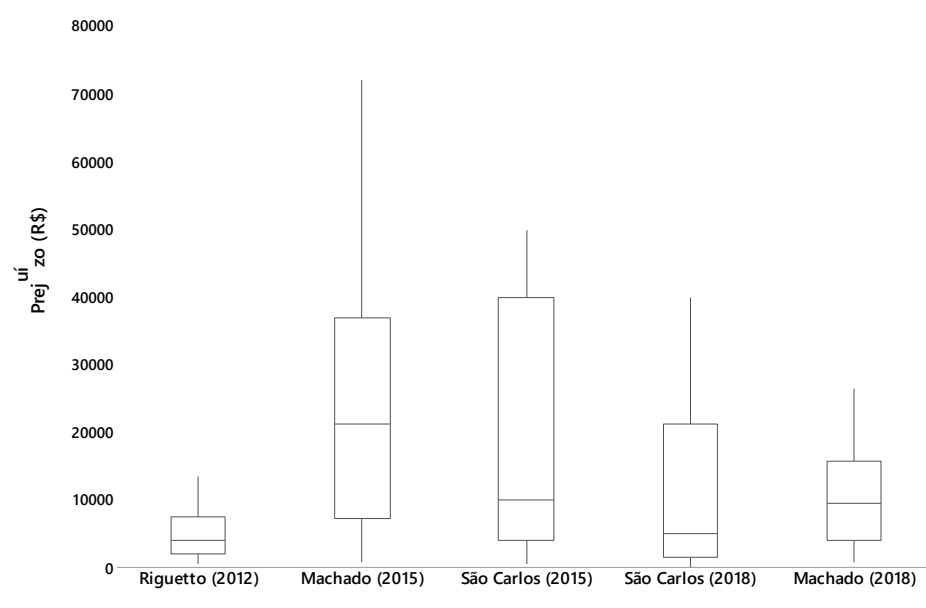

A análise da Figura 6.30 permite comparar os valores de prejuízo entre as pesquisas de Riguetto e as apresentadas nessa pesquisa. É possível perceber os baixos valores declarados de prejuízo na pesquisa de Riguetto (2005), o que corrobora as declarações dos comerciantes da região, que informaram que as inundações de 2015 e 2018 foram as maiores já verificadas na região. Além disso, tendo em vista que as curvas de danos por prejuízo terem apresentado valores semelhantes entre a pesquisa de Machado e as apresentadas nessa pesquisa, verifica-se que a relação interquartil das pesquisas apresenta resultados semelhantes.

\subsubsection{Curvas de Danos por Profundidade de Submersão}

Machado (2005) elaborou curvas para 8 categorias de estabelecimento comercial. Para isso, realizou um total de 200 entrevistas junto aos comerciantes da cidade de Itajubá. Nessa pesquisa, a amostra não foi suficiente para elaborar curvas para todos esses setores, tendo em vista que, predominantemente, o setor de vestuário prevalece na região. Assim, elaborou-se 
uma curva do setor de vestuário para comparação com os valores da autora, apresentados na Figura 6.31.

A Figura 6.31 apresenta um comparativo dos dados obtidos para os eventos de 2015 e 2018 com relação a curva obtida por Machado (2005). Para comparação, foram plotados sob uma única série de dados os valores de danos por metro quadrado para os eventos de $2015 \mathrm{e}$ 2018, sendo selecionados apenas as empresas que declararam prejuízo do setor de vestuário e calçadas (17 no ano de 2015 e 12 no ano de 2018), tendo em vista este ser numericamente o mais representativo da área de estudo. Essa distinção foi realizada para comparar com os dados obtidos por Machado para o mesmo setor e assim poder estabelecer avaliação dos valores obtidos.

Figura 6.31 - Comparação entre as curvas DPS elaboradas por Machado (2005) e as elaboradas nesta pesquisa.

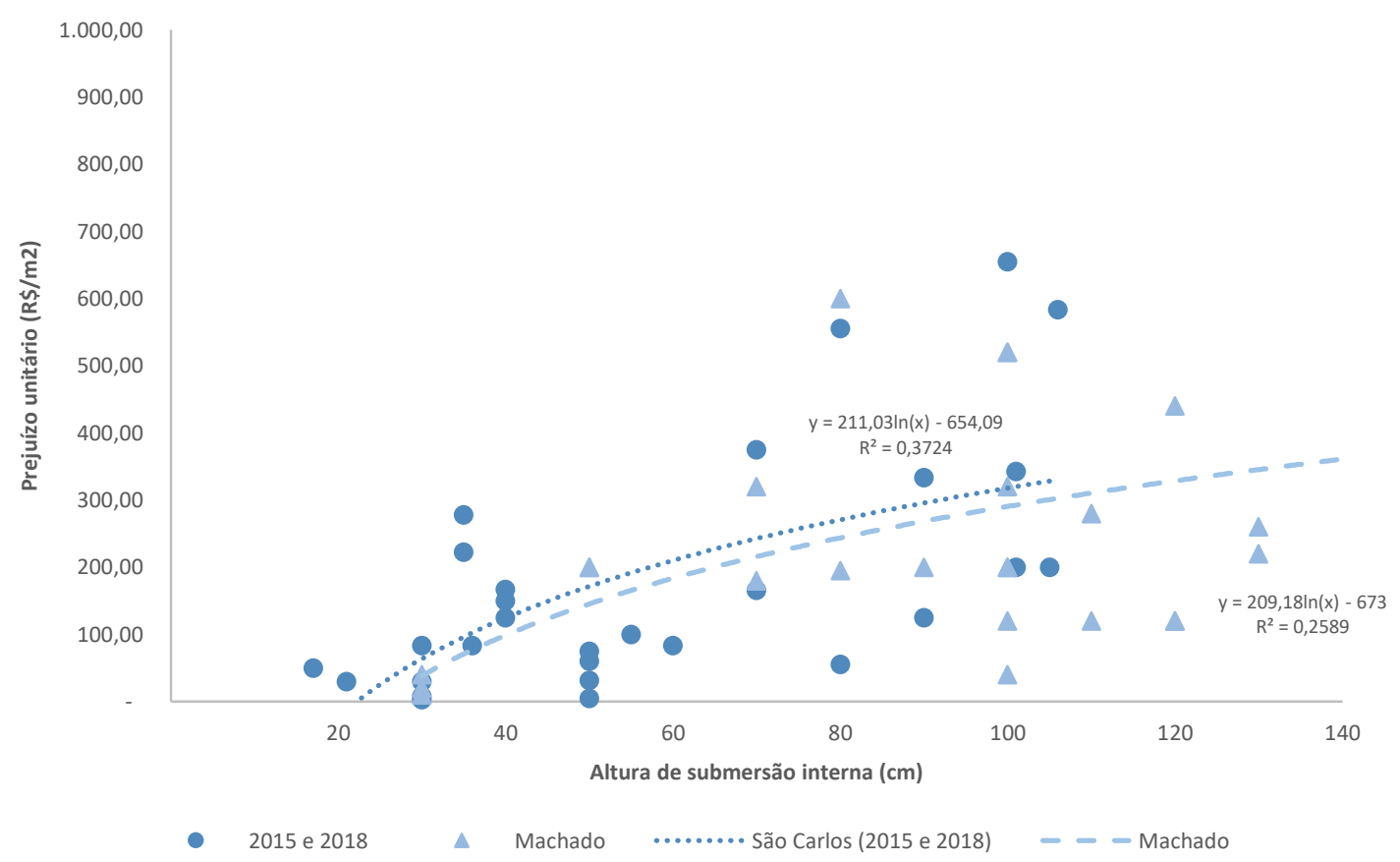

A análise da Figura 6.28 permite inferir que as curvas de tendência possuem baixa correlação com relação aos dados, dado a elevada assimetria entre os dados; apesar disso, tais curvas possuem proximidade entre ambas.

\subsubsection{Disponibilidade a pagar}

Seguro de inundação é uma forma de medida mitigadora não estrutural ainda incipiente no Brasil, porém de extrema importância frente as medidas não-estruturais passíveis de serem utilizadas. Para implementar um seguro inundação, a seguradora deve estabelecer o valor do 
prêmio ótimo pago pelos segurados. Para isso, umas das formas de se averiguar esse valor é diagnosticar a disposição a pagar dos possíveis segurados.

Foram levantadas informações relativas a essa variável após a inundação de 20 de março de 2001. Os resultados são apresentados na Figura 6.32. Nela são comparados os valores obtidos por Riguetto (2005) em amostra por entrevista com 14 comerciantes com aqueles alcançados nas entrevistas realizadas em 2018, com amostra de 31 comerciantes. Na Figura 6.33 são apresentados os gráficos boxplot desses dados.

Figura 6.32 - Valores de disponibilidade a pagar obtidos pelas entrevistas de Riguetto (2005) e nesta pesquisa

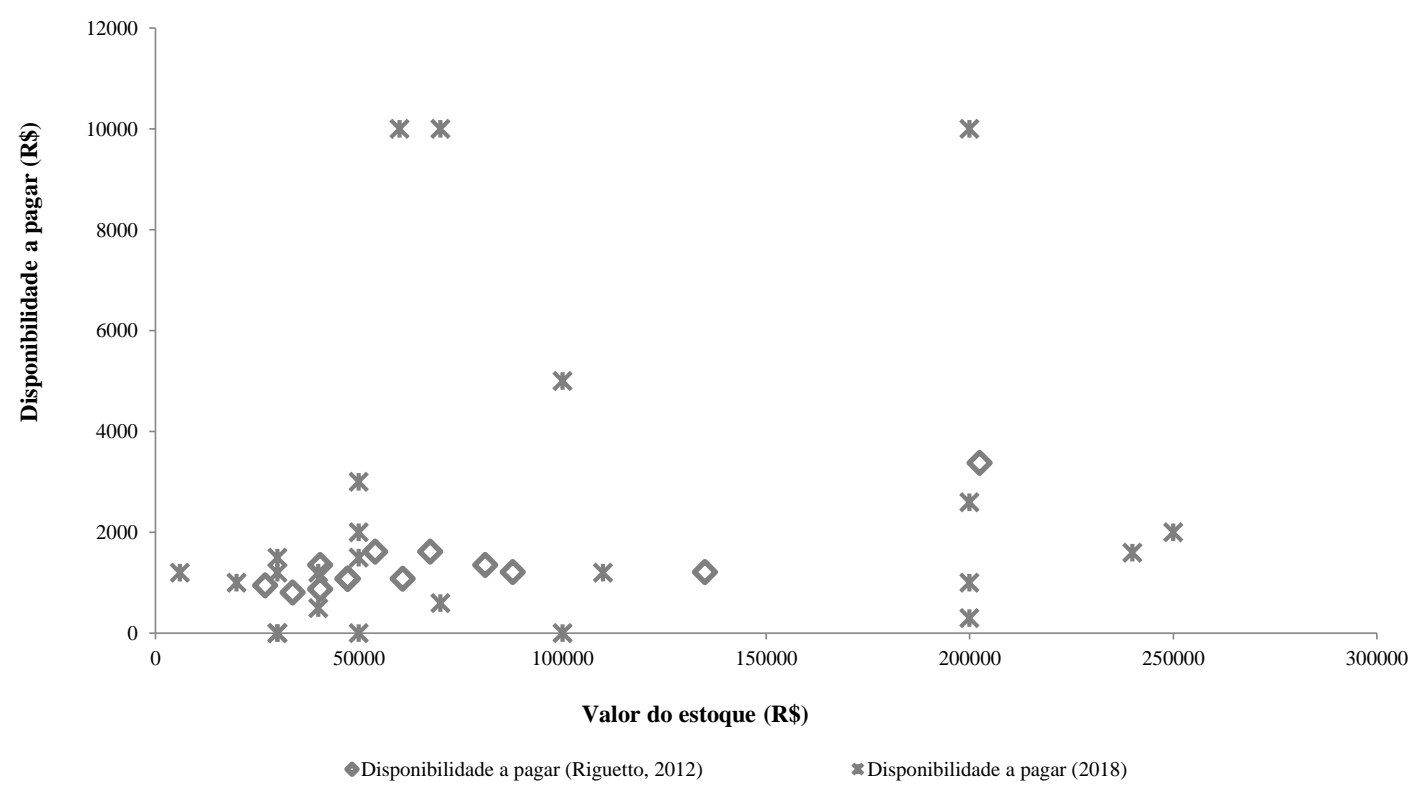

Figura 6.33 - Gráficos boxplot da disponibilidade a pagar obtidos nas entrevistas de Riguetto (2005) e nesta pesquisa

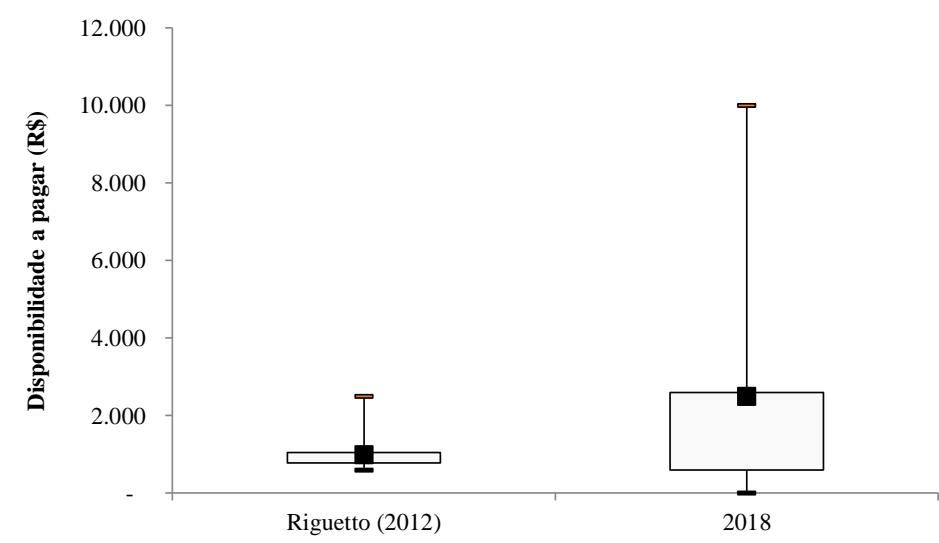


Os dados sugerem que a relação interquartil das duas pesquisas estarem situadas na mesma região, sendo que, na pesquisa de Riguetto, essa estar próxima de $\mathrm{R} \$ 1000$, enquanto que nesta pesquisa entre $\mathrm{R} \$ 600$ e $\mathrm{R}$ \$2.660, com média próxima do terceiro quartil.

A lógica da disponibilidade a pagar por um seguro está em proteger o valor de estoque das empresas, sendo que a tendência é que, quanto mais alto seja o estoque, maior a disponibilidade a pagar por um seguro inundação. Sendo assim, foi elaborado gráfico adimensionalizados para avaliar os incrementos das variáveis e comparados os valores obtidos nesta pesquisa com os obtidos por Riguetto (2005). Os resultados normalizados são apresentados na Figura 6.34.

Figura 6.34 - Curvas de disponibilidade a pagar adimensionalisadas elaboradas baseadas nas entrevistas de Riguetto (2005) e nesta pesquisa

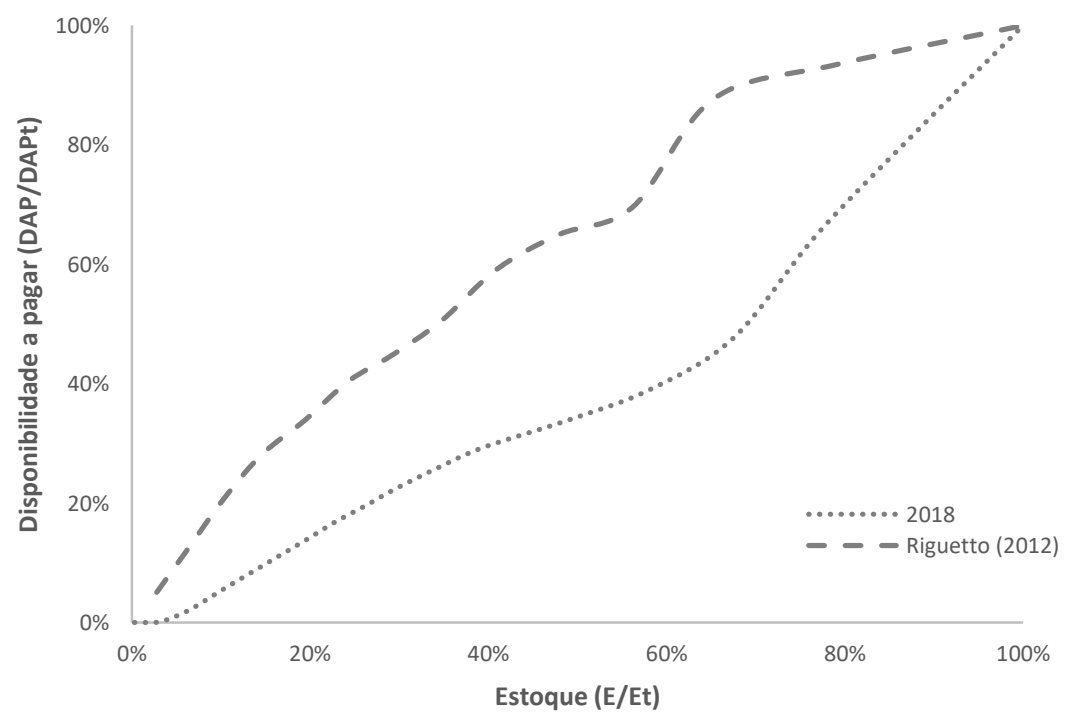

A Figura 6.31 permite inferir diferenças relativas à disponibilidade a pagar entre as pesquisas. Na pesquisa de Riguetto (2005), 60\% do valor da disponibilidade a pagar situava-se quando o estoque da mercadoria com relação ao máximo estoque situava-se em $40 \%$, enquanto na pesquisa de 2018, esse percentual de estoque se situava próximo de $30 \%$. Para compreender essa análise, é necessário então conhecer o estoque médio declarado pelos comerciantes em cada pesquisa. A Figura 6.35 apresenta o estoque médio declarado nas duas pesquisas. 
Figura 6.35 - Estoque médio declarado nas pesquisas de Riguetto (2005) e nesta pesquisa

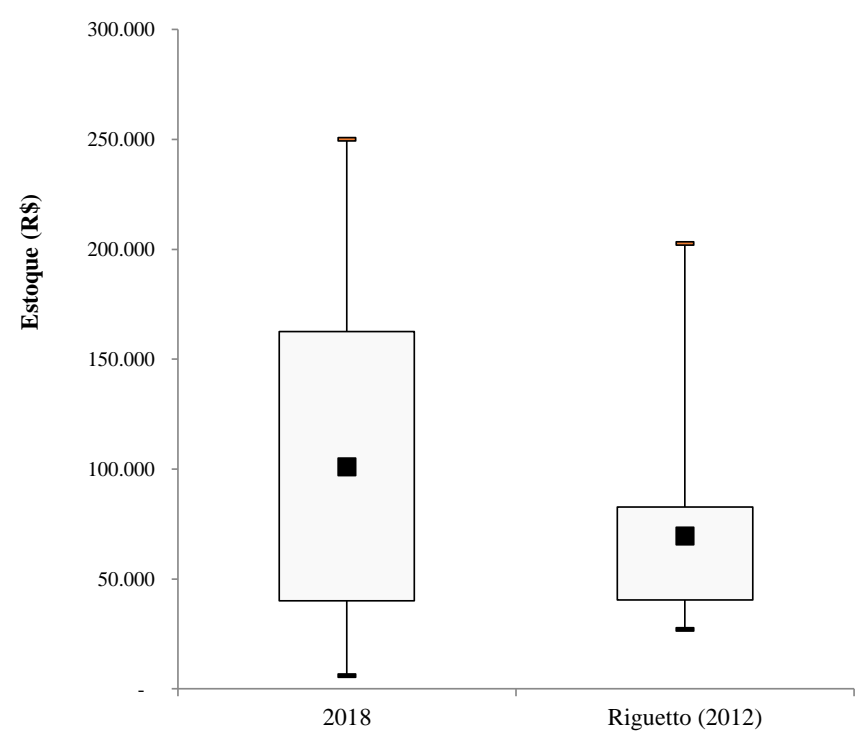

A análise da Figura 6.35 permite verificar que o estoque verificado por Riguetto ser menor que o verificado nesta pesquisa, variando de $\mathrm{R} \$ 40.000$ a 160.000 nesta pesquisa, com média de $\mathrm{R} \$ 101.000$ e entre $\mathrm{R} \$ 40.000$ e $\mathrm{R} \$ 80.000$ na pesquisa de Riguetto para a região interquartis, com média de $\mathrm{R} \$ 70.000$.

A título de comparação com Riguetto (2005) analisou-se também a relação prejuízo/estoque adimensionalizados entre os dados obtidos pelo autor e aqueles obtidos nas entrevistas para o vento de 2015 e de 2018. Os resultados são apresentados na Figura 6.36.

Figura 6.36 - Relação entre estoque e prejuízo normalizado verificado nas pesquisas de Riguetto (2005) e nesta pesquisa

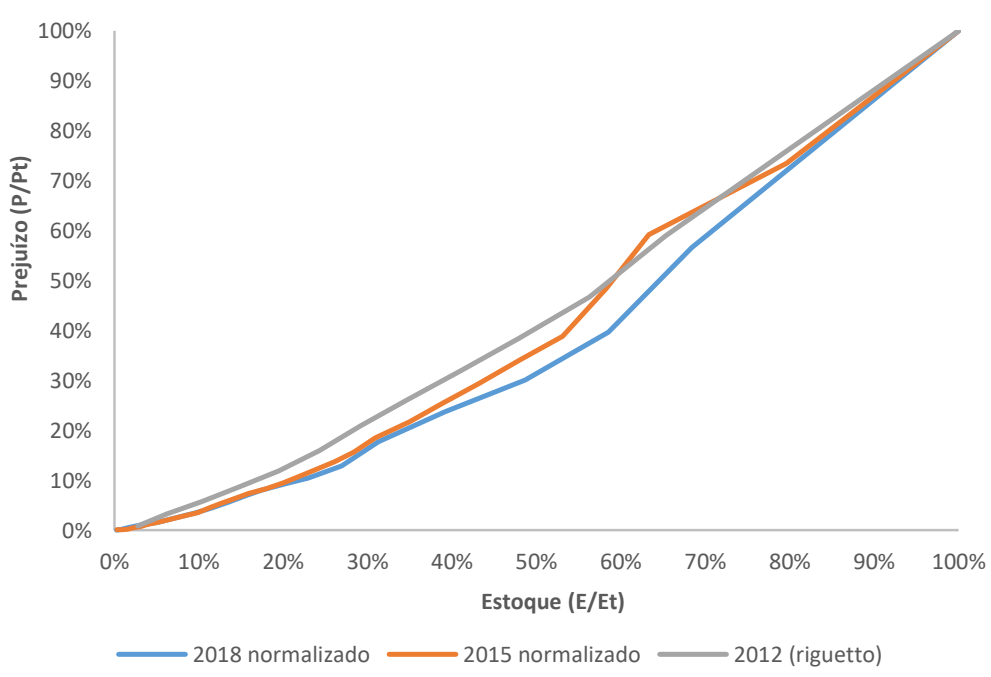


A Figura 6.36 demonstra que a relação prejuízo/estoque tem se mantido constante ao longo do tempo em relação aos dados desta pesquisa e de pesquisas anteriores, sendo uma importante fonte de comparação com trabalhos futuros.

Outra forma de análise comparativa ao trabalho de Riguetto é a relação Estoque/ disponibilidade a pagar e prejuízo disponibilidade a pagar pois, tendo em vista que tais variáveis influenciam no valor do prêmio do seguro. Para isso, foram elaboradas análises boxplot dessas relações para comparar os dados obtidos por Riguetto (2005) e aqueles obtidos por meio das entrevistas, apresentados nas Figuras 6.37 e 6.38.

Figura 6.37 - Comparação entre a disponibilidade a pagar entre a presente pesquisa e a pesquisa de Riguetto (2005)

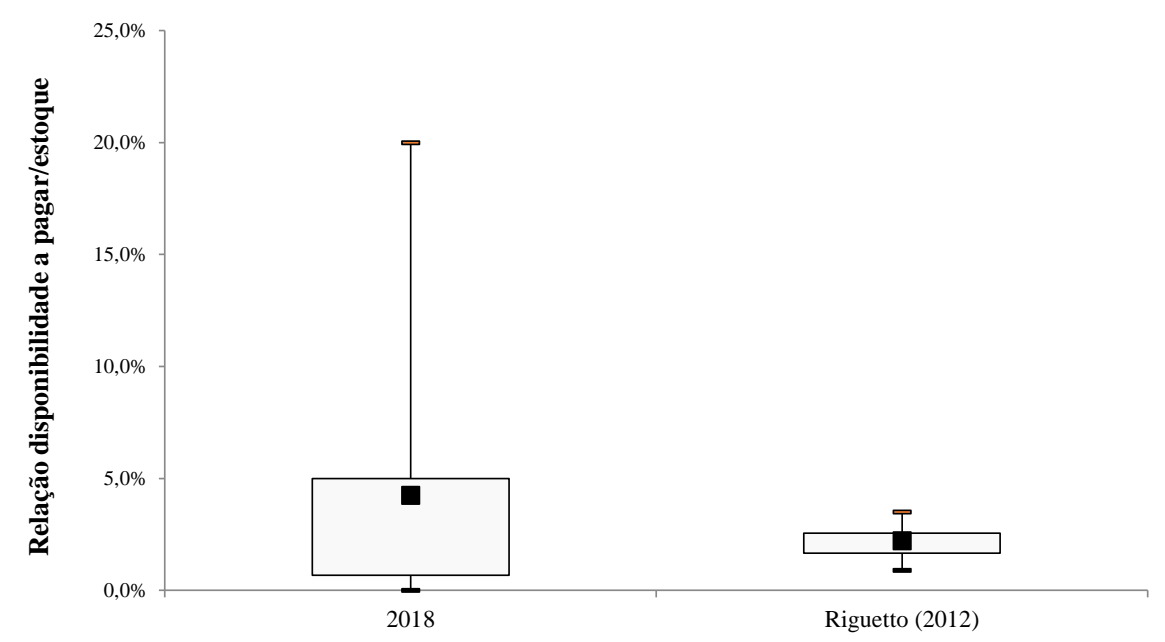

Figura 6.38 - Comparação entre a disponibilidade a pagar entre a presente pesquisa e a pesquisa de Riguetto (2005)

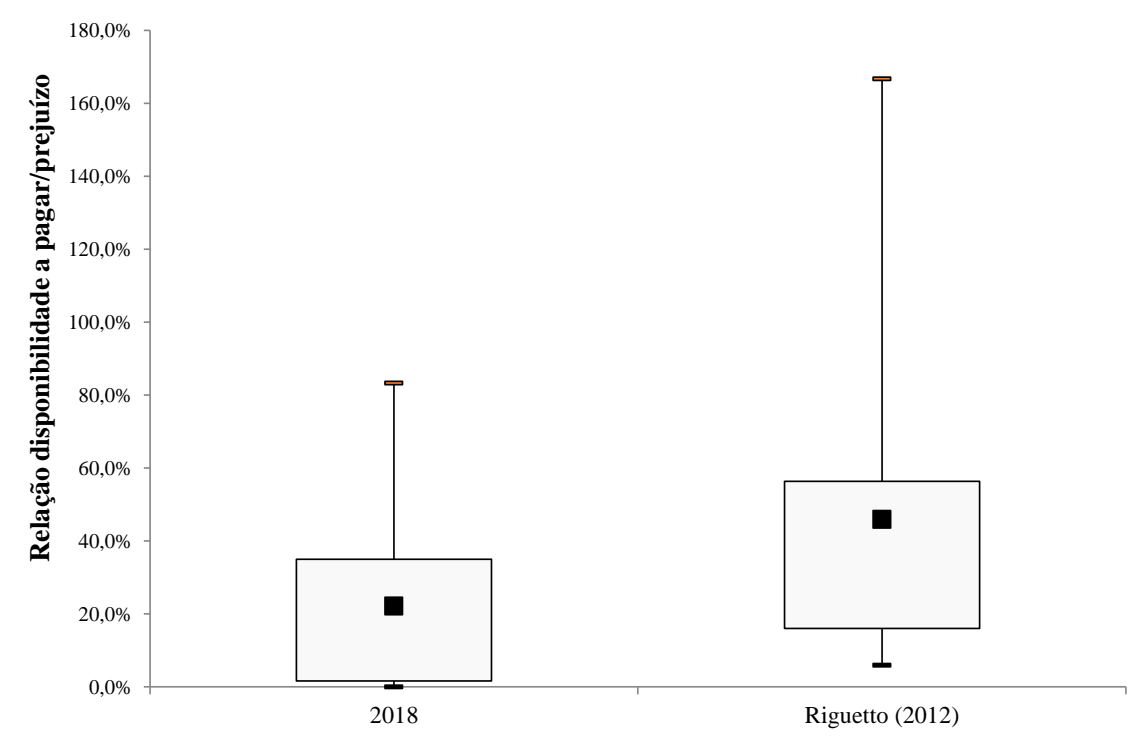


A análise da Figura 6.37 permite inferir que a relação entre o estoque e a disponibilidade a pagar entre as pesquisas localizam-se na mesma região interquartis.

Com relação a disponibilidade a pagar em relação ao prejuízo (Figura 6.38), na pesquisa de Riguetto verifica-se valores mais elevados, sendo a média dos valores ser próxima do dobro da obtida nesta pesquisa. Na pesquisa de Riguetto, o máximo encontra-se em 170\%, concluindo que tal entrevistado estar dispostos a pagar mais pelo seguro do que valor que obtiveram de prejuízo em seus imóveis. Porém, na região interquartis, verifica-se consistência dos dados, variando de 2 a $35 \%$ para a presente pesquisa e 16 a 56\% na pesquisa de Riguetto. 


\subsection{CONCLUSÕES}

Tachini (2010) entende que, se os danos puderem ser quantificados e se forem atribuídos valores monetários aos mesmos, podem ser caracterizados em "prejuízos". Porém, é necessário ajustar as curvas DPS de acordo com as características do local de estudo, sob pena de sub ou super dimensionar seus resultados.

Para isso, a obtenção de informações sociais acerca dos afetados é fator relevante nesse tipo de abordagem, devendo-se avaliar aspectos como: perigo, risco, susceptibilidade, vulnerabilidade, resistência, resiliência, dentre outros, para assim formar um arcabouço de informações passíveis de compreender a problemática do desastre sob uma visão mais abrangente, de caráter interdisciplinar.

A sociohidrologia é disciplina recente que busca trazer subsídios a tais informações, de caráter interdisciplinar e de elevada complexidade. Por meio das informações obtidas com a população afetada, é possível transpor informações qualitativas em indicadores quantitativos para se analisar e comparar metodologias e resultados em diversas regiões de estudo.

Nesta pesquisa, foi possível avançar no entendimento desta problemática tanto com relação aos aspectos qualitativos quanto aos aspectos quantitativos, ao abordar uma série de dados sobre tais aspectos e a transformação desses em dados passíveis de serem analisados e comparados com outras pesquisas, tanto empiricamente (DiBaldassare, 2015), quanto quantitativamente, com trabalhos de outros autores que realizaram pesquisas semelhantes

Dessa forma, entende-se a necessidade de se elaborar um maior número de curvas DPS para diferentes regiões do Brasil, possibilitando fornecer dados factíveis às diversas realidades municipais brasileiras. Além disso, análises relacionadas a sociohidrologia devem ser amplamente realizadas para se formar uma base de dados sólida passível. Assim, com informações quantitativas e qualitativas, podem-se formar indicadores passíveis de serem aplicados na quantificação de prejuízo por curvas DPS (ou outra metodologia quantitativa) para distintas regiões do país com maior confiabilidade e assertividade, face a elevada dispersão de dados apresentada nas pesquisas que utilizam tal metodologia para o setor comercial.

Verifica-se, pela revisão bibliográfica, que a maioria das pesquisas que abordam a os prejuízos para o setor comercial sob a perspectiva quantitativa buscam computar os danos em relação ao estoque (Riguetto, 2005) ou, mais profundamente, relacionam o conteúdo e estrutura dos imóveis (Penning \& Chatternon, 1977; Gissing e Russel, 2004; Machado, 2005). Porém, os danos indiretos raramente são apresentados em pesquisa dessa natureza, apesar de apresentarem 
até $60 \%$ do valore total dos prejuízos na presente pesquisa, sendo fator passível de subdimensionamento dos prejuízos nas pesquisas.

Por fim, considera-se imperativa a implantação de um sistema de previsão e alerta de eventos extremos na região, para na preparação dos comerciantes quanto ao deslocamento de produtos para locais mais elevados, minimizando seus prejuízos. 


\section{REFERÊNCIAS}

CANÇADO, V. Consequências econômicas das inundações e vulnerabilidade- desenvolvimento de metodologia para avaliação do impacto nos domicílios e na cidade. Tese - (Área de concentração: recursos hídricos) - Escola de Engenharia, Universidade Federal de Minas Gerais, Belo Horizonte. 2009.

DI BALDASSARRE, G. et al. Debates-Perspectives on socio-hydrology: Capturing feedbacks between physical and social processes. Water Resources Research, v. 51, n. 6, p. 4770-4781, 2015.

ELEUTÉRIO, J.; PAYRAUDEAU, MOSÉ, S. R.; ROZAN, A. - Cascade of uncertainties in flood damage estimations. 6th International Conference on Flood Managment (ICFM6). São Paulo/SP, Brazil. Setembro de 2014.

FOLKE, C. Resilience: The emergence of a perspective for social-ecological systems analyses. Global Environmental Change. 16pp. 253-267. 2006

GISSING, A.; RUSSELL, B. Accounting for Variability in Commercial Flood Damage Estimation. Australian Geographer, Vol. 35, No. 2, pp. 209-222, July 2004.

IBGE - INSTITUTO BRASILEIRO DE GEOGRAFIA E ESTATÍ́STICA. Pesquisa anual do comércio, Rio de Janeiro, 2016

MACHADO, M. L. Curvas de Inundação versus profundidade de submersão: Desenvolvimento de Metodologia - Estudo de caso da Bacia do Rio Sapucaí, Itajubá - MG - Tese - Universidade Federal de Minas Gerais - Belo Horizonte/MG- 2005

NAGEM, F. R. M. Avaliação econômica dos prejuízos causados pelas cheias urbanas. Universidade Federal Do Rio De Janeiro. Rio De Janeiro, RJ - Brasil. 2008.

PENNINNG-ROWSELL, E.C. e CHATTERTON, J. B. The benefits of flood alleviation: A manual of assessment techniques. Gower Technical Press, Aldershot, Royaume-Uni, Inglaterra, 297p. 1977.

RIGUETTO, J.M. Modelo de segero para riscos hidrológicos no contexto de manejo integrado de bacias hidrográficas. Dissertação (mestrado). Escola de Engenharia de São Carlos, Universidade de São Paulo, São Carlos, 2005.

TACHINI, M. - Avaliação de danos associados às inundações no município de Blumenau. Tese(Doutorado).Universidade Federal de Santa Catarina. UFSC. Programa De Pós-Graduação Em Engenharia Ambiental. Florianópolis/SC. 189p. 2010. 


\section{CONCLUSÕES GERAIS}

\subsection{Simulações hidráulica-hidrológica e alturas de submersão}

A modelagem foi realizada com uso de modelo conceitual do tipo concentrado por subbacias sob regime de escoamento permanente, em que apenas a vazão de pico é considerada. No modelo, o volume referente a vazão de pico é sobreposto ao MDT do terreno, para assim gerar manchas de inundação. Dada a menor complexidade do modelo, esse tipo de modelo é largamente utilizado em projetos de drenagem.

Em vista disso, dois enfoques do uso desse modelo em análise de prejuízos de inundações foram analisados: à posteriori, analisando as diferenças quanto à altura de submersão entre o modelo simulado e o observado, obtido pelas marcas de sedimentos deixadas nas paredes dos imóveis e/ou por questionamento junto aos comerciantes da região (capítulo 5); à priori, de modo a elaborar mapas de inundação para avaliar o prejuízo atribuído com o uso do modelo (Capítulo 3).

Essa análise demonstrou diferenças significativas entre o valor simulado e o observado, sendo que, em algumas ruas, alturas próximas 1 metro eram verificadas in loco, enquanto que, no modelo, a mancha de inundação não atingia esse local. Esse fato se dá por duas características: a significativa relevância de fatores bidimensionais envolvidos na enxurrada e a influência da microdrenagem na área de estudo.

Essa abordagem se justifica, pois, pela observação in loco da dinâmica da inundação circunscrita a essa área: pontos muito próximos apresentavam diferenças significativas quanto à altura de submersão, tanto crescente como ascendente; além disso, dada a elevada declividade das ruas que cruzam esse ponto do talvegue, observou-se que os pontos de risco mais críticos estavam situados nos cruzamentos dessas, locais que apresentam elevada a turbulência da enxurrada e a transformação de energia cinética em potencial, provocando assim tanto o aumento da altura d’água (altura de submersão), quanto o impacto desta enxurrada (força) nos imóveis, que chegaram até mesmo a provocar rupturas de janelas e comportas.

Portanto o provável efeito de alagamento (microdrenagem) nessa área deve ser analisado para além do problema da inundação (macrodrenagem), pelo menos para avaliação de risco de prejuízos, tendo em vista que a altura de submersão é variável determinante nesta análise. 


\subsection{Análise dos riscos e vulnerabilidade da região}

Assim como a modelagem hidrológica, essa avaliação seguiu os mesmos dois procedimentos: a priori e a posteriori.

Para a avaliação de riscos e vulnerabilidade com dados à priori, foram utilizadas tanto informações secundárias quanto primárias. As informações secundárias referem-se aos dados econômicos importados do estudo de Machado (2005) e aplicados a essa bacia, sob a forma de curvas DPS. Para isso, três dados primários tiveram de ser coletados: altura de submersão simulada; a tipologia de venda do comércio e a área do estabelecimento.

Tais informações foram obtidas, respectivamente, por meio de simulação hidráulicahidrológica e uso de SIG; ferramenta Google Street View; e Google Earth Pro. Dessa forma, a justificativa dessa metodologia se dá pelo uso de informações passíveis de serem adquiridas sem visitas in loco, possibilitando seu uso para usuários distantes da área de estudo.

Para a análise a posteriori, foi realizada a análise de riscos de inundação sob comparação entre as alturas de submersão externas simuladas pelo modelo e aquelas medidas a partir da observação das marcas de sedimentos deixadas no local e/ou por meio de questionamento junto aos comerciários. Com relação à vulnerabilidade, foram aplicados questionários a 53 comerciantes para se buscar melhor compreender diversos aspectos dessa população afetada, como a resistência, resiliência, risco e susceptibilidade ao perigo nessa região.

Para isso, foram elaboradas questões que buscassem trazer entendimento tanto do aspecto qualitativo quanto do aspecto quantitativo acerca das inundações. Constatou-se que, principalmente nas entrevistas de 2018, foi verificado um melhor feedback das respostas dos questionamentos pelos comerciantes em detrimento, dentro outros, da melhor preparação do entrevistador/pesquisador à frente da problemática, o que gerou maior confiança para a exposição de informações financeiras e do sentimento dos comerciantes frente aos eventos de inundação.

Com isso, foi possível compreender melhor a temática da vulnerabilidade e correlacionar esse conhecimento com aspectos quantificáveis, como as alterações nas estruturas de proteção, pontualmente medido pelas alturas das comportas e a verificação e medição das alturas do piso em relação à calçada. 


\subsection{Medidas mitigadoras e incertezas}

Nesta pesquisa, foram elaborados 72 cenários diferentes, distinguindo-lhes: 2 configurações de uso e ocupação do solo (atual e futura [com aplicação das diretrizes do plano diretor do município]) junto com a aplicação de medidas mitigadoras e estruturais e não estruturais, aplicadas de forma isolada ou em conjunto, totalizando 6 cenários distintos; alteração da distribuição temporal das chuvas de projeto, intituladas Huff $1^{\circ}$ quartil e blocos alternados, de acordo com a desagregação consagradamente aplicada a essas metodologias (2 configurações). Tais análises foram aplicadas para 6 diferentes tempos de retorno, gerando assim 72 análises distintas.

\subsubsection{Uso e ocupação do solo}

Foram utilizados 2 tipos de uso e ocupação de solo, baseados na pesquisa de Decina (2012), sendo esses denominados cenário atual e cenário plano diretor.

Para o cenário atual, o autor classificou o uso e a ocupação do solo com imagem multiespectral da cena, provinda de imagem do satélite World View II e 0,5 m de resolução espectral na banda PAN, e realizada de forma manual por rasterização dos polígonos.

Para o cenário futuro, foram utilizadas as premissas do plano diretor de São Carlos. No plano, locais onde antes eram tomados predominantemente por vegetação estão alocados como zona de ocupação condicionada, face a pressão imobiliária dessa região, que se localiza próxima ao centro comercial da cidade.

Assim, foi adotado o coeficiente de ocupação de $70 \%$ e coeficiente de permeabilidade de 15\% (Tabela 2.1), que acrescentou valores de $\mathrm{CN}$ de até 22 unidades entre os cenários. Dessa forma, como já consagrado na literatura, a sensibilidade alta do modelo frente a alteração do $\mathrm{CN}$ trouxe aumentos na vazão de pico observado no exutório da sub-bacias 12 , onde encontrase a área de estudo desta pesquisa.

Deve-se considerar que o município possui promulgada a Lei municipal $\mathrm{N}^{\circ} 13.246$ de 27 de novembro de 2003, que dispõe sobre a construção de reservatório de detenção ou retenção de águas em conjuntos habitacionais, áreas comerciais e industriais, loteamentos ou parcelamentos em áreas urbanas. Essa questão não foi abordada nesta pesquisa, sendo encontrada na pesquisa de Martins (2018). 


\subsubsection{Medidas mitigadoras}

Foram consideradas três tipologias de implementação de medidas mitigadoras: uma em são executadas apenas medidas estruturais; outra em que são implantadas apenas medidas não estruturais; e uma última em que as medidas estruturais e não estruturais são executadas conjuntamente.

Com relação às medidas estruturais e não estruturais, aplicadas isoladamente, verificouse que a efetividade de tais medidas foi similar quanto à atenuação da vazão de pico. Dessa forma, em vista do viés financeiro que as medidas estruturais provocam, além do espaço ocupado e das externalidades negativas provocadas ao entorno, a medidas não estruturais não devem ser ignoradas, frente à economia de verbas públicas com tal medida.

Porém, de acordo com os modelos, a vazão de pico em cenários futuros se manteve próxima da vazão atual apenas com a adoção das medidas estruturais e não estruturais propostas no plano de drenagem de São Carlos (PMSC, 2012).

\subsubsection{Distribuição temporal das chuvas}

A distribuição temporal da chuva foi fator de alta sensibilidade, tanto no modelo simulado quanto na análise do risco das chuvas com dados observados.

Tal abordagem se justificou pela observação preliminar de Vasconcelos (2007), já que, das chuvas com mais de $10 \mathrm{~mm}$ analisadas na área de estudo pela autora, tais apresentavam distribuição temporal entre o $1^{\circ}$ e o $2^{\circ}$ quartil para $75 \%$ dos eventos. Assim, a análise das chuvas se deu de modo a abranger essa variabilidade de observações e analisar as incertezas dessa variável.

Com relação ao modelo, verificou-se que a distribuição temporal das chuvas apresenta alta sensibilidade no modelo e, assim, trouxe incertezas em sua quantificação, já que a base da análise de prejuízos é realizada em relação ao tempo de retorno. Assim, mostrou-se que, entre tais distribuições temporais de chuvas para o mesmo tempo de retorno, a vazão do exutório da área de estudo apresentava até o dobro do valor, o que refletia em valores de prejuízo distintos em até 7 vezes, notadamente para cenários de menor ameaça (menor TR).

Dentre outras questões, pode-se inferir a essa análise a alta declividade da bacia hidrográfica, já que se constatou que existe um ponto de inflexão relacionando a vazão com a área e profundidade: entre as vazões de 70 e $80 \mathrm{~m}^{3} / \mathrm{s}$, o aumento da área e da profundidade apresentam elevada sensibilidade (Figura 3.28). 
Com relação às chuvas observadas por meio de pluviógrafo instalado na região, analisou-se os dados de 3 eventos extremos ocorridos na região nos anos de 2013, 2015 e 2018.

Com relação à chuva de 2013, a mesma foi caracterizada, de acordo com a curva IDF de Barbassa (1991), como TR de 20 anos e distribuição temporal próxima do $3^{\circ}$ quartil que gerou vazão de $76 \mathrm{~m}^{3} / \mathrm{s}$. Para a chuva de 2015, TR de 14 anos e distribuição temporal de $2^{\circ}$ quartil sob $90 \%$ de probabilidade excedência, que gerou vazão de $67 \mathrm{~m}^{3} / \mathrm{s}$. Para a chuva de 2018, TR de 32 anos e distribuição temporal entre o $1^{\circ}$ e o $2^{\circ}$ quartil, que gerou vazão de 61 $\mathrm{m}^{3} / \mathrm{s}$.

Para os anos de 2015, e 2018 foi possível verificar a altura in loco, e verificou-se a congruência da modelo frente as alturas observadas, pois verificou-se que, em média, alturas de inundação no ano de 2018 foram ligeiramente inferiores às verificadas em 2015.

Além disso, essa análise preliminar traz luz ao tipo de distribuição a ser escolhida, já que, na região, verificou-se que chuvas com tempo de retorno baixo em termos de macrodrenagem (menor que 25 anos) já apresentam ameaça aos locais suscetíveis a inundação, acentuada de acordo com a distância da intensidade do pico em relação ao início da precipitação (quanto mais afastado maior a resposta hidrológica em termos de vazão de pico).

\subsection{Sócio hidrologia dos desastres}

Por meio das entrevistas e das verificações realizadas in loco, referente aos aspectos qualitativos desta análise, foi possível traçar informações e dados relevantes nesta pesquisa.

Dentre as informações abordadas fundamentais para essa análise, a análise das alturas internas de submersão, juntamente com a medição das alturas das comportas e da planta baixa do estabelecimento em relação ao piso, obtidas para dois eventos de inundação, formaram um arcabouço metodológico passível de ser aplicado em outras regiões no que tange a avaliar a memória da população e como tais experiências são refletidas em termos de preparação da população suscetível na área de estudo.

Essa questão, de difícil observação em curtos espaços de tempo, ficou evidente na região analisada. O fator preponderante para isso foram a ocorrência e a análise de dois eventos extremos em termos de prejuízo na região. A conclusão sobre a extremidade desses eventos se deu por relatos de comerciantes da região, notadamente os que estavam há mais tempo na região (acima de 20 anos), tendo em vista ter sido unânime que os eventos de 2015 e 2018 foram os maiores já presenciados por esses, já que comerciantes com mais de 30 anos na região afirmaram que, apesar de presenciarem eventos de inundação com relativa frequência, suas 
lojas nunca haviam sido tomadas pelas águas ou, ao menos, nunca com tamanha intensidade e altura d’água.

Para se analisar tal questão, ou seja, a maneira pela qual os comerciantes se defendem da ameaça da inundação, verificou-se que a maioria que possui tal defesa a faz sob a forma de elevação da altura do piso de sua loja em relação à calçada e/ou sob a instalação de comportas na entrada de seus estabelecimentos, sendo tais variáveis medidas nesta pesquisa.

Com relação à altura do piso em relação a calçada, pode-se medir a altura dos mesmos; porém, tal variável não é passível de alteração, já que embutiria elevados custos e transtornos relacionados ao longo período de fechamento de seus estabelecimentos para as reformas necessárias.

Porém, as comportas podem ser instaladas com relativa facilidade, e são meios de se proteger frente à ameaça. Pela análise das alturas das comportas, verificou-se que as alturas das comportas, entre os eventos de 2015 e 2018, resultaram no dobro do valor quando somadas nos eventos, evidenciando assim o feedback entre a comunidade os eventos inundação quanto à mitigação (resistência) de seus efeitos.

\section{RECOMENDAÇÕES PARA TRABALHOS FUTUROS}

\subsection{Realizar modelagem-hidrológica mais robustas, envolvendo quatro aspectos: uso do solo; distribuição temporal da chuva; modelagem distribuída e aspectos bidimensionais da área de estudo.}

\subsubsection{Uso do solo}

Nesta pesquisa, foi utilizado o mapa de uso e ocupação do solo elaborado por Decina (2012), que realizou o levantamento com imagem multiespectral da cena do município de São Carlos do ano de 2011, com imagem do satélite World View II com 0,5 m de resolução com uso da banda PAN. O autor classificou o uso do solo de forma manual, o que demanda hercúlea análise de interpretação.

Propõe-se analisar essa questão sob ferramentas de classificação do solo do tipo supervisionada, classificando o solo com ferramentas computacionais e analisando as diferenças entre os métodos de classificação do solo (manual e supervisionada), em termos de acertos relativos a classificação de uso do solo e a questões hidrológicas, para assim se avaliar a sensibilidade do modelo frente à sua classificação. 
Para isso, propõe-se a utilização de imagens de satélite públicas e gratuitas para a classificação do uso de solo de forma supervisionada, realizando assim a análise dos resultados sob o âmbito de imagens públicas x imagens pagas.

Essa questão se justifica pelo preço elevado envolvido na compra de imagens de satélite, o que tende a comprometer o orçamento de projetos de drenagem e assim inviabilizar seu uso.

\subsubsection{Distribuição temporal da chuva}

Dada a alta sensibilidade que essa variável apresentou nas análises, recomenda-se realizar análise de dados de precipitação por meio de pluviógrafo para se analisar as características de distribuição temporal das chuvas ocorridas na região. Tem-se que, na região, o tipo de chuva predominante é do tipo convectiva, que tende a ter picos de intensidade elevados no começo da precipitação e, dessa forma, adotando-se o primeiro quartil para a alocação de seu pico.

Porém, a análise preliminar de três eventos que provocaram danos a região demostrou que, em eventos com baixo tempo de retorno do ponto de vista da macrodrenagem (menor que 25 anos), foram observadas ameaças aos imóveis suscetíveis a inundação, carecendo assim de maiores subsídios à desagregação das chuvas em hietogramas de projeto, já que essa influiu significativamente nos hidrograma.

\subsubsection{Modelagem distribuída}

A modelagem hidrológica realizada neste estudo foi a do tipo concentrado por subbacias, em que o uso e ocupação do solo são transformados em CN pelo método SCS e realizada a média ponderada dos lotes para se atribuir um valor único de $\mathrm{CN}$ à bacia.

Porém, dada a heterogeneidade do uso do solo na bacia, caracterizada como uma bacia semi-urbanizada, a análise do tipo distribuída pode apresentar diferenças significativas, tanto no volume quanto na vazão de saída (outflow) das sub-bacias, influenciando na dinâmica dos reservatórios de detenção e na vazão afluente das sub-bacias.

Portanto, a análise entre os modelos concentrado e distribuído pode trazer luz a essa incerteza frente a análises de risco, tendo em vista que, na maioria das pesquisas, o primeiro tipo é o empregado. 


\subsubsection{Aspectos bidimensionais}

Com relação aos aspectos bidimensionais da área de estudo, pode-se realizar o isolamento dos espações vazios, entre prédios de forma paralela, avaliando-os como canais paralelos e/ou em cruzamento e utilizando dados da microdrenagem (Collodel, 2009) ${ }^{23}$. A autora conclui que "os resultados obtidos com a análise dos diferentes níveis de detalhe evidenciaram a importância da consideração da microdrenagem na representação dos sistemas".

A microdrenagem se faz essencial tendo em vista também ser dimensionada para baixos tempo de retorno (até 10 anos), perdendo seu efeito (se assim dimensionada e sob manutenção estrutural e de limpeza), incrementando verdadeiros córregos canalizados nessas regiões. Com isso, pode ser possível analisar a dinâmica da Energia nesses cruzamentos e sua influência na velocidade e na altura de submersão obtidas.

\subsection{Análise sócio hidrológica da área de estudo}

A presente pesquisa baseou-se, majoritariamente, em aspectos baseados na análise quantitativa dos resultados. Nesta análise, aspectos relacionados a resistência e a resiliência da população não são observados, o que pode sub ou superdimensionar os danos (DiBaldassare, 2015).

Por outro lado, realizou-se um rápido ensaio quanto aos aspectos qualitativos, notadamente ao se relatar os sentimentos dos comerciantes com a temática na área de estudo e se quantificar as alturas das comportas de seus estabelecimentos. Porém, análises mais profundas baseadas nesta recente ciência devem ser analisadas, para que se estabeleça uma análise profunda do feedback de interações entre os aspectos hidrológicos e sociais da região sob outros critérios, parâmetros, variáveis, para assim criar indicadores de valores de referência para estudo sócio hidrológico da região, a exemplo de Buarque (2019) ${ }^{24}$.

Com o intuito de colaborar com esta análise, no Apêndice 8 é apresentado um rápido ensaio socioeconômico da região de estudo, baseado nos microdados por setores censitários do IBGE, disponíveis apenas a partir do censo de 2010.

\footnotetext{
${ }^{23}$ Collodel, M.G. (2009). Aplicação do modelo hidrológico SWMM na avaliação de diferentes níveis de detalhamento da bacia hidrográfica submetida ao processo de transformação chuva-vazão. Dissertação de Mestrado - Escola de Engenharia, Universidade de São Paulo, São Carlos.

${ }^{24}$ Buarque (2019). Understanding Urban Flood Risk and Enigma of Peoples\&\#39; Memory: A SocialHydrological Learning at the Gregorio Creek, Brasil. (Artigo sob revisão)
} 
APÊNDICE 1 - DADOS DO FINANCIAMENTO DAS MEDIDAS MITIGADORAS ESTRUTURAIS

\begin{tabular}{|c|c|c|c|c|c|c|}
\hline \multicolumn{7}{|c|}{ Dados do financiamento } \\
\hline \multicolumn{2}{|c|}{ Valor financiado } & 21.123.895 & \multicolumn{2}{|c|}{ Juros Mensal Efetivo } & \multicolumn{2}{|l|}{$0,4868 \%$} \\
\hline \multicolumn{2}{|c|}{ Taxas de abertura crédito + IOF } & - & Total pago & & $24.409 .484,82$ & \\
\hline \multicolumn{2}{|c|}{ Número de Prestações } & 60 & Total de Juros p: & & $3.285 .589,24$ & \\
\hline \multicolumn{2}{|c|}{ Taxa de juros } & $6,0000 \%$ & \multicolumn{2}{|c|}{ Taxa Mensal ou Anual? } & \multicolumn{2}{|l|}{ Anual } \\
\hline Parcela & Saldo Inicial & Juros & $\begin{array}{c}\text { Saldo Inicial } \\
+ \text { Juros }\end{array}$ & Amortização & Prestação & $\begin{array}{l}\text { Saldo Pós- } \\
\text { Pagamento }\end{array}$ \\
\hline $\mathbf{0}$ & 0 & 0 & 0 & 0 & 0 & $21.123 .895,58$ \\
\hline 1 & $21.123 .895,58$ & $102.821,63$ & $21.226 .717,21$ & $\mathrm{R} \$ 304.003,12$ & $\mathrm{R} \$ 406.824,75$ & $20.819 .892,46$ \\
\hline 2 & $20.819 .892,46$ & $101.341,88$ & $20.921 .234,34$ & $\mathrm{R} \$ 305.482,87$ & $\mathrm{R} \$ 406.824,75$ & $20.514 .409,60$ \\
\hline 3 & $20.514 .409,60$ & $99.854,93$ & $20.614 .264,52$ & $\mathrm{R} \$ 306.969,82$ & $\mathrm{R} \$ 406.824,75$ & $20.207 .439,77$ \\
\hline 4 & $20.207 .439,77$ & $98.360,73$ & $20.305 .800,51$ & $\mathrm{R} \$ 308.464,01$ & $\mathrm{R} \$ 406.824,75$ & $19.898 .975,76$ \\
\hline 5 & $19.898 .975,76$ & $96.859,27$ & $19.995 .835,03$ & $\mathrm{R} \$ 309.965,48$ & $\mathrm{R} \$ 406.824,75$ & $19.589 .010,29$ \\
\hline 6 & $19.589 .010,29$ & $95.350,50$ & $19.684 .360,78$ & $\mathrm{R} \$ 311.474,25$ & $\mathrm{R} \$ 406.824,75$ & $19.277 .536,04$ \\
\hline 7 & $19.277 .536,04$ & $93.834,38$ & $19.371 .370,42$ & $\mathrm{R} \$ 312.990,37$ & $\mathrm{R} \$ 406.824,75$ & $18.964 .545,67$ \\
\hline 8 & $18.964 .545,67$ & $92.310,89$ & $19.056 .856,56$ & $\mathrm{R} \$ 314.513,86$ & $\mathrm{R} \$ 406.824,75$ & $18.650 .031,81$ \\
\hline 9 & $18.650 .031,81$ & $90.779,97$ & $18.740 .811,78$ & $\mathrm{R} \$ 316.044,77$ & $\mathrm{R} \$ 406.824,75$ & $18.333 .987,04$ \\
\hline 10 & $18.333 .987,04$ & $89.241,61$ & $18.423 .228,64$ & $\mathrm{R} \$ 317.583,14$ & $\mathrm{R} \$ 406.824,75$ & $18.016 .403,90$ \\
\hline 11 & $18.016 .403,90$ & $87.695,76$ & $18.104 .099,65$ & $\mathrm{R} \$ 319.128,99$ & $\mathrm{R} \$ 406.824,75$ & $17.697 .274,91$ \\
\hline 12 & $17.697 .274,91$ & $86.142,38$ & $17.783 .417,29$ & $\mathrm{R} \$ 320.682,37$ & $\mathrm{R} \$ 406.824,75$ & $17.376 .592,54$ \\
\hline 13 & $17.376 .592,54$ & $84.581,44$ & $17.461 .173,98$ & $\mathrm{R} \$ 322.243,30$ & $\mathrm{R} \$ 406.824,75$ & $17.054 .349,24$ \\
\hline 14 & $17.054 .349,24$ & $83.012,91$ & $17.137 .362,14$ & $\mathrm{R} \$ 323.811,84$ & $\mathrm{R} \$ 406.824,75$ & $16.730 .537,40$ \\
\hline 15 & $16.730 .537,40$ & $81.436,74$ & $16.811 .974,13$ & $\mathrm{R} \$ 325.388,01$ & $\mathrm{R} \$ 406.824,75$ & $16.405 .149,39$ \\
\hline 16 & $16.405 .149,39$ & $79.852,89$ & $16.485 .002,28$ & $\mathrm{R} \$ 326.971,85$ & $\mathrm{R} \$ 406.824,75$ & $16.078 .177,53$ \\
\hline 17 & $16.078 .177,53$ & $78.261,34$ & $16.156 .438,88$ & $\mathrm{R} \$ 328.563,40$ & $\mathrm{R} \$ 406.824,75$ & $15.749 .614,13$ \\
\hline 18 & $15.749 .614,13$ & $76.662,04$ & $15.826 .276,17$ & $\mathrm{R} \$ 330.162,70$ & $\mathrm{R} \$ 406.824,75$ & $15.419 .451,43$ \\
\hline 19 & $15.419 .451,43$ & $75.054,96$ & $15.494 .506,39$ & $\mathrm{R} \$ 331.769,79$ & $\mathrm{R} \$ 406.824,75$ & $15.087 .681,64$ \\
\hline 20 & $15.087 .681,64$ & $73.440,05$ & $15.161 .121,69$ & $\mathrm{R} \$ 333.384,69$ & $\mathrm{R} \$ 406.824,75$ & $14.754 .296,94$ \\
\hline 21 & $14.754 .296,94$ & $71.817,29$ & $14.826 .114,23$ & $\mathrm{R} \$ 335.007,46$ & $\mathrm{R} \$ 406.824,75$ & $14.419 .289,48$ \\
\hline 22 & $14.419 .289,48$ & $70.186,62$ & $14.489 .476,10$ & $\mathrm{R} \$ 336.638,13$ & $\mathrm{R} \$ 406.824,75$ & $14.082 .651,36$ \\
\hline 23 & $14.082 .651,36$ & $68.548,02$ & $14.151 .199,38$ & $\mathrm{R} \$ 338.276,73$ & $\mathrm{R} \$ 406.824,75$ & $13.744 .374,63$ \\
\hline 24 & $13.744 .374,63$ & $66.901,44$ & $13.811 .276,07$ & $\mathrm{R} \$ 339.923,31$ & $\mathrm{R} \$ 406.824,75$ & $13.404 .451,32$ \\
\hline 25 & $13.404 .451,32$ & $65.246,84$ & $13.469 .698,16$ & $\mathrm{R} \$ 341.577,90$ & $\mathrm{R} \$ 406.824,75$ & $13.062 .873,42$ \\
\hline 26 & $13.062 .873,42$ & $63.584,20$ & $13.126 .457,61$ & $\mathrm{R} \$ 343.240,55$ & $\mathrm{R} \$ 406.824,75$ & $12.719 .632,87$ \\
\hline 27 & $12.719 .632,87$ & $61.913,46$ & $12.781 .546,32$ & $\mathrm{R} \$ 344.911,29$ & $\mathrm{R} \$ 406.824,75$ & $12.374 .721,58$ \\
\hline 28 & $12.374 .721,58$ & $60.234,58$ & $12.434 .956,16$ & $\mathrm{R} \$ 346.590,16$ & $\mathrm{R} \$ 406.824,75$ & $12.028 .131,41$ \\
\hline 29 & $12.028 .131,41$ & $58.547,54$ & $12.086 .678,95$ & $\mathrm{R} \$ 348.277,21$ & $\mathrm{R} \$ 406.824,75$ & $11.679 .854,20$ \\
\hline 30 & $11.679 .854,20$ & $56.852,28$ & $11.736 .706,48$ & $\mathrm{R} \$ 349.972,47$ & $\mathrm{R} \$ 406.824,75$ & $11.329 .881,74$ \\
\hline 31 & $11.329 .881,74$ & $55.148,77$ & $11.385 .030,51$ & $\mathrm{R} \$ 351.675,97$ & $\mathrm{R} \$ 406.824,75$ & $10.978 .205,76$ \\
\hline 32 & $10.978 .205,76$ & $53.436,97$ & $11.031 .642,73$ & $\mathrm{R} \$ 353.387,78$ & $\mathrm{R} \$ 406.824,75$ & $10.624 .817,99$ \\
\hline 33 & $10.624 .817,99$ & $51.716,84$ & $10.676 .534,83$ & $\mathrm{R} \$ 355.107,91$ & $\mathrm{R} \$ 406.824,75$ & $10.269 .710,08$ \\
\hline 34 & $10.269 .710,08$ & $49.988,33$ & $10.319 .698,41$ & $\mathrm{R} \$ 356.836,41$ & $\mathrm{R} \$ 406.824,75$ & $9.912 .873,67$ \\
\hline 35 & $9.912 .873,67$ & $48.251,41$ & $9.961 .125,08$ & $\mathrm{R} \$ 358.573,33$ & $\mathrm{R} \$ 406.824,75$ & $9.554 .300,33$ \\
\hline 36 & $9.554 .300,33$ & $46.506,04$ & $9.600 .806,37$ & $\mathrm{R} \$ 360.318,71$ & $\mathrm{R} \$ 406.824,75$ & $9.193 .981,63$ \\
\hline 37 & $9.193 .981,63$ & $44.752,17$ & $9.238 .733,80$ & $\mathrm{R} \$ 362.072,58$ & $\mathrm{R} \$ 406.824,75$ & $8.831 .909,05$ \\
\hline 38 & $8.831 .909,05$ & $42.989,76$ & $8.874 .898,81$ & $\mathrm{R} \$ 363.834,98$ & $\mathrm{R} \$ 406.824,75$ & $8.468 .074,07$ \\
\hline 39 & $8.468 .074,07$ & $41.218,78$ & $8.509 .292,84$ & $\mathrm{R} \$ 365.605,97$ & $\mathrm{R} \$ 406.824,75$ & $8.102 .468,10$ \\
\hline 40 & $8.102 .468,10$ & $39.439,17$ & $8.141 .907,27$ & $\mathrm{R} \$ 367.385,57$ & $\mathrm{R} \$ 406.824,75$ & $7.735 .082,52$ \\
\hline 41 & $7.735 .082,52$ & $37.650,91$ & $7.772 .733,43$ & $\mathrm{R} \$ 369.173,84$ & $\mathrm{R} \$ 406.824,75$ & 7.365.908,68 \\
\hline 42 & $7.365 .908,68$ & $35.853,93$ & $7.401 .762,61$ & $\mathrm{R} \$ 370.970,81$ & $\mathrm{R} \$ 406.824,75$ & $6.994 .937,87$ \\
\hline 43 & $6.994 .937,87$ & $34.048,21$ & $7.028 .986,08$ & $\mathrm{R} \$ 372.776,53$ & $\mathrm{R} \$ 406.824,75$ & $6.622 .161,33$ \\
\hline 44 & $6.622 .161,33$ & $32.233,71$ & $6.654 .395,04$ & $\mathrm{R} \$ 374.591,04$ & $\mathrm{R} \$ 406.824,75$ & $6.247 .570,29$ \\
\hline 45 & $6.247 .570,29$ & $30.410,36$ & $6.277 .980,66$ & $\mathrm{R} \$ 376.414,38$ & $\mathrm{R} \$ 406.824,75$ & $5.871 .155,91$ \\
\hline 46 & $5.871 .155,91$ & $28.578,15$ & $5.899 .734,06$ & $\mathrm{R} \$ 378.246,60$ & $\mathrm{R} \$ 406.824,75$ & $5.492 .909,31$ \\
\hline 47 & $5.492 .909,31$ & $26.737,01$ & $5.519 .646,33$ & $\mathrm{R} \$ 380.087,73$ & $\mathrm{R} \$ 406.824,75$ & $5.112 .821,58$ \\
\hline 48 & $5.112 .821,58$ & $24.886,92$ & $5.137 .708,50$ & $\mathrm{R} \$ 381.937,83$ & $\mathrm{R} \$ 406.824,75$ & $4.730 .883,75$ \\
\hline 49 & $4.730 .883,75$ & $23.027,82$ & $4.753 .911,56$ & $\mathrm{R} \$ 383.796,93$ & $\mathrm{R} \$ 406.824,75$ & $4.347 .086,82$ \\
\hline 50 & $4.347 .086,82$ & $21.159,66$ & $4.368 .246,48$ & $\mathrm{R} \$ 385.665,08$ & $\mathrm{R} \$ 406.824,75$ & $3.961 .421,74$ \\
\hline 51 & $3.961 .421,74$ & $19.282,42$ & $3.980 .704,16$ & $\mathrm{R} \$ 387.542,33$ & $\mathrm{R} \$ 406.824,75$ & $3.573 .879,41$ \\
\hline 52 & $3.573 .879,41$ & $17.396,04$ & $3.591 .275,45$ & $\mathrm{R} \$ 389.428,71$ & $\mathrm{R} \$ 406.824,75$ & $3.184 .450,70$ \\
\hline 53 & $3.184 .450,70$ & $15.500,47$ & $3.199 .951,18$ & $\mathrm{R} \$ 391.324,27$ & $\mathrm{R} \$ 406.824,75$ & $2.793 .126,43$ \\
\hline 54 & $2.793 .126,43$ & $13.595,68$ & $2.806 .722,11$ & $\mathrm{R} \$ 393.229,06$ & $\mathrm{R} \$ 406.824,75$ & $2.399 .897,37$ \\
\hline 55 & $2.399 .897,37$ & $11.681,62$ & $2.411 .578,99$ & $\mathrm{R} \$ 395.143,13$ & $\mathrm{R} \$ 406.824,75$ & $2.004 .754,24$ \\
\hline 56 & $2.004 .754,24$ & $9.758,24$ & $2.014 .512,48$ & $\mathrm{R} \$ 397.066,50$ & $\mathrm{R} \$ 406.824,75$ & $1.607 .687,74$ \\
\hline 57 & $1.607 .687,74$ & $7.825,50$ & $1.615 .513,24$ & $\mathrm{R} \$ 398.999,25$ & $\mathrm{R} \$ 406.824,75$ & $1.208 .688,49$ \\
\hline 58 & $1.208 .688,49$ & $5.883,35$ & $1.214 .571,84$ & $\mathrm{R} \$ 400.941,39$ & $\mathrm{R} \$ 406.824,75$ & $807.747,10$ \\
\hline 59 & $807.747,10$ & $3.931,75$ & $811.678,85$ & $\mathrm{R} \$ 402.893,00$ & $\mathrm{R} \$ 406.824,75$ & $404.854,10$ \\
\hline 60 & $404.854,10$ & $1.970,65$ & $406.824,75$ & $\mathrm{R} \$ 404.854,10$ & $\mathrm{R} \$ 406.824,75$ & 0,00 \\
\hline
\end{tabular}


APÊNDICE 2 - EXEMPLO DE RELATÓRIO GERADO PELO SOFTWARE DOFORMS
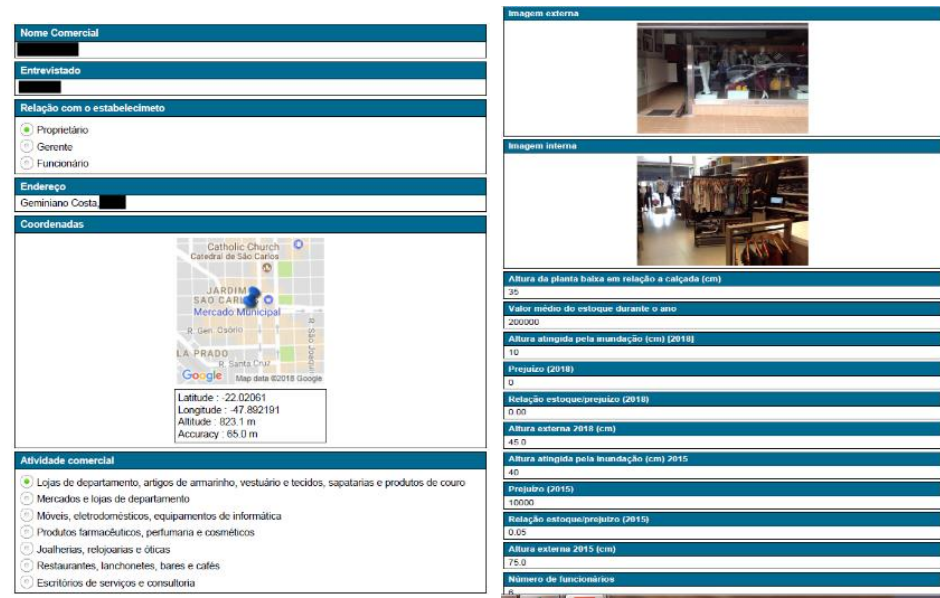

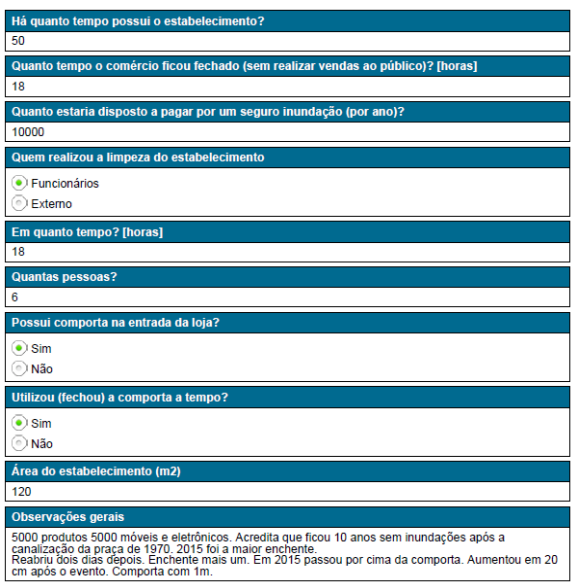




\section{APÊNDICE 3 - TERMO DE LIVRE CONSCENTIMENTO UTILIZADO NAS ENTREVISTAS COM OS COMERCIÁRIOS}

\section{TERMO DE CONSENTIMENTO LIVRE E ESCLARECIDO}

Eu , portador do RG: CPF: , aceito

participar da pesquisa intitulada desenvolvida por Fernando Girardi DE Abreu (CPF 307.427.868-46), doutorando em Engenharia Hidráulica e Saneamento pela USP São Carlos, e permito que obtenha fotografia, filmagem ou gravação de minha pessoa para fins de pesquisa científica. Tenho conhecimento sobre a pesquisa e seus procedimentos metodológicos.

Autorizo que o material e informações obtidas possam ser publicados em aulas seminários, congressos, palestras ou periódicos científicos. Porém não deve ser identificado por nome em qualquer uma das vias de publicação ou uso.

As fotografias, filmagens e gravações de voz ficarão sob a propriedade do pesquisador pertinente ao estudo e, sob a guarda dos mesmos.

São Carlos, de de 2018. 


\section{APÊNDICE 4 - CARTA DE APRESENTAÇÃO APRESENTADA AOS COMERCIÁRIOS NO INÍCIO DE CADA ENTREVISTA}

\section{CARTA DE APRESENTAÇÃO PARA PESQUISA}

A ASSOCIAÇÃO COMERCIAL E INDUSTRIAL DE SÃO CARLOS - ACISC, por seu Presidente, José Fernando Domingues, que ao final assina, por meio desta, apresenta o Doutorando do Departamento de Hidráulica e Saneamento da EESC/USP, Senhor Fernando Girardi de Abreu (CPF 307.427.868-46), para realização de pesquisa, com a finalidade de quantificação dos prejuízos decorrentes das inundações.

Queremos informar que o caráter ético desta pesquisa assegura a preservação da identidade das pessoas participantes.

Uma das metas para a realização deste estudo é o comprometimento do pesquisador em possibilitar aos participantes um retorno dos resultados da pesquisa. Solicitamos a permissão para a divulgação desses resultados e suas conclusões em forma de pesquisa, preservando sigilo e ética, conforme termo de consentimento livre que será assinado pelo participante.

Em caso de dúvida procurar a departamento de Comunicação da ACISC pelo telefone (16) 3362 1900 ou pelo e-mail comunicacao@acisc.com.br.

Agradecemos vossa compreensão e colaboração.

Atenciosamente,

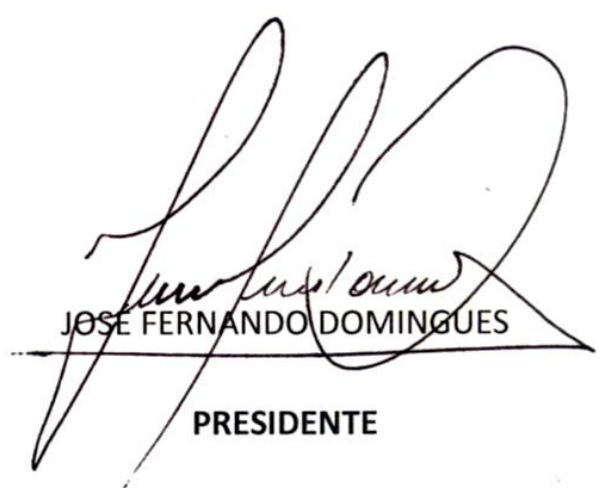




\section{APENDICE 5 - PRINCIPAIS RELATOS OBTIDOS PELOS COMERCIANTES POR MEIO DAS ENTREVISTAS}

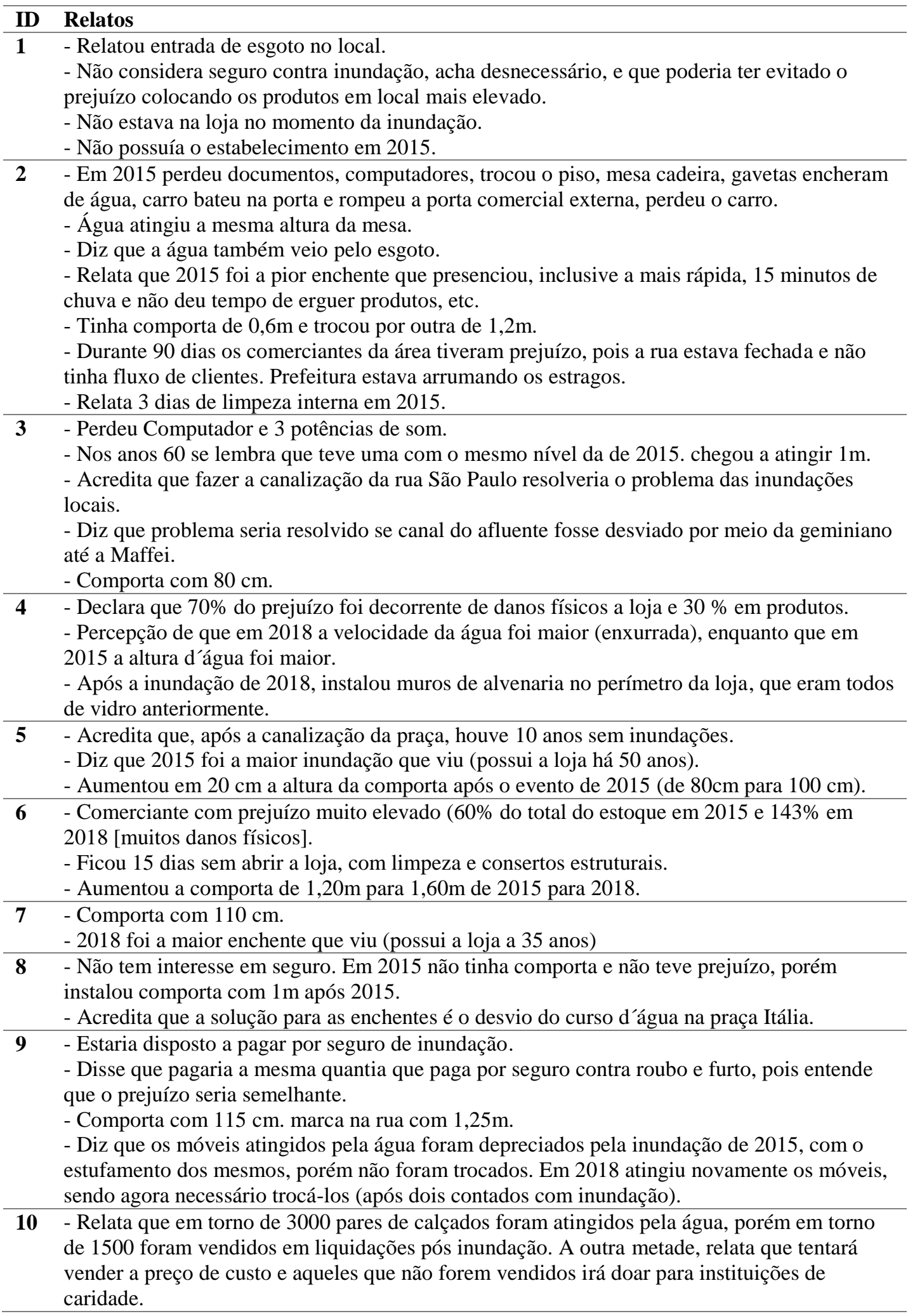


- Não tinha comporta em 2015 e estava instalando após a inundação de 2018.

- Afirma ter o estabelecimento há 30 anos e que nesses apenas em 3 vezes ocorreu entrada de água no estabelecimento.

11 - Teve perda total do estoque e danos físicos a loja.

- Não havia reaberto a loja desde a enchente até maio de 2018 (dia da entrevista)

- Possuía o estabelecimento há 1 ano e foi informada pelo dono do estabelecimento que sua loja não era atingida por inundação.

- Relatou solidariedade por parte dos comerciantes das lojas vizinhas que ajudaram com a limpeza do estabelecimento.

12 - Muitos danos físicos na loja, como quebra de vidros e do piso.

- Alegou cheiro de esgoto.

- Disse que a loja teve que ser limpa 4 vezes para retirar todo o cheiro.

- Cobra da prefeitura que caminhões pipa lavem também a calçada, não apenas a rua, já que essa ficou a cargo dos próprios comerciantes.

- Relatou falta d’água para realizar a limpeza, devido à grande demanda momentânea por parte dos comerciantes.

- Relata trauma e apreensão de novas enchentes, relatando que repentinamente sonhava com questões relacionadas a inundação.

- Acredita que a chuva que causa inundação no local venha de descalvado em direção a são Carlos.

- Está no local a mais de 20 anos, tinha comércio no camelódromo e abriu a loja há 1 ano.

13 - Relata que a água atingiu a calçada em torno de 15 minutos após o início da chuva.

- Parte externa da loja atingiu $120 \mathrm{~cm}$.

- Percebeu que a água começou a extravasar do bueiro e em minutos já atingiu sua loja.

14 - Inundação atingiu apenas os móveis, que sofreram depreciação, mas não foram trocados.

15 - Relata danos psicológicos.

- Mudou-se do local após a inundação, sofrendo prejuízo por quebra de contrato.

- Relata que funcionária caiu durante a inundação e machucou o cotovelo.

- Loja estava aberta desde outubro de 2017 (6 meses)

- Relata diversos prejuízos (Perdeu computador $\mathrm{R} \$ 1000$, impressora $\mathrm{R} \$ 800$, máquinas de cartão $R$ \$ 700, bebedor de água $R$ \$ 800. Balcão $R$ \$ 1500. Custo mudança $R$ \$ 3500 referente a quebra de contrato. $R$ \$ 1500 com instalação da comporta. Perdeu câmera $R$ \$ 1400 . R \$ 11200 de móveis. Perdeu perto de 500 sapatos. Cada um torno de 30. R 15000 em sapatos. Ficou fechado 1 semana.)

- Informou que entraram ladrões para roubar o que sobrou da loja, já que as janelas estavam fechadas e impossível de fechar a loja.

- Reabriu a loja por 15 dias e fechou para abrir em novo endereço, a 100 metros do local

(mais elevado)

- Relatou muito cheiro de esgoto, que mesmo após a limpeza se mantinha no local

(impregnado)

- Possuía comporta de 1,20m, sendo que água não ultrapassou a mesma. Porém, a loja ao lado não possuía comporta e as paredes eram frágeis. Assim, as paredes da loja vizinha foram destruídas e a água entrou na sua loja.

- Relata que desconhecia a magnitude das inundações.

- Em 2015 estava instalada no local outra loja, que também fechou após a inundação de 2015.

16 - Inundação atingiu 1,2m na parte exterior da loja, porém em sua loja apenas alguns centímetros.

- Em 2015 não perdeu nada, porém água entrou em contado com os móveis, que depreciaram, mas não foram substituídos.

- Em 2018 a água atingiu novamente os móveis, que estufaram mais umas vezes e tiveram que ser trocados.

- Relata que pagaria por um seguro inundação o mesmo que pagaria por roubo ou furto (em torno de 1600 reais para sua loja).

17 - Considera que em 2015 havia mais sedimentos que em 2018.

- Sofreu muito prejuízo com a perda de dados que estava em seu computador, como crediário, fornecedores, etc.

- Alegou falta d’água para realizar a limpeza do local, tendo que utilizar baldes com água de fora para finalizar. 
- Diz que foi oferecido seguro contra inundação após o evento (entrevistado não se recorda do nome da seguradora).

\section{APÊNDICE 6 - RELAÇÃO RECEITA/ESTOQUE (LUCRO CESSANTE)}

\begin{tabular}{|c|c|c|c|c|c|}
\hline Empresa & Atividade comercial & $\begin{array}{l}\text { Valor médio } \\
\text { do estoque }\end{array}$ & $\begin{array}{c}\text { Quanto } \\
\text { tempo o } \\
\text { comércio } \\
\text { ficou } \\
\text { fechado? }\end{array}$ & $\begin{array}{r}\text { Receita } \\
\text { estimada }\end{array}$ & $\begin{array}{r}\text { Lucro } \\
\text { cessante }\end{array}$ \\
\hline 1 & Escritórios de serviços e consultoria & $40.000,00$ & 6 & $132.000,00$ & 357,56 \\
\hline 2 & Joalherias, relojoarias e óticas & $250.000,00$ & 6 & $1.217 .500,00$ & $3.297,97$ \\
\hline 3 & Joalherias, relojoarias e óticas & $30.000,00$ & 6 & $146.100,00$ & 395,76 \\
\hline 4 & $\begin{array}{l}\text { Lojas de departamento, artigos de armarinho, vestuário e tecidos, } \\
\text { sapatarias e produtos de couro }\end{array}$ & $100.000,00$ & 6 & $340.000,00$ & 920,99 \\
\hline 5 & $\begin{array}{l}\text { Lojas de departamento, artigos de armarinho, vestuário e tecidos, } \\
\text { sapatarias e produtos de couro }\end{array}$ & $70.000,00$ & 6 & $238.000,00$ & 644,70 \\
\hline 6 & $\begin{array}{l}\text { Lojas de departamento, artigos de armarinho, vestuário e tecidos, } \\
\text { sapatarias e produtos de couro }\end{array}$ & $30.000,00$ & 48 & $102.000,00$ & $2.210,38$ \\
\hline 7 & $\begin{array}{l}\text { Lojas de departamento, artigos de armarinho, vestuário e tecidos, } \\
\text { sapatarias e produtos de couro }\end{array}$ & $200.000,00$ & 6 & $680.000,00$ & $1.841,99$ \\
\hline 8 & $\begin{array}{l}\text { Lojas de departamento, artigos de armarinho, vestuário e tecidos, } \\
\text { sapatarias e produtos de couro }\end{array}$ & $100.000,00$ & & $340.000,00$ & 920,99 \\
\hline 9 & $\begin{array}{l}\text { Lojas de departamento, artigos de armarinho, vestuário e tecidos, } \\
\text { sapatarias e produtos de couro }\end{array}$ & $110.000,00$ & & $374.000,00$ & $1.013,09$ \\
\hline 10 & $\begin{array}{l}\text { Lojas de departamento, artigos de armarinho, vestuário e tecidos, } \\
\text { sapatarias e produtos de couro }\end{array}$ & $250.000,00$ & & $850.000,00$ & $2.302,48$ \\
\hline 11 & $\begin{array}{l}\text { Lojas de departamento, artigos de armarinho, vestuário e tecidos, } \\
\text { sapatarias e produtos de couro }\end{array}$ & $200.000,00$ & 6 & $680.000,00$ & $1.841,99$ \\
\hline 12 & $\begin{array}{l}\text { Lojas de departamento, artigos de armarinho, vestuário e tecidos, } \\
\text { sapatarias e produtos de couro }\end{array}$ & $100.000,00$ & 6 & $340.000,00$ & 920,99 \\
\hline 13 & $\begin{array}{l}\text { Lojas de departamento, artigos de armarinho, vestuário e tecidos, } \\
\text { sapatarias e produtos de couro }\end{array}$ & $200.000,00$ & 18 & $680.000,00$ & $5.525,96$ \\
\hline 14 & $\begin{array}{l}\text { Lojas de departamento, artigos de armarinho, vestuário e tecidos, } \\
\text { sapatarias e produtos de couro }\end{array}$ & $200.000,00$ & 6 & $680.000,00$ & $1.841,99$ \\
\hline 15 & $\begin{array}{l}\text { Lojas de departamento, artigos de armarinho, vestuário e tecidos, } \\
\text { sapatarias e produtos de couro }\end{array}$ & $250.000,00$ & 6 & $850.000,00$ & $2.302,48$ \\
\hline 16 & $\begin{array}{l}\text { Lojas de departamento, artigos de armarinho, vestuário e tecidos, } \\
\text { sapatarias e produtos de couro }\end{array}$ & $240.000,00$ & 6 & $816.000,00$ & $2.210,38$ \\
\hline 17 & $\begin{array}{l}\text { Lojas de departamento, artigos de armarinho, vestuário e tecidos, } \\
\text { sapatarias e produtos de couro }\end{array}$ & $200.000,00$ & 18 & $680.000,00$ & $5.525,96$ \\
\hline 18 & $\begin{array}{l}\text { Lojas de departamento, artigos de armarinho, vestuário e tecidos, } \\
\text { sapatarias e produtos de couro }\end{array}$ & $50.000,00$ & & $170.000,00$ & 460,50 \\
\hline 19 & $\begin{array}{l}\text { Lojas de departamento, artigos de armarinho, vestuário e tecidos, } \\
\text { sapatarias e produtos de couro }\end{array}$ & $50.000,00$ & 6 & $170.000,00$ & 460,50 \\
\hline 20 & $\begin{array}{l}\text { Lojas de departamento, artigos de armarinho, vestuário e tecidos, } \\
\text { sapatarias e produtos de couro }\end{array}$ & $30.000,00$ & & $102.000,00$ & 276,30 \\
\hline 21 & $\begin{array}{l}\text { Lojas de departamento, artigos de armarinho, vestuário e tecidos, } \\
\text { sapatarias e produtos de couro }\end{array}$ & $80.000,00$ & 6 & $272.000,00$ & 736,79 \\
\hline 22 & $\begin{array}{l}\text { Lojas de departamento, artigos de armarinho, vestuário e tecidos, } \\
\text { sapatarias e produtos de couro }\end{array}$ & $75.000,00$ & & $255.000,00$ & 690,74 \\
\hline 23 & $\begin{array}{l}\text { Lojas de departamento, artigos de armarinho, vestuário e tecidos, } \\
\text { sapatarias e produtos de couro }\end{array}$ & $30.000,00$ & 10 & $102.000,00$ & 460,50 \\
\hline 24 & $\begin{array}{l}\text { Lojas de departamento, artigos de armarinho, vestuário e tecidos, } \\
\text { sapatarias e produtos de couro }\end{array}$ & $6.000,00$ & 10 & $20.400,00$ & 92,10 \\
\hline 25 & $\begin{array}{l}\text { Lojas de departamento, artigos de armarinho, vestuário e tecidos, } \\
\text { sapatarias e produtos de couro }\end{array}$ & $50.000,00$ & 6 & $170.000,00$ & 460,50 \\
\hline 26 & $\begin{array}{l}\text { Lojas de departamento, artigos de armarinho, vestuário e tecidos, } \\
\text { sapatarias e produtos de couro }\end{array}$ & $125.000,00$ & & $425.000,00$ & $1.151,24$ \\
\hline 27 & $\begin{array}{l}\text { Lojas de departamento, artigos de armarinho, vestuário e tecidos, } \\
\text { sapatarias e produtos de couro }\end{array}$ & $30.000,00$ & & $102.000,00$ & 276,30 \\
\hline 28 & $\begin{array}{l}\text { Lojas de departamento, artigos de armarinho, vestuário e tecidos, } \\
\text { sapatarias e produtos de couro }\end{array}$ & $70.000,00$ & 6 & $238.000,00$ & 644,70 \\
\hline 29 & $\begin{array}{l}\text { Lojas de departamento, artigos de armarinho, vestuário e tecidos, } \\
\text { sapatarias e produtos de couro }\end{array}$ & $100.000,00$ & & $340.000,00$ & 920,99 \\
\hline
\end{tabular}




\begin{tabular}{|c|c|c|c|c|c|}
\hline 30 & $\begin{array}{l}\text { Lojas de departamento, artigos de armarinho, vestuário e tecidos, } \\
\text { sapatarias e produtos de couro }\end{array}$ & $60.000,00$ & 6 & $204.000,00$ & 552,60 \\
\hline 31 & $\begin{array}{l}\text { Lojas de departamento, artigos de armarinho, vestuário e tecidos, } \\
\text { sapatarias e produtos de couro }\end{array}$ & $70.000,00$ & 80 & $238.000,00$ & $8.595,94$ \\
\hline 32 & $\begin{array}{l}\text { Lojas de departamento, artigos de armarinho, vestuário e tecidos, } \\
\text { sapatarias e produtos de couro }\end{array}$ & $200.000,00$ & 6 & $680.000,00$ & $1.841,99$ \\
\hline 33 & Mercados e lojas de departamento & $120.000,00$ & 6 & $394.800,00$ & $1.069,44$ \\
\hline 34 & Mercados e lojas de departamento & $1.000 .000,00$ & 6 & $3.290 .000,00$ & $8.911,96$ \\
\hline 35 & Mercados e lojas de departamento & $15.000,00$ & 6 & $49.350,00$ & 133,68 \\
\hline 36 & Mercados e lojas de departamento & $100.000,00$ & & $329.000,00$ & 891,20 \\
\hline 37 & Mercados e lojas de departamento & $100.000,00$ & & $329.000,00$ & 891,20 \\
\hline 38 & Móveis, eletrodomésticos, equipamentos de informática & $20.000,00$ & 6 & $150.000,00$ & 406,32 \\
\hline 39 & Móveis, eletrodomésticos, equipamentos de informática & $40.000,00$ & 48 & $300.000,00$ & $6.501,13$ \\
\hline 40 & Móveis, eletrodomésticos, equipamentos de informática & $800.000,00$ & 20 & $6.000 .000,00$ & $54.176,07$ \\
\hline 41 & Móveis, eletrodomésticos, equipamentos de informática & $50.000,00$ & 12 & $375.000,00$ & $2.031,60$ \\
\hline 42 & Produtos farmacêuticos, cosméticos, perfumaria & $100.000,00$ & & $436.000,00$ & $1.181,04$ \\
\hline 43 & Produtos farmacêuticos, cosméticos, perfumaria & $40.000,00$ & & $174.400,00$ & 472,42 \\
\hline 44 & Restaurantes, lanchonetes, bares e cafés & $20.000,00$ & 6 & $87.200,00$ & 236,21 \\
\hline & TOTAL & $6.001 .000,00$ & 412 & 24.548.750,00 & $128.599,59$ \\
\hline
\end{tabular}

Obs.: Espaços vazios da variável "Quanto tempo o comércio ficou fechado?” foram preenchidos com o número " 6 " para realizar o cálculo. 


\section{APÊNDICE 7 - RESPOSTA DA PREFEITURA RELATIVA AO PROCESSO}

$6025 / 2018$

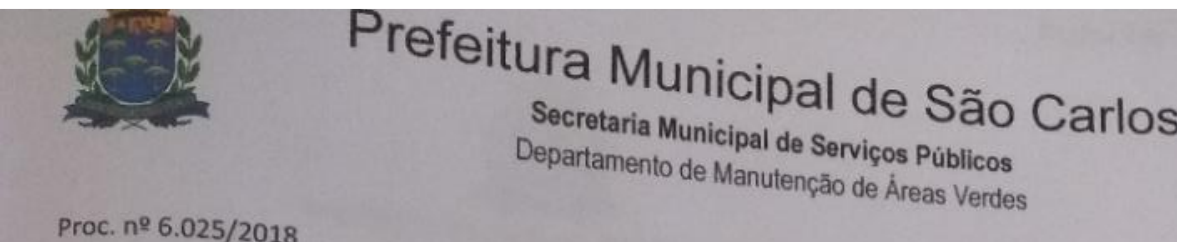

Proc. $n \div 6.025 / 2018$

Sr. Secretário

Respondendo as solicitações de fls. 03, temos a dizer:

foram efetuados com equipamentos e mão de obra corte de árvores e desassoreamento de córregos próximo a pontes e galerias e por empresas de obra da própria Prefeitura em pontos localizados Carlos.

Valores gastos em 2018 com contratação de serviços emergenciais provocados por chuva:

redes de galerias de águas pluviais. Contrato $n^{0} 30 / 2018-$ aerreira Aluviais.

Contrato ne 30/2018 - Ferreira Agroterra Ltda.

Valor: R\$ 265.584,00.

e córregos. Processo $n \cong 6.600 / 2018$ - Contrataçăo emergencial de reparos e manutenção dos leitos

Contrato 29/2018 - Engenharia e Comércio Bandeirantes Ltda.
Valor: R\$ 734.683,44. galerias.

$\operatorname{con} 1820$

Contrato n 31/2018 - Beacon Engenharia e Construções - EIRILI

Valor: R\$ 411.180,00.

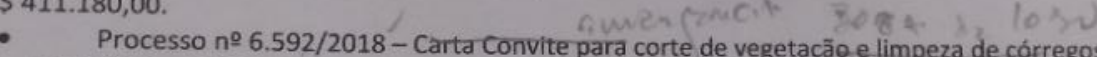
Contrato n2 28/2018 - PERSA Constion de córregos. Valor: R\$ 54.000,00.

- Processo n 6.597/2018 - Contrataçăo emergencial para manutenção arbórea.

Contrato n? 31/2018 - Caio Fioroni-ME

Valor: $\mathrm{R} \$ 313.200,00$

São Carlos, 28 de julho de 2018

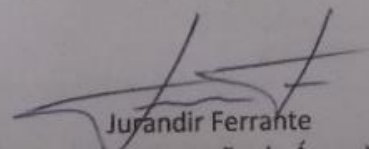

Diretor de Manutenção de Áreas Verdes

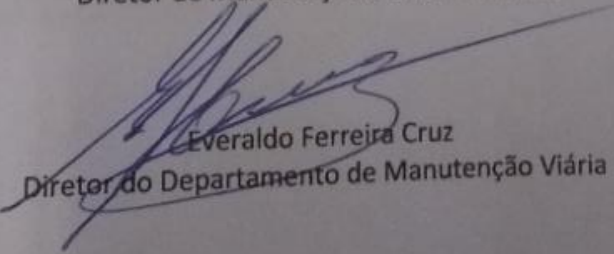




\section{APÊNDICE 8 - CUSTOS DE LIMPEZA DOS IMÓVEIS}

\begin{tabular}{|c|c|c|c|c|c|c|}
\hline Empresa & $\begin{array}{r}\text { Número de } \\
\text { funcionários }\end{array}$ & $\begin{array}{r}\text { Em quanto tempo? } \\
\text { (horas) }\end{array}$ & $\begin{array}{l}\text { Quantas } \\
\text { pessoas? }\end{array}$ & $\begin{array}{r}\text { Área do } \\
\text { estabelecimento }\end{array}$ & $\begin{array}{r}\text { Custo de } \\
\text { limpeza }\end{array}$ & Horas/m2/pessoa \\
\hline 1 & 22 & 6 & 10 & 180,0 & 5.830 &, 33 \\
\hline 2 & 6 & 18 & 6 & 120 & 1.166 &, 90 \\
\hline 3 & 2 & 6 & 4 & 20,0 & 2.332 & 1,20 \\
\hline 4 & 5 & 7 & 5 & 140,0 & 2.499 &, 25 \\
\hline 5 & 10 & 6 & 10 & 154,0 & 5.830 & ,39 \\
\hline 6 & 1 & 5 & 3 & 50,0 & 2.099 &, 30 \\
\hline 7 & 2 & 6 & 2 & 40,0 & 1.166 &, 30 \\
\hline 8 & 2 & 8 & 4 & 160 & 1.749 & ,20 \\
\hline 9 & 3 & 6 & 3 & 28,0 & 1.749 & ,64 \\
\hline 10 & 2 & 2 & 5 & 63,0 & 8.746 &, 16 \\
\hline 11 & 12 & 6 & 20 & 250 & 11.661 &, 48 \\
\hline 12 & 1 & 6 & 1 & 35,0 & 583 &, 17 \\
\hline 13 & 1 & 18 & 6 & 50,0 & 1.166 & 2,16 \\
\hline 14 & 4 & 6 & 4 & 100 & 2.332 &, 24 \\
\hline 15 & 2 & 6 & 8 & 150,0 & 4.664 &, 32 \\
\hline 16 & 0 & 8 & 4 & 48,0 & 1.749 & ,67 \\
\hline 17 & 3 & 6 & 6 & 50,0 & 3.498 &, 72 \\
\hline 18 & 2 & 6 & 10 & 90 & 5.830 & ,67 \\
\hline 19 & 3 & 6 & 4 & 35,0 & 2.332 & ,69 \\
\hline 20 & 2 & 18 & 3 & 60 & 583 & ,90 \\
\hline 21 & 2 & 6 & 3 & 60,0 & 1.749 &, 30 \\
\hline 22 & 0 & 10 & 5 & 40,0 & 1.749 & 1,25 \\
\hline 23 & 2 & 48 & 2 & 48,0 & 146 & 2,00 \\
\hline 24 & 1 & 10 & 2 & 35,0 & 700 &, 57 \\
\hline 25 & 1 & 6 & 8 & 50,0 & 4.664 & ,96 \\
\hline 26 & 1 & 5 & 5 & 24,0 & 3.498 & 1,04 \\
\hline 27 & 0 & 10 & 2 & 16,0 & 700 & 1,25 \\
\hline 28 & 2 & 20 & 8 & 40,0 & 1.399 & 4,00 \\
\hline 29 & & 15 & 2 & 27,0 & 466 & 1,11 \\
\hline 30 & 1 & 60 & 3 & 40 & 175 & 4,50 \\
\hline 31 & 0 & 14 & 15 & 40,0 & 3.748 & 5,25 \\
\hline 32 & 3 & 80 & 6 & 30,0 & 262 & 16,00 \\
\hline 33 & 3 & 6 & 4 & 42,0 & 2.332 &, 57 \\
\hline 34 & 3 & 3 & 2 & 114 & 2.332 &, 05 \\
\hline 35 & 4 & 2 & 4 & 75,0 & 6.997 &, 11 \\
\hline 36 & & 4 & 12 & 220,0 & 10.495 &, 22 \\
\hline Total & 108 & 455 & 201 & 2724 & 108.979 & 1,41 \\
\hline
\end{tabular}




\section{APÊNDICE 9 - CARACTERIZAÇÃO SÓCIO ECONÔMICA LOCAL COM USO DOS MICRODADOS CENSITÁRIO DA ÁREA IMPACTADA}

Para as residências, foram utilizados microdados censitários agregados por setor censitário das regiões delimitadas geograficamente pelo censo do IBGE (2010).

\section{Microdados Censitários}

O Censo Demográfico é a mais complexa estatística realizada por um país, em que características de toda a população e dos domicílios do território nacional são estudadas. De acordo com o Instituto Brasileiro de Geografia e Estatística (IBGE) (2011), o censo demográfico constitui a única fonte de referência para o conhecimento das condições socioeconômicas da população.

As informações obtidas no censo pelo IBGE (2011) sobre as características dos domicílios e das pessoas provêm de dois questionários: questionário básico, com 37 variáveis, aplicado a todas as unidades domiciliares; questionário da amostra, com 108 variáveis, aplicado aos domicílios selecionados para a mostra. Este questionário contém, além das informações contidas no questionário básico, informações econômicas e demográficas de seus moradores.

Os arquivos com dados agregados por setor censitário são aqueles que abrangem todos os municípios da federação com informações em nível de bairros e distritos municipais. Estes foram utilizados inicialmente pelo IBGE como cadastro básico de áreas para a seleção de amostras de pesquisas domiciliares.

Inicialmente, os arquivos com dados agregados por setor censitário eram compostos por variáveis da divisão territorial brasileira e algumas variáveis de porte ou tamanho de setores. A partir do censo demográfico de 1991, foram incorporadas variáveis em nível de setor. Para o censo de 2000, foi criado um primeiro arquivo agregado com base nos dados da sinopse preliminar deste censo. Com a conclusão dos trabalhos, foi produzida uma primeira edição do arquivo agregado por setores censitários, com 527 variáveis sobre características dos domicílios, dos seus responsáveis e das pessoas residentes. Com os dados deste censo, foi criado uma segunda edição com mais de 3200 variáveis.

No censo demográfico de 2010 foi produzido, pela primeira vez na instituição, arquivos com dados em nível de setor censitário. Além das variáveis de identificação geográfica (Grande Região, Unidade da Federação, Mesorregião, Microrregião, Região Metropolitana, Município, Distrito, Subdistrito, Bairro, Setor e Situação do Setor), são distribuídas em planilhas mais de 
154 variáveis, que abrangem os domicílios por espécie e as pessoas residentes por sexo e idade. Para tanto, foram utilizados, na presente pesquisa, apenas os dados dos domicílios do tipo particular permanente, que são aqueles domicílios construídos para servir exclusivamente à habitação e com a finalidade de servir de moradia a uma ou mais pessoas.

A coleta do Censo Demográfico 2010 foi realizada no período de $1^{\circ}$ de agosto a 30 de outubro de 2010, utilizando a base territorial que se constituiu de 316.574 setores censitários.

O setor censitário é a unidade territorial de controle cadastral da coleta, constituída por áreas contíguas, respeitando-se os limites da divisão político-administrativa, do quadro urbano e rural legal e de outras estruturas territoriais de interesse, além dos parâmetros de dimensão mais adequados à operação de coleta.

De acordo com IBGE,

“O setor censitário é a menor unidade territorial, formada por área contínua, integralmente contida em área urbana ou rural, com dimensão adequada à operação de pesquisas e cujo conjunto esgota a totalidade do Território Nacional, o que permite assegurar a plena cobertura do País”. (IBGE, 2011, p.4)

O IBGE disponibiliza um arquivo contendo as variáveis estudadas por setor censitário para cada Unidade da Federação ${ }^{25}$. Este arquivo contém 18 planilhas, das quais foram utilizadas:

Descrição - O arquivo "Descrição_UF_SP_Exceto_Capital.xls" contém todos os setores censitários do Estado de São Paulo, com o código e a descrição

do percurso que abrange todo o perímetro do setor censitário;

$\checkmark$ Básico - O arquivo "Basico_UF_SP_Exceto_capital.xls" contém os códigos e nomes das subdivisões geográficas e a informação básica do cadastro de áreas (totais, médias e variâncias);

$\checkmark \quad$ Domicilio - Contém três planilhas (Domicilio01_SP.xls; Domicilio02_SP.xls; domicilio_renda_SP.xls) que fornecem informações sobre características dos domicílios, informações sobre seus moradores por sexo, idade, renda e tipo de domicílio;

\footnotetext{
${ }^{25}$ Disponível em:
}

ftp://ftp.ibge.gov.br/Censos/Censo_Demografico_2010/Resultados_do_Universo/Agregados_por_Setores_Censit arios/Base_informacoes_setores_2010_universo_SP_Exceto_Capital.zip 
$\checkmark \quad$ Pessoa - Contém três planilhas (Pessoa11UF.xls a Pessoa13UF.xls), que fornecem informação sobre a população residente por sexo e idade.

Cada linha de cada planilha fornece os dados de um setor censitário e cada coluna corresponde a uma variável, descrita em código numérico, relacionadas ao domicílio, responsável ou pessoa.

Este código numérico contém 15 dígitos divididos da seguinte forma: UFMMMMMDDSDSSSS, em que:

$$
\begin{array}{ll}
\checkmark & \text { UF - Unidade da Federação; } \\
\checkmark & \text { MMMMM-Município } \\
\checkmark & \text { DD - Distrito } \\
\checkmark & \text { SD - Subdistrito } \\
\checkmark & \text { SSSS - Setor }
\end{array}
$$

\section{Caracterização das residências}

A descrição da delimitação pelo IBGE foi elaborada com base em um percurso, em que se estabelece o caminho a ser percorrido para delimitar o perímetro do setor, de acordo com as esquinas dos logradouros a serem percorridos, com início e fim estabelecidos (arquivo Descrição_SP_Exceto_Capital.xls). Assim, foram mapeados os setores próximos à mancha de inundação e extraídos do arquivo que contém a base de informações por setores. Foram selecionados dois setores, os quais se encontram descritos na Tabela x. O mapa com os setores censitários é apresentado na Figura 3.

Tabela $\mathrm{x}$ - Descrição dos setores censitários contidos na mancha de inundação da área central de São Carlos

\begin{tabular}{c|c|c} 
Geocódigo & Posição incial & Perímetro \\
\hline 354890605000014 & $\begin{array}{c}\text { Rua Treze de Maio com } \\
\text { Rua Nove de Julho. }\end{array}$ & $\begin{array}{c}\text { Do ponto inicial segue Rua Treze de Maio - Rua São Joaquim - Rua Jesuíno de Arruda - Rua } \\
\text { Dona Alexandrina - Rua Geminiano Costa - Rua Nove de Julho - por esta até o ponto inicial. }\end{array}$ \\
\hline 354890605000015 & $\begin{array}{c}\text { Rua Conde do Pinhal com } \\
\text { Rua José Bonifácio }\end{array}$ & $\begin{array}{c}\text { Do ponto inicial Rua Conde do Pinhal - Rua Nove de Julho - Rua Geminiano Costa - Rua Dona } \\
\text { Alexandrina - Rua General Osório - Rua José Bonifácio - por esta até o ponto inicial. }\end{array}$
\end{tabular}

Fonte: IBGE (2011) 


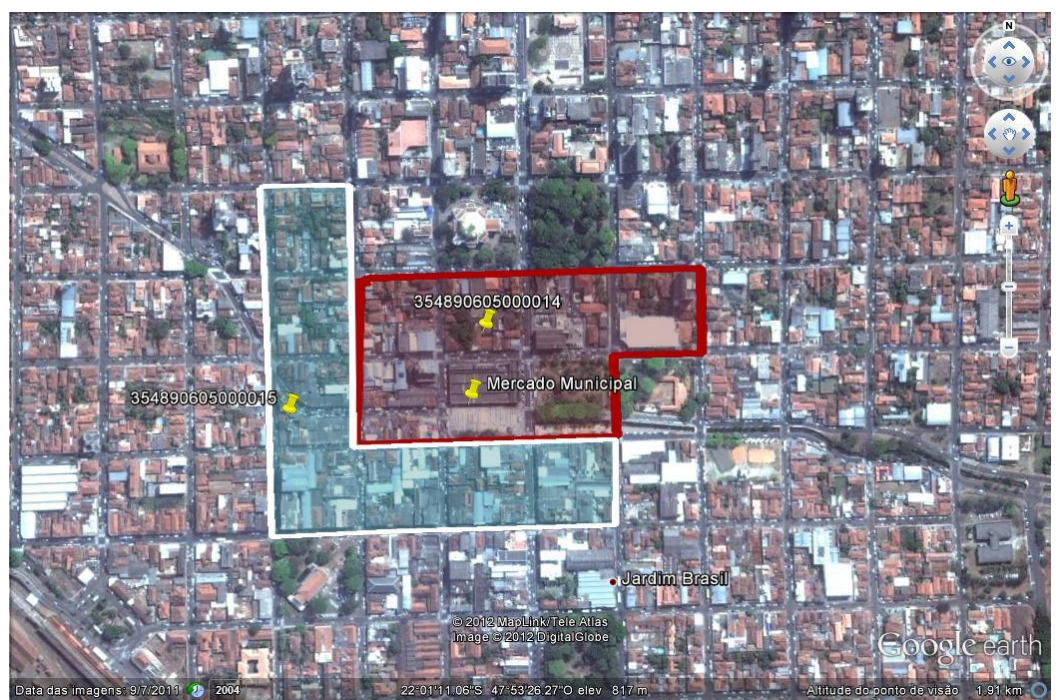

Figura 3 - Delimitação das áreas por setores censitários objeto do estudo

\section{Caracterização dos imóveis}

Após a delimitação do percurso, procedeu-se a obtenção das variáveis investigadas pelo IBGE para os setores. Para isso, utilizaram-se as planilhas com informações básicas, sobre pessoas e domicílios descritas anteriormente. As variáveis extraídas das planilhas de interesse para esse estudo são mostradas nas tabelas a seguir, com informações socioeconômicas das pessoas e dos domicílios contidas nos setores censitários.

Tabela x - Caracterização dos moradores presentes nos setores censitários

\begin{tabular}{c|c|c|c|c|c} 
Geocódigo & $\begin{array}{c}\text { Domicílios } \\
\text { particulares } \\
\text { permanentes }\end{array}$ & $\begin{array}{c}\text { Moradores em } \\
\text { domicílios } \\
\text { particulares } \\
\text { permanentes }\end{array}$ & $\begin{array}{c}\text { Média do número de } \\
\text { moradores em } \\
\text { domicílios particulares } \\
\text { permanentes }\end{array}$ & $\begin{array}{c}\text { Variância do número } \\
\text { de moradores em } \\
\text { domicílios particulares } \\
\text { permanentes }\end{array}$ & $\begin{array}{c}\text { Valor do rendimento } \\
\text { nominal médio mensal dos } \\
\text { responsáveis por domicílios } \\
\text { particulares permanentes }\end{array}$ \\
\hline 354890605000014 & 60 & 119 & 1,98 & 1,07 & $2.801,40$ \\
\hline 354890605000015 & 46 & 118 & 2,57 & 1,85 & $2.637,33$ \\
\hline TOTAIS & $\mathbf{1 0 6}$ & $\mathbf{2 3 7}$ & $\mathbf{2 , 2 8}$ & $\mathbf{1 , 4 6}$ & $\mathbf{2 . 7 1 9 , 3 7}$
\end{tabular}

Fonte: Adaptado de IBGE (2010)

Tabela x - Caracterização dos domicílios contidos na mancha de inundação

\begin{tabular}{c|c|c|c|c|c|c} 
Geocódigo & $\begin{array}{c}\text { Domicílios } \\
\text { tipo casa }\end{array}$ & $\begin{array}{c}\text { Domicílios tipo } \\
\text { apartamento }\end{array}$ & $\begin{array}{c}\text { Domicílios } \\
\text { próprios ou } \\
\text { quitados }\end{array}$ & $\begin{array}{c}\text { Domicílios com } \\
\text { 1 morador }\end{array}$ & $\begin{array}{c}\text { Domicílios com 2 } \\
\text { moradores }\end{array}$ & $\begin{array}{c}\text { Domicílios com 3 ou } \\
\text { mais moradores }\end{array}$ \\
\hline 354890605000014 & 8 & 52 & 21 & 23 & 22 & 10 \\
\hline 354890605000015 & 41 & 5 & 23 & 13 & 10 & 12 \\
\hline TOTAL & $\mathbf{4 9}$ & $\mathbf{5 7}$ & $\mathbf{4 4}$ & $\mathbf{3 6}$ & $\mathbf{3 2}$ & $\mathbf{2 2}$
\end{tabular}.

Fonte: Adaptado de IBGE (2010) 
Foi verificado que as residenciais contidas na mancha de inundação localizam-se exclusivamente no setor de geocódigo 354890605000015, ignorados, desta forma, os dados do geocódigo com final 14. Dentre os microdados agregados por setores censitários do IBGE (2010), cabe destaque neste estudo os dados desagregados para o geocódigo 354890605000015 com os valores de rendimento nominal mensal domiciliar per capita dos domicílios pesquisados. Os dados são apresentados na tabela x.

Tabela $\mathrm{x}$ - Rendimento nominal mensal domiciliar per capita dos domicílios

\begin{tabular}{c|c|c|c|c|c|c}
\multirow{2}{*}{ Geocódigo } & \multicolumn{6}{|c}{$\begin{array}{r}\text { Domicílios particulares com rendimento nominal mensal } \\
\text { domiciliar per capita de (salários mínimos) }\end{array}$} \\
\cline { 2 - 7 } & $\mathbf{1 / 2}$ a 1 & $\mathbf{1}$ a 2 & $\mathbf{2}$ a 3 & $\mathbf{3}$ a 5 & $\mathbf{5}$ a 10 & mais de 10 \\
\cline { 2 - 7 } 354890605000015 & 8 & 13 & 7 & 7 & 5 & 1 \\
\hline Salário mínimo de 2009 (R\$) & 540 & 1080 & 1620 & 2700 & 5400 & 5400
\end{tabular}

Fonte: IBGE (2010)

Os valores de rendimento nominal mensal domiciliar das residências serviram de base para definir a classe econômica de cada residência. As classes econômicas foram definidas com base em ABEP (2009), que definiu as classes econômicas brasileiras de acordo com a tabela $\mathrm{x}$.

Tabela $\mathrm{x}$ - Classificação das residências brasileiras quanto à classe econômica

\begin{tabular}{cc|c|c|c|c|c|c|c}
\multicolumn{1}{c}{ Classificação econômica das residências brasileiras } \\
Classe Econômica & A1 & A2 & B1 & B2 & C1 & C2 & D & E \\
\cline { 2 - 10 } Rendimento nominal mensal & 11480 & 8295 & 4754 & 2656 & 1459 & 962 & 680 & 415
\end{tabular}

Fonte: Adaptado de ABEP (2009) 


\section{APÊNDICE 10 - MODELAGEM HIDRÁULICA E HIDROLÓGICA}

A modelação hidrológica foi realizada pelo método NRCS (Natural Resources Conservation Service), antigo SCS (Soil Conservation Service), desenvolvido pelo Departamento de Agricultura dos Estados Unidos. O método consiste na determinação da precipitação efetiva (precipitação que gera escoamento superficial) por meio do Curve Number $(C N)$. O CN está associado: ao tipo de solo; às condições de uso e ocupação do solo; e à umidade antecedente, relacionada à precipitação acumulada dos últimos cinco dias (PORTO, 1995). Seu valor pode variar entre 0 e 100 , de modo que quanto maior for o número, maior será o escoamento superficial em relação à precipitação total. A fórmula proposta pelo método e adaptada pelo USDA (1986) é representada pela Equação 2.1.

$$
Q=\frac{(P-0,2 S)^{2}}{P+0,8 S} ; \text { para } P>0,2 * S \quad \text { (Equação 2.1) }
$$

Onde:

$\mathrm{Q}=$ escoamento superficial direto $(\mathrm{mm})$

$\mathrm{P}=$ precipitação $(\mathrm{mm})$

$\mathrm{S}=$ retenção potencial do solo $(\mathrm{mm})$

O valor da retenção potencial do solo "S" depende do tipo e da ocupação do solo e pode ser determinado facilmente por meio de tabelas próprias, ou ainda in loco por meio de ensaios de infiltração. O método estabelece que $20 \%$ do total precipitado fica retido devido à interceptação e retenção em depressões e não é contabilizado nos cálculos de escoamento superficial, ou seja, o método somente será aplicado se o total precipitado superar este valor denominado perdas iniciais $\left(\mathrm{A}_{\mathrm{i}}\right)$. As variáveis do método SCS são apresentadas na Figura 0.1. 
Figura 0.1 - Variáveis do método SCS

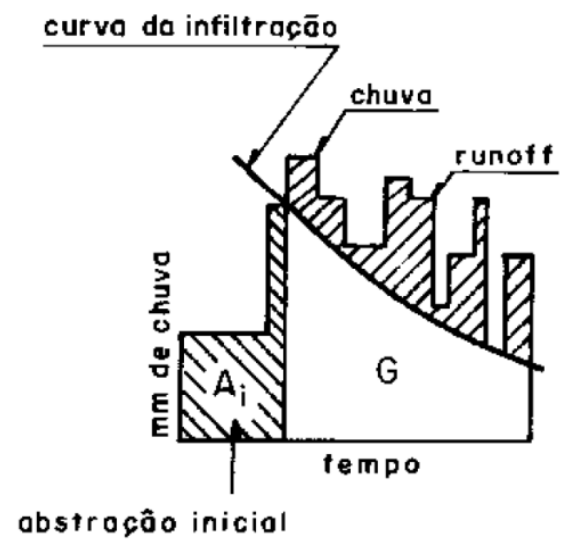

Fonte: CHOW (1988)

Dentre as funções da modelagem em drenagem urbana, está a de simular cenários a fim de obter manchas de inundação, e a partir destas alcançar valores de perdas econômicas decorrentes de inundações urbanas. Esse tipo de modelo tem se tornado uma tendência na área de estudo de recursos hídricos e planejamento urbano. A aplicação desta modelagem pode servir de suporte à tomada de decisão quando se objetiva analisar os parâmetros quantitativos que envolvem o processo de perdas: precipitação máxima e período de retorno, impermeabilização das superfícies da bacia e metodologia para quantificação das perdas.

A plataforma HEC, desenvolvido pelo Hydrologic Engineering Centre, do Corpo de Engenheiros do Exército dos EUA (US Army Corps of Engineers) é uma plataforma capaz de simular os processos chuva-deflúvio em bacias hidrográficas dendríticas e dispõe de módulos hidráulicos, hidrológicos e econômicos para simulação, entre os quais os de maior destaque nesta pesquisa são o módulo $H E C-H M S$ - hidrológico, o módulo HEC-RAS.

O módulo HMS (Hydrologic Modeling System) simula vários processos hidrológicos. Dentre eles, destaca-se o processo de transformação chuva-vazão em bacias hidrográficas urbanas e rurais. Como dados de entrada, têm-se as equações intensidade-duração-frequência, a área da bacia e o curve-number $(\mathrm{CN})$, entre outras características físicas e hidrológicas da bacia.

O módulo RAS (River Analysis System) é aplicado à simulação de perfis de linha de água em rios e reservatórios, na hipótese de fluxo unidimensional e regime de escoamento permanente, gradualmente variado, subcrítico, supercrítico ou misto, bem como em regime não permanente (transiente). Como dados de entrada, são necessárias seções transversais da calha 
do rio, perfil longitudinal, definição das condições de contorno e dos coeficientes de rugosidade de Manning, bem como os valores de vazão a serem escoados no trecho.

O módulo RAS apresenta a possibilidade de se comunicar com o software ArcGIS 9.3 através da plataforma HecGeoRas, que permite a retirada de informações necessárias à modelagem hidráulica a partir de modelos digitais de terreno (MDT).

Com este, podem ser traçadas através do HecGeoRas, suplemento do ArcGIS, as manchas de inundação pela sobreposição dos níveis de água simulados no software hidráulico Hec-RAS ao modelo de digital do terreno (MDT).

\section{ANEXO 1 - CURVA DPS DO SETOR DE COMÉRCIO E SERVIÇOS}

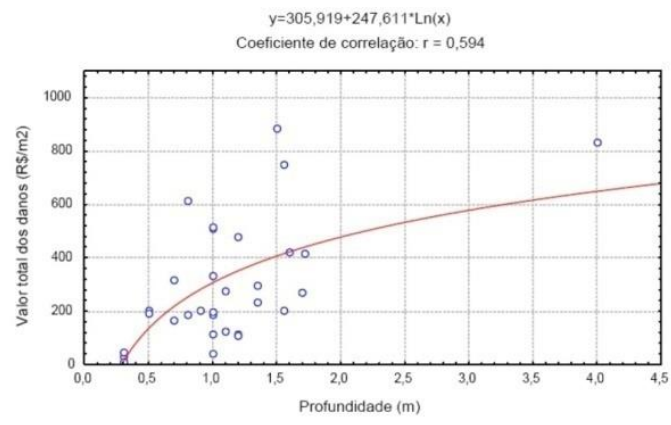

Curva DPS do setor de comércio de lojas de departamento, artigos de armarinho, vestuário e tecidos, sapatarias e produtos de couro Fonte: Machado (2005)

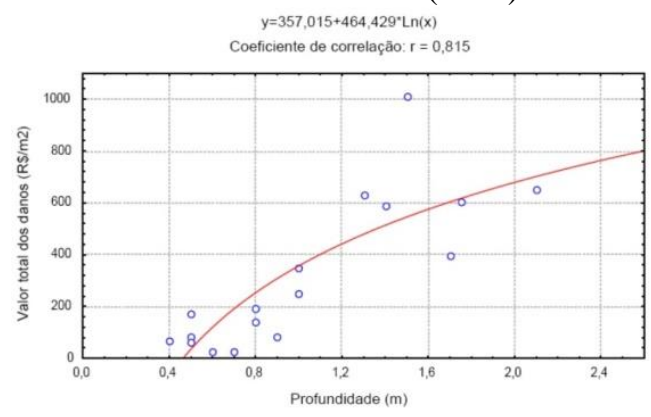

Curva DPS do setor de comércio de móveis, eletrodomésticos, equipamentos de informática Fonte: Machado (2005)

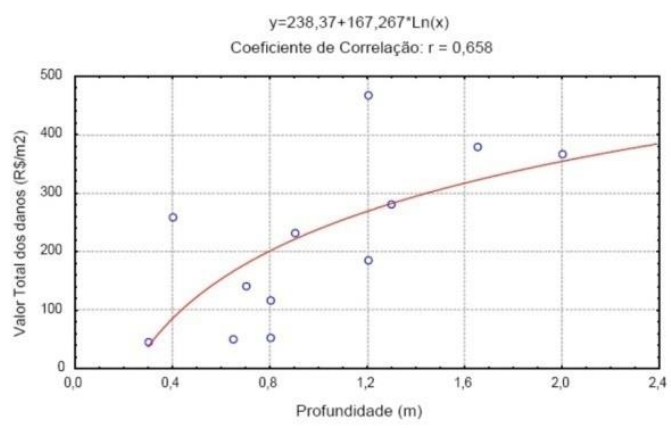

Curva DPS do setor de comércio de mercados e lojas de departamento Fonte: Machado (2005)

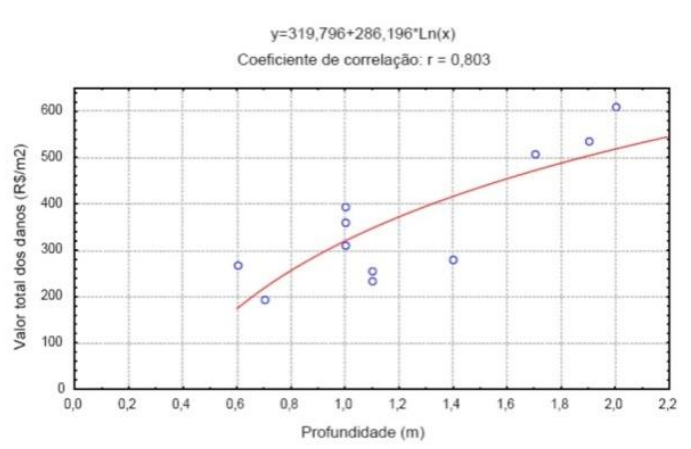

Curva DPS do setor de comércio de produtos farmacêuticos, perfumaria e cosméticos Fonte: Machado (2005) 


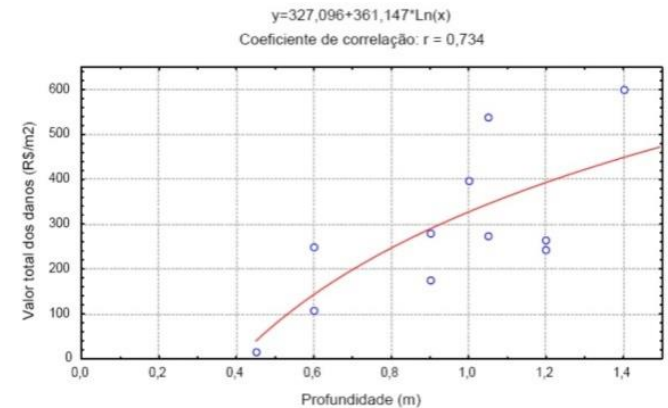

Curva DPS do setor de comércio de joalherias, relojoarias e óticas

Fonte: Machado (2005)

$y=96,339+21,618^{*} \operatorname{Ln}(x)$

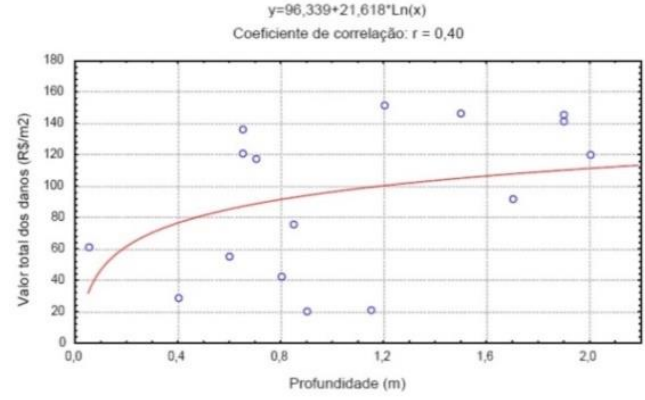

Curva DPS do setor de serviços de Escritórios e consultoria

Fonte: Machado (2005)

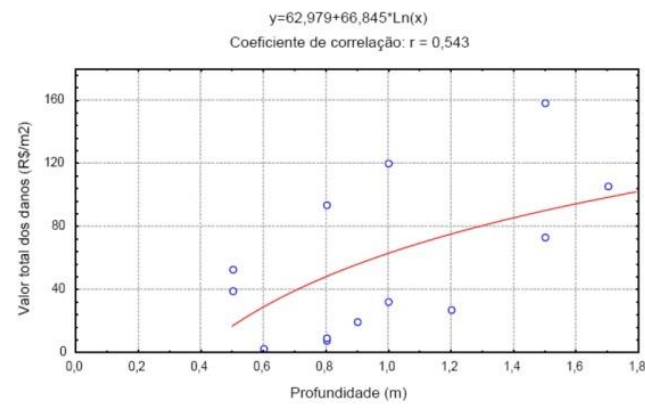

Curva DPS do setor de comércio Restaurantes, lanchonetes, bares e cafés Fonte: Machado (2005)

\section{ANEXO 2 - CURVA COTA-ÁREA E COTA-VOLUME DOS RESERVATÓRIOS PREVISTOS NA BACIA DO CÓRREGO DO GREGÓRIO}

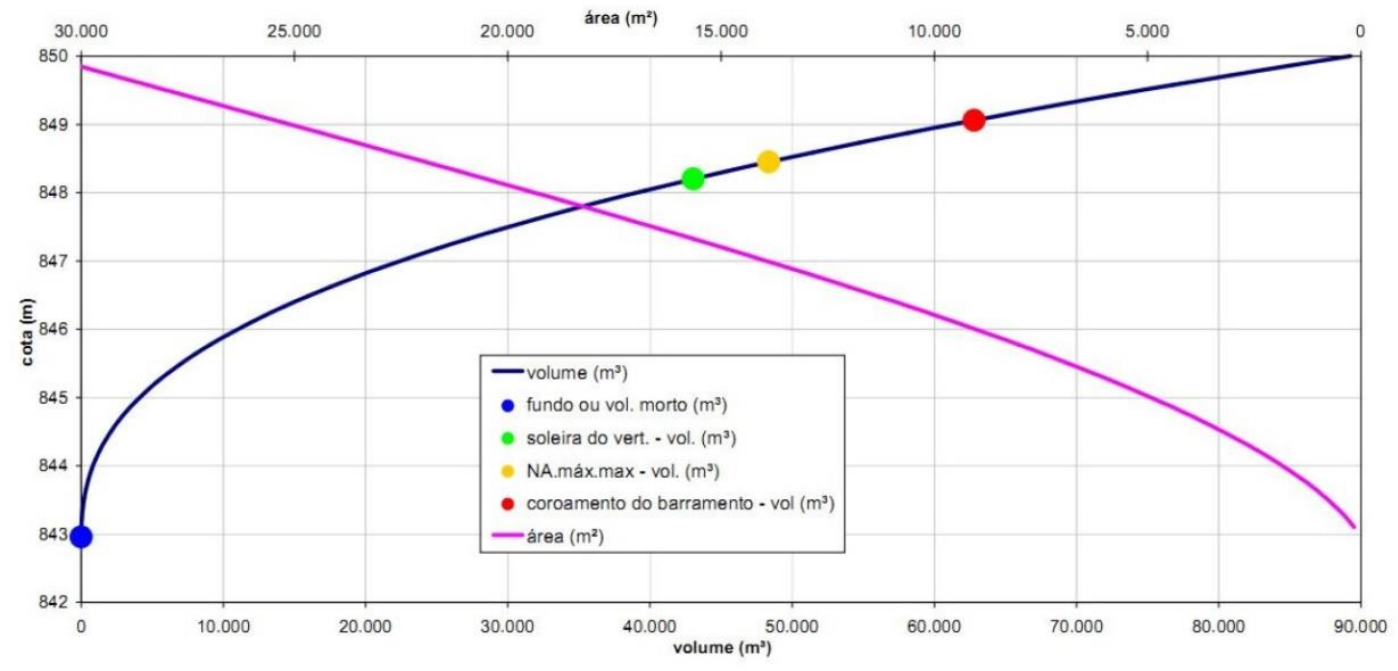

Curva cota-área e cota-volume do reservatório G2 B 83.5

Fonte: PMSC (2011) 


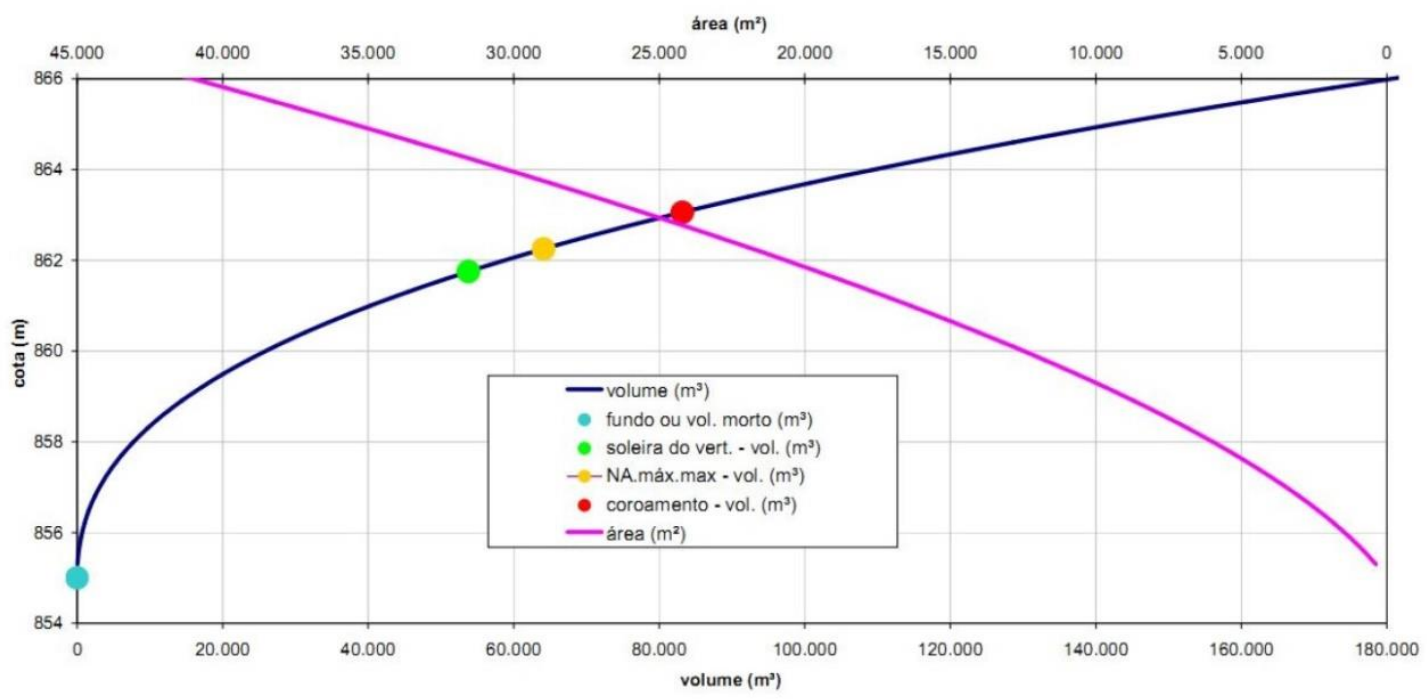

Curva cota-área e cota-volume do reservatório S1 B 84.5

Fonte: PMSC (2011)

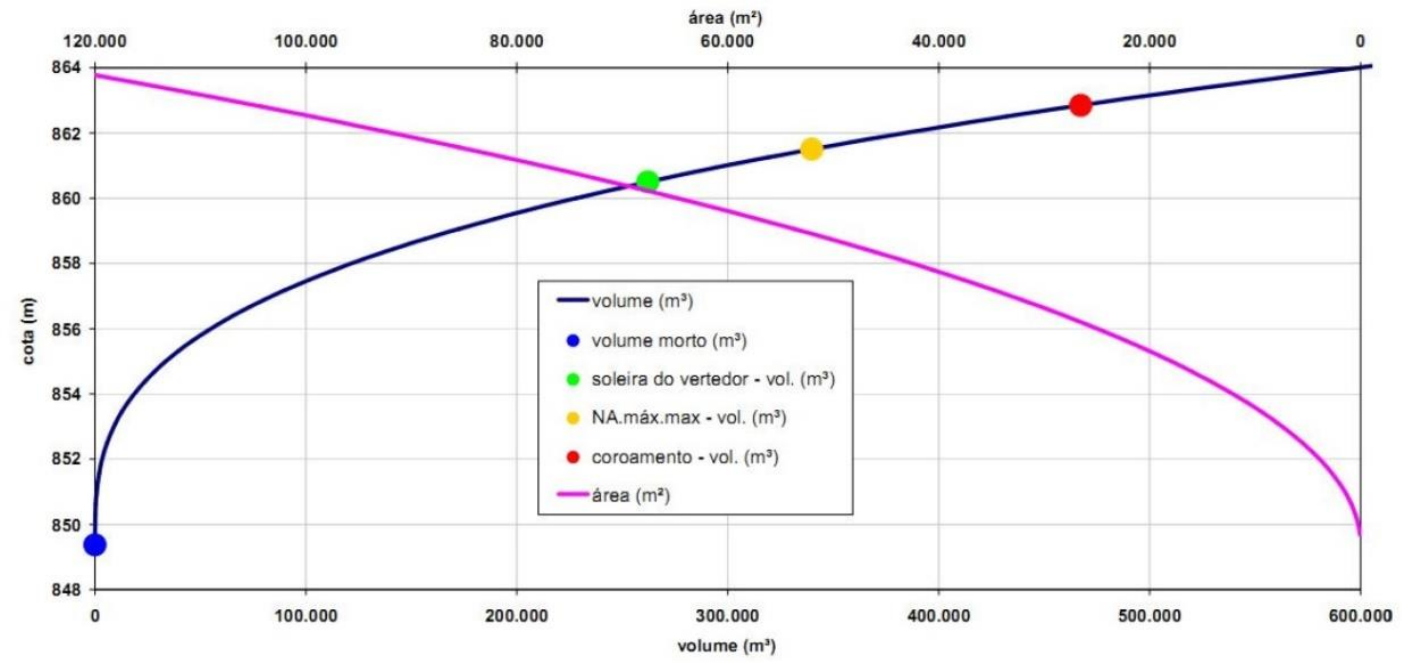

Curva cota-área e cota-volume do reservatório G1 B 93.5

Fonte: PMSC (2011)

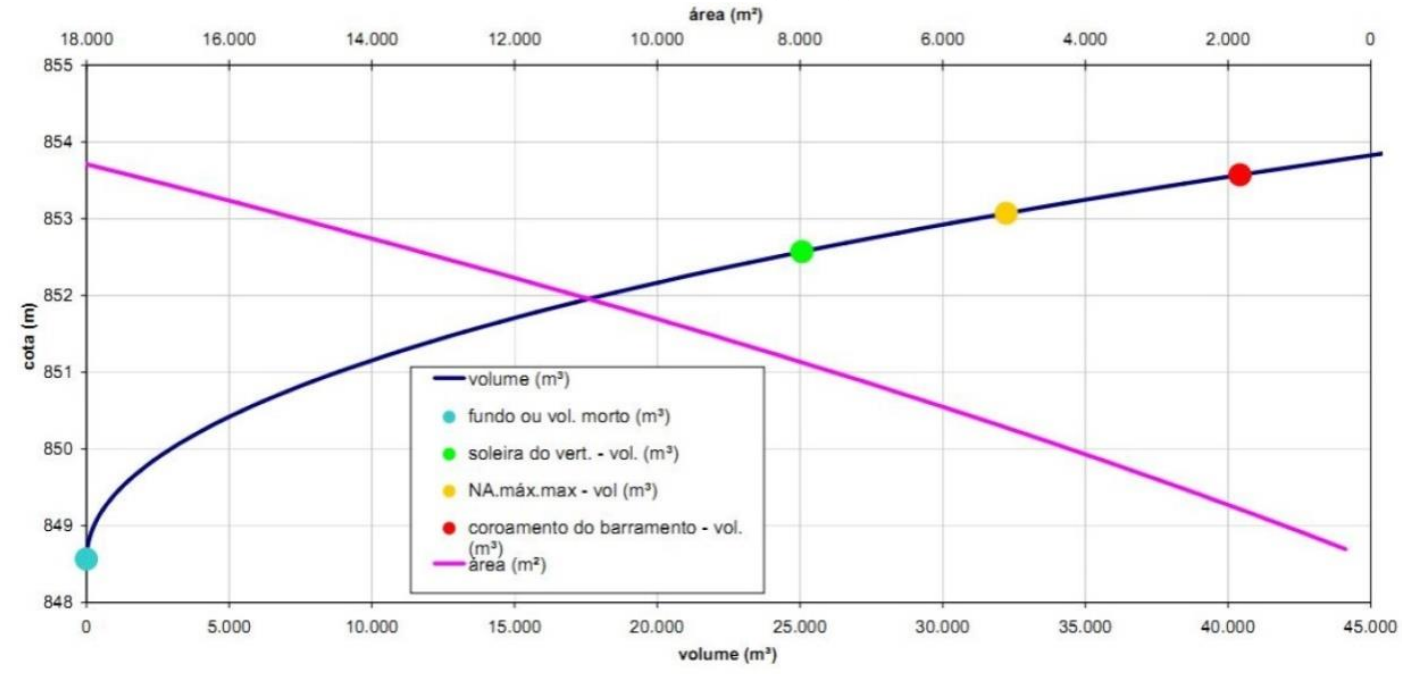

Curva cota-área e cota-volume do reservatório La1 B 97.5

Fonte: PMSC (2011) 


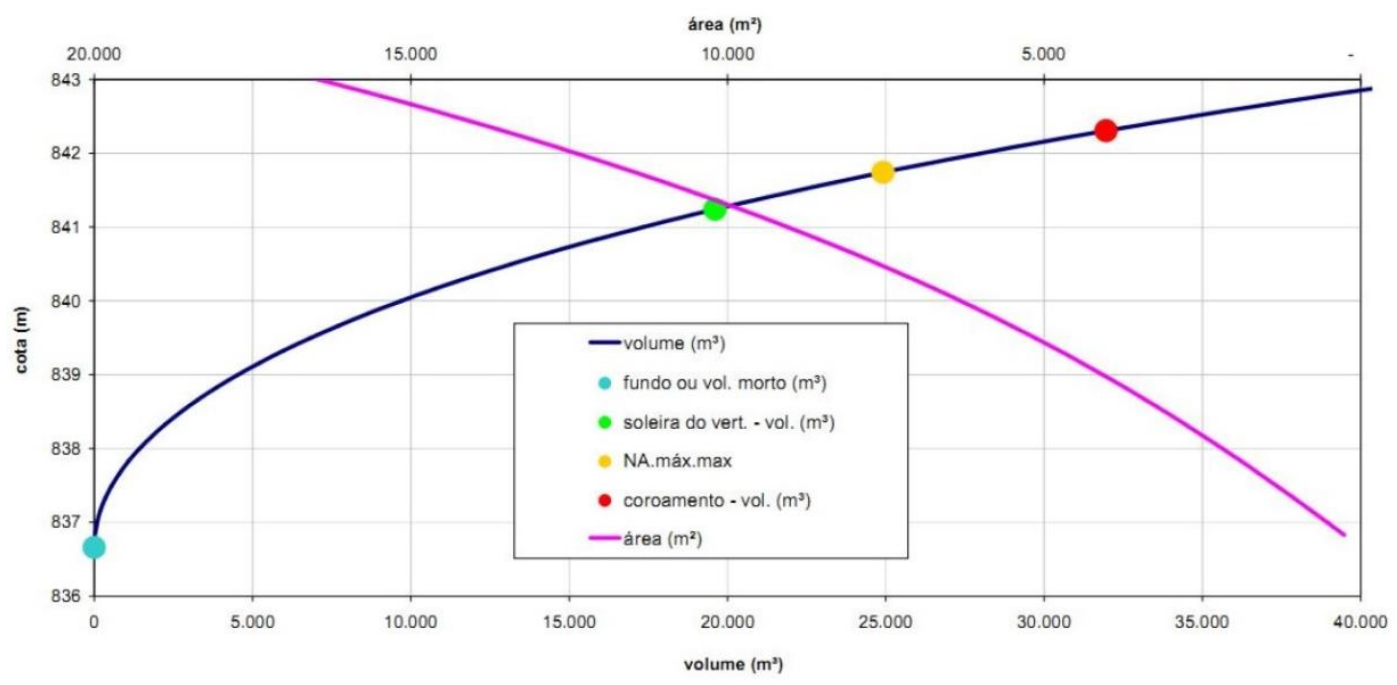

Curva cota-área e cota-volume do reservatório La2 B 98.5

Fonte: PMSC (2011) 